\title{
energies
}

MTDGEACHS for

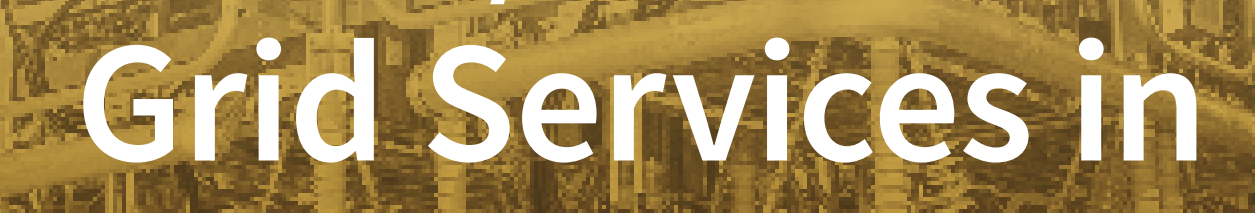

Electric Power

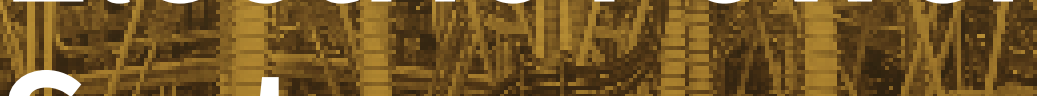

Systems
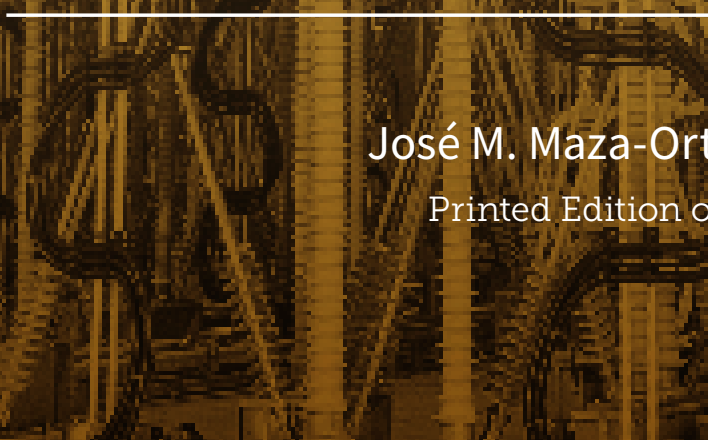

José M. Maza-Ortega and Antonio Gómez-Expósito Printed Edition of the Special Issue Published in Energies 


\section{HVDC/FACTS for Grid Services in Electric Power Systems}





\section{HVDC/FACTS for Grid Services in Electric Power Systems}

Special Issue Editors

José M. Maza-Ortega

Antonio Gómez-Expósito 
Special Issue Editors

José M. Maza-Ortega

University of Seville

Spain
Antonio Gómez-Expósito

University of Seville

Spain

Editorial Office

MDPI

St. Alban-Anlage 66

4052 Basel, Switzerland

This is a reprint of articles from the Special Issue published online in the open access journal Energies (ISSN 1996-1073) (available at: https://www.mdpi.com/journal/energies/special_issues / HVDC_FACTS_grid).

For citation purposes, cite each article independently as indicated on the article page online and as indicated below:

LastName, A.A.; LastName, B.B.; LastName, C.C. Article Title. Journal Name Year, Article Number, Page Range.

ISBN 978-3-03928-376-7 (Pbk)

ISBN 978-3-03928-377-4 (PDF)

Cover image courtesy of REE.

Voltage Source Converter substation at Santa Llogaia side of the 320-kVHVDC line between Spain and France

(C) 2020 by the authors. Articles in this book are Open Access and distributed under the Creative Commons Attribution (CC BY) license, which allows users to download, copy and build upon published articles, as long as the author and publisher are properly credited, which ensures maximum dissemination and a wider impact of our publications.

The book as a whole is distributed by MDPI under the terms and conditions of the Creative Commons license CC BY-NC-ND. 


\section{Contents}

About the Special Issue Editors $\ldots \ldots \ldots \ldots \ldots \ldots \ldots$ vii

Preface to "HVDC/FACTS for Grid Services in Electric Power Systems" $\ldots \ldots \ldots \ldots \ldots$ ix

Abhimanyu Kaushal and Dirk Van Hertem

An Overview of Ancillary Services and HVDC Systems in European Context

Reprinted from: Energies 2019, 12, 3481, doi:10.3390/en12183481 . . . . . . . . . . . . 1

José M. Maza-Ortega, Juan M. Mauricio, Manuel Barragán-Villarejo, Charis Demoulias and Antonio Gómez-Expósito

Ancillary Services in Hybrid AC/DC Low Voltage Distribution Networks

Reprinted from: Energies 2019, 12, 3591, doi:10.3390/en12193591 . . . . . . . . . . . . . . 21

Panos Kotsampopoulos, Pavlos Georgilakis, Dimitris T. Lagos, Vasilis Kleftakis and Nikos Hatziargyriou

FACTS Providing Grid Services: Applications and Testing

Reprinted from: Energies 2019, 12, 2554, doi:10.3390/en12132554 .

Weiming Liu, Tingting Zheng, Ziwen Liu, Zhihua Fan, Yilong Kang, Da Wang, Mingming Zhang and Shihong Miao

Active and Reactive Power Compensation Control Strategy for VSC-HVDC Systems under Unbalanced Grid Conditions

Reprinted from: Energies 2018, 11, 3140, doi:10.3390/en11113140 . . . . . . . . . . . . . 67

Sungchul Hwang, Sungyoon Song, Gilsoo Jang and Minhan Yoon

An Operation Strategy of the Hybrid Multi-Terminal HVDC for Contingency

Reprinted from: Energies 2019, 12, 2042, doi:10.3390/en12112042 . . . . . . . . . . . . . . .

Chao Xiao, Wei Han, Jinxin Ouyang, Xiaofu Xiong and Wei Wang

Ride-Through Control Method for the Continuous Commutation Failures of HVDC Systems Based on DC Emergency Power Control

Reprinted from: Energies 2019, 12, 4183, doi:10.3390/en12214183 . . . . . . . . . . . . . . 109

Waqar Uddin, Nadia Zeb, Kamran Zeb, Muhammad Ishfaq, Imran Khan, Saif Ul Islam, Ayesha Tanoli, Aun Haider, Hee-Je Kim and Gwan-Soo Park

A Neural Network-Based Model Reference Control Architecture for Oscillation Damping in Interconnected Power System

Reprinted from: Energies 2019, 12, 3653, doi:10.3390/en12193653 . . . . . . . . . . . . . . . 12

Javier Renedo, Aurelio García-Cerrada; Luis Rouco, Lukas Sigrist

Coordinated Controlin VSC-HVDC Multi-Terminal Systems to Improve Transient Stability: The Impact of Communication Latency

Reprinted from: Energies 2019, 12, 3638, doi:10.3390/en12193638 . . . . . . . . . . . . . 141

Muhammad Ahmad and Zhixin Wang

A Hybrid DC Circuit Breaker with Fault-Current-Limiting Capability for VSC-HVDC Transmission System

Reprinted from: Energies 2019, 12, 2388, doi:10.3390/en12122388 . . . . . . . . . . . . . 173 
Minh-Quan Tran, Minh-Chau Dinh, Seok-Ju Lee, Jea-In Lee, Minwon Park, Chur Hee Lee and JongSu Yoon

Analysis and Mitigation of Subsynchronous Resonance in a Korean Power Network with the First TCSC Installation

Reprinted from: Energies 2019, 12, 2847, doi:10.3390/en12152847 . . . . . . . . . . . . . . . . . 189

Xiaosheng Wang, Ke Dai, Xinwen Chen, Xin Zhang, Qi Wu and Ziwei Dai

Reactive Power Compensation and Imbalance Suppression by Star-Connected Buck-Type D-CAP

Reprinted from: Energies 2019, 12, 1914, doi:10.3390/en12101914 . . . . . . . . . . . . . . . . . 205

Andres Tarraso, Ngoc-Bao Lai, Gregory N. Baltas and Pedro Rodriguez

Power Quality Services Provided by Virtually Synchronous FACTS

Reprinted from: Energies 2019, 12,3292, doi:10.3390/en12173292 . . . . . . . . . . . . . . . . . . . 221

Minwu Chen, Yinyu Chen and Mingchi Wei

Modeling and Control of a Novel Hybrid Power Quality Compensation System for 25-kV

Electrified Railway

Reprinted from: Energies 2019, 12,3303, doi:10.3390/en12173303 . . . . . . . . . . . . . . . . . 239 


\section{About the Special Issue Editors}

José M. Maza-Ortega (Associate Professor, IEEE Member) received Electrical Engineering and Ph.D. degrees from the University of Seville, Spain, in 1996 and 2001, respectively. Since 1997, he has been with the Department of Electrical Engineering, University of Seville, where he is currently an Associate Professor. His primary areas of interest are power quality, harmonic filters, integration of renewable energies, and power electronics.

Antonio Gómez-Expósito (Professor, IEEE Fellow) received Electrical Engineering and Ph.D. degrees (both with honors) from the University of Seville, Spain, in 1982 and 1985, respectively. Since 2007, he has been the Endesa Red Chair Professor at the University of Seville. In addition to some 300 technical publications, he has coauthored a dozen textbooks and monographs about circuit theory and power systems, among which Power System State Estimation: Theory and Implementation (Marcel Dekker, 2004) and Electric Energy Systems: Analysis and Operation (CRC Press, 2008, 2nd ed. 2018) stand out. Prof. Gómez-Expósito served on the Editorial Board of the IEEE Transactions on Power Systems from 2011 to 2016 and received the IEEE-PES 2019 Outstanding Power Engineering Educator Award. 



\section{Preface to "HVDC/FACTS for Grid Services in Electric Power Systems"}

Electric power systems are headed for a true changing of the guard, due to the urgent need for sustainable energy delivery. Fortunately, the development of new technologies is driving the transition of power systems toward a carbon-free paradigm while maintaining the current standards of quality, efficiency, and resilience. The introduction of HVDC and FACTS in the 20th century, taking advantage of dramatic improvements in power electronics and control, gave rise to unprecedented levels of flexibility and speed of response in comparison with traditional electromechanical devices. This flexibility is nowadays required more than ever in order to solve a puzzle with pieces that do not always fit perfectly. This Special Issue aims to address the role that FACTS and HVDC systems can play in helping electric power systems face the challenges of the near future.

The Special Issue is composed of 13 papers submitted from Asia and Europe that cover three major areas:

\section{Review papers;}

Transmission system applications;

Distribution system applications.

The first review paper by Dr. Kaushal et al. from KU Leuven gives an overview of the role that HVDC lines are playing on the provision of ancillary services in the current European Network of Transmission System Operators for Electricity (ENTSO-E). Transmission system interconnections play a significant role in decarbonized power systems to reduce the energy from fossil-based sources. From this point of view, controllable DC interconnections are key to foster this energy transition. In addition, the use of DC assets is also of interest on the distribution side. In this regard, the second review paper by Dr. Maza-Ortega et al. from the University of Sevilla analyzes the new possibilities that hybrid AC/DC networks may have in future last-mile distribution systems. The proliferation of DC devices (loads, renewable energy sources, and storage systems) in low voltage networks allows the envisioning of the coexistence of $\mathrm{AC}$ and DC networks, which may considerably reduce the use of auxiliary AC/DC power interfaces and open new possibilities from the ancillary service provision point of view. The last paper in the review section of this Special Issue highlights the importance of the controller and power hardware in the loop (CHIL and PHIL, respectively) testing practices. Dr. Kotsampopoulos et al. from the National Technical University of Athens underline the benefits and limitations of using these cutting-edge industry practices.

The second block of papers in this Special Issue is devoted to transmission system applications. The flexibility provided by voltage source converter (VSC) HVDC (VSC-HVDC) systems by means of the simultaneous controllability of active and reactive power flows is unquestionable. The provision of high-quality ancillary services, however, requires precise and advanced control algorithms that are capable of satisfying the most stringent requirements even with adverse network conditions, such as voltage unbalance. In this regard, the paper by Dr. Miao et al. proposes a novel control technique intended to reduce the active and reactive double frequency ripple caused by voltage unbalance. In addition, VSC-HVDC may increase the stability of the system in case of contingencies in complex power systems composed of AC parts as well as conventional line-commutated converter (LCC) HVDC (LCC-HVDC). This topic is explored in the paper by Dr. Yoon et al. which exemplifies the proposed control algorithm in a modified version of the IEEE 39 bus test system. The paper by Dr. Xiao et al., also related with LCC-HVDC, proposes a novel technique to improve the endurance 
capability of an AC system facing continuous commutation failures and to reduce the blocking risk of HVDC converters. Dr. Kim et al. also explore new controller applications for FACTS by presenting a neural network controller for reducing the oscillations between interconnected power systems using a unified power flow controller (UPFC). The provision of ancillary services by FACTS and/or HVDC devices may require the intervention of advanced communication infrastructures to provide remote measurements required by the control algorithms. The paper by Dr. Renedo et al. analyzes the impact that the communication delay may have on the transient stability of the system and how the critical clearing time is affected. All of these academic contributions focus on the application of new controllers to FACTS or HVDC devices in order to enhance the operation of the system by means of advanced ancillary services. However, it is also important to highlight that new contributions on alternative power electronics-based devices or components continuously emerge. This is the case of the DC circuit breaker with fault current limiting capability presented by Dr. Wang. Finally, this section closes with a detailed analysis of the installation of the first thyristor-controlled series capacitor (TCSC) installed in Korea for the mitigation of subsynchronous resonance. Dr. Park et al. compare in their paper the performance of a conventional fixed series capacitor compensation with the TCSC, which reveals the TCSC's superior performance.

The third block of papers of this Special Issue refers to distribution system applications where the focus is probably to enhance, as much as possible, the power quality perceived by the final user. In this regard, the paper by Dr. Dai proposes a three-phase, star-connected, Buck-type dynamic capacitor (D-CAP) for reactive power compensation and unbalance reduction. This Special Issue also includes the paper by Dr. Rodríguez et al. that proposes advanced synchronous power controllers (SPC) capable of controlling unbalance currents during faults with the aim of balancing the voltages as much as possible and attenuating the harmonic distortion in steady-state conditions. Finally, this section closes with a paper devoted to the increasingly important electrified railway sector where the application of FACTS and DC technology may bring several benefits. The paper by Mr. Chen et al. proposes a novel hybrid power quality compensator to compensate the voltage unbalance and harmonic distortion.

In closing, we would like to thank the authors for their work and contributions to the development of new technologies in this area and the reviewers for their valuable comments, which have helped to finalize the papers. We also appreciate the continuous support of the Energies Editorial Office and especially Dr. Billy Bay, MDPI Managing Editor, who greatly facilitated our work in inviting the editors of this Special Issue.

José M. Maza-Ortega, Antonio Gómez-Expósito Special Issue Editors 




\title{
An Overview of Ancillary Services and HVDC Systems in European Context
}

\author{
Abhimanyu Kaushal ${ }^{1,2, *}$ and Dirk Van Hertem ${ }^{1,2}$ \\ 1 ELECTA Research Group, Department of Electrical Engineering (ESAT), KU Leuven, 3001 Leuven, Belgium; \\ dirk.vanhertem@esat.kuleuven.be \\ 2 EnergyVille, 3600 Genk, Belgium \\ * Correspondence: abhimanyu.kaushal@kuleuven.be
}

Received: 17 July 2019; Accepted: 26 August 2019; Published: 9 September 2019

\begin{abstract}
Liberalization of electricity markets has brought focus on the optimal use of generation and transmission infrastructure. In such a scenario, where the power transmission systems are being operated closer to their critical limits, Ancillary Services (AS) play an important role in ensuring secure and cost-effective operation of power systems. Emerging converter-based HVDC technologies and integration of renewable energy sources (RES) have changed the power system dynamics which are based on classical power plant operation and synchronous generator dynamics. Transmission system interconnections between different countries and integrated energy markets in Europe have led to a reduction in the use of energy from non-renewable fossil-based sources. This review paper gives an insight into ancillary services definitions and market practices for procurement and activation of these ancillary services in different control areas within the European Network of Transmission System Operators for Electricity (ENTSO-E). The focus lies particularly on ancillary services from HVDC systems. It is foreseen that DC elements will play an important role in the control and management of the future power system and in particular through ancillary services provision. Keeping this in view, the capability of HVDC systems to provide ancillary services is presented.
\end{abstract}

Keywords: ancillary services; HVDC systems; loss management; frequency control; voltage and reactive power control; black start; congestion management

\section{Introduction}

In a vertically integrated power system, the main task of the system operator is to operate the power system in a reliable and secure manner. With unbundling, the vertically integrated power systems have been unbundled into generating units, transmission system operators (TSO), and distribution system operators (DSO). Electricity markets have been established for a transparent and cost-effective trade of energy. However, with energy trade, other so-called ancillary services are also exchanged between different market players. Ancillary services are the resources required by TSO for reliable and secure power system operation [1]. Important power system characteristics such as frequency, voltage, load and system restart process are maintained by these services [2]. The nomenclature for ancillary services varies in different parts of the world. For example in the USA, for PJM operator area ancillary services for frequency control are known as regulations and reserves [3] (operating, primary, synchronized and quick start reserves [4]), for CAISO (The California Independent System Operator) area the services are termed as regulation up, regulation down, spinning reserve and non-spinning reserve [5]. The ancillary services for frequency control has been categorized as regulation and contingency by Australian Energy Market operator [6] whereas in Europe as per guidelines on electricity balancing the frequency control services are known as frequency containment reserves, frequency restoration reserves and replacement reserves [7]. These all services enable respective system operator with same functionality i.e., frequency control in this example however the names 
are different in different energy markets. As in this review paper the emphasis has been placed on ancillary services in European context so the terminology as used in Europe is considered.

Real-time power system operation involves several uncertainties and these uncertainties have been further increasing as a consequence of augmented integration of distributed power generation from RES. For secure power system operation in such a scenario, ancillary services market has gained critical importance. Ancillary services can be market-based or non-market-based [8]. Market-based ancillary services are procured by the TSOs from different stakeholders from electricity market [9]. In some control areas it is mandatory for power system entities to provide ancillary services with or without payment, these ancillary services are termed as non-market-based ancillary services. While the ancillary services have been defined by ENTSO-E for the interconnected European power system, their implementation, the method of procurement, and activation for these services varies in different member states $[10,11]$.

In this paper, a review of ancillary services definitions, procurement, and implementation methods in different ENTSO-E areas is presented. Various methods through which the HVDC system elements can participate in providing ancillary services are also reviewed. The paper is organized in 6 sections. Section 2, provides insight into definitions and technical aspects of ancillary services for ENTSO-E control areas. The overview of activation and market practices for procurement of ancillary services followed in different ENTSO-E member states has been addressed in Section 3. Section 4, is dedicated to an overview of HVDC system types, connection topologies, control structures, and time constants associated with HVDC systems. A review of various literature work about use of HVDC systems for participation in ancillary services has been undertaken and a comprehensive summary is shown in Section 5. Finally, the conclusion of this survey paper is presented in Section 6.

\section{Ancillary Services Overview}

The functions or services needed by a TSO to guarantee power system security (reliable and secure power system operation) are termed as "Ancillary Services" [10]. These services are either provided by TSO itself or procured from other stakeholders, for carrying out the power transmission from generating units to the load centers while meeting power quality standards $[12,13]$. The authors in [14] have mentioned that as per the definition, the number and types of the services is very broad. The ancillary services are used to provide the stakeholders with the following capabilities:

1. Loss compensation

2. Frequency Control

3. Black start capability

4. Voltage or reactive power Control

5. Oscillation damping

6. Congestion management

The details of the ancillary services shown in Figure 1 are presented in the following subsections.

\subsection{Loss Compensation}

The TSO must compensate for all the losses incurred in the process of power transmission from generation units to load centers. These losses correspond to transmission line losses and losses in various other equipments. The TSO must procure energy to make up for these losses. If the generation plant for this energy is not located in the TSO control area, the TSO must take into account the losses for the power transmission in other zones also [14]. 


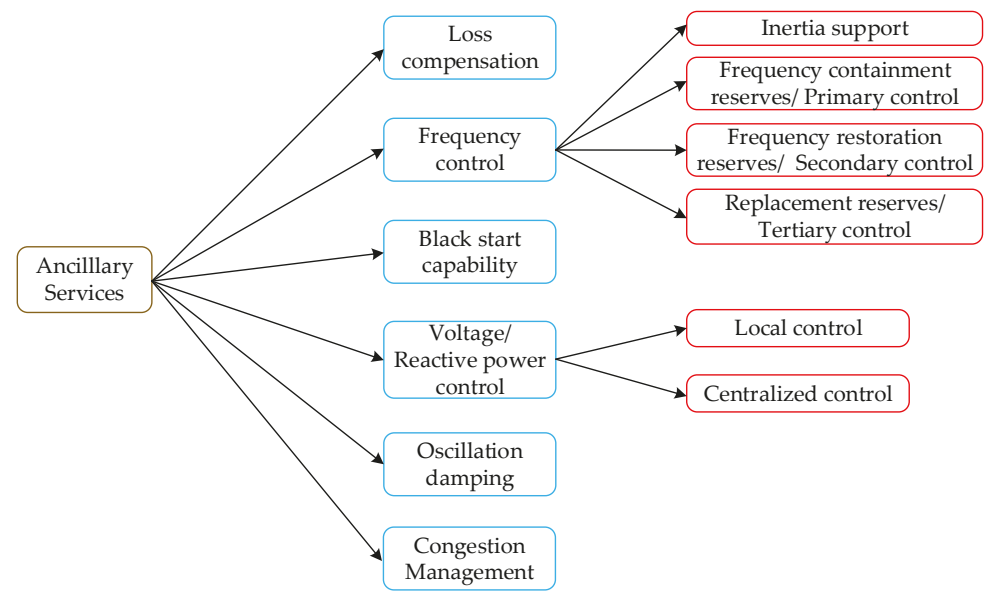

Figure 1. Ancillary services classification.

\subsection{Frequency Control}

In conventional $\mathrm{AC}$ power system, the system frequency is a universal characteristic for the synchronous system i.e., it remains same at every measurement point in the system. For reliable and secure power system operation, it is desired that the frequency of the system shall remain constant at nominal system frequency value (50 Hz for ENTSO-E area). Any deviation in frequency can be attributed to a mismatch in power generation and power consumption (load). A set of parameters have been defined for the assessment of reliability and quality of frequency for ENSTO-E area by European Union commission regulations vide guideline on electricity transmission system operation [15]. These parameters are defined as follows:

a Time to recover frequency: The maximum expected time (for the synchronous area of Continental Europe (CE), Great Britain (GB) and Ireland \& Northern Ireland (IE/NI)) after the occurrence of an imbalance (smaller than or equal to the reference incident) in which the system frequency returns to the maximum steady-state frequency deviation [15]. This time varies depending upon the time constants of equipments participating in the frequency control. The different time constants associated with AC and DC systems are presented in more detail in Section 4.

b Frequency recovery range: The range for the system frequency within which the system frequency is expected to be restored within the time of recover frequency in event of an imbalance (equal to or smaller than the reference incident) in the synchronous area of CE, GB and IE/NI [15].

c Frequency restoration range: The system frequency range (for GB, IE/NI and Nordic synchronous areas) to which the system frequency is expected to return within the time to restore frequency, after the occurrence of an imbalance (equal to or smaller than the reference incident) [15].

d Standard frequency range: Defined symmetrical interval around the nominal frequency within which the system frequency of a synchronous area is supposed to be operated [15].

e Standard frequency deviation: Absolute value of the frequency deviation limiting the standard frequency range [15].

f Steady-state frequency deviation: Absolute value of frequency deviation once the system frequency has stabilized after occurrence of an imbalance [15].

The frequency ranges (recovery, standard, steady state, and frequency deviation) vary from system to system depending upon the size of the system, typical generation mix, and the time required 
for activation of reserves. For a smaller islandic system such as GB or IE/NI, these frequency ranges are larger as compared to the larger CE power system. This is due to the fact that deviation in frequency has direct relation with deviation in active power and same power imbalance will result in large frequency deviation for the smaller systems as compared to the same for larger CE system [16] i.e., $\left(\Delta P / \sum P_{\text {large }}\right)<\left(\Delta P / \sum P_{\text {small }}\right)$. The range for these parameters as defined in the grid code for CE, GB, IE/NI and Nordic power system [15] is shown in Table 1.

Table 1. Frequency quality parameters [15].

\begin{tabular}{lcccc}
\hline Parameter & CE & GB & IE/NI & Nordic System \\
\hline Standard frequency range $(\mathrm{mHz})$ & \pm 50 & \pm 200 & \pm 200 & \pm 100 \\
\hline Maximum instantaneous deviation $(\mathrm{mHz})$ & 800 & 800 & 1000 & 1000 \\
\hline Maximum steady-state deviation $(\mathrm{mHz})$ & 200 & 500 & 500 & 500 \\
\hline
\end{tabular}

Frequency control is a set of control actions aimed at maintaining the system frequency at its nominal value. Frequency control is implemented in different stages, the commonly defined services for frequency control in ENTSO-E area are categorized as follows:

i Inertia Support

ii Frequency Containment Reserve or Primary Control

iii Frequency Restoration Reserve or Secondary Control

iv Replacement Reserve or Tertiary Control

i Inertia Support: Inertia support is the autonomous response of power system components to frequency deviations. When provided by synchronous machines, it represents the kinetic energy in rotating parts of the synchronous generators which is released on occurrence of system imbalance events [17]. Whenever there is any deviation in the frequency (from predefined nominal frequency value), the generators vary the power generation accordingly and makeup for the small deviations in frequency. For frequency decrease below the nominal frequency value, the power generation is increased by the synchronous generators which in turn brings the frequency back to its nominal value and the reverse happens in case of an increase in frequency [18]. The inertial response is the fastest response for any deviation in frequency (it starts as soon as any deviation in the system frequency is observed) [19]. Inertia of power system is an important parameter for frequency stability, and it influences the initial rate of change of frequency after a system imbalance. If a system has higher inertia the frequency deviation will be slower and hence TSO will have margin for activation of reserves [20].

ii Frequency Containment Reserve or Primary Control: Active power reserves available to contain the deviation in the frequency whenever there is mismatch between load and generation (system imbalance) are termed as 'frequency containment reserves' or 'FCR' [15]. The FCR are activated within a few seconds of imbalance and remains active for a limited period of time. The active power injection set points of the generators remains unchanged during this time [21].

iii Frequency Restoration Reserve or Secondary Control: 'Frequency restoration reserves' or 'FRR' are active power reserves which are available to recover the frequency back to nominal frequency value after any disturbance. FRR are also used for fine regulation of frequency. FRR reestablish the power balance to scheduled value for a control area with more than one Load frequency control (LFC) areas [15]. FRR brings the area control error (ACR) to zero by restoring the power exchanges between different zones to original values. The active power set points of various generators in the control area with imbalance are changed so that the committed FCR are again available [21]. FRR can be activated automatically and manually [10].

iv Replacement Reserve or Tertiary Control: 'Replacement reserves' or 'RR' are the active power reserves available to restore and support the required level of FRR and to be prepared for further 
system imbalances, including generation reserves [15]. RR are activated manually as a result of system optimization by the system operator [21].

The sequence of activation of above-mentioned frequency control services followed by Belgian TSO (Elia) after an imbalance is shown in Figure 2 [22]. Inertia support acts immediately and FCR reacts within a few seconds (full activation within $30 \mathrm{~s}$ to any discrepancy between power generation and load with the objective of restricting the frequency deviation. FRR are activated starting from $30 \mathrm{~s}$ to bring the system frequency back to its nominal value after the imbalance. RR are activated within $15 \mathrm{~min}$ to make FRR available for any other system imbalance. New re-dispatch set points are updated by Elia for economical system operation within $1 \mathrm{~h}$. The sequence of activation for reserves is same for other ENTSO-E control areas also; however, the implementation varies (activation time, threshold value, participating entities etc.).

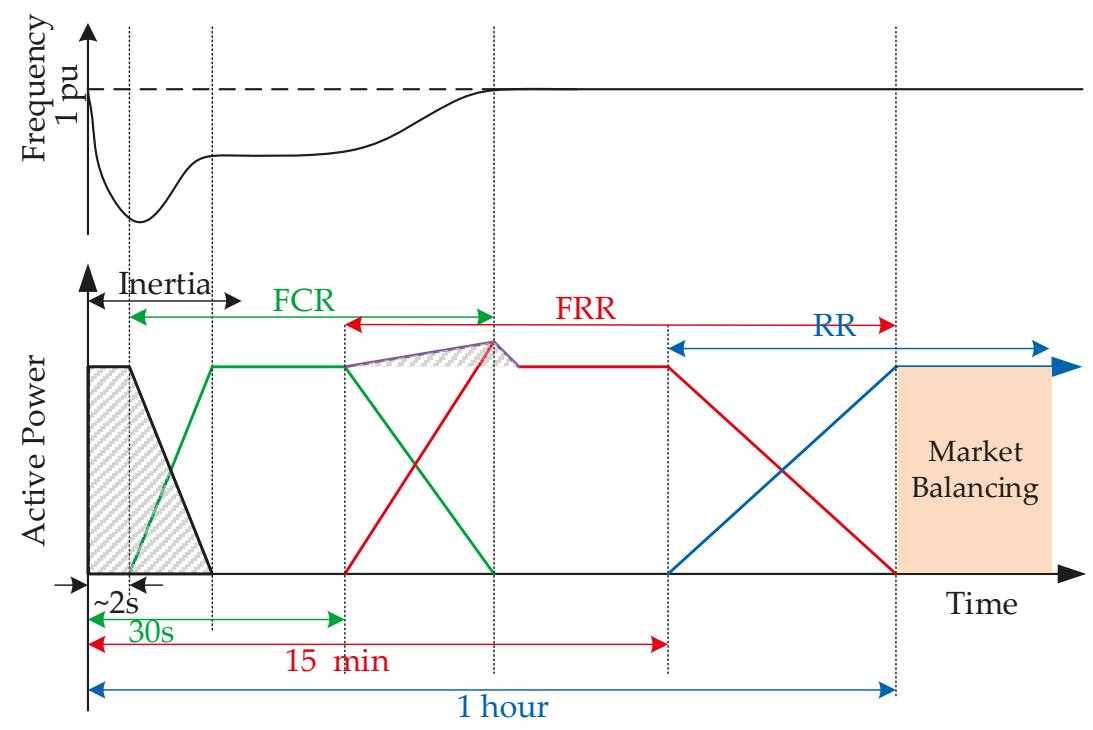

Figure 2. Frequency control ancillary services activation time [23,24].

\subsection{Black Start Capability}

The ability of a power system to perform black start operation is known as 'Black Start Capability' [25]. Black start operation is the process of reviving a power system or a part of power system back to the operational mode from a partial or full shutdown (independent of another power system). Blackouts (situation of total or partial power loss in power system due to unexpected transmission system or generation failure) are the least desired scenarios for power systems and result in social and economic loss [26]. Restoration of power system after a blackout comprises a set of coordinated actions of many power system components and is very complex given the numerous generators, loads and transmission system constraints [27]. In present power systems, it is necessary to recognize the generating units capable of starting without external support and provide power locally. As a consequence of electricity market de-regularization, black start service is treated as a separate ancillary service and is procured by the TSOs from the energy market [28]. As per the regulations, a TSO must identify the generators with black start capabilities in its control area and use these capabilities in a manner to minimize the system restoration time. 


\subsection{Voltage or Reactive Power Control}

'Voltage or reactive power control' is a set of measures or control actions intended to maintain a constant voltage level or reactive power value at each node of the system [15]. These control actions are carried out at different nodes (generation nodes or transformers or AC transmission line ends or HVDC systems or other means) of the power systems. Contrary to frequency, which is a system wide variable, voltage is a local quantity varying for every node of the system. The voltage varies depending upon the system topology, generator, or load location and type of loads. Frequency in the power system is affected by active power balance, voltage is affected in the similar manner by the reactive power balance. Voltage control is implemented by controlling the injection of reactive power in the power system and for this purpose automatic voltage regulators, static VAR compensators, capacitor banks, and reactors are deployed. As it is difficult to transmit reactive power, it is important to control the voltage locally [29]. In view of this limitation, it is very crucial that voltage control equipment is located at critical locations.

Depending on the connection point voltage, the operational voltage limits for steady-state power system operation have been defined for ENTSO-E control area by the European Union commission regulation on electricity transmission system operation [15]. These limits are given in Table 2.

Table 2. Steady-state operational voltage range [15].

\begin{tabular}{cccccc}
\hline \multicolumn{1}{c}{ CE } & Nordic & GB & IE \& NI & Baltic \\
\hline Connection point voltage & $\mathbf{1 1 0} \mathbf{~ k V - 3 0 0 ~ k V}$ \\
\hline Voltage range $(\mathrm{pu})$ & $0.9-1.118$ & $0.9-1.05$ & $0.9-1.10$ & $0.9-1.118$ & $0.9-1.118$ \\
\hline Connection point voltage & $\mathbf{3 0 0} \mathbf{~ k V - 4 0 0 ~ k V}$ \\
\hline Voltage range $(\mathrm{pu})$ & $0.9-1.05$ & $0.9-1.05$ & $0.9-1.05$ & $0.9-1.05$ & $0.9-1.097$ \\
\hline
\end{tabular}

Ensuring adequate volume and time response of remedial actions to keep voltage within the limits in its control area is one of the tasks of TSO [15]. Thus, a TSO must ensure that sufficient reactive power regulating capacity is available, and this capacity can be activated when needed. The regulating actions to control voltage level can be tap change of power transformer or switching of capacitors/reactors or control of HVDC systems or change in reactive power output of generators etc. The voltage or reactive control service can be split into two hierarchical levels i.e., local and centralized control [29].

i Local Control: An automatic control in which the participating devices adjust their reactive power to maintain a constant voltage value at a local measurement point [29]. The local voltage control service is activated within a few seconds to voltage profile [30].

ii Centralized control: 'Centralized voltage control' is a national/utility level manual voltage control that is activated on the request of the TSO by the control service provider. This control is aimed at optimizing the set points of pilot nodes based on centralized power flow studies. Centralized control manages the reactive power in the system so as to minimize system losses, increase dispatch control efficiency, reactive power resources co-ordination in real time in normal grid operation and recover the voltage level deviation [31].

In some countries for example France, voltage control is implemented in three hierarchical levels i.e., primary, secondary, and tertiary control. Primary control is activated locally and is activated automatically. Secondary control is an automatic control and controls the voltage at main transmission buses. Tertiary control is activated manually at utility level after power flow analysis to free reactive power reserves.

\subsection{Oscillation Damping}

In power system operation, it is desired that the frequency and voltage values shall remain within the stable operation range during or after internal (excitation loss, generator instability etc.) or external 
disturbances (transmission line fault, loss of generation or load etc.) [32]. As a consequence of these disturbances, low frequency oscillations occur in the power system. These oscillations can be local (to a single plant or generator or a region) or inter-area (geographically spread and involving several remote generators) [33]. Local oscillations (0.7-2 Hz [34]) occur due to presence of fast exciters in the power system whereas inter-area oscillations $(0.1-0.7 \mathrm{~Hz}$ [34]) are a result of over loading of weak transmission links [35]. If not damped properly, these oscillations may cause partial or total power system blackouts. Automatic voltage regulators equipped with a power system stabilizer (PSS) [36] and flexible AC transmission system (FACTS) devices [33] such as static VAR compensator (SVC) and static synchronous compensator (STATCOM) are employed in the power system for damping these oscillations.

\subsection{Congestion Management}

Congestion in power system is a situation in which the transmission system is not able to fulfill all the desired transactions due to power system's physical and operational limitations [37]. These physical and operational limitations can be thermal limits of transmission lines and transformer, voltage limitations, and transient or other stability limits [38].

In grid codes for capacity allocation and congestion management (CACM) [39], 3-types of congestion i.e., market, physical, and structural congestion has been defined. A situation when cross-zonal capacity or allocation constraints limits the economic surplus for single day-ahead or intraday coupling is termed as 'Market congestion'. When the thermal limits of grid elements and voltage or angle stability limits of power system are breached during forecasted or realized power flows, it is defined as 'Physical congestion'. 'Structural congestion' has been defined as transmission system congestion that is predictable, geographically stable over time, and occurs frequently under normal power system conditions. In electricity markets power system congestion leads to price split between various regions. One such case was observed on 3rd October 2018 when the price difference for day-ahead wholesale price between Germany and Belgium was € 105-152 per MWh. This price difference was due to physical congestion between Belgium and Germany [40].

Congestion management is the process of making use of available power system infrastructure (economical and operational) while operating within system constraints [41]. Congestion management gives long-term investment signals to the TSO for strengthening local (to a single TSO) or cross-zonal (shared with other TSOs) transmission system infrastructure. A TSO responsible for a given control area or multiple TSOs responsible for the concerned control area must compensate the cost for remedial actions for congestion management [15]. A number of methods have been proposed for congestion management in [38-43], these can be broadly categorized into two methods i.e., technical and non-technical methods. Technical methods of congestion management can be cost free and not cost free [44]. Use of FACTS devices, phase-shifters, and transformer tap change for congestion management comes under cost free congestion management methods. These methods are readily available with the TSO, have limited economic impact and do not involve other stakeholders such as generation or distribution companies. Load shedding and rescheduling of generating units for the purpose of congestion management comes under not cost-free methods. Technical methods are ordered by the TSO. Non-technical congestion management methods can be market-based (auctioning, counter trading, nodal, or zonal pricing etc.) and non-market-based (pro rata or first come first serve). There is no involvement of TSO in non-technical congestion management methods and these are just observed by the TSO. Classification of various congestion management methods has been illustrated in Figure 3. 


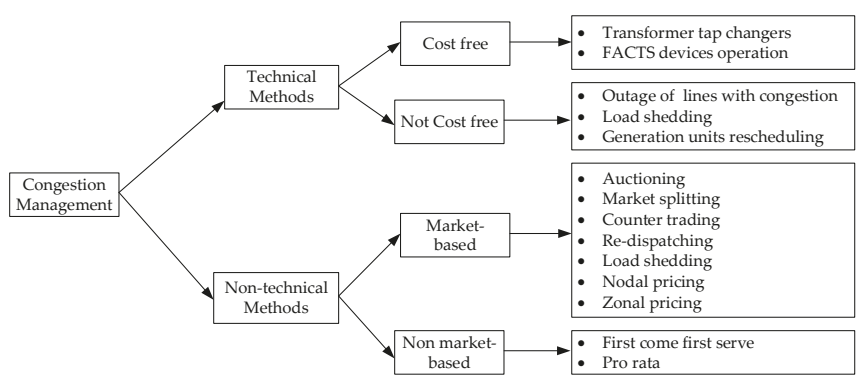

Figure 3. Congestion management classification [45].

\section{Ancillary Services in De-Regularized Electricity Market Context}

Although ancillary services have been defined by ENTSO-E, the methods for procurement and implementation of these ancillary services vary across different control areas of ENTSO-E. A survey carried out by ENTSO-E on 'ancillary services procurement, balancing market design 2018' [11] shows that different EU member states have implemented the centrally defined ancillary services in very different manners. For instance, different balancing and ancillary services markets in EU member states have different market closing time for procurement of the ancillary services, different set of participants, different activation time (deadband before activation or instantaneous activation) and different procedure for recovering the cost of ancillary services. As an illustrative example, few features related to FRR (energy) ancillary services for balancing and ancillary services markets in Germany, Belgium, France and Norway are tabulated in Table 3. From this table it is clear that the ancillary services are different products in each of these countries, even when defined in a single grid code.

It has been set in [15] that each TSO must procure 30\% FCR from within its load flow block. The volume for FRR and RR to be procured from within load flow block is $50 \%$. A platform for primary and secondary control reserves has been established in Germany for sharing the reserves among the TSOs from Germany, France, Belgium, the Netherlands, Austria and Switzerland [46]. Such flexibility in procurement of services from other control areas gives the TSOs an economical opportunity and encourages the optimal use of inter-zonal transmission capacity. This flexibility of balancing and ancillary services markets has motivated the TSOs to enhance the cross-zonal or inter-country transmission capacities. While procuring the services from different control areas, care needs to be taken about various features of the offered service. From Table 3, it can be observed that the product resolution in time is $1 \mathrm{~h}$ for the FRR in balancing and ancillary services market in Germany whereas the same is 30 and 15 min for markets in France and Belgium, respectively. Therefore, to buy the same FRR from Belgian and French markets, a TSO must procure 4 and 2 products respectively as compared to 1 in balancing and ancillary services market in Germany.

Table 3. Frequency restoration reserve-balancing and ancillary services market implementation in 4 countries [11].

\begin{tabular}{|c|c|c|c|c|}
\hline \multicolumn{5}{|c|}{ Frequency Restoration Reserve-Energy } \\
\hline & Germany & Belgium & France & Norway \\
\hline Activation rule & Merit order & & Pro rata & \\
\hline Procurement Scheme & Market only & & Mandatory only & - \\
\hline Product Resolution (MW) & $1<x \leq 5$ & $x \leq 1$ & no minimum bid size & - \\
\hline Product Resolution (in time) & $1 \mathrm{~h}$ & $15 \mathrm{~min}$ & $30 \mathrm{~min}$ & - \\
\hline Distance to real time for auction & $x \leq 1 \min$ & & $5<x \leq 15 \min$ & - \\
\hline Provider & Generators + load + pun & o storage & Generators+ pump storage & Generators \\
\hline Activation time (0 to max) & $90 \mathrm{~s}<\mathrm{x} \leq 5 \mathrm{~min}$ & & $5 \min <x \leq 15 \min$ & $90 \mathrm{~s}<\mathrm{x} \leq 5 \mathrm{~min}$ \\
\hline Settlement rule & Bid price & & - & Marginal price \\
\hline Cost Recovery Scheme & Balance responsible party & Grid users & Balance responsible party & Grid users \\
\hline
\end{tabular}




\section{HVDC Transmission Systems, Control and Dynamics}

HVDC transmission systems are seen as a key enabler for bulk power transmission over long distances with better controllablity as compared to conventional AC systems. HVDC transmission systems can be asynchronous interconnection, embedded transmission line in synchronous system and offshore to onshore grid interconnections. Asynchronous HVDC interconnection is the connection between $\mathrm{AC}$ systems operating at different frequencies or systems operating at same frequency but different phase angles [47]. An example of such interconnection is NORNED HVDC link between Norway and the Netherlands. HVDC synchronous interconnection or embedded HVDC is the connection between two nodes in a synchronous area such as ALEGrO link between Belgium and Germany. For evacuation of bulk power from remotely located offshore windfarms, HVDC interconnections are becoming a preferred option. HVDC transmission link BorWin1 in Germany is an example of such system. The representative line diagrams of HVDC transmission systems for asynchronous, synchronous and offshore HVDC connection are shown in Figure 4a-c, respectively.

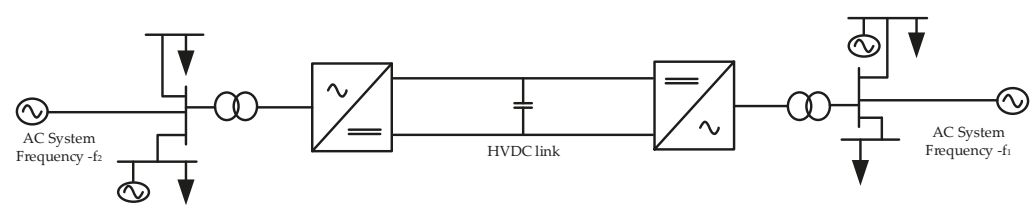

(a)

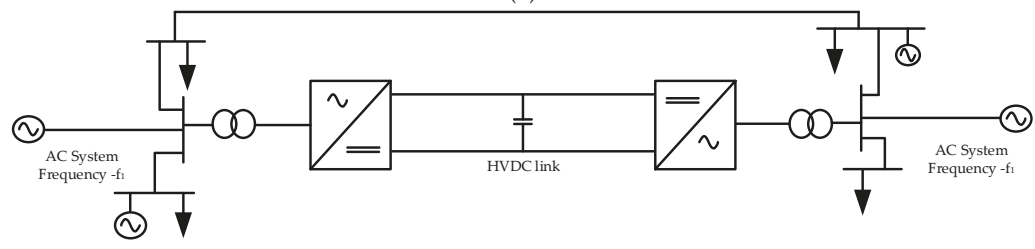

(b)

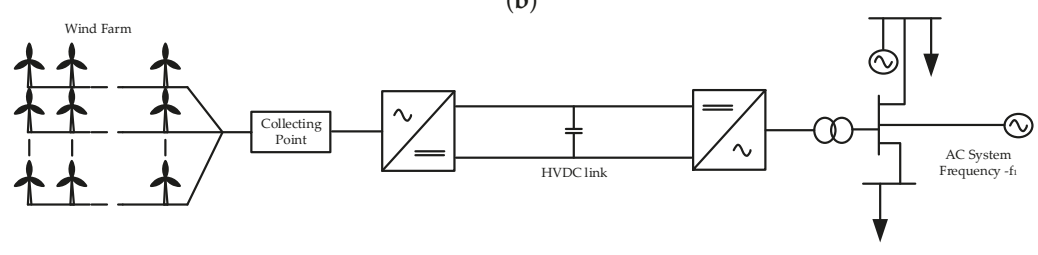

(c)

Figure 4. Line diagram for (a) asynchronous HVDC transmission system interconnection (b) synchronous HVDC transmission system (embedded line) and (c) offshore HVDC transmission system.

For HVDC converter stations two types of HVDC technologies are used namely Line commutated converter (LCC) which uses thyristors in current source converters(CSC) topology and voltage source converters (VSC) that uses gate turn-off thyristors (GTOs) or insulated gate bipolar transistors (IGBTs) [48] as shown in Figure 5a,b respectively. Both technologies have some advantages and disadvantages. LCC technology is a very mature technology, cheaper, has less converter station losses, more short-term overload capability and has higher converter ratings in comparison to VSC-based HVDC systems [12]. However, this technology requires large AC and DC harmonic filters, significant dependency of active and reactive power, no blackstart capability and requirement of strong connecting AC systems. It is complicated to use LCC-based technology when power reversal is frequently required because the voltage polarity needs to be changed to change direction of power flow [14]. LCC-based HVDC systems are normally used for back-to-back or point-to-point interconnection of asynchronous 
systems [49]. VSC-based HVDC technology is relatively new and can be used to control both active and reactive power separately. This technology can provide AC voltage to blacked-out grids and provide reactive power support similar to statcom [14]. VSC converters are smaller due to requirement of smaller filters [12] and more dynamic in particular with respect to power reversal. VSC-based technology is considered to be a better choice for multi-terminal HVDC grids.

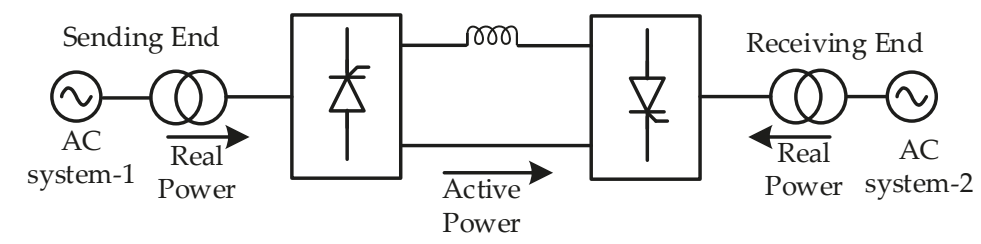

(a)

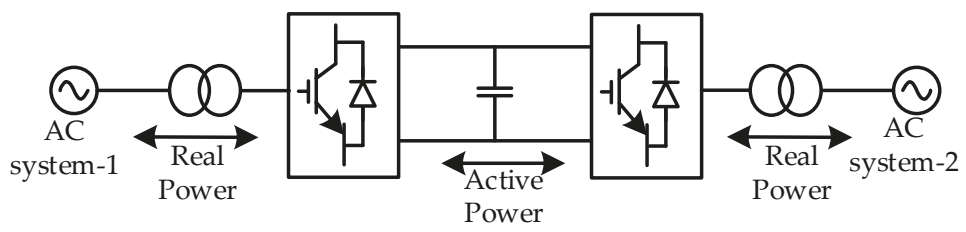

(b)

Figure 5. (a) CSC and (b) VSC-based HVDC systems [48].

Interactions between HVDC systems and AC systems have increased due to the increasing number of HVDC systems. A control structure as per Figure 6 has been proposed in [50] to highlight the similarities for primary, secondary, and tertiary control for HVDC and AC system using well known power system interaction between lower controllers and power dispatch.

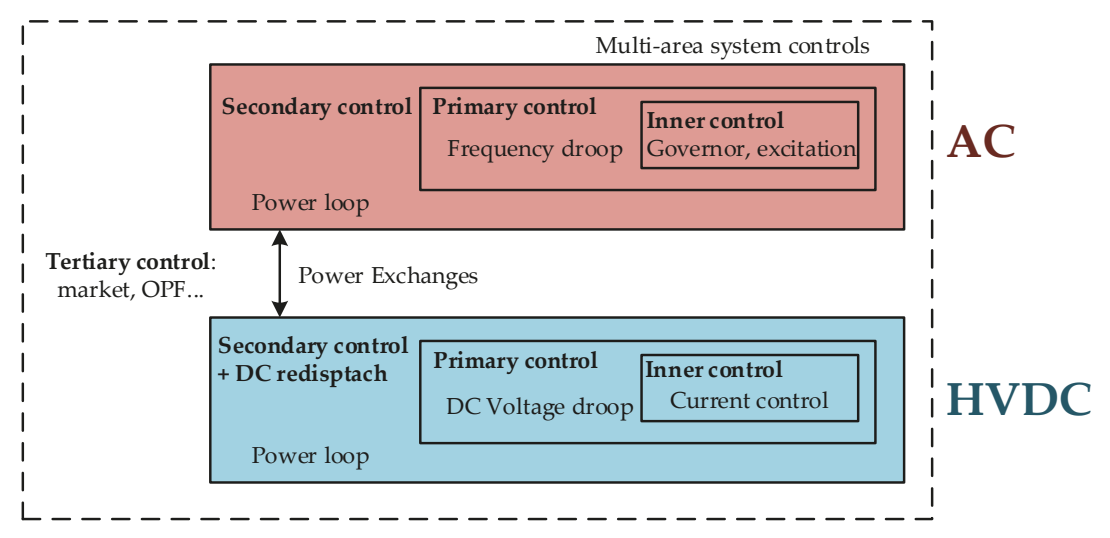

Figure 6. Combined AC and DC control scheme [50].

It is expected that HVDC systems shall also participate in ensuring secure power system control and operation. A converter control for VSC-based HVDC systems as illustrated in Figure $7[51,52]$ is generally used for controlling the firing of the IGBTs to control the HVDC grid and AC system voltage. The active power balance in the HVDC system is reflected by the DC voltage in a manner similar to frequency in the AC system [12]. Active power-DC voltage control in the DC system is therefore 
similar to active power-frequency control in AC systems. Furthermore, it is possible to implement active power and reactive power droop control from the converter stations by controlling the values $k_{p}$ and $k_{a}$ as shown in Figure 8a,b, respectively. However, as mentioned earlier for LCC-based HVDC systems it is not possible to control reactive power independent of active power and extra reactive power compensation is required to change reactive power independently [14]. $k_{p}$ and $k_{a}$ in Figure 8a,b are the active power-dc voltage and reactive power-ac voltage droop coefficients respectively.

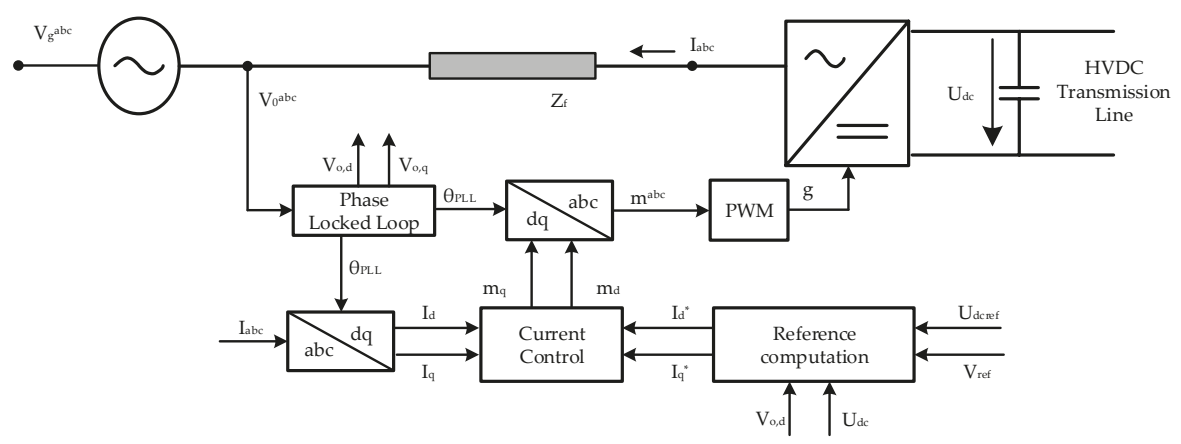

Figure 7. Control scheme for VSC converter station.
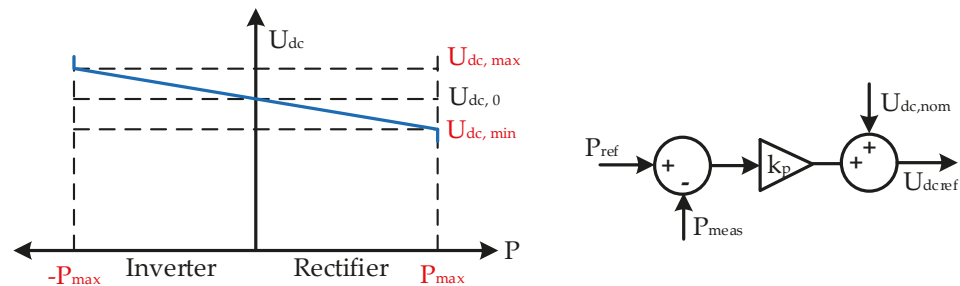

(a)
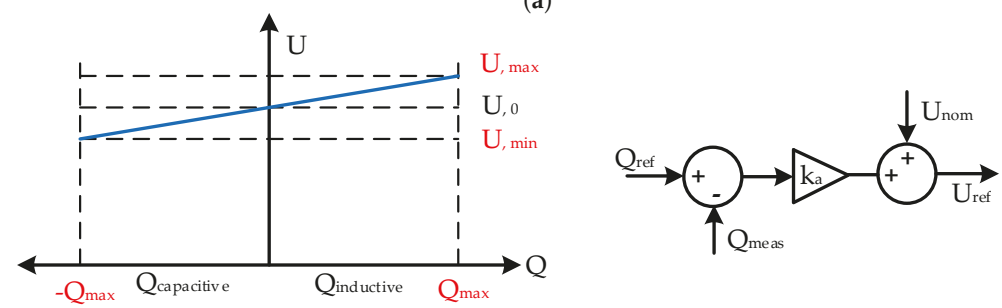

(b)

Figure 8. Reference (a) DC voltage based on active power-DC voltage droop and (b) AC voltage based on reactive power-AC voltage droop.

It is also possible to incorporate AC system frequency-active power droop to make the converter react to the frequency deviations in the AC system. The control diagram is presented in Figure $9 . k_{1}$ in Figure 9 is the frequency-active power droop coefficients. 


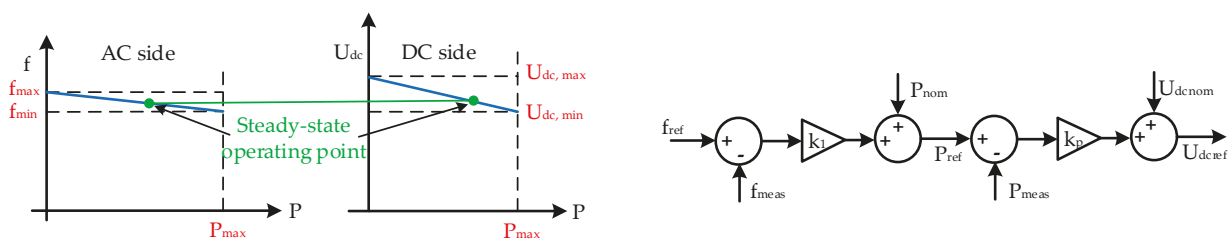

Figure 9. AC system frequency-based active power-DC voltage droop control [53].

In contrast to AC systems which have large inertia, the DC systems have negligible inertia (only small amount of energy is stored in cables and capacitors). A consequence of this small inertia is that the DC systems respond faster to system imbalances than AC systems [54]. An overview of time constants associated with various services for AC and DC systems is presented in Figure 10.

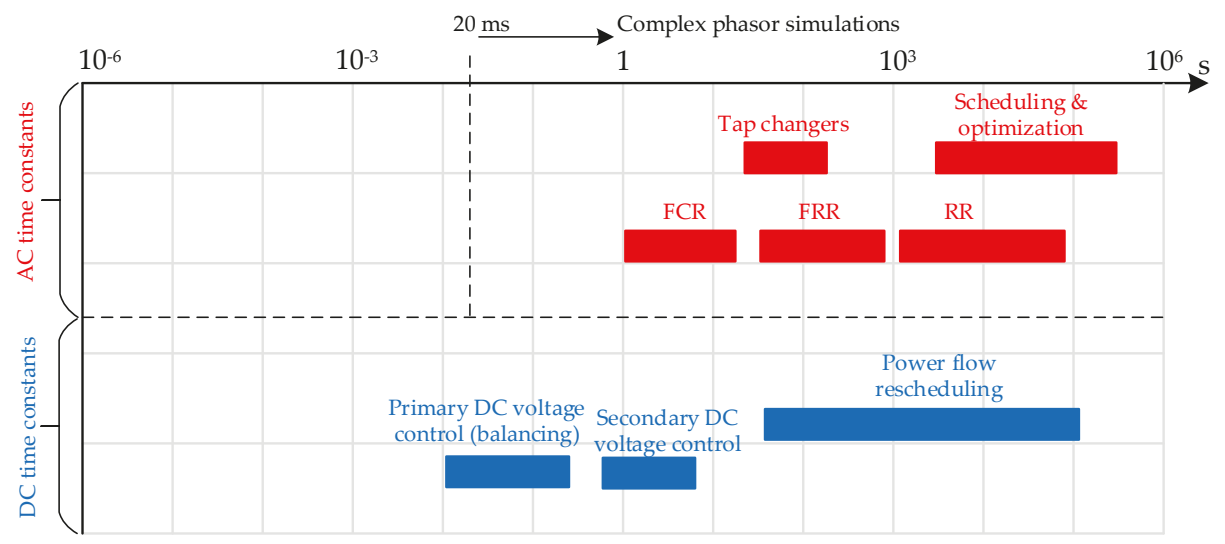

Figure 10. Time constants for activation of services for AC \& DC system elements [54].

As stated earlier, DC voltage in HVDC systems plays the same role as frequency in the AC systems and can be considered to be an indicator of stable grid operation. Hence, active power imbalances can be controlled by controlling the DC voltage. It can be observed from Figure 10 that the activation time of DC equipments is two orders of magnitude lower than AC system equipments. Primary DC voltage control is activated much faster than FCR and it can play a similar role of inertia support (if frequency-based active power droop is implemented). Using HVDC for frequency control also results in improvement of frequency nadir [55]. It has been concluded in [56] that combining the frequency control reserves (among CE, Nordic and GB systems) using HVDC systems improves ROCOF, frequency nadir, and frequency quality. It can be deduced from these studies that HVDC systems can be an alternative to provide frequency support in the manner which is equivalent to inertia support. Various scenarios for providing frequency support (inertia, FCR, FRR and RR) by providing required active power from HVDC interconnections are shown in Figure 11. It is pertinent to mention here that inertia support and FCR can only be provided by asynchronous or offshore windfarm HVDC interconnections and cannot be provided by the HVDC connections embedded in synchronous zone (as HVDC systems do not store/generate power themselves and the additional power comes from other generation sources). It is possible to provide FRR and RR using synchronous HVDC systems by making remote generation units contribute by changing their set points. It is not possible to provide blackstart using HVDC systems independent of other AC system as some power source is required. 


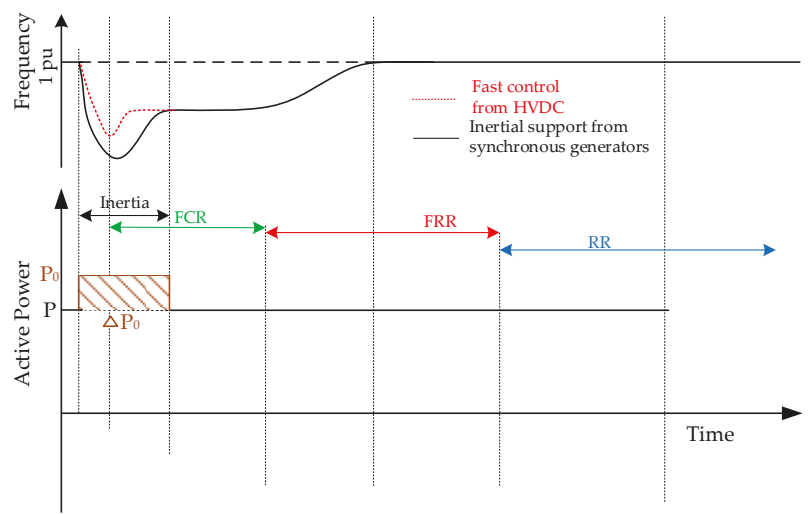

(a)

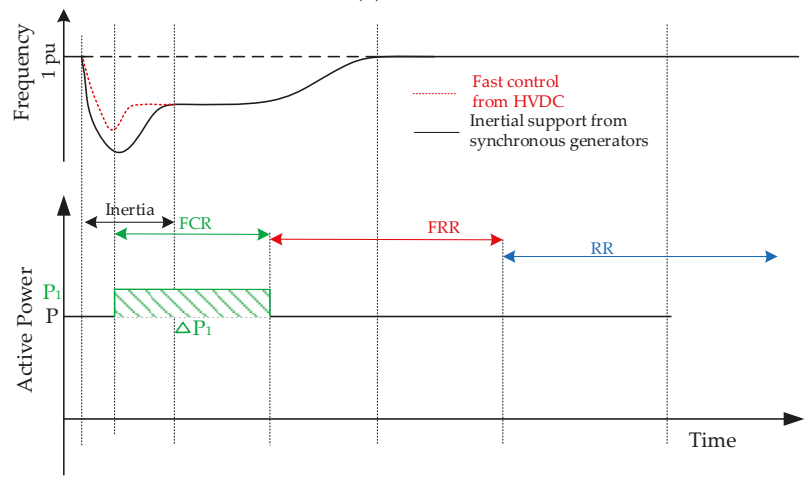

(b)

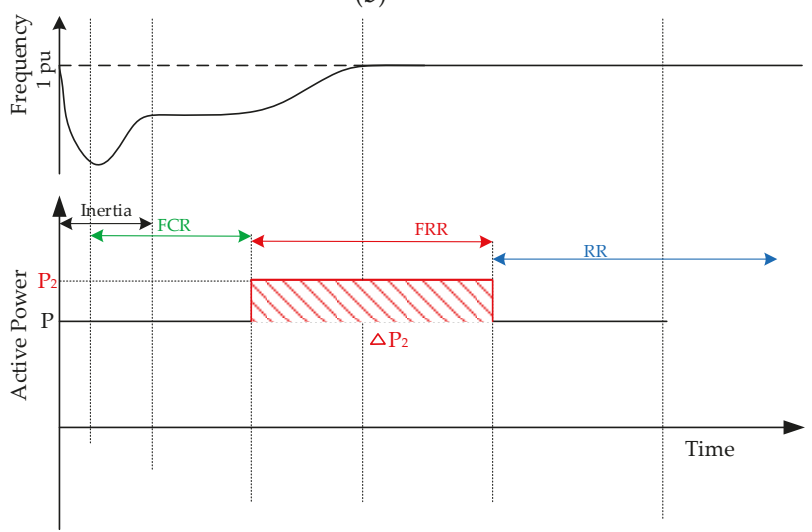

(c)

Figure 11. Cont. 


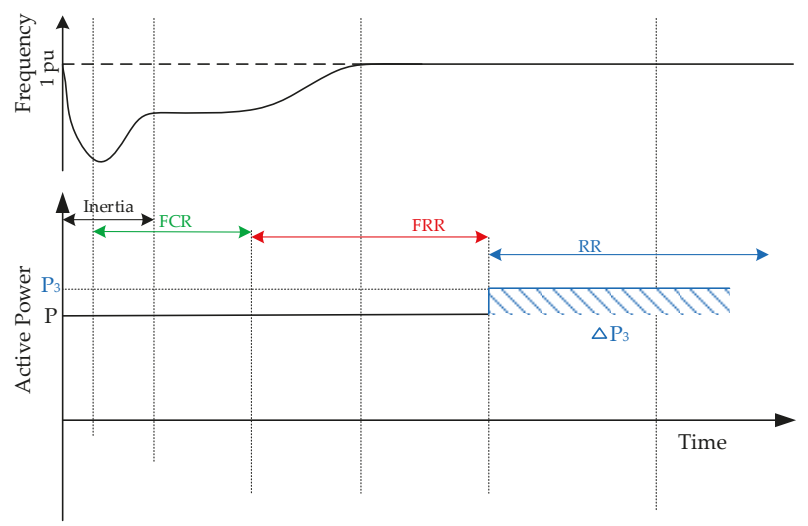

(d)

Figure 11. Change in active power flow through HVDC transmission line for providing (a) inertia support, (b) frequency containment reserves, (c) frequency restoration reserves and (d) replacement reserves.

\section{Ancillary Services and HVDC Systems}

As mentioned in Section 3, liberalized electricity markets and integration of remote renewable energy sources have highlighted the need for enhanced cross-zonal transmission capacity among various European countries. HVDC transmission systems seems to be the most viable solution for cross-zonal interconnection as these can carry more power and have better controllability. Also, for integrating offshore renewables generation HVDC systems are being preferred. It will not be an over statement that in near future the DC elements will play an important role in power system management. Guidelines have also been published for participation of HVDC systems in power system operation support in ENTSO-E area [57]. For instance, the guidelines allows the TSO to require the HVDC system to control the active (and reactive) power output to maintain stable AC system frequency, provide synthetic inertia in event of frequency deviation in the connected AC system and remain connected and in operation if the network frequency changes at a rate from -2.5 to $+2.5 \mathrm{~Hz} / \mathrm{s}$.

HVDC systems can actively participate in providing ancillary services to AC systems [14] as detailed in Section 4 also. At the same time HVDC systems will also need ancillary services such as energy balance, loss compensation, black start and restoration for smooth operation [12]. In [58], the capability of windfarms connected through HVDC to provide ancillary services to DC systems has been presented. The aspects of ancillary services required by HVDC systems are not further covered in this paper.

Based on the requirements of ancillary services for AC system, research has been going on to develop the possible solution for providing the ancillary services from HVDC systems to AC systems and in the literature several possible solutions have been proposed. The literature review of possible methods for ancillary services provisions from LCC-based and VSC-based HVDC systems is presented below:

i LCC-based HVDC system: The authors in [59-62] have proposed some approaches to control the system voltage from LCC-based HVDC systems. Voltage stability analysis for multi-feed HVDC system using STATCOM has been presented by authors in [63]. Various methods for providing frequency control service from such HVDC systems are presented in [64,65]. In [66], the authors have proposed virtual synchronous generators (VSG) approach for providing frequency control from islanded windfarms. Methods for providing blackstart service with LCC-based HVDC 
systems has been detailed in $[67,68]$. Methods for power oscillation damping using LCC-based HVDC systems for connected AC systems are detailed in $[62,69,70]$.

ii VSC-based HVDC system: In [71,72], the authors have proposed VSG approach for providing fast frequency control and virtual inertia from the VSC-based HVDC converter stations. Fast frequency and $\mathrm{AC}$ system voltage control has been proposed by the authors in [73]. For providing primary frequency support (FCR) from offshore windfarms, HVDC converter control techniques have been proposed in [74-78]. In [59,79-81], the authors have discussed the provisions for AC system voltage control service from HVDC systems. The method for providing frequency from the energy stored in HVDC link is highlighted in [82]. The authors in [83-85] have presented the various studies on blackstart capabilities of VSC-based HVDC systems. In [86-90], the authors have highlighted the control aspects for oscillation damping for VSC-based HVDC systems.

Based on the literature review, some of distinctive features of HVDC systems and their possible use for providing ancillary services have been summarized in Table 4. It is assumed that sufficient reserves are available in the systems to provide the considered ancillary services.

Table 4. Ancillary Services from HVDC Transmission systems.

\begin{tabular}{|c|c|c|c|c|c|c|c|}
\hline \multirow{2}{*}{ System } & \multicolumn{2}{|c|}{ Asynchronous } & \multicolumn{2}{|c|}{ Synchronous } & \multicolumn{2}{|c|}{ Offshore } & \multirow{2}{*}{ Remarks } \\
\hline & LCC Based & VSC Based & LCC Based & VSC Based & LCC Based & VSC Based & \\
\hline Inertia & ++ & ++ & NA & NA & $++^{*}$ & $+++^{*}$ & $\begin{array}{l}\text { VSC-based HVDC systems offer better } \\
\text { controllability for offshore connections }\end{array}$ \\
\hline FCR & ++ & ++ & NA & NA & $++^{*}$ & $++^{*}$ & $\begin{array}{l}\text { Synchronous zone embedded HVDC systems } \\
\text { cannot provide Inertia and FCR }\end{array}$ \\
\hline FRR & +++ & +++ & NA & NA & $++^{*}$ & $++^{*}$ & $\begin{array}{l}\text { HVDC systems provide better controllability as } \\
\text { compared to AC systems }\end{array}$ \\
\hline RR & +++ & +++ & NA & NA & $++^{*}$ & $++^{*}$ & \\
\hline $\begin{array}{l}\text { Voltage } \\
\text { control }\end{array}$ & - & +++ & - & +++ & - & +++ & $\begin{array}{l}\text { LCC-based HVDC systems cannot provide voltage } \\
\text { control and Black start capability }\end{array}$ \\
\hline Black start & - & ++ & - & ++ & - & ++ & \\
\hline $\begin{array}{l}\text { Congestion } \\
\text { Management }\end{array}$ & +++ & +++ & +++ & +++ & - & - & $\begin{array}{l}\text { HVDC systems have better power carrying } \\
\text { capability than AC systems }\end{array}$ \\
\hline $\begin{array}{l}\text { Oscillation } \\
\text { damping }\end{array}$ & ++ & +++ & ++ & +++ & + & + & $\begin{array}{l}\text { VSC-based HVDC systems have better oscillation } \\
\text { damping capabilities }\end{array}$ \\
\hline
\end{tabular}

Note. The symbol,,-+++ and +++ means that the HVDC systems cannot provide the service, are able to provide the service, are able to provide the service similar to conventional AC systems and can provide the service better than AC systems respectively. ${ }^{*}$ implies that the HVDC system requires appropriate controls at the offshore side to provide this service. NA implies that it is not possible to provide this service from respective HVDC system.

\section{Conclusions}

Ancillary services play a pivotal role in ensuring reliable power system operation. It is critical that various power system equipments which can provide these services could be used in an economical way while enabling smooth power system operation. This review paper details the definitions of ancillary services, procurement, and activation practices for these services as followed in different control areas of ENTSO-E. It can be concluded from this study that every control area in ENTSO-E follows its own practice for procurement and activation of ancillary services, despite these services being defined by one grid code.

A major outcome of this review paper is the significant potential of HVDC systems (specially VSC-based) in providing ancillary services. A comprehensive analysis of possible control methods and time frame of activation of HVDC equipments highlights the robustness and fast control aspects of HVDC systems. These characteristics are the major drivers for considering ancillary service support from HVDC systems especially within the context of an interconnected grid and offshore grids. From the comparative analysis for different HVDC systems it can be inferred that VSC-based HVDC systems can provide ancillary services in a manner better than or similar to that of the conventional AC systems. This analysis expands on the features of HVDC connections types in providing different ancillary services based on a literature review. 
To facilitate the sharing of ancillary services from HVDC among different operators of an interconnected system, a coordinated evaluation of the most optimal use of ancillary services on pan-European level would be necessary. The categorization of different ancillary services from HVDC systems and their characteristics as presented in this paper, could be a starting point for such analysis.

Funding: This work is supported by the project HVDC Inertia Provision (HVDC Pro), financed by the ENERGIX program of the Research Council of Norway (project number 268053/E20) and the industry partners; Statnett, Equinor, RTE, and ELIA. https:/ / www.sintef.no/en/projects/hvdc-inertia-provision/.

Conflicts of Interest: The authors declare no conflict of interest.

\section{References}

1. Rebours, Y.G.; Kirschen, D.S.; Trotignon, M.; Rossignol, S. A Survey of Frequency and Voltage Control Ancillary Services-Part I: Technical Features. IEEE Trans. Power Syst. 2007, 22, 350-357. [CrossRef]

2. Australian Energy Market Operator: Ancillary Services. Available online: https://www.aemo.com. au/Electricity/National-Electricity-Market-NEM/Security-and-reliability/Ancillary-services (accessed on 9 September 2019).

3. PJM: Ancillary Services Market: Reserves. Available online: https://learn.pjm.com/three-priorities/buyingand-selling-energy/ancillary-services-market/reserves.aspx (accessed on 9 September 2019).

4. PJM: Ancillary Services Market. Available online: https://learn.pjm.com/three-priorities/buying-andselling-energy/ancillary-services-market.aspx (accessed on 9 September 2019).

5. California ISO: Market Operations: Market Processes. Available online: http://www.caiso.com/market/ Pages/MarketProcesses.aspx (accessed on 9 September 2019).

6. AEMO: Guide to Ancillary Services in the National Electricity Market. Available online: https://www. aemo.com.au/-/media/Files/PDF/Guide-to-Ancillary-Services-in-the-National-Electricity-Market.pdf (accessed on 9 September 2019).

7. Official Journal of the European Union: Commission Regulation(EU) 2017/2195 of 23 November 2017 Establishing a Guideline on Electricity Balancing. Available online: https:/ / eur-lex.europa.eu/legal-content/ EN/TXT/PDF/?uri=CELEX:32017R2195\&from=GA (accessed on 9 September 2019).

8. Australian Energy Market Operator: Non-Market Ancillary Services. Available online: https://www.aemo.com.au/-/media/Files/Electricity/NEM/Security_and_Reliability/Power_System_ Ops/Procedures/SO_OP_3708---Non-market-Ancillary-Services.pdf (accessed on 9 September 2019).

9. ANEXT: KRAFTWERKE: Balancing Markets. Available online: https://www.next-kraftwerke.be/en/ knowledge-hub/balancing-markets/ (accessed on 9 September 2019).

10. ENTSO-E: Balancing and Ancillary Services Markets. Available online: https://www.entsoe.eu/about/ market/\#balancing-and-ancillary-services-markets (accessed on 9 September 2019).

11. Survey on Ancillary Services Procurement, Balancing Market Design 2018 by ENTSO-E WGAS, March 2019. Available online: https://www.entsoe.eu/publications/market-reports/\#survey-on-ancillary-servicesprocurement-and-electricity-balancing-market-design (accessed on 9 September 2019).

12. Van Hertem, D.; Robert, H.; Renner, R.H.; Johan Rimez, J. Chapter 10-Power system operation with HVDC grids. In HVDC Grids For Offshore and Supergrid of the Future; Van Hertem, D., Gomis-Bellmunt, O., Liang, J., Eds.; IEEE Press Series on Power Engineering; John Wiley \& Sons: Hoboken, NJ, USA, 2016; pp. 230-235, ISBN 978-1-118-85915-5.

13. ENTSO-E. Requirements for Grid Connection Applicable to All Generators; Technical Report; ENTSO-E: Brussels, Belgium, 2013.

14. Renner, R.H.; Van Hertem, D. Ancillary services in electric power systems with HVDC grids. IET Gener. Transm. Distrib. 2015, 9, 1179-1185. [CrossRef]

15. Official Journal of the European Union: Commission Regulation(EU) 2017/1485 of 2 August 2017 Establishing a Guideline on Electricity Transmission System Operation. Available online: https:/ / eur-lex.europa.eu/ legal-content/EN/TXT/PDF/?uri=CELEX:32017R1485\&from=EN (accessed on 9 September 2019).

16. Kirschen, D.S.; Strbac, G. Chapter 5-System security and ancillary services. In Fundamental of Power System Ecconomics; John Wiley \& Sons Ltd.: Chichester, UK, 2004; pp. 105-139, ISBN 0-470-84572-4. 
17. Tielens, P.; Van Hertem, D. The relevance of inertia in power systems. Renew. Sustain. Energy Rev. 2016, 55, 999-1009. [CrossRef]

18. Future System Inertia: ENTSO-E Report. Available online: https://docstore.entsoe.eu/Documents/ Publications/SOC/Nordic/Nordic_report_Future_System_Inertia.pdf (accessed on 9 September 2019).

19. Future Ancillary Services in ERCOT. ERCOT concept paper, Draft version 1.0, 2013. Available online: https: // www.ferc.gov / CalendarFiles / 20140421084800-ERCOT-ConceptPaper.pdf (accessed on 9 September 2019).

20. Need for Synthetic Inertia (SI) for Frequency Regulation: ENTSO-E Guidance Document for National Implementation for Network Codes on Grid Connection 2 November 2017. Available online: https:/ / consultations.entsoe.eu/system-development/entso-e-connection-codes-implementationguidance-d-4/user_uploads/6---igd-on-si.pdf (accessed on 9 September 2019).

21. Beerten, J. Chapter 15-Control Principles of HVDC Grids. In HVDC Grids For Offshore and Supergrid of the Future; Van Hertem, D., Gomis-Bellmunt, O., Liang, J., Eds.; IEEE Press Series on Power Engineering; John Wiley \& Sons: Hoboken, NJ, USA, 2016; pp. 315-331, ISBN 978-1-118-85915-5.

22. Elia Product Desciption for Ancillary Services. Available online: http://www.elia.be/en/suppliers/purchasingcategories/energy-purchases/Ancillary-services/Product-Description (accessed on 9 September 2019).

23. Final Report on "Qualitative Analysis of Cross-Border Exchange of Balancing Energy and Operational Reserves between Netherlands and Belgium"; DNV KEMA Energy \& Sustainability: Bonn, Germany, August 2013.

24. Renner, R.H. Interaction of HVDC Grids and AC Power Systems Operation and Control. Ph.D. Thesis, KU Leuven, Leuven, Belgium, 2016.

25. Knight, U.G. Power Systems in Emergencies: From Contingency Planning to Crisis Management; John Wiley \& Sons: Hoboken, NJ, USA, 2001; ISBN 978-0-471-49016-6.

26. Pentayya, P.; Gartia, A.; Das, A.P.; Kumar, C. Black Start Exercises Experience in Western Region, India. In Proceedings of the 2013 Annual IEEE India Conference (INDICON), Mumbai, India, 13-15 December 2013; pp. 1-5. [CrossRef]

27. Sun, W.; Liu, C.; Zhang, L. Optimal Generator Start-Up Strategy for Bulk Power System Restoration. IEEE Trans. Power Syst. 2011, 26, 1357-1366. [CrossRef]

28. Saraf, N.; McIntyre, K.; Dumas, J.; Santoso, S. The Annual Black Start Service Selection Analysis of ERCOT Grid. IEEE Trans. Power Syst. 2009, 24, 1867-1874. [CrossRef]

29. Elia pRoduct Desciption for Ancillary Services-Voltage and Reactive Power Control. Available online: http:/ / www.elia.be/ / media/files/Elia/Products-and-services/ProductSheets/S-Ondersteuning-net/ S6_EN_2016.pdf (accessed on 9 September 2019).

30. IEEE Recommended Practice for Excitation System Models for Power System Stability Studies; IEEE Std 421.5-2005 (Revision of IEEE Std 421.5-1992); IEEE: Piscataway, NJ, USA, 2006; pp. 1-93. [CrossRef]

31. Corsi, S. Voltage Control and Protection in Electrical Power Systems-From System Components to Wide-Area Control; Springer: London, UK, 2015; pp. 163-190, ISBN 978-1-4471-6636-8.

32. Panda, S. Multi-objective evolutionary algorithm for SSSC-based controller design. Electric Power Syst. Res. 2009, 79, 937-944. [CrossRef]

33. Mithulananthan, N.; Canizares, C.A.; Reeve, J.; Rogers, G.J. Comparison of PSS, SVC, and STATCOM controllers for damping power system oscillations. IEEE Trans. Power Syst. 2003, 18, 786-792. [CrossRef]

34. Dominguez-Garcia, J.L.; Ugalde-Loo, C.E. Chapter 19-Power System Oscillation damping by means of VSC-HVDC systems. In HVDC Grids For Offshore and Supergrid of the Future; Van Hertem, D., Gomis-Bellmunt, O., Liang, J., Eds.; IEEE Press Series on Power Engineering; John Wiley \& Sons: Hoboken, NJ, USA, 2016; pp. 315-331, ISBN 978-1-118-85915-5.

35. Klein, M.; Rogers, G.J.; Kundur, P. A fundamental study of inter-area oscillations in power systems. IEEE Trans. Power Syst. 1991, 6, 914-921. [CrossRef]

36. Larsen, E.V.; Sanchez-Gasca, J.J.; Chow, J.H. Concepts for design of FACTS controllers to damp power swings. IEEE Trans. Power Syst. 1995, 10, 948-956. [CrossRef]

37. Kumar, A.; Srivastava, S.C.; Singh, S.N. A zonal congestion management approach using real and reactive power rescheduling. IEEE Trans. Power Syst. 2004, 19, 554-562. [CrossRef]

38. Yusoff, N.I.; Zin, A.A. Congestion Management in Power Systems-A review. In Proceedings of the 3rd International Conference on Power Generation Systems and Renewable Energy Technologies (PGSRET), Johor Bahru, Malaysia, 4-6 April 2017; pp. 22-27. [CrossRef] 
39. Official Journal of the European Union: Commission Regulation(EU) 2015/1222 of 24 July 2015 Establishing a Guideline on Capacity Allocation and Congestion Management. Available online: https:/ / eur-lex.europa. eu/legal-content/EN/TXT/PDF/?uri=CELEX:32015R1222\&from=EN (accessed on 9 September 2019).

40. CREG Paper (Z)1847: Paper on the Belgian Day-Ahead Wholesale Electricity Market from 1 to 7 October 2018, Focusing on the Market Outcomes for 3 October 2018. Available online: https: / www.creg.be/sites / default/files/assets/Publications/Notes/Z1847EN.pdf (accessed on 9 September 2019).

41. Emami, H.; Sadri, J.A. Congestion management of transmission lines in the market environment. Int. Res. J. Appl. Basic Sci. 2012, 3, 2572-2580. [CrossRef]

42. Singh, N.; David, A.K. Towards dynamic security-constrained congestion management in open power market. IEEE Power Eng. Rev. 2000, 20, 45-47. [CrossRef]

43. Yousefi, A.; Nguyen, T.T.; Zareipour, H.; Malik, O.P. Congestion management using demand response and FACTS devices. Int. J. Electr. Power Energy Syst. 2012, 37, 78-85. [CrossRef]

44. Pillay, A.; Karthikeyan, S.P.; Kothari, D.P. Congestion management in power systems-A review. Int. J. Electr. Power Energy Syst. 2015, 70, 83-90. [CrossRef]

45. Mwanza, K.; Shi, Y. Congestion Management: Re-Dispatch and Application of Facts. Master's Thesis, Department of Energy and Environment, Chalmers University of Technology, Goteborg, Sweden, 2006.

46. Regelleistung Website. Available online: https://www.regelleistung.net (accessed on 9 September 2019).

47. Wang, H.; Redfern, M.A. The advantages and disadvantages of using HVDC to interconnect AC networks. In Proceedings of the 45th International Universities Power Engineering Conference UPEC, Cardiff, Wales, UK, 31 August-3 September 2010; pp. 1-5.

48. Flourentzou, N.; Agelidis, V.G.; Demetriades, G.D. VSC-Based HVDC Power Transmission Systems: An Overview. IEEE Trans. Power Electron. 2009, 24, 592-602. [CrossRef]

49. ENTSO-E report on Technologies for Transmission Systems. Available online: https://tyndp.entsoe.eu/2016/ insight-reports/technology/\#line-commutated-converter-lcc-technology (accessed on 9 September 2019).

50. Egea-Alvarez, A.; Beerten, J.; Van Hertem, D.; Gomis-Bellmunt, O. Primary and secondary power control of multiterminal HVDC grids. In Proceedings of the IET International Conference on AC and DC Power Transmission, Birmingham, UK, 4-5 December 2012; pp. 1-6. [CrossRef]

51. Egea-Alvarez, A.; Junyent-Ferre, A.; Gomis Bellmunt, O. Modeling and Control of Sustainable Power Systems: Towards Smarter and Greener Electric Grids; Series: Green energy and technology; Springer: Berlin, Germany, 2012; pp. 47-81.

52. Beerten, J.; Diaz, G.B.; D'Arco, S.; Suul, J.A. Comparison of small-signal dynamics in MMC and two-level VSC HVDC transmission schemes. In Proceedings of the IEEE International Energy Conference (ENERGYCON), Leuven, Belgium, 4-8 April 2016; pp. 1-6. [CrossRef]

53. Loh, P.C.; Li, D.; Chai, Y.K.; Blaabjerg, F. Autonomous Operation of Hybrid Microgrid with AC and DC Subgrids. IEEE Trans. Power Electron. 2013, 28, 2214-2223. [CrossRef]

54. Beerten, J.; Gomis-Bellmunt, O.; Guillaud, X.; Rimez, J.; van der Meer, A.; Van Hertem, D. Modeling and control of HVDC grids: A key challenge for the future power system. Power Syst. Comput. Conf. 2014, 1-21. [CrossRef]

55. Kou, P.; Liang, D.; Wu, Z.; Ze, Q.; Gao, L. Frequency Support From a DC-Grid Offshore Wind Farm Connected Through an HVDC Link: A Communication-Free Approach. IEEE Trans. Energy Convers. 2018, 33, 1297-1310. [CrossRef]

56. De Haan, J.E.S.; Concha, C.E.; Gibescu, M.; van Putten, J.; Doorman, G.L.; Kling, W.L. Stabilising system frequency using HVDC between the Continental European, Nordic, and Great Britain systems. Sustain. Energy Grids Netw. 2016, 5, 125-134. [CrossRef]

57. Official Journal of the European Union: Commission Regulation(EU) 2016/1447 of 26 August 2016 Establishing a Network Code on Requirements for Grid Connection of High Voltage Direct Current Systems and Direct Current-Connected Power Park Modules. Available online: https:/ / eur-lex.europa.eu/legalcontent/EN/TXT/PDF/?uri=CELEX:32016R1447\&from=EN (accessed on 9 September 2019).

58. Renner, R.H.; Van Hertem, D. Potential of Wind Farms Connected to HVdc Grid to Provide DC Ancillary Services. IEEE Trans. Sustain. Energy 2018, 9, 1011-1020. [CrossRef]

59. Xue, Y.; Zhang, X. Reactive Power and AC Voltage Control of LCC HVDC System with Controllable Capacitors. IEEE Trans. Power Syst. 2017, 32, 753-764. [CrossRef] 
60. Yin, H.; Fan, L.; Miao, Z. Fast Power Routing Through HVDC. IEEE Trans. Power Deliv. 2012, 27, 1432-1441. [CrossRef]

61. Liu, H.; Sun, J. Small-signal stability analysis of offshore wind farms with LCC HVDC. In Proceedings of the 2013 IEEE Grenoble Conference, Grenoble, France, 16-20 June 2013; pp. 1-8. [CrossRef]

62. Azad, S.P.; Taylor, J.A.; Iravani, R. Decentralized Supplementary Control of Multiple LCC-HVDC Links. IEEE Trans. Power Syst. 2016, 31, 572-580. [CrossRef]

63. Saichand, K.; Padiyar, K.R. Analysis of voltage stability in multi-infeed HVDC systems with STATCOM. In Proceedings of the 2012 IEEE International Conference on Power Electronics, Drives and Energy Systems (PEDES), Bengaluru, India, 16-19 December 2012; pp. 1-6. [CrossRef]

64. Kaur, J.; Yogarathinam, A.; Chaudhuri, N.R. Frequency control for weak AC grid connected to wind farm and LCC-HVDC system: Modeling and stability analysis. In Proceedings of the IEEE Power and Energy Society General Meeting (PESGM), Boston, MA, USA, 17-21 July 2016; pp. 1-5. [CrossRef]

65. Fan, L.; Miao, Z.; Osborn, D. Wind Farms With HVDC Delivery in Load Frequency Control. IEEE Trans. Power Syst. 2009, 24, 1894-1895. [CrossRef]

66. He, X.; Geng, H.; Yang, G.; Zou, X. VSG Control for DFIG-based Islanded Wind Farm with LCC-HVDC Integration. In Proceedings of the IEEE Power \& Energy Society General Meeting (PESGM), Portland, OR, USA, 5-10 August 2018; pp. 1-5. [CrossRef]

67. Xue, Y.; Yang, C.; Zhang, X. Investigation of black start capability of LCC HVDC system with controllable capacitors. In Proceedings of the 12th IET International Conference on AC and DC Power Transmission (ACDC 2016), Beijing, China, 28-29 May 2016; pp. 1-6. [CrossRef]

68. Andersson, M.; Cai, R.; Yang, C. Black start of a passive AC network using bipolar LCC HVDC. In Proceedings of the 3rd Annual Conference of HVDC and Power Electronics Special Committee, Wuhan, China, 29 October-1 November 2014.

69. Azad, S.P.; Iravani, R.; Tate, J.E. Stability Enhancement of a DC-Segmented AC Power System. IEEE Trans. Power Deliv. 2015, 30, 737-745. [CrossRef]

70. Rauhala, T.; Järventausta, P. On feasibility of SSDC to improve the effect of HVDC on subsynchronous damping on several lower range torsional oscillation modes. In Proceedings of the IEEE PES General Meeting, Providence, RI, USA, 25-29 July 2010; pp. 1-8. [CrossRef]

71. Driesen, J.; Visscher, K. Virtual synchronous generators. In Proceedings of the IEEE Power and Energy Society General Meeting-Conversion and Delivery of Electrical Energy in the 21st Century, Pittsburgh, PA, USA, 20-24 July 2008; pp. 1-3. [CrossRef]

72. D'Arco, S.; Suul, J.A.; Fosso, O.B. Small-Signal Modeling and Parametric Sensitivity of a Virtual Synchronous Machine in Islanded Operation. Int. J. Electr. Power Energy Syst. 2015, 72, 3-15. [CrossRef]

73. Musa, A.; Kaushal, A.; Gurumurthy, S.K.; Raisz, D.; Ponci, F.; Monti, A. Development and Stability Analysis of LSD-Based Virtual Synchronous Generator for HVDC Systems. In Proceedings of the 44th Annual Conference of the IEEE Industrial Electronics Society, Washington, DC, USA, 21-23 October 2018; pp. 3535-3542. [CrossRef]

74. Hughes, F.M.; Anaya-Lara, O.; Jenkins, N.; Strbac, G. Control of DFIG-based wind generation for power network support. IEEE Trans. Power Syst. 2005, 20, 1958-1966. [CrossRef]

75. Ullah, N.R.; Thiringer, T.; Karlsson, D. Temporary Primary Frequency Control Support by Variable Speed Wind Turbines-Potential and Applications. IEEE Trans. Power Syst. 2008, 23, 601-612. [CrossRef]

76. Keung, P.; Li, P.; Banakar, H.; Ooi, B.T. Kinetic Energy of Wind-Turbine Generators for System Frequency Support. IEEE Trans. Power Syst. 2009, 24, 279-287. [CrossRef]

77. Vidyanandan, K.V.; Senroy, N. Primary frequency regulation by deloaded wind turbines using variable droop. IEEE Trans. Power Syst. 2013, 28, 837-846. [CrossRef]

78. Tavakoli, M.; Pouresmaeil, E.; Adabi, J.; Godina, R.; Catalão, J.P.S. Load-frequency control in a multi-source power system connected to wind farms through multi terminal HVDC systems. Comput. Oper. Res. 2018, 96, 305-315. [CrossRef]

79. Li, S.; Haskew, T.A.; Xu, L. Control of HVDC Light System Using Conventional and Direct Current Vector Control Approaches. IEEE Trans. Power Electron. 2010, 25, 3106-3118. [CrossRef]

80. Rabiee, A.; Soroudi, A.; Keane, A. Risk-Averse Preventive Voltage Control of AC/DC Power Systems Including Wind Power Generation. IEEE Trans. Sustain. Energy 2015, 6, 1494-1505. [CrossRef] 
81. Li, Z.; He, Y.; Li, Y.; Gu, W.; Tang, Y.; Zhang, X. Hybrid Control Strategy for AC Voltage Stabilization in Bipolar VSC-MTDC. IEEE Trans. Power Syst. 2019, 34, 129-139. [CrossRef]

82. Junyent-Ferr, A.; Pipelzadeh, Y.; Green, T.C. Blending HVDC-Link Energy Storage and Offshore Wind Turbine Inertia for Fast Frequency Response. IEEE Trans. Sustain. Energy 2015, 6, 1059-1066. [CrossRef]

83. Becker, H.; Naranovich, A.; Hennig, T.; Akbulut, A.; Mende, D.; Stock, S.; Hofmann, L. System restoration using VSC-HVDC connected offshore wind power plant as black-start unit. In Proceedings of the 19th European Conference on Power Electronics and Applications (EPE'17 ECCE Europe), Warsaw, Poland, 11-14 September 2017; pp. 1-8. [CrossRef]

84. Macleod, N.; Cowton, N.; Egan, J. System restoration using the "black" start capability of the 500MW EIRGRID East- West VSC-HVDC interconnector. In Proceedings of the IET International Conference on Resilience of Transmission and Distribution Networks (RTDN), Birmingham, UK, 22-24 September 2015; pp. 1-5. [CrossRef]

85. Li, L.; Zhou, M.; Li, S.; Li, Y. A New Method of Black Start Based on VSC-HVDC. In Proceedings of the International Conference on Computing, Control and Industrial Engineering, Wuhan, China, 5-6 June 2010; pp. 300-303. [CrossRef]

86. Preece, R.; Milanović, J.V.; Almutairi, A.M.; Marjanovic, O. Damping of inter-area oscillations in mixed AC/DC networks using WAMS based supplementary controller. IEEE Trans. Power Syst. 2013, 28, 1160-1169. [CrossRef]

87. Pipelzadeh, Y.; Chaudhuri, B.; Green, T.C. Control Coordination Within a VSC HVDC Link for Power Oscillation Damping: A Robust Decentralized Approach Using Homotopy. IEEE Trans. Control Syst. Technol. 2013, 21, 1270-1279. [CrossRef]

88. D'Arco, S.; Suul, J.A.; Molinas, M. Implementation and analysis of a control scheme for damping of oscillations in VSC-based HVDC grids. In Proceedings of the 16th International Power Electronics and Motion Control Conference and Exposition, Antalya, Turkey, 21-24 September 2014; pp. 586-593. [CrossRef]

89. Preece, R.; Almutairi, A.M.; Marjanovic, O.; Milanović, J.V. Damping of inter-area oscillations using WAMS based supplementary controller installed at VSC based HVDC line. In Proceedings of the IEEE Trondheim PowerTech, Trondheim, Norway, 19-23 June 2011; pp. 1-8. [CrossRef]

90. Corsi, S.; Danelli, A.; Pozzi, M. Emergency-stability controls through HVDC links. In Proceedings of the IEEE Power Engineering Society Summer Meeting, Chicago, IL, USA, 21-25 July 2002; Volume 2, pp. 774-779. [CrossRef]

(C) 2019 by the authors. Licensee MDPI, Basel, Switzerland. This article is an open access article distributed under the terms and conditions of the Creative Commons Attribution (CC BY) license (http:/ / creativecommons.org/licenses/by/4.0/). 


\title{
Ancillary Services in Hybrid AC/DC Low Voltage Distribution Networks
}

\author{
José M. Maza-Ortega ${ }^{1, *}$, Juan M. Mauricio ${ }^{1}$, Manuel Barragán-Villarejo ${ }^{1}$, Charis Demoulias ${ }^{2}$ \\ and Antonio Gómez-Expósito ${ }^{1}$ \\ 1 Department of Electrical Engineering, Universidad de Sevilla, Camino de los Descubrimientos s/n, \\ 41092 Seville, Spain; jmmauricio@us.es (J.M.M.); manuelbarragan@us.es (M.B.-V.); age@us.es (A.G.-E.) \\ 2 Department of Electrical and Computer Engineering, Aristotle University of Thessaloniki, \\ University Campus, 54124 Thessaloniki, Greece; chdimoul@auth.gr \\ * Correspondence: jmmaza@us.es
}

Received: 31 August 2019; Accepted: 18 September 2019; Published: 20 September 2019

\begin{abstract}
In the last decade, distribution systems are experiencing a drastic transformation with the advent of new technologies. In fact, distribution networks are no longer passive systems, considering the current integration rates of new agents such as distributed generation, electrical vehicles and energy storage, which are greatly influencing the way these systems are operated. In addition, the intrinsic DC nature of these components, interfaced to the AC system through power electronics converters, is unlocking the possibility for new distribution topologies based on AC/DC networks. This paper analyzes the evolution of AC distribution systems, the advantages of AC/DC hybrid arrangements and the active role that the new distributed agents may play in the upcoming decarbonized paradigm by providing different ancillary services.
\end{abstract}

Keywords: distribution networks; hybrid AC/DC networks; ancillary services

\section{Introduction}

Distribution systems have been traditionally designed, built and operated to fulfill the requirements of the large number of customers who are connected to them. Most of these traditional final users are characterized by absorbing power in an almost inelastic manner from the grid, i.e., irrespective of the energy price, to supply mainly electromechanical loads. The usual network design approach has considered these inherent characteristics of customers to achieve a reasonable quality of supply with the minimal investment cost and always considering the network expansion to face the gradual demand increase [1]. Nowadays, however, this traditional customer is steadily evolving to take advantage of the technological evolution which is paving the way to the smart grid paradigm. On the one hand, customers now may play an active role with the advent of the information and communication technologies (ICT), which offer the possibility of changing their consumption according to economic signals. On the other hand, the electronic-based loads are shifting the traditional electromechanical ones. This trend is unstoppable considering the expected massive deployment of electromobility [2-4] and distributed generation [5-7]. Without any doubt, this is a priority of our society which is focused on decarbonizing the transportation sector and increasing the participation of renewable energies in pursuit of the energy self-sufficiency. The most conservative forecast of the International Energy Agency (IEA) envisions an increase of the worldwide electric vehicle (EV) fleet from the current 2 millions up to 56 millions in 2030 [8]. Similarly, the International Renewable Energy Agency (IRENA) predicts a worldwide increase of the photovoltaic (PV) technology in the generation mix used to cover the demand from the current 233 TWh up to 1.104 TWh in 2030 [9]. In this new context, it will be of utmost importance to incorporate into the system new devices and procedures to provide the required flexibility for a safe and secure network operation. Finally, a huge increase of 
battery energy storage systems [10-12] (BESSs) is expected at the distribution level from three major drivers: EV deployment, utility-scale applications to tackle the network congestions, and domestic storage units used to modulate the final user demand. It is important to note that IRENA predicts an increase of BESS installed power from the current $1 \mathrm{GW}$ to $250 \mathrm{GW}$ in 2030 [13].

As a result, the distribution business has to evolve to cope with the new constraints imposed by these new agents distributed throughout the network, with stringent regulatory issues, scarce investment capability and final users more and more concerned with the power quality of supply. However, it is possible to take advantage of the flexibility that these new agents may provide to the distribution system, turning the problem into a solution. In fact, PVs, EVs, BESSs (collectively referred to as "PEB" in the sequel) and other power electronic based devices may bring several benefits to the distribution system operation, if properly managed so that they provide a number of ancillary services to the distribution system in addition to their corresponding primary functionality.

Moreover, note that in this new context a huge number of electrical devices connected to the low voltage (LV) distribution networks (PEBs, variable-speed drives associated to different appliances such as air conditioning systems, etc.) could be connected to a DC supply. Therefore, it is arguable whether the current $\mathrm{AC}$ networks are still the most efficient way of distributing electricity, owing to the need to include AC/DC converters for these loads. These front-end components, based on power electronic elements, increase the cost of these loads, reduce their efficiency and pollute the distribution system with harmonic currents affecting the system power quality. The use of hybrid AC/DC networks can be considered a logical step forward from the current AC distribution system, allowing loads of DC nature to be directly connected to the DC side of the network.

This paper elaborates on the role that the new agents (PEBs) and other power-electronic devices (DFACTS) may play in the current AC and future hybrid AC/DC LV distribution systems to provide flexibility by means of ancillary services. The paper is organized as follows: First, the main characteristics of traditional AC LV distribution systems are analyzed, followed by an update of the challenges that they are facing with the incorporation of the new distributed devices. Second, a comprehensive review of the most promising hybrid AC/DC LV network topologies is included. Third, different ancillary services for both conventional AC and future hybrid AC/DC networks are detailed. Finally, the paper closes with the main conclusions and future research work on this topic.

\section{AC LV Distribution Networks}

The aim of the distribution system is to supply the loads of a large number of customers considering safety, service continuity, power quality, flexibility and expandability issues at the minimum cost [14]. The design of traditional distribution systems comprising MV and LV networks can be broadly grouped into the so-called American or European layouts. The American distribution scheme is characterized by an unbalanced MV network comprising three-phase main feeders with several single-phase or two-phase laterals which directly supply a group of LV loads through pole-mounted MV/LV transformers of reduced rated power. Therefore, the LV network of the American layout is not large, as the main network extension is done in MV in order to reduce the system power losses as much as possible. On the contrary, the European layout is based on a balanced three-phase distribution using three-wire and four-wire configurations for MV and LV networks, respectively. In this case, the MV/LV transformers are always three-phase units and the phase-to-neutral connection of single-phase LV customers is balanced as much as possible among the three phases. Therefore, the LV network extension for the European layout is typically much larger than in the American case. For this reason, the following subsections focus only on the European LV distribution systems.

\subsection{One-Way LV Distribution Feeders}

Figure 1a shows the one-line diagram of a typical European LV distribution system, which is fed from a secondary substation equipped with a MV/LV three-phase power transformer. Usually, 
the connection group of the transformer is Dyn or Yzn to distribute the neutral wire for connecting the single-phase LV customers. The transformer secondary winding is connected to a LV switchboard where the protection of the different radial feeders is embedded. This protection customarily consists of simple fuses, the most cost-effective solution considering the short-circuit power levels of LV distribution systems, the large number of existing LV feeders and their radial nature. The number of LV radial feeders mainly depends on the rated power of the MV/LV transformer, but it typically ranges 4-10. Unlike in the MV case, the LV feeders are structurally radial in most cases, i.e., there is no way to modify the normal topology by acting on normally open switches, which would be helpful for instance to reduce the restoration time after a fault [1]. It is common, however, to find specific locations where the end nodes of those radial feeders are really close to each other, especially in urban areas.
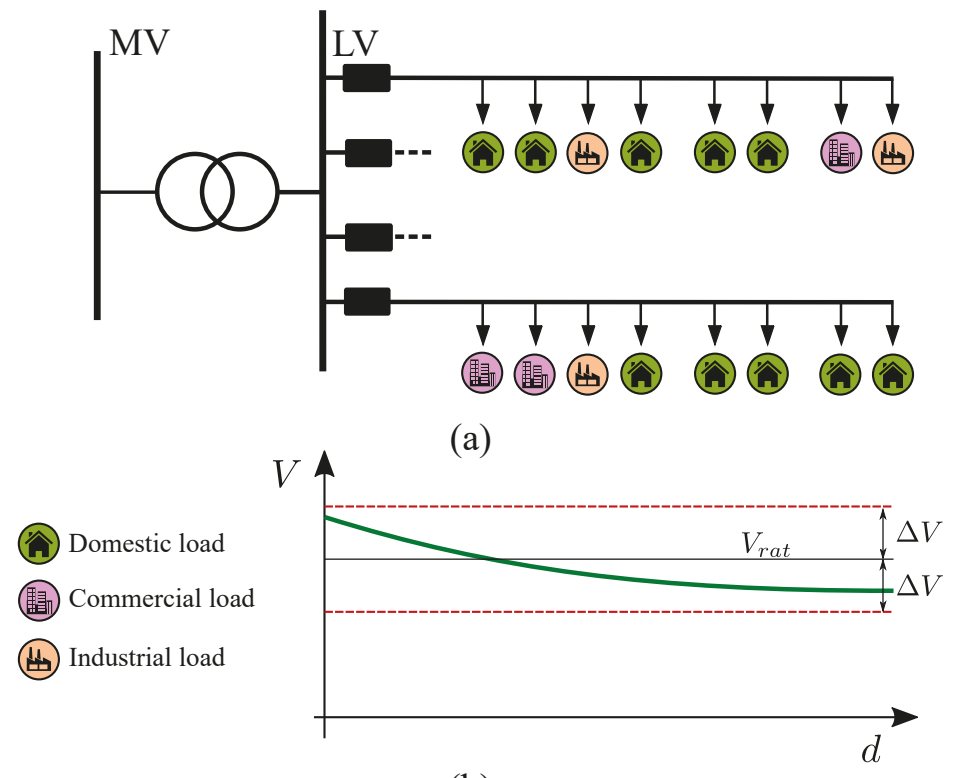

(b)

Figure 1. One-way LV distribution feeders: (a) one-line diagram; and (b) voltage profile along the feeder.

As a consequence of the radial design and the passive character of the final users, the power always flows in the same direction, from the secondary substation to the customers, and the voltage magnitude decreases monotonically, as shown in Figure 1b. In any case, the receiving voltage must be within the limits imposed by the standards [15]. For this purpose, the MV/LV transformers are equipped with off-load tap changers, allowing the utility to adjust the LV voltage at the head of the feeder to fulfill the voltage requirements. However, this device can be exclusively operated by disconnecting the transformer and interrupting the service to the final user. For this reason, the tap position is seldom readjusted once the transformer is commissioned. Those secondary substations close to the primary one feature higher MV voltages and, therefore, upper tap positions are usually selected to reduce the LV voltage. On the contrary, lower tap positions are used in those secondary substations far from the primary ones.

\subsection{Two-Way Distribution Feeders}

Figure 2 is the counterpart of Figure 1, updated in accordance with the smart grid paradigm arising by the incorporation of PEBs, which are transforming consumers into prosumers. These can play now 
a more active role by controlling their consumption/production profiles, considerably complicating the operation of the LV radial distribution system. First, the simultaneity coefficients of rooftop PV production and EV charging can be much higher than those of traditional commercial, residential or industrial loads. Second, the deployment of these new technologies within the distribution network is not homogeneous, being it possible to find different traditional customer versus prosumer ratios depending on several external factors. Third, the power flows are no longer one way, from the secondary substations to the final users. This completely modifies the voltage profiles along the feeders, as shown in Figure 2b, being it more difficult to guarantee that the final user voltage lies within the regulatory limits. Moreover, it is worth noting that this load/generation scenario is dramatically changing throughout the day, as the PV generation and the EV demand should be peaking during noon and midnight hours, respectively. Therefore, a massive penetration of PEBs may create distribution network congestions, i.e., currents above the ampacity ratings or voltages beyond regulatory limits, which cannot be alleviated by merely acting on the off-load tap changer of the MV/LV transformer.

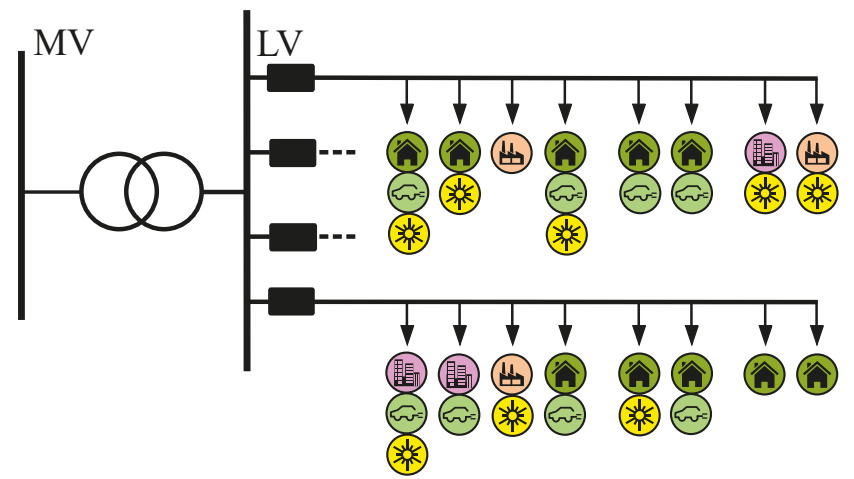

(a)

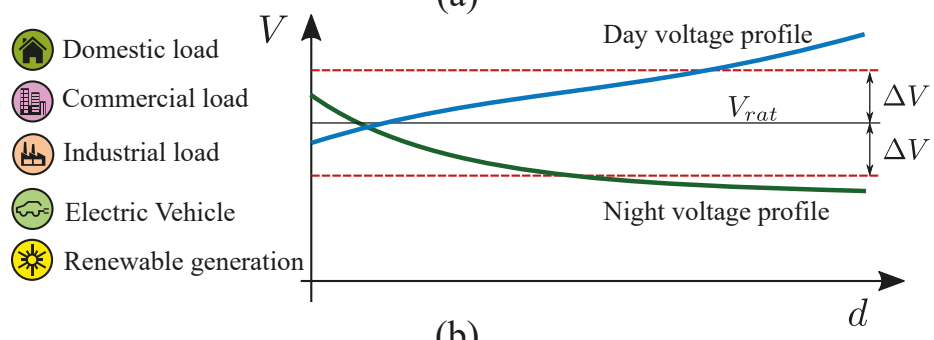

(b)

Figure 2. Two-way LV distribution feeders: (a) one-line diagram; and (b) voltage profile along the feeder.

Classical network reinforcement, i.e., increasing the cross-section area of cables or installing new LV feeders, may solve the voltage regulation problem. However, in cases where the feeder congestions arise a few days a year, it is questionable whether the investments in new assets are really justified. Moreover, those network reinforcements are not always straightforward from a practical point of view in densely populated urban areas where underground installations are used. The main issue, however, is that network reinforcement does not tackle the root of the problem, namely the radial topology of the LV distribution network, which constitutes the main technical barrier to the deployment of the new decarbonizing technologies.

A promising alternative solution to this problem comes from the application of new smart-grid technologies, particularly new power electronics-based devices and new control systems, as proposed in Figure 3 and discussed in the following subsections. 


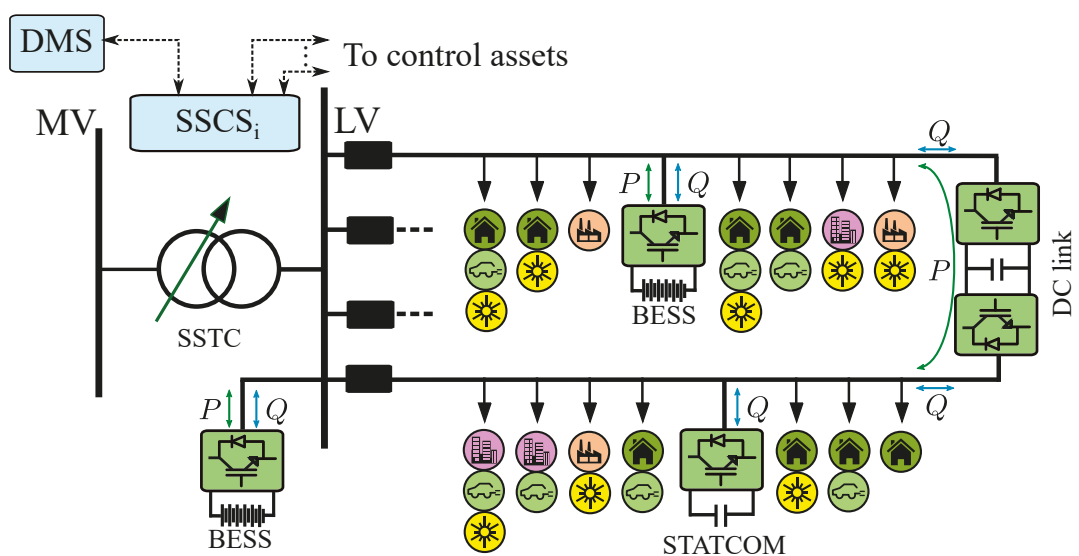

(a)

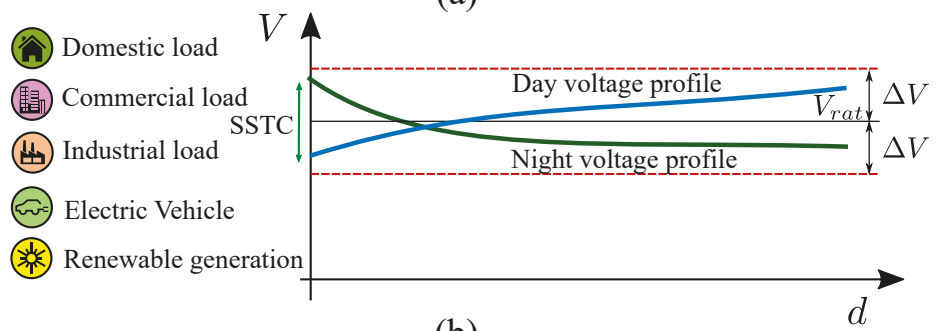

(b)

Figure 3. Advanced two-way LV distribution feeders: (a) one-line diagram; and (b) voltage profile along the feeder.

\subsubsection{Utility-Scale Power Electronic Devices}

Four different utility-scale devices are incorporated in Figure 3 to host as much PEBs as possible by providing additional flexibility:

- Solid-State Tap Changer (SSTC). The objective of this device is to regulate the voltage on the LV side by changing the turns ratio of the MV/LV transformer. This device uses a set of static switches, usually made up of two antiparallel thyristors instead of the traditional mechanical switches. These switches, installed in the MV transformer regulation winding, are always operated in on/off mode, therefore preventing the risk of introducing harmonic distortion in the system, at the cost of regulating the voltage in a stepwise manner, as shown in Figure 4a [16]. Other SSTC topologies based on IGBT technology have been proposed in the specialized literature, which are able to regulate the LV voltage in a continuous manner, at the cost of higher power losses and harmonic distortion [17]. In any case, these devices are serious competitors of the traditional on-load tap changer (OLTC) based on mechanical switches, owing to the absence of movable parts, unlimited number of maneuvers, fast voltage regulation and almost null maintenance cost.

- $\quad$ STATCOM. This device is based on a Voltage Source Converter (VSC) equipped with IGBTs and an isolated DC bus, as shown in Figure $4 \mathrm{~b}$. The aim of this device is to inject reactive power to the system to control the voltage of its point of connection $[16,18,19]$. In addition, it is possible to operate this device to mitigate the inherent imbalance of the LV system [20]. For this purpose, four-wire topologies are preferred so that zero-sequence components can be compensated [21-24].

- $\quad$ BESS. This asset is composed of a VSC with a battery for energy storage connected to the DC bus, as shown in Figure 4c [25]. The main goal of this device is to inject or absorb active power to the system to provide different ancillary services, ranging from frequency regulation [26], 
peak shaving [27] and energy shifting [28]. In addition, it is possible to contribute to the voltage regulation by means of active and/or reactive power injections.

- DC link. The aim of this device, also known as flexible link, is to create a controllable loop between the radial feeders to which it is connected. It is composed of two VSCs connected in back-to-back configuration sharing a common DC bus, as shown in Figure 4d [29]. This device may control the active power flow between the interconnected feeders and two independent reactive power injections. This provides an extraordinary flexibility to the distribution system operation [30,31]. In fact, this device can fully overcome the barrier related to the radial nature of the LV distribution system, because network congestions in one feeder can be alleviated using the neighbor feeder as a back-up supply point. The use of this DC link is advantageous when compared to a conventional meshed operation, where the active and reactive loop flows cannot be controlled. In addition, the meshed operation requires an expensive protection system to cope with short-circuit faults [32]. On the one hand, the short-circuit current increases as both interconnected feeders contribute to the fault current. On the other hand, note that the protections of both interconnected feeders should trip in the case of a short-circuit fault and, therefore, disconnecting a larger number of customers in comparison to the radial operation case. The use of DC links, based on back-to-back VSCSs, prevents this undesired effect, as the healthy feeder can be quickly isolated from the faulted one by just inhibiting the gating signals to the IGBTs. This way, it is possible to maintain the conventional, simple and reliable protection system used in $\mathrm{LV}$ radial distribution networks. It is worth noting that it is possible to interconnect $N$ feeders by means of multi-terminal arrangements. This multi-terminal device, composed of $N$ converters, has $2 N-1$ degrees of freedom, $N-1$ of them corresponding to active power flows (as one of the VSCs must control the DC bus voltage) and $N$ to reactive power flows [33]. Finally, it is interesting to highlight that the DC bus of this device may incorporate a PV generator, a battery or even an EV fast charger station, providing even more flexibility of operation [31]. Alternative topologies have also been proposed to reduce as much as possible the rating of the power electronic components, aimed at reducing its cost [34].

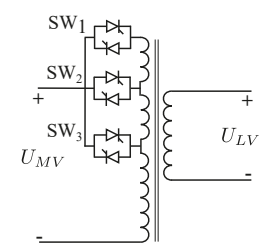

(a)

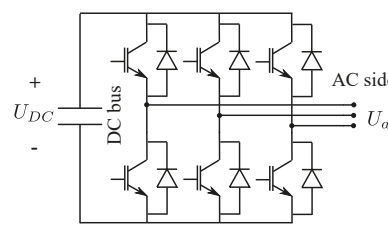

(b)

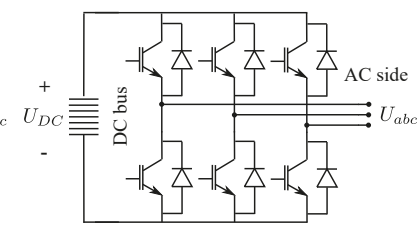

(c)

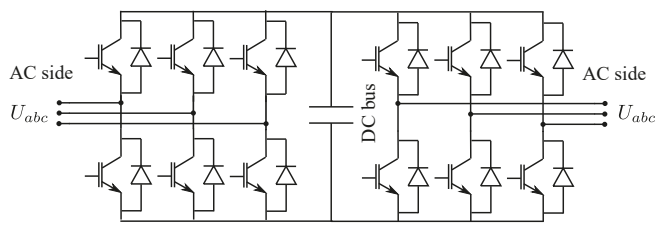

(d)

Figure 4. Power electronic devices incorporated in the smart grid distribution system: (a) solid state tap changer (SSTC); (b) three-phase, three-wire STATCOM; (c) three-phase, three-wire BESS; and (d) DC link composed of two back-to-back VSCs.

\subsubsection{Control Systems}

The new paradigm arising around the active distribution systems discussed above and depicted in Figure 3, involves the development of a Secondary Substation Control System (SSCS) [35]. After decades of incremental technological advances, this constitutes a leapfrog with respect to 
the current status of LV AC distribution networks. Nowadays, those networks are unobservable in real-time, being equipped in the best cases with just a data concentrator to gather the data from the smart meters downstream [36]. This Advanced Metering Infrastructure (AMI), however, is thus far exclusively used for billing purposes, its extension for improving the network operation still being on the blackboard. The aim of the control system included in Figure 3 is twofold:

- Determine, in a coordinated fashion, the control actions of the different assets spread along the distribution system to improve its operation. In this sense, the control assets may belong either to the utility or third-parties, such as PV generator or EV charger, which may provide different ancillary services. These control actions can be obtained by means of algorithms specially tailored to each specific application. Mimicking the customary structure of AC transmission control systems, those algorithms can be hierarchically organized in three control layers with different time scales. The primary control level provides fast reactions aimed at rejecting any system perturbation and maintaining the controlled variables close to their reference values. This is usually implemented locally, following a linear droop, which calls for a slower secondary control intended to eliminate the steady-state error associated to the primary control. Finally, the third and slower control layer is devoted to computing the optimal reference values for the controlled variables by introducing some optimization criteria [37].

- Interact with the Distribution Management System (DMS) of the utility: (i) to provide aggregated data of the downstream system state; and (ii) to receive control requirements to provide ancillary services to the MV network.

The adoption of this hierarchical control scheme, as shown in Figure 5, is advisable in case of distribution systems where the number of power assets and prosumers is huge [38,39]. The traditional centralized approach, where a unique control center is in charge of receiving and processing all the raw field measurements, as well as computing the required control actions for the set of control assets [40], is not scalable if the whole LV network is incorporated, as this may entail thousands of components for a single primary substation. Undoubtedly, ICTs will play a crucial role in this new context, as they are required for exchanging the information between the different agents [14]. The ICT requirements are quite demanding if real-time network operation is envisaged, in addition to back-office functionalities such as billing of customers. Therefore, special attention must be paid to ICT resiliency, time latencies and cybersecurity issues.

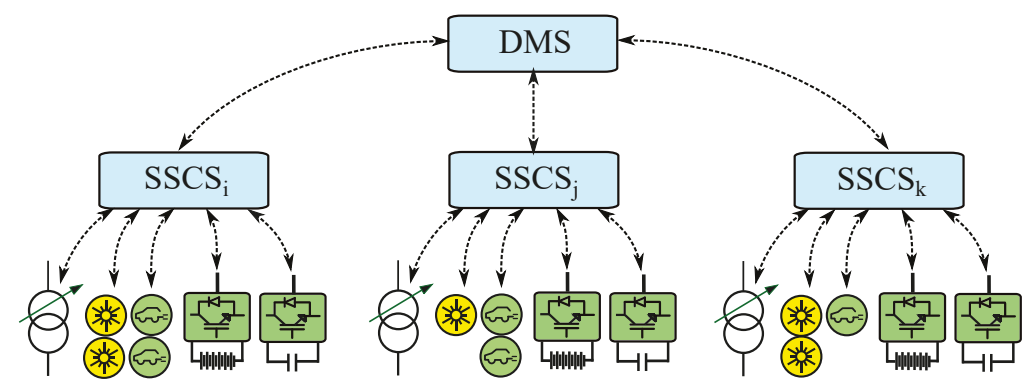

Figure 5. Hierarchical control of active distribution systems.

\section{Hybrid AC/DC Networks}

Hybrid networks, composed of AC and DC parts, are not new in power systems. Their existence dates back to the fifties of the last century in transmission applications when the first HVDC was built to supply the Götland Island [41]. The use of HVDC has been mostly restricted to applications characterized by the need of transmitting large power through large distances, where AC lines are constrained by stability issues [42]. The technological evolution in terms of rated power and DC 
voltage has since been impressive. Some installations of modern HVDC based on VSC technology reach $1.8 \mathrm{GW}$ with a rated voltage of $\pm 500 \mathrm{kV}[43,44]$ while some traditional HVDC units based on thyristors go up to $8 \mathrm{GW}$ and $\pm 800 \mathrm{kV}[45,46]$. HVDC has also been used to evacuate the active power of large off-shore wind power plants to the transmission system due to the reduced capability of long AC submarine cables [47,48].

In the opposite extreme of the grid spectrum, hybrid AC/DC networks have also been explored in microgrids. The microgrid concept [49], originally proposed in 2002 as a building block of the future distribution system, has been of interest for the scientific community due to the new advances in power electronics and digital processors with extended computation capability [50,51]. During the last years, different microgrid proposals based on either DC or AC technologies have emerged without a clear consensus on the best topology aiming at optimizing DC [52] and AC [53] resources simultaneously. Hybrid AC/DC networks represent a natural evolution of microgrids, merging their advantages. Wang et al. [54] proposed these hybrid networks as an efficient solution for supplying DC loads. This achieves a reduction of intermediate conversion stages with the subsequent cost reduction of electronic devices. In addition, the power quality of the AC network, mainly imbalances and harmonic distortion, can improve, because of the use of advance control algorithms in the centralized power converters used for connecting both networks. Multiple configurations of hybrid AC/DC networks can be found in the specialized literature, which can be classified according to different criteria: network topologies, involved power electronics converters and applied control algorithms. The following subsections are devoted to analyzing each of these topics.

\subsection{Network Topologies}

The simplest hybrid AC/DC network is based on the use of the back-to-back VSCs for supplying the DC loads from the DC bus [55,56]. However, it is also possible to find more futuristic approaches where a hierarchically organized power system composed of several hybrid AC/DC subnetworks connect each other by a number of power electronic converters, somehow mimicking the architecture and behavior of the Internet [57,58]. Due to this diversity of solutions, [59] raised an interesting taxonomy of the different existing topologies including a comparison with regard to different technical criteria.

In any case, to assure an adequate deployment of hybrid AC/DC networks, it is required to rely on two basic design principles: (1) to leverage as much as possible the already existing infrastructure of the existing AC network in line with [60]; and (2) to minimize the number and complexity of power devices used for the active management of the network. Considering these underlying ideas, Figure 6 shows a straightforward derivation of a LV hybrid AC/DC distribution network by adding just the DC conductors to the already existing four-wire AC branches. The existing reserve conduits of underground installations can be sometimes used for placing the new conductors. In this topology, the DC network is supplied from a central VSC within the secondary substation but also from other AC/DC links which can be distributed along the network. AC loads are supplied as usual while DC ones are directly plugged into the DC network, eventually using DC/DC converters. It is important to point out that the bridges between the AC and DC networks allow a bidirectional flow of active power. This opens the possibility of optimizing the power flows between the AC and DC sides to obtain the best operation in terms of power losses while maintaining the power quality to the final user. 


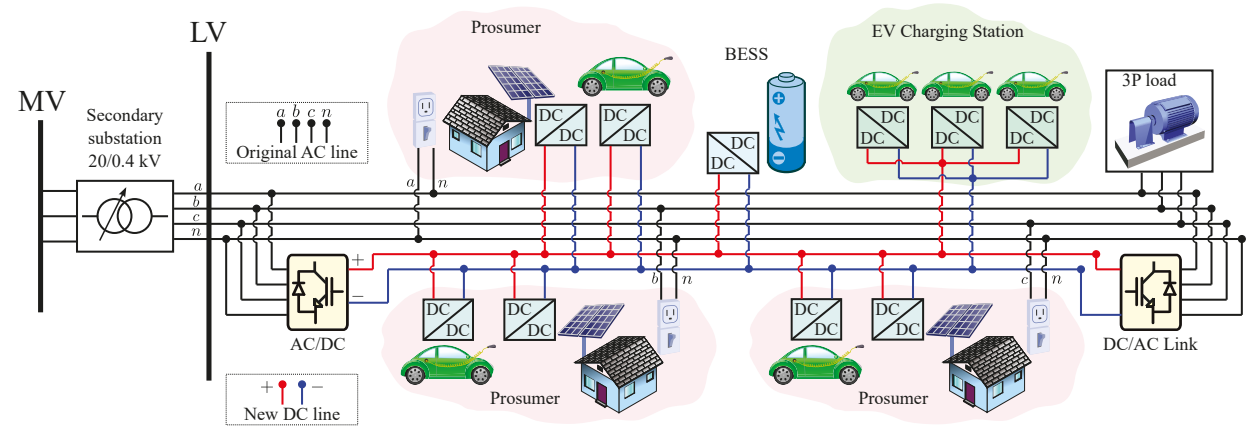

Figure 6. Hybrid AC/DC LV distribution network by adding new DC conductors.

It is worth noting that the hybrid AC/DC grid proposed in Figure 6, which is derived from an original AC grid, increases the network loadability because of the new DC lines. However, this loadability increase is limited by the rated power of the MV/LV transformer within the secondary substation. A possible alternative, which maintains the existing LV line infrastructure, is shown in Figure 7. In this case, two AC phases are transformed into DC lines. The single-phase AC and DC loads are directly fed from the AC and DC networks, respectively, while the three-phase ones require the use of three-phase VSCs supplied from the DC bus (in general, however, three-phase loads are a minority in LV systems). The DC network is supplied from the secondary substation with a three-phase and four-wire central VSC but additional single-phase VSCs can be connected to create bridges between the $\mathrm{AC}$ and $\mathrm{DC}$ sides.

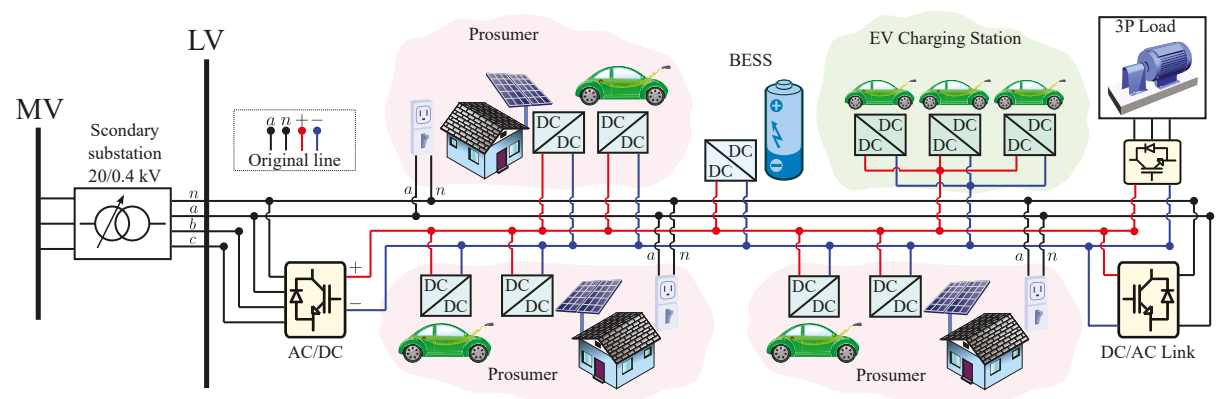

Figure 7. Hybrid AC/DC LV distribution network by replacing two AC conductors by DC ones.

Finally, it is worth noting that those two network topologies are not mutually exclusive, depending on the characteristics of the customers. This way, LV networks with a predominant presence of domestic users, which are characterized by DC and single-phase AC loads, should be adapted to the topology proposed in Figure 7. On the contrary, Figure 6 is preferred for those networks with commercial and industrial users with DC and three-phase AC loads.

\subsection{Power Electronic Converters}

Undoubtedly, AC/DC and DC/DC power electronic converters are the cornerstone of the AC/DC hybrid networks. In the case of three-phase AC systems, traditional three-phase converters are usually applied [54,55]. However, for single-phase AC systems, it is possible to find different alternative solutions to the conventional single-phase VSC [61]. For example, the authors of $[62,63]$ presented a single-phase high-power density converter with two stages composed of a DC/DC regulator and a classical AC/DC bridge. 
On the other hand, DC/DC converters have been widely used for adapting the voltage levels of renewable power sources and energy storage systems, both in isolated $[64,65]$ and non-isolated arrangements [66].

\subsection{Control Algorithms}

Hybrid AC/DC networks are inherently flexible distribution systems, as they are composed of several AC/DC converters bridging AC and DC sides at different nodes. As a result, it is possible to apply different real-time control strategies aimed at maximizing the network performance. For instance, [67] controlled the EV charges in an effective way so that technical constraints violations are eliminated. In [68], the distributed generation is scheduled to satisfy the demand at minimum supply cost. [69] solved a centralized dispatch of generation and storage units in a hybrid AC/DC network considering the variability of the renewable energy sources. [70] analyzed the application of hybrid AC/DC networks within buildings equipped with renewable energy sources, energy storage and controllable loads. As can be noticed, a wide range of control algorithms can be found in the specialized literature. The interested reader is referred to the hierarchical classification and technical characterization proposed in [71].

It is important to highlight that the control architecture usually poses a hierarchical layout, similar to the one shown in Figure 3 and discussed in Section 2.2.2, where the centralized controller acts as a tertiary control level in charge of computing the optimal set-points for the AC/DC and DC/DC converters. In turn, those devices are equipped with primary controllers which are in charge of tracking the references sent by the central secondary controller [72]. In this sense, it is worth stressing that the centralized controller solves an optimization problem to minimize a given objective function, including a set of inequality an equality constraints, of the form:

$$
\begin{array}{cl}
\min & f(\mathbf{x}, \mathbf{u}) \\
\text { s.t. } & \mathbf{g}(\mathbf{x}, \mathbf{u})=\mathbf{0} \\
& \mathbf{h}(\mathbf{x}, \mathbf{u}) \leq \mathbf{0}
\end{array}
$$

where vector $\mathbf{x}$ comprises the dependent or state variables and vector $\mathbf{u}$ the control variables. The inequality constraints take into account the technical limits of the network (ampacity limits of lines and maximum nodal voltage variations) and the AC/DC and DC/DC converters (maximum converter current and DC voltage range). The equality constraints stand for the network equations comprising both $\mathrm{AC}$ and $\mathrm{DC}$ parts. This requires specific formulations, such as the one proposed in [73-75] for solving the load flow problem in the presence of VSC-based HVDC networks and/or microgrid systems. Finally, note that these optimization problems should be fed with real-time measurements from the field, if they are to be used for control purposes. For this reason, it is essential to rely on state estimators for computing the maximum likelihood state of the network from the raw field measurements [76]. However, suitable models for the specific case of HVDC systems have recently been developed [77-79].

\section{Ancillary Services in AC and Hybrid AC/DC LV Distribution Systems}

The advanced AC and hybrid AC/DC LV distribution grids presented in the previous sections, comprising several power electronics based components with accurate and fast control capabilities, allow an unprecedented and sophisticated active network management. In this upcoming paradigm, the new controllable assets may improve the distribution grid operation by providing different ancillary services, mimicking to a large extent the well-known operation of transmission systems.

The definition of ancillary service is somewhat fuzzy, as it encompasses any service required by the transmission or distribution system operator to maintain the integrity, stability and power quality of the system [80]. In fact, there is no unique or harmonized definition even for countries within the European Union, where different provision schemes are articulated [81]. In this work, 
the following ancillary services for AC and hybrid AC/DC LV distribution grids can be defined: voltage control, congestion release, imbalance reduction, harmonic distortion mitigation, power smoothing, inertial response and power frequency response. A classification of these ancillary services and the side of the network where they can be applied is detailed in Table 1. The following subsections outline each of these ancillary services, some of them related to the frequency and voltage control, others dealing with power quality issues.

Table 1. Classification of ancillary services for AC and hybrid AC/DC distribution networks.

\begin{tabular}{lcccc}
\hline Ancillary Service & Nature & Dynamic Charac. & AC Side & DC Side \\
\hline Voltage control & Voltage control & Dynamic & $\checkmark$ & $\checkmark$ \\
\hline Congestion release & Congestion release & Quasi steady-state & $\checkmark$ & $\checkmark$ \\
\hline Unbalance reduction & Power quality issue & Quasi steady-state & $\checkmark$ & \\
\hline Harmonic distortion mitigation & Power quality issue & Quasi steady-state & $\checkmark$ & $\checkmark$ \\
\hline Power smoothing & Power quality issue & Dynamic & $\checkmark$ & $\checkmark$ \\
\hline Inertial response & Frequency control & Dynamic & $\checkmark$ & \\
\hline Power frequency response & Frequency control & Dynamic & $\checkmark$ & \\
\hline
\end{tabular}

\subsection{Voltage Control}

The objective of this ancillary service is to maintain the voltage levels at the different nodes of the distribution system within the technical limits [15]. The presence of distributed generation within the AC distribution system may create voltage rises due to inverse power flows that were not common in distribution systems [82]. On the contrary, the massive EV integration may create deep undervoltages. Active power curtailment has been proposed to mitigate this problem [83,84]. However, the practical difficulties of its implementation, related to a fair curtailed power allocation between the involved generators, and the high cost of the curtailed power, prevent its use. As an alternative, reactive power injections by distributed generators [85-87] or EV charging stations [88] can be used for controlling the voltage. The reactive power injections can be done depending on local voltage measurements [89] or according to control signals computed by a centralized algorithm [90]. The utility-scale power electronic devices previously outlined (BESSs, STATCOMs and DC links) can also be used for providing this ancillary service. Note that BESSs [91] and DC links [30] may also contribute with adequate active power management. In addition, SSTCs play an important role in the voltage control of LV distribution systems [92]. This is even more relevant in those cases where the high $\mathrm{R} / \mathrm{X}$ ratio leads to a low sensitivity of voltage with respect to the reactive power injections [93]. In those situations, controlling the voltage by means of reactive power injection is not a cost-effective solution, which prevents the use of large utility-scale devices or oversized distributed generators. Undoubtedly, a coordinated control of all these resources is the best option to provide the voltage regulation within the AC distribution system [94].

Regarding the voltage control on the DC side of the hybrid AC/DC distribution systems, it is important to highlight the lack of standards on DC networks, beyond those related to data centers and ICT infrastructures $[95,96]$. In any case, this ancillary service has to be done by adequate active power management of the DC generators, BESSs and AC/DC converters supplying the DC network from the AC side [97-99]. In this sense, the use of AC/DC bidirectional converters spread along the network is of special interest to regulate the active power flow on the DC and/or AC sides, depending on the network loading.

\subsection{Congestion Release}

This ancillary service aims to maintain the power flows through the different branches of the distribution system below the ampacity limits. In traditional passive systems, this problem can 
only be solved by network reinforcement. However, this is not the best solution considering the cost, connection time and the spare capacity of the new assets over a large number of hours per year $[100,101]$. The active management of the future LV distribution systems offers multiple solutions for maximizing the loadability of the existing assets below their ratings. Considering the utility-scale devices, in addition to BESS [102], the DC link is probably the most promising solution for congestions release in radial distribution systems [30,31,34]. Moreover, PV generation or EV charging can be connected to its DC bus, facilitating the integration of these new components [33]. As far as distributed generation is concerned, it is possible to resort to generation curtailment [103], but also to the exchange of reactive power aimed at maintaining the voltages within acceptable bounds $[104,105]$. Similarly, the EV charging can be done in a controlled fashion to minimize its impact on the distribution system $[106,107]$. However, the most interesting results are obtained by exploiting the synergies between the distributed generation and EV charging [108,109]. In fact, the use of hybrid AC/DC networks maximizes this synergy, as the active power flow through the AC/DC bridges corresponds to the net active power of $\mathrm{EV}$ and distributed generation, minimizing their impact on the AC side.

\subsection{Unbalance Reduction}

Load unbalance, mainly due to the presence of unevenly distributed single-phase customers but also to domestic single-phase PV installations, is one of the main power quality problems of LV distribution networks $[20,110]$. The phase unbalances lead to several problems such as neutral and ground currents, neutral point-shifting and higher losses than in balanced operation [111]. For this reason, the voltage unbalance is usually limited in the current standards $[15,112]$. In this situation, those technologies based on VSCs (STATCOMs, BESSs, PV generation and DC links) may provide the unbalance reduction as ancillary service to the distribution grid. Some of these devices may have the unbalance reduction as their main target (e.g., STATCOM) but it is also possible to rely on alternative devices equipped with advanced control algorithms with other primary functionalities (e.g., BESSs, $\mathrm{PV}$ generation or DC links). For this purpose, those devices have to inject different current in each phase trying to balance the current upstream of their point of connection [113-115]. This implies injecting not only positive sequence current but also negative and zero sequence components. Particularly, the VSC plays an import role in this regard [21]. As three-phase, three-wire VSCs may only inject positive and negative sequence components, four-wire topologies are needed capable of injecting zero sequence currents. Different topologies have been proposed for the three-phase, four-wire VSC [22,23], which can be also composed of a set of three single-phase units [24]. Finally, it is also worth noting that the use of SSTCs with individual phase operation capability may also contribute to reduce the system voltage unbalance [116,117].

\subsection{Harmonic Mitigation}

Harmonic distortion is a relevant power quality issue in AC distribution systems because of the proliferation of non-linear loads. The use of power electronic devices, thyristors and/or diodes, for rectification purposes creates $m \cdot k \pm 1$ low order harmonics where $m$ represents the number of pulses of the device. The problems created by these harmonics are well documented, including increase of power losses, overload of capacitor banks, electromagnetic interferences, overvoltages, malfunction of protection devices, and overload of neutral conduct and resonances among others [118]. Harmonic distortion is limited by several standards $[15,112,119]$ and traditionally have been reduced by applying passive filtering techniques [120]. However, the development of power electronics, particularly the self-commutated technology [121], has enabled the application of active filtering [122]. Despite the shunt active filter being probably the most common topology, series and shunt-series active filters have also been proposed for reducing the rating of the power electronic components and increasing the filtering performance [123]. However, any device based on VSCs (STATCOMs, BESSs, PV generation and DC links) may incorporate this advanced functionality and provide this ancillary service to the distribution system [124]. Basically, the operation principle is 
similar to the one used for the unbalance mitigation: injection of harmonic currents to achieve an almost sinusoidal current upstream of the point of connection. However, note that the local compensation of harmonic currents usually does not lead to a global reduction of the harmonic distortion [125]. For this reason, coordinated control strategies have to be applied for achieving this global goal [126-128]. Regarding the harmonic reduction on the DC side of hybrid AC/DC networks, the harmonics caused by the previously mentioned line commutated converters are of orders $m \cdot k$. Despite methods for computing the harmonics of DC networks being available for special applications, such as HVDC installations [129], there is not a clear standard limiting them. However, the harmonic reduction on the DC side of the hybrid AC/DC systems can be provided either by the DC/DC or AC/DC converters connected to them.

\subsection{Power Smoothing}

The introduction of renewable generation relying on uncontrollable primary energy sources may produce large variations of the active power injections, which may lead to several problems in the power system. These variations are perceived by the conventional power plants based on synchronous generators as power ramps, which have to be compensated to maintain the power balance in the system [130]. These power ramps are especially problematic in weak AC networks where system operators try to limit their magnitude to assure the system stability [131-133]. Conversely, the power variations also have to be limited on the DC side of hybrid AC/DC networks to control as much as possible the DC voltage fluctuations [99]. This ancillary service can be provided by distributed generators, BESSs and other energy storage systems [134] depending on the rate of power change. Fast power variations, with time scales lower than $60 \mathrm{~s}$, can be compensated by distributed generation equipped with advanced controllers, such as the rotor inertia control [135] and pitch angle control [136] in wind energy systems, without even involving complementary energy storage device. In addition, it is possible to use fast energy storage systems, such as supercapacitors [137], which are able to manage large amounts of active power in short-time periods without any risk of accelerated aging. Conversely, BESSs are most suitable for slow power variations [138] with different control strategies based on moving average [139] or ramp-rate control [140] algorithms.

\subsection{Inertial Response}

The introduction of renewable generation is displacing the conventional units based on synchronous machines, which are the main source of inertia of the power system. The inertia of a synchronous generator counteracts the frequency changes by injecting or absorbing an additional active power, instantly taken from the kinetic energy of the rotor [37]. Thus, as the penetration level of renewable generation increases, the system inertia decreases and its dynamic control becomes challenging [141]. A possible solution to overcome this shortcoming is to incorporate BESSs, either in standalone installations or combined with generation assets, to emulate the behavior of the synchronous generators, namely to provide virtual inertia. This ancillary service can be provided following different strategies [142]:

- $\quad$ Exact synchronous generators model-based methods, where the objective is to mimic the exact dynamic behavior of the electrical machine by means of a detailed mathematical model in the control algorithm of the converter interfacing the storage system. The following methods can be framed within this category: synchronverters [143,144], virtual synchronous machine [145] and KHI topology [146].

- $\quad$ Swing equation-based control schemes. These control schemes simplify the exact equations of the synchronous generators, retaining only those terms related to the swing equation. ISE topology [147] and Synchronous Power Controller [148] can be cited within this group.

- $\quad$ Frequency-based response techniques. In this case, the control algorithm reacts on any frequency disturbance and, therefore, provides an inertial response on an indirect way. Virtual synchronous generators [149] have been proposed within this category. 


\subsection{Power Frequency Response}

The objective of this ancillary service is to contribute to the frequency regulation of the power system when a frequency disturbance, due to an imbalance between generation and load or any frequency stability issue, appears in the power system. Primary frequency response is implemented in the governor control of the synchronous generators by defining a given power versus frequency droop curve. This local implementation allows an immediate reaction against frequency variations without the intervention of any higher supervisory control [141]. This primary frequency response is slower than the inertial one outlined in the previous subsection, with an actuation time scale from a few milliseconds up to 30-40 s. The progressive integration of renewable energy sources replacing traditional generation requires the provision of this ancillary services by BESSs. On the one hand, it has to be considered that BESS, as a power electronics based device, has a faster response in comparison to traditional synchronous generators. On the other hand, it has to be considered the limitations of this technology. First, BESSs are constrained in energy which prevents its use as conventional generation units. Second, BESSs are constrained in power with limited ramping rates. Third, the number of frequency events and their duration are related to the number of cycles and the depth of discharge of the battery which are strongly related to its aging [150,151]. A straightforward way of providing this ancillary service is by implementing a power versus frequency droop curve in the BESS controller in such a way that active power is injected or absorbed when the frequency decreases or decreases, respectively [152,153]. To reduce the cycling of the battery, it is usual to incorporate a dead band around the fundamental frequency [154]. In addition, this ancillary service can be at least partly provided by renewable generation units, which usually operate maximizing the power conversion from the primary energy source [155]. As an alternative, the plant can be operated below the maximum power point, allowing reactions to frequency excursions of both signs [156,157]. Otherwise, the non-dispatchable generation units may act exclusively on over frequency events.

\section{Conclusions}

This paper analyzes the evolution of LV distribution systems from the traditional AC passive networks to future hybrid AC/DC systems, and the role that the new power electronics based technologies may play in this new distribution paradigm by providing ancillary services. This change is being driven by the technological substitution of the traditional electromechanical devices by the new power electronics ones and the development of control systems based on advanced communication infrastructure. The new distributed agents, including PV generation, EV chargers and other utility-scaled devices such as SSTCs, STATCOMs, BESS and DC links, allow an active management of the distribution system to be implemented. The paper outlines the basic operational principles of each of those technologies and their use for an improved operation of the distribution grid. Actively operating the LV distribution grid requires the intervention of a control system in charge of supervising and determining the adequate set-points for each control asset. For this purpose, a hierarchical scheme is described where each LV distribution network departing from a secondary MV / LV substation is locally controlled. Once the LV AC distribution system has been transformed from a passive to an active network, by incorporating the power and control elements previously mentioned, it is questionable if the AC topology is the most adequate one, considering the DC nature of many of those power devices. The authors' opinion is that hybrid AC/DC LV networks constitute the logical way of incorporating new DC components to the existing AC LV systems. This is envisioned as a smooth transition, trading off the need to maximize the use of the AC legacy assets while allowing a massive roll-out of the DC technology. In any case, irrespective of whether the LV network is purely AC or hybrid AC/DC, it is of utmost importance to duly consider the contribution that the new controllable assets may bring to the whole system, by the provision of ancillary service. The paper has ended by outlining different ancillary services related to frequency regulation, voltage control and power quality issues, which will be required in the near future at the distribution level. The evolution of the power systems throughout the 20th century declared Tesla as the undisputed winner of the war of the 
currents after Edison's fleeting initial success. The expected evolution over the 21st century, however, will very likely reveal that the last battle has not yet finished. The DC system revival for integrating the new technologies described in this paper is technically and economically feasible nowadays for the last mile distribution systems. In the authors' opinion, however, the harmonized coexistence of both systems through the deployment of hybrid AC/DC networks is the most cost-effective solution for integrating the new technologies into the current AC networks. Undoubtedly, hybrid AC/DC grids will provide extended flexibility allowing the new technologies to provide the required ancillary services for an optimal, secure and sustainable network operation.

Author Contributions: All the authors have equally contributed to the final version of this paper.

Funding: This research was funded by the Spanish Ministry of Economy and Competitiveness with grant number ENE2017-84813-R and the European Union Horizon 2020 Program with grant number 764090.

Conflicts of Interest: The authors declare no conflict of interest.

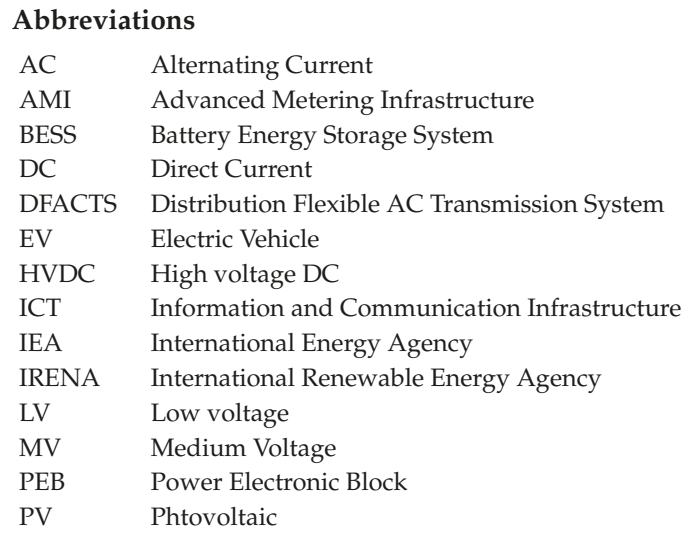

\section{References}

1. Willis, H.L. Power Distribution Planning Reference Book; Marcel Dekker: New York, NU, USA, 2004.

2. Habib, S.; Khan, M.M.; Abbas, F.; Sang, L.; Shahid, M.U.; Tang, H. A Comprehensive Study of Implemented International Standards, Technical Challenges, Impacts and Prospects for Electric Vehicles. IEEE Access 2018, 6, 13866-13890. [CrossRef]

3. Grunditz, E.A.; Thiringer, T. Performance Analysis of Current BEVs Based on a Comprehensive Review of Specifications. IEEE Trans. Transp. Electrif. 2016, 2, 270-289. [CrossRef]

4. Cheng M.; Tong, M. Development status and trend of electric vehicles in China. Chin. J. Electr. Eng. 2017, 3, 1-13.

5. Burger, S.P.; Jenkins, J.D.; Huntington S.C.; Perez-Arriaga, I.J. Why Distributed? A Critical Review of the Tradeoffs Between Centralized and Decentralized Resources. IEEE Power Energy Mang. 2019, 17, $16-24$. [CrossRef]

6. Blaabjerg, F; Yang, Y.; Yang, D.; Wang, X. Distributed Power-Generation Systems and Protection. Proc. IEEE 2017, 105, 1311-1331. [CrossRef]

7. Wu, Y.; Lin, J.; Lin, H. Standards and Guidelines for Grid-Connected Photovoltaic Generation Systems: A Review and Comparison. IEEE Trans. Ind. Appl. 2017, 53, 3205-3216. [CrossRef]

8. Global EV Outlook 2017; International Energy Agency (IEA): Paris, France, 2017.

9. REmap: Roadmap for a Renewable Energy Future; International Renewable Energy Agency (IRENA): Masdar City, Abu Dhabi, 2016.

10. Boicea, V.A. Energy Storage Technologies: The Past and the Present. Proc. IEEE 2014, 102, 1777-1794. [CrossRef] 
11. Wang, G.; Konstantinou, G; Townsend, C.D.; Pou, J.; Vázquez, S.; Demetriades, G.D.; Agelidis, V.G. A Review of Power Electronics for Grid Connection of Utility-Scale Battery Energy Storage Systems. IEEE Trans. Sustain. Energy 2016, 7, 1778-1790. [CrossRef]

12. Chang, L.; Zhang, W.; Xu, S.; Spence, K. Review on distributed energy storage systems for utility applications. Cpss Trans. Power Electron. Appl. 2017, 2, 267-276. [CrossRef]

13. Battery Electricity Storage Costs and Market Outlook to 2030; International Renewable Energy Agency (IRENA): Masdar City, Abu Dhabi, 2016.

14. Gómez-Expósito, A; Arcos-Vargas, A.; Maza-Ortega, J.M.; Rosendo-Macías, J.A.; Álvarez-Cordero, G; Carillo-Aparicio, S.; González-Lara, J.; Morales-Wagner, D.; González-García, T. City-Friendly Smart Network Technologies and Infrastructures: The Spanish Experience. Proc. IEEE 2018, 106, 626-660.

15. Markiewicz, H.; Klajn, A. EN50160, Voltage Characteristics of Electricity Supplied by Public Distribution Systems; CENELEC: Brussels, Belgium, 2011.

16. Hingorani, N.G.; Gyugyi, L. Understanding FACTS: Concepts and Technology of Flexible AC Transmission Systems; Wiley-IEEE Press; New York, NY, USA, 2000.

17. Bauer, P.; de Haan, S.W.H. Electronic tap changer for 500 kVA/10 kV distribution transformers: Design, experimental results and impact in distribution networks. In Proceedings of the 33rd IEEE Industry Applications Society (IAS) Conference, St. Louis, MI, USA, 12-15 October 1998; Volume 2, pp. 1530-1537.

18. Acha, E.; Agelidis, V.G.; Anaya-Lara, O.; Miller, T.H.E. Power Electronic Control in Electrical Systems; Newnes Power Engineering Series; Elsevier: Oxford, UK, 2001.

19. Sood, V.K. HVDC and FACTS Controllers: Applications of Static Converters in Power Systems; Springer: Boston, MA, USA, 2004.

20. Ghosh, A.; Ledwich, G. Power Quality Enhancement Using Custom Power Devices; Kluwer Academic Publishers: Boston, MA, USA, 2002.

21. Meersman, B.; Renders, B.; Degroote, L.; Vandoorn, T.; De Kooning J.; Vandevelde, L. Overview of three-phase inverter topologies for distributed generation purposes. In Proceedings of Innovation for Sustainable Production i-SUP, Bruges, Belgium, 18-21 April 2010; pp. 24-28,

22. Verdelho, P.; Marques, G.D. Four-wire current-regulated PWM voltage converter. IEEE Trans. Ind. Electron. 1998, 45, 761-770. [CrossRef]

23. Liang, J.; Green, T.C.; Feng, C.; Weiss, G. Increasing voltage utilization in spilt-link four-wire inverters. IEEE Trans. Power Electron. 2009, 24, 1562-1569. [CrossRef]

24. Carrasco, J.M.; García Franquelo, L; Bialasiewicz, J.T.; Galván, E.; Portillo Guisado, R.C.; Martín Prats, M.A.; León, I.; Moreno-Alfonso, N. Power-Electronic Systems for the Grid Integration of Renewable Energy Sources: A Survey. IEEE Trans. Ind. Electron. 2006, 53, 1002-1016. [CrossRef]

25. Lawder, M.T.; Suthar, B.; Northrop, P.W.C.; De, S.; Hoff, C.M.; Leitermann, O.; Crow, M.L.; Santhanagopalan, S.; Subramanian, V.R. Battery Energy Storage System (BESS) and Battery Management System (BMS) for Grid-Scale Applications. Proc. IEEE 2014, 102, 1014-1030. [CrossRef]

26. Oudalov, A.; Chartouni, D.; Ohler, C. Optimizing a Battery Energy Storage System for Primary Frequency Control. IEEE Trans. Power Syst. 2007, 22, 1259-1266. [CrossRef]

27. Yang, Y.; Li, H.; Aichhorn, A.; Zheng, J.; Greenleaf, M. Sizing Strategy of Distributed Battery Storage System With High Penetration of Photovoltaic for Voltage Regulation and Peak Load Shaving. IEEE Trans. Smart Grid 2014, 5, 982-991. [CrossRef]

28. Abdelrazek, S.A.; Kamalasadan, S. Integrated PV Capacity Firming and Energy Time Shift Battery Energy Storage Management Using Energy-Oriented Optimization. IEEE Trans. Ind. Appl. 2016, 52, 2607-2617. [CrossRef]

29. Okada, N.; Takasaki, M.; Sakai, H.; Katoh, S. Development of a 6.6 kV-1 MVA Transformerless Loop Balance Controller. In Proceedings of the 2007 IEEE Power Electronics Specialists Conference, Orlando, FL, USA, 17-21 June 2007.

30. Romero-Ramos, E.; Gómez-Expósito, A.; Marano, A.; Maza-Ortega, J.M.; Martínez-Ramos, J.L. Assessing the loadability of active distribution networks in the presence of DC controllable links. IET Gener. Transm. Distrib. 2011, 5, 1105-1113. [CrossRef]

31. Gómez-Expósito, A.; Maza-Ortega, J.M.; Romero-Ramos, E.; Marano, A. Enhancing Integration of Renewables in Radial Distribution Networks through Smart Links in Iniewski, K; Smart Grid: Infrastructure and Networking, Ed.; McGraw-Hill: New York, NY, USA, 2012; pp. 155-179. 
32. Lazarou, S.; Vita, V.; Ekonomou, L. Protection Schemes of Meshed Distribution Networks for Smart Grids and Electric Vehicles. Energies 2018, 11, 3106-3122. [CrossRef]

33. García López, F.P.; Barragán-Villarejo, M.; Maza-Ortega, J.M. Grid-friendly integration of electric vehicle fast charging station based on multiterminal DC link. Int. J. Electr. Power Energy Syst. 2020, 114, 1-15. [CrossRef]

34. Maza-Ortega, J.M.; Gómez-Expósito, A.; Barragán-Villarejo, M.; Romero-Ramos, E.; Marano-Marcolini, A. Voltage source converter-based topologies to further integrate renewable energy sources in distribution systems. IET Renew. Power Gener. 2012, 6, 435-445. [CrossRef]

35. Tsikalakis, A.G.; Hatziargyriou, N.D. Centralized Control for Optimizing Microgrids Operation. IEEE Trans. Energy Convers. 2008, 23, 241-248. [CrossRef]

36. Sun, Q.; Li, H.; Ma, Z.; Wang, C.; Campillo, J.; Zhang, Q.; Wallin, F.; Guo, J. A Comprehensive Review of Smart Energy Meters in Intelligent Energy Networks. IEEE Internet Things J. 2016, 3, 464-479. [CrossRef]

37. Gómez-Expósito, A; Conejo, A.; Canizares, A. Electric Energy Systems: Analysis and Operation; CRC Press: Boca Raton, FL, USA, 2008.

38. Bose, A. Smart transmission grid applications and their supporting infrastructure. IEEE Trans. Smart Grid 2010, 1, 11-19. [CrossRef]

39. Wang, Y.; Yemula, P.; Bose, A. Decentralized communication and control systems for power system operation. IEEE Trans. Smart Grid 2015, 6, 885-893. [CrossRef]

40. Cassel, W.R. Distribution management systems: Functions and payback. IEEE Trans. Power Syst. 1993, 8, 796-801. [CrossRef]

41. Long, W.; Nilsson, S. HVDC transmission: yesterday and today. IEEE Power Energy Mag. 2007, 5, $22-31$. [CrossRef]

42. Flourentzou, N.; Agelidis V.G.; Demetriades, G.D. VSC-Based HVDC Power Transmission Systems: An Overview. IEEE Trans. Power Electron. 2009, 24, 592-602. [CrossRef]

43. Lundberg, P.; Gustafsson, A.; Jeroense, M. Recent advancements in HVDC systems. HVDC and power electronics technology and development. In Proceedings of the 2015 CIGRE, Paris, France, 26-31 August 2015.

44. Sellick, R.L.; Akerberg, M. Comparison of HVDC Light (VSC) and HVDC Classis (LCC) site aspects, for a $500 \mathrm{MW} 400 \mathrm{kV}$ HVDC transmission scheme. In Proceedings of the 2012 IET AC/DC Conference, Birmingham, UK, 4-5 December 2012.

45. Oni, O.E.; Davidson, I.E.; Mbangula, K.N.I. A review of LCC-HVDC and VSC-HVDC technologies and applications. In Proceedings of the 2016 IEEE 16th International Conference on Environment and Electrical Engineering (EEEIC), Florence, Italy, 7-10 June 2016.

46. Lin, W.; Jovcic, D.; Yao, L.; Sun, W.; Lu, X.; Wen, J. Investigation of interconnecting two Chinese LCC-HVDC through LCL DC/DC converter. In Proceedings of the 2015 IEEE PES Asia-Pacific Power and Energy Engineering Conference (APPEEC), Brisbane, Australia, 15 November 2015.

47. Korompili, A.; Wu, Q.; Zhao, H. Review of VSC HVDC connection for offshore wind power integration, Renew. Sust. Energy Rev. 2016, 59, 1405-1414. [CrossRef]

48. Bresesti, P.; Kling, W.L.; Hendriks, R.L.; Vailati, R. HVDC Connection of Offshore Wind Farms to the Transmission System. IEEE Trans. Energy Convers. 2007, 22, 37-43. [CrossRef]

49. Lasseter, R. White Paper on Integration of Distributed Energy Resources-The CERTS MicroGrid Concept; Technical Report; California Energy Commission: Berkeley, CA, USA, 2002.

50. Dragicevic, T.; Lu, X.; Vasquez, J.C.; Guerrero, J.M. DC Microgrid - Part II: A Review of Power Architectures, Applications, and Standardization Issues. IEEE Trans. Power Electron. 2016, 31, 3528-3549. [CrossRef]

51. Zubieta, L.E. Are Microgrids the Future of Energy?: DC Microgrids from Concept to Demonstration to Deployment. IEEE Electrif. Mag. 2016, 4, 37-44. [CrossRef]

52. Elsayed, A.T.; Mohamed, A.A.; Mohammed, O.A. DC microgrids and distribution systems: An overview, Electr. Power Syst. Res. 2015, 119, 407-417. [CrossRef]

53. Justo, J.J.; Mwasilu, F.; Lee, J.; Jung, J.W. AC-microgrids versus DC-microgrids with distributed energy resources: A review. Renew. Sustain. Energy Rev. 2013, 24, 387-405. [CrossRef]

54. Wang, P.; Goel, L.; Liu, X.; Choo, F.H. Harmonizing AC and DC: A Hybrid AC/DC Future Grid Solution. IEEE Power Energy Mag. 2013, 11, 76-83. [CrossRef]

55. Majumder, R. A hybrid microgrid with dc connection at back to back converters. IEEE Trans. Smart Grid 2014, 5, 251-259. [CrossRef] 
56. Kakigano, H.; Miura, Y.; Ise, T. Low-voltage bipolar-type dc microgrid for super high quality distribution. IEEE Trans. Power Electron. 2010, 25, 3066-3075. [CrossRef]

57. Huang, A.Q.; Crow, M.L.; Heydt, G.T.; Zheng J.P.; Dale, S.J. The Future Renewable Electric Energy Delivery and Management (FREEDM) System: The Energy Internet. Proc. IEEE 2010, 99, 133-148. [CrossRef]

58. Boroyevich, D.; Cvetkovic, I.; Burgos, R.; Dong, D. Intergrid: A Future Electronic Energy Network? IEEE J. Emer. Sel. Top. Power Electron. 2013, 1, 127-138. [CrossRef]

59. Unamuno E.; Barrena, J.A. Hybrid ac/dc microgrids-Part I: Review and classification of topologies. Renew. Sustain. Energy Rev. 2015, 52, 1251-1259. [CrossRef]

60. Antoniou, D.; Tzimas, A.; Rowland, S.M. Transition from alternating current to direct current low voltage distribution networks. IET Gener. Transm. Distrib. 2015, 9, 1391-1401. [CrossRef]

61. Wu, T.F.; Kuo, C.L.; Lin, L.C.; Chen, Y.K. DC-Bus Voltage Regulation for a DC Distribution System With a Single-Phase Bidirectional Inverter. IEEE J. Emerg. Sel. Top. Power Electron. 2016, 4, 210-220. [CrossRef]

62. Dong, D.; Cvetkovic, I.; Boroyevich, I.; Zhang, W.; Wang, R.; Mattavelli, P. Grid-interface bidirectional converter for residential DC distribution systems-Part one: High-density two-stage topology. IEEE Trans. Power Electron. 2013, 28, 1655-1666. [CrossRef]

63. Dong, D.; Luo, F.; Zhang, X.; Boroyevich, D.; Mattavelli, P. Grid-interface bidirectional converter for residential DC distribution systems-Part 2: AC and DC interface design with passive components minimization. IEEE Trans. Power Electron. 2013, 28, 1667-1679. [CrossRef]

64. Tofoli, F.L.; Pereira, D.C.; Josias de Paula, W.; Oliveira Júnior, D.S. Survey on non-isolated high-voltage step-up dc-dc topologies based on the boost converter. IET Power Electron. 2015, 8, 2044-2057. [CrossRef]

65. Rehman, Z.; Al-Bahadly, I.; Mukhopadhyay, S. Multi-input DC-DC converters in renewable energy applications-An overview. Renew. Sustain. Energy Rev. 2015, 41, 521-539. [CrossRef]

66. Inoue S.; Akagi, H. A Bidirectional DC-DC Converter for an Energy Storage System With Galvanic Isolation. IEEE Trans. Power Electron. 2007, 22, 2299-2306. [CrossRef]

67. Shaaban, M.F.; Eajal, A.A. Coordinated charging of plug-in hybrid electric vehicles in smart hybrid AC/DC distribution systems. Renew. Energy 2015, 82, 92-99. [CrossRef]

68. Mohamed, A.; Mohammed, O. Real-time energy management scheme for hybrid renewable energy systems in smart grid applications. Electr. Power Syst. Res. 2013, 96, 133-143. [CrossRef]

69. Eajal, A.A.; Member, S.; Shaaban, M.F.; Member, S. Stochastic Centralized Dispatch scheme for Hybrid AC/DC Smart Distribution Systems. IEEE Trans. Sustain. Energy 2016, 7, 1046-1059. [CrossRef]

70. Keles, C.; Karabiber, A.; Akcin, M.; Kaygusuz, A.; Baykant Alagoz, B.; Gul, O. A smart building power management concept: Smart socket applications with DC distribution. Int. J. Electr. Power Energy Syst. 2015, 64, 679-688. [CrossRef]

71. Unamuno, E.; Barrena, J.A. Hybrid ac/dc microgrids - Part II: Review and classification of control strategies. Renew. Sustain. Energy Rev. 2015, 52, 1123-1134. [CrossRef]

72. Lopes, J.A.P.; Moreira, C.L.; Madureira, A.G. Defining control strategies for MicroGrids islanded operation. IEEE Trans. Power Syst. 2006, 21, 916-924. [CrossRef]

73. Chai, R.; Zhang, B.; Dou, J.; Hao, Z.; Zheng, T. Unified Power Flow Algorithm Based on the NR Method for Hybrid AC/DC Grids Incorporating VSCs. IEEE Trans. Power Syst. 2016, 31, 4310-4318. [CrossRef]

74. Eajal, A.A.; Abdelwahed, M.A.; El-Saadany, E.F.; Ponnambalam, K. A Unified Approach to the Power Flow Analysis of AC/DC Hybrid Microgrids. IEEE Trans. Sust. Ener. 2016, 7, 1145-1158. [CrossRef]

75. Hamad, A.A.; Azzouz, M.A.; El Saadany, E.F. A Sequential Power Flow Algorithm for Islanded Hybrid AC/DC Microgrids. IEEE Trans. Power Syst. 2016, 31, 3961-3970. [CrossRef]

76. Abur, A.; Gómez-Expósito, A. Power System State Estimation: Theory and Implementation; Marcel Dekker: New York, NY, USA, 2004.

77. Villa-Jaén, A.; Acha, E.; Gómez-Expósito, A. Voltage Source Converter Modeling for Power System State Estimation: STATCOM and VSC-HVDC. IEEE Trans. Power Syst. 2008, 23, 1552-1559. [CrossRef]

78. Donde, V.; Feng, X.; Segerqvist, I.; Callavik, M. Distributed State Estimation of Hybrid AC/HVDC Grids by Network Decomposition. IEEE Trans. Smart Grid 2016, 7, 974-981. [CrossRef]

79. Zamora-Cárdenas, E.A.; Fuerte-Esquivel, C.R.; Pizano-Martinez, A.; Estrada-García, H.J. Hybrid state estimator considering SCADA and synchronized phasor measurements in VSC-HVDC transmission links. Electr. Power Syst. Res. 2016, 133, 42-50. [CrossRef] 
80. Elsen, R.; Ancillary Services Unbundling Electricity Products-An Emerging Market; Eurelectric: Brussels, Belgium, 2004.

81. Survey on Ancillary Service Procurement, Balancing Market Design 2017; ENTSO-E: Brussels, Belgium, 2018.

82. Karimi, M.; Mokhlis, H.; Naidu, K.; Uddin, S.; Bakar, A.H.A. Photovoltaic penetration issues and impacts in distribution network-A review. Renew. Sustain. Energy Rev. 2016, 53, 594-605. [CrossRef]

83. Stetz, T.; Marten, F.; Braun, M. Improved Low Voltage Grid-Integration of Photovoltaic Systems in Germany. IEEE Trans. Sustain. Energy 2013, 4, 534-542. [CrossRef]

84. Chalise, S.; Atia, H.R.; Poudel, B.; Tonkoski, R. Impact of Active Power Curtailment of Wind Turbines Connected to Residential Feeders for Overvoltage Prevention. IEEE Trans. Sustain. Energy 2016, 7, 471-479. [CrossRef]

85. Farag, H.E.; El-Saadany, E.F.; Seethapathy, R. A Two Ways Communication-Based Distributed Control for Voltage Regulation in Smart Distribution Feeders. IEEE Trans. Smart Grid 2012, 3, 271-281. [CrossRef]

86. Robbins, B.A.; Hadjicostis, C.N.; Domínguez-García, A.D. A Two-Stage Distributed Architecture for Voltage Control in Power Distribution Systems. IEEE Trans. Power Syst. 2013, 28, 1470-1482. [CrossRef]

87. Yeh, H.; Gayme, D.F.; Low, S.H. Adaptive VAR Control for Distribution Circuits With Photovoltaic Generators. IEEE Trans. Power Syst. 2012, 27, 1656-1663. [CrossRef]

88. Yong, J.Y.; Ramachandaramurthy, V.K.; Tan, K.M.; Mithulananthan, N. Bi-directional electric vehicle fast charging station with novel reactive power compensation for voltage regulation. Int. J. Electr. Power Energy Syst. 2015, 64, 300-310. [CrossRef]

89. Demirok, E.; González, P.C.; Frederiksen, K.H.B.; Sera, D.; Rodriguez P.; Teodorescu, R. Local Reactive Power Control Methods for Overvoltage Prevention of Distributed Solar Inverters in Low-Voltage Grids. IEEE J. Photovoltaics 2011, 1, 174-182. [CrossRef]

90. Calderaro, V.; Galdi, V.; Lamberti, F.; Piccolo, A. A Smart Strategy for Voltage Control Ancillary Service in Distribution Networks. IEEE Trans. Power Syst. 2015, 30, 494-502. [CrossRef]

91. Wang, L.; Bai, F.; Yan, R.; Saha, T.K. Real-Time Coordinated Voltage Control of PV Inverters and Energy Storage for Weak Networks With High PV Penetration. IEEE Trans. Power Syst. 2018, 33, 3383-3395. [CrossRef]

92. Monroy, D.; Gómez-Expósito, A.; Romero-Ramos, E. Improving the voltage regulation of secondary feeders by applying solid-state tap changers to MV/LV transformers. In Proceedings of the 9th International Conference on Electrical Power Quality and Utilisation, Barcelona, Spain, 9-11 October 2007; pp. 1-6.

93. Marano-Marcolini, A.; Maza-Ortega, J.M.; Martínez-Ramos, J.L.; Trebolle, D. Voltage control of active distribution networks by means of dispersed generation. In Proceedings of the CIRED Workshop 2012 Lisboa, Lisbon, Portugal, 29-30 May 2012.

94. García-López, F.P.; Barragán-Villarejo, M.; Marano-Marcolini, A.; Maza-Ortega, J.M.; Martínez-Ramos, J.L. Experimental Assessment of a Centralised Controller for High-RES Active Distribution Networks. Energies 2018, 11, 3364-3380. [CrossRef]

95. Prabhala, V.A.; Baddipadiga, B.P.; Fajri, P.; Ferdowsi, M. An Overview of Direct Current Distribution System Architectures \& Benefits. Energies 2018, 11, 2463-2483.

96. Marchionini, B. Direct Current In Buildings; Technical Report; NEMA: Rosslyn, VA, USA, 2018.

97. Reed, G.F.; Grainger, B.M.; Sparacino, A.R.; Mao, Z. Ship to Grid: Medium-Voltage DC Concepts in Theory and Practice. IEEE Power Energy Mag. 2012, 10, 70-79. [CrossRef]

98. Jin, C.; Wang, P.; Xiao, J.; Tang Y.; Choo, F.H. Implementation of Hierarchical Control in DC Microgrids. IEEE Trans. Ind. Electron. 2014, 61, 4032-4042. [CrossRef]

99. Liu, X.; Wang, P.; Loh, P.C. A Hybrid AC/DC Microgrid and Its Coordination Control. IEEE Trans. Smart Grid 2011, 2, 278-286.

100. Walling, R.A.; Saint, R.; Dugan, R.C.; Burke, J.; Kojovic, L.A. Summary of Distributed Resources Impact on Power Delivery Systems. IEEE Trans. Power Deliv. 2008, 23, 1636-1644. [CrossRef]

101. Assessing the Impact of Low Carbon Technologies on Great Britain's Power Distribution Networks; Technical Report; Office of Gas and Electricity Markets: London, UK, 2012.

102. Bahramipanah, M.; Torregrossa, D.; Cherkaoui R.; Paolone, M. A Decentralized Adaptive Model-Based Real-Time Control for Active Distribution Networks Using Battery Energy Storage Systems. IEEE Trans. Smart Grid 2018, 9, 3406-3418. [CrossRef] 
103. Ueda, Y.; Kurokawa, K.; Tanabe, T.; Kitamura, K.; Sugihara, H.. Analysis Results of Output Power Loss Due to the Grid Voltage Rise in Grid-Connected Photovoltaic Power Generation Systems. IEEE Trans. Ind. Electron. 2008, 55, 2744-2751. [CrossRef]

104. Molina-García, A.; Mastromauro, R.A.; García-Sánchez, T.; Pugliese, S.; Liserre, M.; Stasi, S. Reactive Power Flow Control for PV Inverters Voltage Support in LV Distribution Networks. IEEE Trans. Smart Grid 2017, 8, 447-456. [CrossRef]

105. Karagiannopoulos, S.; Aristidou, P.; Hug, G. Hybrid approach for planning and operating active distribution grids. IET Gener. Transm. Distrib. 2017, 11, 685-695. [CrossRef]

106. Arias, N.B.; Franco, J.F.; Lavorato, M.; Romero, R. Metaheuristic optimization algorithms for the optimal coordination of plug-in electric vehicle charging in distribution systems with distributed generation. Electr. Power Syst. Res. 2017, 142, 351-361. [CrossRef]

107. Shi, Y.; Tuan, H.D.; Savkin, A.V.; Duong, T.Q.; Poor, H.V. Model predictive control for smart grids with multiple electric-vehicle charging stations. IEEE Trans. Smart Grid 2019, 10, 2127-2136. [CrossRef]

108. Lee, W.; Xiang, L.; Schober, R.; Wong, V.W.S. Electric vehicle charging stations with renewable power generators: A game theoretical analysis. IEEE Trans. Smart Grid 2015, 6, 608-617. [CrossRef]

109. Ashique, R.H.; Salam, Z.; Bin Abdul Aziz, M.J.; Bhatti, A.R. Integrated photovoltaic-grid dc fast charging system for electric vehicle: A review of the architecture and control. Renew. Sustain. Energy Rev. 2017, 69, 1243-1257. [CrossRef]

110. Short, T.A. Electric Power Distribution Handbook; CRC Press: Boca Raton, FL, USA, 2004.

111. Beharrysingh, S. Phase Unbalance on Low-Voltage Electricity Networks and Its Mitigation Using Static Balancers. Ph.D. Thesis, Loughborough University, Leicestershire, UK, March 2014.

112. IEC/TR 61000-3-14: 2011 Electromagnetic compatibility (EMC)—Part 3-14: Assessment of Emission Limits for Harmonics, Interharmonics, Voltage Fluctuations and Unbalance for the Connection of Disturbing Installations to LV Power Systems; Technical Report for International Electrotechnical Commission: Geneva, Switzerland, October 2011.

113. Meersman, B.; Renders, B.; Degroote, L.; Vandoorn, T.; Vandevelde, L. Three-phase inverter-connected DG-units and voltage unbalance. Electr. Power Syst. Res. 2011, 81, 899-906. [CrossRef]

114. Geth, F.; Tant, J.; Belmans, R.; Driesen, J. Balanced and unbalanced inverter strategies in battery storage systems for low-voltage grid support. IET Gener. Transm. Distrib. 2015, 9, 929-936. [CrossRef]

115. Weckx, S.; Driesden, J. Load Balancing with EV Chargers and PV Inverters in Unbalanced Distribution Grids. IEEE Trans. Sustain. Energy 2015, 6, 635-643. [CrossRef]

116. Coppo, M.; Turri, R.; Marinelli, M.; Han, X. Voltage management in unbalanced low voltage networks using a decoupled phase-tap-changer transformer. In Proceedings of the 49th International Universities Power Engineering Conference (UPEC), Cluj-Napoca, Romania, 2- 5 September 2014; pp. 1-6.

117. Zecchino, A.; Marinelli, M.; Hu, J.; Coppo, M.; Turri, R. Voltage control for unbalanced low voltage grids using a decoupled-phase on-load tap-changer transformer and photovoltaic inverters. In Proceedings of the 50th International Universities Power Engineering Conference (UPEC), Stoke on Trent, UK, 1-4 September 2015; pp. 1-6.

118. Dugan, R.; McGranaghan, M.; Santoso, S.; Beaty, H. Electrical Power System Quality; McGraw-Hill: New York, NY, USA, 2004.

119. IEEE Std 519-2014 IEEE Recommended Practices and Requirements for Harmonic Control in Electrical Power Systems. Available online: https: / /ieeexplore.ieee.org/document/ 6826459 (accessed on 1 September 2019).

120. Maza-Ortega, J.M.; Burgos-Payán, M.; Izquierdo-Mitchell, C. A new design method of passive tuned filters for harmonic mitigation and reactive power compensation. Eur. Trans. Electr. Power 2006, 16, $219-233$. [CrossRef]

121. Maza-Ortega, J.M.; Acha, E.; García, S.; Gómez-Expósito, A. Overview of power electronics technology and applications in power generation transmission and distribution. J. Mod. Power Syst. Clean Energy 2017, 5, 499-514. [CrossRef]

122. Akagi, H. Active harmonic filters. Proc. IEEE 2005, 93, 2128-2141. [CrossRef]

123. Akagi, H; Watanabe, E.H.; Aredes, M. Instantaneous Power Theory and Applications to Power Conditioning; John Wiley \& Sons: Hoboken, NJ, USA, 2007.

124. Liang, X.; Andalib -Bin- Karim, C. Harmonics and Mitigation Techniques Through Advanced Control in Grid-Connected Renewable Energy Sources: A Review. IEEE Trans. Ind. Appl. 2018, 54, 3100-3111. [CrossRef] 
125. Wada, K.; Fujita, H.; Akagi, H. Considerations of a shunt active filter based on voltage detection for installation on a long distribution feeder. IEEE Trans. Ind. Appl. 2002, 38, 1123-1130. [CrossRef]

126. Blanco, C.; Reigosa, D.; Vasquez, J.C.; Guerrero, J.M.; Briz, F. Virtual Admittance Loop for Voltage Harmonic Compensation in Microgrids. IEEE Trans. Ind. Appl. 2016, 52, 3348-3356. [CrossRef]

127. Wu, D.; Tang, F.; Dragicevic, T.; Vasquez, J.C.; Guerrero, J.M. A Control Architecture to Coordinate Renewable Energy Sources and Energy Storage Systems in Islanded Microgrids. IEEE Trans. Smart Grid 2015, 6, 1156-1166. [CrossRef]

128. Pogaku, N.; Green, T.C. Harmonic mitigation throughout a distribution system: A distributed-generatorbased solution. IEE Proc. Gener. Transm. Distrib. 2006, 153, 350-358. [CrossRef]

129. IEEE Std 1124-2003, Guide for the Analysis and Definition of DC-Side Harmonic Performance of HVDC Transmission Systems; IEEE: Piscataway, NJ, USA, 2003.

130. Xinyu, Z.; Lei, D. A smooth scheme of wind power generation based on wind power prediction. In Proceedings of the 2011 International Conference on Transportation, Mechanical, and Electrical Engineering (TMEE), Changchun, China, 16-18 December 2011; pp. 958-961.

131. Gevorgian, V.; Booth, S. Review of PREPA Technical Requirements for Interconnecting Wind and Solar Generation; Technical Report, NREL/TP-5D00-57089; NREL: Denver, CO, USA, 2013. Available online: http:/ /www.nrel. gov/docs/fy14osti/57089.pdf (accessed on 1 September 2019).

132. Bomer, J.; Burges, K.; Nabe, C.; Poller, M. All Island TSO Facilitation of Renewables Studies; Technical Report; EirGrid Plc: Dublin, Ireland 2010. Available online: http:/ / www.ecofys.com/en/publication/all-island-tsofacilitation-of-renewables-studies / (accessed on 1 September 2019).

133. Enslin, J.H.R. Integration of Photovoltaic Solar Power-The Quest towards Dispatchability. IEEE Instrum. Meas. Mag. 2014, 17, 21-26. [CrossRef]

134. Howlader, A.M.; Urasaki, N.; Yona, A.; Senjyu, T.; Saber, A.Y. A review of output power smoothing methods for wind energy conversion systems. Renew. Sustain. Energy Rev. 2013, 26, 135-146. [CrossRef]

135. Sato, D.; Saitoh, H. Smoothing Control of Wind Farm Output by Using Kinetic Energy of Variable Speed Wind Power Generators. IEEJ Trans. Power Energy 2009, 129, 580-590. [CrossRef]

136. Sakamoto, R.; Senjyu, T.; Kaneko, T.; Urasaki, N.; Takagi, T.; Sugimoto, S. Output power levelling of wind turbine generator by pitch angle controller using H-infinity control. Electr. Eng. Jpn. 2008, 162, 45-57. [CrossRef]

137. Dimitra Tragianni, S.; Oureilidis, K.O.; Demoulias, C.S. Supercapacitor sizing based on comparative study of PV power smoothing methods. In Proceedings of the 52nd International Universities Power Engineering Conference (UPEC), Heraklion, Greece, 28-31 August 2017; pp. 1-6.

138. Li, X.; Hui, D.; Lai, X. Battery Energy Storage Station (BESS)-Based Smoothing Control of Photovoltaic (PV) and Wind Power Generation Fluctuations. IEEE Trans. Sustain. Energy 2013, 4, 464-473. [CrossRef]

139. Ellis, A.; Schoenwald, D.; Hawkins, J.; Willard, S.; Arellano, B. PV output smoothing with energy storage. In Proceedings of the 2012 38th IEEE Photovoltaic Specialists Conference, Austin, TX, USA, 3-8 June 2012; pp. 1523-1528.

140. Marcos, J.; Storkél, O.; Marroyo, L.; Garcia, M.; Lorenzo, E. Storage requirements for PV power ramp-rate control. Sol. Energy 2014, 99, 28-35. [CrossRef]

141. Aswani, D.; Clarke-Johnson, R.; Runyan, G. The Impact of Hydroelectric Power and Other Forms of Generation on Grid Frequency Stability for The WECC Region; Technical Report; American Governor Company: Ivyland, PA, USA, 2011.

142. Tamrakar, U.; Shrestha, D.; Maharjan, M.; Bhattarai, B.; Hansen, T.; Tonkoski, R. Virtual Inertia: Current Trends and Future Directions. Appl. Sci. 2017, 7, 654-682. [CrossRef]

143. Zhong, Q.; Weiss, G. Synchronverters: Inverters That Mimic Synchronous Generators. IEEE Trans. Ind. Electron. 2011, 58, 1259-1267. [CrossRef]

144. Zhong, Q.; Nguyen, P.; Ma, Z.; Sheng, W. Self-Synchronized Synchronverters: Inverters Without a Dedicated Synchronization Unit. IEEE Trans. Power Electron. 2014, 29, 617-630. [CrossRef]

145. Turschner, D.; Hesse, R.; Beck, H. Virtual Synchronous Machine. In Proceedings of the 9th International Conference Electrical Power Quality and Utilisation, Barcelona, Spain, 9-11 October 2007.

146. Bevrani, H.; Ise, T.; Miura, Y. Virtual synchronous generators: A survey and new perspectives. Int. J. Electr. Power Energy Syst. 2014, 54, 244-254. [CrossRef] 
147. Sakimoto, K.; Miura, Y.; Ise, T. Stabilization of a power system with a distributed generator by a Virtual Synchronous Generator function. In Proceedings of the 8th International Conference on Power Electronics-ECCE Asia, Jeju, Korea, 30 May-3 June 2011; pp. 1498-1505.

148. Zhang, W.; Cantarellas, A. M.; Rocabert, J.; Luna, A.; Rodriguez, P. Synchronous Power Controller With Flexible Droop Characteristics for Renewable Power Generation Systems. IEEE Trans. Sustain. Energy 2016, 7, 1572-1582. [CrossRef]

149. Karapanos, V.; de Haan, S.; Zwetsloot, K. Real time simulation of a power system with VSG hardware in the loop. In Proceeding of the 37th Annual Conference of the IEEE Industrial Electronics Society (IECON), Melbourne, VIC, Australia, 7-10 November 2011.

150. Greenwood, D.M.; Lim, K.Y.; Patsios, C.; Lyons, P.F.; Lim, Y.S.; Taylor, P.C. Frequency response services designed for energy storage. Appl. Energy 2017, 203, 115-127. [CrossRef]

151. Thorbergsson, E.; Knap, V.; Swierczynski, M.; Stroe, D.; Teodorescu, R. Primary Frequency Regulation with Li-Ion Battery Based Energy Storage System-Evaluation and Comparison of Different Control Strategies. In Proceedings of the 35th International Telecommunications Energy Conference, Smart Power and Efficiency, Hamburg, Germany, 13-17 October 2013.

152. Guerrero, J.M.; Vasquez, J.C.; Matas, J.; de Vicuna, L.G.; Castilla, M. Hierarchical Control of Droop-Controlled AC and DC Microgrids-A General Approach Toward Standardization. IEEE Trans. Ind. Electron. 2011, 58, 158-172. [CrossRef]

153. Stroe, D.; Knap, V.; Swierczynski, M.; Stroe, A.; Teodorescu, R. Suggested operation of grid-connected lithium-ion battery energy storage system for primary frequency regulation: Lifetime perspective. In Proceedings of the 2015 IEEE Energy Conversion Congress and Exposition (ECCE), Montreal, QC, Canada, 20-24 September 2015.

154. Sharma, S.K.; Chandra, A.; Saad, M.; Lefebvre, S.; Asber, D.; Lenoir, L. Voltage Flicker Mitigation Employing Smart Loads With High Penetration of Renewable Energy in Distribution Systems. IEEE Trans. Sustain. Energy 2017, 8, 414-424. [CrossRef]

155. Pourbeik, P.; Soni, S.; Gaikwad, A.; Chadliev, V. Providing Primary Frequency Response from Photovoltaic Power Plants. In Proceedings of the 2017 CIGRE Symposium, Dublin, Ireland, 29 May-2 June 2017.

156. Lyu, X.; Xu, Z.; Zhao, J. A coordinated frequency control strategy for photovoltaic system in microgrid. J. Int. Counc. Electr. Eng. 2018, 8, 37-43. [CrossRef]

157. Wu, Z.; Gao, W.; Gao, T. State-of-the-art review on frequency response of wind power plants in power systems. J. Mod. Power Syst. Clean Energy 2018, 6, 1-16. [CrossRef] 


\title{
FACTS Providing Grid Services: Applications and Testing
}

\author{
Panos Kotsampopoulos *, Pavlos Georgilakis, Dimitris T. Lagos, Vasilis Kleftakis and \\ Nikos Hatziargyriou \\ School of Electrical and Computer Engineering, National Technical University of Athens, 15780 Zografou, Greece \\ * Correspondence: kotsa@power.ece.ntua.gr; Tel.: +30-2107721499
}

Received: 17 May 2019; Accepted: 28 June 2019; Published: 3 July 2019

\begin{abstract}
The role of flexible alternating current transmission systems (FACTSs) in the provision of grid services is becoming increasingly important, due to the massive integration of intermittent renewable energy sources, energy storage systems, and the decommissioning of thermal plants. A comprehensive literature review of grid services offered by FACTS is performed, focusing on the different grid services that they can provide, such as power flow control, reactive power control, voltage control, power quality improvement, harmonic mitigation, improvement of transient stability, and damping of inter-area and intra-area oscillations. These grid services need to be realistically and economically validated in suitable testing environments. A review of relevant standards, guides, and the literature is performed, which covers the entire range from functional specification and factory testing up to the field testing of FACTS. Advanced industry practices, such as controller hardware in the loop (CHIL) testing of FACTS controllers by the manufacturer, and recent trends, such as CHIL testing of replica controllers by the owner, are underlined. Limitations of conventional testing and CHIL testing are explained and the use of power hardware in the loop (PHIL) simulation for FACTS testing is discussed. CHIL and scaled-down PHIL tests on a transmission static synchronous compensator (STATCOM) are performed and a comparison of the results is presented.
\end{abstract}

Keywords: FACTS; grid services; CHIL; PHIL; lab testing; field testing; standards; STATCOM; replica; review

\section{Introduction}

Power systems are subject to an unprecedented transformation, characterized by the wide integration of intermittent distributed generation, energy storage, consumer engagement, and the decommissioning of thermal plants, in order to meet environmental goals, while maintaining the quality of supply [1-3]. In this transformation, flexible alternating current transmission systems (FACTSs) can play an important role by facing several challenges of the transmission system [4]. They can offer a variety of grid services, such as power flow control, reactive power control, voltage control, power quality improvement, harmonic mitigation, improvement of transient stability, damping of inter-area and intra-area oscillations, and black-start capability, among others.

Many researchers have investigated various models and methods for the analysis of FACTS devices and their optimal operation and planning within power systems. In addition to research articles, there are also important review papers that summarize the research findings on FACTS devices and their grid services in a comprehensive manner. There are review articles devoted to the review of one particular FACTS device [5-7], and articles that review more FACTS devices [8-10]. The study of [5] reviews the models and methods of unified power flow controllers (UPFCs) in smart grids, sets the future research goals, and provides future research directions in this field. Another [6] provides a comprehensive review on static synchronous compensators (STATCOMs) and their future research 
potentials. Furthermore, [7] provides a systematic review of static phase sifters (SPSs), compares SPS configurations, and highlights their advantages and limitations. The work of [8] presents a bibliography review of FACTS applications for enhancing power quality and ensuring efficient utilization of energy in power systems with increased penetration of renewable energy sources. The work of [9] presents a review of methodologies for optimum allocation and coordination of FACTS devices and distributed generation units. Finally, paper [10] reviews electromagnetic transient models of FACTS devices that do not use voltage source converters and summarizes key characteristics of each model.

There is no review paper focused on the different grid services provided by various FACTS devices. This paper aims to cover this gap by providing a comprehensive review of the grid services offered by FACTS. These services include power flow control, reactive power control, voltage control, power quality improvement, harmonic mitigation, improvement of transient stability, and the damping of inter-area and intra-area oscillations. Due to space limitations, only a small set of representative research works is reviewed in Section 2 for each one of the different grid services offered by FACTS.

Moreover, suitable testing procedures and setups for testing grid services by FACTS are necessary. In the last decade, several standards and guides related to FACTS testing have been published. These include factory testing and field testing for specific types of FACTS, such as static var compensator (SVC) and STATCOM; however limited attention has been placed on grid services. A method for efficiently testing the provision of grid services is hardware in the loop simulation [11], where a hardware controller (controller hardware in the loop simulation, CHIL) or hardware power device (power hardware in the loop simulation, PHIL) is connected to a real-time simulated power system. Testing of the control systems of FACTS using CHIL simulation has been performed by manufacturers for several years and more recently by transmission system operators (TSOs).

Although there is a plethora of papers that have performed simulation studies of FACTS, limited experiences on hardware testing have been reported, concerning both laboratory testing and field testing. Most of these papers describe specific test cases for a specific FACTS device at a specific location (as described in Sections 3.1 and 3.2). A review on the testing of FACTS is still missing. This paper addresses this gap by reviewing papers, standards, and guides on the testing of FACTS. It efficiently presents all the different testing stages, including conventional testing, i.e., factory and field testing, and emerging industry practices, such as the CHIL testing of FACTS controllers by manufacturers and CHIL testing of replicas by utilities. Particular attention is placed on the testing of grid services.

The contributions of this review paper are manifold:

- It is the only review paper of the bibliography that is focused on the different grid services provided by various FACTS devices.

- It is the first paper that reviews the different testing stages of FACTS. It addresses conventional testing and advanced industry practices.

- It proposes the use of PHIL simulation for the testing of FACTS, as an additional stage before field testing, and presents laboratory results.

The structure of the paper is as follows: Section 2 presents a literature review on the grid services offered by FACTS. Section 3 reviews the conventional testing of FACTS, advanced industry practices, and recent trends. The CHIL and PHIL results of a STATCOM performing voltage control are presented and discussed. Section 4 concludes the paper and summarizes the main findings.

\section{FACTS Providing Grid Services: A Review}

FACTS devices are based on power electronics and are used in order to improve the control of electric power transmission systems in both steady state and transient state conditions [12]. FACTS devices also help increase transmission lines' power transfer capacity [12]. The ability of an alternating current (AC) transmission line to transfer AC electric power is constrained by various factors, including the thermal limit, voltage limit, transient stability limit, and short circuit current limit. These limits 
define the maximum power, called the power transfer capability, which can be transferred through the AC transmission line without causing damage to the transmission line and the electrical equipment.

A FACTS device provides control of one or more parameters of an AC transmission system. These parameters include the voltage magnitude, voltage angle, and the impedance of the transmission line. Through the control of these parameters, the FACTS device can control the real and reactive power flow, the voltage magnitude, and the shunt reactive power compensation. There are four different types of FACTS [12]:

1. Series devices. These are variable impedance devices that inject voltage in a series with the transmission line. Depending on the phase angle between the injected voltage and the line current, they can help control the real and reactive power. Examples of series devices include thyristor controlled series capacitor (TCSC), thyristor switched series capacitor (TSSC), and static synchronous series compensator (SSSC).

2. Shunt devices. These are variable impedance devices that inject current at the point of connection. Depending on the phase angle between the injected current and the line voltage, these devices can control the real and reactive power. Examples of shunt devices include SVC and STATCOM.

3. Series-series devices. These are a combination of series devices, where each series device provides series compensation for each line and also transfers active power among the transmission lines. An example of such a device is the interline power flow controller (IPFC).

4. Shunt-series devices. These are a combination of series and shunt devices, which are controlled in a coordinated way. An example of such a device is the UPFC, which is the most versatile among all FACTS devices, because it can control, selectively or concurrently, the real and reactive power flow via the transmission line, the bus voltage magnitude, and the compensation of reactive power [5].

In this section, representative research works are reviewed for each one of the different grid services offered by FACTS.

\subsection{Power Flow Control}

The power flow control services include:

- Control of power flow [13-18]. The split TCSC provides better power flow control services than the single TCSC [13]. An adaptive TSSC with discrete nonlinear control provides power flow control and improves power system transient stability [14]. An SSSC with an oscillation damping controller simultaneously achieves power flow control and low frequency oscillation damping in a system with a wind farm [15]. The modular multilevel converter-based UPFC regulates the power flow of the power system in both steady state and transient state conditions [16]. A hybrid UPFC, composed of a smaller capacity UPFC and a larger capacity Sen transformer, provides the same services of active and reactive power flow control, with the advantage of much lower installation costs [17].

- Congestion management [19-22]. A method for the optimum location of TCSC relieves congestion in both the normal state and contingency state with single line outage [19]. An analytical method determines the optimum location of the TCSC and SSSC and relieves congestion in both the normal state and contingency state with a single line fault [20]. A pricing-based method finds the optimum location of the UPFC that mitigates line congestion and minimizes system operation costs [21]. A sensitivity-based optimization method finds the optimum location and rated capacity of the UPFC that minimizes congestion costs [22].

- $\quad$ Reactive power dispatch (RPD) [23-26]. RPD is a grid service that simultaneously minimizes reactive power flow in lines, total active power loss in transmission lines, and voltage deviation in buses. The optimal allocation of four TCSCs and three SVCs at the IEEE 30 bus system significantly reduces the total reactive power flow in lines [23]. The optimal reactive power allocation of three 
different FACTS, namely TCSC, SVC, and thyristor controlled phase angle regulator (TCPAR), shows that a SVC is slightly better in the improvement of the voltage profile, while a TCPAR is better in reducing the total active power loss [24]. In comparison with the case without a UPFC, the optimal allocation of one UPFC provides a greater reduction of transmission lines' total active power loss and buses' voltage deviation for both the IEEE 57-bus and the IEEE 118-bus test systems [25]. In an AC-DC power system with $96 \mathrm{AC}$ buses and two DC terminals, the optimal allocation of one UPFC, under contingency conditions, has a significant impact on the minimization of power loss and voltage deviation [26].

- Available transfer capability enhancement [27-33]. The available transfer capability (ATC) measures the capability of interconnected power systems to transfer electric power from one power system to another through the transmission lines. The increase of ATC is important because it helps transfer low cost energy to the loads. FACTS devices can increase the ATC by redistributing power flows. The optimal allocation of one UPFC increases the ATC for the IEEE reliability test system as well as for a 196-bus power system in North America [27]. Since series FACTSs help increase the ATC, it is proposed that these devices should be simultaneously optimized with power generation in a market environment [28]. The UPFC provides a higher increase of the ATC in comparison to STATCOM and SSSC [29], and in comparison to a SVC and thyristor controlled phase shifter (TCPS) [30]. The optimal allocation of multiple FACTS, namely TCSC, TCPS, SVC, and UPFC, provides a significant increase of the ATC [31].

- Power loss reduction. Several research works have shown the use of FACTS devices for the reduction of total active power loss [23-26,30,34].

- Load curtailment minimization. An optimally allocated UPFC is more effective than an optimally allocated TCSC in the minimization of load curtailment on IEEE 14-bus and IEEE 30-bus test systems [35].

- Minimization of wind power curtailment [36-39]. Wind power curtailment is minimized by an optimally allocated TCSC [36] and an optimally allocated distributed power flow controller [37]. An optimally allocated SVC is more effective than an optimally allocated TCSC in the minimization of wind power curtailment [38]. The combined optimal allocation of SVC and TCSC significantly reduces wind power curtailment [39].

\subsection{Voltage Control}

The voltage control capability of the SVC was investigated and a reactive power dispatch model was developed that restores the SVC operating point and regulates the bus voltage [40]. A photovoltaic inverter is controlled as a STATCOM and provides voltage control in power distribution systems [41]. The limits of the UPFC were included into a steady state power flow model, which was validated by simulations that highlight the capabilities of a UPFC for coordinated voltage control and power flow control [42]. An optimization methodology was developed that identifies the optimal parameter settings of one UPFC and manages to relieve voltage violations and overloads that are caused by line outages [43]. A probabilistic methodology improved the steady state bus voltage profile by optimally sizing the TCSC, STATCOM, and UPFC [44].

\subsection{Improvement of Power Quality}

FACTS devices, such as SVC, STATCOM, and UPFC, offer significant power quality services to the grid, including enhancement of the power system reliability and mitigation of voltage sags, harmonics, and unbalance [8,45-49]. The capability of the SVC, STATCOM, and dynamic voltage restorer (DVR) to mitigate voltage sags, harmonics, and unbalance was shown in [45]. Distribution STATCOM and SVC minimize voltage sags and the economic losses in power distribution systems [46]. SVC, STATCOM, and DVR minimize economic losses due to voltage sags [47]. An appropriate control strategy allows the UPFC to provide harmonic isolation in case of nonlinear loads [48]. In order to 
improve the reliability problem that is due to the loading of a transmission line, a UPFC was installed on that line and, as a result, power system reliability as improved [49].

\subsection{Improvement of Power System Stability}

FACTS devices offer significant stability services, including:

- Damping of inter-area and intra-area oscillations [50-52]. A nonlinear control method of UPFC and STATCOM was developed for damping inter-area oscillations, which was validated on a power system with 16 generators and 68 buses [50]. A single FACTS device (STATCOM, UPFC, or multi-terminal UPFC) successfully damps inter-area oscillations and intra-area (local) oscillations [51]. The UPFC provides robust damping of inter-area oscillations at different load conditions [52].

- Transient stability improvement [53-58]. The coordinated control of STATCOM and generator excitation achieves transient stability and voltage regulation [53]. A hardware in the loop validation verified the transient stability enhancement obtained by a wide-area controlled SVC [54]. STATCOM in combination with energy storage system enhances the transient stability of power systems with induction generators and synchronous generators [55]. UPFC offers vast improvement of first swing transient stability [56,57]. The coordinated use of SSSC, TCSC, and STATCOM improved the transient stability of a power system with photovoltaics and wind farms [58].

- Voltage stability improvement [59-64]. Eigen-value analysis or modal analysis can be applied to identify buses (locations) sensitive to voltage collapse and buses where power injections are the most beneficial. Modal analysis identifies the optimum location of SVC for voltage support [59]. Optimally allocated UPFCs enhance power system voltage stability under single outage contingency criterion [60]. The coordinated optimal allocation of SVCs and TCSCs enhance security against voltage collapse by keeping bus voltages and ensuring voltage stability margins [61]. In case of low loads or low voltages, regarding voltage stability, the SSSC is superior to the controllable series compensator (CSC) [62]. An analytical method was used estimate the efficiency of CSC, SSSC, SVC, and STATCOM for voltage stability enhancement [63].

\subsection{Multiple Grid Services}

The coordinated use of multi-type FACTS devices offers multiple grid services [65-69]. The multiple grid services are mathematically formulated as multi-objective optimization problems. An optimally allocated UPFC simultaneously minimizes total active power loss and maximizes power system predictability in systems with a high penetration of wind power [65]. In these systems, predicting the system state is very difficult due to the uncertainties in wind power generation.

An optimally allocated UPFC simultaneously minimizes transmission lines' total active power loss and maximizes the voltage stability limit [66]. The best results are obtained when the transformer taps are optimized in combination with the optimization of the UPFC location and parameter settings.

Optimally allocated TCSCs and SVCs simultaneously minimize the total active power loss, minimize load voltage deviation, and maximize static voltage stability margin, considering single outage contingency criterion, line thermal limits, and bus voltage limits [67].

An optimally allocated hybrid flow controller (HFC), phase shifting transformer (PST), and UPFC simultaneously minimize total active power loss, total fuel cost, and cost of FACTS installation, and maximize power system loadability [68]. The HFC provides better results in comparison with PST and UPFC.

Optimally allocated TCSC, SVC, and UPFC simultaneously minimize total active power loss, and minimize system operation cost that includes the cost of FACTS, the energy loss cost, and the congestion cost [69]. The FACTS' location, size, and parameter settings are optimized in combination with existing reactive power sources. 


\section{Current Practices and Future Trends in the Testing of FACTS}

\subsection{Conventional Testing of FACTS}

The testing of distributed energy resource inverters according to ancillary service requirements has been well established recently. Several standards and guidelines are in place stating requirements and respective testing procedures $[70,71]$. Factory testing takes place at manufacturer's facilities, compliance testing at independent accredited institutes, and, finally, commissioning testing occurs in the field. On the other hand, the testing of FACTS is more challenging mainly due to their high rating and large size. For example, the typical capacities of recent transmission STATCOMs applied in the USA are +/-100 to +/-200 MVAr with some large units reaching +/-250 MVAr, while SVCs can have capacities up to 500 to 600 MVAr [4]. For this reason, most of the studies on FACTS preform digital simulations, while fewer involve laboratory or field tests.

In practice, digital simulations (e.g., transient stability, dynamic performance) are used for the functional specification of a FACTS device, which refers to the definition of equipment requirements, typically performed by the buyer (typically the TSO) or a consultant [72]. IEEE 1031: 2011 [73] proposes an approach to prepare a specification for a transmission SVC using conventional thyristor technology, which can be partly used for STATCOM and other devices. The guide describes newer developments in SVC component equipment and, particularly, control systems and also the latest practices for SVC applications among other topics. Similarly, IEEE P1052/08 [74] aims to assist users in specifying the functional requirements for transmission STATCOMs, using forced commutated technology based on voltage source converter topologies. The guide covers specifications, applications, engineering studies, main component characteristics, system functions and features, factory testing, commissioning, and operations of the STATCOM systems. It addresses the following functions: Reactive power compensation, voltage regulation and control, transient and dynamic stability, and control and protection.

The manufacturing of the device, based on the specification, is followed by factory testing at the facilities of the manufacturer. This includes the testing of the valves as the most critical component. Standards for the testing of valves are IEC 61954:2011 [75] for the thyrisors of SVCs and IEC 62927:2017 [76] for voltage source converter valves of STATCOMs. More specifically, IEC 61954:2011 defines the type, production, and optional tests on thyristor valves used in thyristor controlled reactors, thyristor switched reactors, and thyristor switched capacitors, forming part of SVCs. Type tests aim to verify that the valve design meets the requirements specified (e.g., dielectric and operational tests), production tests aim to verify proper manufacturing (e.g., voltage withstand check), and optional tests are additional to the type and production tests (e.g., voltage transient test). IEC 62927:2017 applies to self-commutated valves for use in voltage source converters for STATCOMs. It includes type tests (e.g., dielectric, operational and electromagnetic interference tests) and production tests (e.g., voltage withstand check) for air insulated valves. Moreover, the manufacturer also tests all other components of the FACTS device (e.g., transformer, circuit breakers, etc.) according to their respective standards. Particular attention needs to be paid to the testing of the control system, which includes dynamic performance tests and protection system tests, among others. More information on the testing of the control system is provided Section 3.2.

When factory testing by the manufacturer is completed, field testing follows in order to verify the specified performance in real operating conditions. It should be noted that this is an important step as in many cases, FACTS are built to satisfy the needs of specific projects. According to IEEE 1303:2011 [77], a field testing program for SVCs should include the following: Equipment tests within the SVC system, tests of the various subsystems that comprise the SVC system, commissioning tests for the complete SVC system, and acceptance testing of the complete SVC system. Equipment, subsystem, and commissioning tests are usually performed by the supplier, while the acceptance tests are performed by the buyer or user. The standard provides general guidelines and criteria for the field testing of SVCs, before they are placed in-service. It identifies the main elements of a field testing program 
so that the user can formulate a specific plan that is most suited for his/her own SVC. Parts of the standard are useful for compensator systems using gate turn-off thyristor technology (STATCOM) or other semiconductor devices, such as insulated gate commutated transistors.

Apart from the aforementioned standards and guides, which focus on SVC and STATCOM, other relevant standards and guides have been published. IEEE 1676:2010 [78] defines control architectures for high-power electronics. It covers FACTS, high voltage direct current (HVDC) systems, distributed generation, and energy storage, among others, with a power range from hundreds of $\mathrm{kW}$ to thousands of MW, but with emphasis on 1 MW to hundreds of MW. IEEE 1534:2009 [79] provides recommended practices for specifying TCSC installations used in series with transmission lines. Ratings for TCSC thyristor valve assemblies, capacitors, and reactors as well as TCSC control characteristics, protective features, testing, commissioning, training, operation, etc. are addressed in this standard. IEEE P2745.1 [80] provides functional requirements for UPFCs, using modular multilevel converters (MMCs), including application conditions, system architecture, function requirements, performance requirements, primary equipment requirements, control and protection requirements, testing, etc. Concerning the testing of valves, IEEE 857:1996 [81] and IEC 60700-1:2015 [82] provide recommendations for the type testing of thyristor valves for HVDC power transmission systems. IEC 62501:2009 [83] deals with the testing of self-commutated converter valves, for use in voltage source converters for HVDC power transmission.

In the literature, a plethora of papers performing simulation studies of FACTS is available, as shown in Section 2. On the other hand, limited experiences on hardware testing are reported. Indicative papers are presented next. Concerning lab testing, [84] explains the difficulty of testing HV thyristor valves, due to the increasing capacity of FACTS devices. A synthetic test setup was applied, where the large current and the high voltage are generated by different power supplies. Moreover, test facilities that can perform operational tests on thyristor valves are reported (e.g., [85]). In [86], real scale validation tests in the laboratory of a large 40 MVAr voltage source converter for a SSSC were carried out. The device is formed by four 3-level 10 MVA inverters, and a series of tests was carried out, including dynamic performance and harmonics. In [87], the performance of prototype tests of a 26 MVA STATCOM and a 13 MVA back-to-back, comprising smaller units connected in parallel, is described. A scaled-down setup for testing series connected FACTS (e.g., SSSC, UPFC, TCSC) was proposed in [88].

Experiences of field testing of FACTS can be found in the literature, starting from more than 20 years ago [89]. Aspects of the planning and execution of the commissioning and testing of +300 MVAr (capacitive) to -100 MVAr (inductive) SVC are described in [90]. Challenges concerning the commissioning and testing of the SVC connected to a relatively weak grid are reported, while considerations on the impact of the tests on transmission and distribution system equipment, generating facilities, and customers are provided. Dynamic performance tests were performed, by varying the reference voltage of the SVC, due to the difficulty of controlling the grid voltage in the field. In [91], a comparative analysis between field tests during commissioning of a -50/+70 MVAr SVC and computer simulations was carried out. The tests included the application of steps in the reference voltage of the SVC and the switching off a capacitor bank among others. In [92], a 1 MVA FACTS device, entitled "power router", designed for power flow control was tested in the field, including dynamic tests. In [93], a large load disturbance test on an HV line with a TCSC was performed (by opening-reclosing of a circuit breaker) combined with a wide area measurement system (WAMS). The field tests and simulations showed that the current issue of a transmission bottleneck of hydroelectric power could be resolved. Additional experiences on the field testing of FACTS have been reported e.g. [94-96].

From the above review, it is clear that important progress in the development of appropriate setups and procedures for laboratory/factory and field testing of FACTS has been performed. However, the standards and guides cover only some types of FACTS devices, while grid services are not thoroughly addressed. Due to the large rating of FACTS devices, it remains a challenge to fully validate all the device functionalities, and especially grid services provision, in the laboratory. For example, 
inverters that are interfacing distributed generation are typically tested in the lab by a grid simulator that can simulate several network conditions (e.g., voltage dip, frequency rise, etc.). However, such devices are hard and expensive to build for high ratings. Moreover, conventional lab testing treats the FACTS device as an independent component, while neglecting interactions with other devices (e.g., distributed generation, other FACTS, etc.) and the overall power system. This is becoming increasingly important due to the need of FACTS to provide advanced grid services in the complex contemporary environment. On the other hand, field tests can validate the performance of FACTS in actual conditions; however, limitations are present, such as limited flexibility and repeatability, as well as the possibility of adversely influencing network equipment. Digital real-time simulation is a promising tool that can tackle some of the aforementioned limitations. Its use for the lab testing of FACTS will be discussed in the following section.

\subsection{Hardware in the Loop Testing of FACTS}

Real-time hardware in the loop (HIL) simulation is gaining significant attention as an advanced power system testing method [11,97-100]. It allows the connection of a physical device to a power system that is simulated in real-time in a digital real-time simulator (DRTS). Exhaustive testing can be achieved in realistic, flexible, controllable, and repeatable conditions that allow de-risking equipment. The two main categories of HIL simulation are shown in Figure 1. In CHIL simulation, a hardware controller is connected to a simulated system executed in the DRTS. In PHIL simulation, a physical power device (e.g., motor, inverter) is connected to a real-time simulated system. In PHIL simulation, a power interface consisting of a power amplifier and sensor is required in order to connect the hardware under test with the DRTS. The voltage of the common node between the simulation and hardware is amplified and applied on the hardware under test. The measured current of the hardware under test is fed back to the DRTS and is inserted in a controllable current source in the real-time simulation. Stability and accuracy issues arise during PHIL simulation due to the non-ideal power interface, which needs to be considered.

CHIL Simulation

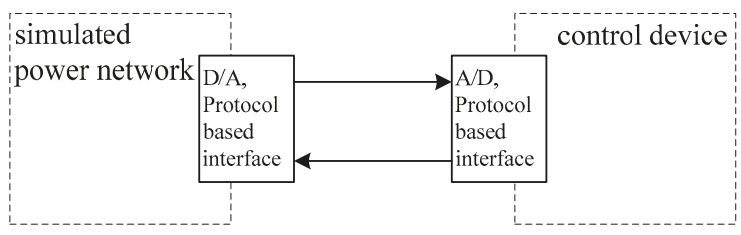

PHIL Simulation

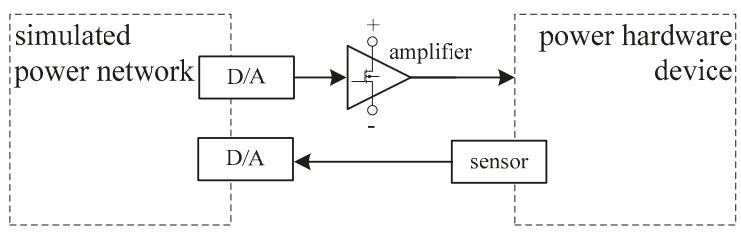

Figure 1. Basic topologies of controller hardware in the loop (CHIL) and power hardware in the loop (PHIL) testing [101].

Decades ago, analogue simulators or transient network analyzers (TNAs), composed of scaled-down physical models, were used for FACTS and HVDC controller testing, which were simplified and presented limited flexibility [102,103]. The emergence of digital real-time simulation allowed a realistic representation of the network and FACTS converter, allowing efficient testing of FACTS controllers and thus leading to fewer problems at the commissioning phase and field operation. This allowed the optimal tuning of the controller parameters, debugging, and repairing. Since then, 
several HVDC and FACTS manufacturers have been using digital-real-time simulation, and specifically CHIL simulation, for dynamic performance and factory acceptance tests [102,103]. It should be noted that the possibility of using digital real-time simulation for FACTS controllers testing is mentioned in guides/standards [73]. The FACTS actual control system is connected to a DRTS that simulates the power network and also the FACTS power circuit (valves, filters, circuit breakers, etc.) [104]. The actual control system receives measurements from the simulated VTs/CTs, sends firing pulses to the simulated converter, and trip commands to simulated breakers. More recently, voltage source converters, which are part of certain FACTS devices, have made use of MMCs, which can include hundreds of sub-modules, therefore requiring hundreds of input/output channels and posing additional challenges for testing and real-time simulation. Indicative examples of CHIL testing of FACTS are briefly presented below. In [105], an SVC controller intended to damp sub-synchronous oscillation was tested using CHIL simulation. In [106], comparisons between CHIL tests and field tests of an SVC were performed. The CHIL tests allowed the efficient tuning of the SVC controller, as well as effective fault tracing. A wide-area control of a STATCOM using a hybrid CHIL and software-in-the loop configuration was validated in [107]. The transient stability enhancement using a wide-area controlled SVC was investigated in a CHIL configuration [54]. Additional applications of CHIL simulation for the testing of FACTS and HVDC controllers are reported in [108].

A more recent trend is the CHIL testing of replicas of the control system of HVDC and FACTS devices by utilities, mainly TSOs. The complexity and increasing importance of HVDC and FACTS in contemporary power systems, the difficulty of maintaining simulation models (e.g., black box models provided by the manufacturer) - leading to differences between the modeled controllers and the actual controllers in the field-and the need to test control changes in a safe environment before field implementation are key drivers for this development [102,103,109]. Certain utilities operate a DRTS, and obtain from the HVDC or FACTS manufacturer a replica of the control/protection system, which is an exact copy of the actual control/protection system installed on site [110]. Moreover, the human-machine interface of the replica offers the same functionalities with the one installed in the field [102]. CHIL platforms with hardware replicas of the control system allow the investigation of system events and the optimum tuning of the control and protection systems [111]. Moreover, interactions between several HVDC systems and FACTS devices can be studied (e.g., provided by multiple vendors), maintenance can be supported, future software updates can be validated, and the training of engineers can be facilitated [112]. As a major source of modeling uncertainty is removed, such platforms are considered to be a reliable tool for longer term studies $[109,111]$.

The application of CHIL simulation for FACTS testing is an industry practice, either with factory testing of the control system by the manufacturer, or in cases with the testing of a replica by the utility. On the other hand, the use of PHIL simulation for testing of FACTSs has been much less explored. PHIL simulation has been successfully used in the testing of PV inverters, wind generation systems, motors, drives, etc., and is also under consideration for standardized testing [97,99,113]. Concerning FACTSs, PHIL simulations were performed in [114]; however, a hardware PV inverter was used, while a D-STATCOM was simulated in the DRTS. PHIL simulation for studying the synchronization issues of voltage source converters, including STATCOMs, was performed in [115]. Contrary to CHIL simulation, where only the control system is tested, in PHIL simulation, the hardware power device is tested, which includes both the control system and power circuit. PHIL simulation can test the actual end-product that is going to be installed in the field, which is not possible with CHIL simulation. Physical valves, filters, circuit breakers, etc. are used, instead of a real-time simulation model. In this way, complex interactions of the actual device with other simulated power system components (e.g., distributed generation, FACTS from different vendors, etc.) within the power system can be examined. This is increasingly important for testing the grid services provided by FACTSs. Therefore, it is suggested that efficient PHIL tests could reduce the need for some of the field tests, or reveal hidden issues prior to field testing. On the other hand, the performance of PHIL testing of full-scale transmission FACTSs is difficult, as a power amplification unit is required with at least the same rating 
as the hardware under test. PHIL simulation capabilities in the 5 MVA [97] and 7 MVA [116] range have been reported, while the rating of AC grid simulators (that can be used as power amplifiers) is constantly increasing (e.g., 12 MVA or higher [117]). However, reaching the rating of large transmission FACTSs is not feasibly nowadays. One solution would be the PHIL testing of each converter separately, if the transmission FACTS is composed of different converters. Another approach would be the PHIL testing of a scaled-down model of the FACTS device. Initial results of this approach are presented in Section 3.3.2. Special investigations are necessary to ensure that the scaled-down model adequately represents the full-scale device. It should also be noted that the non-ideal power interface used in PHIL simulation can, in certain cases, render the experiment unstable or compromise the accuracy, therefore, attention should be paid to this issue $[118,119]$.

Figure 2 summarizes the development and testing stages of FACTSs that were described in Section 3.1 (i.e., functional specification, factory testing, and field testing), including advanced approaches, such as the CHIL testing of the control system by the manufacturer and the CHIL testing of a replica controller by the owner, as presented in Section 3.2. Moreover, the option of performing the proposed PHIL tests (full scale or scaled-down) is included as a new step after the CHIL testing by the manufacturer.

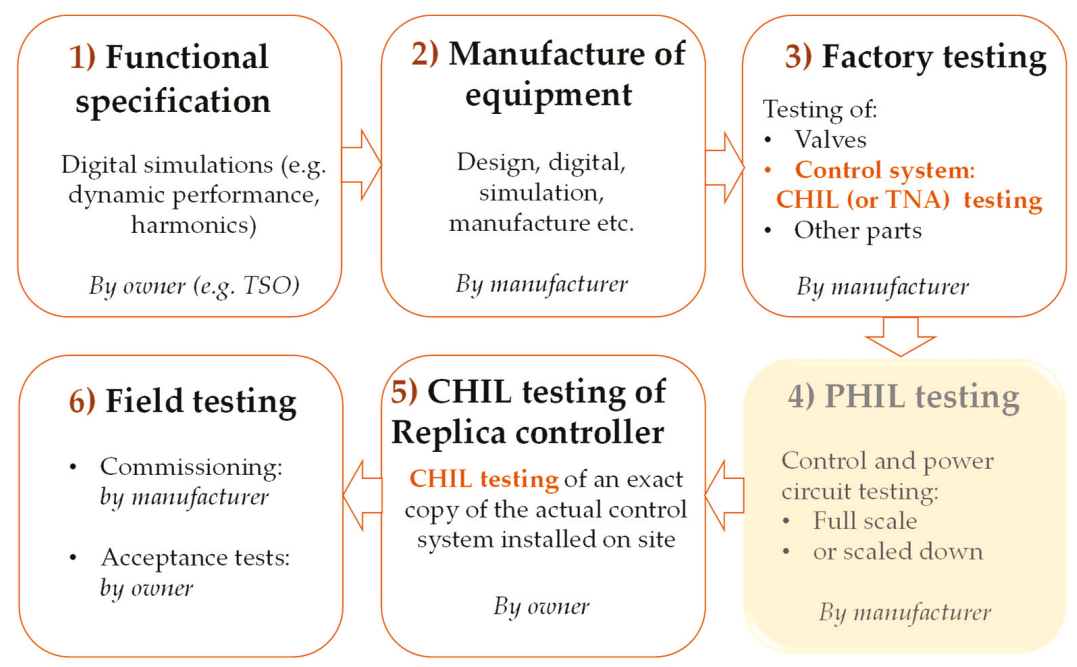

Figure 2. Process from the functional specification to field testing of flexible alternating current transmission systems (FACTS), including the proposed PHIL testing stage.

\subsection{Testing Results}

Laboratory testing of a transmission STATCOM providing voltage control was carried out. First, the controller of a 100 MVA STATCOM was tested in a CHIL configuration. Then, a physical scaled-down model of the STATCOM (1 kVA) was tested in a PHIL configuration.

\subsubsection{Controller Hardware in the Loop Tests}

The Electric Energy Systems laboratory of the National Technical University of Athens (NTUA) operates a DRTS by RTDS Technologies Inc. (including 2 GPC processors), which allows the simulation of switching phenomena in small time-steps in the range of 1 to $4 \mu \mathrm{s}$. A transmission system was designed in the DRTS, as shown in Figure 3. A 3-level 3-phase DC/AC voltage source converter of a 100 MVA STATCOM, including DC bus, filters, and transformer, was simulated in the DRTS, while its control algorithm was executed on a hardware controller. Voltage and current measurements from the real-time simulation were fed to the hardware controller, which returned the modulation signal to the 
simulated DC/AC converter. It should be noted that the conversion of the modulation signal to PWM pulses was performed in the real-time simulation, in order to match the operation of the actual voltage source converter used for PHIL tests in Section 3.3.2. The control algorithm of the STATCOM aims to provide dynamic and steady state voltage control by comparing the locally measured grid voltage (bus 2) with a reference voltage and providing or absorbing reactive power. The model of the STATCOM was based on [120] using the following values for the proportional integral (PI) controller of the outer AC voltage control loop: $K_{i}=1000, K_{p}=10$.

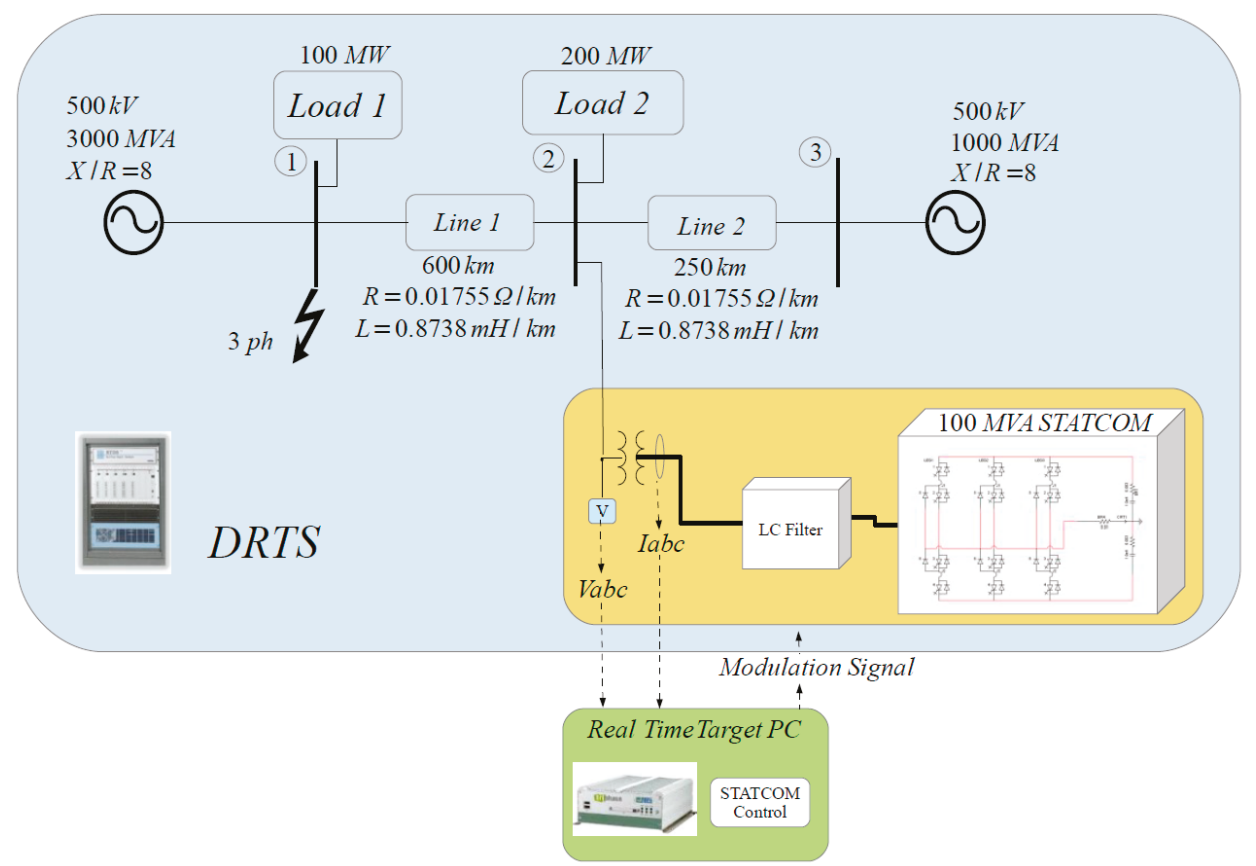

Figure 3. CHIL test setup for the STATCOM controller.

A 3-phase symmetrical fault occurred at bus 1, which was cleared after 13 cycles (fault impedance equals to $100 \mathrm{Ohm}$ resistive). CHIL tests were performed and the results are described below. The 3-phase current at the faulted bus is shown in Figure 4. Figure 5 shows the increase of the current of the STATCOM during the fault in order to provide voltage control, where only one phase is shown in order to facilitate comparison with the PHIL tests in Section 3.3.2 (in the PHIL test, a hardware single-phase voltage source converter was used). 


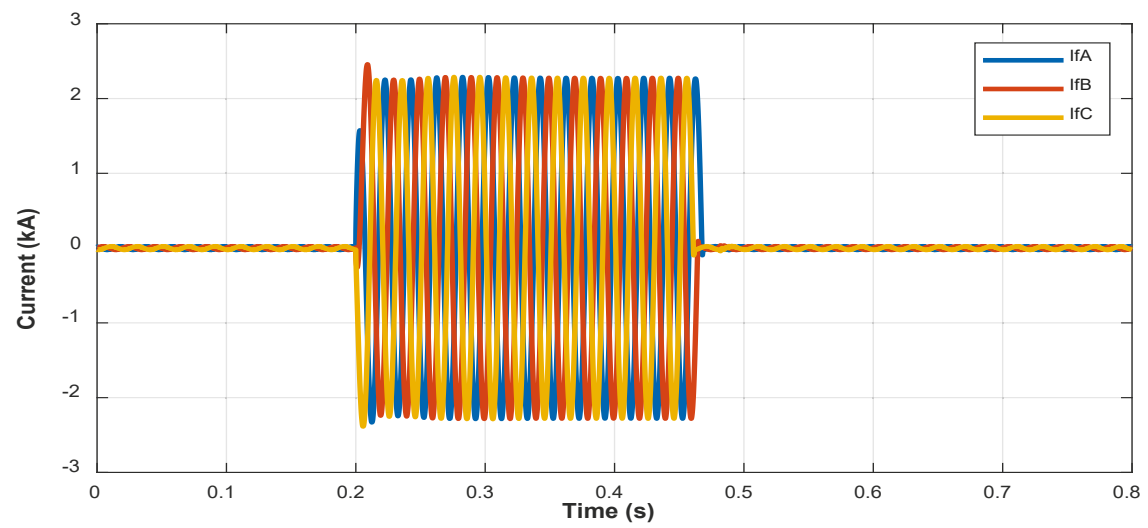

Figure 4. Current at the faulted bus (CHIL test).

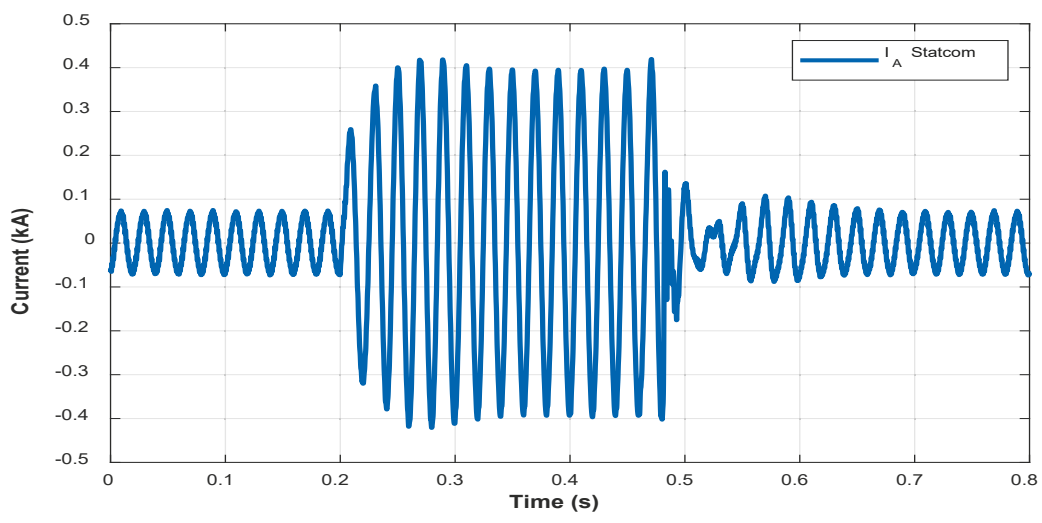

Figure 5. Current contribution of the STATCOM during the fault (CHIL test).

Figures 6 and 7 show the resulting voltages of bus 2 and bus 3 during the short circuit, with and without the STATCOM. The CHIL results show that the mitigation of voltage deviations in dynamic and steady state conditions by the STATCOM is clear. The voltage improvement is greater at bus 2, as this is the point of connection of the STATCOM. The dynamic behavior of the STATCOM influences the grid voltages shortly after fault clearance, however, without adverse effects. Figure 8 shows the reactive power provision by the STATCOM in steady state and dynamic conditions in order to mitigate the voltage sag. Naturally, the reactive power provision is reduced after fault clearance. Active power is absorbed by the STACOM in order to maintain a constant DC bus voltage and it is shown that the active power is increased when the reactive power provision rises. 


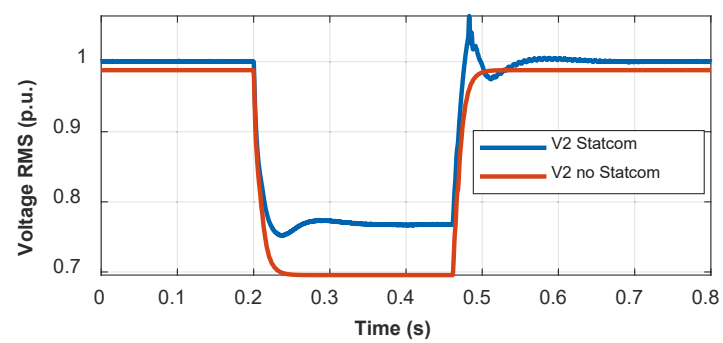

Figure 6. Voltage of bus 2 during the short circuit, with and without the STATCOM (CHIL test).

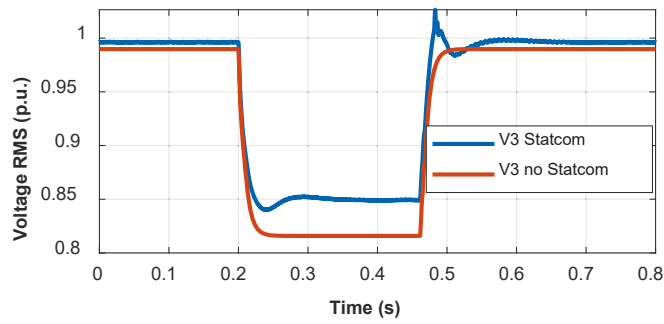

Figure 7. Voltage of bus 3 during the short circuit with and without the STATCOM (CHIL test).

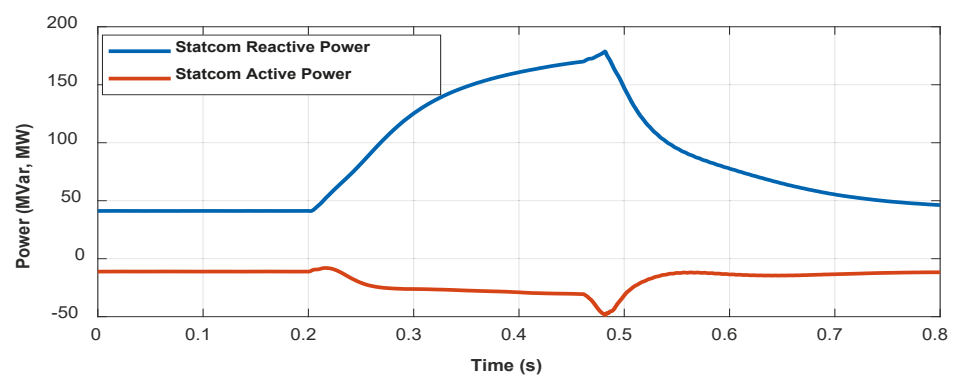

Figure 8. Active and reactive power of the STATCOM during the short circuit (CHIL test).

\subsubsection{Power Hardware in the Loop Tests}

After the successful completion of the CHIL tests, the hardware controller was connected to a physical voltage source converter in order to verify the performance of the device in a PHIL setup (Figure 9). As the rating of the transmission STATCOM is high (i.e., 100 MVA, 3-phase), it was not possible to perform full-scale tests. A small-scale 2-level voltage source converter (i.e., $1 \mathrm{kVA}, 1$ phase) was used in order to verify the performance of the full-scale device. The converter was connected to the real-time simulated system using a suitable power interface consisting of a fast and accurate linear power amplifier and a current sensor. The current sensor used was a current probe (Tektronix A622, scaling $100 \mathrm{mV} / \mathrm{A}$ ), with a small time-delay and compatible output voltage range with the analogue input card of the RTDS. The high voltage of the transmission system was scaled down in the DRTS, in order to reach the low voltage level of the physical converter, while the actual current provided by the converter was scaled up in order to virtually increase the rating of the device, following a similar approach to [119]. Specifically, the voltage from the simulation was multiplied by the ratio of the nominal voltage of the hardware under test $\left(V_{H W_{n}}\right)$ and the full scale device $\left(V_{S W_{n}}\right)$ according to Equation (1). Similarly, the measured current of the hardware was multiplied by the ratio of the nominal current of the full scale device $\left(I_{S W_{n}}\right)$ and the nominal current of the hardware under test 
$\left(I_{H W_{n}}\right)$ according to Equation (2). It should be noted that the single phase hardware under test (1 kVA) was seen as a 3-phase in the simulation (i.e., $3 \mathrm{kVA}$ ) by applying a similar approach to [114]:

$$
\begin{gathered}
a=\frac{V_{H W_{n}}}{V_{S W_{n}}}=\frac{400 \mathrm{~V}}{500 \mathrm{kV}}=0.0008, \\
b=\frac{I_{S W n}}{I_{H W n}}=\frac{100 \mathrm{MVA} /(\sqrt{3} \cdot 500 \mathrm{kV})}{3 \mathrm{kVA} /(\sqrt{3} \cdot 400 \mathrm{~V})}=26.67 .
\end{gathered}
$$

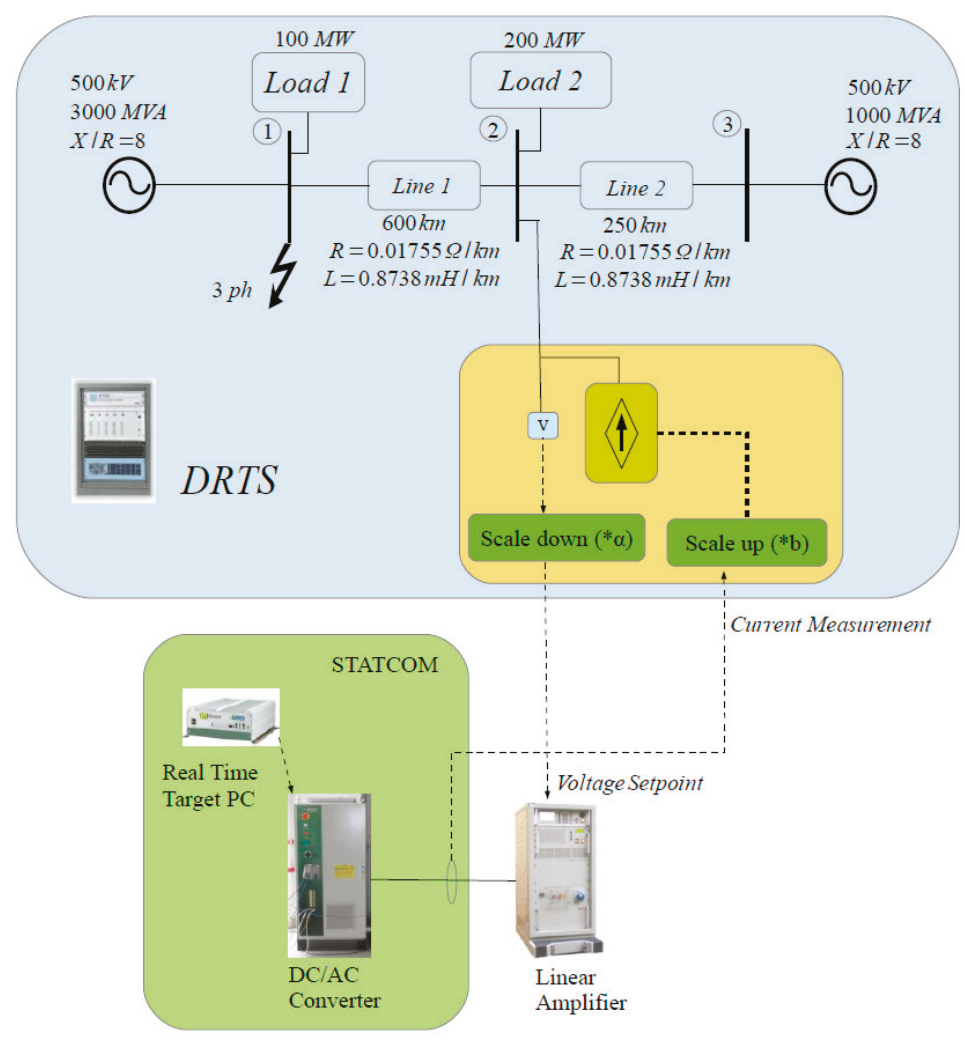

Figure 9. PHIL test setup of the scaled-down STATCOM.

The CHIL tests of Section 3.3.1 were repeated in a PHIL configuration. Figure 10 shows the current at the faulted bus during the short circuit in the PHIL test, which is very similar to the CHIL test. Figure 11 shows the current of the actual voltage source converter before, during, and after the fault is cleared, measured by the aforementioned current probe and obtained from the software of the DRTS. This current was scaled up in the DRTS and was injected in the simulated power system via a controllable current source. 


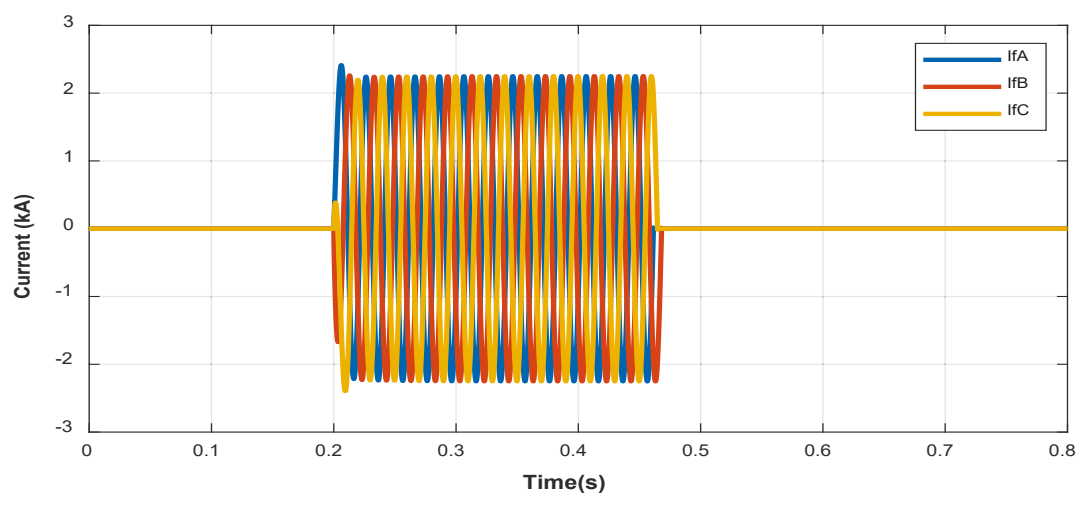

Figure 10. Current at the faulted bus (PHIL test).

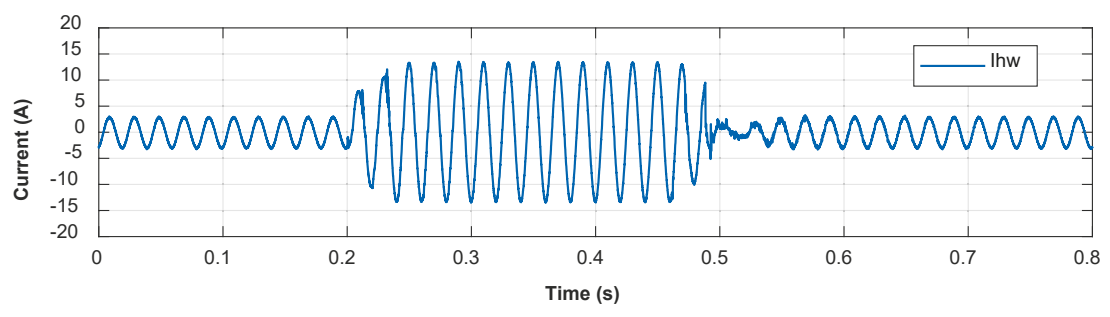

Figure 11. Current of the hardware voltage source converter during the short circuit (PHIL test).

The voltages of bus 2 and bus 3 during the short circuit, with and without the STATCOM, are shown in Figures 12 and 13. It is clear that the STATCOM manages to mitigate the voltage sag at both buses, similarly to the CHIL tests. The occurring voltages in the steady state and dynamic conditions are similar to the CHIL test (Figures 6 and 7), however, there is a smaller voltage improvement under dynamic conditions (around 2 p.u less at bus 2). The smaller voltage improvement is due to less reactive power provided by the converter in the PHIL test (Figure 14), compared to the CHIL test (Figure 8). The hardware voltage source converter exhibits additional constraints on its maximum admissible current, based on its actual switching devices and power circuit. In the CHIL test, where the voltage source converter was purely simulated, this was not considered accurately. Therefore, in the PHIL test, the less reactive current allowed to mitigate the voltage sag resulted in a smaller improvement of the voltage compared to the CHIL test.

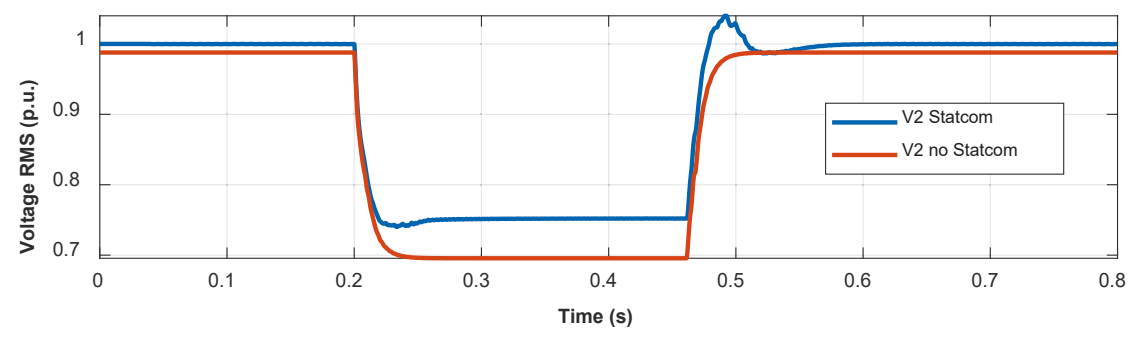

Figure 12. Voltage of bus 2 during the short circuit with and without the STATCOM (PHIL test). 


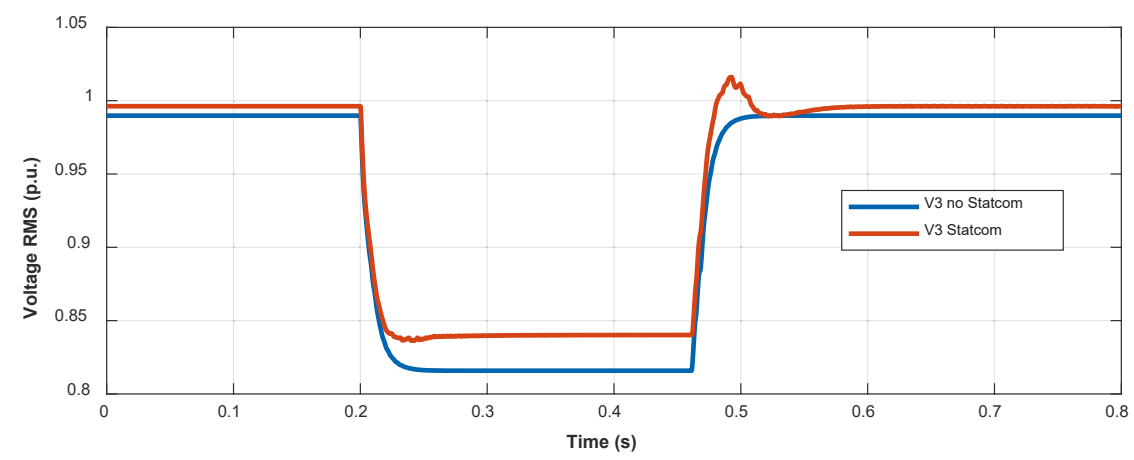

Figure 13. Voltage of bus 3 during the short circuit with and without the STATCOM (PHIL test).

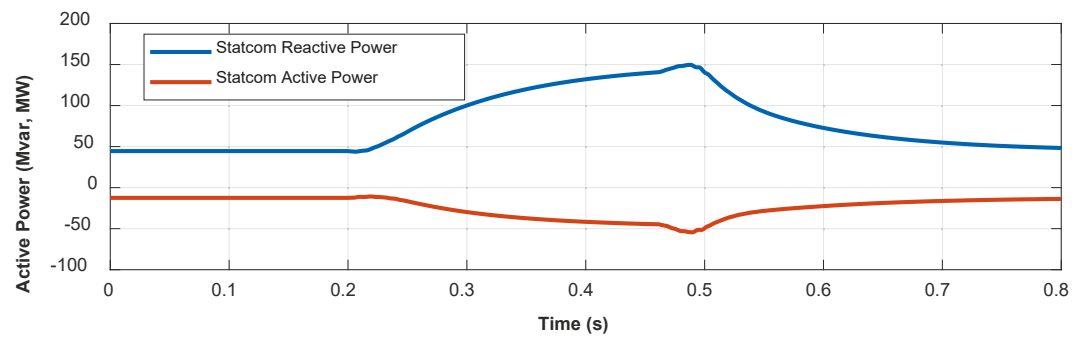

Figure 14. Active and reactive power of the STATCOM during the short circuit (PHIL test).

Finally, the aforementioned CHIL and PHIL test results were compared with pure digital simulations. In the pure digital simulations, the power system, the control algorithm of the STATCOM as well as its power circuit were simulated in real-time using the software of the RTDS (RSCAD). Figure 15 shows that the pure simulation and CHIL test result in very similar voltages at bus 2 with the operation of the STATCOM. Small deviations are shown shortly after fault clearance. On the other hand, the PHIL test results in a smaller voltage improvement, which is due to the less reactive power provided, as already explained. Similarly, Figure 16 shows the similar behavior of the current contribution of the STATCOM during the pure simulation and CHIL test. It is clear that the reactive current of the hardware voltage source converter (scaled up in the simulation) during the fault was smaller in the PHIL test. Moreover, the non-ideal behavior of the hardware device at fault clearance $(t$ $=0.48-0.52 \mathrm{~s}$ ) was shown in the PHIL tests.

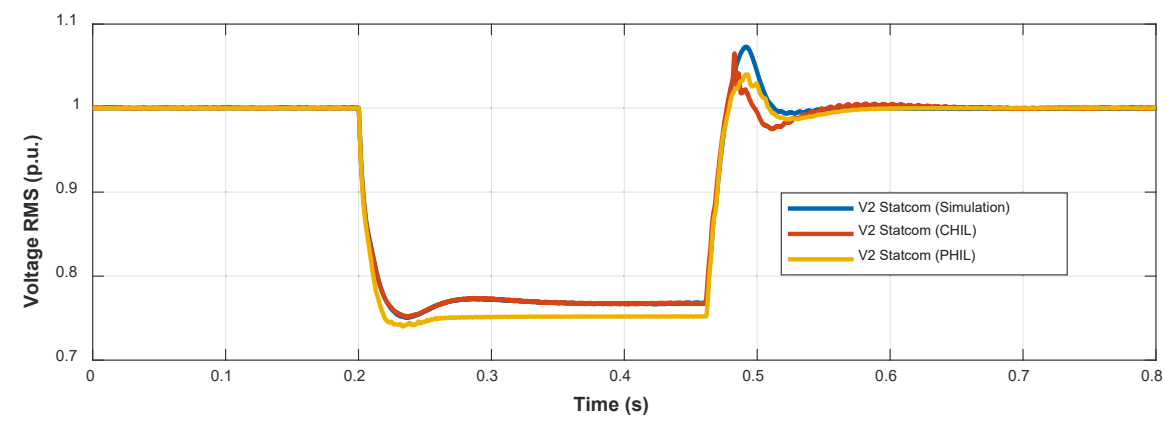

Figure 15. Voltage of bus 2: comparison of pure digital simulation, CHIL test, and PHIL test. 


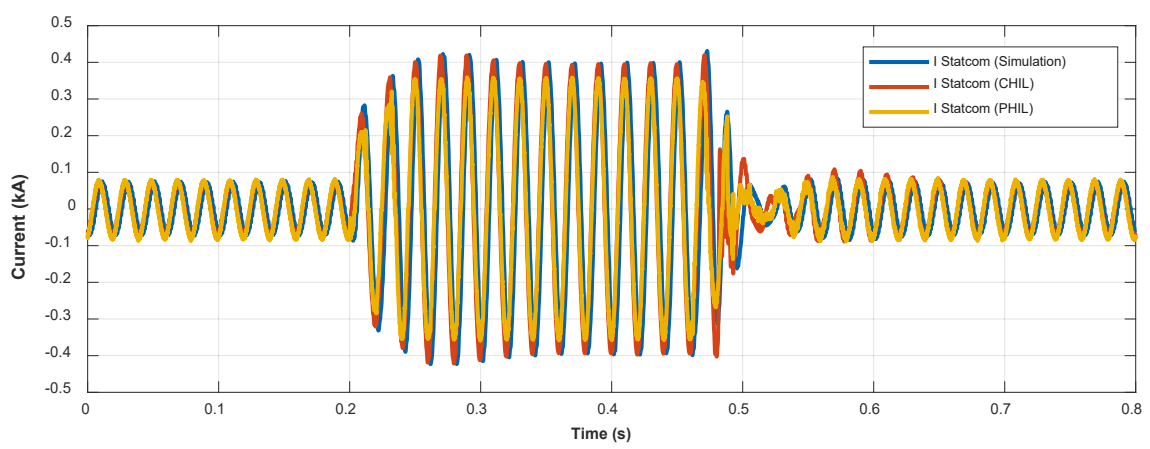

Figure 16. Current contribution of the STATCOM: comparison of pure digital simulation, CHIL test, and PHIL test.

\section{Discussion}

This paper addressed the provision of grid services by FACTS and their testing considering complex contemporary and future power systems. Several research articles, but also review papers summarize the research findings on FACTS devices and their grid services in a comprehensive manner. However, there is no review paper focusing on the different grid services provided by various FACTS devices. This paper aimed to cover this gap by providing a comprehensive literature review on the different grid services provided by various FACTS devices. Moreover, limited experiences on hardware testing of FACTS have been reported that mostly present specific test cases, for a specific FACTS device at a specific location, while a review on the testing of FACTS is missing. This paper addressed this gap by providing a literature review of standards, guides, and scientific papers on the testing of FACTS and presented an overview of all the different testing stages, including conventional testing and emerging industry practices. Moreover, PHIL simulation for the testing of FACTS was suggested as an efficient testing method prior to field testing.

Conventional laboratory testing of FACTS treats the device as an independent component, while neglecting interactions with other devices and the power system. On the other hand, field testing has limited flexibility and repeatability, as well as the possibility of adversely influencing network equipment. The advantages of CHIL testing of FACTS controllers to overcome the above limitations were explained, which is already a practice of manufacturers. It was explained that recently, owners of FACTS, like TSOs, obtain a replica of the control and protection system by the manufacturer and perform CHIL tests, in order to reduce modeling uncertainty in the long-term, provide optimal tuning of parameters, and facilitate maintenance and future updates. As CHIL simulation allows testing of only the control system and not the actual end-product, the use of PHIL simulation is suggested as a further step. PHIL simulation can test both the control system and power circuit (i.e., valves, filters, transformer, circuit breakers, etc.), reducing the uncertainty towards field testing. Full-scale PHIL testing of D-STATCOMs and relatively small transmission STATCOMs, if they consist of several converters that are tested separately, is feasible. However, the full-scale PHIL testing of large transmission STATCOMs is not feasible nowadays. Therefore, the execution of scaled-down PHIL tests was discussed. Indicative CHIL and scaled-down PHIL tests of a transmission STATCOM providing voltage control were performed. The CHIL and PHIL results presented a similar behavior at steady state and dynamic conditions. The differences were due to the current limitations of the hardware device that were not considered accurately in the CHIL tests. The CHIL and PHIL results were also compared with pure digital simulations.

In future work, PHIL testing of a full-scale D-STATCOM could be performed in a suitable laboratory in order to compare with conventional factory tests and CHIL tests. In this way, the specific benefits of performing PHIL simulation prior to field testing could be highlighted. Moreover, the 
effectiveness of scaled-down PHIL tests and their accurate representation of full-scale tests could be further investigated.

Author Contributions: P.K. and P.G. developed the main idea and structure of the paper. D.T.L. and V.K. performed the hardware in the loop tests. P.K. and P.G. wrote the paper. N.H. supervised the work and reviewed the paper.

Funding: This work is supported in part by the European Commission within the Horizon 2020 framework ERIGrid project under Grant agreement 654113.

Conflicts of Interest: The authors declare no conflict of interest.

\section{References}

1. Lopes, J.P.; Hatziargyriou, N.; Mutale, J.; Djapic, P.; Jenkins, N. Integrating distributed generation into electric power systems: A review of drivers, challenges and opportunities. Electr. Power Syst. Res. 2007, 77, 1189-1203. [CrossRef]

2. Strasser, T.; Andrén, F.; Kathan, J.; Cecati, C.; Buccella, C.; Siano, P.; Leitao, P.; Zhabelova, G.; Vyatkin, V.; Vrba, P.; et al. A review of architectures and concepts for intelligence in future electric energy systems. IEEE Trans. Ind. Electron. 2014, 62, 2424-2438. [CrossRef]

3. Reza, M.; Slootweg, J.G.; Schavemaker, P.H.; Kling, W.L.; Van der Sluis, L. Investigating impacts of distributed generation on transmission system stability. In Proceedings of the IEEE Power Tech Conference, Bologna, Italy, 23-26 June 2003.

4. Sullivan, D.; Buterbaugh, B.; Paramalingam, J.; Nakamura, F.; Paramalingam, J.; Nakamura, F.; Matsuda, A.; Yamanaka, D.; Tsuchiya, T. Application of FACTS Devices for a Dynamic Power System within the USA. In Proceedings of the International Power Electronics Conference (IPEC), Niigata, Japan, 20-24 May 2018.

5. Georgilakis, P.S.; Hatziargyriou, N.D. Unified power flow controllers in smart power systems: models, methods, and future research. IET Smart Grid 2019, 2, 2-10. [CrossRef]

6. Singh, B.; Saha, R.; Chandra, A.; Al-Haddad, K. Static synchronous compensators (STATCOM): A review. IET Power Electron. 2009, 2, 297-324. [CrossRef]

7. Iravani, M.R.; Maratukulam, D. Review of semiconductor-controlled (static) phase shifters for power system applications. IEEE Trans. Power Syst. 1994, 9, 1833-1839. [CrossRef]

8. Gandoman, F.H.; Ahmadi, A.; Sharaf, A.M.; Siano, P.; Pou, J.; Hredzak, B.; Agelidis, V.G. Review of FACTS technologies and applications for power quality in smart grids with renewable energy systems. Renew. Sustain. Energy Rev. 2018, 82, 502-514. [CrossRef]

9. Singh, B.; Mukherjee, V.; Tiwari, P. A survey on impact assessment of DG and FACTS controllers in power systems. Renew. Sustain. Energy Rev. 2015, 42, 846-882. [CrossRef]

10. Faruque, M.O.; Dinavahi, V.; Santoso, S.; Adapa, R. Review of electromagnetic transient models for non-VSC FACTS. IEEE Trans. Power Delivery 2005, 20, 1065-1079. [CrossRef]

11. Faruque, M.O.; Strasser, T.; Lauss, G.; Jalili-Marandi, V.; Forsyth, P.; Dufour, C.; Dinavahi, V.; Monti, A.; Kotsampopoulos, P.; Martinez, J.A.; et al. Real-time simulation technologies for power systems design, testing, and analysis. IEEE Power Energy Technol. Syst. J. 2015, 2, 63-73. [CrossRef]

12. Hingorani, N.G.; Gyugyi, L. Understanding FACTS: Concepts and technology of Flexible AC Transmission Systems; IEEE Press: Piscataway, NJ, USA, 2000; pp. 1-35.

13. Meikandasivam, S.; Nema, R.K.; Jain, S.K. Fine power flow control by split TCSC. Int. J. Electr. Power Energy Syst. 2013, 45, 519-529. [CrossRef]

14. Johansson, N.; Angquist, L.; Nee, H.P. An adaptive controller for power system stability improvement and power flow control by means of a thyristor switched series capacitor (TSSC). IEEE Trans. Power Syst. 2010, 25, 381-391. [CrossRef]

15. Wang, L.; Vo, Q.S. Power flow control and stability improvement of connecting an offshore wind farm to a one-machine infinite-bus system using a static synchronous series compensator. IEEE Trans. Sustain. Energy 2013, 4, 358-369. [CrossRef]

16. Liu, J.; Xu, Z.; Fei, W.; Chen, L.; Chen, B.; Chen, B. Comprehensive power flow analyses and novel feedforward coordination control strategy for MMC-based UPFC. Energies 2019, 12, 824. [CrossRef] 
17. Yuan, J.; Liu, L.; Xiao, L. Hybrid electromagnetic unified power flow controller: A novel flexible and effective approach to control power flow. IEEE Trans. Power Delivery 2018, 33, 2061-2069. [CrossRef]

18. Georgantzis, G.J.; Hatziargyriou, N.D.; Leonidaki, E.A.; Papadias, B.C.; Vlachogiannis, J.G. Application of thyristor controlled series capacitor to load flow redistribution in the Hellenic transmission system. In Proceedings of the International Conference on Electric Power Engineering PowerTech, Budapest, Hungary, 29 August-2 September 1999.

19. Besharat, H.; Taher, S.A. Congestion management by determining optimal location of TCSC in deregulated power systems. Int. J. Electr. Power Energy Syst. 2008, 30, 563-568. [CrossRef]

20. Lim, J.U.; Moon, S.I. An analytical approach for the operation of series compensators to relieve power flow congestion. Euro. Trans. Electr. Power 2003, 13, 247-252. [CrossRef]

21. Reddy, A.K.; Singh, S.P. Congestion mitigation using UPFC. IET Gener. Transm. Distrib. 2016, 10, $2433-2442$.

22. Chong, B.; Zhang, X.P.; Godfrey, K.R.; Yao, K.R.; Yao, L.; Bazargan, M. Optimal location of unified power flow controller for congestion management. Euro. Trans. Electr. Power 2010, 20, 600-610. [CrossRef]

23. Bhattacharyya, B.; Gupta, V.K. Fuzzy based evolutionary algorithm for reactive power optimization with FACTS devices. Int. J. Electr. Power Energy Syst. 2014, 61, 39-47. [CrossRef]

24. Preedavichit, P.; Srivastava, S.C. Optimal reactive power dispatch considering FACTS devices. Electr. Power Syst. Res. 1998, 46, 251-257. [CrossRef]

25. Dutta, S.; Mukhopadhyay, P.; Roy, P.K.; Nandi, D. Unified power flow controller based reactive power dispatch using oppositional krill herd algorithm. Int. J. Electr. Power Energy Syst. 2016, 80, 10-25. [CrossRef]

26. Thukaram, D.; Yesuratham, G. Optimal reactive power dispatch in a large power system with AC-DC and FACTS controllers. IET Gener. Transm. Distrib. 2008, 2, 71-81. [CrossRef]

27. Sawhney, H.; Jeyasurya, B. Application of unified power flow controller for available transfer capability enhancement. Electr. Power Syst. Res. 2004, 69, 155-160. [CrossRef]

28. Shahraei-Ardakani, M.; Blumsack, S.A. Transfer capability improvement through market-based operation of series FACTS devices. IEEE Trans. Power Syst. 2016, 31, 3702-3714. [CrossRef]

29. Kumar, A.; Kumar, J. ATC with ZIP load model - A comprehensive evaluation with third generation FACTS in restructured electricity markets. Int. J. Electr. Power Energy Syst. 2014, 54, 546-558. [CrossRef]

30. Xiao, Y.; Song, Y.H.; Liu, C.C.; Sun, Y.Z. Available transfer capability enhancement using FACTS devices. IEEE Trans. Power Syst. 2003, 18, 305-312. [CrossRef]

31. Jirapong, P.; Ongsakul, W. Optimal placement of multi-type FACTS devices for total transfer capability enhancement using hybrid evolutionary algorithm. Electr. Power Compon. Syst. 2007, 35, 981-1005. [CrossRef]

32. Leonidaki, E.; Hatziargyriou, N.; Manos, G.; Papadias, B. A systematic approach for effective location of series compensation to increase available transfer capability. In Proceedings of the IEEE PowerTech, Porto, Portugal, 10-13 September 2001.

33. Leonidaki, E.A.; Georgiadis, D.P.; Hatziargyriou, N.D. Decision trees for determination of optimal location and rate of series compensation to increase power system loading margin. IEEE Trans. Power Syst. 2006, 21, 1303-1310. [CrossRef]

34. Packiasudha, M.; Suja, S.; Jerome, J. A new cumulative gravitational search algorithm for optimal placement of FACT device to minimize system loss in the deregulated electrical power environment. Int. J. Electr. Power Energy Syst. 2017, 84, 34-46. [CrossRef]

35. Singh, J.G.; Qazi, H.W.; Ghandhari, M. Load curtailment minimization by optimal placement of unified power flow controller. Int. Trans. Electr. Energ. Syst. 2016, 26, 2272-2284. [CrossRef]

36. Nasri, A.; Conejo, A.J.; Kazempour, S.J.; Ghandhari, M. Minimizing wind power spillage using an OPF with FACTS devices. IEEE Trans. Power Syst. 2014, 29, 2150-2159. [CrossRef]

37. Tang, Y.; Liu, Y.; Ning, J.; Zhao, J. Multi-time scale coordinated scheduling strategy with distributed power plow controllers for minimizing wind power spillage. Energies 2017, 10, 1804. [CrossRef]

38. Rasoulzadeh-Akhijahani, A.; Mosallanejad, A. Analyzing TCSC and SVC effects in wind power curtailment mitigation. Int. Trans. Electr. Energ. Syst. 2016, 26, 2445-2462. [CrossRef]

39. Kapetanaki, A.; Levi, V.; Buhari, M.; Schachter, J.A. Maximization of wind energy utilization through corrective scheduling and FACTS deployment. IEEE Trans. Power Syst. 2017, 32, 4764-4773. [CrossRef]

40. Li, S.; Ding, M.; Wang, J.; Zhang, W. Voltage control capability of SVC with var dispatch and slope setting. Electr. Power Syst. Res. 2009, 79, 818-825. [CrossRef] 
41. Varma, R.K.; Siavashi, E.M. PV-STATCOM: A new smart inverter for voltage control in distribution systems. IEEE Trans. Sustain. Energy 2018, 9, 1681-1691. [CrossRef]

42. Liu, J.Y.; Song, Y.H.; Mehta, P.A. Strategies for handling UPFC constraints in steady state power flow and voltage control. IEEE Trans. Power Syst. 2000, 15, 566-571.

43. Sao, W.; Vittal, V. LP-based OPF for corrective FACTS control to relieve overloads and voltage violations. IEEE Trans. Power Syst. 2006, 21, 1832-1839. [CrossRef]

44. Faried, S.O.; Billinton, R.; Aboreshaid, S. Probabilistic technique for sizing FACTS devices for steady state voltage profile enhancement. IET Gener. Transm. Distrib. 2009, 3, 385-392. [CrossRef]

45. Liao, H.; Milanovic, J.V. On capability of different FACTS devices to mitigate a range of power quality phenomena. IET Gener. Transm. Distrib. 2017, 11, 1202-1211. [CrossRef]

46. Goswami, A.K.; Gupta, C.P.; Singh, G.K. Minimization of voltage sag induced financial losses in distribution systems using FACTS devices. Electr. Power Syst. Res. 2011, 81, 767-774. [CrossRef]

47. Milanovic, J.V.; Zhang, Y. Global minimization of financial losses due to voltage sags with FACTS based devices. IEEE Trans. Power Delivery 2010, 25, 298-306. [CrossRef]

48. Enslin, J.H.R.; Zhao, J.; Spee, R. Operation of the unified power flow controller as harmonic isolator. IEEE Trans. Power Electron. 1996, 11, 776-784. [CrossRef]

49. Rajabi-Ghahnavieh, A.; Fotuhi-Firuzabad, M.; Shahidehpour, M.; Feuillet, R. UPFC for enhancing power system reliability. IEEE Trans. Power Delivery 2010, 25, 2881-2890. [CrossRef]

50. Zarghami, M.; Crow, M.L.; Jagannathan, S. Nonlinear control of FACTS controllers for damping interarea oscillations in power systems. IEEE Trans. Power Delivery 2010, 25, 3113-3121. [CrossRef]

51. Du, W.; Wu, X.; Wang, H.F.; Dunn, R. Feasibility study to damp power system multi-mode oscillations by using a single FACTS device. Int. J. Electr. Power Energy Syst. 2010, 32, 645-655. [CrossRef]

52. Pal, B.C. Robust damping of interarea oscillations with unified power-flow controller. IEE Proc. Gener. Transm. Distrib. 2002, 149, 733-738. [CrossRef]

53. Cong, L.; Wang, Y. Co-ordinated control of generator excitation and STATCOM for rotor angle stability and voltage regulation enhancement of power systems. IEE Proc. Gener. Transm. Distrib. 2002, 149, 659-666. [CrossRef]

54. Esparza, A.; Segundo, J.; Nunez, C.; Visairo, N.; Barocio, E.; Garcia, H. Transient stability enhancement using a wide-area controlled SVC: An HIL validation approach. Energies 2018, 11, 1639. [CrossRef]

55. Kanchanaharuthai, A.; Chankong, V.; Loparo, K.A. Transient stability and voltage regulation in multimachine power systems vis-a-vis STATCOM and battery energy storage. IEEE Trans. Power Syst. 2015, 30, 2404-2416. [CrossRef]

56. Mihalic, R.; Zunko, P.; Povh, D. Improvement of transient stability using unified power flow controller. IEEE Trans. Power Delivery 1996, 11, 485-492. [CrossRef]

57. Gholipour, E.; Saadate, S. Improving of transient stability of power systems using UPFC. IEEE Trans. Power Delivery 2005, 10, 1677-1682. [CrossRef]

58. Movahedi, A.; Niasar, A.H.; Gharehpetian, G.B. Designing SSSC, TCSC, and STATCOM controllers using AVURPSO, GSA, and GA for transient stability improvement of a multi-machine power system with PV and wind farms. Int. J. Electr. Power Energy Syst. 2019, 106, 455-466. [CrossRef]

59. Mansour, Y.; Xu, W.; Alvarado, F.; Rinzin, C. SVC placement using critical modes of voltage instability. IEEE Trans. Power Syst. 1994, 9, 757-763. [CrossRef]

60. Kumar, G.N.; Kalavathi, M.S. Cat swarm optimization for optimal placement of multiple UPFC's in voltage stability enhancement under contingency. Int. J. Electr. Power Energy Syst. 2014, 57, 97-104. [CrossRef]

61. Yorino, N.; El-Araby, E.E.; Sasaki, H.; Harada, S. A new formulation for FACTS allocation for security enhancement against voltage collapse. IEEE Trans. Power Syst. 2003, 18, 3-10. [CrossRef]

62. Gasperic, S.; Mihalic, R. The impact of serial controllable FACTS devices on voltage stability. Int. J. Electr. Power Energy Syst. 2015, 64, 1040-1048. [CrossRef]

63. Gasperic, S.; Mihalic, R. Estimation of the efficiency of FACTS devices for voltage-stability enhancement with PV area criteria. Renew. Sustain. Energy Rev. 2019, 105, 144-156. [CrossRef]

64. Leonidaki, E.A.; Manos, G.A.; Hatziargyriou, N.D. An effective method to locate series compensation for voltage stability enhancement. Electr. Power Syst. Res. 2005, 74, 73-81. [CrossRef] 
65. Galvani, S.; Hagh, M.T.; Sarifian, M.B.B.; Mahammadi-Ivatloo, B. Multiobjective predictability-based optimal placement and parameters setting of UPFC in wind power included power systems. IEEE Trans. Ind. Inf. 2009, 15, 878-888. [CrossRef]

66. Tripathy, M.; Mishra, S. Bacteria foraging-based solution to optimize both real power loss and voltage stability limit. IEEE Trans. Power Syst. 2007, 22, 240-248. [CrossRef]

67. Benabid, R.; Boudour, M.; Abido, M.A. Optimal location and setting of SVC and TCSC devices using non-dominated sorting particle swarm optimization. Electr. Power Syst. Res. 2009, 79, 1668-1677. [CrossRef]

68. Lashkar Ara, A.; Kazemi, A.; NabaviNiaki, S.A. Multiobjective optimal location of FACTS shunt-series controllers for power system operation planning. IEEE Trans. Power Delivery 2012, 27, 481-490. [CrossRef]

69. Bhattacharyya, B.; Kumar, S. Approach for the solution of transmission congestion with multi-type FACTS devices. IET Gener. Transm. Distrib. 2016, 10, 2802-2809. [CrossRef]

70. Brundlinger, R.; Strasser, T.; Lauss, G.; Hoke, A.; Chakraborty, S.; Martin, G.; Kroposki, B.; Johnson, J.; de Jong, E. Lab tests: Verifying that smart grid power converters are truly smart. IEEE Power Energy Mag. 2015, 13, 30-42. [CrossRef]

71. Kotsampopoulos, P.; Hatziargyriou, N.; Bletterie, B.; Lauss, G.; Strasser, T. Introduction of advanced testing procedures including PHIL for DG providing ancillary services. In Proceedings of the 39th Annual Conference of the IEEE Industrial Electronics Society (IECON), Vienna, Austria, 10-13 November 2013.

72. Sullivan, D.; Mader, D. Fundamentals and Characteristics of Dynamic Reactive Power Control. In Proceedings of the IEEE PES Webinar, 18 December 2018.

73. IEEE. IEEE 1031:2011. IEEE Guide for the Functional Specification of Transmission Static Var Compensators; IEEE: Piscataway, NJ, USA, 2011.

74. IEEE. IEEE P1052/08. IEEE Approved Draft Guide for the Functional Specifications for Transmission Static Synchronous Compensator (STATCOM) Systems; IEEE: Piscataway, NJ, USA, 2018.

75. IEC. IEC 61954:2011. Static var Compensators (SVC)—Testing of Thyristor Valves; International Electrotechnical Commission: Geneva, Switzerland, 2011.

76. IEC. IEC 62927:2017. Voltage Sourced Converter (VSC) Valves for Static Synchronous Compensator (STATCOM)_Electrical Testing; International Electrotechnical Commission: Geneva, Switzerland, 2017.

77. IEEE. IEEE 1303:2011. IEEE Guide for Static Var Compensator Field Tests; IEEE: Piscataway, NJ, USA, 2011.

78. IEEE. IEEE 1676:2010. IEEE Guide for Control Architecture for High Power Electronics (1 MW and Greater) Used in Electric Power Transmission and Distribution Systems; IEEE: Piscataway, NJ, USA, 2010.

79. IEEE. IEEE 1534:2009. IEEE Recommended Practice for Specifying Thyristor-Controlled Series Capacitors; IEEE: Piscataway, NJ, USA, 2009.

80. IEEE. IEEE P2745.1. IEEE Draft Guide for Technology of Unified Power Flow Controller Using Modular Multilevel Converter: Part 1 Functions; IEEE: Piscataway, NJ, USA, 2018.

81. IEEE. IEEE 857:1996. IEEE Recommended Practice for Test Procedures for High-Voltage Direct-Current Thyristor Valves; IEEE: Piscataway, NJ, USA, 1996.

82. IEC. IEC 60700-1:2015. Thyristor Valves for high Voltage Direct Current (HVDC) Power Transmission-Part 1: Electrical Testing; International Electrotechnical Commission: Geneva, Switzerland, 2015.

83. IEC. IEC 62501:2009. Voltage Sourced Converter (VSC) Valves for High-Voltage Direct Current (HVDC) Power Transmission-Electrical Testing; International Electrotechnical Commission: Geneva, Switzerland, 2009.

84. Tang, G.; Zha, K.; He, Z.; Wang, H. Study on operational tests for FACTS thyristor valves. IEEE Trans. Power Delivery. 2013, 28, 1525-1532. [CrossRef]

85. Lal, G.; Dutta, D.; Arunachalam, M. Design and testing of thyristor valves of TCSC for Kanpur-Ballabhgarh $400 \mathrm{kV}$ line. In Proceedings of the IEEE/PES Transmission and Distribution Conference and Exposition, Chicago, IL, USA, 21-24 April 2008.

86. Chivite-Zabalza, F.J.; Izurza, P.; Calvo, G.; Rodriguez, M.A. Laboratory tests of the voltage source converter for a 47 MVAR Series Static Synchronous Compensator for the Spanish high voltage transmission grid. In Proceedings of the 7th IET International Conference on Power Electronics, Machines and Drives (PEMD 2014), Manchester, UK, 8-10 April 2014.

87. Sato, T.; Matsushita, Y.; Temma, K.; Morishima, N.; Iyoda, I. Prototype test of STATCOM and BTB based on voltage source converter using GCT thyristor. In Proceedings of the IEEE/PES Transmission and Distribution Conference and Exhibition, Yokohama, Japan, 6-10 October 2002. 
88. Valdez-Resendiz, J.E.; Mayo-Maldonado, J.C.; Rosas-Caro, J.C.; Alejo-Reyes, A.; Llamas-Terres, A.; Valderrabano-Gonzalez, A.; Del-Valle-Soto, C.; Valdivia, L.J. Energy Recycling Laboratory Experimental Test Bench for Three-Phase FACTS Devices Prototypes. In Proceedings of the International Conference on Electronics, Communications and Computers (CONIELECOMP), Cholula, Mexico, 27 February-1 March 2019.

89. Hauer, J.F.; Mittelstadt, W.A.; Piwko, R.J.; Damsky, B.L.; Eden, J.D. Modulation and SSR tests performed on the BPA $500 \mathrm{kV}$ thyristor controlled series capacitor unit at Slatt substation. IEEE Trans. Power Syst. 1996, 11, 801-806. [CrossRef]

90. O'Connor, J.; Reed, G.F.; Sullivan, D.; Shimokaji, N.; Birsa, J. Testing and Commissioning Experiences for the Duke Energy Progress Static VAR Compensator at Jacksonville, NC. In Proceedings of the IEEE PES T\&D Conference and Exposition, Chicago, IL, USA, 14-17 April 2014.

91. Geraldes, W.; Rose, E.H.; Machado, C.; Honda, J.T.; Vendramini, P.M. Static VAR compensator from Coxipo Substation (Brazil)-comparison between computer simulations and field tests. In Proceedings of the International Conference on AC and DC Power Transmission, London, UK, 17-20 September 1991.

92. Kandula, R.P.; Chen, H.; Prasai, A.; Lambert, F.; Heidel, T.; Schauder, C.; Schatz, J.; Powell, T.; Divan, D. Field test results for a 3-phase $12.47 \mathrm{kV} 1$ MVA power router. In Proceedings of the IEEE Energy Conversion Congress and Exposition (ECCE), Milwaukee, WI, USA, 18-22 September 2016.

93. He, S.; Zhou, X.; Liu, J. Large load disturbance test of south Gansu power grid based on WAMS. In Proceedings of the International Conference on Advanced Power System Automation and Protection, Beijing, China, 16-20 October 2011.

94. Hauer, J.F.; Mittelstadt, W.A.; Piwko, R.J.; Damsky, B.L.; Eden, J.D. Test results and initial operating experience for the BPA $500 \mathrm{kV}$ thyristor controlled series capacitor-modulation, SSR and performance monitoring. In Proceedings of the IEEE Technical Applications Conference and Workshops, Northcon/95, Portland, OR, USA, 10-12 October 1995.

95. Kinney, S.J.; Mittelstadt, W.A.; Suhrbier, R.W. Test results and initial operating experience for the BPA 500 $\mathrm{kV}$ thyristor controlled series capacitor design, operation, and fault test results. In Proceedings of the IEEE Technical Applications Conference and Workshops, Northcon/95, Portland, OR, USA, 10-12 October 1995.

96. Kalsi, S.S.; Madura, D.; Snitchler, G.; Ross, M.; Voccio, J.; Ingram, M. Discussion of test results of a superconductor synchronous condenser on a utility grid. IEEE Trans. Appl. Supercond. 2007, 17, 2026-2029. [CrossRef]

97. Steurer, M.; Edrington, C.S.; Sloderbeck, M.; Ren, W.; Langston, J. A megawatt-scale power hardware-in-the-loop simulation setup for motor drives. IEEE Trans. Ind. Electron. 2010, 57, 1254-1260. [CrossRef]

98. Molitor, C.; Benigni, A.; Helmedag, A.; Chen, K.; Calì, D.; Jahangiri, P.; Muller, D.; Monti, A. Multiphysics test bed for renewable energy systems in smart homes. IEEE Trans. Ind. Electron. 2013, 60, 1235-1248. [CrossRef]

99. Lauss, G.F.; Faruque, M.O.; Schoder, K.; Dufour, C.; Viehweider, A.; Langston, J. Characteristics and design of power hardware-in-the-loop simulations for electrical power systems. IEEE Trans. Ind. Electron. 2015, 63, 406-417. [CrossRef]

100. Maniatopoulos, M.; Lagos, D.; Kotsampopoulos, P.; Hatziargyriou, N. Combined control and power hardware in-the-loop simulation for testing smart grid control algorithms. IET Gener. Transm. Distrib. 2017, 11, 3009-3018. [CrossRef]

101. Kotsampopoulos, P.; Lagos, D.; Hatziargyriou, N.; Faruque, M.O.; Lauss, G.; Nzimako, O.; Forsyth, P.; Steurer, M.; Ponci, F.; Monti, A.; et al. A Benchmark System for Hardware-in-the-Loop Testing of Distributed Energy Resources. IEEE Power Energy Technol. Syst. J. 2018, 5, 94-103. [CrossRef]

102. Kuffel, R.; Forsyth, P.; Peters, C. The Role and Importance of Real Time Digital Simulation in the Development and Testing of Power System Control and Protection Equipment. IFAC-PapersOnLine 2016, 49, 178-182. [CrossRef]

103. Iyoda, I.; Belanger, J. History of Power System Simulators to Analyze and Test of Power Electronics Equipment. In Proceedings of the IEEE History of Electrotechnolgy conference (HISTELCON), Kobe, Japan, 7-8 August 2017.

104. Yoon, Y.B.; Kim, T.K.; Cha, S.T.; Kuffel, R.; Wierckx, R.; Yu, M. HVDC control and protection testing using the RTDS simulator. In Proceedings of the 4th International HVDC Transmission Operating Conference, Yichang, China, 6-8 September 2001. 
105. Xiao, X.; Zhao, Y.; Zhang, Y.; Ye, M.; Wang, X. Closed loop test platform for SVC controller based on RTDS. In Proceedings of the International Conference on Electrical Machines and Systems, Wuhan, China, 17-20 October 2008.

106. Boshoff, S.; van Dyk, C.; Becker, L.; Halonen, M.; Rudin, S.; Lidholm, J.; Maguire, T. Auas SVC, performance verification by RTDS and field tests. In Proceedings of the Seventh International Conference on AC-DC Power Transmission, London, UK, 28-30 November 2001.

107. Musleh, A.S.; Muyeen, S.M.; Al-Durra, A.; Kamwa, I. Testing and validation of wide-area control of STATCOM using real-time digital simulator with hybrid HIL-SIL configuration. IET Gener. Transm. Distrib. 2017, 11, 3039-3049. [CrossRef]

108. Guillaud, X.; Faruque, M.O.; Teninge, A.; Hariri, A.H.; Vanfretti, L.; Paolone, M.; Dinavahi, V.; Mitra, P.; Lauss, G.; Dufour, C.; et al. Applications of real-time simulation technologies in power and energy systems. IEEE Power Energy Technol. Syst. J. 2015, 2, 103-115. [CrossRef]

109. Cowan, I.L.; Marshall, S.C.M. Installation and interfacing HVDC control replicas at the national HVDC centre. In Proceedings of the 15th IET International Conference on AC and DC Power Transmission (ACDC 2019), Coventry, UK, 5-7 February 2019.

110. Saad, H. System Studies of HVDC links using Real-Time Simulation. In Vortragsreihe des Vereins Freunde des Instituts für Stromrichtertechnik und Antriebsregelung; Technische Universität Darmstadt: Darmstadt, Germany, 2018.

111. Saad, H.; Vernay, Y.; Dennetière, S.; Rault, P.; Clerc, B. System dynamic studies of power electronics devices with real time simulation-A TSO operational experience. In CIGRE Session Papers \& Proceedings; E-Cigré: Paris, France, 2018.

112. Martin, C. The use of real time simulation to de-risk and manage HVDC and FACTS schemes-Experiences on the French Transmission grid. In Proceedings of the OPAL-RT's 9th International Conference on Real-Time Simulation, Montreal, QC, Canada, 5-8 September 2017.

113. Kotsampopoulos, P.C.; Kleftakis, V.A.; Hatziargyriou, N.D. Laboratory education of modern power systems using PHIL simulation. IEEE Trans. Power Syst. 2017, 32, 3992-4001. [CrossRef]

114. Kleftakis, V.; Rigas, A.; Vassilakis, A.; Kotsampopoulos, P.; Hatziargyriou, N. Power-Hardware-in-the-loop simulation of a D-STATCOM equipped MV network interfaced to an actual PV inverter. In Proceedings of the IEEE PES Innovative Smart Grid Technologies Europe (ISGT Europe), Lyngby, Denmark, 6-9 October 2013.

115. Vodyakho, O.; Edrington, C.S.; Steurer, M.; Azongha, S.; Fleming, F. Synchronization of three-phase converters and virtual microgrid implementation utilizing the power-hardware-in-the-loop concept. In Proceedings of the Twenty-Fifth Annual IEEE Applied Power Electronics Conference and Exposition (APEC), Palm Springs, CA, USA, 21-25 February 2010.

116. Koralewicz, P.; Gevorgian, V.; Wallen, R. Multi-megawatt-scale Power-hardware-in-the-loop interface for testing ancillary grid services by converter-coupled generation. In Proceedings of the IEEE 18th Workshop on Control and Modeling for Power Electronics (COMPEL), Stanford, CA, USA, 9-12 July 2017.

117. Product Note-ACS 6000 Grid Simulator. Available online: https:/library.e.abb.com/public/ 19178deab3265e81c1257abf002e9e4a/ACS\%206000\%20grid\%20simulator_lowres.pdf (accessed on 14 May 2019).

118. Ren, W.; Steurer, M.; Baldwin, T.L. Improve the stability and the accuracy of power hardware-in-the-loop simulation by selecting appropriate interface algorithms. IEEE Trans. Ind. Appl. 2008, 44, 1286-1294. [CrossRef]

119. Kotsampopoulos, P.C.; Lehfuss, F.; Lauss, G.F.; Bletterie, B.; Hatziargyriou, N.D. The limitations of digital simulation and the advantages of PHIL testing in studying distributed generation provision of ancillary services. IEEE Trans. Ind. Electron. 2015, 62, 5502-5515. [CrossRef]

120. Yazdani, A.; Iravani, R. A generalized state-space averaged model of the three-level NPC converter for systematic DC-voltage-balancer and current-controller design. IEEE Trans. Power Delivery. 2005, 20, 1105-1114. [CrossRef]

(C) 2019 by the authors. Licensee MDPI, Basel, Switzerland. This article is an open access article distributed under the terms and conditions of the Creative Commons Attribution (CC BY) license (http://creativecommons.org/licenses/by/4.0/). 

Article

\title{
Active and Reactive Power Compensation Control Strategy for VSC-HVDC Systems under Unbalanced Grid Conditions
}

\author{
Weiming Liu ${ }^{1}$, Tingting Zheng ${ }^{1}$, Ziwen Liu ${ }^{2, *}$, Zhihua Fan ${ }^{2}$, Yilong Kang ${ }^{2}$, Da Wang ${ }^{1}$, \\ Mingming Zhang ${ }^{1}$ and Shihong Miao ${ }^{2, *}$ \\ 1 State Grid East Inner Mongolia Electric Power Research Institute, Hohhot 010020, China; \\ liuweiming@md.sgcc.com.cn (W.L.); zhengtingting@md.sgcc.com.cn (T.Z.); wangda@md.sgcc.com.cn (D.W.); \\ zhangmingming@md.sgcc.com.cn (M.Z.) \\ 2 State Key Laboratory of Advanced Electromagnetic Engineering and Technology, School of Electrical and \\ Electronic Engineering, Huazhong University of Science and Technology, Wuhan 430074, China; \\ fzhhust@hust.edu.cn (Z.F.); ylkang@hust.edu.cn (Y.K.) \\ * Correspondence: liuziwen@hust.edu.cn (Z.L.); shmiao@hust.edu.cn (S.M.); \\ Tel.: +86-027-87543228 (Z.L. \& S.M.)
}

Received: 23 October 2018; Accepted: 8 November 2018; Published: 13 November 2018

\begin{abstract}
This paper presents a power compensation strategy to suppress the double frequency power ripples of Voltage source converter high-voltage direct current (VSC-HVDC) systems under unbalanced grid voltage conditions. The mathematical control equations of the double frequency ripple power of VSC under unbalanced operating conditions are firstly derived and established, where the dynamic behaviors of the double frequency ripples in active and reactive power are regarded as being driven by current-relevant components and voltage-relevant components, respectively. Based on the equations, a power compensation control strategy of VSC-HVDC is proposed via the passivity-based control with disturbance observer to suppress both the current-relevant and voltage-relevant components in the power ripples. With this control strategy, the double frequency ripples in active and reactive power are suppressed simultaneously and system performance is significantly enhanced with the implementation of the disturbance observer in the passivity-based control. Theoretical stability analysis and simulation cases show the effectiveness and superiority of the proposed strategy.
\end{abstract}

Keywords: VSC-HVDC; unbalanced grid conditions; double frequency ripples; power compensation; passive-based control; disturbance observer

\section{Introduction}

Recently, the voltage source converter based high voltage direct current (VSC-HVDC) is widely used in dc transmission, renewable energy generation, island network supply and other fields [1-4]. In general control scheme of VSC-HVDC, the three-phase AC grid voltage is usually assumed to be balanced. However, once the unbalanced grid conditions occur (e.g., due to AC grid voltage unbalance and unsymmetrical faults), the converter will operate in abnormal condition and the negative sequence components in voltage and current will do great harm to system operation. If no compensation measures are adopted, the double frequency ripples will appear in the output power of VSC, which affects output quality of the converter [5-7] and may even make the converter malfunction. Therefore, how to suppress the double frequency ripples under unbalanced grid conditions becomes a hot topic in the research of VSC-HVDC control.

To suppress the double frequency power ripples, the additional active power filter is utilized in Reference [8-10] to eliminate the asymmetric components. The active power filter has ideal 
performance in regulating asymmetrical components but the cost input is high. Hence improving the control strategy of the converter is the mainstream research on the suppression of double frequency power ripples. The VSC control strategies in ideal balance grid have been relatively mature and the most common schemes are the voltage oriented control (VOC). The existing unbalance control research of VSC under the framework of VOC is mainly realized by obtaining the control reference value according to some kind of control objective (e.g., elimination of active power ripple, reactive power ripple or negative-sequence current component) and tracking this reference value with suitable method [11,12]. In Reference [13], a novel method of separating the instantaneous positive and negative sequence components is proposed and well applied for different control objectives of VSC under unbalanced grid voltage. In Reference [14], an optimal active and reactive power control is proposed to achieve multi-objectives for VSC-HVDC under unbalanced grid voltage conditions. A flexible control strategy is proposed in Reference [15] for oscillation control of the active and reactive power by introducing a control parameter k. In Reference [16], an improved model predictive current control for VSC is presented when unbalanced grid voltages occur to reduce power fluctuations. In Reference [17], a direct power control for grid-connected VSC under unbalanced network is proposed by applying a virtual phase angle for coordinated transformations. The optimal power control strategies for VSC-HVDC systems under unbalanced grid voltage conditions are proposed in Reference [18,19], which enable the system to provide flexible power control. In Reference [20], a power control of VSC-HVDC converters is presented to limit the influence of AC unbalanced faults on multi-terminal DC grids. In Reference [21], a novel unified dynamic model and control strategy are presented to improve the power quality for VSC-HVDC under unbalanced grid conditions. These control strategies are verified to be effective but the fluctuations of active and reactive power cannot be suppressed at the same time.

For past few years, the passivity-based control has attracted more and more attentions because of the flexible adjustment and simplified control structure and has been applied in power converter control $[22,23]$. The passivity-based control of the doubly fed induction generator under unbalanced grid voltage is proposed in Reference [24]. However, the passivity-based control is applied to replace the traditional PI (Proportional-Integral) control for system response improvement instead of eliminating the double frequency ripple power. Therefore, the double frequency ripples in active and reactive power still cannot be suppressed simultaneously. On the other hand, although the passivity-based control gives the controller design by configuring system energy and injecting damping to achieve the satisfactory transient response, it is sensitive to unmodeled dynamics and model errors. To handle the issue, a perturbation observer-based passivity-based control is proposed in Reference [25] but the implementation of high-order observer brings in serious noise and complicates system structure, which means the enhanced passivity-based control also needs further study.

In this paper, a power compensation strategy to suppress the double frequency ripples in active and reactive power of VSC-HVDC systems under unbalanced grid voltage conditions is proposed. The main work of this paper can be drawn as:

(1) The mathematical control equations of the double frequency ripple power of VSC under unbalanced grid conditions are derived and established. In the equations, the dynamic behaviors of the double frequency ripples in active and reactive power are regarded as being driven by current-relevant components and voltage-relevant components, which can be controlled respectively for double frequency ripple suppression.

(2) Based on the established control equations, a power compensation control strategy of VSC-HVDC is proposed via the passivity-based control with disturbance observer. The passivity-based control is responsible for the tracking control of current-relevant components with the expected value, while the disturbance observer focuses on the compensation of the voltage-relevant components. With this control strategy, the double frequency ripples in active and reactive power of VSC-HVDC under unbalanced grid conditions are suppressed simultaneously and system performance is significantly enhanced with the implementation of the disturbance observer in the passivity-based control. 
Theoretical stability analysis and simulations of a two-terminal VSC-HVDC system on PSCAD/EMTDC verify the validity and superiority of the proposed control strategy.

\section{Analysis and Control Equations Establishment of Double Frequency Ripple power of VSC}

The VSC structure adopted in this paper is the two-level topology and shown in Figure 1. The representations of the variables in Figure 1 are shown in the Nomenclature Section. Although the modular multilevel converter (MMC) is recognized as the promising converter technology applied in high-voltage and high-power transmission technology, the system-level control of MMC is similar to that in two-level converter since they have same vector control model in dq coordinate system [26], which mean the response characteristics of the two converters under unbalanced grid conditions are also same. Therefore, the two-level converter is used as the study object in this paper for explicit explanations.

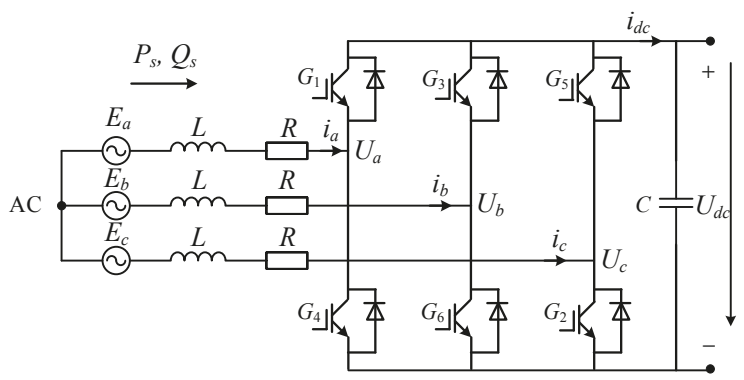

Figure 1. The VSC topological structure.

Under balanced grid voltage condition, the mathematical model of VSC in synchronous rotating reference frame is [11]

$$
\left[\begin{array}{l}
U_{d} \\
U_{q}
\end{array}\right]=\left[\begin{array}{l}
E_{d} \\
E_{q}
\end{array}\right]-R\left[\begin{array}{l}
i_{d} \\
i_{q}
\end{array}\right]-L \frac{d}{d t}\left[\begin{array}{l}
i_{d} \\
i_{q}
\end{array}\right]+\omega L\left[\begin{array}{r}
i_{q} \\
-i_{d}
\end{array}\right]
$$

When asymmetric fault occurs in the grid, the dissymmetry in system electrical quantities is mainly caused by negative sequence components, since the zero sequence components are isolated by the $\mathrm{Y} / \Delta$ transformer in the grid side. Considering that in the synchronous rotating reference frame, the positive sequence component is equal to the dc component, while the negative sequence component is equal to the double frequency component, the double frequency ripple power in the forward direction dq rotating frame can be written as (2) according to [17] ( $d$ axis is chosen to be coincided with grid voltage vector)

$$
\left\{\begin{array}{c}
P_{2}=\frac{3}{2}\left(i_{d 0} E_{d 2}+i_{q 0} E_{q 2}+E_{d 0} i_{d 2}\right) \\
Q_{2}=\frac{3}{2}\left(i_{d 0} E_{q 2}-i_{q 0} E_{d 2}-E_{d 0} i_{q 2}\right)
\end{array},\right.
$$

where the right subscript " 0 " stands for dc component and " 2 " stands for double frequency component. It is seen from (2) that the factors that cause the double frequency ripples in the output power include the double frequency components of grid voltage $\left(E_{d 2}\right.$ and $\left.E_{q 2}\right)$ and the double frequency components of VSC current $\left(i_{d 2}\right.$ and $\left.i_{q 2}\right)$. Therefore, the double frequency ripple power can be regard as the results driven by the current-relevant components and voltage-relevant components which can be described as

$$
\left\{\begin{array}{l}
P_{2}=P_{2 i}+P_{2 u} \\
Q_{2}=Q_{2 i}+Q_{2 u}
\end{array}\right.
$$


where $P_{2 i}, P_{2 u}, Q_{2 i}$ and $Q_{2 u}$ are defined as

$$
\left\{\begin{array}{l}
P_{2 i}=\frac{3}{2} E_{d 0} i_{d 2}, P_{2 u}=\frac{3}{2}\left(i_{d 0} E_{d 2}+i_{q 0} E_{q 2}\right) \\
Q_{2 i}=-\frac{3}{2} E_{d 0} i_{q 2}, Q_{2 u}=\frac{3}{2}\left(i_{d 0} E_{q 2}-i_{q 0} E_{d 2}\right)
\end{array},\right.
$$

To control double frequency ripple power, take the derivative of (4). Since the derivative of dc component is zero, it results in

$$
\left\{\begin{array}{l}
\frac{d P_{2}}{d t}=\frac{d P_{2 i}+d P_{2 u}}{d t}=\frac{3}{2} E_{d 0} \frac{d i_{d 2}}{d t}+\frac{d P_{2 u}}{d t} \\
\frac{d Q_{2}}{d t}=\frac{d Q_{2 i}+d Q_{2 u}}{d t}=-\frac{3}{2} E_{d 0} \frac{d i_{q 2}}{d t}+\frac{d Q_{2 u}}{d t}
\end{array},\right.
$$

Since the independent control equation of VSC double frequency voltage can be derived as

$$
\left[\begin{array}{l}
U_{d 2} \\
U_{q 2}
\end{array}\right]=\left[\begin{array}{c}
E_{d 2} \\
E_{q 2}
\end{array}\right]-R\left[\begin{array}{c}
i_{d 2} \\
i_{q 2}
\end{array}\right]-L \frac{d}{d t}\left[\begin{array}{c}
i_{d 2} \\
i_{q 2}
\end{array}\right]+\omega L\left[\begin{array}{r}
i_{q 2} \\
-i_{d 2}
\end{array}\right],
$$

By substituting (6) into (5), it results in

$$
\left\{\begin{array}{l}
L \frac{d P_{2}}{d t}=\frac{3}{2} E_{d 0}\left(E_{d 2}-R i_{d 2}-U_{d 2}+\omega L i_{q 2}\right)+L \frac{d P_{2 u}}{d t} \\
L \frac{d Q_{2}}{d t}=-\frac{3}{2} E_{d 0}\left(E_{q 2}-R i_{q 2}-U_{q 2}-\omega L i_{d 2}\right)+L \frac{d Q_{2 u}}{d t}
\end{array},\right.
$$

Furtherly, the differential equations which take double frequency power $P_{2}$ and $Q_{2}$ as state variables can be obtained as

$$
\left\{\begin{array}{l}
L \frac{d P_{2}}{d t}=\frac{3}{2} E_{d 0} E_{d 2}-R P_{2}-u_{P}-\omega L Q_{2}+\left(L \frac{d P_{2 u}}{d t}+R P_{2 u}+\omega L Q_{2 u}\right) \\
L \frac{d Q_{2}}{d t}=-\frac{3}{2} E_{d 0} E_{q 2}-R Q_{2}+u_{Q}+\omega L P_{2}+\left(L \frac{d Q_{2 u}}{d t}+R Q_{2 u}-\omega L P_{2 u}\right)
\end{array},\right.
$$

where $u_{P}$ and $u_{Q}$ satisfy $u_{P}=1.5 E_{d 0} U_{d 2}, u_{Q}=1.5 E_{d 0} U_{q 2}$. Let $w_{P u}$ and $w_{Q u}$ be defined as

$$
\left\{\begin{array}{l}
w_{P u}=\frac{3}{2} E_{d 0} E_{d 2}+L \frac{d P_{2 u}}{d t}+R P_{2 u}+\omega L Q_{2 u} \\
w_{Q u}=-\frac{3}{2} E_{d 0} E_{q 2}+L \frac{d Q_{2 u}}{d t}+R Q_{2 u}-\omega L P_{2 u}
\end{array},\right.
$$

In (9), the voltage-relevant components that cause the double frequency power ripples are included in $w_{P u}$ and $w_{Q u}$, which can be regarded as the "double frequency voltage disturbance" of the differential Equations (8). Meanwhile, to furtherly improve the robustness of control system, the error terms $\varepsilon_{P}$ and $\varepsilon_{Q}$ are introduced in the disturbances $w_{P u}$ and $w_{Q u}$ to describe the unmodeled dynamics including modelling errors and unknown time-varying external disturbances. Then it yields that

$$
\left\{\begin{array}{l}
w_{P u}=\frac{3}{2} E_{d 0} E_{d 2}+L \frac{d P_{2 u}}{d t}+R P_{2 u}+\omega L Q_{2 u}+\varepsilon_{P} \\
w_{Q u}=-\frac{3}{2} E_{d 0} E_{q 2}+L \frac{d Q_{2 u}}{d t}+R Q_{2 u}-\omega L P_{2 u}+\varepsilon_{Q}
\end{array},\right.
$$

Finally, the control equations of the double frequency ripple power can be depicted by

$$
\left\{\begin{array}{c}
L \frac{d P_{2}}{d t}=-R P_{2}-u_{P}-\omega L Q_{2}+w_{P u} \\
L \frac{d Q_{2}}{d t}=-R Q_{2}+u_{Q}+\omega L P_{2}+w_{Q u}
\end{array},\right.
$$


In (11), $w_{P u}$ and $w_{Q u}$ reflect the influence of voltage-relevant components and unmodeled dynamics on the double frequency ripple power. Apart from $w_{P u}$ and $w_{Q u}$, the control Equation (11) reflect the double frequency ripple behaviors caused by current-relevant components. Hence through proper double frequency power compensation control based on (11), the current-relevant and voltage-relevant components that cause double frequency ripples can be suppressed simultaneously.

\section{Power Compensation Strategy for VSC-HVDC via Passivity-Based Control with Disturbance Observer}

In normal condition, the common vector double loop control is adopted in VSC for desired control aims. However, under unbalanced grid voltage, a power compensation controller is needed to suppress the double frequency power ripples with no impact on the normal operation of VSC. The compensation strategy should be effective in controlling the double frequency components of the unbalanced voltage and current to compensate the output voltage of inner loop PI control. In this paper, the passivity-based control with disturbance observer are proposed to form the power compensation control, which serves as the auxiliary adjustment of VSC under unbalanced grid condition. The design of passivity-based control aims at minimizing the double frequency ripple power $P_{2}$ and $Q_{2}$ with the double frequency voltage disturbance $w_{P u}$ and $w_{Q u}$ observed and compensated in the control scheme.

\subsection{PCHD Model of the VSC-HVDC Systems and the Passivity-Based Control Strategy}

Consider the PCHD (Port-Controlled Hamiltonian with Dissipation) model [23] of control Equation (11) described as

$$
\left\{\begin{array}{l}
\dot{x}=[J(x)-\Re(x)] \frac{\partial H(x)}{\partial x}+G(x) u \\
y=G^{T}(x) \frac{\partial H(x)}{\partial x}
\end{array},\right.
$$

where $x(t), u(t)$ and $y(t)$ denote the system state, the control input and the system output, respectively. It is noted that with the positive defined Hamiltonian function $H(x)$ to be system storage function, the system (12) is passive from the input $u$ to output $y$. The system state and input variables are shown as

$$
\left\{\begin{array}{l}
\boldsymbol{x}=\left[\begin{array}{ll}
L P_{2} & L Q_{2}
\end{array}\right]^{T}=\boldsymbol{D}\left[\begin{array}{ll}
P_{2} & Q_{2}
\end{array}\right]^{T}, \boldsymbol{u}=\left[\begin{array}{ll}
u_{2} & u_{2}
\end{array}\right]^{T} \\
\boldsymbol{D}=\left[\begin{array}{ll}
L & 0 \\
0 & L
\end{array}\right], \boldsymbol{G}=\left[\begin{array}{cc}
-1 & 0 \\
0 & 1
\end{array}\right]
\end{array},\right.
$$

The disturbance $w_{P u}$ and $w_{Q u}$ is involved in the control input, which means $u_{1}=u_{P}-w_{P u}$ and $u_{2}=u_{Q}+w_{Q u}$. Then the Hamiltonian function $\boldsymbol{H}(\boldsymbol{x})$ are obtained as

$$
\boldsymbol{H}=\frac{1}{2} x^{T} \boldsymbol{D}^{-1} \boldsymbol{x}=\frac{1}{2}\left(\frac{1}{L} x_{1}^{2}+\frac{1}{L} x_{2}^{2}\right),
$$

The interconnection matrix and damping matrix shown in (15) satisfy $J=-J^{T}$ and $\Re=\Re^{T} \geq 0$

$$
J=\left[\begin{array}{cc}
0 & -\omega L \\
\omega L & 0
\end{array}\right], \Re=\left[\begin{array}{cc}
R & 0 \\
0 & R
\end{array}\right],
$$

The control objective of the passivity-based control based on PCHD model is to seek a control input $u$ to ensure that the closed-loop system (12) is asymptotically stable within the desired equilibrium point $x^{*}$

$$
x^{*}=\left[\begin{array}{ll}
x_{1}^{*} & x_{2}^{*}
\end{array}\right]^{T}=\left[\begin{array}{ll}
L P_{2}^{*} & L Q_{2}^{*}
\end{array}\right]^{T} .
$$


To achieve the control objective that system (12) can be asymptotically stable, a closed-loop desired Hamiltonian function $\boldsymbol{H}_{\boldsymbol{d}}(\boldsymbol{x})$ with the feedback control $\boldsymbol{u}=\boldsymbol{\beta}(\boldsymbol{x})$ should be considered so that system energy is minimum in the equilibrium point and that the system can be described by the equations.

$$
\dot{x}=\left[J_{d}(x)-\Re_{d}(x)\right] \frac{\partial H_{d}(x)}{\partial x},
$$

where $J_{d}$ and $\Re_{d}$ satisfy

$$
\left\{\begin{array}{l}
J_{d}(x)=J(x)+J_{a}(x)=-J_{d}^{T}(x) \\
\Re_{d}(x)=\Re(x)+\Re_{a}(x)=\Re_{d}^{T}(x), \\
H_{d}(x)=H(x)+H_{a}(x)
\end{array}\right.
$$

Designers should have high freedom in selecting the matrix $J_{d}, \Re_{d}$ and $\boldsymbol{H}_{\boldsymbol{d}}$ to satisfy the desired objective. For general speaking, it is defined that

$$
\left\{\begin{array}{l}
J_{a}=\mathbf{0} \\
\Re_{a}=\left[\begin{array}{cc}
r_{1} & 0 \\
0 & r_{2}
\end{array}\right]
\end{array}\right.
$$

The closed-loop desired Hamiltonian function $\boldsymbol{H}_{\boldsymbol{d}}(\boldsymbol{x})$ is taken as

$$
H_{\boldsymbol{d}}(\boldsymbol{x})=\frac{1}{2}\left(x-x^{*}\right)^{T} \boldsymbol{D}^{-1}\left(x-x^{*}\right),
$$

Then it can be obtained in (21) by substituting (18), (19) and (20) into (12)

$$
\begin{aligned}
\dot{x} & =\left[\left(J_{d}-J_{a}\right)-\left(\Re_{d}-\Re_{a}\right)\right]\left(\frac{\partial H_{d}(x)}{\partial x}-\frac{\partial H_{a}(x)}{\partial x}\right)+G u \\
& =\left(J_{d}-\Re_{d}\right) \frac{\partial H_{d}(x)}{\partial x}-\left(J_{a}-\Re_{a}\right) \frac{\partial H(x)}{\partial x}-\left(J_{d}-\Re_{d}\right) \frac{\partial H_{a}(x)}{\partial x}+G u
\end{aligned}
$$

To ensure that (21) is equivalent to system Equation (17), the following relationship is forced to be satisfied

$$
\left(J_{d}-\Re_{d}\right) \frac{\partial H_{a}(x)}{\partial x}=-\left(J_{a}-\Re_{a}\right) \frac{\partial H(x)}{\partial x}+G u,
$$

Hence the feedback control is depicted by

$$
\boldsymbol{u}=\boldsymbol{\beta}(\boldsymbol{x})=\boldsymbol{G}^{-1}\left[\begin{array}{c}
R P_{2}^{*}+\omega L Q_{2}^{*}+r_{1}\left(P_{2}^{*}-P_{2}\right) \\
R Q_{2}^{*}-\omega L P_{2}^{*}+r_{2}\left(Q_{2}^{*}-Q_{2}\right)
\end{array}\right]
$$

Furtherly it can be obtained that

$$
\left\{\begin{array}{l}
u_{P}=-R P_{2}^{*}-\omega L Q_{2}^{*}-r_{1}\left(P_{2}^{*}-P_{2}\right)+w_{P u} \\
u_{Q}=R Q_{2}^{*}-\omega L P_{2}^{*}+r_{2}\left(Q_{2}^{*}-Q_{2}\right)-w_{Q u}
\end{array},\right.
$$

With the control law in (23), it can be proved that

$$
\left\{\begin{array}{l}
\frac{\partial H_{d}(x)}{\partial x}=D^{-1}\left(x-x^{*}\right) \\
\frac{\partial^{2} H_{d}(x)}{\partial x^{2}}=D^{-1}
\end{array},\right.
$$

When $x=x^{*}$, it has $\partial \boldsymbol{H}_{\boldsymbol{d}} / \partial \boldsymbol{x}=0$ and $\partial^{2} \boldsymbol{H}_{\boldsymbol{d}} / \partial x^{2}>0$, which proves that $\boldsymbol{H}_{\boldsymbol{d}}(\boldsymbol{x})$ takes the minimal value at $x^{*}$. Therefore, the minimum system energy is achieved and the closed-loop system tends to be asymptotically stable within the desired equilibrium point [23]. 


\subsection{Robust Passivity-Based Control Strategy via Disturbance Observer}

In the passivity-based control law (24), it is seen that the disturbance value $w_{P u}$ and $w_{Q u}$ must be available to realize the asymptotical stability of the closed-loop system. From the definition of $w_{P u}$ and $w_{Q u}$ in (10), if the unmodeled dynamics and errors $\left(\varepsilon_{P}\right.$ and $\left.\varepsilon_{Q}\right)$ are not considered, the terms $w_{P u}$ and $w_{Q u}$ can be calculated through (9). Nevertheless, to improve the robustness of controller regarding to unmodeled dynamics and errors and to avoid complicated calculation of (9), terms $w_{P u}$ and $w_{\mathrm{Q} u}$ are estimated online via the double-disturbance observer (DDO) to eliminate and compensate the disturbance.

It is known that the disturbance $w_{P u}$ and $w_{\mathrm{Qu}}$ are time-varying hence they can be viewed as the polynomials with respect to time $t$ according to Taylor's formula

$$
\left\{\begin{array}{l}
w_{P u}(t)=p_{10}+p_{11} t+p_{12} t^{2}+\cdots \\
w_{Q u}(t)=p_{20}+p_{21} t+p_{22} t^{2}+\cdots
\end{array},\right.
$$

where $p_{i j}(i, j=0,1,2, \ldots)$ is the constant coefficient of the polynomial. As it can be seen, the dynamic behavior of the time-varying disturbance is approximated as a high-order polynomial. Nevertheless, considering that the noise becomes more serious and the structure becomes more complicated in higher order observer, a first-order observer is adopted for the disturbance observation [27]. Then the standard form of the state equation and the output equation of (11) are represented as follows

$$
\left\{\begin{array}{l}
\dot{\chi}(t)=f(\chi)+g_{1}(\chi) u_{P Q}(t)+g_{2}(\chi) w(t) \\
y(t)=\chi(t)
\end{array}\right.
$$

where

$$
\left\{\begin{array}{l}
\chi=\left[\begin{array}{ll}
\chi_{1} & \chi_{2}
\end{array}\right]^{T}=\left[\begin{array}{ll}
P_{2} & Q_{2}
\end{array}\right]^{T} \\
u_{P Q}=\left[\begin{array}{ll}
u_{P} & u_{Q}
\end{array}\right]^{T}, w=\left[\begin{array}{ll}
w_{P u} & w_{Q u}
\end{array}\right]^{T} \\
f(\chi)=\left[\begin{array}{l}
f_{1}(\chi) \\
f_{2}(\chi)
\end{array}\right]=\left[\begin{array}{c}
-R \chi_{1} / L-\omega \chi_{2} \\
\omega \chi_{1}-R \chi_{2} / L
\end{array}\right], \\
g_{1}=\left[\begin{array}{cc}
-1 / L & 0 \\
0 & 1 / L
\end{array}\right], g_{2}=\left[\begin{array}{cc}
1 / L & 0 \\
0 & 1 / L
\end{array}\right]
\end{array}\right.
$$

A double-disturbance observer (DDO), which is the extension form of the observer in Reference [28], is introduced here to estimate the disturbance in (28)

$$
\left\{\begin{array}{l}
\hat{w}=k+\mu(\chi) \\
\frac{d k}{d t}=-\left(l(\chi) g_{2}(\chi)\right) k-l(\chi)\left[g_{2}(\chi) \mu(\chi)+f(\chi)+g_{1}(\chi) u_{P Q}\right]
\end{array}\right.
$$

where $\mu(\chi)$ and $l(\chi)$ are given as

$$
\left\{\begin{array}{l}
\boldsymbol{\mu}(\chi)=\left[\begin{array}{ll}
\mu_{1} & \mu_{2} \\
l^{T}=l(\chi) \cdot \chi
\end{array}\right. \\
\mathbf{l}(\chi)=\left[\begin{array}{ll}
l_{1} & 0 \\
0 & l_{2}
\end{array}\right]
\end{array},\right.
$$

If the observation error is defined as

$$
\left\{\begin{array}{l}
e_{w p}=w_{P u}-\hat{w}_{P u} \\
e_{w Q}=w_{Q u}-\hat{w}_{Q u}
\end{array},\right.
$$


Then the dynamic equation of the observation error is depicted by

$$
\left\{\begin{array}{l}
\dot{e}_{w p}+l_{1} e_{w p} / L=0 \\
\dot{e}_{w Q}+l_{2} e_{w Q} / L=0
\end{array},\right.
$$

To ensure that the above disturbance equation is globally asymptotically stable, the observer gain should be chosen as $l_{j}>0(j=1,2)$, which means that the observation value $\hat{w}$ can converge to the actual value exponentially. Furtherly the relationship of the estimated value and actual value of the disturbances are

$$
\left\{\begin{array}{l}
\hat{w}_{P u}(s)=\frac{1}{1+T_{1} s} \cdot w_{P u}(s) \\
\hat{w}_{Q u}(s)=\frac{1}{1+T_{2} s} \cdot w_{Q u}(s)
\end{array},\right.
$$

where $T_{1}=l_{1} / L$ and $T_{2}=l_{2} / L$; $s$ is the differential operator. In order to realize the estimation at a certain speed and accuracy, the observer gains should be large to make the dynamic response of the observer faster than that of the control system. But the system may subject to saturation or noise during implementation if $l_{1}$ and $l_{2}$ are too large. Therefore, the observer gains need to be chosen properly to realize this balance.

In order to eliminate and compensate the disturbance, a compensation control $G_{f d}$ is designed and added into the closed loop structure base on the estimated disturbance. The compensation control $G_{f d}$ satisfies

$$
G_{f d j}(s)=1+s T_{j}(j=1,2),
$$

Along with the disturbance compensation value, the power compensation control is

$$
\left\{\begin{array}{l}
u_{P}=-R P_{2}^{*}-\omega L Q_{2}^{*}-r_{1}\left(P_{2}^{*}-P_{2}\right)+\hat{w}_{P u} \cdot G_{f d 1} \\
u_{Q}=R Q_{2}^{*}-\omega L P_{2}^{*}+r_{2}\left(Q_{2}^{*}-Q_{2}\right)-\hat{w}_{Q u} \cdot G_{f d 2}
\end{array},\right.
$$

The overall block diagram of the proposed passivity-based control with DDO is shown in Figure 2. To apply the proposed control scheme, electrical measurements are acquired for the dq transformation and calculation of the double frequency power $P_{2}$ and $Q_{2}$. Then the proposed passivity-based power compensation control via the disturbance observer can be realized according to the above mathematical derivation. The obtained unbalanced control signals $U_{d 2}$ and $U_{q 2}$ together with the modulation voltage signals from the common vector double loop control form the overall control scheme for VSC-HVDC under unbalanced grid conditions and finally, the voltage command for VSC converter can be available. 


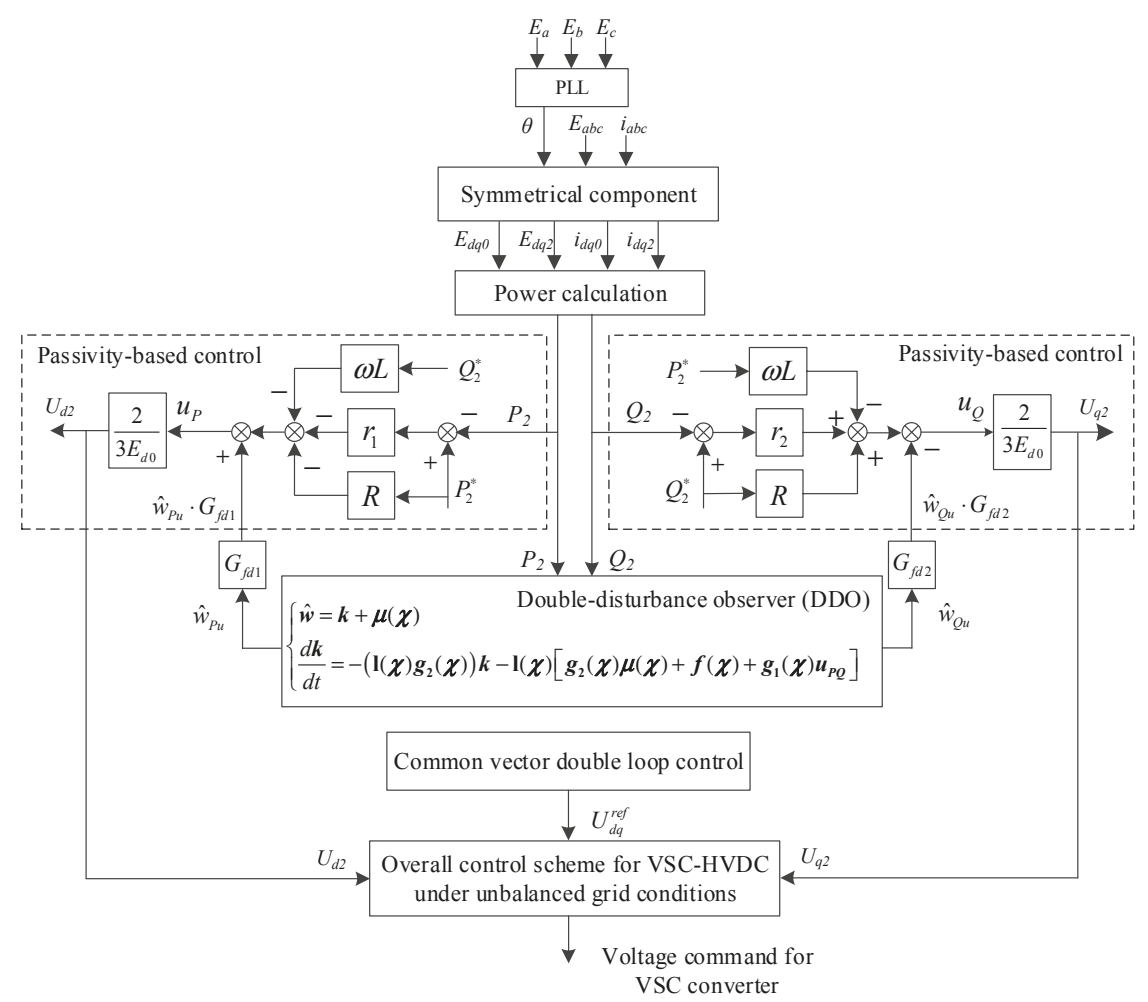

Figure 2. The block diagram of the proposed passivity-based control with DDO.

3.3. Stability Analysis of the Proposed Power Compensation Strategy via Passivity-Based Control with Disturbance Observer

The stability analysis of the proposed power compensation strategy via passivity-based control with disturbance observer is conducted in this part. From (29) and (30), the estimated disturbance value can be depicted as

$$
\left\{\begin{array}{c}
\hat{w}_{P u}(s)=\frac{l_{1}(R+L s)}{l_{1}+L s} P_{2}(s)+\frac{l_{1} \omega L}{l_{1}+L s} Q_{2}(s)-\frac{l_{1}}{l_{1}+L s} u_{P}(s) \\
\hat{w}_{Q u}(s)=\frac{-l_{2} \omega L}{l_{2}+L s} P_{2}(s)+\frac{l_{2}(R+L s)}{l_{2}+L s} Q_{2}(s)-\frac{l_{2}}{l_{2}+L s} u_{Q}(s)
\end{array},\right.
$$

It can be seen in (36) that the active and reactive disturbance components are associated with both the double frequency active and reactive power, which means (36) is the MIMO (Multiple Input Multiple Output) system equation. By substituting (36) into (35), it can be obtained as

$$
\left\{\begin{array}{l}
\left(1-\frac{l_{1} G_{f d 1}}{l_{1}+L s}\right) u_{P}(s)=-\left(R+r_{1}\right) P_{2}^{*}(s)-\omega L Q_{2}^{*}(s)+\left[r_{1}+G_{f d 1} \frac{l_{1}(R+L s)}{l_{1}+L s}\right] P_{2}(s)+G_{f d 1} \frac{l_{1} \omega L}{l_{1}+L s} Q_{2}(s) \\
\left(1-\frac{l_{2} G_{f d 2}}{l_{2}+L s}\right) u_{Q}(s)=-\omega L P_{2}^{*}(s)+\left(R+r_{2}\right) Q_{2}^{*}(s)+G_{f d 2} \frac{l_{2} \omega L}{l_{2}+L s} P_{2}(s)-\left[r_{2}+G_{f d 2} \frac{l_{2}(R+L s)}{l_{2}+L s}\right] Q_{2}(s)
\end{array} .\right.
$$

Furtherly, by substituting (37) into system Equation (11) and by replacing the state variables with the small disturbance variables, it can be depicted by 


$$
\left[\begin{array}{c}
\Delta P_{2} \\
\Delta Q_{2}
\end{array}\right]=G_{M} \cdot\left[\begin{array}{c}
\Delta w_{P u} \\
\Delta w_{Q u}
\end{array}\right]
$$

where $\triangle$ is defined as the small signal disturbance of each variable and $G_{M}$ is derived as

$$
\left\{\begin{array}{l}
G_{M}=\left[\begin{array}{ll}
m_{11} & m_{12} \\
m_{21} & m_{22}
\end{array}\right] \\
m_{11}=\frac{\left(R+r_{2}+L s\right)\left(l_{1}+L s-G_{f d 1} \cdot l_{1}\right)}{\left(l_{1}+L s\right)\left[\left(R+r_{1}+L s\right)\left(R+r_{2}+L s\right)+\omega^{2} L^{2}\right]} \\
m_{12}=\frac{-\omega L\left(l_{2}+L s-G_{f d 2} \cdot l_{2}\right)}{\left(l_{2}+L s\right)\left[\left(R+r_{1}+L s\right)\left(R+r_{2}+L s\right)+\omega^{2} L^{2}\right]} \\
m_{21}=\frac{\omega L\left(l_{1}+L s-G_{f d 1} \cdot l_{1}\right)}{\left(l_{1}+L s\right)\left[\left(R+r_{1}+L s\right)\left(R+r_{2}+L s\right)+\omega^{2} L^{2}\right]} \\
m_{22}=\frac{\left(R+r_{1}+L s\right)\left(l_{2}+L s-G_{f d 2} \cdot l_{2}\right)}{\left(l_{2}+L s\right)\left[\left(R+r_{1}+L s\right)\left(R+r_{2}+L s\right)+\omega^{2} L^{2}\right]}
\end{array}\right.
$$

The zero-pole theory of the MIMO system [29] points out that, for a system with transfer function matrix $G_{M}(s)$, the pole polynomial $\varphi(s)$ corresponding to a minimal realization is the least common denominator of all non-identically-zero minors of all orders of $G_{M}(s)$ and the zero polynomial $z(s)$ corresponding to a minimal realization is the greatest common divisor of all the numerators of all order-r minors of $G_{M}(s)$, where $r$ is the normal rank of $G_{M}(s)$, provided that these minors are adjusted in such a way as to have the pole polynomial $\varphi(s)$ as their denominators. According to this theory, the zero and pole polynomials of $G_{M}(s)$ in (39) are

$$
\left\{\begin{array}{l}
z(s)=\left(l_{1}+L s-G_{f d 1} \cdot l_{1}\right)\left(l_{2}+L s-G_{f d 2} \cdot l_{2}\right)\left[\left(R+r_{1}+L s\right)\left(R+r_{2}+L s\right)+\omega^{2} L^{2}\right] \\
\varphi(s)=\left(l_{1}+L s\right)\left(l_{2}+L s\right)\left[\left(R+r_{1}+L s\right)\left(R+r_{2}+L s\right)+\omega^{2} L^{2}\right]^{2}
\end{array},\right.
$$

Then the zero-pole map of the closed-loop system can be obtained and the system stability can be determined according to the root locus curve of the predominant pole.

When the basic parameter values in (40) are selected as stated in Section 4 for system control, the zero-pole maps of $G_{M}(s)$ are plotted in Figure 3. It is known from (40) that there are four poles of $G_{M}(s)$, among which two are determined by $r_{1}$ and $r_{2}$ (namely $P_{r}$ ) and two are determined by $l_{1}$ and $l_{2}$ (namely $P_{l}$ ). As seen in Figure 3, the poles of the closed-loop transfer function are all located in the left half of the imaginary axis and ensure a stable system. From Figure $3 \mathrm{a}, \mathrm{b}$ different values of $r_{1}$ and $r_{2}$ have an effect on the pole positions of $P_{r}$ and system dynamics as a result. During the increasing of $r_{1}$ and $r_{2}$, poles $P_{r}$ moves away from the imaginary axis and may be located to the two sides of real axis. Hence the dynamic response gets faster and oscillation may occur. When $r_{1}$ and $r_{2}$ get too much larger, the poles $P_{r}$ are too much away from the imaginary axis and the predominant effect is attenuated. From Figure $3 c, d$ it is seen that the observer gains $l_{1}$ and $l_{2}$ of the DDO also have impacts on system dynamic response. When $l_{1}$ and $l_{2}$ are increasing, poles $P_{l}$ are located in the real axis and moves away from the imaginary axis, which means system dynamic response gets faster. The predominant poles of $G_{M}(s)$ are determined by the poles distribution of $P_{r}$ and $P_{l}$, which indicates that proper parameters should be chosen for superior system dynamic performance. 


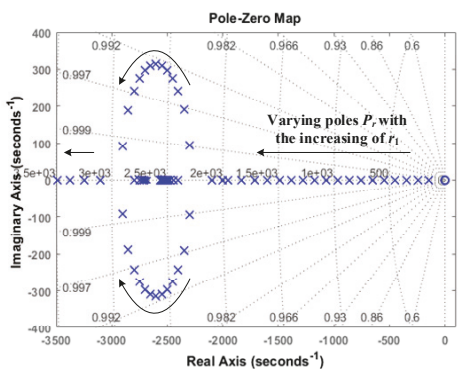

(a)

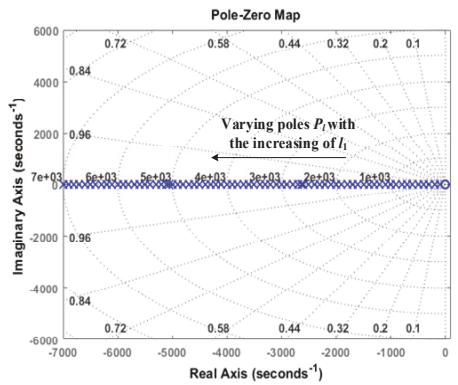

(c)

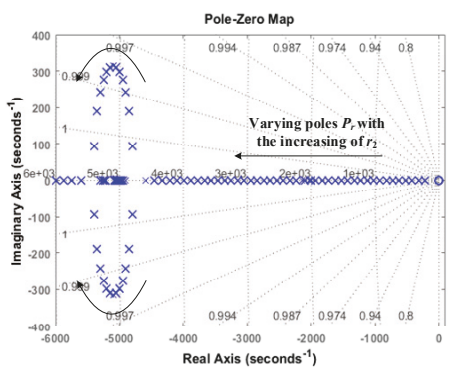

(b)

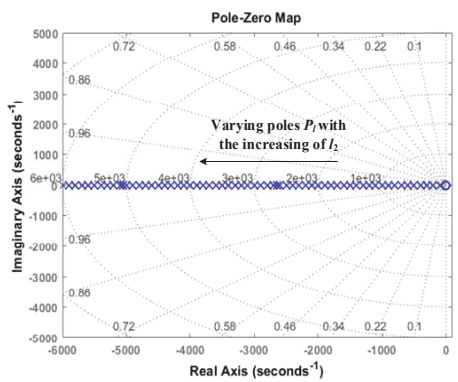

(d)

Figure 3. Zero-pole maps with different parameters. (a) Zero-pole maps with varying $r_{1}$. (b) Zero-pole maps with varying $r_{2}$. (c) Zero-pole maps with varying $l_{1}$. (d) Zero-pole maps with varying $l_{2}$.

\section{Simulation Results}

To verify the validity of the proposed control strategy, the dc transmission simulation model with a two-terminal VSC-based converter shown in Figure 4 is established in PSCAD/EMTDC. The rated VSC line voltage and DC bus voltage are $230 \mathrm{kV}$ and $330 \mathrm{kV}$, respectively. The passivity parameters $r_{1}$ and $r_{2}$ are set as 50 and 30, while the observer gain $l_{1}$ and $l_{2}$ are set as 150 and 200. To reflect the superiority of the proposed control, the comparison cases are set in the simulations. However, since most existing control strategies are ineffectual in suppressing the active and reactive power ripples at the same time, we adopt a resonance controller with properly adjusted parameters [13] as the conventional compensation control for comparison. This resonance control is also implemented based on the double frequency ripple power control Equation (8) but superior system response cannot be achieved compared with the proposed control strategy according to the simulation results.

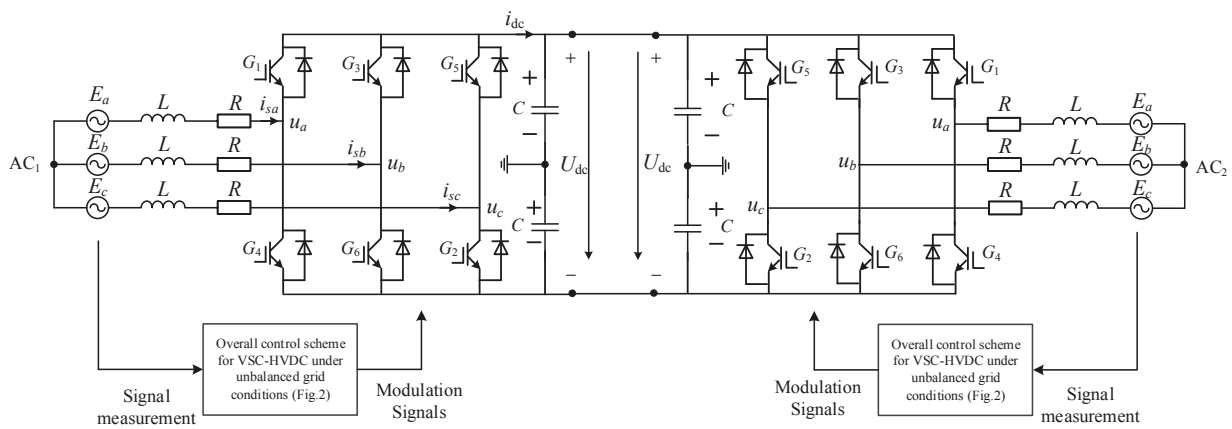

Figure 4. Simulation model with a two-terminal VSC. 


\subsection{Case 1}

In this case, the suppression performance of the double frequency ripples with different control strategies is tested. Before $2.5 \mathrm{~s}$, the system operates under normal grid condition. At time $2.5 \mathrm{~s}$, the B phase and $\mathrm{C}$ phase voltage of source $\mathrm{AC}_{2}$ have a drop of $4.23 \mathrm{kV}(50 \%)$ shown in Figure 5 . As for the control system, it remains unchanged with the common vector double loop control during $2.5 \mathrm{~s}$ to $3.5 \mathrm{~s}$. After $3.5 \mathrm{~s}$, the proposed power compensation strategy and the conventional resonance compensation strategy are added as the auxiliary controllers respectively for the suppression of the double frequency ripples. The simulation results are shown in Figures 6-8.

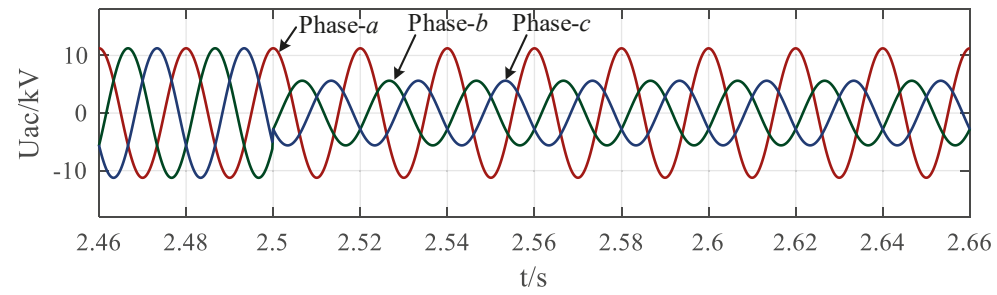

Figure 5. The three-phases voltage of source AC2.
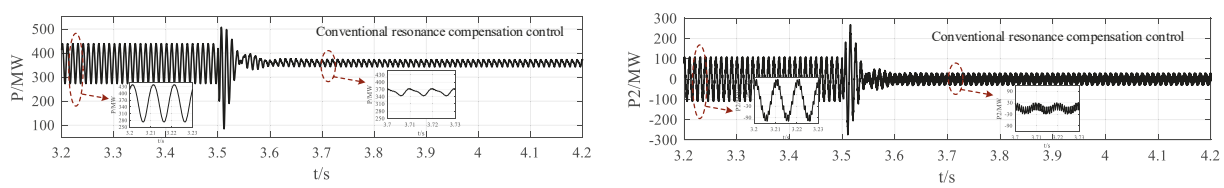

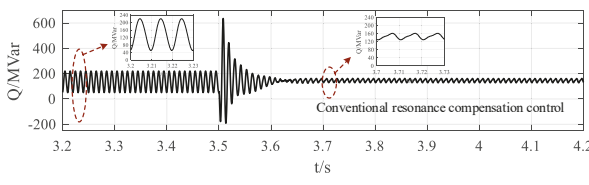

(a)

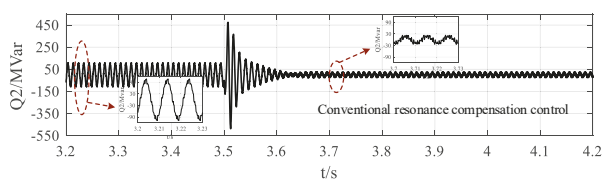

(b)

Figure 6. Simulation results with conventional resonance compensation strategy. (a) Simulation results of active and reactive power. (b) Simulation results of double frequency components of active and reactive power.
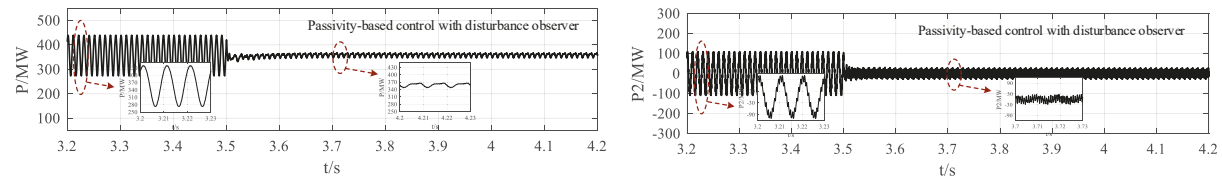

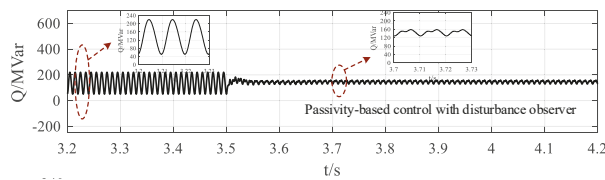

(a)

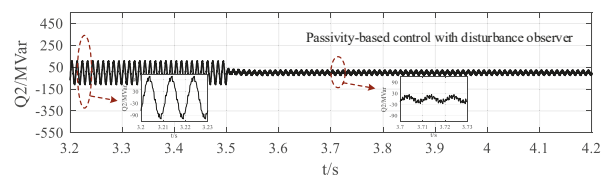

(b)

Figure 7. Simulation results with proposed passivity-based power compensation strategy via disturbance observer. (a) Simulation results of active and reactive power. (b) Simulation results of double frequency components of active and reactive power. 

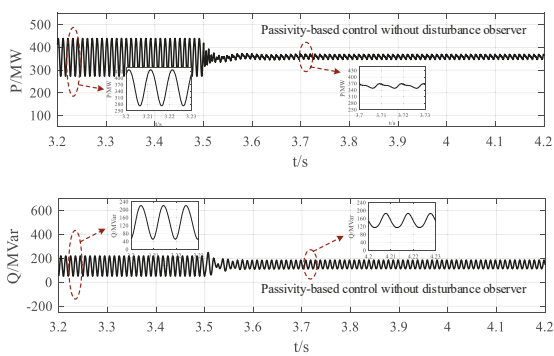

(a)
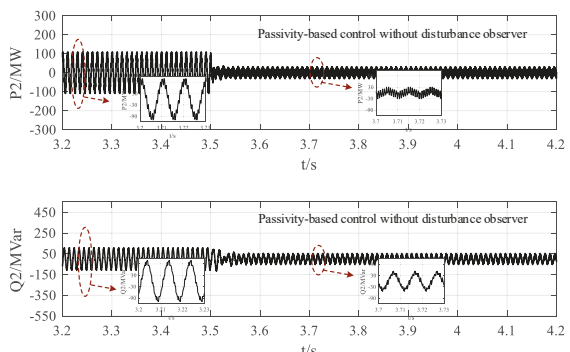

(b)

Figure 8. Simulation results with only passivity-based power compensation strategy. (a) Simulation results of active and reactive power. (b) Simulation results of double frequency components of active and reactive power.

It is seen from the simulation results that under unbalanced grid conditions with no auxiliary power compensation strategy (2.5-3.5 s), the double frequency ripples with large amplitudes appear in the active and reactive power. By comparing Figures 6 and 7, it is known that both the proposed passivity-based power compensation strategy (with the disturbance observer) and the conventional resonance compensation strategy can suppress the double frequency ripples in active and reactive power simultaneously, which verify the effectiveness of the established double frequency ripple power control Equation (8). Nevertheless, the steady-state suppression performance of the proposed strategy is better than conventional strategy through the partial enlarged figures in Figures 6 and 7. More significantly, the dynamic response at $3.5 \mathrm{~s}$ of the proposed compensation strategy is much better than the conventional resonance compensation strategy. Figure 6 shows that the active and reactive power reach to stable state with much large overshoot and longer transient time under the conventional strategy. Therefore, the effectiveness of the proposed passivity-based control with disturbance observer in suppressing the double frequency power ripples are verified with superior dynamic response.

To furtherly show the superior performance of the proposed passivity-based power compensation strategy with disturbance observer, the simulations with only passivity-based control is shown in Figure 8 . In this scheme, the double-frequency voltage disturbances $w_{P u}$ and $w_{Q u}$ are calculated through (9) instead of the observer. It can be seen from Figure 8 that the dynamic response and the suppression performance both become worse compared with that in Figure 7 . The observed and calculated values of the double-frequency voltage disturbance $w_{P u}$ and $w_{Q u}$ shown in Figure 9 indicate that there exists difference between the observed and calculated values caused by modelling errors and external impacts, which cause the performance degradation of the passivity-based control with calculated values of $w_{P u}$ and $w_{Q u}$. It can be concluded that the response performance of the passivity-based power compensation strategy is significantly improved with the implementation of disturbance observer.
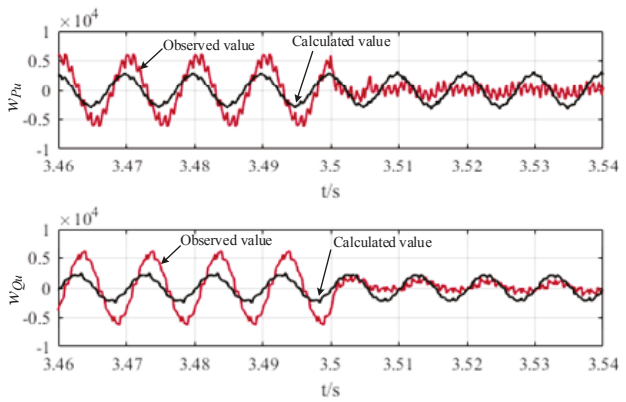

Figure 9. The observed and calculated values of the double-frequency voltage disturbance $w_{P u}$ and $w_{Q u}$. 


\subsection{Case 2}

To verify the control effects of the proposed strategy with different control parameters, the simulation results of the double frequency power ripples (take reactive $Q_{2}$ as an example) under the proposed passivity-based power compensation strategy via disturbance observer with different parameters are shown in Figures 10 and 11.
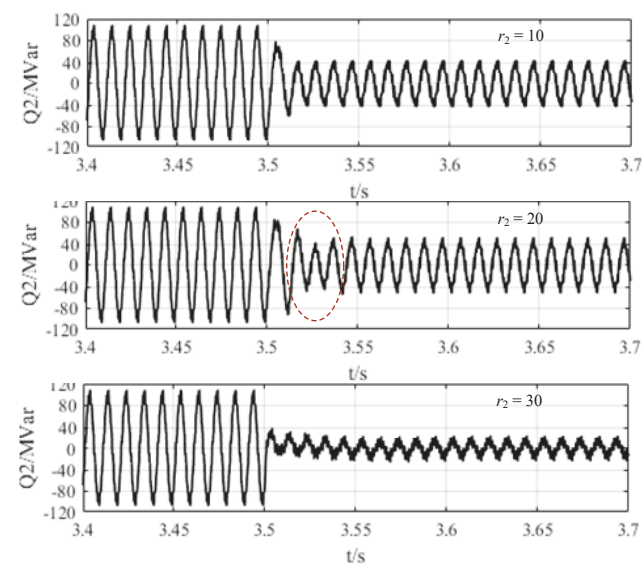

Figure 10. Simulation results of double frequency components of reactive power with different passivity parameters $r_{2}$.
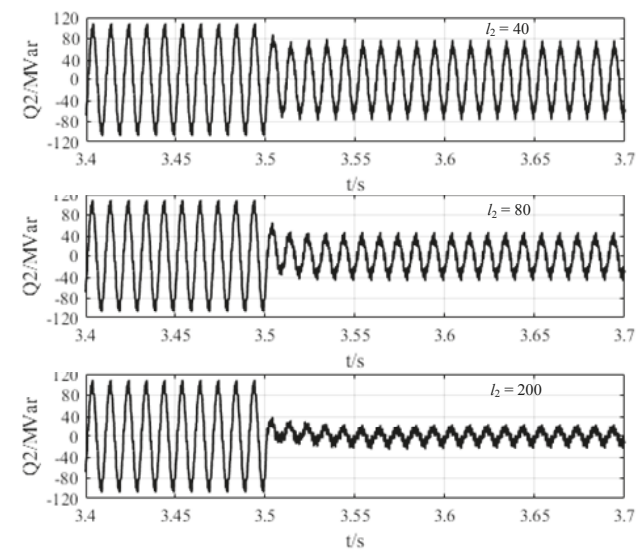

Figure 11. Simulation results of double frequency components of reactive power with different observer gain.

Figure 10 shows the simulation results of the double frequency ripples in reactive power with different passivity parameter $r_{2}$. It indicates that during the increasing of $r_{2}$, power oscillation may occur and the control effect is attenuated (marked in red in Figure 10) and this depends on the pole positions caused by specific value of $r_{2}$ which also confirms the previous theoretical analysis. From Figure 11, it is seen that different observer gains have significant impacts on system performance and control effects will be weakened if the observer gain is too small. Therefore, with properly chosen passivity parameters and observer gains, expected suppression performance and dynamic response can be obtained under the proposed passivity-based power compensation strategy with disturbance observer. 


\subsection{Case 3}

In this case, the situation of single-phase grounding short-circuit fault is tested. Before $3 \mathrm{~s}$, the system operates under normal condition. At time $3 \mathrm{~s}$, the A phase grounding fault with the ground resistance $\mathrm{Rg}=0.0005 \Omega$ in $\mathrm{AC}_{2}$. The simulation results with no auxiliary control, the conventional resonance compensation strategy and the proposed passivity-based compensation strategy via disturbance observer are shown in Figures 12-14 respectively.

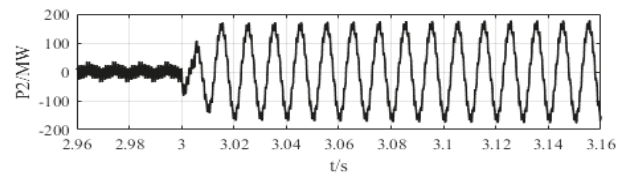

(a)

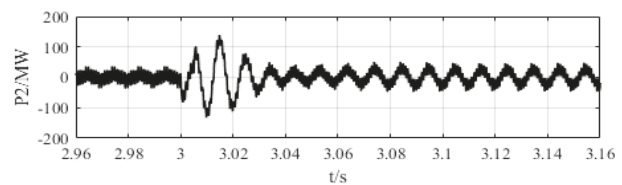

(b)

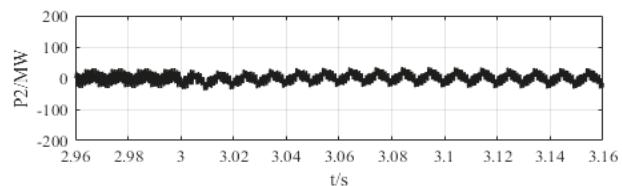

(c)

Figure 12. Simulation results of double frequency ripples in active power. (a) With no auxiliary control. (b) With conventional resonance compensation strategy. (c) With proposed passivity-based compensation strategy via disturbance observer.

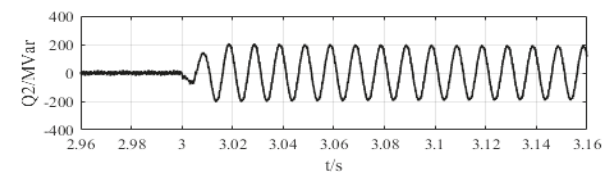

(a)

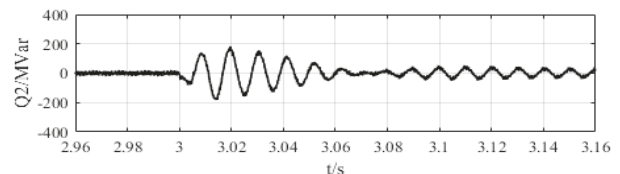

(b)

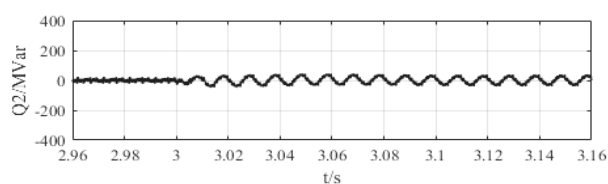

(c)

Figure 13. Simulation results of double frequency ripples in reactive power. (a) With no auxiliary control. (b) With conventional resonance compensation strategy. (c) With proposed passivity-based compensation strategy via disturbance observer. 


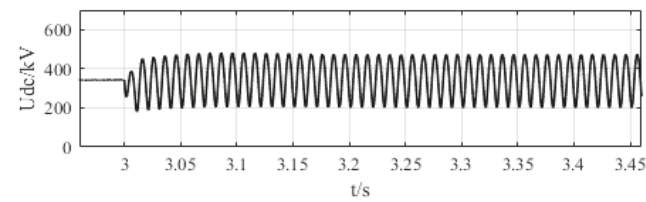

(a)

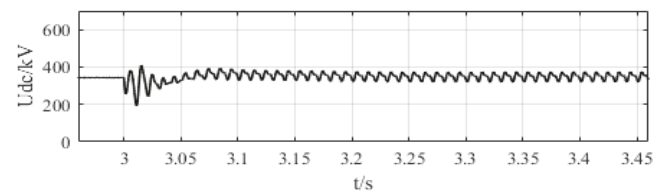

(b)

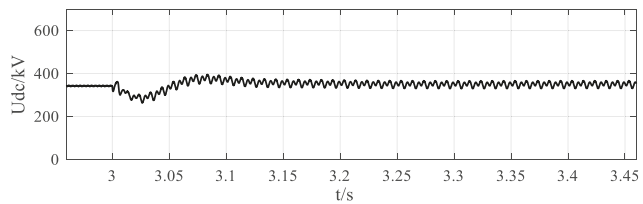

(c)

Figure 14. Simulation results of dc voltage. (a) With no auxiliary control. (b) With conventional resonance compensation strategy. (c) With proposed passivity-based compensation strategy via disturbance observer.

It is seen that under single-phase grounding short-circuit fault, large amount of double frequency ripples exists in the active and reactive with no auxiliary compensation strategy adopted, which also causes dc voltage fluctuation in double frequency. By comparing the simulation results, it can be found that double frequency ripples in active and reactive power are reduced to a large degree with the proposed compensation strategy and the conventional resonance compensation strategy and the suppression performance with the proposed strategy is relatively better. Additionally, the transient process at time $3 \mathrm{~s}$ under the proposed strategy is much improved with no overshoot and fast transient time. The response of dc voltage in Figure 14 also indicates the satisfactory dynamic performance of the system. Therefore, the proposed control shows superior properties in suppressing the double frequency power ripples and responding to external disturbance.

\subsection{Comparable Evaluation}

It can be concluded from the above three cases performed on the dc transmission simulation model of Figure 8 that:

(1) under the proposed control strategy, the double frequency ripples in active and reactive power are regulated with better steady-state suppression performance and enhanced dynamic response compared with the conventional resonance compensation strategy and the only passivity-based compensation strategy;

(2) different passivity parameters and different observer gains have significant impacts on system performance and control effects will be weakened if these parameters are chosen improperly;

(3) in this case of single-phase grounding short-circuit fault, the double frequency ripples in active and reactive power are reduced largely with the proposed control strategy and the transient process can be much improved with little overshoot and fast transient time. 


\section{Discussion}

When the unbalanced grid conditions occur, the VSC converter operates in abnormal condition and the negative sequence electrical components is adverse for the system normal operation. Most exist literatures (listed in the Reference) mainly aim at obtaining some specific kind of control objective, which means the fluctuations of active and reactive power cannot be suppressed at the same time. In this case, a novel control strategy to suppress the double frequency ripples in active and reactive power of VSC-HVDC systems under unbalanced grid voltage conditions is proposed. This control strategy is based on the derived mathematical control equations of the double frequency ripple power of VSC converter. The passivity-based control together with the disturbance observer forms the basic control framework of VSC. Theoretical analysis and simulation results show that with this control, the double frequency ripples in active and reactive power of VSC-HVDC under unbalanced grid conditions are suppressed simultaneously and system performance is significantly enhanced. It should be noticed that the control parameters of the proposed strategy should be chosen properly for the desired performance response according to the respective system structure.

\section{Conclusions}

In this paper, the mathematical model of the double frequency ripple power for VSC-HVDC systems under unbalanced grid conditions is derived and then a power compensation strategy to suppress the double frequency ripples in active and reactive power is proposed. The main contribution of this paper is that with this proposed control strategy, the double frequency ripples in active and reactive power of VSC-HVDC under unbalanced grid conditions can be suppressed simultaneously and system performance is significantly enhanced with the implementation of the disturbance observer in the passivity-based control. The compensation strategy is proved to be effective in regulating the double frequency components of the unbalanced voltage and current without affecting the normal operation of VSC converter. The stability analysis of the proposed power compensation strategy is also conducted in this paper to analyze the system response with different control parameters. Theoretical analysis and simulations in PSCAD/EMTDC show the validity and superiority of the proposed control strategy. The research outcomes are applicative in real conditions of renewable energy generation, island network supply and microgrid, while the control parameters should be chosen carefully for the desired operation performance according to the actual system structure characteristics. The challenging issue of the application of the research outcomes is that robust PLL (Phase Locking Loop) technology should be available for accurate phase tracking under the unbalanced grid voltage conditions.

Author Contributions: Conceptualization, S.M.; Data curation, M.Z.; Investigation, T.Z., Z.F. and D.W.; Methodology, W.L.; Validation, Y.K.; Writing-original draft, Z.L.; Writing-review \& editing, Z.L.

Funding: This research was funded by the Science-Tech Project of State Grid East Inner Mongolia Electric Power Research Institute [SGMDDK00DJJS1800053]; the National Natural Science Foundation of China [51777088]; and the National Key Research and Development Program of China [2017YFB0903601].

Conflicts of Interest: The authors declare no conflict of interest.

\section{Nomenclature}

$U_{a, b, c}, i_{a, b, c} \quad$ the three phase voltage and current of the converter

$E_{a, b, c} \quad$ the three phase voltage of the AC grid

$R, L \quad$ the per-phase resistance and inductance of the AC filter

C the DC filter capacitor

$U_{d c}, i_{d c} \quad$ the DC voltage and current of the converter

$P_{S}, Q_{s} \quad$ the transmission active and reactive power of the converter

$U_{d}, U_{q} \quad$ the $\mathrm{d}$ axis and q axis components of VSC voltage

$i_{d}, i_{q} \quad$ the $\mathrm{d}$ axis and $\mathrm{q}$ axis components of VSC current

$E_{d}, E_{q} \quad$ the $\mathrm{d}$ axis and $\mathrm{q}$ axis components of AC grid voltage 


\begin{tabular}{|c|c|}
\hline$P_{2 i}, Q_{2 i}$ & $\begin{array}{l}\text { the current-relevant components that cause the double frequency ripples in active and } \\
\text { reactive power }\end{array}$ \\
\hline$P_{2 u}, Q_{2 u}$ & $\begin{array}{l}\text { the voltage-relevant components that cause the double frequency ripples in active and } \\
\text { reactive power }\end{array}$ \\
\hline$u_{P}, u_{Q}$ & the double frequency power control inputs of VSC \\
\hline$J(x), J_{d}(x)$ & the original and the desired interconnection matrix \\
\hline$\Re(x), \Re_{d}(x)$ & the original and the desired damping matrix \\
\hline$H(x), H_{d}(x)$ & the original and the desired Hamiltonian function \\
\hline$G(x)$ & the coefficient matrix with full rank \\
\hline$\hat{w}$ & the estimation of the disturbance \\
\hline$k$ & the internal state of the observer \\
\hline$\mu(\chi), l(\chi)$ & the observer function and the observer gain \\
\hline
\end{tabular}

\section{References}

1. Shah, R.; Sánchez, J.C.; Preece, R.; Barnes, M. Stability and control of mixed AC-DC systems with VSC-HVDC: A review. IET Gener. Trans. Dis. 2018, 12, 2207-2219. [CrossRef]

2. Korompili, A.; Wu, Q.; Zhao, H.Z. Review of VSC HVDC connection for offshore wind power integration. Renew. Sustain. Energy Rev. 2016, 59, 1405-1414. [CrossRef]

3. Li, Y.; Tang, G.; An, T.; Pang, H.; Wang, P.; Yang, J.; Wu, Y.; He, Z. Power compensation control for interconnection of weak power systems by VSC-HVDC. IEEE Trans. Power Del. 2017, 32, 1964-1974. [CrossRef]

4. Tirtashi, M.R.S.; Samuelsson, O.; Svensson, J. Impedance matching for VSC-HVDC and energy storage damping controllers. IEEE Trans. Power Del. 2017, 33, 1016-1017. [CrossRef]

5. Liang, Y.; Liu, J.; Zhang, T.; Yang, Q. Arm current control strategy for MMC-HVDC under unbalanced conditions. IEEE Trans. Power Del. 2017, 32, 125-134. [CrossRef]

6. Schönleber, K.; Prieto-Araujo, E.; Ratés-Palau, S.; Gomis-Bellmunt, O. Handling of unbalanced faults in HVDC-connected wind power plants. Electr. Power Syst. Res. 2017, 152, 148-159. [CrossRef]

7. Schönleber, K.; Prieto-Araujo, E.; Ratés-Palau, S.; Gomis-Bellmunt, O. Extended current limitation for unbalanced faults in MMC-HVDC-connected wind power plants. IEEE Trans. Power Del. 2018, 33, 1875-1884. [CrossRef]

8. Biricik, S.; Redif, S.; Ozerdem, Ö.C.; Khadem, S.K.; Basu, M. Real-time control of shunt active power filter under distorted grid voltage and unbalanced load condition using self-tuning filter. IET Power Electron. 2014, 7, 1895-1905. [CrossRef]

9. Hogan, D.J.; Gonzalez-Espin, F.J.; Hayes, J.G.; Lightbody, G.; Foley, R. An adaptive digital control scheme for improved active power filtering under distorted grid conditions. IEEE Trans. Ind. Electron. 2017, 65, 988-999. [CrossRef]

10. Wang, L.; Lam, C.S.; Wong, M.C. Unbalanced control strategy for a thyristor controlled LC-coupling hybrid active power filter in three -phase three-wire systems. IEEE Trans. Power Electron. 2016, 32, 1056-1069. [CrossRef]

11. Guan, M.; Cheng, J.; Wang, C.; Hao, Q.; Pan, W.; Zhang, J.; Zheng, X. The frequency regulation scheme of interconnected grids with VSC-HVDC links. IEEE Trans. Power Syst. 2017, 32, 864-872. [CrossRef]

12. Tirtashi, M.R.S.; Samuelsson, O.; Svensson, J.; Pates, R. Impedance matching for VSC-HVDC damping controller gain selection. IEEE Trans. Power Syst. 2018, 33, 5226-5235. [CrossRef]

13. Wang, X.; Sun, D.; Zhu, Z.Q. Resonant-based backstepping direct power control strategy for DFIG under both balanced and unbalanced grid conditions. IEEE Trans. Ind. Appl. 2017, 53, 4821-4830. [CrossRef]

14. Sun, L.X.; Lu, S.; Wang, Z.; Jin, Y.Q.; Chen, Q.; Yu, Y.P. Optimal control strategy of VSC-based high-voltage direct current under unbalanced grid voltage conditions. IET Gener. Transm. Dis. 2016, 10, 444-451. [CrossRef]

15. Zhu, M.; Hang, L.; Li, G.; Jiang, X. Protected control method for power conversion interface under unbalanced operating conditions in AC/DC hybrid distributed grid. IEEE Trans. Energy Convers. 2015, 31, 57-68. [CrossRef]

16. Jin, N.; Gan, C.; Guo, L. Predictive control of bidirectional voltage source converter with reduced current harmonics and flexible power regulation under unbalanced grid. IEEE Trans. Energy Convers. 2018, 33, 1118-1131. [CrossRef] 
17. Cheng, P.; Nian, H. Direct power control of voltage source inverter in a virtual synchronous reference frame during frequency variation and network unbalance. IET Power Electron. 2016, 9, 502-511. [CrossRef]

18. Yang, W.; Zhang, A.; Li, J.; Li, G.; Zhang, H.; Wang, J. Integral plus resonant sliding mode direct power control for VSC-HVDC systems under unbalanced grid voltage conditions. Energies 2017, 10, 1528. [CrossRef]

19. Sun, L.X.; Zhu, P.F.; Wang, Z.; Chen, Y. An optimal control strategy of VSC-HVDC under unbalanced grid voltage conditions. In Proceedings of the IEEE International Conference on Cyber Technology in Automation, Control and Intelligent Systems, Shenyang, China, 8-12 June 2015.

20. Suul, J.A.; Luna, A.; Rodríguez, P. Power control of VSC HVDC converters for limiting the influence of AC unbalanced faults on multi-terminal DC grids. In Proceedings of the 10th IET International Conference on AC and DC Power Transmission (ACDC 2012), Birmingham, UK, 4-5 December 2012.

21. Wei, X.; Sun, H.; Wei, X.; Ma, Q.; Xu, F. Control strategy for VSC-HVDC power quality improvement under unbalanced grid conditions. Int. J. Emerg. Electr. Power Syst. 2011, 12, 1-22. [CrossRef]

22. Wang, X.; Blaabjerg, F.; Loh, P.C. Passivity-based stability analysis and damping injection for multi-paralleled VSCs with LCL filters. IEEE Trans. Power Electron. 2017, 32, 8922-8935. [CrossRef]

23. Meshram, R.V.; Bhagwat, M.; Khade, S.; Wagh, S.R.; Stan, A.M.; Singh, N.M. Port-controlled phasor hamiltonian modeling and IDA-PBC control of solid-state transformer. IEEE Trans. Control Syst. Technol. 2018. [CrossRef]

24. Huang, J.; Wang, H.; Wang, C. Passivity-based control of a doubly fed induction generator system under unbalanced grid voltage conditions. Energies 2017, 10, 1139. [CrossRef]

25. Sang, Y.; Yang, B.; Yao, W.; Jiang, L. Design and implementation of perturbation observer-based robust passivity-based control for VSC-MTDC systems considering offshore wind power integration. IET Gener. Transm. Dis. 2018, 12, 2415-2524. [CrossRef]

26. Yang, H.; Dong, Y.; Li, W.; He, X. Average-value model of modular multilevel converters considering capacitor voltage ripple. IEEE Trans. Power Del. 2017, 2, 723-732. [CrossRef]

27. Natori, K.; Tsuji, T.; Ohnishi, K.; Hace, A.; Jezernik, K. Time-delay compensation by communication disturbance observer for bilateral teleoperation under time-varying delay. IEEE Trans. Ind. Electron. 2010, 57, 1050-1062. [CrossRef]

28. Yang, J.; Li, S.; Yu, X. Sliding-mode control for systems with mismatched uncertainties via a disturbance observer. IEEE Trans. Ind. Electron. 2012, 60, 160-169. [CrossRef]

29. Skogestad, S.; Postlethwaite, I. Multivariable Feedback Control: Analysis and Design; Jon Wiley \& Sons: New York, NY, USA, 1988; pp. 139-141.

(C) 2018 by the authors. Licensee MDPI, Basel, Switzerland. This article is an open access article distributed under the terms and conditions of the Creative Commons Attribution (CC BY) license (http:/ / creativecommons.org/licenses/by/4.0/). 



\title{
An Operation Strategy of the Hybrid Multi-Terminal HVDC for Contingency
}

\author{
Sungchul Hwang ${ }^{1}$, Sungyoon Song ${ }^{1}$, Gilsoo Jang ${ }^{1}$ and Minhan Yoon ${ }^{2, *}$ \\ 1 School of Electrical Engineering, Korea University, 145 Anam-ro, Seongbuk-gu, Seoul 02841, Korea; \\ adidas@korea.ac.kr (S.H.); blue6947@korea.ac.kr (S.S.); gjang@korea.ac.kr (G.J.) \\ 2 Department of Electrical Engineering, Tongmyong University, 428 Sinseon-ro, Nam-gu, Busan 48520, Korea \\ * Correspondence: mhyoon@tu.ac.kr; Tel.: +82-51-629-1313
}

Received: 24 April 2019; Accepted: 24 May 2019; Published: 28 May 2019

\begin{abstract}
The application of the direct current (DC) transmission is increasing through the interconnection between grids or the renewable energy resource integration. Various types of DC transmission topology are researched, and the hybrid multi-terminal high voltage DC (HVDC), called the "MTDC", is one of the research subjects. The hybrid multi-terminal HVDC is the MTDC system that is composed with the Line Commutated Converter (LCC) and Voltage Source Converter (VSC). Most hybrid MTDC research has been focused on the connection of the renewable energy generation sources, especially offshore wind farms. However, the DC grid built with a hybrid MTDC was recently proposed due to the development of the converter technology. Therefore, the DC grid is expected to be able to substitute some parts of the transmission grid instead of the alternating current (AC) system, and the operation strategies of the DC grid are still being researched. The DC grid has the advantage of being able to control the power flow, which can even improve the stability of the connected AC system. The dynamic model is required to analyze the improvement of the AC system by the operation strategy of the hybrid MTDC, however, there is no generic model for the system. In this paper, an operation strategy of the hybrid MTDC is proposed to improve the stability of the $\mathrm{AC}$ power system by increasing the utilization of parallel $\mathrm{AC}$ transmission lines under the contingency condition. Furthermore, studies on the modeling method for a hybrid MTDC analysis were performed. The proposed modeling method and operation strategy were verified in simulations for which a modified IEEE 39 bus test system was used. The improvement of transient stability by the proposed hybrid MTDC system was shown in the simulation results.
\end{abstract}

Keywords: HVDC transmission; hybrid multi-terminal HVDC; LCC; MTDC; power system analysis; VSC

\section{Introduction}

The power system has been growing steadily according to the development of alternating current (AC) technology. However, the development of the AC system has been recently saturated, and the construction of a new AC transmission line is becoming more difficult, due to problems such as environmental issues or protests from local residents regarding the right of way. The new construction of a transmission line or the utilization of the existing AC lines is required to supply power stably for increasing loads. The flexible AC transmission system (FACTS) is now regarded as a promising option, due to the capability to utilize the existing AC system by controlling the power flow or the voltage compensation [1-3]. It is expected that the development of power electronics technology promotes the FACTS device extensively [4]. The direct current (DC) transmission system is especially on the rise around the world and consistently examined in terms of an alternative to the AC transmission line. Furthermore, research on the DC grid is actively performed to provide a power control capability. Studies on the feasibility of the DC grid with various topologies, grid controls, and protection schemes 
are being conducted [5]. In addition, much research is performed on grid management and the voltage droop control strategy [6-8].

The control and operation technology of the multi-terminal high voltage DC (HVDC), known as the "MTDC", is fundamental for building and operating the DC grid. The MTDC is used for the HVDC systems consisting of three or more converters and can control the power flow between the converter stations. At the beginning of the MTDC study, the system configuration and normal operation point is introduced in [9] and operation characteristic of MTDC is studied in [10]. Although the Line Commutate Converter (LCC) type was mainly studied in the early research, Voltage Source Converter (VSC)-type MTDC has been mainly researched recently, due to the development of VSC technology. Various research studies on the VSC MTDC, such as the AC and DC system power flow calculations with the VSC MTDC [11,12], the transmission loss minimization [13], and the frequency control [14], have been performed. The recent subjects of research on the hybrid MTDC are mainly control for the system, such as droop control, fault ride through, and voltage-dependent current order limiter [15-17]. Regarding the system stability, small signal stability is studied in [18].

Notably, numerous MTDC studies have dealt with the integration of offshore wind farms [19-21], because the MTDC system possesses the advantages for the integration of remote renewable resources. Since fine wind resources are abundant on the sea offshore and as offshore wind farms are generally far from main land, the length of the AC cables presents an issue. The MTDC is therefore an attractive option for the collection and integration of several wind farms. The hybrid MTDC systems have also been proposed, due to the advantage of the VSC with weak AC systems. The advantages of the VSC include independent control of active power and reactive power, $\mathrm{AC}$ voltage compensation, and a compact size for installation [22]. The power system of remote renewable resources can be seen as weak systems, and the structure of an offshore wind farm is particularly small for the installation of large scale equipment. Therefore, the VSC can be a proper type of converter to interconnect the resources. Alternatively, the capacity of the LCC is more highly rated compared with the VSC, plus the LCC is cheaper than the VSC in terms of the installation and the operating cost. For this reason, the LCC HVDC has been used for bulk power transmission. Therefore, the hybrid MTDC could be attractive in terms of the advantages of both the LCC and the VSC.

The hybrid HVDC system topologies were introduced in [23] and the technical feasibility of the hybrid MTDC has been studied [24,25]. The integration of the wind farm using the MTDC system and the control strategy were studied in [26-28]. Recently, as the need for DC grid application has increased, the DC grid is expected to coexist with the AC grid; consequently, a study on the control and operation strategy of the MTDC is necessary to establish the DC grid foundation.

In this paper, the proposed operation strategy of the hybrid MTDC seeks to increase the utilization of the AC transmission line in parallel with the MTDC for the power transmission between two regions, in consideration of the contingency condition. To construct the MTDC systems, it is possible to construct a new system in addition to the extension of the existing HVDC system [10,29]. Numerous existing HVDC systems were installed for a bulk power transmission from the generation area to the load area. In the case that the existing LCC HVDC in the AC system is extended to the hybrid MTDC, the constructed DC grid provides flexibility to the AC system through the power flow control. Additionally, it is difficult for the LCC to change the direction of the power flow because power flow reversing with the LCC is discontinuous and has line discharging problems [30]. But the VSC can change the power flow direction more flexibly than the LCC. Therefore, the hybrid MTDC could be relatively more flexible than the LCC MTDC. In the case of the third terminal installation at the parallel AC transmission lines, which is achieved by the extension of the existing LCC HVDC, the utilization of the lines is expected to increase. The method for the increase of the utilization of the AC transmission lines in parallel with the HVDC system through the extension of the HVDC system to the hybrid MTDC system was studied in this paper. The proposed operation strategy was evaluated using a simulation analysis. The hybrid MTDC system was modeled and applied in the modified IEEE 39 bus New England test system (NETS) [31,32]. The utilization was estimated by considering the 
contingencies of the AC lines, and the simulation analysis was performed using the Transient Stability Analysis (TSA) tool, PSS ${ }^{\circledR}$ E. The simulation tool is commonly used for large power system analysis and transient stability simulation. The tool has a generic dynamic model for various power devices, except the hybrid MTDC model. The proposed operation strategy was applied in the actual power system data, which is Korean power system data, and the stability improvement of the system by the hybrid MTDC was evaluated.

The structure of the paper is as follows: Section 2 presents the operation strategy for the hybrid MTDC and the modeling method is described and verified in Section 3. The case studies conducted in the test system are introduced in Section 4 . Section 5 presents the results of a case study applying the proposed operation strategy to the actual Korean power system data. Discussion is in Section 6.

\section{Proposed Operation Strategy for the Hybrid MTDC}

The existing LCC HVDC systems in the AC grid supply bulk power from the generation area to the load area. The power can be flowed through certain AC transmission lines according to the magnitude and phase angle of the voltage between two areas. The corridor AC lines can be seen as the lines that are parallel with the HVDC. The HVDC can be extended by installing the third terminal at the bus of the parallel line, thereby establishing the DC grid in the AC grid. The DC grid can provide flexibility to the AC grid via the power flow control. Figure 1 illustrates the power system for which the extended MTDC is applicable.

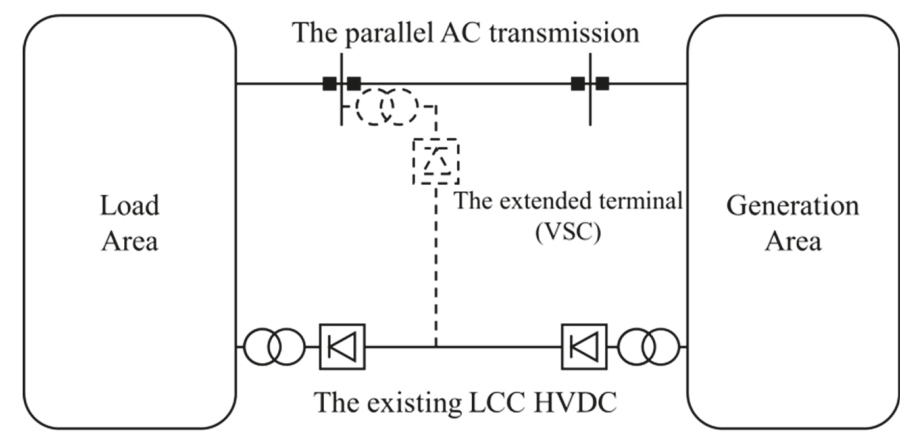

Figure 1. Extended multi-terminal high voltage direct current (MTDC) application in the power system between the generation and load areas.

In this paper, a hybrid MTDC operation strategy that increases the utilization of the parallel AC lines is proposed in consideration of the transient stability. Figure 2 presents the operation strategy briefly in terms of the transient state and the post-contingency condition. When the maintenance or fault occurs on the parallel AC lines, the utilization of remaining lines decreases. The extended terminal can be operated as an inverter or a rectifier to utilize the remaining lines by the operation strategy. The VSC terminal operates as an inverter when an event occurs at the generation side and as a rectifier when an event occurs at the load side. 


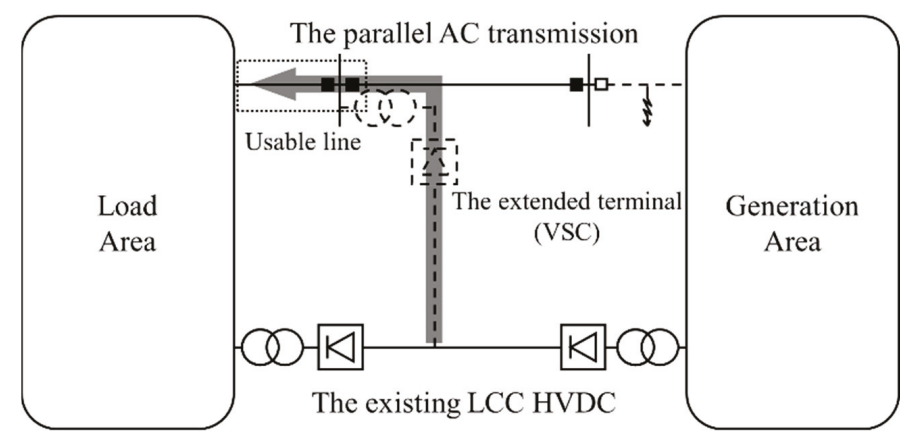

(a)

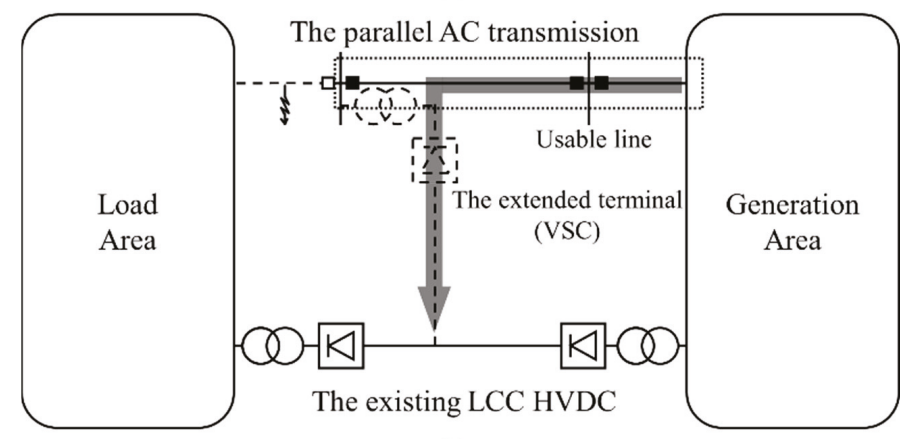

(b)

Figure 2. Brief operation strategy for the extended MTDC: (a) Power flow direction of the Voltage Source Converter (VSC) with the event at the generation side. (b) Power flow direction of the VSC with the event at the load side.

Because the VSC can reverse the power flow direction dynamically, the VSC can provide power to the $\mathrm{AC}$ line at the load area side for the generation side $\mathrm{AC}$ line event. In contrast, the generation side AC line can be used via the VSC when the event occurs at the load area AC line. Therefore, the hybrid MTDC is proposed in this paper instead of the LCC MTDC, owing to the consideration of the transient stability.

The need of the existing LCC HVDC system to change the general power flow direction is minor because the purpose of the system is the supply of power from the generation area to the load area. Consequently, the transient stability is expected to improve even with a hybrid MTDC system where the VSC is applied only to the third terminal.

Furthermore, the overload of the DC system was considered in the operation strategy. In the transient status, the unbalanced condition between the generation and load areas causes instability, and even several overload seconds can improve the transient stability; therefore, the proposed operation strategy considered the overload control during the transient status and verified the stability improvement.

\section{Modeling and Analysis Method of the Hybrid MTDC}

Even though the hybrid HVDC system has been researched since 1994, a practical operation has not yet been implemented. In addition, a model of the hybrid HVDC system for a power system analysis with the TSA tool is nonexistent. In light of this circumstance, the users developed the special model for the analysis of the hybrid MTDC via the TSA. In this paper, the method for the hybrid MTDC approximate modeling was studied using a generic multi-terminal model and a Controllable Reactive 
Power Source (CRPS). The LCC multi-terminal HVDC model is a generic MTDC model of PSS ${ }^{\circledR}$ E. The hybrid MTDC model is built by connecting the controllers of the generic model with a programming language Python and making the LCC terminal and CRPS operate as one device. For the analysis of the hybrid MTDC, the third terminal convertor should be a VSC. The important features of the VSC in terms of the AC system are the AC bus voltage control and the independent control of the active and reactive powers. The active power can be controlled by the LCC MTDC model, but the LCC generally consumes the reactive power; therefore, the CRPS model was used to provide the control ability and to compensate for the reactive power. A generic model of Static Compensation (STATCOM) from the PSS ${ }^{\circledR} \mathrm{E}$ is also used for CRPS. The models are explained in the manual of the program [33].

\subsection{Steady State Model of the Hybrid MTDC}

A steady state model is needed for the power flow calculation and the dynamic simulation initialization. To calculate the power flow, the MTDC system is modeled using the generic MTDC model. The angle of the converters, DC voltage, DC current by the order and the active power, and reactive power is calculated in the power flow analysis stage.

The proposed hybrid MTDC has the VSC at the third terminal, and the extended terminal should have the VSC features. A CRPS can control the reactive power and the AC bus voltage, so the CRPS model is composed of the same bus of the LCC MTDC third terminal, as shown in Figure 3. The existing LCC can control the active power, but it consumes the reactive power. The CRPS compensates for the reactive power and provides the control ability as well; therefore, the active and reactive powers can be controlled independently from the viewpoint of the AC bus. The AC bus voltage can also be controlled by the reactive power from the CRPS. The power orders are defined by the main controller to match the requirement of the power system balance and the main controller is implemented using the python programming language. According to the power order produced by the main controller, active power is controlled by the MTDC controller and reactive power is controlled by the CRPS controller. Consequently, the performance of the devices is equivalent to the single VSC performance at the point of the connected AC bus.

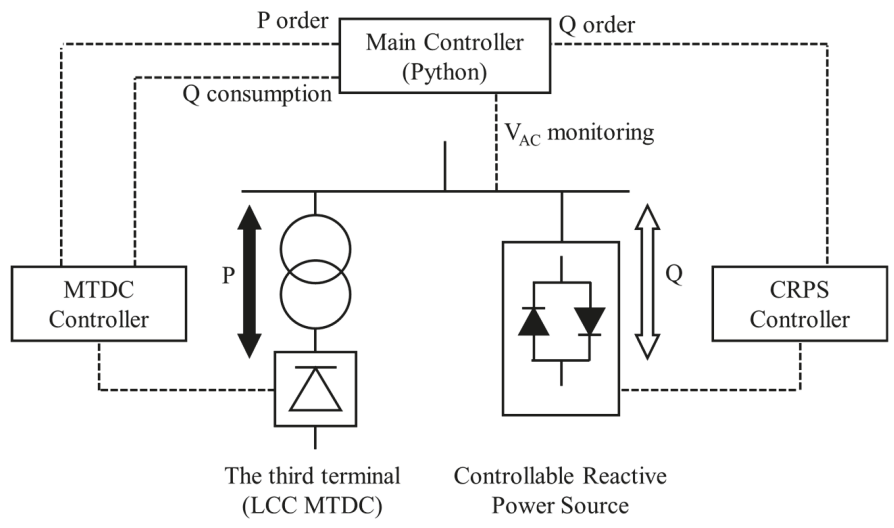

Figure 3. VSC terminal model from the use of the MTDC and the Controllable Reactive Power Source (CRPS).

The reactive power supply, however, is generally limited by the critical frontier, maximum voltage, and current limitation [34]. Figure 4a describes the operation range sample of the VSC. A simplified operation range was applied in this paper, as shown in Figure 4b. The per unit (p.u.) value is based on the rated converter capacity. 


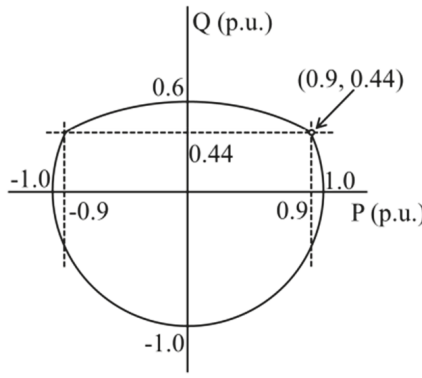

(a)

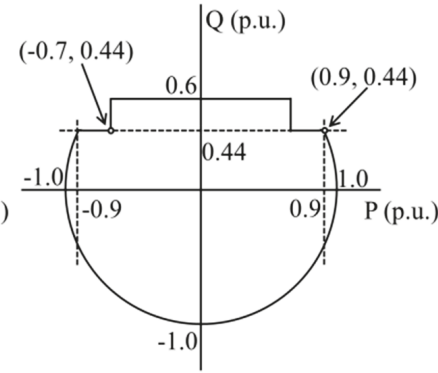

(b)

Figure 4. VSC operation range limitation: (a) Sample of actual operation limitation; (b) simplified operation limitation.

The VSC operation range shown in Figure $4 \mathrm{~b}$ is constrained by the active power order and can be defined by Equations (1) to (3), as follows:

$$
\begin{gathered}
-\sqrt{S^{2}-P^{2}} \leq Q \leq \sqrt{S^{2}-P^{2}}(P \geq 0.9 \times S), \\
-\sqrt{S^{2}-P^{2}} \leq Q \leq 0.44 \times S(0.9 \times S>P \geq 0.7 \times S), \\
-\sqrt{S^{2}-P^{2}} \leq Q \leq 0.60 \times S(0.7 \times S \geq P),
\end{gathered}
$$

where $S$ is the rated capacity of the converter and $P$ is the active power.

For the definition of the CRPS operation range, the reactive-power compensation, which was consumed by the LCC MTDC, was considered. Consequently, Equations (1)-(3) were modified to set the CRPS operation range, according to Equations (4)-(6).

$$
\begin{gathered}
-\sqrt{S^{2}-P^{2}}+Q_{d} \leq Q_{S T C} \leq \sqrt{S^{2}-P^{2}}+Q_{d}(P \geq 0.9 \times S), \\
-\sqrt{S^{2}-P^{2}}+Q_{d} \leq Q_{S T C} \leq 0.44 \times S+Q_{d}(0.9 \times S>P \geq 0.7 \times S), \\
-\sqrt{S^{2}-P^{2}}+Q_{d} \leq Q_{S T C} \leq 0.60 \times S+Q_{d}(0.7 \times S \geq P),
\end{gathered}
$$

where $Q_{d}$ is the consumed reactive power of the converter and $Q_{S T C}$ is the CRPS output. For the selection of the CRPS maximum output, the LCC MTDC active power capacity was employed.

\subsection{Dynamic Model of the Hybrid MTDC}

The LCC MTDC dynamic model and the CRPS dynamic model were used for the dynamic simulation as well. The MTDC model controlled the active power and the CRPS model compensated for and controlled the reactive power. Generally, the current limitation of an MTDC model converter is lower for the normal operation, due to the ripple of the DC current; however, the DC current lower limit was set as zero for the proposed hybrid MTDC model, owing to the simulation of the situation wherein the power flow direction was changed dynamically.

The CRPS model parameters reflect the current limitation. The capacitive current limitation and the inductive current limitation can be set individually, and the current limitation means the operation range. The reactive power consumption was considered for the CRPS operation range. In contrast to the steady state, the reactive power consumption continually changes in the dynamic simulation, along with the active power change. The CRPS operation range should therefore continue changing during the simulation. In this paper, the main controller is proposed and the controller changes the parameters for CRPS. The dynamic simulation has a time step, and the dynamic system status is calculated at each step. The main controller connects two generic model controllers of LCC MTDC and CRPS, thus, 
the third terminal is operated as one device. Active and reactive power order is defined in the main controller and limitation as well.

For the CRPS operation range, the reactive power consumption was calculated, and the controller changed the CRPS current limitation between the time steps. The inductive current limitation is the same, irrespective of the active power output, as described in Equation (7). Meanwhile, the capacitive current limitation should be selected by the active power output of the LCC. The current limitations according to the active power output are represented in Equations (8) to (10), as follows:

$$
\begin{gathered}
I_{L, \text { limitation }}=\sqrt{S^{2}-P^{2}}-Q_{d}, \\
I_{C, \text { limitaion }}=\sqrt{S^{2}-P^{2}}+Q_{d}(P \geq 0.9 \times S), \\
I_{C, \text { limitaion }}=0.44 \times S+Q_{d}(0.9 \times S>P \geq 0.7 \times S), \\
I_{C, \text { limitaion }}=0.60 \times S+Q_{d}(0.7 \times S \geq P),
\end{gathered}
$$

where $I_{L, \text { limitation }}$ is the inductive current limitation and $I_{C \text {,limitation }}$ is the capacitive current limitation.

Even though the CRPS operation range was modified at every time step, it is likely that the sum of the LCC reactive power consumption and the CRPS output is in the operation range of the VSC reactive power. Therefore, the active power order is transfer to the MTDC controller and the amount of reactive power consumption is calculated. The main controller defines the reactive power order, considering $\mathrm{AC}$ voltage and the reactive power consumption. To make the reactive power output meet the order value, CRPS limitation parameters are changed by the main controller. The order calculation and parameters changing are performed at every time step. The block diagram for the dynamic model operation is shown in Figure 5.

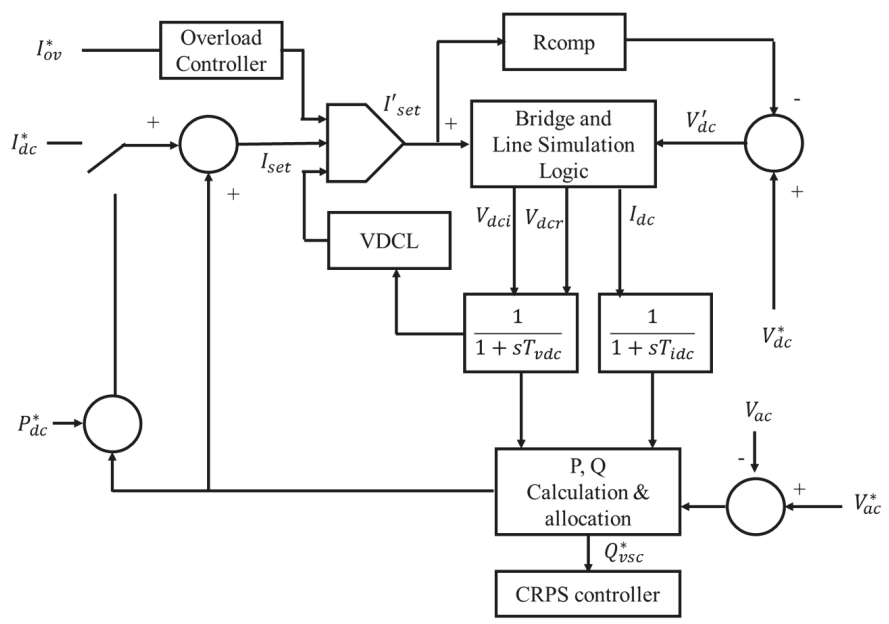

Figure 5. Block diagram of the dynamic model for the hybrid MTDC.

\subsection{Model Verification}

The proposed hybrid MTDC model was verified through the dynamic simulation. The performance of the VSC reactive power control was observed in terms of the reactive power control for the AC bus voltage. The VSC rated capacity was set as $500 \mathrm{MVA}$, and a disturbance (bus fault) was applied at the VSC station to verify the reactive power operation range. The different CRPS operation ranges are compared in Figure 6, and the active power outputs of the VSC with respect to each of their rated capacities are $450 \mathrm{MW}, 350 \mathrm{MW}$, and $200 \mathrm{MW}$. The CRPS capacitive output should be limited 
by Equations (8) to (10) at each time step. The analysis of the VSC reactive power outputs for each active power case for which the LCC consumption capacity and the CRPS output were considered are presented in Figure 7. As shown in Figure 6, CRPS outputs were limited by Equations (8) to (10), considering $Q_{d}$ at each time step. Consequently, the limitation value was changed for each step. However, the VSC reactive power outputs were limited in the operation range shown in Figure 4, thus the limited output is fixed, as shown in Figure 7.

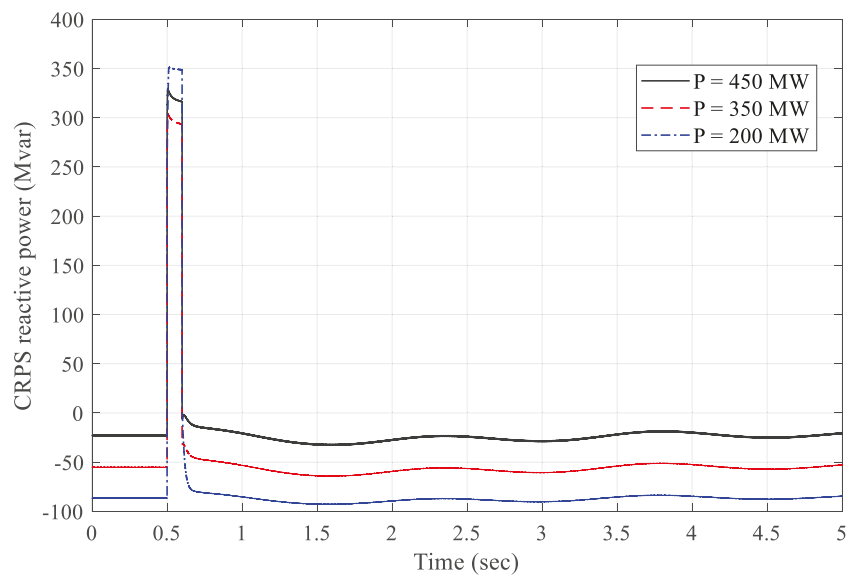

Figure 6. CRPS reactive power output by the different active power outputs of the VSC.

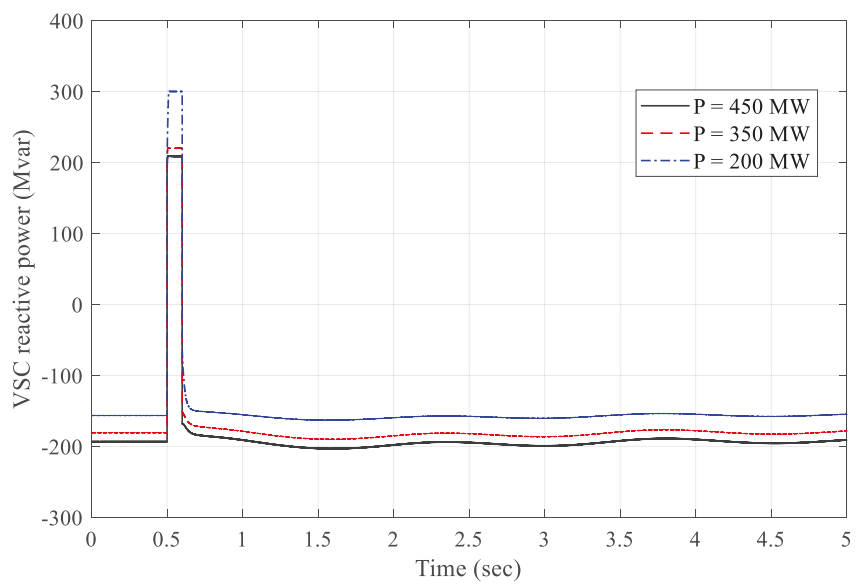

Figure 7. VSC reactive power output by the different active power outputs of the VSC.

When the active power output is 0.4 p.u., the limitation of the reactive power output, modeled according to Equation (3), is 3 Mvar and corresponds to the rated capacity of 0.6 p.u. The limitations of the reactive power outputs of the other cases were modeled according to Equations (1) and (2).

The active power change was simulated to verify the dynamic flow direction change. The VSC was proposed to change the power flow dynamically in the transient status, but the active power of the VSC changes with a delay, even if the power order is switched from the original value to the new order value as a step function [35]. For this reason, the time constant for the power output delay was applied in the model. As presented in Figure 8, the active power order changed at $0.5 \mathrm{~s}$ in the simulation. The active power of the VSC changed from a positive value to a negative value with the applied delay. 
Therefore, the VSC operated the inverter mode at the beginning, but the mode changed to the rectifier mode. The changed active power amount was taken by the LCC inverter of the hybrid MTDC system.

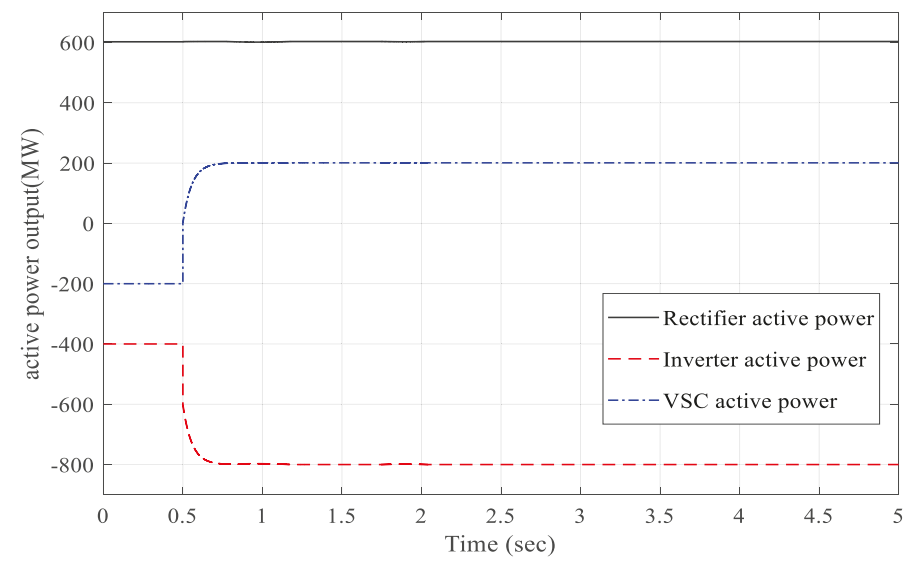

Figure 8. The active power for each converter.

Verified through the simulations, the proposed model is an approximate model that is focused on the following two features: AC bus voltage control and power flow direction change.

The VSC can control the reactive power in a defined operation range to maintain the AC bus voltage with the proposed model. The converter can also control the active power dynamically, even with the flow direction. Therefore, the hybrid MTDC model was used for the evaluation of the operation strategy.

\section{Evaluation of the Proposed Operation Strategy}

The operation strategy for the hybrid MTDC system is proposed in this paper. The proposed DC system was extended from a point-to-point (PTP) HVDC system and the extended terminal consists of the VSC. The modeling method for which the LCC MTDC and CRPS models are used for the hybrid MTDC was studied and verified.

The control scheme of the proposed operation strategy is described in Figure 9. When the event occurs at the parallel AC lines, the hybrid MTDC system will get a signal from the grid operator. The active power order is calculated depending on the fault location, while the reactive power order is calculated depending on the operation range of the VSC by Equations (1)-(3). The reactive power limitation for CRPS is calculated by Equations (7)-(10) as well. If the system considers the overload operation, the active power order will be overwritten by the overload factor, which defines the overloading percentage while the power order for LCC converters is calculated. The calculated power order for the converters is transferred to the main controller. 


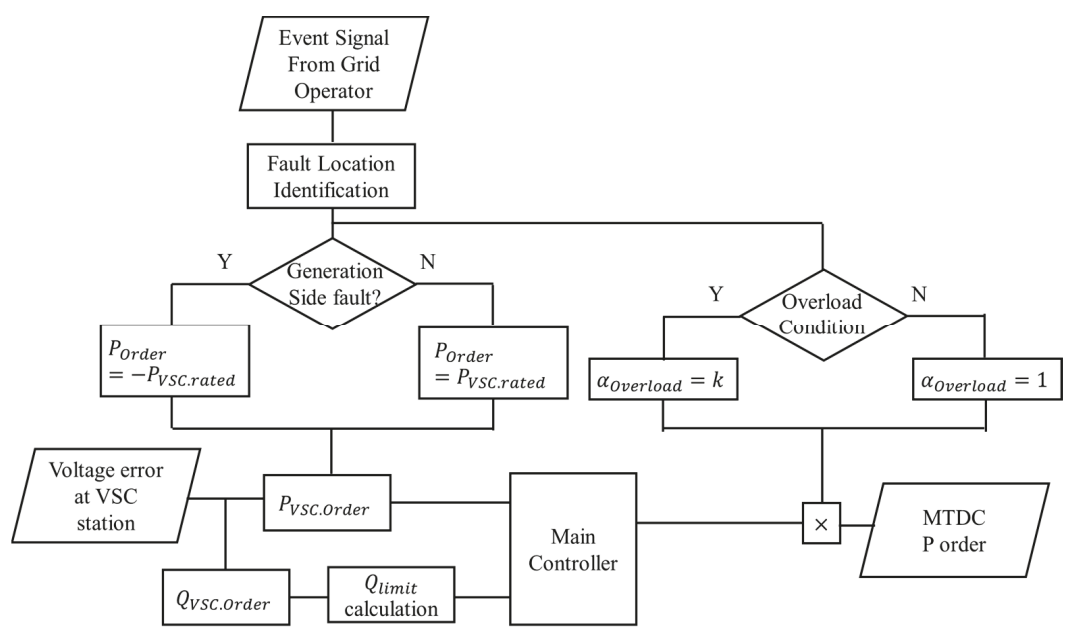

Figure 9. Control algorithm of the proposed operation strategy.

The simulations were performed to evaluate the operation strategy for the extended DC system, and they were compared with the PTP HVDC and LCC MTDC topologies. The PTP HVDC was applied to the IEEE 39 bus test system and the DC transmission system was extended to the LCC MTDC. In addition, the proposed modeling method was applied at the third terminal of the LCC MTDC system to compose the hybrid MTDC system. The applied PTP HVDC and LCC MTDC operation characteristics are indicated in Figure 10. The DC current was controlled by the rectifier, and the inverter controlled the DC voltage for both the PTP HVDC and LCC MTDC systems. The extended terminal can be operated as the rectifier and the inverter, and the current control mode was applied to the converter. The Voltage Dependent Current Order Limitation (VDCOL) was applied to the current control converters. The third terminal, however, is the VSC in the case of the hybrid MTDC, and therefore, the operation characteristic was changed, as shown in Figure 11, and the VDCOL function was removed from the third terminal.

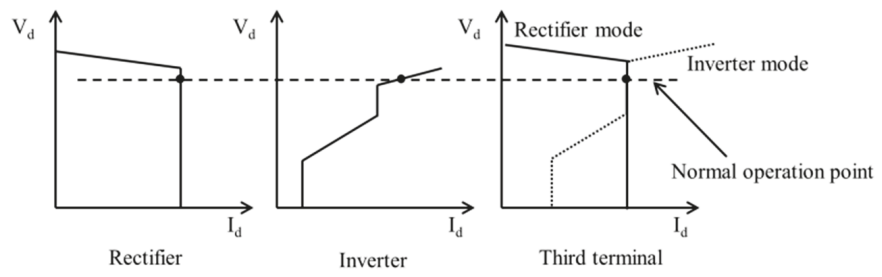

Figure 10. Line Commutate Converter (LCC) MTDC operation characteristics.

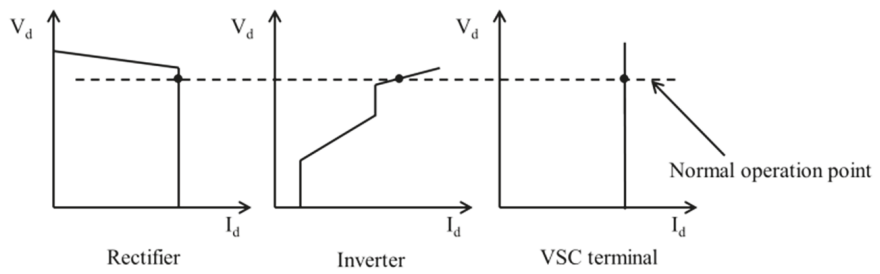

Figure 11. Hybrid MTDC operation characteristics. 
The topologies of the DC transmission system were applied to the IEEE 39 bus test system, and the system was modified to comprise generation and load areas. In the test system, the PTP HVDC system was applied from bus 22 to bus 4 . The extended terminal was composed at bus 17 . The route of the AC transmission line from bus 16 to bus 3 is the parallel line for the transfer of the power between the areas. The modified system is represented in Figure 12.

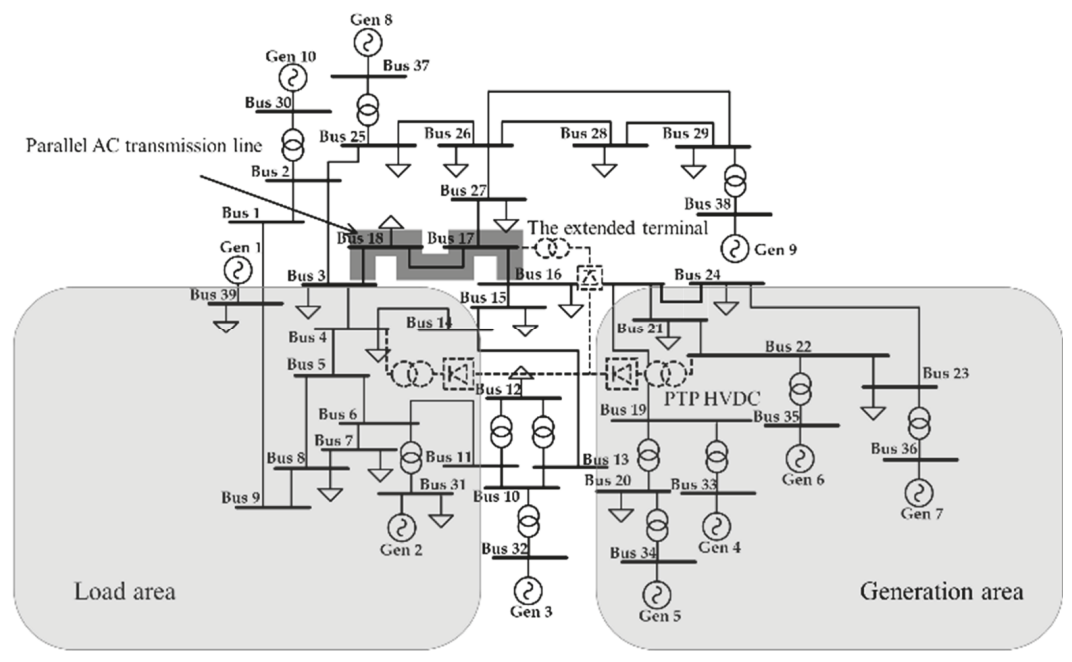

Figure 12. Modified IEEE 39 bus test system and the applied DC system.

\subsection{Utilization of the Parallel AC Transmission Line}

The utilizations of the parallel AC transmission line were evaluated through the performance of a steady state calculation for each topology. The third terminal was operated as the inverter to provide the active power to the AC lines. The transmission power capacities are $600 \mathrm{MW}$ for the rectifier, 400 MW for the inverter, and $200 \mathrm{MW}$ for the third converter. The analysis results are indicated in Table 1. Line 1 is from bus 16 to bus 17 , line 2 is from bus 17 to bus 18 , and line 3 is from bus 18 to bus 3 . The third terminal provided the active power for bus 17, thereby increasing the power flows of lines 2 and 3 for the MTDC topologies. Even though the power flow of line 1 decreased, the total power flow amount through the AC line increased. Therefore, the utilization of the parallel AC line increased. Table 2 indicates the results of the power flow calculation for the cases where the active power output of the third terminal is $400 \mathrm{MW}$. As the output of the third terminal was increased, the utilization of line 1 decreased and the utilizations of lines 2 and 3 increased.

Table 1. Parallel alternating current (AC) transmission line power flow results of the third terminal 200 MW output.

\begin{tabular}{ccccc}
\hline CASE & Line 1 (MW) & Line 2 (MW) & Line 3 (MW) & Total (MW) \\
\hline PTP HVDC & 232.64 & 183.73 & 25.49 & 441.86 \\
LCC MTDC & 149.46 & 257.90 & 117.37 & 542.73 \\
Hybrid MTDC & 148.88 & 273.74 & 115.23 & 537.85 \\
\hline
\end{tabular}


Table 2. Parallel AC transmission line power flow results of the third terminal $400 \mathrm{MW}$ output.

\begin{tabular}{ccccc}
\hline CASE & Line 1 (MW) & Line 2 (MW) & Line 3 (MW) & Total (MW) \\
\hline PTP HVDC & 232.64 & 183.73 & 25.49 & 441.86 \\
LCC MTDC & 67.08 & 368.00 & 209.10 & 644.18 \\
Hybrid MTDC & 66.53 & 366.01 & 207.11 & 639.65 \\
\hline
\end{tabular}

Regarding the extended DC system, the total utilization of the parallel AC line can be controlled by the third terminal active power output. The hybrid MTDC can control the rate using the AC voltage control as well. However, due to the decrease of the load of the AC lines between the third terminal and the generation area, the appropriate third terminal output should be considered at the operation planning stage.

The utilization of the parallel AC transmission line is improved by $20 \%$ for $200 \mathrm{MW}$ output and $45 \%$ for 400 MW output.

\subsection{Transient Stability Improvement}

Dynamic simulations were implemented to evaluate the transient stability of the power system with the hybrid MTDC. The proposed operation strategy is for the improvement of the AC line utilization, including the post-transient status.

In the case of the parallel AC line trip, the third terminal can provide or take the power from the usable AC lines, as shown in Figure 2. To evaluate the effect of the extended DC system, dynamic simulations were performed with the proposed model in Section 3 for two scenarios. The first scenario is an event at the AC line of the generation side, and the second scenario is an event at the load side.

The third terminal power flow direction changed after the event occurred in the proposed operation strategy. To utilize the usable AC line, the third terminal was operated in the inverter mode after the generation side event. To consider a severe case, the initial operation mode of the third terminal served as a rectifier and the output was $200 \mathrm{MW}$ in the first scenario. Figures 13-15 show the simulation results for the event. The active power output for each converter is represented in Figure 13 for the cases with the operation strategy. Figures 14 and 15 show the angle spread of the power system and the $\mathrm{AC}$ voltage of the inverter station.

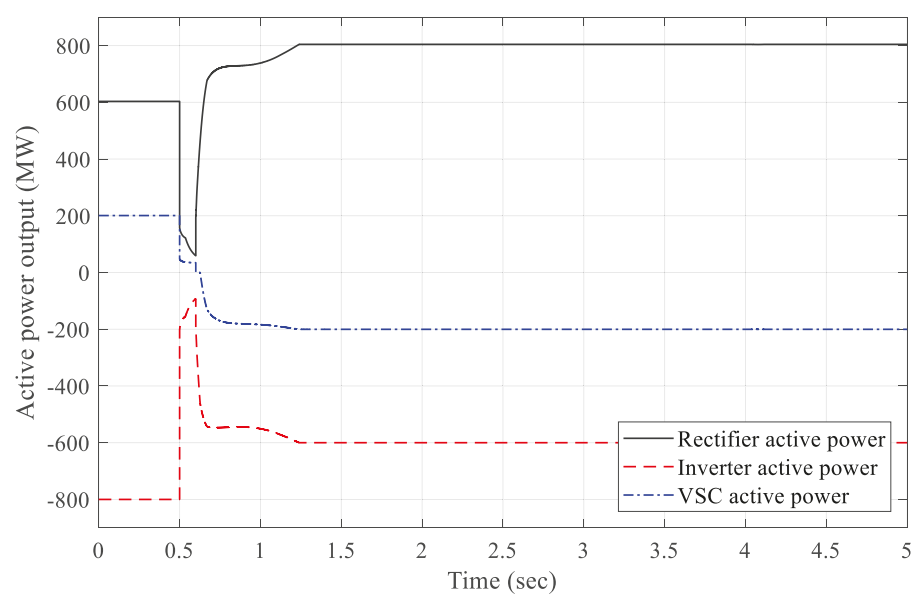

Figure 13. The active power output for each converter for the generation side event with the operation strategy. 


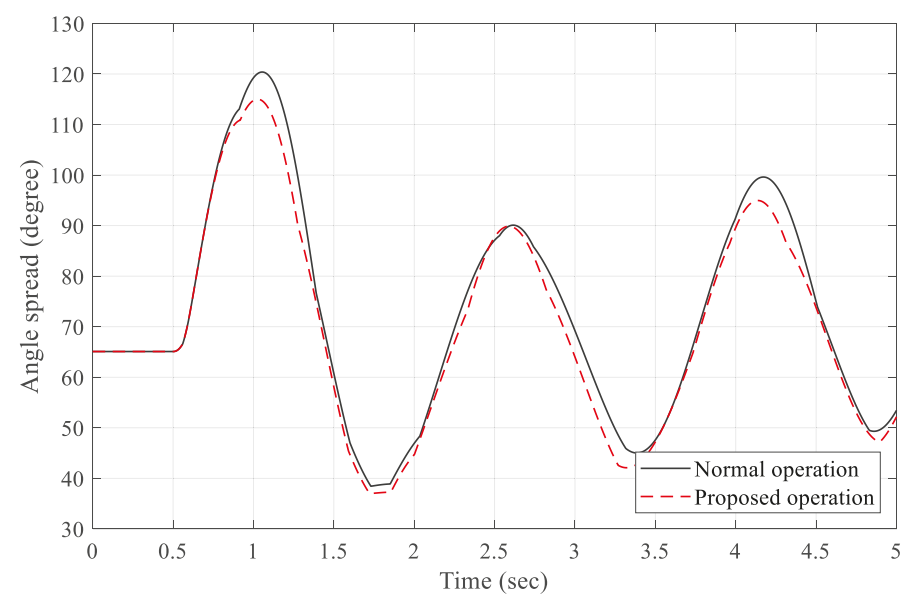

Figure 14. The angle spread for the generation side event.

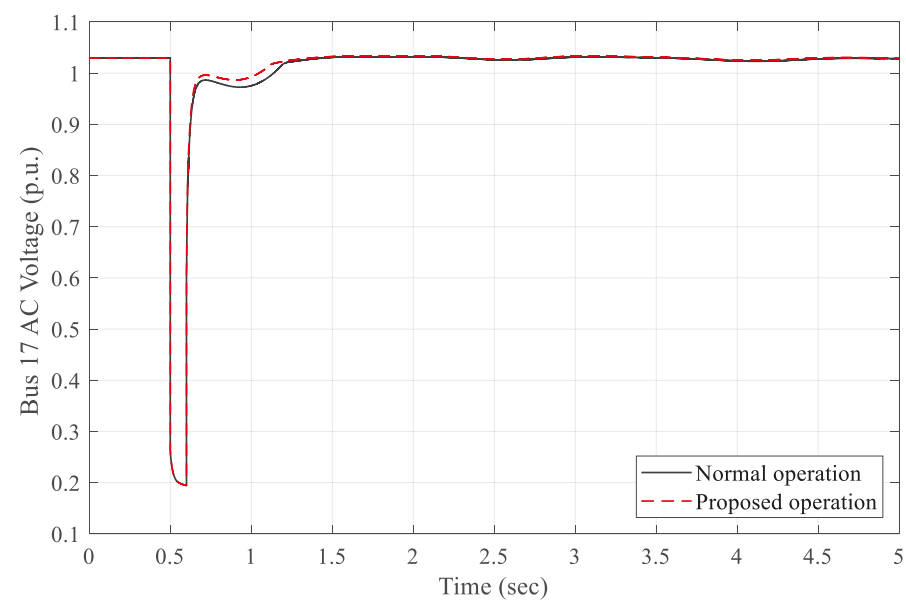

Figure 15. The AC voltage of the inverter station for the generation side event.

As shown in Figure 13, the total power exchange amount is the same, irrespective of the operation strategy; that is, the load area received the same amount of power. The transient stability was improved in Figure 14, even though the power exchange amount between the two areas was the same.

The angle spread is one of the indices that is used to evaluate the transient stability, especially the angle stability. The system is more stable during the transient status if the maximum angle spread value is smaller. The maximum angle spread of the case without the operation strategy is 120.38 degrees; however, with the operation strategy, the value decreased to 115.01 degrees. The voltage recovery feature of the load area was improved, as shown in Figure 15; therefore, the operation strategy improved the transient stability of the system.

Simulation results of the second scenario are represented in Figures 16-18. Figure 16 indicates the active power output of each converter for the cases with and without the operation strategy, and Figure 17 shows the angle spread from the load side event simulation results. The voltage recovery feature of the load area was improved, as shown in Figure 18. In the case of the second scenario, the generation side voltage recovery feature was improved, due to the operation strategy. 


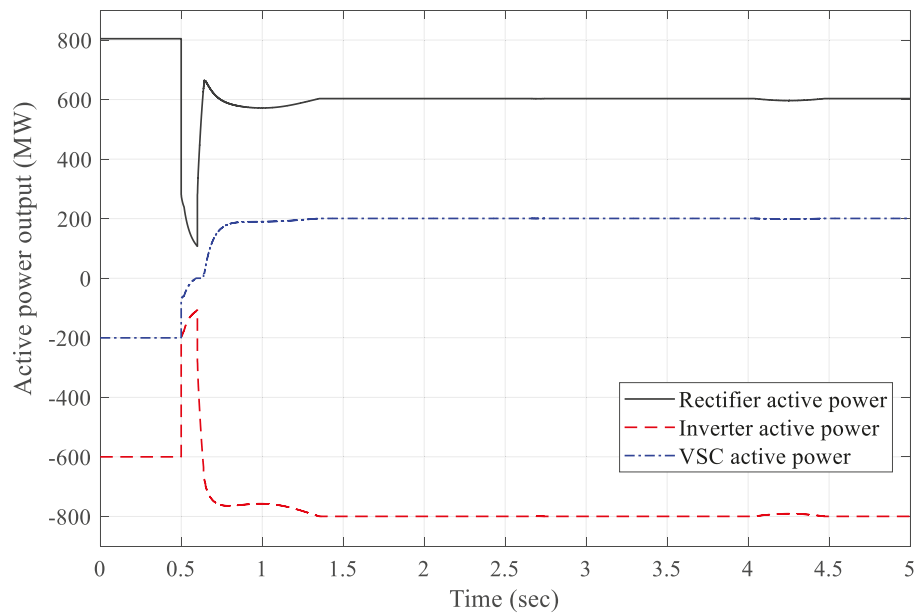

Figure 16. The active power output for each converter for the load side event with the operation strategy.

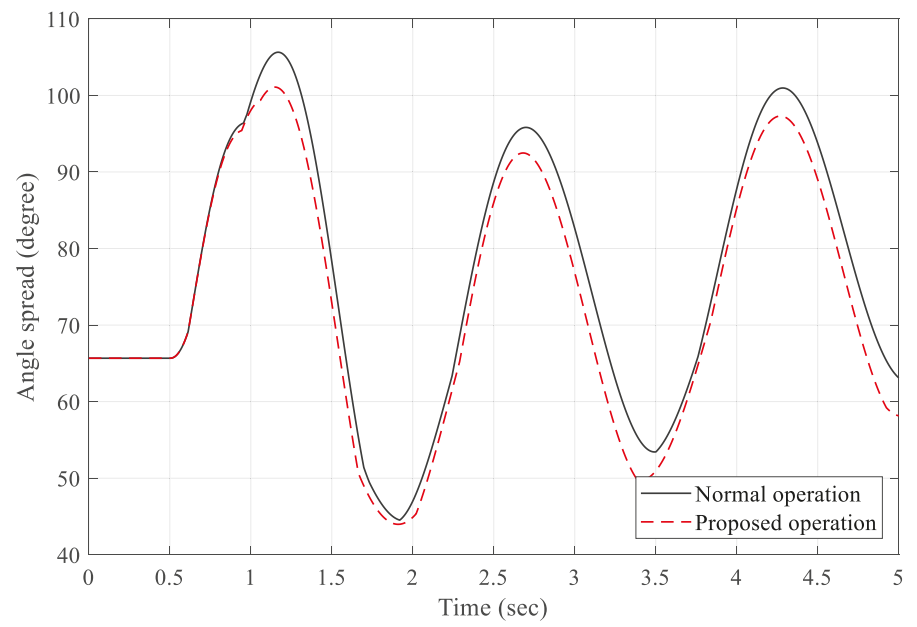

Figure 17. The angle spread for the load side event. 


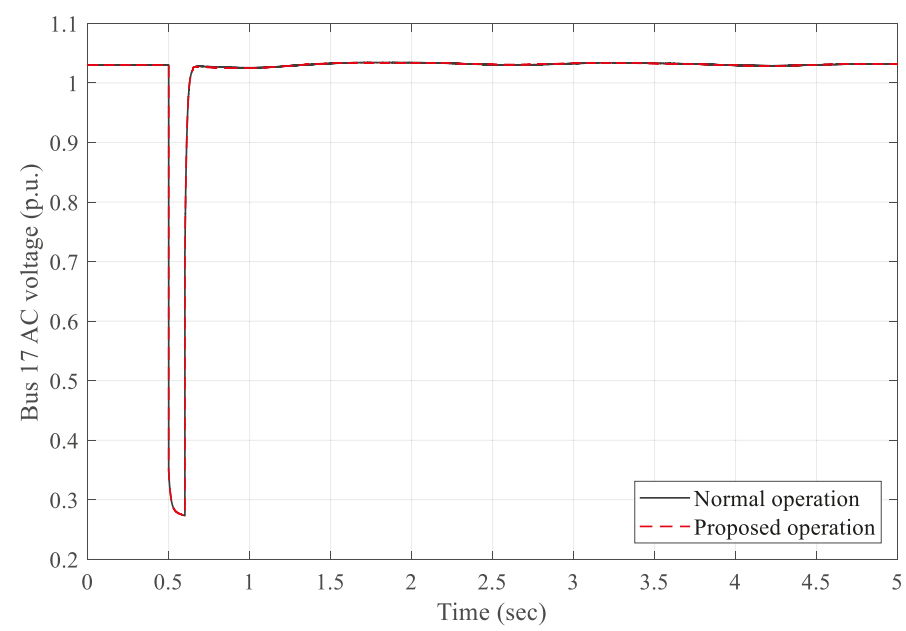

Figure 18. The AC voltage of the inverter station for the load side event.

In the load side event simulation, the VSC initial operation mode is an inverter mode for the consideration of a severe event case, and the active power output is also $200 \mathrm{MW}$. In the second scenario, the transient stability was improved as well, even though the effect is relatively low. The maximum value of the angle spread decreased from 105.64 degrees to 101.08 degrees.

Although the effect of the transient stability improvement is small for the test system, due to the scale of the system and the DC transmission also being small, the effect is expected to increase for the larger scales of the power system and the DC transmission system.

\subsection{Overload Consideration}

The overload operation was considered for the proposed operation strategy in this paper. A temporary overload can initially mitigate the imbalance between the generation and the load area. The simplified overload simulation was performed for each topology. The event that causes voltage problems at the third terminal was considered. The AC voltage of the third terminal from the simulation results is represented in Figures 19 and 20 for the same event. The transient stability for the LCC MTDC case is unstable, as opposed to the hybrid MTDC because of the voltage stability of the third terminal. LCC HVDC cannot change the direction of power flow dynamically and requires more reactive power for overload, thus the power system transient stability would be worse for the event. As shown in Figure 20, only the overload case was stable.

A detailed overload simulation with the operation strategy was implemented for the hybrid MTDC topology, and the second scenario, which is the event at the load side, was simulated. The active power output from the simulation result is indicated in Figure 21. The inverter output was overloaded to $1000 \mathrm{MW}$; therefore, the temporarily provided load area is $200 \mathrm{MW}$ more than the original scenario. The surplus power mitigated the imbalance between the power and the load, thereby improving the transient stability. 


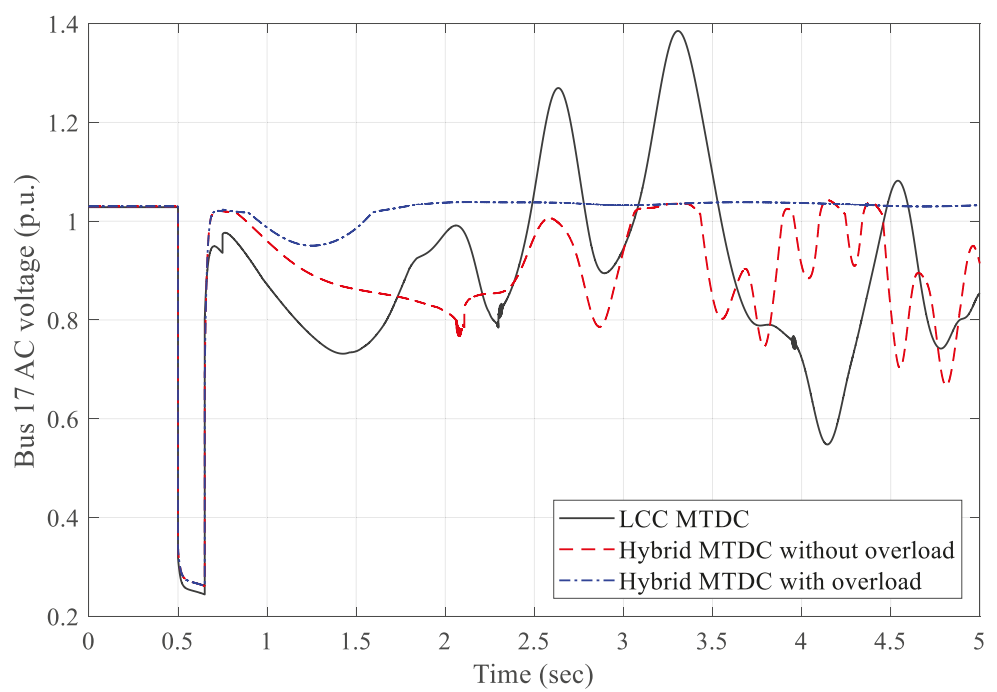

Figure 19. The AC voltage of third terminal from the simple overload simulation for each topology.

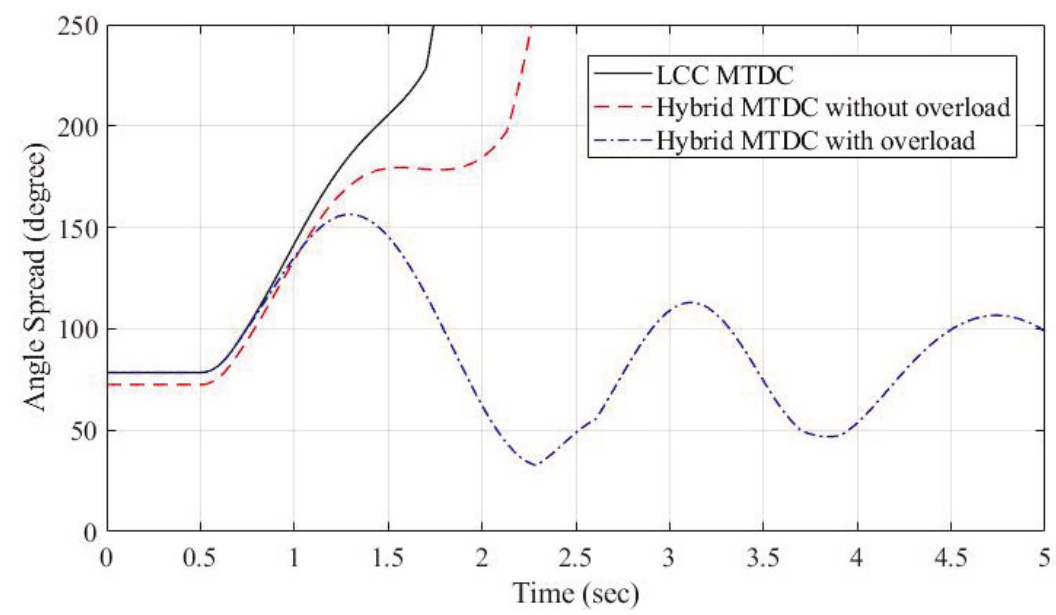

Figure 20. The angle spread from the simple overload simulation for each topology. 


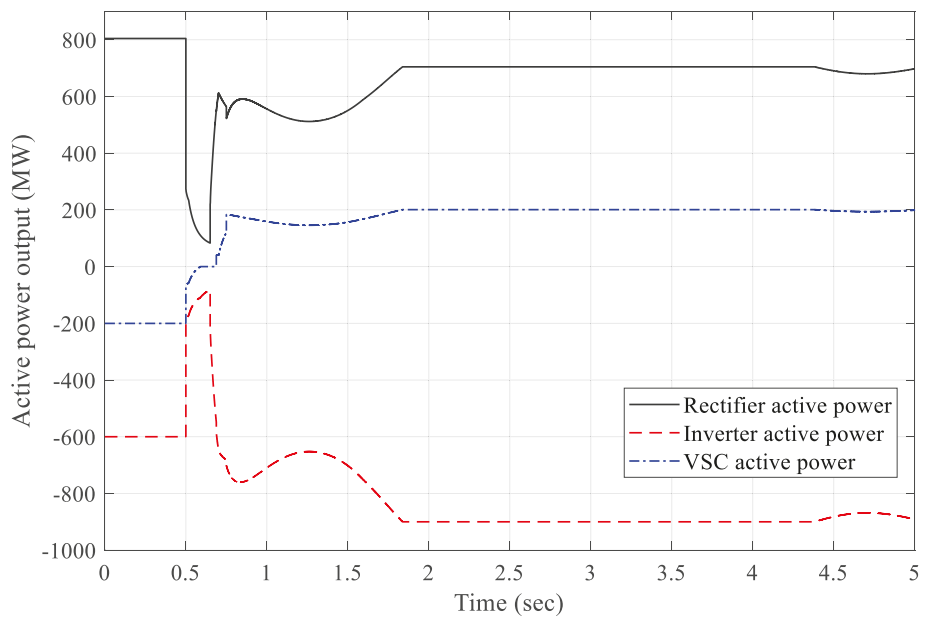

Figure 21. The active power output for each converter with the overload.

The effect of the transient stability improvement is expected to increase for the larger scales of the power system and the DC transmission system.

\section{Case Study of the Actual System Data}

The case study using the actual power system data, which is Korean power system data, was conducted. The hybrid MTDC system is applied in the 2024 planning data. The existing LCC HVDC systems are extended to the hybrid MTDC system and the $765 \mathrm{kV}$ transmission lines are the parallel AC transmission lines. Figure 22 is a simplified single line diagram of the hybrid MTDC system and the Korean power system near the MTDC.

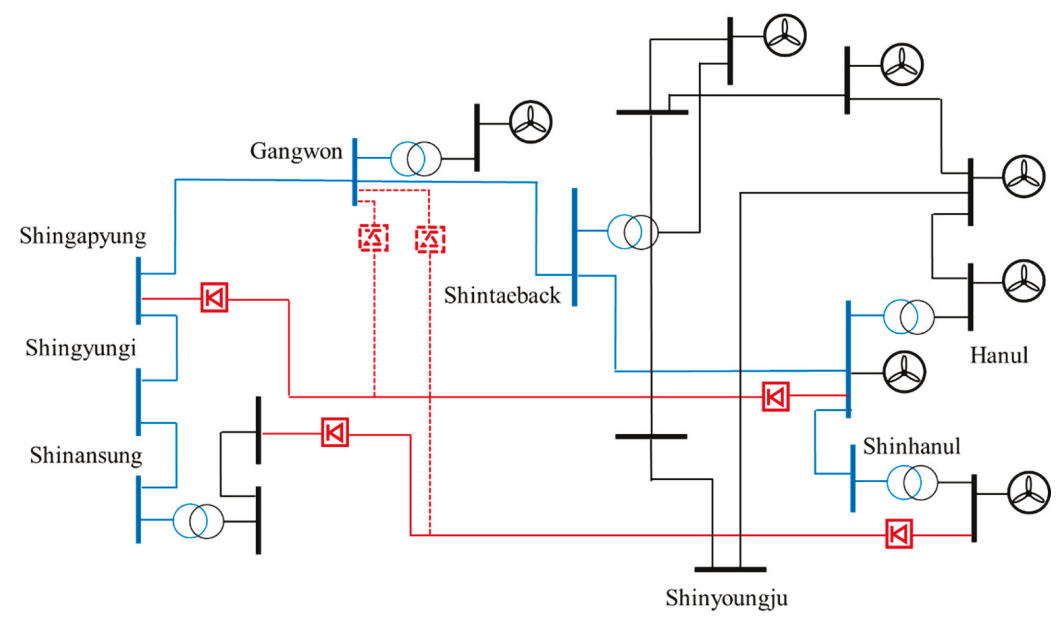

Figure 22. Actual power system data with the hybrid MTDC system.

The system has the generation area and the load area similar to the modified 39 bus system used in this paper. The east coastal area is a large-scale generation area and the generated power from the area is transmitted to the west metropolitan area of the system, which is the load area. The power 
system total load is approximately $102 \mathrm{GW}$, while the exiting LCC HVDC systems are two bipolar and the rated capacity is $8 \mathrm{GW}$. Furthermore, the HVDC system has an overload operation mode to $10 \mathrm{GW}$ and the available overload operation period is five seconds. The third terminal is connected to the parallel AC transmission line and the rated capacity is 600 MVA.

Dynamic simulations were conducted for the event at the load area and the stability improvement of the system by the operation strategy was compared. The simulation scenario for the load side event is as follows:

- $\quad 765 \mathrm{kV}$ bus fault at $0.5 \mathrm{~s}$;

- $\quad$ Clear fault after 5 cycles and trip branches (0.5833 s);

- $\quad$ Generator trip after 4 cycles (0.65 s);

- Thyristor Controlled Series Compensator (TCSC) Boost up and HVDC overload if required at $0.7 \mathrm{~s}$;

- Run until $10 \mathrm{~s}$.

The simulation results are shown in Figures 23 and 24, and the actual system stability with normal operation and with the operation strategy was evaluated.

In the case of an original power system with two-terminal LCC HVDC, a machine has to be tripped for stable operation of the system. However, the stable operation of the system is possible without the machine trip in the case of the hybrid MTDC system. The maximum angle spread of the two-terminal LCC HVDC case was 165.51 degrees with a machine trip. A hybrid MTDC system can stabilize the system without the machine trip in the same event, as shown in Figure 24, and the maximum angle spread was 182.58 degrees.

The overload operation was considered as well for the actual power system data because the existing LCC HVDC system had the overload operation mode. The simulation results of the overload operation cases are presented in Figures 25 and 26.

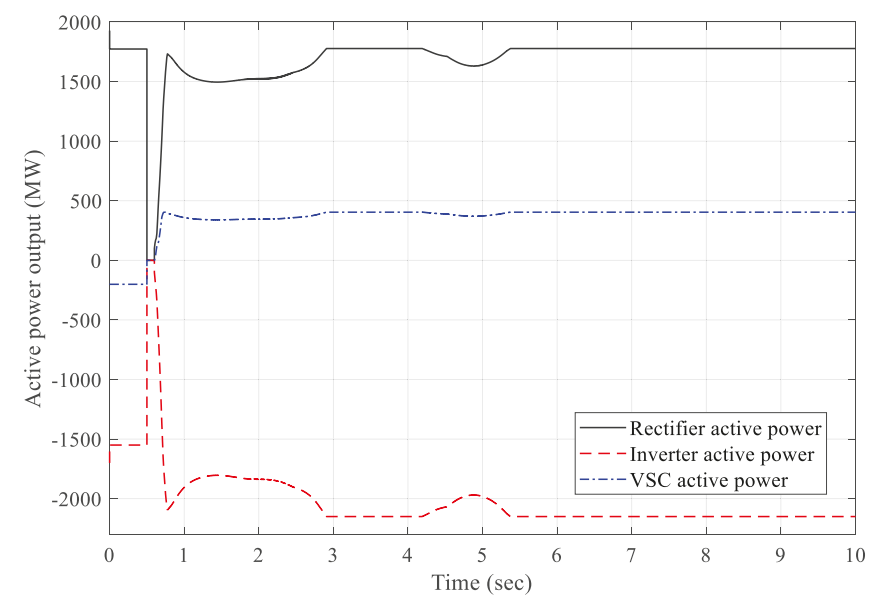

Figure 23. The active power output of each converter for the load side event with the operation strategy in the actual system data. 


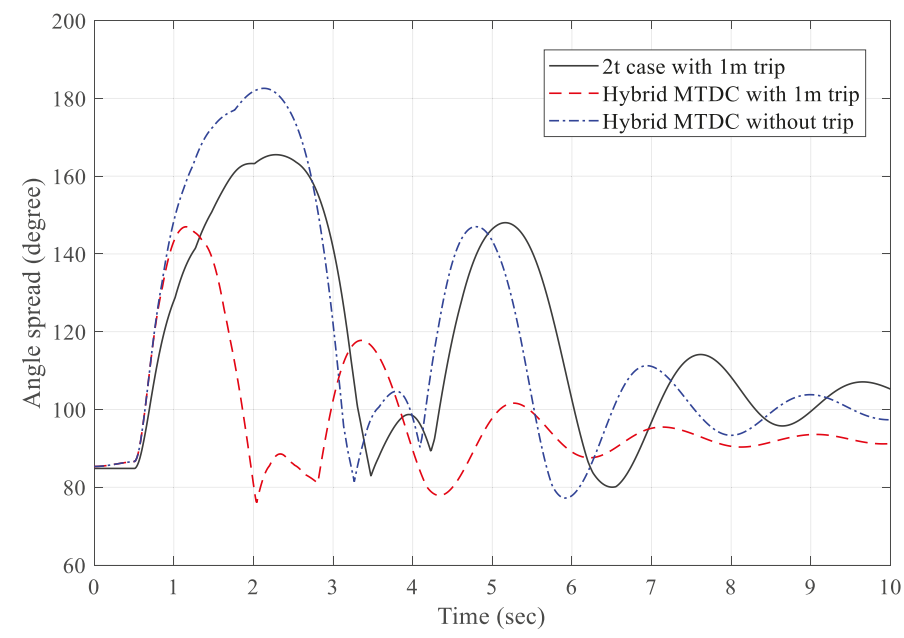

Figure 24. The system angle spread for the load side event in the actual system data.

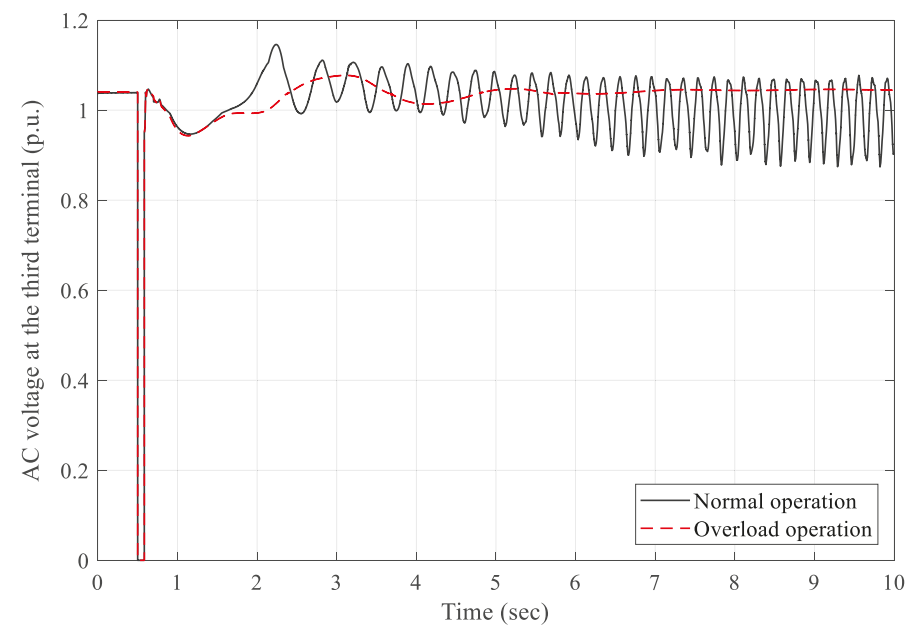

Figure 25. The AC voltage at the third terminal for each case in the actual system data. 


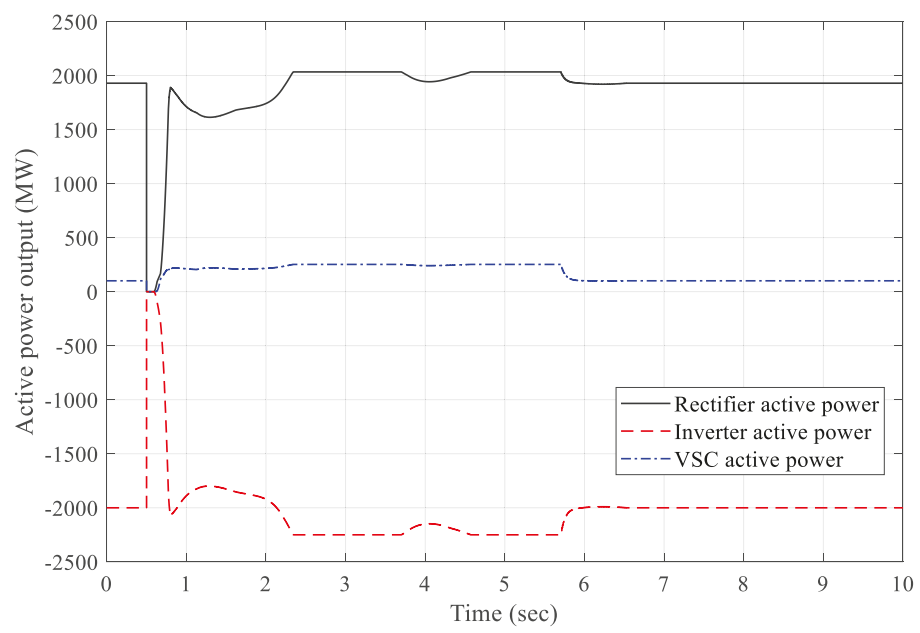

Figure 26. The active power outputs of the overload operation in the actual system data.

The severe load side event occurred and overload operation started after the event was cleared. The initial VSC output was $100 \mathrm{MW}$ and increased to $250 \mathrm{MW}$ during the overload operation. The overload operation was held for five seconds and the active power output of converters returned to the original value. For the event, the normal operation case was unstable after the event was cleared. Even though the voltage recovery feature was similar to the overload case until $1.5 \mathrm{~s}$, the system became unstable and the voltage swing occurred without overload operation. On the other hand, the system was stabilized by the overload operation.

\section{Conclusions}

A generic LCC MTDC model and a CRPS model were used in the approximate hybrid MTDC model; the MTDC model controlled the active power, and the reactive power was controlled by the CRPS model. The control of the hybrid MTDC model, in terms of the active power and the reactive power, was verified via simulations. The proposed modeling method is for a power system analysis, and the focus of the model is the independent control of the active power and the reactive power.

The operation strategy for the hybrid MTDC is proposed and evaluated, according to a dynamic simulation. The model was applied to the test system, and the operation strategy was evaluated. A multi terminal DC grid improved the AC system utilization, and the proposed operation strategy improved the transient stability of the power system. To add, the overload was considered and the effect was verified. The stability improvement by the operation strategy is verified in the actual system data as well. The hybrid MTDC system is applied in the Korean power system and the transient stability analysis was conducted. The hybrid DC system can reduce the generator outage in the severe contingency by the operation strategy proposed.

Author Contributions: The hybrid MTDC system modeling method and the operation strategy were proposed by S.H., S.S., M.Y., and G.J. The experiment results were collected and analyzed by S.H., S.S., M.Y., and G.J.

Funding: This research was supported by Korea Electric Power Corporation. (R18XA06-62) and under the framework of the international cooperation program managed by the National Research Foundation of Korea. (No. 2017K1A4A3013579).

Conflicts of Interest: The authors declare no conflict of interest. 


\section{References}

1. Gotham, D.J.; Heydt, G. Power flow control and power flow studies for systems with facts devices. IEEE Trans. Power Syst. 1998, 13, 60-65. [CrossRef]

2. Hingorani, N.G.; Gyugyi, L. Understanding FACTS: CONCEPTS and Technology of Flexible AC Transmission Systems; Wiley-IEEE Press: New York, NY, USA, 2000; p. 452.

3. Xiao, Y.; Song, Y.; Sun, Y. Power flow control approach to power systems with embedded facts devices. IEEE Trans. Power Syst. 2002, 17, 943-950. [CrossRef]

4. Gaigowal, S.R.; Renge, M. Some studies of distributed series facts controller to control active power flow through transmission line. In Proceedings of the 2013 International Conference on Power, Energy and Control (ICPEC), Sri Rangalatchum, Dindigul, India, 6-8 February 2013; pp. 124-128.

5. Jovcic, D.; Van Hertem, D.; Linden, K.; Taisne, J.-P.; Grieshaber, W. Feasibility of dc transmission networks. In Proceedings of the 2011 2nd IEEE PES International Conference and Exhibition on Innovative Smart Grid Technologies (ISGT Europe), Manchester, UK, 5-7 December 2011; pp. 1-8.

6. Rouzbehi, K.; Miranian, A.; Candela, J.I.; Luna, A.; Rodriguez, P. A generalized voltage droop strategy for control of multiterminal dc grids. IEEE Trans. Ind. Appl. 2015, 51, 607-618. [CrossRef]

7. Xu, L.; Yao, L.; Bazargan, M. Dc grid management of a multi-terminal hvdc transmission system for large offshore wind farms. In Proceedings of the 2009 International Conference on Sustainable Power Generation and Supply, Nanjing, China, 6-7 April 2009; pp. 1-7.

8. Xu, L.; Yao, L. Dc voltage control and power dispatch of a multi-terminal hvdc system for integrating large offshore wind farms. IET Renew. Power Gener. 2011, 5, 223-233. [CrossRef]

9. Reeve, J. Multiterminal hvdc power systems. IEEE Trans. Power Appar. Syst. 1980, 2, 729-737. [CrossRef]

10. Nguyen, T.-T.; Son, H.-I.; Kim, H.-M. Estimating stability of mtdc systems with different control strategy. J. Electr. Eng. Technol. 2015, 10, 443-451. [CrossRef]

11. Beerten, J.; Cole, S.; Belmans, R. Generalized steady-state vsc mtdc model for sequential ac/dc power flow algorithms. IEEE Trans. Power Syst. 2012, 27, 821-829. [CrossRef]

12. Haileselassie, T.M.; Uhlen, K. Impact of dc line voltage drops on power flow of mtdc using droop control. IEEE Trans. Power Syst. 2012, 27, 1441-1449. [CrossRef]

13. Cao, J.; Du, W.; Wang, H.F.; Bu, S. Minimization of transmission loss in meshed ac/dc grids with vsc-mtdc networks. IEEE Trans. Power Syst. 2013, 28, 3047-3055. [CrossRef]

14. Haileselassie, T.M.; Uhlen, K. Primary frequency control of remote grids connected by multi-terminal hvdc. In Proceedings of the IEEE PES General Meeting, Providence, RI, USA, 25-29 July 2010; pp. 1-6.

15. Liu, Y.; Zhang, L.; Liang, H. Dc voltage adaptive droop control strategy for a hybrid multi-terminal hvdc system. Energies 2019, 12, 380. [CrossRef]

16. Haleem, N.M.; Rajapakse, A.D.; Gole, A.M.; Fernando, I.T. Investigation of fault ride-through capability of hybrid vsc-lcc multi-terminal hvdc transmission systems. IEEE Trans. Power Deliv. 2019, 34, 241-250. [CrossRef]

17. Nguyen, M.H.; Saha, T.K.; Eghbal, M. Master self-tuning vdcol function for hybrid multi-terminal hvdc connecting renewable resources to a large power system. IET Gener. Trans. Distrib. 2017, 11, 3341-3349. [CrossRef]

18. Guo, C.; Zheng, A.; Yin, Z.; Zhao, C. Small-signal stability of hybrid multi-terminal hvdc system. Int. J. Electr. Power Energy Syst. 2019, 109, 434-443. [CrossRef]

19. Bu, S.; Du, W.; Wang, H.; Liu, Y.; Liu, X. Investigation on economic and reliable operation of meshed mtdc/ac grid as impacted by offshore wind farms. IEEE Trans. Power Syst. 2017, 32, 3901-3911. [CrossRef]

20. Liang, J.; Jing, T.; Gomis-Bellmunt, O.; Ekanayake, J.; Jenkins, N. Operation and control of multiterminal hvdc transmission for offshore wind farms. IEEE Trans. Power Deliv. 2011, 26, 2596-2604. [CrossRef]

21. Silva, B.; Moreira, C.; Leite, H.; Lopes, J.P. Control strategies for ac fault ride through in multiterminal hvdc grids. IEEE Trans. Power Deliv. 2014, 29, 395-405. [CrossRef]

22. Reed, G.; Pape, R.; Takeda, M. Advantages of voltage sourced converter (vsc) based design concepts for facts and hvdc-link applications. In Proceedings of the 2003 IEEE Power Engineering Society General Meeting, Toronto, ON, Canada, 13-17 July 2003.

23. Zhao, Z.; Iravani, M. Application of GTO voltage source inverter in a hybrid hvdc link. IEEE Trans. Power Deliv. 1994, 9, 369-377. [CrossRef] 
24. Yuan, X.; Cheng, S. Performance analysis of a hybrid multi-terminal hvdc system. In Proceedings of the 2005 International Conference on Electrical Machines and Systems, Nanjing, China, 27-29 September 2005; pp. 2169-2174.

25. Yuan, X.; Cheng, S.J. Simulation study for a hybrid multi-terminal hvdc system. In Proceedings of the 2005/2006 IEEE/PES Transmission and Distribution Conference and Exhibition, Dallas, TX, USA, 21-24 May 2006; pp. 720-725.

26. Chen, X.; Sun, H.; Wen, J.; Lee, W.-J.; Yuan, X.; Li, N.; Yao, L. Integrating wind farm to the grid using hybrid multiterminal hvdc technology. IEEE Trans. Ind. Appl. 2011, 47, 965-972. [CrossRef]

27. Li, C.; Zhan, P.; Wen, J.; Yao, M.; Li, N.; Lee, W.-J. Offshore wind farm integration and frequency support control utilizing hybrid multiterminal hvdc transmission. IEEE Trans. Ind. Appl. 2014, 50, 2788-2797. [CrossRef]

28. Torres-Olguin, R.E.; Molinas, M.; Undeland, T. Offshore wind farm grid integration by vsc technology with lcc-based hvdc transmission. IEEE Trans. Sustain. Energy 2012, 3, 899-907. [CrossRef]

29. Krishnayya, P.; Lefebvre, S.; Sood, V.; Balu, N. Simulator study of multiterminal hvdc system with small parallel tap and weak ac systems. IEEE Trans. Power Appar. Syst. 1984, 103, 3125-3132. [CrossRef]

30. Athay, T.; Podmore, R.; Virmani, S. A practical method for the direct analysis of transient stability. IEEE Trans. Power Appar. Syst. 1979, 98, 573-584. [CrossRef]

31. Yoon, M.; Yoon, Y.-T.; Jang, G. A study on maximum wind power penetration limit in island power system considering high-voltage direct current interconnections. Energies 2015, 8, 14244-14259. [CrossRef]

32. Ferreira, C.M.; Barbosa, F.M.; Agreira, C.F. Transient stability preventive control of an electric power system using a hybrid method. In Proceedings of the 2008. 12th International Middle-East Power System Conference (MEPCON), Aswan, Egypt, 12-15 March 2008; pp. 141-145.

33. Siemens Power Technologies International. PSS/E 33.4 Model Library, 1st ed.; Siemens Power Technologies International: Schenectady, NY, USA, 2013

34. Pinto, R.T.; Rodrigues, S.; Bauer, P.; Pierik, J. Grid code compliance of vsc-hvdc in offshore multi-terminal dc networks. In Proceedings of the IECON 2013-39th Annual Conference of the IEEE Industrial Electronics Society, Vienna, Austria, 10-13 November 2013; pp. 2057-2062.

35. Amin, M.; Molinas, M.; Lyu, J.; Cai, X. Impact of power flow direction on the stability of vsc-hvdc seen from the impedances nyquist plot. IEEE Trans. Power Electron. 2016, 32, 8204-8217. [CrossRef]

(C) 2019 by the authors. Licensee MDPI, Basel, Switzerland. This article is an open access article distributed under the terms and conditions of the Creative Commons Attribution (CC BY) license (http://creativecommons.org/licenses/by/4.0/). 


\title{
Ride-Through Control Method for the Continuous Commutation Failures of HVDC Systems Based on DC Emergency Power Control
}

\author{
Chao Xiao ${ }^{1, *}$, Wei Han ${ }^{1}$, Jinxin Ouyang ${ }^{2}$, Xiaofu Xiong ${ }^{2}$ and Wei Wang ${ }^{2}$ \\ 1 State Grid Henan Electric Power Research Institute, Zhengzhou 450052, China; hnlhhw@126.com \\ 2 State Key Laboratory of Power Transmission Equipment \& System Security and New Technology, \\ Chongqing University, Chongqing 400044, China; exphujian@foxmail.com (J.O.); xc0212@foxmail.com (X.X.); \\ cquwangwei@cqu.edu.cn (W.W.) \\ * Correspondence: sngeet@163.com
}

Received: 13 August 2019; Accepted: 19 September 2019; Published: 2 November 2019

\begin{abstract}
Continuous commutation failures $(\mathrm{CFs})$ are serious malfunctions in line-commutated converter high-voltage direct current (HVDC) systems that cause the continuous and rapid sag of transmitted power and may threaten the stability of AC systems. The conventional emergency control strategies of AC systems exhibit difficulty in responding quickly and accurately. After suffering from continuous $\mathrm{CFs}$, the forced blocking of direct current (DC) converter to prevent AC system instability might also cause other adverse effects. This study proposes a ride-through control method to improve the endurance capability of AC systems against continuous CFs. An active power output model of inverter station under continuous CFs is built, while considering the process and mechanism of CFs. The impact of continuous DC power sag on the stability of sending-end system is analyzed through a four-area AC/DC equivalent model. A rolling calculation model for the power angle and acceleration area variations of the sending-end system during continuous $\mathrm{CFs}$ is established on the basis of model predictive control theory. A calculation method for the emergency power control reference is obtained by using the aforementioned models. Lastly, a ride-through control method for continuous CFs is developed by utilizing the emergency control of adjacent HVDC link. Simulation results show that the proposed control method can improve the endurance capability of an AC system to continuous $\mathrm{CFs}$ and reduce blocking risk in an HVDC link.
\end{abstract}

Keywords: High voltage direct current (HVDC); continuous commutation failures; DC blocking; emergency power support; stability

\section{Introduction}

With the rapid development of large-capacity high-voltage direct current (HVDC) transmission technology and the accelerating construction of HVDC projects, hybrid AC/DC power grids are rapidly developing [1,2]. For a large-scale asynchronous grid interconnected by DC systems, the dynamic response of a DC system exerts an increasingly significant impact on an AC grid due to the increased level of DC power transmission capacity. Commutation failure (CF) is a frequent dynamic event in an HVDC system that is generally caused by a disturbance in an AC grid. During CF, the transmitted power of a DC system is considerably reduced, which will affect the stability margin of an AC grid and seriously threaten the safe operation of a power system [3-5].

In recent years, the impact of HVDC CF on the safety and stability of an AC power grid has elicited increasing attention [6-12]. The influence mechanism of CF on the stability of a sending-end AC grid was investigated in [6]. To overcome the instability problem caused by $\mathrm{CF}$, control measures, such as setting a delay time when reclosing a device or implementing generator tripping from the 
sending-end grid, were proposed in [7,8] to improve the stability of an AC grid. In [9], a scheme for solving the problem of simultaneous and multiple HVDC CFs was proposed, and field tests verified that the system can satisfy power grid stability control requirements. The recovery time of generators after tripping was generally tens of minutes; however, the duration of a single CF only lasted 160-200 ms [10]. When the commutation process of a DC system returns to normal, the low power recovery rate will result in continuous power imbalance in an AC grid. In consideration of the fast power control capability of a DC system [11], a DC power compensation modulation method that is implemented after CF recovery was proposed in [12]; this method can reduce tripped generator capacity in a sending-end system. The aforementioned studies focused on control methods that can address the impact of a single $C F$.

If a receiving-end system is weak or if grid fault lasts for a long time, then continuous CFs may occur in an HVDC system. A power sag caused by continuous CFs has a short duration and a large amplitude. Thus, quantifying power variations during continuous CFs is difficult, and emergency control strategies for continuous CFs lack an effective quantitative control method. To avoid AC system instability during continuous $\mathrm{CFs}$, converter stations are forcibly blocked once $\mathrm{CF}$ frequency reaches a certain number of times. For example, in practical HVDC systems in East China, HVDC converter stations are blocked once continuous CFs are detected thrice [13]. However, if a DC system can recover after several continuous $\mathrm{CFs}$, then its forced blocking may lead to large-scale generator tripping, load shedding, and long-term recovery. If the stability of an AC system can be guaranteed by an emergency control strategy during continuous CFs, then the risk of DC blocking caused by continuous CFs can be reduced. Once the commutation process returns to normal, a system can recover quickly and ride through continuous CFs.

In a multi-paralleled DC system scenario, the risk of $\mathrm{CF}$ varies with different locations and a DC system without CF provides an important means of emergency power control for an AC system. Accordingly, a ride-through control method for continuous CFs in an HVDC system based on model predictive control (MPC) theory is presented in the current study. First, an active power output model of a DC inverter under continuous CFs is established by analyzing the CF process. Then, the impact of a transmitted power sag on the stability of a sending-end system during continuous CFs is determined. Subsequently, a rolling calculation model of the equivalent rotor angle and acceleration area variation of a sending-end system during DC continuous CFs is established in accordance with MPC theory. The calculation method for the emergency power control reference is then obtained by considering the aforementioned models. Finally, a ride-through control method for continuous CFs is developed through the emergency control of adjacent HVDC, case studies are performed in MATLAB/SIMULINK to verify the effectiveness of the proposed control method.

\section{Analysis of Power Characteristics during DC Continuous CFs}

Commutation failure is a frequent dynamic event in the LCC-HVDC system. CF is considered to occur when a thyristor valve that is supposed to be turned off, continues to conduct current without transferring it to the next valve in the firing sequence [14]. CF occurs in a rectifier only if the firing circuit fails.

For a six-pulse inverter, valves 1 to 6 are turned on in sequence at a normal interval of $60^{\circ}$. When CF occurs, CF from valves 1 to 3 is used as an example. If the voltage drop occurs before the triggering moment of the valve 3 , the valve 1 is not extinguished normally, current in valve 3 will decrease to zero and the valve will extinguish. When valve 4 fires next, because valve 1 is still conducting, a short circuit is placed across the DC side of the bridge. The zero DC voltage keeps the voltage across valve 5 negative so that valve 5 cannot conduct. Valve 4 is extinguished and valve 6 is ignited in the normal fashion [15]. For the period when valves 1 and 4 are both conducting, the inverter DC voltage is zero and the corresponding electrical angle is $120^{\circ}+\mu$, where, $\mu$ is the overlap angle. The reduction of the extinction angle and the increase in DC current during grid fault will trigger the 
extinction angle controller and the voltage-dependent current order limiter (VDCOL). If CF is within the range of DC regulation, then the CF process returns to normal; otherwise, continuous CFs occur.

In accordance with the DC converter station control equation, the DC voltage and transmitted active power at the inverter side can be expressed as follows:

$$
\begin{gathered}
U_{d}=N_{c}\left(1.35 U_{B} \cos \gamma-\frac{3}{\pi} X_{c} I_{d}\right) \\
P_{d}=N_{c}\left(1.35 U_{B} \cos \gamma-\frac{3}{\pi} X_{c} I_{d}\right) I_{d}
\end{gathered}
$$

where $N_{C}$ is the number of six-pulse thyristor bridge converter at inverter side, $U_{B}$ is the RMS voltage of AC system on the inverter side, $I_{d}$ is the DC current, $\gamma$ is the extinction angle of inverter, $X_{C}$ is commutating reactance, $U_{d}$ is the DC voltage at inverter side, $P_{d}$ is the transmitted active power by inverter station.

During AC voltage sag, the DC current reference value of line-commutated converter HVDC is determined by the VDCOL control characteristic:

$$
I_{d}^{\prime}= \begin{cases}I_{d l} & , U_{d} \leq U_{d l} \\ \frac{I_{d h}-I_{d l}}{U_{d h}-U_{d l}} U_{d}+\frac{U_{d h} I_{d l}-U_{d I} I_{d h}}{U_{d h}-U_{d l}}, & U_{d l}<U_{d} \leq U_{d h} \\ I_{d h} & , U_{d h} \leq U_{d}<U_{\text {rated }}\end{cases}
$$

where $I_{d l}$ and $I_{d h}$ are the minimum and maximum DC current reference value, respectively; $U_{d l}$ and $U_{d h}$ are the DC voltage thresholds value, $U_{\text {rated }}$ is the rated DC voltage.

Continuous CFs typically occur during the recovery process, and the maximum transmitted power during CF recovery is determined by the magnitude of AC fault voltage reduction and DC current. In accordance with (1), when the extinction angle $\gamma=0$, the maximum transmitted active power can be obtained by

$$
P_{d 1}=N_{c}\left(1.35 U_{B}^{\prime}-\frac{3}{\pi} X_{c} I_{d}^{\prime}\right) I_{d}^{\prime}
$$

where $U^{\prime}{ }_{B}$ is RMS voltage at the AC side of the inverter station at the initial time of grid fault, $\mathrm{P}_{d 1}$ is maximum transmitted active power during grid fault.

Given that the period of the CF recovery process is short and the power variation rate is high, the power recovery process can be approximated as linear. Accordingly, the variation in transmitted power by a DC inverter station under continuous CFs is shown in Figure 1, where, $P_{d 0}$ is the transmitted active power by inverter station under steady state conditions. The transmitted power sag duration $\Delta T$ caused by $C F$ is affected by the control parameters of the rectifier and inverter station, which are generally 160-200 ms [16]. The duration of the zero transmitted power $\Delta T_{1}$ is generally $10 \mathrm{~ms}$ based on the period when DC voltage is zero during CF. When continuous CFs occur, the amplitude of the AC voltage reduction will be greater, the transmitted power recovery peak value $P_{d 1}$ will be smaller, and CF recovery time will be shorter. When the commutation process returns to normal, DC transmitted power will be restored to the steady-state value $P_{d 0}$.

During continuous CFs, the transmitted active power of a DC inverter can be expressed as:

$$
P_{d}=\left\{\begin{array}{l}
P_{d 0} \quad t \in\left[0, t_{1}\right) \\
0 \quad, t \in\left[t_{1}, t_{1}+j \Delta T_{1}+(j-1) \Delta T_{2}\right) \\
\frac{P_{d 1}\left(t-t_{1}-j \Delta T_{1}-(j-1) \Delta T_{2}\right)}{\Delta T_{2}}, t \in\left[t_{1}+j \Delta T_{1}+(j-1) \Delta T_{2}, t_{1}+j \Delta T_{1}+j \Delta T_{2}\right)(j<N) \\
\frac{P_{d 0}\left(t-t_{1}-j \Delta T_{1}-(j-1) \Delta T_{2}\right)}{\Delta T_{2}}, t \in\left[t_{1}+j \Delta T_{1}+(j-1) \Delta T_{2}, t_{1}+j \Delta T_{1}+j \Delta T_{2}\right)(j=N) \\
P_{d 0}, t \in\left[t_{1}+N \Delta T_{1}+N \Delta T_{2}, \infty\right)
\end{array}\right.
$$


where $t_{1}$ is the time of first CF occurs, and $j$ is the frequency of continuous CFs, $j=1,2,3, \ldots, N$.

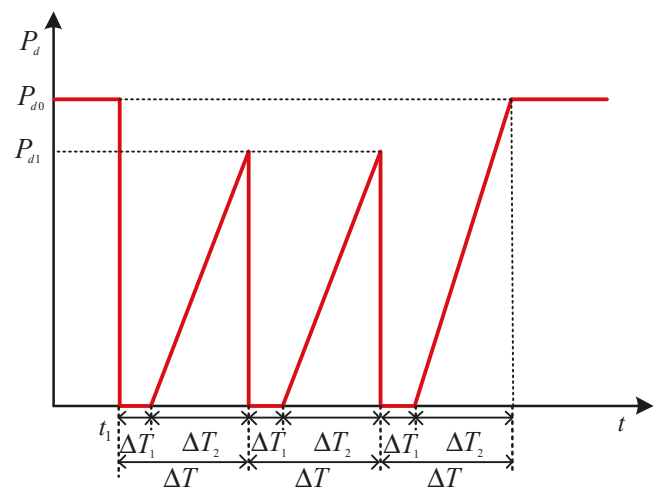

Figure 1. Transmitted power of DC inverter under continuous commutation failures (CFs).

\section{Effect of Continuous CFs on Sending-end Grid}

Figure 2 shows a schematic of a four-area AC/DC interconnected equivalent model. Under steady-state operation, the sending-end and receiving-end grids are connected by two DC links. $x_{1}$ and $x_{2}$ are the equivalent reactance of generators G1 and G2, respectively; $x_{12}$ is the tie line reactance between bus B1 and bus B2; $E_{s 1} \angle \delta_{s 1}$ and $E_{s 2} \angle \delta_{s 2}$ are the internal potential and rotor angle of equivalent generators $\mathrm{G} 1$ and $\mathrm{G} 2$, respectively; $U_{1}$ and $U_{2}$ are the voltage amplitude at bus $\mathrm{B} 1$ and B2, respectively; $\theta_{1}$ and $\theta_{2}$ are the phase angle at bus B1 and B2, respectively; $P_{G 1}$ and $P_{G 2}$ are the output mechanical power of the equivalent generators, respectively; $P_{L 1}$ and $P_{L 2}$ are the load power represented by L1 and $\mathrm{L} 2$, respectively; $P_{12}$ is the transmitted power from bus $\mathrm{B}_{1}$ to bus $\mathrm{B}_{2} ; P_{D C 1}$ and $P_{D C 2}$ are the transmitted power by $\mathrm{DC}_{1}$ and $\mathrm{DC}_{2}$ inverter station, respectively.

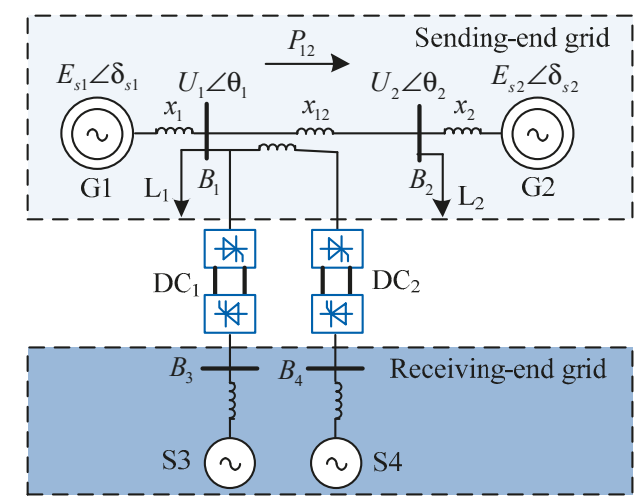

Figure 2. Equivalent model of AC/DC interconnected system.

The rotor motion equation of the equivalent generators G1 and G2 can be expressed by [17]

$$
\left\{\begin{array}{l}
\frac{T_{J 1}}{\omega_{0}} \frac{d^{2} \delta_{s 1}}{d t^{2}}=P_{G 1}-P_{D C}-P_{L 1}-\frac{U_{1} U_{2} \sin \left(\theta_{1}-\theta_{2}\right)}{x_{12}} \\
\frac{T_{J 2}}{\omega_{0}} \frac{d^{2} \delta_{s 2}}{d t^{2}}=P_{G 2}-P_{L 2}+\frac{U_{1} U_{2} \sin \left(\theta_{1}-\theta_{2}\right)}{x_{12}}
\end{array}\right.
$$

where $T_{J 1}$ and $T_{J 2}$ are the inertia time constants of equivalent generator, respectively. $\omega_{0}$ is the rated angular velocity, $P_{D C}$ is the sum of the active power transmitted by all DC links. 
Assume that the interconnection between areas 1 and 2 is weak, then the reactance of tie line $x_{12}$ is considerably larger than equivalent generator reactance. Then, $\theta_{1} \approx \delta_{s 1}$ and $\theta_{2} \approx \delta_{s 2}$ can be approximated.

By subtracting the two formulas in (6), the equivalent single machine rotor motion equation can be given by

$$
\frac{d \delta^{2}}{d t^{2}}=P_{m}-P_{e \max } \sin \delta
$$

where $\delta$ is the rotor angle deviations between G1 and $\mathrm{G} 2, \delta=\delta_{s 1}-\delta_{s 2}$.

The equivalent mechanical power $P_{m}$ can be obtained as

$$
P_{m}=\left(\frac{P_{G 1}}{M_{1}}-\frac{P_{G 2}}{M_{2}}\right)-\left(\frac{P_{L 1}}{M_{1}}-\frac{P_{L 2}}{M_{2}}\right)-\frac{P_{D C}}{M_{1}}
$$

The peak value of equivalent electromagnetic power $P_{e \max }$ can be obtained as

$$
P_{\text {emax }}=\left(\frac{1}{M_{1}}+\frac{1}{M_{2}}\right) \frac{U_{1} U_{2}}{x_{12}}
$$

where $M_{1}=T_{J 1} / \omega_{0}, M_{2}=T_{J 2} / \omega_{0}$.

Assume that $j$ times continuous CFs are caused by a short circuit fault at bus B3. Then, the voltage magnitude at bus $\mathrm{B} 4$ is less affected and $\mathrm{DC}_{2}$ can continue operating in normal state. In accordance with (7-9), the power characteristic curve during the continuous CFs of DC $_{1}$ is illustrated in Figure 3. Where, $A_{a}$ and $A_{d}$ are acceleration area and deceleration area caused by continuous CFs.

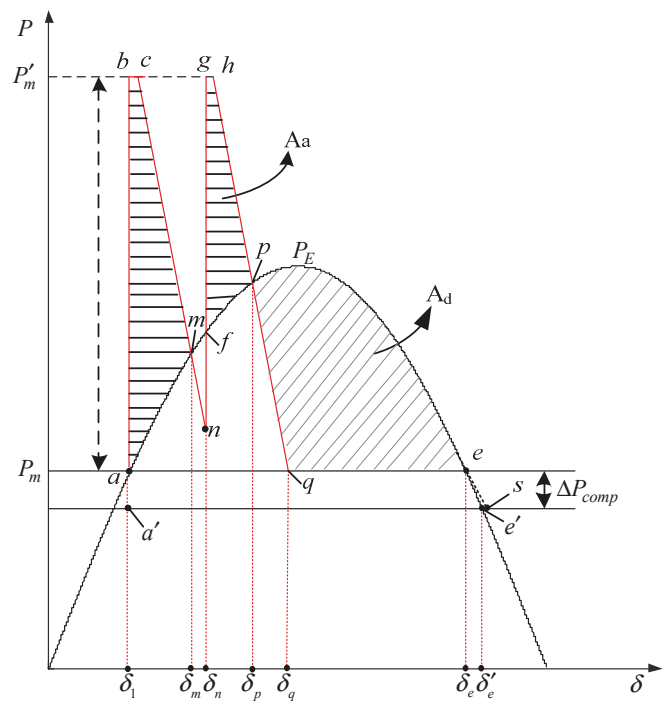

Figure 3. Power characteristic curve of sending-end grid under continuous CFs.

Before CF occurs, the steady-state operating point is $a$ and its corresponding rotor angle is $\delta_{1}$. As shown in (7-9), continuous CFs cause a continuous sag of the power transmitted by $\mathrm{DC}_{1}$, thereby increasing the equivalent mechanical power $P_{m}$ to $P_{m}^{\prime}$. During the period when the equivalent mechanical power is greater than the electromagnetic power, the rotor accelerates and the rotor angle $\delta$ is gradually increased. Consequently, the operating point moves along the power curve from point $a$ to point $m$, and the corresponding acceleration area is $A_{a b c m}$. During CF recovery, the equivalent electromagnetic power becomes gradually higher than the equivalent mechanical power, and the 
rotor starts to decelerate. However, the rotor angle $\delta$ will continue increasing to point $f$, and the corresponding deceleration area is $A_{m n f}$.

Similarly, the rotor angle $\delta$ in the $j$-th CF process will gradually increase during the period when the equivalent mechanical power $P_{m}$ is higher than the equivalent electromagnetic power due to the transmitted power sag. The operating point $f$ moves along the power curve to point $p$, and the acceleration area is $A_{f g h p}$. After the time of point $p$, the equivalent mechanical power is less than the electromagnetic power. The rotor speed decelerates, but the rotor angle continues to increase gradually. The operating point continues to move along the electromagnetic power curve from point $p$ until the deceleration area becomes equal to the acceleration area. Thereafter, the rotor angle reaches its maximum value and starts to decrease gradually.

If the deceleration area $A_{p q e}$ remains smaller than the cumulative acceleration area when the operating point moves to point $e$, then the sending-end system will lose stability. The requirement for maintaining the stability of the sending-end grid during continuous CFs is that the cumulative acceleration area should be smaller than the deceleration area; that is,

$$
A_{a b c m}+A_{f g h p}<A_{p q e}
$$

\section{Emergency Power Support Control for System Transient Stability}

\subsection{Control Principle}

Given the constant variation in equivalent mechanical power during continuous CFs, an accurate calculation of the rotor angle and the acceleration area is difficult. Therefore, the equivalent mechanical power and electromagnetic power curve are piecewise linearized following a certain step size, and the power angle and acceleration area variations of the sending-end system can be obtained point-by-point. When CF is detected, the emergency power control reference is obtained on the basis of the relative magnitudes of the acceleration area and deceleration area. According to the model predictive control theory [18], the feedback correction calculation of the rotor angle and acceleration area variations of the sending-end system considering the emergency power control is performed. Subsequently, a closed loop rolling control process is achieved. When the next CF is detected, the maximum rotor angle variation of the sending-end system obtained in the first CF process is set as the initial rotor angle for the next $\mathrm{CF}$, and the deceleration area is corrected. The amount of emergency power control can be calculated to ensure the stability of the sending-end system. Therefore, the DC system that occurs during continuous CFs should not be forced blocked immediately, and DC blocking risk due to continuous CFs is reduced. The basic principle of the proposed emergency power control is illustrated in Figure 4.

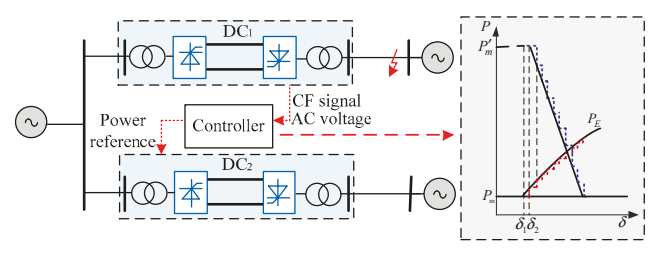

Figure 4. DC emergency power control schematic diagram.

\subsection{Calculation of Emergency Power Control Reference}

The emergency power control reference can be obtained as follows.

Step 1: Following (6-8), the rotor angle $\delta_{1}$ that corresponds to the steady-state operating point $a$ and the rotor angle $\delta_{e}$ that corresponds to the stability critical point $e$ can be obtained. When the first CF signal is detected, the number of continuous CFs $j$ is set as 1 . The variation process of the equivalent mechanical power and the electromagnetic power caused by one CF is divided into $n$ cycles for piecewise 
linearization in steps of $\Delta t$, where $\Delta t$ is set as $10 \mathrm{~ms}$. Thus, the sampled horizon is $\left[t_{1}, t_{2}, t_{3}, \cdots, t_{n}\right]$, where $t_{1}$ is the time when the first CF is detected, and $n=\Delta T / \Delta t, t_{n}=t_{1}+(n-1) \Delta t . P^{\prime}{ }_{m i}$ and $P_{e \max } \sin \delta_{i}$ are the equivalent mechanical power and the electromagnetic power that correspond to sampling point $i$, respectively.

Let $i=1$. By integrating the formula (7) for rotor motion, the analytical expression of $\delta_{i+1}$ can be given by

$$
\delta_{i+1}=\frac{1}{2}\left(P_{m i}^{\prime}-P_{e \max } \sin \delta_{i}\right) \Delta t^{2}+\delta_{i}
$$

In accordance with (11), the sequence of the equivalent rotor angle of the sending-end system that corresponds to each sample point in the process of the first CF can be obtained as $\left[\delta_{1}, \delta_{2}, \cdots, \delta_{m}, \cdots, \delta_{n}\right]$, where $\delta_{m}$ represents the maximum rotor angle value during the acceleration process.

Step 2: The estimated acceleration area for the $j$-th CF can be given by

$$
A_{a_{-j} j}=\sum_{i=1}^{m-1} \int_{\delta_{i}}^{\delta_{i+1}}\left(P^{\prime}{ }_{m i}-P_{e \max } \sin \delta\right) d \delta
$$

The deceleration area $A_{\mathrm{d}}$ in the interval $\left(\delta_{n}, \delta_{e}\right)$ can be obtained as

$$
A_{d}=\int_{\delta_{n}}^{\delta_{e}}\left(P_{e \max } \sin \delta-P_{m}\right) d \delta
$$

Step 3: In the calculation of the deceleration area in equation (13), the deceleration area $A_{m n f}$ in each recovery process of CF is neglected. Therefore, a certain stability margin can be guaranteed with the emergency control reference obtained by directly comparing the acceleration area with deceleration area. If $A_{a_{-} j} \leq A_{d}$, then the emergency power control reference is set as zero, $P_{e m_{-} j}=0$. If $A_{a_{-} j}>A_{d}$, then the emergency power control reference $P_{e m_{-} j}$ is obtained by comparing the relative magnitudes of $A_{a_{-} j}$ and $A_{d}$.

As shown in Figure 3, the unstable points before and after the emergency power control is implemented are assumed to be $e$ and $e^{\prime}$, respectively. The electromagnetic power variation in this interval can be approximated by a straight-line $e s$. The intersection of the electromagnetic power and the mechanical power is point $e$, and the tangential slope of the electromagnetic power curve at point $e$ is $k$; thus,

$$
k=\frac{P_{e m_{-} j}}{\delta_{e}-\delta_{e^{\prime}}}
$$

To achieve the acceleration area, the deceleration area that should be increased under emergency power control is

$$
\Delta A_{d_{-} j}=A_{a_{-} j}-A_{d} \approx \frac{1}{2}\left(\delta_{e}+\delta_{e^{\prime}}-2 \delta_{1}\right) P_{e m_{-} j}
$$

When (14) and (15) are combined, the rotor angle value $\delta_{e^{\prime}}$ at point $e^{\prime}$ and the emergency power control reference $P_{e m_{-} j}$ can be obtained. $P_{e m_{-} j}$ can be calculated as

$$
P_{e m_{-} j}=\sqrt{-2 k\left(A_{a_{-} j}-A_{d}\right)+k^{2}\left(\delta_{e}-\delta_{1}\right)^{2}}+k\left(\delta_{e}-\delta_{1}\right)
$$

Step 4: If the maximum emergency power support capacity $\Delta P_{\mathrm{DC} \_ \text {max }}$ of $\mathrm{DC}_{2}$ is equal to or higher than $P_{e m \_j}$, then $P_{e m \_j}$ is selected as the DC emergency control reference. Otherwise, if $\Delta P_{\text {DC_max }}$ is less than $P_{e m \_}$, then the maximum DC emergency control capacity is applied. The selective tripping of generating units should also be used to satisfy the stability control requirement, and the minimum generator tripping capacity is $\Delta P_{\text {comp }}=P_{e m_{-} j}-\Delta P_{\mathrm{DC} \_ \text {max }}$.

Step 5: In accordance with (11) and considering the obtained emergency power control reference $P_{e m_{-} j}$, the rotor angle variation sequence of the $j$-th CF period is corrected as $\left[\delta_{1}, \delta^{\prime}{ }_{2}, \cdots, \delta_{m}^{\prime}, \cdots, \delta_{n}^{\prime}\right]$. 
Considering the emergency power control, the acceleration area $A_{a_{-} j}^{\prime}$ is given as

$$
A^{\prime}{ }_{a_{-} j}=\sum_{i=1}^{m-1} \int_{\delta^{\prime} i}^{\delta^{\prime}{ }_{i+1}}\left(P^{\prime}{ }_{m i}-P_{e m_{-} j}-P_{e \max } \sin \delta\right) d \delta
$$

Step 6: If no continuous $\mathrm{CF}$ is detected, then the emergency power control will exit; otherwise, if continuous $\mathrm{CFs}$ are detected, then let $j=j+1$ and set the maximum rotor angle variation calculated in the $(j-1)$-th CF process as the initial rotor angle of $j$-th CF. Equation (18) indicates that the equivalent rotor angle variation of the sending-end system that corresponds to each sampling point during the $j$-th CF can be calculated as $\left[\delta_{1}, \delta_{2}, \cdots, \delta_{m}, \cdots, \delta_{n}\right]$.

$$
\delta_{i+1}=\frac{1}{2}\left(P_{m i}^{\prime}-P_{e m_{-j}-1}-P_{e \max } \sin \delta_{i}\right) \Delta t^{2}+\delta_{i}
$$

Therefore, the acceleration area for the $j$-th CF can be given by

$$
A_{a_{-} j}=\sum_{i=1}^{m-1} \int_{\delta_{i}}^{\delta_{i+1}}\left(P_{m i}^{\prime}-P_{e m_{-} j-1}-P_{e \max } \sin \delta_{i}\right) d \delta
$$

The accumulated acceleration area produced by continuous CFs is

$$
A_{a}=A_{a_{-} j}+\sum_{j=1}^{j-1} A^{\prime}{ }_{a_{-} j}
$$

The deceleration area $A_{d_{-j}}$ in the interval $\left(\delta_{n}, \delta_{e^{\prime}}\right)$ can be obtained as:

$$
A_{d_{-} j}=\int_{\delta_{n}}^{\delta_{e^{\prime}}}\left(P_{e \max } \sin \delta-P_{m}-P_{e m_{-} j-1}\right) d \delta
$$

Step 7: By combining the acceleration and deceleration areas after the $j$-th $\mathrm{CF}$, the additional emergency power control reference $P_{e m_{-} j}$ can be calculated using (16). Thus, the emergency power control reference when the $j$-th $\mathrm{CF}$ occurs can be obtained by

$$
P_{e m}=P_{e m_{-} j}+\sum_{j=1}^{j-1} P_{e m \_j}
$$

In accordance with the obtained emergency power control reference, return to Step 5 for the correct calculation of the rotor angle variation and the acceleration area.

If no continuous CFs are detected, then the emergency power control will exit; otherwise, Steps (6-7) will be repeatedly executed. If $\delta_{n} \geq \delta_{e^{\prime}}$, then the stability margin of the sending-end system is low, the DC converter should be actively blocked, and the stability control strategy should be adopted. On the basis of the aforementioned emergency power control strategy during continuous CFs, the stability of the first swing of the sending-end grid can be improved to the greatest extent, and the amount of generator tripping can be reduced. Furthermore, the risk of converter blocking due to the first swing angle instability of the sending-end grid during continuous CFs can be reduced. If the continuous CF process can return to normal, then the system can immediately recover to normal operation.

When continuous CFs occurs in one of DC links, the flowchart of DC emergency power control is shown in Figure 5. During continuous CFs, the emergency power support control of an adjacent non-CF DC system can reduce the equivalent mechanical power variation and improve the first swing transient stability of the sending-end system; however, the HVDC emergency control should exit on 
time to avoid the adverse effects on the reverse swing stability $[19,20]$. Considering that the first swing instability mode after the disturbance generally occurs approximately $1.5 \mathrm{~s}$ after the fault [21], the exit time of the DC emergency power control is set as $1.5 \mathrm{~s}$ after the fault. In addition, considering the time delay of CF detection and AC voltage acquisition, the implementation time of the proposed control method will slightly lag behind the actual occurrence time of CF. However, the control method is a continuous dynamic adjustment process. The time delay due to signal acquisition and transmission does not affect the regulation trend of the emergency control.

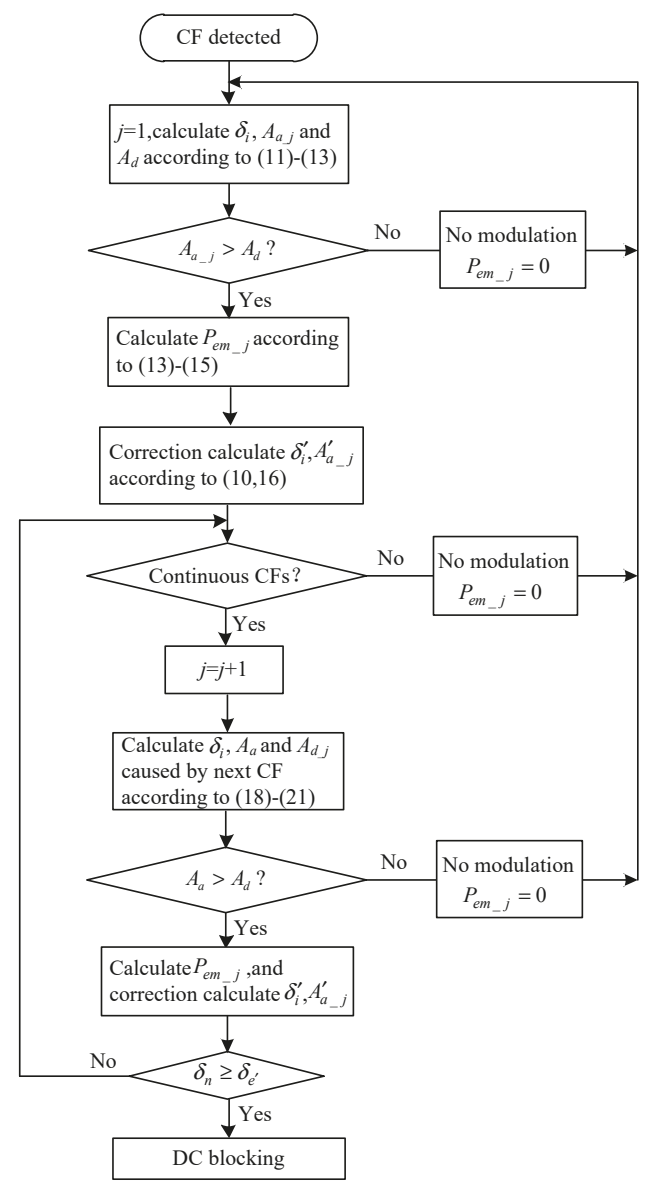

Figure 5. Flow chart of DC emergency power control.

\section{Simulation Analysis}

To validate the performance of the proposed control method, case studies on the AC/DC interconnection system (Figure 2) are conducted using MATLAB/Simulink. The system parameters are as follows. The system base capacity is $100 \mathrm{MW}$, the rated frequency is $50 \mathrm{~Hz}$, and the RMS voltage of AC grid is $230 \mathrm{kV}$. Four synchronous generators are found in G1. Two of the generators have an output power of 10.0 p.u., capacity of the other two generators are 2.0 p.u. and 4.0 p.u., respectively. G2 contains a synchronous generator with an output power of 10.0 p.u. The inertia time constants of each generator in sending-end grids are $3.2 \mathrm{~s}$. The receiving-end grids S3 and S4 are modeled with the voltage sources and series impedance for the sake of simplicity, and the short circuit ratio 
(SCR) of receiving-end grid is 2.5, respectively. Load capacity of L1 and L2 are 2.2 p.u. and 13.8 p.u., respectively. Each DC link adopts 12-pulse converter and DC rated transmitted power is 10.0 p.u., respectively. The rectifier side adopts the constant current control, while the inverter side adopts the constant extinction angle control and constant current control. The reactance $x_{12}$ of tie-line between bus B1 and B2 is $87 \Omega$. The parameters of VDCOL are $I_{d l}$ and $I_{d h}$ are 0.5 p.u. and 1.0 p.u., respectively; $U_{d l}$ and $U_{d h}$ are 0.5 p.u. and 0.9 p.u., respectively. The maximum recovery period of single CF is $160 \mathrm{~ms}$. The DC emergency power control reference $\Delta P_{\mathrm{DC} \_ \text {max }}$ is limited to 1.2 times of the rated active power to avoid the considerable effect of the DC emergency power control on the voltage magnitude at the AC grid. That is, the maximum emergency power control amount of the DC converter is 12.0 p.u.

A three-phase short circuit occurs at bus B3 at $15 \mathrm{~s}$ and is cleared $0.4 \mathrm{~s}$ later. The RMS voltage of bus $\mathrm{B} 3$ is reduced to 0.94 p.u., and the short-circuit fault causes continuous $C F$ s at the $\mathrm{DC}_{1}$ inverter station. Figure 6 presents the simulated output power and extinction angle of the $\mathrm{DC}_{1}$ inverter station. As shown in the figure, three continuous $\mathrm{CFs}$ at the $\mathrm{DC}_{1}$ inverter are caused by the short-circuit fault and lead to the continuous DC-transmitted power sag. The maximum recovery power during continuous CF $P_{d c 1}=9.7$ p.u. can be calculated using (4). The red dotted line in Figure 6a represents the output power of the inverter calculated using (5), which is basically consistent with the simulated power waveform.

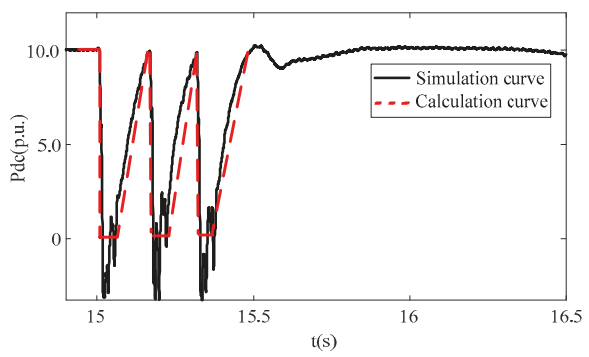

(a) Output power

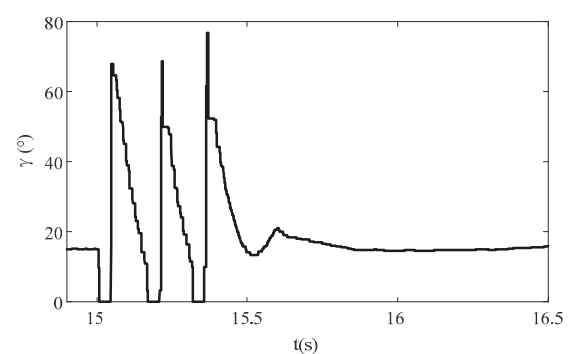

(b) Extinction angle

Figure 6. Operation characteristic of $\mathrm{DC}_{1}$ under continuous $\mathrm{CFs}$.

Figure 7 shows the transmitted power and extinction angle of the $\mathrm{DC}_{2}$ inverter station. Under the influence of the continuous $\mathrm{CFs}$ of $\mathrm{DC}_{1}$, the delivered active power and extinction angle of the $\mathrm{DC}_{2}$ inverter output fluctuate slightly, and power fluctuation is approximately $5 \%$ of the rated transmitted power. The extinction angle does not decrease considerably, and no $\mathrm{CF}$ occurs at the $\mathrm{DC}_{2}$ inverter.

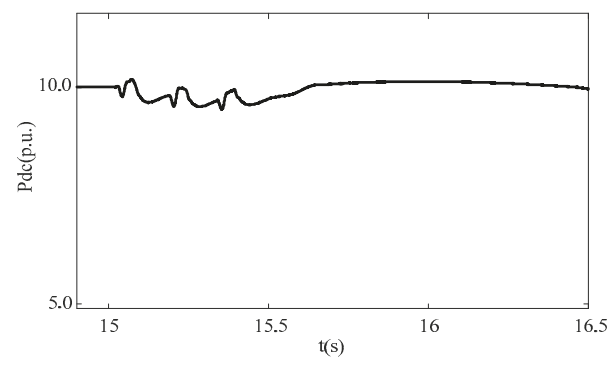

(a) Output power

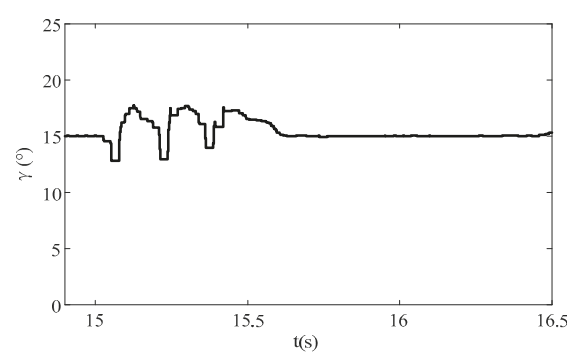

(b) Extinction angle

Figure 7. Operation characteristic of $\mathrm{DC}_{2}$ under continuous $\mathrm{CFs}$.

The variation in rotor angle difference between G1 and G2 is depicted in Figure 8. The continuous DC power sag causes the first swing angle instability in the sending-end system. Given that three 
occurrences of continuous CFs will result in the instability of the sending-end system, DC should be blocked before the third CF occurrence and a corresponding generator tripping strategy should be adopted to ensure the stability of the sending-end system.

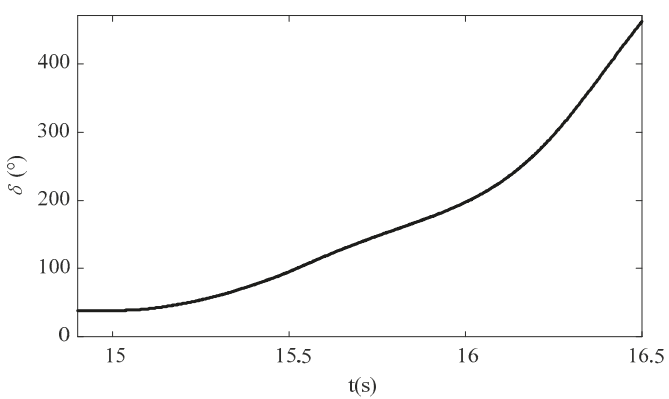

Figure 8. Rotor angle difference between G1 and G2.

\subsection{Simulation Comparison under Different Control Methods}

Different emergency power control methods are adopted for comparison to verify the effectiveness of the proposed control method. The DC power energy compensation modulation method adopted in [12] is selected as the conventional control method (Case 1). The emergency control reference is calculated and implemented at the end of the continuous CFs. The power control reference of $\mathrm{DC}_{2}$ is 12.0 p.u. based on the control method, and the auxiliary generator tripping of 4.0 p.u. should be implemented in Area 1. In accordance with the emergency power control method (Case 2) proposed in Section 4, the exit time of the DC emergency power control is set as $1.5 \mathrm{~s}$ after the fault. Figure 9 shows the variation in delivered power of the $\mathrm{DC}_{2}$ inverter and the equivalent rotor angle under different control methods.

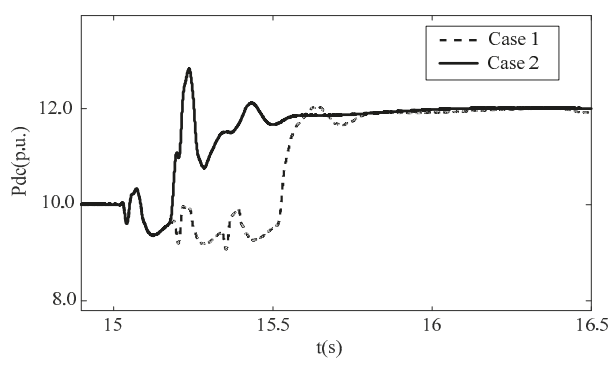

(a) Delivered power by inverter of $\mathrm{DC}_{2}$

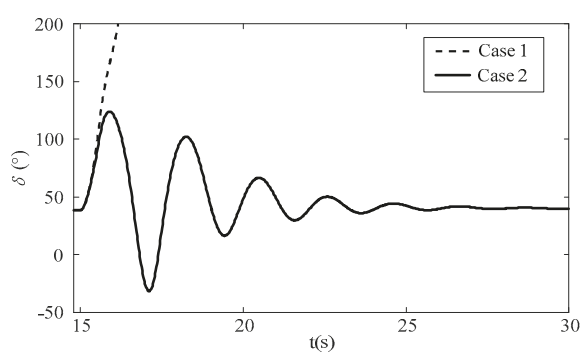

(b) Rotor angle difference between G1 and G2

Figure 9. Control effect under different control method.

The simulation results presented in Figure 9 indicate that if the emergency power control is implemented after the continuous CFs, then the rotor angle of the sending-end grid will lose stability. The acceleration and deceleration areas are calculated in real time on the basis of the proposed calculation method of the emergency control reference. The emergency power control is started once the second CF is detected, and the DC power control reference is adjusted to 12.0 p.u. to ensure the stability of the first swing of the sending-end system. Once the commutation process returns to normal, the system can immediately recover to normal operation. Compared with the conventional control method, the proposed emergency power control can be enabled in advance, and thus, the system stability margin can avoid insufficiency due to an excessive power angle change 
at the end of continuous CFs. Figure 10 shows the transmission power and extinction angle of $\mathrm{DC}_{1}$ under the proposed emergency power control. It can be seen that the proposed emergency control does not affect the operating characteristics of $\mathrm{DC}_{1}$.

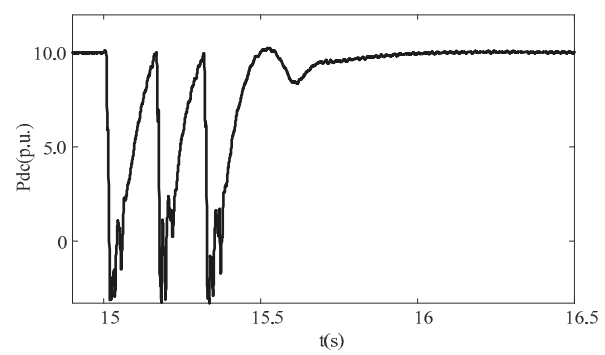

(a) Output power

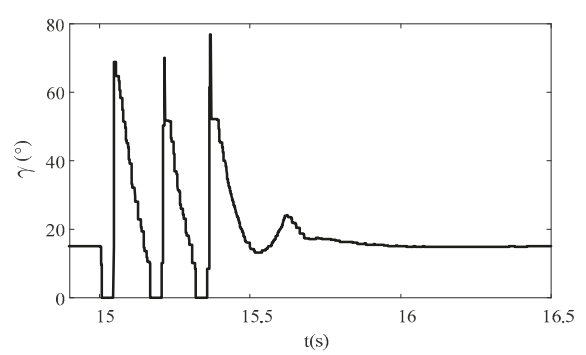

(b) Extinction angle

Figure 10. Operation characteristic of $\mathrm{DC}_{1}$ under continuous $\mathrm{CFs}$.

\subsection{Simulation Comparison under Different Capacity Ratios}

In order to verify the adaptability of the proposed control method under different DC capacity ratios, the transmitted capacity of $\mathrm{DC}_{1}$ is adjusted to 6.0 p.u. and generator capacity in Area 1 should be correspondingly reduced 4.0 p.u. Similarly, a three-phase short circuit occurs at bus B3 at $15 \mathrm{~s}$ and is cleared $0.4 \mathrm{~s}$ later. Three continuous $\mathrm{CFs}$ of $\mathrm{DC}_{1}$ are produced by this short-circuit fault. Figure 11 shows the variation in output power of the $\mathrm{DC}_{2}$ inverter and the equivalent rotor angle under different control methods with varying DC capacity ratios. Figure 12 shows the transmission power and extinction angle of $\mathrm{DC}_{1}$ under the proposed emergency power control. As shown in Figure 11, the continuous sag of DC power causes the instability of first swing in the sending-end system. The instability of the sending-end gird can be avoided using both control methods. In particular, the conventional control method improves the $\mathrm{DC}_{2}$ control reference to 12.0 p.u. and the 2.0 p.u. generator will be tripped in Area 1. Using the proposed control method, the emergency power control of $\mathrm{DC}_{2}$ can be enabled at the initiation time of the third $\mathrm{CF}$, and the emergency power control reference of $\mathrm{DC}_{2}$ is approximately 12.0 p.u., which ensures the stability of the sending-end grid. Compared with the conventional control method, the proposed control method can reduce generator tripping capacity at the sending-end grid. The simulation results show that the threshold time and control reference of the proposed emergency power control depend not only on the times of CFs, but also on the transmission capacity of DC system where continuous $\mathrm{CFs}$ occur.

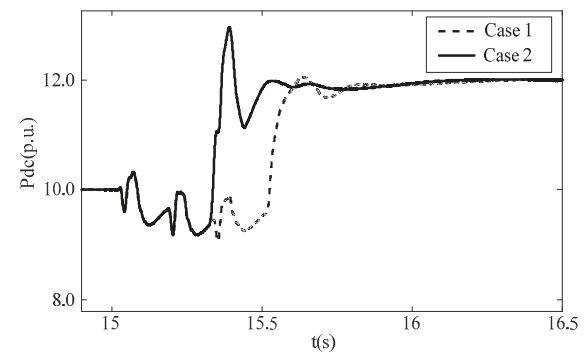

(a) Delivered power by inverter of $\mathrm{DC}_{2}$

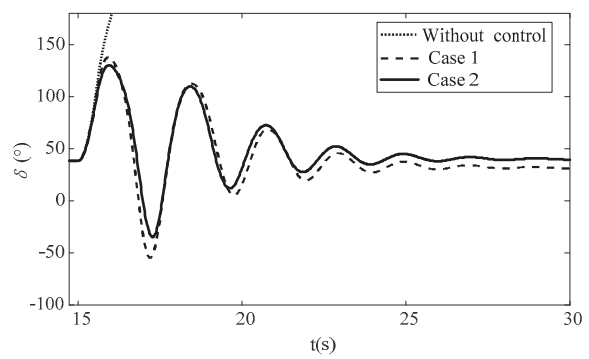

(b) Rotor angle difference between G1 and G2

Figure 11. Control effect under different control method. 


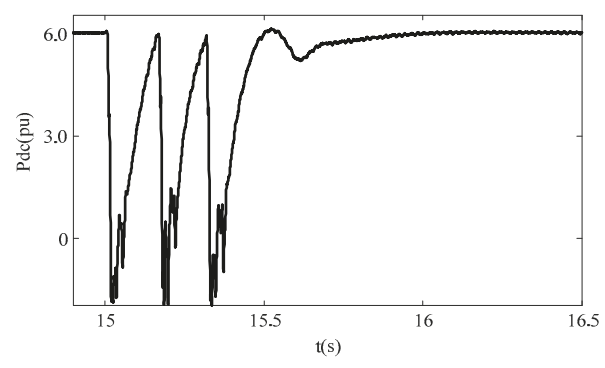

(a) Output power

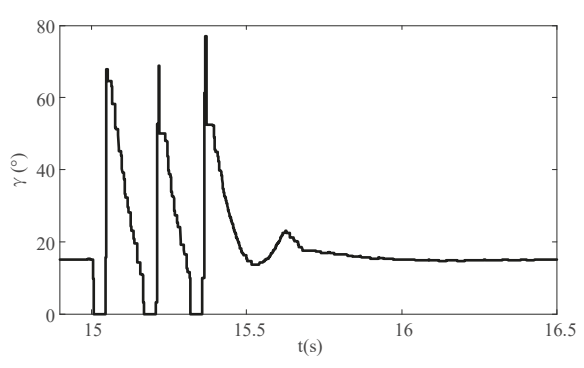

(b) Extinction angle

Figure 12. Operation characteristic of $\mathrm{DC}_{1}$ under continuous $\mathrm{CFs}$.

\subsection{Influence of Reactive Power Variation on the Control Effect}

Large sag of the active power transmitted by the DC system during continuous CFs is the key factor that cause the transient angle instability of the sending-end grid. However, a large variation in transmission power will also affect the reactive power characteristics at AC side of rectifier station. The influence of reactive power during CF on the sending-end AC system is mainly reflected in the transient overvoltage resulted by reactive power surplus of rectifier station [22]. The transient overvoltage at the rectifier side will increase the equivalent electromagnetic power peak of the sending-end gird to a certain extent, which causes the decrease of acceleration area and the increase of deceleration area during continuous CFs. Thus, by ignoring the influence of reactive power surplus in the proposed emergency control reference calculation method, the stability margin at the sending-end grid can be increased.

In order to verify the influence of reactive power surplus during continuous CFs on the proposed control, on the basis of the proposed control method, the reactive power compensation of 80 Mvar is inputted and removed during continuous $\mathrm{CFs}$, respectively. Different power angle variation at sending-end grid can be obtained as shown in Figure 13. It can be seen that the minimum peak value of rotor angle during the first swing is achieved under the case of inputted reactive power compensation. Considering that the simulation results in Figures 9 and 11, actually, are obtained under the influence of reactive power variation. Therefore, ignoring the influence of reactive power during continuous CFs in the calculation method can increase the stability margin of the sending-end grid, which will improve the control effect of proposed control method.

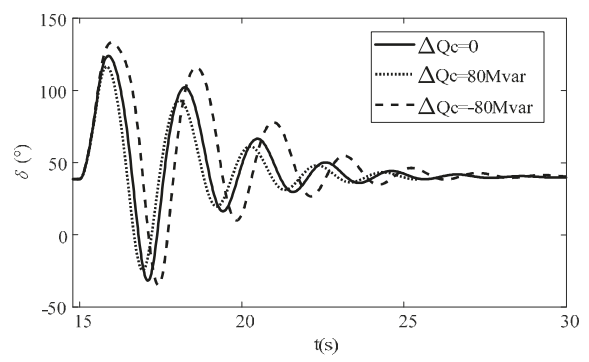

Figure 13. Comparison of control effects under reactive power variation at rectifier side.

\section{Conclusions}

In large-scale HVDC asynchronous interconnected power systems, continuous CFs will result in the continuous and rapid sag of DC transmission power and threaten the stability of grid. This paper presented a ride-through control method to improve the endurance capability of AC systems against 
continuous $\mathrm{CFs}$ To quantify the influence of continuous $\mathrm{CFs}$ on the stability of the sending-end grid, an active output model of a DC inverter station during continuous CFs is established. In order to improve the ride through capacity during the continuous commutation failures, a rolling calculation model of the rotor angle and acceleration area of the sending-end grid during continuous CFs is established in accordance with MPC theory. On this basis, a calculation method for the emergency power control reference value is obtained. Simulation results have demonstrated this control method can improve the endurance capability of $\mathrm{AC}$ systems against continuous $\mathrm{CFs}$, reduce the blocking risk of the DC converter during continuous $\mathrm{CFs}$, and ride through continuous $\mathrm{CFs}$.

Author Contributions: C.X., X.X., J.O. proposed the core idea and developed the models; C.X. and W.W. performed the simulations and analyzed the data; W.H. and J.O. revised the paper; C.X. contributed to the writing of this manuscript.

Funding: This work has been supported by the National Key R\&D Program of China(2016YFB0900600), Technology Projects of State Grid Corporation of China(52170218000M).

Conflicts of Interest: The authors declare no conflict of interest.

\section{Nomenclature}

$U_{d} \quad$ DC voltage at inverter side

$I_{d} \quad$ DC current

$N_{c} \quad$ Number of six-pulse thyristor bridge converter at inverter side

$U_{B} \quad$ RMS voltage of AC system on the inverter side

$\gamma \quad$ Extinction angle of inverter

$X_{\mathrm{c}} \quad$ Commutating reactance.

$I_{d l}, I_{d h} \quad$ The minimum and maximum DC current reference value

$U_{d l}, U_{d h} \quad$ DC voltage thresholds value

$U_{\text {rated }} \quad$ Rated DC voltage

$P_{d}$

$P_{d 0}$

Transmitted active power of DC inverter

Transmitted active power of DC inverter under steady state conditions

Maximum transmitted active power during grid fault

$P_{d 1}$

$U^{\prime}{ }_{B}$

$\Delta T$

$t_{1}$

j

$P_{D C}$

$x_{1}, x_{2}$

$x_{12}$

RMS voltage at the AC side of inverter station at the initial time of grid fault

Duration of transmitted power sag caused by $\mathrm{CF}$

Time of first CF occurs

Frequency of continuous CFs

Sum of the active power transmitted by all DC links

Equivalent reactance of generators G1 and G2

$E_{s 1} \angle \delta_{s 1}, E_{s 2} \angle \delta_{s 2} \quad$ Internal potential and rotor angle of equivalent generators G1 and G2

$U_{1}, U_{2}$

$\theta_{1}, \theta_{2}$

$P_{G 1}, P_{G 2}$

$P_{L 1}, P_{L 2}$

$P_{m}$

$P_{e \max }$

$P_{\text {em_j }}$

$\triangle P_{\text {DC_max }}$

$\Delta P_{\text {comp }}$

$P_{12}$

$P_{D C 1}, P_{D C 2}$

$A_{a}, A_{d}$

$T_{\mathrm{J} 1}, T_{\mathrm{J} 2}$

$\omega_{0}$

$P_{D C}$

$\delta$

Tie line reactance between bus B1 and bus B2

Voltage amplitude at bus B1 and B2

Phase angle at bus B1 and B2

Output mechanical power of the equivalent generators

Load power represented by L1 and L2

Equivalent mechanical power

Peak value of equivalent electromagnetic power

Emergency power control reference during $j$-th $\mathrm{CF}$

Maximum emergency power support capacity of DC system

Minimum generator tripping capacity

Transmitted power from bus $B_{1}$ to bus $B_{2}$

Transmitted power by $\mathrm{DC}_{1}$ and $\mathrm{DC}_{2}$ inverter station

Acceleration area and deceleration area

Inertia time constants of equivalent generator

Rated angular velocity

Sum of the active power transmitted by all DC links

Rotor angle deviations between G1 and G2

Step of piecewise linearization 


\section{References}

1. Sigrist, L.; Echavarren, F.; Rouco, L.; Panciatici, P. A fundamental study on the impact of HVDC lines on transient stability of power systems. In Proceedings of the IEEE Eindhoven PowerTech, Eindhoven, The Netherlands, 29 June-2 July 2015; pp. 1-6.

2. Shah, R.; Sánchez, J.; Preece, R.; Barnes, M. Stability and control of mixed AC-DC systems with VSC-HVDC: a review. IET Gener. Transm. Distrib. 2018, 12, 2207-2219. [CrossRef]

3. Tu, J.; Pan, J.; Zhang, J.; Jia, J.; Qin, X.; Yi, J. Study on the stability mechanism of the sending-side three-machine-group system after multiple HVDC commutation failure. IET J. Eng. 2017, 2017, 1140-1145. [CrossRef]

4. Liu, C.; Zhao, Y.; Li, G.; Annakkage, U.D. Design of LCC HVDC wide-area emergency power support control based on adaptive dynamic surface control. IET Gener. Transm. Distrib. 2017, 11, 3236-3245. [CrossRef]

5. Rahimi, E.; Gloe, A.M.; Davies, J.B.; Fernando, I.T.; Kent, K.L. Commutation Failure Analysis in Multi-Infeed HVDC Systems. IEEE Trans. Power Deliv. 2011, 26, 378-384. [CrossRef]

6. Tu, J.; Zhang, J.; Bu, G.; Yi, J.; Yin, Y.; Jia, J. Analysis of the sending-side system instability caused by multiple HVDC commutation failure. CSEE J. Power Energy Syst. 2015, 1, 37-44. [CrossRef]

7. Jia, J.; Zhang, J.; Zhong, W.; Tu, J.; Yu, Q.; Yi, J. Research on the security and stability control measures of the sending side system coping with multiple parallel-operation HVDCs simultaneous commutation failure. Proc. CSEE. 2017, 37, 6320-6327.

8. Liu, H.; Liu, B.; Chen, Z. Impact and suppression measures of repeated and simultaneous commutation failure in multiple HVDC power transmission system between two regional power grids. High Volt. Eng. 2016, 42, 3315-3320.

9. Zhuang, W.; Li, D.; Yu, Z.; Li, H.; Liu, T.; Li, Z. Security and Stability Control System Coping With Simultaneous Multi-UHVDC Commutation Failure. Power Syst. Technol. 2016, 40, 3420-3426.

10. Kundur, P. Power System Stability and Control, 1st ed.; McGraw Hill: New York, NY, USA, 1994; pp. $533-543$.

11. Kwon, D.; Kim, Y.J.; Moon, S.I. Modeling and analysis of an LCC HVDC system using DC voltage control to improve transient response and short-term power transfer capability. IEEE Trans. Power Del. 2018, 33, 1922-1933. [CrossRef]

12. Wang, S.; Tang, F.; Liu, D.; Zhou, S.; Liu, F.; Hou, Y. DC Power Energy Compensation Modulation Method Coping With Simultaneous Multiple HVDC Commutation Failures. Power Syst. Technol. 2018, 42, 2876-2884.

13. Zhou, Y.; Wu, H.; Song, Y.; Ling, W.; Lou, B.; Deng, H. Analyses of static and dynamic reactive power allocation between synchronous compensators and shunt capacitors to counter commutation failures. Int. Trans. Electr. Energ. Syst. 2018, 28,1-14. [CrossRef]

14. Guo, C.; Liu, Y.; Zhao, C.; Wei, X.; Xu, W. Power Component Fault Detection Method and Improved Current Order Limiter Control for Commutation Failure Mitigation in HVDC. IEEE Trans. Power Del. 2015, 30, 1585-1593. [CrossRef]

15. Mirsaeidi, S.; Dong, X.; Tzelepis, D.; Said, D.M.; Dysko, A.; Booth, C. A Predictive Control Strategy for Mitigation of Commutation Failure in LCC-Based HVDC Systems. IEEE Trans. Power Electron. 2019, 34, 160-172. [CrossRef]

16. Li, M. Characteristic Analysis and Operational Control of Large-Scale Hybrid UHV AC/DC Power Grids. Power Syst. Technol. 2016, 40, 985-991.

17. He, J.; Tang, Y.; Zhang, J.; Guo, Q.; Yi, J.; Bu, G. Fast calculation of power oscillation peak value on ac tie-line after HVDC commutation failure. IEEE Trans. Power Syst. 2015, 30, 2194-2195. [CrossRef]

18. Darabian, M.; Jalilvand, A. Improving power system stability in the presence of wind farms using STATCOM and predictive control strategy. IET Renew. Power Gener. 2018, 12, 98-111. [CrossRef]

19. Zhou, X.; Sun, H.; Zhao, B.; Wen, J.; Waqar, A. Applying high-voltage direct current emergency control to suppress the peak value of ultra-high-voltage tie-line power oscillation. IET Gener. Transmiss Distrib. 2015, 9, 2485-2492. [CrossRef]

20. Elizondo, M.A.; Fan, R.; Kirkham, H.; Ghosal, M.; Bernal, F.W.; Schoenwald, D.; Lian, J. Interarea Oscillation Damping Control Using High Voltage DC Transmission: A Survey. IEEE Trans. Power Syst. 2018, 33, 6915-6923. [CrossRef] 
21. Du, Z.; Gan, D.; Liu, Y.; Xia, D. A fast numerical integration method for power system on line dynamic security assessment. Proc. CSEE. 1996, 16, 29-32.

22. Tu, J.; Pan, Y.; Zhang, J.; Zeng, B.; Jia, J.; Yi, J. Transient reactive power characteristics of HVDC during commutation failure and impact of HVDC control parameters. IET J. Eng. 2017, 2017, 1134-1139. [CrossRef]

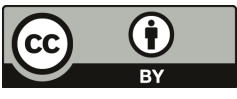

(C) 2019 by the authors. Licensee MDPI, Basel, Switzerland. This article is an open access article distributed under the terms and conditions of the Creative Commons Attribution (CC BY) license (http://creativecommons.org/licenses/by/4.0/). 
Article

\title{
A Neural Network-Based Model Reference Control Architecture for Oscillation Damping in Interconnected Power System
}

\author{
Waqar Uddin ${ }^{1}$, Nadia Zeb ${ }^{2}$, Kamran Zeb ${ }^{1,3}$, Muhammad Ishfaq ${ }^{1}$, Imran Khan ${ }^{1}$, Saif Ul Islam ${ }^{1}$, \\ Ayesha Tanoli ${ }^{4}$, Aun Haider ${ }^{4}$, Hee-Je Kim ${ }^{1, *}$ and Gwan-Soo Park ${ }^{1}$ \\ 1 School of Electrical and Computer Engineering, Pusan National University, 2 Busandaehak-ro 63 beon-gil, \\ Geumjeong-gu, Busan-City 46241, Korea; waqudn@pusan.ac.kr (W.U.); kami_zeb@yahoo.com (K.Z.); \\ engrishfaq1994@gmail.com (M.I.); imrankhan@pusan.ac.kr (I.K.); shaheen_575@yahoo.com (S.U.I.); \\ gspark@pusan.ac.kr (G.-S.P.) \\ 2 Department of Electrical Engineering, COMSATS University Islamabad, Abbottabad Campus, Abbottabad \\ 22010, Pakistan; nadia.zeb@gmail.com \\ 3 Department of Electrical Engineering, National University of Science and Technology, Islamabad 44000, \\ Pakistan \\ 4 Department of Electrical Engineering, University of Management and Technology, Lahore, Sialkot Campus, \\ Sialkot 51040, Pakistan; ieesha_tanoli@yahoo.com (A.T.); aun.haider@skt.umt.edu.pk (A.H.) \\ * Correspondence: heeje@pusan.ac.kr; Tel.: +82-10-3492-9677
}

Received: 12 July 2019; Accepted: 20 September 2019; Published: 24 September 2019

\begin{abstract}
In this paper, a model reference controller (MRC) based on a neural network (NN) is proposed for damping oscillations in electric power systems. Variation in reactive load, internal or external perturbation/faults, and asynchronization of the connected machine cause oscillations in power systems. If the oscillation is not damped properly, it will lead to a complete collapse of the power system. An MRC base unified power flow controller (UPFC) is proposed to mitigate the oscillations in 2-area, 4-machine interconnected power systems. The MRC controller is using the NN for training, as well as for plant identification. The proposed NN-based MRC controller is capable of damping power oscillations; hence, the system acquires a stable condition. The response of the proposed MRC is compared with the traditionally used proportional integral (PI) controller to validate its performance. The key performance indicator integral square error (ISE) and integral absolute error (IAE) of both controllers is calculated for single phase, two phase, and three phase faults. MATLAB/Simulink is used to implement and simulate the 2-area, 4-machine power system.
\end{abstract}

Keywords: power oscillations; UPFC; non-linear control; neural network; model reference control

\section{Introduction}

The electric power system is composed of various interconnected generating stations that are connected to load centers through the transmission and distribution systems. The interconnection of different generating stations increases the complexity of the power network. Due to the stochastic nature of the consumer profile, a mismatch occurs between the load demand and supply. The load variation causes a change in system frequency, voltage, active power, and mechanical power. The variation in these parameters causes fluctuation in the rotor speed. As a result, a low frequency $(0.1 \mathrm{~Hz}$ to few hertz) oscillation in active power takes place, known as a power oscillation. These power oscillation either decays after a specified time or increases in magnitude until the system collapse (blackout) occurs [1,2].

In order to overcome the issues of stability due to power oscillations and control power flow in a system, a Flexible AC Transmission System (FACTS) has been proposed by scientists and researchers. 
FACTS devices serve many functions in a power system, i.e., control of power flow, oscillation damping, voltage control, and improvement of transient stability. The Unified Power Flow Controller (UPFC) is an important member of the FACTS family. The UPFC is composed of two voltage source converters coupled through a DC link. The converters provide both series and shunt compensation to the transmission line, hence separating control of active and reactive power becomes possible.

The problem of Low-Frequency Oscillation (LFO) is tackled through FACTS devices in the modern power system. FACT devices and a UPFC based on FACT devices are used mostly for mitigating the LFOs. These devices are also used for enhancing the stability of the power system. The UPFC ensures the security and stability of the system and damps out the LFOs.

Different linear and nonlinear control techniques are applied to mitigate the LFOs [2]. A modified non-dominated sorting genetic algorithm-II (MNSGA-II) is proposed for control of the UPFC to damp out power oscillation in [3]. The proposed design of the UPFC controller is based on a multi-objective optimization problem. However, the controller response is slow in the case of a heavy loaded condition. In [4], the authors presented Variable Neighborhood Search (VNS) optimization algorithm for tackling the problem of oscillations. Although the design process includes high complexity, the proposed controller responds well during normal conditions. However, the author did not consider the heavy loaded or fault condition. An imperialist competition algorithm is used for damping power oscillation in [5]. The controller is designed for wide range of operating conditions, but the author considered a Single Machine Infinite Bus (SMIB) system. The artificial bee colony (ABC) algorithm [6] and Support Vector Regression (SVR) [7] are also proposed for design of a supplementary damping controller. However, the design is equipped with an additional Power System Stabilizer (PSS), along with the UPFC, which will increase system cost and complexity. The author in [8] proposed adaptive input-output feedback linearization control to achieve a non-linear stability estimator and 4th order linearized model. However, due to the parallel application of these procedures, the system faces instability during disturbances. The linear observer excludes the system nonlinearities and only approximate system parameters. The sub-transient state of the synchronous generator is neglected after the fault clearance, while the FACTS device is turned on and off by using an input-output controller. In [9], the researcher proposed a co-evolutionary cultural algorithm (CPCA) based on particle swarm optimization. The author proposed a PSS, along with UPFC, for oscillation damping. But the response of the controller is slow as it takes too much time in damping the power oscillations. In [10], a PSS is used to stabilize the LFOs. Also, in case of failure of the PSS, a supplementary control based on a Linear Quadratic Regulator (LQR) regulates the control input to FACTS devices. In [11], the author proposed a Fuzzy Neural Non-linear Proportional Integral controller for damping LFOs. The positive aspects of this controller are its adaptive nature in learning rate, online tuning, simple structure, and parameter identification. Inter-area oscillations can be efficiently damped through neural predictive control. It will also enhance the stabilization of the power system [12]. A Takagi-Sugeno controller produces gain over the large operating region. However, it cannot guarantee the stability of the system, the robustness of uncertain perturbation in the system, and parameter variations. Transient stability of a machine connected to an infinite bus system is enhanced by using non-linear coordination of generator excitation in [13].

In our paper, we present the neural network (NN)-based model reference controller (MRC) control scheme with a UPFC for mitigation and damping LFOs that is caused by the fault, disturbances, or due to loss of synchronism in connected machines. The MRC controller uses a NN that has the capability to learn and store information of non-linearities, using the auto-regression model instead of tuning of input parameters. The MRC is the integration of the (1) reference model, (2) NN plant, (3) NN controller, and (4) plant. The incorporation of all these four parts promises the robustness, intelligence, and adaptation of parameters. The MRC has an inherently adaptive mechanism, which will help in tracking of variation of process variables. The ability of a NN to learn and model complex and nonlinear relationships plays a vital role in control of a complex problem with uncertainties. After initial weight adjustment, it acquires the ability to predict uncertainties. These features of an 
NN-based MRC controller will tackle the uncertainties and will have a better response than other conventional control schemes. The weight of the NN is adjusted with the Back Propagation (BP) algorithm. Eventually, it will damp out the oscillation quickly and protect the system from complete collapse. Moreover, the performance of proposed controller is compared with the PI controller for the same system to validate our claim.

The paper is organized as follows: Section 2 shows the general system model, while Section 3 discusses the mathematical modelling of the system. The supplementary control and results are discussed in Sections 4 and 5, respectively. Section 6 concludes this paper.

\section{System Model}

A UPFC installed, 2-area, 4-generator connected power system is depicted in Figure 1. This model is used to study LFOs of 0.1 to few Hertz.

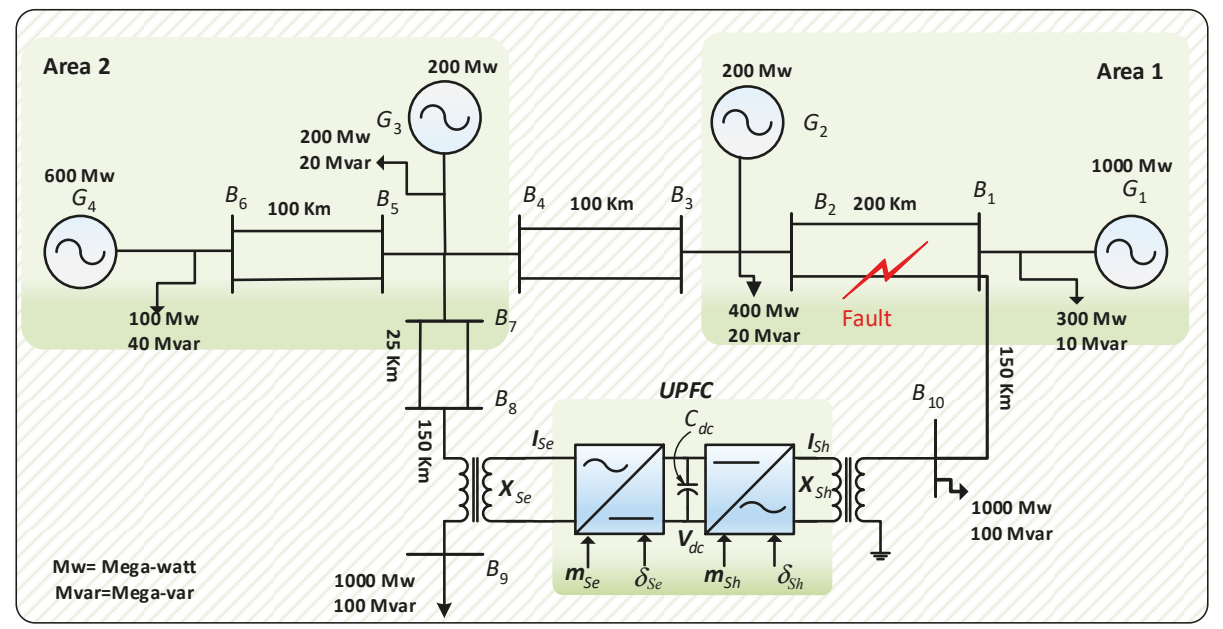

Figure 1. One-line diagram of power system with installed unified power flow controller (UPFC).

A DC capacitor voltage regulator is used to damp out the oscillation produces due to the occurrence of disturbances in power, but it has a negative impact on the generated transients [14] because the required amount of power is transmitted to the series inverter for injection to the transmission line through DC link. Similarly, when variations in magnitude of DC link voltage occurs, it affects power transfer capability of the shunt inverter. Hence, the active power is injected into the system with the help of series inverter [15].

The synchronous generator connected to the system is used to generate power that is delivered through the transmission lines. The installation point of the UPFC is between bus 8 and bus 9 .

The DC link capacitor is used to make the back to back connection of Voltage Sources Converters (VSCs) possible and transfer the power from the shunt converter to the series converter [16]. The main purpose of Series VSC (VSC-SE) is to control the injection of active power and reactive power to the system, while Shunt VSC (VSC-SH) is used to adjust active power flow to series converter and maintain DC link voltage. The connection of the shunt and series VSC is depicted in Figure 1. The connection of both the converters is such that it diminishes the total power injection to the system.

$$
P_{S e}+P_{S h}=0 .
$$

The input control signal to UPFC are $m_{S e}, m_{S h}, \delta_{S e}$, and $\delta_{S h} . m_{S e}$ and $m_{S h}$ is used to represent the amplitude modulation index of series and shunt compensation, respectively. However, $\delta_{S e}$ and $\delta_{S h}$ 
are used for the representation of series and shunt compensation phase angles [2,17]. In the case of a series converter, $\delta_{S e}$ and $m_{S e}$ are the important factors that need to be determined. Because $\delta_{S e}$ is used to control real power flow in to the high voltage direct current (HVDC) transmission line, and $m_{S e}$ is responsible for voltage control. Similarly, in the case of the shunt converter, the reactive power of the AC terminal can be controlled through $m_{S h}$, and $\delta_{S h}$ is used to control DC link voltage $\left(V_{d c}\right)$. VSC-SE injects voltage to the AC transmission line through a series connected transformer. This series injected voltage is used to tackle different problems, i.e., phase shift, series compensation, voltage control, and combination of these parameters. VSC-SH is used to take real power from AC terminal and transfer it to DC terminal. This power is then transferred by VSC-SE to the system for compensation. These features make the UPFC a flexible FACTS device that has the properties of all other FACTS devices. The block diagram of the UPFC general control is depicted in Figure 2. $V_{1}$ and $V_{2}$ are bus voltages to which VSC-SH and VSC-SE are connected, respectively, while " $i$ " is line current.

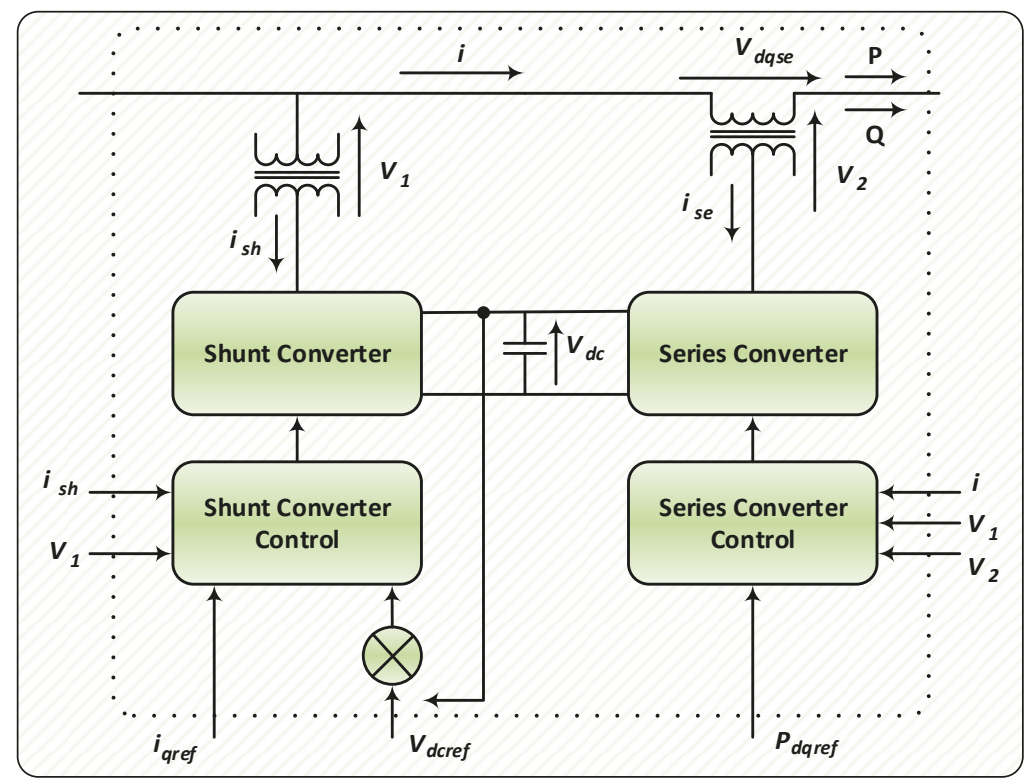

Figure 2. UPFC control.

\section{Mathematical Modelling of Power System}

The model used in this paper is composed of a UPFC installed, 4-machine, two-area power system. The UPFC is composed of a VSC - SH, VSC - SE, and DC link.

\section{Mathematical Model}

The non-linear model of the UPFC is presented below from Equation (2) to Equation (3). This model is used for the analysis of stability of the power system. The parameters that affect the dynamics of the system are considered in this model, and resistance and transients of transformer is neglected. The modelling equations given below are transformed to dq - axis by using Park's transformation $[17,18]$. Series VSC and shunt VSC are modelled as:

$$
\left[\begin{array}{c}
V_{d s e} \\
V_{q s e}
\end{array}\right]=\left[\begin{array}{cc}
0 & -X_{s e} \\
X_{s e} & 0
\end{array}\right]\left[\begin{array}{c}
I_{d s e} \\
I_{q s e}
\end{array}\right]+\frac{m_{s e} V_{d c}}{2} *\left[\begin{array}{c}
\cos \delta_{s e} \\
\sin \delta_{s e}
\end{array}\right]
$$




$$
\left[\begin{array}{l}
V_{d s h} \\
V_{q s h}
\end{array}\right]=\left[\begin{array}{cc}
0 & -X_{s h} \\
X_{s h} & 0
\end{array}\right]\left[\begin{array}{c}
I_{d s h} \\
I_{q s h}
\end{array}\right]+\frac{m_{s h} V_{d c}}{2} *\left[\begin{array}{c}
\cos \delta_{s h} \\
\sin \delta_{s h}
\end{array}\right]
$$

The subscript 'sh' and 'se' is used for shunt and series converter parameters, respectively. $X_{s e}, X_{s h}$ are equivalent reactance of series and shunt transformer. $V_{d s e}, V_{q s e}$ are the dq voltage component of series branch, while $I_{d s e}, I_{q s e}$ are $d q$-component of series converter current. The dynamic of DC voltage at DC link is represented as:

$$
\frac{d v_{d c}}{d t}=\frac{3 m_{s h}}{4 C_{d c}}\left[\begin{array}{cc}
\cos \delta_{s h} & \sin \delta_{s h}
\end{array}\right]\left[\begin{array}{c}
I_{d s h} \\
I_{q s h}
\end{array}\right]+\frac{3 m_{s e}}{4 C_{d c}}\left[\begin{array}{cc}
\cos \delta_{s e} & \sin \delta_{s e}
\end{array}\right]\left[\begin{array}{c}
I_{d s e} \\
I_{q s e}
\end{array}\right]
$$

$V_{d c}$ shows the DC link voltage, and $C_{d c}$ is the capacitances of the DC link capacitor. The model of the UPFC connected power system is presented by:

$$
\begin{gathered}
\dot{\delta}=\omega_{0} \Delta \omega, \\
\dot{\omega}=\frac{P_{\text {mech }}-P_{\text {elec }}-D \Delta \omega}{M}, \\
\dot{E_{f d}}=-\frac{E_{f-d}}{T_{A}}+\frac{K_{A}}{T_{A}}\left(V_{s 0}-V_{s}\right), \\
\dot{E_{s q}^{\prime}}=\frac{E_{f-d}-\left(x_{d}-x_{d}^{\prime}\right) i_{d}-E_{s q}^{\prime}}{T_{d 0}^{\prime}} .
\end{gathered}
$$

$P_{\text {mech }}$ and $P_{\text {elec }}$ represent mechanical and electrical power, respectively, where $M$ and $D$ represent inertia and damping coefficient, respectively. $\omega_{0}$ represents synchronous speed. $\delta$ and $\omega$ are rotor angle and rotor speed, respectively, while $\Delta \omega=(\omega-1) . E_{f d}, E_{s q}^{\prime}$, and $V$ are field, internal, and the terminal voltage of generator. $T_{d 0}^{\prime}$ represents the time constant of the open circuit. $T_{A}$ and $K_{A}$ are time constant and exciter gain, respectively, while $V_{s 0}$ represents reference voltage. $x_{d}$ is the $d$-axis reactance of generator, and $x_{d}^{\prime}$ is transient reactance. Furthermore, the different terms used in Equation (5) to Equation (8) are given as:

$$
\left.\begin{array}{c}
P_{\text {elec }}=V_{s-q} I_{s-q}+V_{s-d} I_{s-d} \\
V_{s}=\sqrt{V_{d}^{2}+V_{q}^{2}}, \\
V_{d}=X_{d} I_{q}, V_{q}=E_{q}^{\prime}-X_{d}^{\prime} I_{d} \\
I_{d}=I_{E d}+I_{B d}, I_{q}=I_{E q}+I_{B q}
\end{array}\right\} .
$$

Similarly, the line current for VSC-SE and VSC-SH can be obtained as [17-19]:

$$
\begin{gathered}
I_{s e d}=-\frac{X_{s h}}{X_{d} \Sigma} E_{q}^{\prime}+\frac{X_{s h d} m_{s h} \sin \delta_{s h} V_{d c}}{2 X_{d} \Sigma}-\frac{X_{t d}}{X_{d} \Sigma}\left(\frac{m_{s e} \sin \delta_{s e} V_{d c}}{2}+V_{b} \cos \delta\right), \\
I_{s e q}=-\frac{X_{s h q} m_{s h} \sin \delta_{s h} V_{d c}}{2 X_{q} \Sigma}+\frac{X_{s h q}}{X_{q} \Sigma}\left(\frac{m_{s e} \sin \delta_{s e} V_{d c}}{2}+V_{b} \sin \delta\right) \\
I_{s h d}=\frac{X_{s e}}{X_{d} \Sigma} E_{q}^{\prime}-\frac{X_{s e d} m_{s h} \sin \delta_{s h} V_{d c}}{2 X_{d} \Sigma}+\frac{X_{s h d}}{X_{d} \Sigma}\left(\frac{m_{s h} \sin \delta_{s h} V_{d c}}{2}+V_{b} \cos \delta\right), \\
I_{s h q}=-\frac{X_{s h q} m_{s h} \cos \delta_{s h} V_{d c}}{2 X_{q} \Sigma}+\frac{X_{t q}}{X_{q} \Sigma}\left(\frac{m_{s e} \cos \delta_{s e} V_{d c}}{2}+V_{b} \sin \delta\right)
\end{gathered}
$$

where as $X_{d} \Sigma, X_{t d}, X_{q} \Sigma$, and $X_{t q}$ are defined in [18]. 


\section{Supplementary Control Design}

Supplementary control schemes with the MRC are introduced for mitigating LFOs in the power system. The control design is used in the UPFC internal control structure to enhance the stability of the power system. As the faults occur on the transmission system, the speed of a different generator connected to the power system deviates and become out of synchronism. This speed deviation $(\Delta \omega)$ is treated as an input to the supplementary controller, as depicted in Figure 3. The controllers mitigate the LFOs by providing suitable input to the UPFC, hence improving the power quality and stabilizing the power system. The design of the controllers is based on model reference neural control, and it uses a nonlinear autoregressive moving average model. The MRC is the integration of the (1) reference model, (2) NN plant, (3) NN controller, and (4) plant. The different parts of controller will be discussed in detail in a subsection of this section.

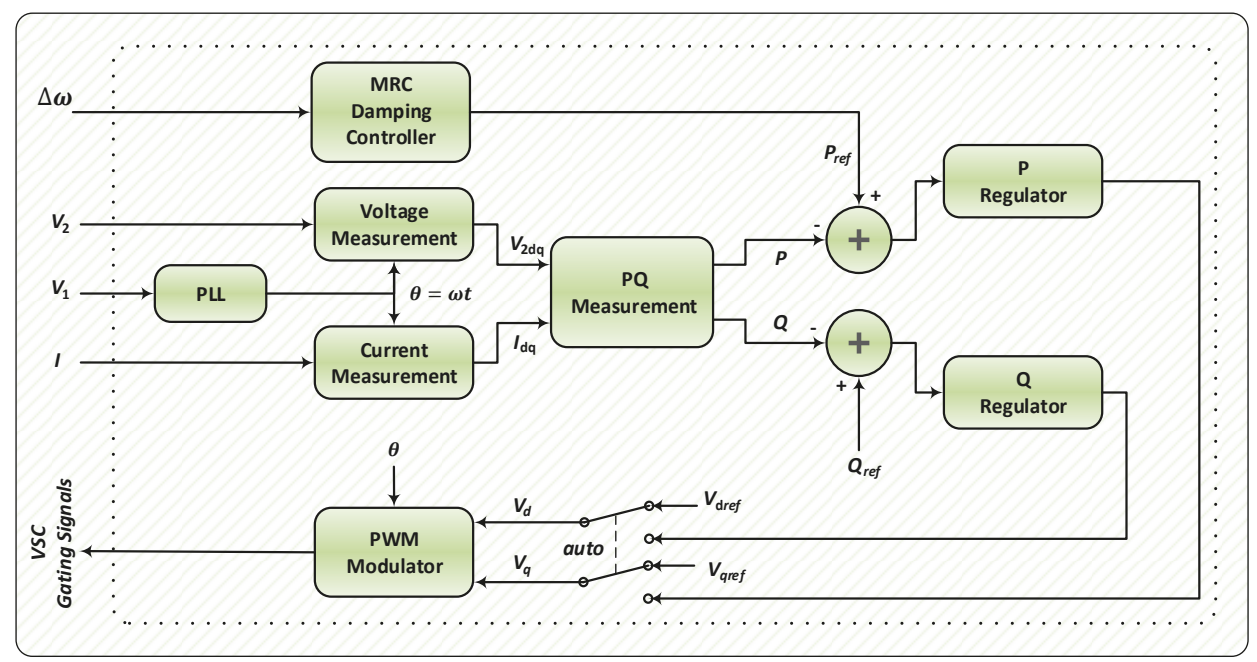

Figure 3. Control structure for oscillation damping. $\mathrm{MRC}=$ model reference controller; VSC $=$ Voltage Sources Converters; PQ = Active Power, Reactive Power; PWM = Pulse Width Modulation; PLL = Phase Lock Loop.

\subsection{Neural Network (NN)}

The NN, inspired by the biological system, is composed of interconnected building blocks known as neurons. The interconnection weight quantifies the strength of interconnection. Because of these interconnected weights, the NN acquires the ability to learn and model complex relationships. Hence, it becomes more intelligent in predicting the uncertainties. Due to the learning capability of NN, it has a wide range of applications in automation and optimization [20], image processing [21,22], speech recognition [23,24], control [25,26], modelling, and time series prediction $[27,28]$.

The architecture of $\mathrm{NN}$ is composed of multiple input layer and hidden layers, as depicted in Figure 4. This architecture is known as " $N-1$ " feedforward NNs. Whereas ' $N$ ' represents the number of hidden neurons and it has only one output node. The design of the architecture of NN depends on the input weights ' $z_{i j}$ ' and output weights ' $\gamma_{i}$ '. The formulation of the $\mathrm{NN}$ through the nonlinear function of hidden layer activation function ' $\psi_{i}$ ' is presented as:

$$
\hat{y}(k+1)=\sum_{i=1}^{N} \gamma_{i} \psi_{i}\left(\sum_{j=1}^{n+m} z_{i j} X_{j}\right)
$$


where $X=\left[u_{1}, u_{2}, \ldots, u_{m+n}\right]$ is the input vector to $\mathrm{NN}$ and ' $\psi_{i}$ ' is the activation function of the ' $i$ 'th' hidden layer. The neuron in the hidden layer uses the nonlinear logistic function given by Equation (15):

$$
\psi_{i}\left(\sum_{j=1}^{n+m} z_{i j} X_{j}\right)=\frac{1}{1+\exp \left(\sum_{j=1}^{n+m} z_{i j} X_{j}\right)} .
$$

The equation can be rearranged as:

$$
\hat{y}(k+1)=\theta^{T} \psi,
$$

whereas $\psi \triangleq\left(\psi_{1}, \psi_{2}, \ldots, \psi_{N}\right)^{T}, \theta^{T} \triangleq\left(\gamma_{1}, \gamma_{2}, \ldots, \gamma_{N}\right)$. The gradient descent optimization technique is used to tune and update the output weight only. This will, in turn, reduce the computational complexity of the NN. The update equation of the $\mathrm{NN}$ is given as:

$$
\gamma_{k+1}=\gamma_{k} \alpha\left(\left(y_{r} \times \hat{y}\right) \times\left(y_{r} \times \hat{y}\right)^{\prime}\right) .
$$

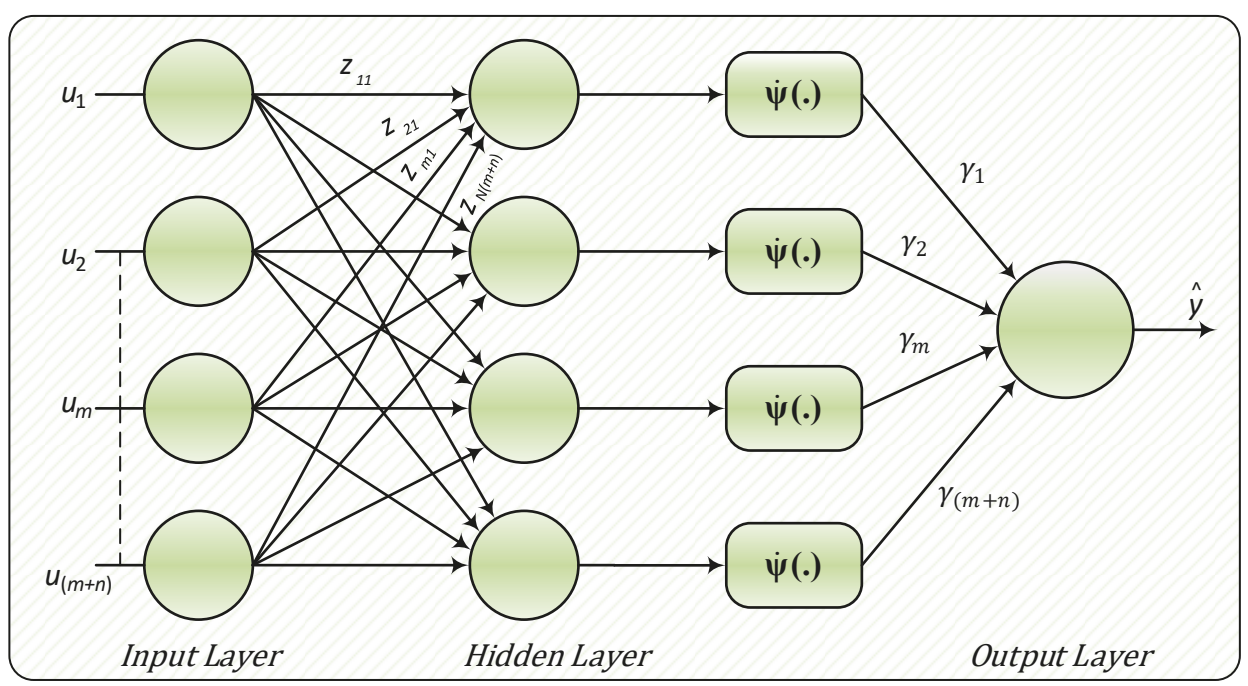

Figure 4. Neural network (NN) architecture.

\subsection{Model Reference Controller}

The NN controller is used in the MRC for tracking the reference signal, as well as for plant identification. The MRC uses two NN controllers and minimal online computation. One NN is used to train the controller, and the other is used for plant identification. The data set for training the NN controller is given in Appendix A. The architecture of the MRC is depicted in Figure 5. The controller produces a controlled output signal $u(t)$ that acts as input to the plant. This control signal brings the output signal $y_{p}(t)$ closer to the reference signal $y_{r}(t)$.

According to [29], the different inputs and their respective outputs define the characteristics of the real-time process. The previous information of input and output is used to introduce system dynamics. Equation (18) is sampled at a regular interval of time:

$$
y_{p}(t)=f_{p}\left[y_{p}(t-1), \ldots y_{p}\left(t-n_{a}\right), u(t-k), \ldots u\left(t-k-n_{b}\right)\right],
$$


where $k \geq 1$ shows the time delay in number of samples, $f_{p}[(y, u)]$ is processed by non-linearity, and $n_{a}$, $n_{b}+1$ represents the process output and input, respectively. Equation (18) gets into the shape of the transfer function below by linearizing the process about the operating point.

$$
\frac{y_{p}(t)}{u(t)}=q^{-k} \frac{B\left(q^{-1}\right)}{A\left(q^{-1}\right)}=q^{-k} \frac{b_{0}+b_{1} q^{-1}+\ldots+b_{n_{b}} q^{-n_{b}}}{1+a_{1} q^{-1}+\ldots+a_{n_{a}} q^{-n_{a}}} .
$$

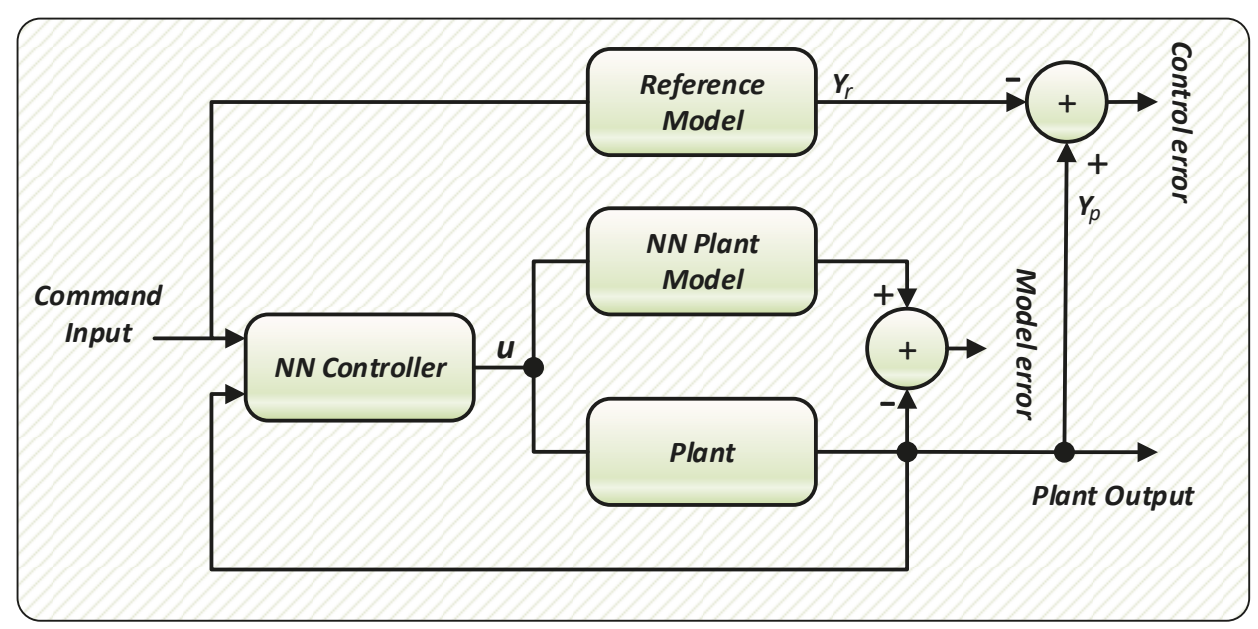

Figure 5. NN-based MRC.

In Equation (19), $y_{p}(t)$ and $u(t)$ represents the deviation of process from its operating points. The parameters $a_{i}$ and $b_{i}$ are dependent on the operating condition, while $q^{-1}$ represents the backward shift operator. The equation for the generalized linear controller is given in Equation (20)

$$
u(t)=\frac{1}{F\left(q^{-1}\right)}\left(H\left(q^{-1}\right) R(t)-G\left(q^{-1}\right) y_{p}(t)\right),
$$

where ' $R$ ' is set point, while $F, G$, and $H$ are the polynomial defined below:

$$
\left\{\begin{array}{c}
F\left(q^{-1}\right)=1+f_{1} q^{-1}+\ldots+f_{n_{f}} q^{-n_{f}} \\
G\left(q^{-1}\right)=g_{0}+g_{1} q^{-1}+\ldots+g_{n_{g}} q^{-n_{g}} . \\
H\left(q^{-1}\right)=h_{0}+h_{1} q^{-1}+\ldots+h_{n h} q^{-n h}
\end{array}\right.
$$

The closed-loop transfer function of a linearized system is given by:

$$
\frac{y_{p}(t)}{R(t)}=q^{-k} \frac{B\left(q^{-1}\right) H\left(q^{-1}\right)}{A\left(q^{-1}\right) F\left(q^{-1}\right)+q^{-k} B\left(q^{-1}\right) G\left(q^{-1}\right)} .
$$

Equation (20) and the control structure $n_{f}, n_{g}$ and $n_{h}$ of Equation (21) is used to design a linear controller model to track the reference point. The polynomial B is neglected to make Equation (22) equal to the characteristic equation of the system. Hence, $B$ is replaced with another term, i.e., $B\left(q^{-1}\right)=$ $b_{0} B^{+}\left(q^{-1}\right)$. Equation (22) will transform into the following equation:

$$
\frac{y_{p}(t)}{R(t)}=q^{-k} \frac{b_{0} H\left(q^{-1}\right)}{A\left(q^{-1}\right) F\left(q^{-1}\right)+q^{-1} b_{0} G\left(q^{-1}\right)}
$$




$$
\frac{y_{p}(t)}{R(t)}=q^{-k_{m}} \frac{s_{0}+s_{1} q^{-1}+\ldots+s_{n_{s}} q^{-n_{s}}}{1+t_{1} q^{-1}+\ldots+t_{n_{t}} q^{-n t}}
$$

$S\left(q^{-1}\right)$ and $T\left(q^{-1}\right)$ are the polynomial that is used to set closed-loop response to a desired value. $k_{m}$ is the time delay of the reference model. In order to enable the cancellation of $B^{+}\left(q^{-1}\right), F\left(q^{-1}\right)$ is replaced with $B^{+}\left(q^{-1}\right) F_{1}\left(q^{-1}\right)$, i.e., $F\left(q^{-1}\right)=B^{+}\left(q^{-1}\right) F_{1}\left(q^{-1}\right)$. The minimal order of the unique controller solution is:

$$
n_{g}=n_{a}-1, n_{f}=n_{b}+k-1, k_{m}=k, \text { while } H\left(q^{-1}\right)=\frac{1}{b_{0}} S\left(q^{-1}\right)
$$

and

$$
n_{t} \leq n_{a}+k-1 .
$$

Hence, the structure of process $n_{a}$ and $k$ is used to limit the order of denominator of closed-looped transfer function $n_{t}$. The order of $n_{t}$ should fulfill the condition given in Equation (25). The lower order of denominator is possible by making unused $t_{i}$ coefficient equal to zero. The following Equation (26) is used to introduce an observer into the controller design.

$$
C\left(q^{-1}\right)=1+c_{1} q^{-1}+c_{2} q^{-2}+c_{n_{c}} q^{-n_{c}}
$$

while

$$
n_{c} \leq n_{a}+k-1-n_{t} .
$$

Then, Equation (25) is updated as:

$$
H\left(q^{-1}\right)=\frac{1}{b_{0}} V\left(q^{-1}\right) C\left(q^{-1}\right) .
$$

Although due to nonlinearity, the parameter of controller will change, but the controller designed structure in Equation (20) will not change for any operating point of the plant in Equation (18) despite setting the observer polynomial $C\left(q^{-1}\right)=1$ and $t_{i}$ coefficient to zero. As in Equation (20), a nonlinear controller design with the same input and output can smoothly interpolate between different parameters of linear controllers as the operating points of the plant changes. The MRC in Equation (29) is proposed by considering Equation (20) in difference equation form and linearizing a nonlinear system into the form of Equation (20)

$$
u(t)=f_{r}\left[u(t-1), \ldots u\left(t-n_{f}\right), r_{f}(t), y_{p}(t), \ldots y_{p}\left(t-n_{g}\right)\right] .
$$

In Equation (29), the NN will be used to realize $f_{r}[\boldsymbol{\bullet}]$, and Equation (24) will define the order of $n_{g}$ and $n_{f}$, while Equation (27) defines $n_{c}$ and $r_{f}(t)=S\left(q^{-1}\right) C\left(q^{-1}\right) r(t)$.

Controller Adaption with BP

The gradient descent algorithm with time delay is implemented to update the parameter of NN. The output of NN with a multilayer of a neuron is given as:

$$
u(t)=f_{0}\left(\sum_{j} z_{j}^{2}\left(f_{h}\left(\sum_{j} z_{i j}^{1} x_{i}(t)+b_{j}^{1}\right)\right)+b^{2}\right) .
$$

$x_{i}$ is the input to the $\mathrm{NN}$, and $b$ and $z$ are biases and weights of the NN, respectively. $f_{0}$ represents the nonlinear function of the input layer, and $f_{h}$ is function of the hidden layer. The cost function that needs to be minimized is given as:

$$
J(t)=\frac{1}{2} e(t j)^{2}=\frac{1}{2}\left(y_{r}(t)-y_{p}(t)\right)^{2} .
$$


$y_{r}$ and $y_{p}$ are the reference and measured output of the system, respectively. The weight parameter ' $z$ ' is used in opposite direction in cost function gradient to minimize the error, given as:

$$
z(t)=z(t-1)-\eta \frac{\partial J(t)}{\partial z}
$$

The unknown ' $\eta$ ' represents the learning rate. The BP algorithm is used to calculate the gradient algorithm of Equation (32) Hence, Equation (18) and $\frac{\partial J(t)}{\partial y_{p}(t)}=-e(t)$ gives:

$$
\frac{\partial J(t)}{\partial z}=-e(t) \frac{\partial y_{p}(t)}{\partial u(t-k)} \frac{\partial u(t-k)}{\partial z} .
$$

In Equation (33), the first derivative is called process Jacobian. The second NN is used to estimate it as a process model, i.e., the NN model given by:

$$
y^{m}(t)=f_{m}[\mathbf{m}]=f_{0}\left\{\sum_{j} z_{j}^{2 m}\left(f_{h}\left(\sum_{i} z_{i j}^{1 m} x_{i}^{m}(t)+b_{j}^{1 m}\right)\right)+b^{2 m}\right\} .
$$

The delayed model inputs/outputs are represented by $x_{i}^{m}(t)$, as shown in Equation (18) in the form of $u(t-k)$. Equation (35) shows one of the estimations of Jacobian.

$$
\frac{\partial y_{p}(t)}{\partial u(t-k)} \approx \frac{\partial y^{m}(t)}{\partial u(t-k)}=f_{0}^{\prime} \sum_{j} z_{j}^{2 m} f_{h_{j}}^{\prime} z_{1 j}^{1 m} .
$$

The process sign is used to approximate Jacobian if the model is not available. Equation (36) shows the update rule for the different parameter of the controller.

$$
z(t)=z(t-1)+\eta e(t) \operatorname{sgn}\left(\frac{\partial y_{p}(t)}{\partial u(t-k)}\right) \frac{\partial u(t-k)}{\partial z} .
$$

This equation is used to update the rule to get better dynamics of the system.

\section{Results and Discussion}

The performance of the designed controller is evaluated and compared with the PI controller under symmetrical and asymmetrical faults. The faults are applied for $50 \mathrm{~ms}$, i.e., the fault is initiated is at $t=200 \mathrm{~ms}$ and cleared at $t=250 \mathrm{~ms}$. Moreover, the fault is applied on the mid-point of the lower line of the double circuit line between buses $B_{1}$ and $B_{2}$, as depicted in Figure 1 . The proposed controller has the capability to mitigate the LFOs and enhance the stability of the power system. The parameters used for comparison of the proposed control structure are: (1) load bus, voltage, (2) speed deviation $(\Delta w)$, and (3) performance indices of controllers.

\subsection{Asymmetrical Faults}

Both asymmetrical and symmetrical faults are applied to the system for $50 \mathrm{~ms}$ (at $t=200 \mathrm{~ms}$ ) to create oscillations in the system. The fault creates a voltage dip of $10 \%$ during the $1-\Phi$ fault, while a $25 \%$ dip is created during the $2-\Phi$ to ground fault. After the clearance of the 1- $\Phi$ fault, the voltage profile is restored at $t=2 \mathrm{~s}$ due to the adaptive and predictive nature of MRC, while the response with conventional PI is oscillatory and oscillation is damped out after $t=12 \mathrm{~s}$, as shown in Figures 6 and 7, respectively. Similarly, the speed deviation shows high amplitude oscillation in the case of the PI controller, while the MRC has the capability to damp out the oscillation in comparatively less time. Figure 8 shows that the MRC has damped out the oscillation at $t=2 \mathrm{~s}$, and speed deviation $(\Delta w \approx 0)$ is approximately zero, while in comparison with MRC, the PI controller deviates from zero till $t=6 \mathrm{~s}$, as depicted in Figure 8. 


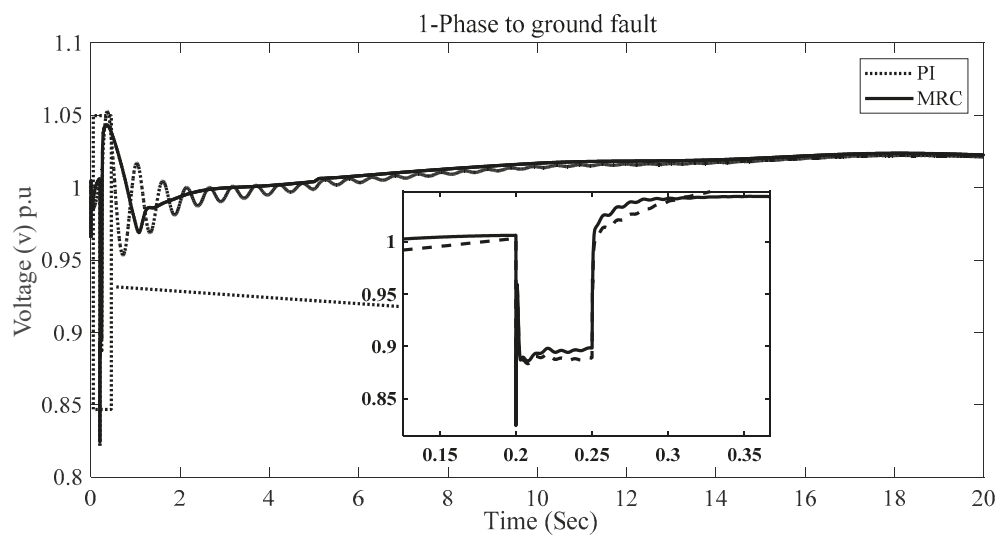

Figure 6. Load bus voltage 1- $\Phi$ to ground fault.

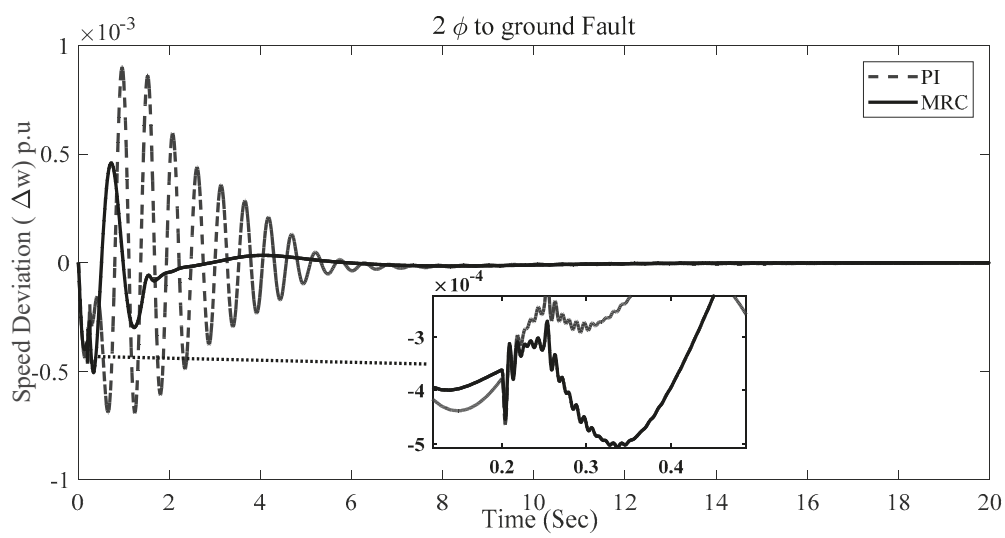

Figure 7. Speed deviation during 2- $\Phi$ to ground fault.

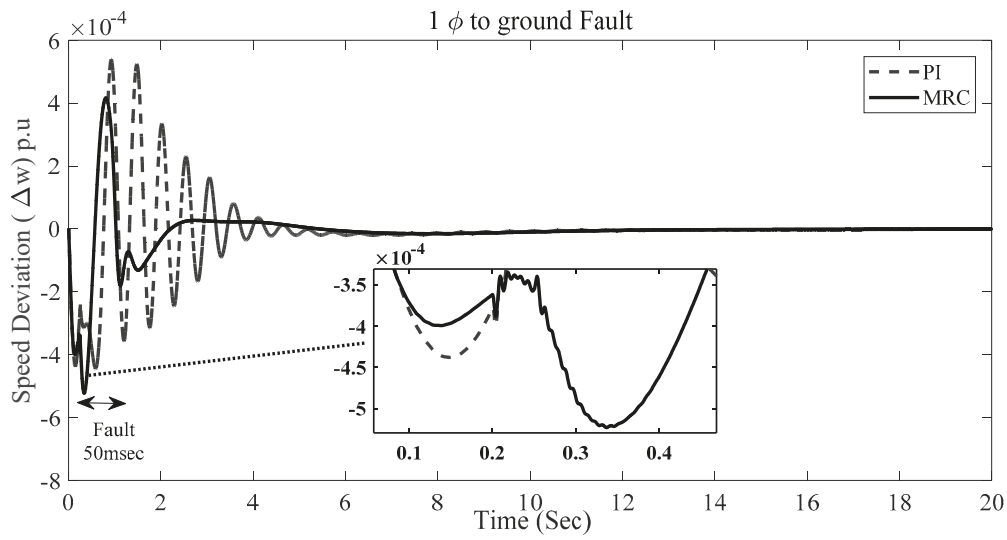

Figure 8. Speed deviation during $1-\Phi$ to ground fault.

Similarly, during the 2- $\Phi$ to ground fault, the MRC has a better response in mitigation of oscillation as compared to the PI. As depicted in Figure 9, the MRC has smoothed the voltage response abruptly 
after fault clearance at $t=2.5 \mathrm{~s}$, while the PI controller failed to show the robustness. The oscillation is completely damped out at $t=12 \mathrm{~s}$, as shown in Figure 7. Similarly, speed deviation becomes zero at $t=2 \mathrm{~s}$ in the case of the MRC, while the PI vanishes the oscillations at $t=8 \mathrm{~s}$.

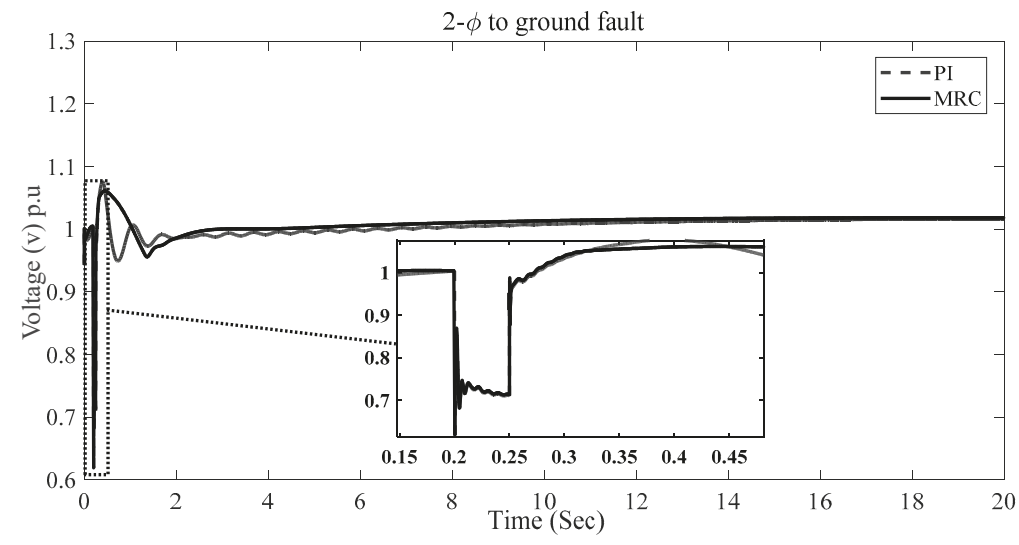

Figure 9. Load bus voltage 2- $\Phi$ to ground fault.

\subsection{Symmetrical Faults}

In the case of an asymmetrical fault, the 3- $\Phi$ to ground fault is applied to evaluate the performance of the proposed controller, as depicted in Figure 10. The MRC has a better approach toward the mitigation of oscillations occurring after the voltage dip, as shown in Figure 11. The oscillation is completely damped out at $t=2.5 \mathrm{~s}$ in the case of the MRC, while the PI has low amplitude oscillations till $t=8 \mathrm{~s}$. Similarly, speed deviation is subjected to larger amplitude high frequency oscillation and higher settling time using the PI, while the proposed controller settles the response to zero at $t=3 \mathrm{~s}$.

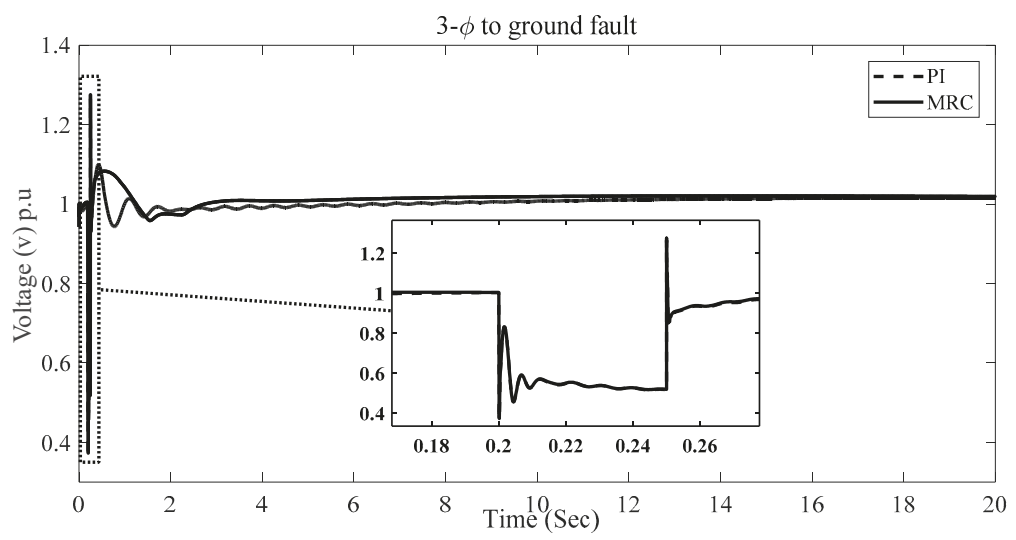

Figure 10. Load bus voltage 3- $\Phi$ to ground fault. 


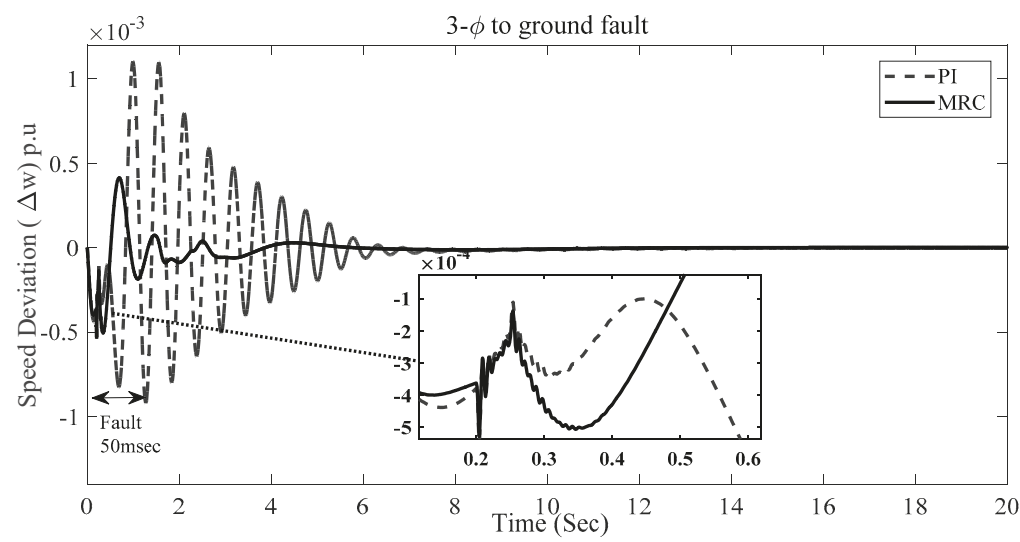

Figure 11. Speed deviation during $3-\Phi$ to ground fault.

Besides other performance evaluation parameter, Table 1 shows the performance indices of both controllers during all three types of faults. The lower value of integral square error (ISE) and integral absolute error (IAE) shows better response of controller. The MRC controller has both a lower value of ISE error and IAE.

Table 1. Performance indices. ISE = integral square error; IAE = integral absolute error.

\begin{tabular}{ccccccc}
\hline \multirow{2}{*}{ Controllers } & \multicolumn{2}{c}{ 1- $\boldsymbol{\Phi}$ Fault } & \multicolumn{2}{c}{ 2- $\boldsymbol{\Phi}$ Faults } & \multicolumn{2}{c}{ 3- $\boldsymbol{\Phi}$ Fault } \\
\cline { 2 - 7 } & ISE & IAE & ISE & IAE & ISE & IAE \\
\hline PI & 0.0009028 & $2.432 \times 10^{-7}$ & 0.001574 & $6.569 \times 10^{-7}$ & 0.00253 & $1.07 \times 10^{-6}$ \\
MRC & 0.0005561 & $1.301 \times 10^{-7}$ & 0.0005802 & $1.41 \times 10^{-7}$ & 0.0005248 & $1.111 \times 10^{-7}$ \\
\hline
\end{tabular}

\section{Conclusions}

The mitigation of power oscillations is a demanding task to enhance the stability of the power system. An intelligent, optimized, and robust design of the UPFC plays a vital role in damping of these oscillations. With these abilities, the MRC controller has shown tremendous performance in mitigating power oscillations, enhancing system stability, and improving the capability of the control system. Moreover, our control scheme shows robustness and intelligence during system perturbation. In order to show the effectiveness of proposed control scheme, it was compared with a traditional PI controller. The results clearly show the superiority of the NN-based MRC over the traditional PI controller, as it is better in oscillation damping. The NN-based MRC diminishes the amplitude of power oscillation, produced due to fault.

However, the MRC-based on a NN is complex algorithm. Due to its complexity, it requires considerable amount of time for calculation and implementation. Due to the integration of the $\mathrm{NN}$ controller in the MRC frame, it is associated with several issues and complications. The complications include selecting the input and output of the controller, as well as training of the NN for its weight adjustment.

Moreover, soon the proposed control will be extended to more than a 2-area system with a greater number of generation stations. Additionally, a new control scheme will be designed, and its results will be compared with both the PI and the MRC.

Author Contributions: W.U., N.Z., and K.Z. propose the main idea of the paper. W.U., M.I., S.U.I., A.T. and A.H have implemented the mathematical derivations, simulation verifications, and analyses. The paper is written by W.U. and is revised by N.Z., I.K., A.H., and H.-J.K. All the authors were involved in preparing the final version of this manuscript. Besides, this whole work is supervised and funded by H.-J.K. and G.-S.P. 
Funding: This research was supported by Basic Research Laboratory through the National Research Foundations of Korea funded by the Ministry of Science, ICT and Future Planning (NRF-2015R1A4A1041584).

Conflicts of Interest: The authors declare no conflict of interest.

\section{Appendix A}

Table A1. Parametric Value of NN.

\begin{tabular}{cc}
\hline Parameters & Value \\
\hline Controller training Epochs & 50 \\
Controller Training sample & 100 \\
Sampling Interval (sec) & 0.05 \\
Maximum interval value (sec) & 20 \\
Minimum interval value (sec) & 5 \\
Controller training segment & 50 \\
Number of hidden layers & 2 \\
No. of delayed Plant Inputs & 1 \\
No. of delayed Plant outputs & 1 \\
\hline
\end{tabular}

\section{References}

1. Wu, W.; Chen, Y.; Fei, Y.; Zhen, H.; Zhou, B.; Wang, Z.; Chen, W. A novel damping strategy for low-frequency oscillation suppression with MMC-type unified power flow controller. In Proceedings of the IEEE International Conference on Industrial Technology, Lyon, France, 20-22 February 2018.

2. Gandoman, F.H.; Ahmadi, A.; Sharaf, A.M.; Siano, P.; Pou, J.; Hredzak, B.; Agelidis, V.G. Review of FACTS technologies and applications for power quality in smart grids with renewable energy systems. Renew. Sustain. Energy Rev. 2018, 82, 502-514. [CrossRef]

3. Kannayeram, G.; Manoharan, P.S.; Iruthayarajan, M.W.; Sivakumar, T. UPFC damping controller design using multi-objective evolutionary algorithms. Int. J. Bus. Intell. Data Min. 2018, 13, 52-74. [CrossRef]

4. Fortes, E.; Macedo, L.; Araujo, P.B.; Romero, R. A VNS algorithm for the design of supplementary damping controllers for small-signal stability analysis. Int. J. Electr. Power Energy Syst. 2018, 94, 41-56. [CrossRef]

5. Banaei, M.R.; Toloue, H.; Kazemi, F.M.; Oskuee, M.R.J. Damping of power system oscillations using imperialist competition algorithm in power system equipped by HVDC. Int. J. Ain Shams Eng. J. 2015, 6, 75-85. [CrossRef]

6. Martins, L.F.B.; Araujo, P.B.; De Vargas Fortes, E.; Macedo, L.H. Design of the PI-UPFC-POD and PSS Damping Controllers Using an Artificial Bee Colony Algorithm. J. Control Autom. Electr. Syst. 2017, 28, 762-773. [CrossRef]

7. Shahriar, M.S.; Shafiullah, M.; Rana, M.J. Stability enhancement of PSS-UPFC installed power system by support vector regression. Electr. Eng. 2018, 100, 1601-1612. [CrossRef]

8. Shojaeian, S.; Soltani, J.; Arab Markadeh, G. Damping of low-frequency oscillations of multi-machine multi-UPFC power systems, based on adaptive input-output feedback linearization control. IEEE Trans. Power Syst. 2012, 27, 1831-1840. [CrossRef]

9. Esmaili, M.R.; Khodabakhshian, A.; Bornapour, M. A new coordinated design of UPFC controller and PSS for improvement of power system stability using CPCE algorithm. In Proceedings of the IEEE Conference on Electrical Power and Energy EPEC, Ottawa, ON, Canada, 12-14 October 2016.

10. Pandey, R.K.; Gupta, D.K. Knowledge domain states mapping concept for controller tuning in an interconnected power network. Int. J. Electr. Power Energy Syst. 2016, 80, 160-170. [CrossRef]

11. Tavakoli, A.R.; Seifi, A.R.; Arefi, M.M. Fuzzy-PSS and fuzzy neural network non-linear PI controller-based SSSC for damping inter-area oscillations. Trans. Inst. Meas. Control 2016, 40, 733-745. [CrossRef]

12. Moravej,Z.; Pazoki, M.; Khederzadeh, M. New Pattern-Recognition Method for Fault Analysis in Transmission Line With UPFC. IEEE Trans. Power Deliv. 2015, 30, 1231-1242. [CrossRef]

13. Mahmud, M.A.; Pota, H.R.; Hossain, M.J. Full-order nonlinear observer-based excitation controller design for interconnected power systems via exact linearization approach. Int. J. Electr. Power Energy Syst. 2012, 41, 54-62. [CrossRef] 
14. Parimi, A.M.; Elamvazuthi, I.; Kumar, A.V.P.; Cherian, V. Fuzzy logic based control for IPFC for damping low-frequency oscillations in the multimachine power system. In Proceedings of the 2015 IEEE IAS Joint Industrial and Commercial Power Systems/Petroleum and Chemical Industry Conference (ICPSPCIC), Hyderabad, India, 19-21 November 2015.

15. Singh, B.; Mukherjee, V.; Tiwari, P. A survey on impact assessment of DG and FACTS controllers in power systems. Renew. Sustain. Energy Rev. 2015, 42, 846-882. [CrossRef]

16. El-Zonkoly, A. Optimal sizing of SSSC controllers to minimize transmission loss and a novel model of SSSC to study transient response. Electr. Power Syst. Res. 2008, 78, 1856-1864. [CrossRef]

17. Rodríguez, O.; Medina, A.; Andersson, G. Closed-form analytical characterization of non-linear oscillations in power systems incorporating a unified power flow controller. IET Gener. Transm. Distrib. 2015, 9, 1019-1032. [CrossRef]

18. Wang, H. A unified model for analysis of FACTS Devices in Damping Power System Oscillations. Part III: Unified Power Flow Controller. IEEE Trans. Power Deliv. 2000, 15, 978-983. [CrossRef]

19. Torkzadeh, R.; Nasrazadani, H.; Aliabad, A.D. A genetic algorithm optimized fuzzy logic controller for UPFC in order to damp of low-frequency oscillations in power systems. In Proceedings of the 2014 22nd Iranian Conference on Electrical Engineering (ICEE), Tehran, Iran, 20-22 May 2014.

20. Li, Z.; Xia, Y.; Su, C.Y.; Deng, Y.; Fu, J.; He, W. Missile guidance Law Based on robust model predictive control using Neural Network Optimization. IEEE Trans. Neural Netw. Learn. Syst. 2015, 26, 1803-1809. [CrossRef] [PubMed]

21. Xu, R.; Tao, Y.; Lu, Z.; Zhong, Y. Attention-Mechanism-Containing Neural networks for high resolution remote sensing image classification. Electronics 2018, 10,1602. [CrossRef]

22. Barone, E.R.; Salerno, V.; Siniscalchi, S.M. An introductory study on deep neural networks for high resolution areal images. AIP Conf. Proc. 2013, 1558, 1232. [CrossRef]

23. Sinniscalchi, S.M.; Salerno, V.M. Adaptation to new microphones using artificial neural networks with trainable activation functions. IEEE Trans. Neural Netw. Learn. Syst. 2017, 28, 1959-1965. [CrossRef]

24. Hautamaki, V.; Sinniscalchi, S.M.; Behravan, H.; Salerno, V.M.; Kukanov, I. Boosting universal speech attributes classification with deep Neural Network for foreign accent characterization. In Proceedings of the 16th Annual Conference of the International Speech Communication Association, Dresden, Germany, 6-10 September 2015.

25. Fu, Y.; Chai, T. Neural Network Based nonlinear adaptive dynamical decoupling control. IEEE Trans. Neural Netw. 2007, 18, 921-925. [CrossRef]

26. Zeb, K.; Mehmood, C.A.; Khan, B.; Ali, S.M.; Jadoon, A.M.; Uddin, W. Fault tolerant speed regulation of induction motor using artificial neural network. In Proceedings of the IEEE Conference on Emerging Technologies, Peshawar, Pakistan, 19-20 December 2015.

27. Chae, S.; Kwon, S.; Lee, D. Predicting infectious Disease Using Deep learning and Big Data. Int. J. Environ. Res. Public Health 2018, 15, 1596. [CrossRef] [PubMed]

28. Salerno, V.M.; Rabbeni, G. An Extreme learning machine approach to effective energy disaggregation. Electronics 2018, 7, 235. [CrossRef]

29. Douratsos, I.; Gomm, J.B. Neural Network based model reference adaptive control for process with time delay. Int. J. Inf. Syst. Sci. 2006, 3, 161-179.

(C) 2019 by the authors. Licensee MDPI, Basel, Switzerland. This article is an open access article distributed under the terms and conditions of the Creative Commons Attribution (CC BY) license (http://creativecommons.org/licenses/by/4.0/). 



\title{
Article \\ Coordinated Control in VSC-HVDC Multi-Terminal Systems to Improve Transient Stability: The Impact of Communication Latency
}

\author{
Javier Renedo *, Aurelio García-Cerrada, Luis Rouco and Lukas Sigrist \\ Instituto de Investigación Tecnológica (IIT), ETSI ICAI, Universidad Pontificia Comillas, Madrid 28015, Spain; \\ aurelio@iit.comillas.edu (A.G.-C.); luis.rouco@iit.comillas.edu (L.R.); lukas.sigrist@iit.comillas.edu (L.S.) \\ * Correspondence: javier.renedo@iit.comillas.edu
}

Received: 31 July 2019; Accepted: 19 September 2019; Published: 24 September 2019

\begin{abstract}
Power transmission is the main purpose of high voltage direct current systems based on voltage source converters (VSC-HVDC). Nevertheless, this type of system can also help to improve transient stability by implementing suitable supplementary controllers. Previous work proposed active- $(\mathrm{P})$ and reactive-power $(\mathrm{Q})$ control strategies in VSC-HVDC multi-terminal systems (VSC-MTDC, for short) to improve transient stability, producing significant improvements. In those strategies, each VSC station of the MTDC system compares its frequency measurement with the average of the frequencies measured by all converter stations of the MTDC system (weighted-average frequency, WAF) in order to modulate its own P and Q injections. Hence, a communication system is required. This paper presents a detailed analysis of the impact of communication latency on the performance of those control strategies. The communication delays have been modelled using a Padé's approximation and their impact on the performance of the control strategies have been assessed by means of time-domain simulation in PSS/E. The effect of the control strategies on transient stability has been quantified with the critical clearing time (CCT) of a set of faults. Results show that the control strategies analysed present good results for realistic values of communication delays.
\end{abstract}

Keywords: power systems; high voltage direct current (HVDC) transmission; HVDC systems based on voltage source converters (VSC-HVDC); multi-terminal; transient stability; control strategies; communication latency

\section{Introduction}

The main applications of high voltage direct current (HVDC) systems are: (a) transmission of large amounts of power over long overhead lines; (b) power transmission over middle-to-long isolated cables (underground or submarine cables); and (c) interconnection of asynchronous power systems. These characteristics make HVDC a key facilitating technology in several scenarios of present and future power systems. For example, almost all electrical energy systems around the world are being urged to integrate an ever-increasing number of renewable resources which are often in remote sites and will require power transmission over long distances. Hence, grid reinforcement with HVDC links is already in place in many locations and it is an attractive alternative of high voltage alternating current (HVAC) transmission in many others [1]. Furthermore, there is a conceptual proposal for building a pan-European multi-terminal HVDC grid (the so-called "supergrid") interconnecting several countries and connecting offshore wind energy from the North Sea [2-5]. This "supergrid" would be connected at different points to the conventional HVAC transmission system. Undoubtly, the most appropriate technology for a multi-terminal HVDC system is the one based on voltage source converters (VSC-HVDC), which has several advantages for certain applications, in comparison with the classic line commutated converter technology based on thyristors (LCC-HVDC) [1]. 
Key aspects for the deployment of multi-terminal VSC-HVDC grids are converter technology, control of the voltage of the HVDC grid, HVDC breakers and HVDC protection strategies. The most recent converter technology for VSC-HVDC systems is the so-called modular multi-level converter (MMC) [6,7], which makes it possible to obtain output AC voltages with a very-low harmonic content. For example, MMC technology is already being used in the VSC-HVDC interconnector between France and Spain through the Catalonian Pyrenees (INELFE) [8]. DC-voltage control in VSC-HVDC multi-terminal systems must always be guaranteed and there are different control alternatives [9,10]. It can be classified into: (a) centralised DC-voltage control; and (b) distributed DC-voltage control (with local DC-voltage droop control). In the former, only one converter controls the DC voltage (the DC slack), while in the latter approach, DC-voltage control is shared among the converters $[11,12]$ and it is more suitable for large VSC-MTDC systems. There are also more advanced distributed DC-voltage control strategies, aiming to improve the accuracy in power sharing: the so-called pilot-voltage droop control [13], which uses global measurements and a recent control approach based on a power sharing index [14], in which each converter uses measurements of a nearby converter. VSC-HVDC grids need HVDC breakers to be capable to isolate faults in the HVDC grid, while maintaning the system in operation. The interruption of the current in DC is much more difficult than the interrumption of the current in AC, since the former does not pass through zero. Furthermore, HVDC breakers need to open the circuit in a few milliseconds, in order to protect the converters. The main manufacturers already have prototypes for HVDC breakers $[15,16]$, although the technology is not mature yet. VSC-HVDC systems also need effective protection algorithms to detect and locate faults in the HVDC grid within milliseconds. Different protection algorithms for VSC-HVDC grids have been proposed recently [17-25].

VSC-HVDC systems are very expensive and, although their main purpose will always be to facilitate power transmission overcoming the limitations of traditional HVAC systems, any additional contribution to the control and operation of power systems should be welcome. For example, several publications have already explored control strategies in point-to-point VSC-HVDC links to improve transient stability of power systems [26-29]. Transient stability (angle stability against large disturbances [30]) margins deteriorate seriosly when long and heavily loaded HVAC lines are used. In multi-machine systems, transient stability is a global problem involving synchronism of all generators of the system and the most effective control actions to improve those margins use global measurements, such as the speed of the centre of inertia (COI) of the system [31-33].

Recently, several control strategies for multi-terminal VSC-HVDC systems (VSC-MTDC, for short) have been proposed to improve transient stability. A supplementary control strategy for active- $(\mathrm{P})$ and reactive-power $(\mathrm{Q})$ injections of the VSC stations, using a linear combination of the speed deviations of the generators of the system as input signal, was proposed in [34]. The work in [35] proposed a bang-bang-type supplementary $\mathrm{P}$ controller at each VSC station, using a combination of the speed deviations of all generators of the system with respect to the speed of the COI as input signal. A sliding-mode control strategy for P injections in VSC-MTDC systems, also using the speed of the COI, was proposed in [36]. The speed of the COI for P and Q modulation in VSC-MTDC systems is also used in the control strategy proposed in [37]. All these control strategies require a Wide Area Measurement System (WAMS), so that each VSC can know the speeds of all generators of the system in real time. Alternatively, the work in [38] proposed a control strategy for P injections of converter stations in VSC-MTDC systems using the average of the frequencies measured at the connection point of the VSC stations (weighted-average frequency, or WAF for short), to improve transient stability. This strategy will be referred to as P-WAF in the rest of the paper. Similarly, the WAF was used to modulate Q injections at the converter stations in VSC-MTDC systems in [39] (strategy Q-WAF, for short), also to improve transient stability.

Although the speed of the COI seems to be the most comprehensive measurement to be used, strategies P-WAF and Q-WAF have two key advantages with respect this approach: each VSC station 
already measures the frequency at its AC terminals, for synchronisation purposes and a communication system within the VSC-MTDC system, only, is required.

Recent work has derived an analytical formula to approximate the bus frequencies as a linear combination of the speeds of all generators of the system [40], proving the idea that the speeds of the generators can be observed in the bus frequencies. In fact, the speed of the COI can also be approximated as a linear combination of a set of bus frequencies of the system [41].

Since control strategies P-WAF and Q-WAF require a communication system between the stations of the VSC-MTDC systems, their performance might be affected by communication latency. Previous work was restricted to prove that strategies P-WAF and Q-WAF could stand a reasonable communication latency. However, a detailed analysis of the impact of communication delays on these control strategies has not been reported in the literature so far. Along this line, the contributions of this paper include:

- A comprehensive analysis of the impact of communication latency on strategies P-WAF (P injections of the VSC stations) and Q-WAF (Q injections of the VSC stations).

- A comprehensive analysis of the impact of communication latency on simultaneous modulation of $\mathrm{P}$ and $\mathrm{Q}$ injections of the VSC stations by implementing strategies P-WAF and Q-WAF together (PQ-WAF, for short).

- A detailed analysis of the impact of different tipes of communication delays on strategies P-WAF, Q-WAF and PQ-WAF.

- Analysis of the impact of communication delays on strategy P-WAF, depending on the approach used for DC-voltage control in the VSC-MTDC system (a single DC-slack converter or DC-voltage droop control).

The rest of the paper is organised as follows. Section 2 describes a suitable model for VSC-MTDC systems for electro-mechanical simulation. Section 3 describes the proposed transient-stability-tailored control strategies in VSC-MTDC systems based on the WAF. Section 4 presents a small case study (Kundur's two-area test system with an embedded VSC-MTDC system) to illustrate impact of communication latency on the performance of the control strategies. Section 5 presents the results of a larger case study (Cigré Nordic32A test system with an embedded VSC-MTDC system). Section 6 presents the conclusions of the paper. Finally, data of the case study are provide in Appendixes A and B.

\section{VSC-HVDC Multi-Terminal Systems}

A VSC-MTDC system consists of several VSC stations connecting a DC grid to one or more AC grids. Figure 1 shows a hybrid AC/DC system with an embedded VSC-MTDC system while Figure 2 illustrates the dynamic model of a VSC station connected to an AC grid and to a DC grid, following the guidelines of $[42,43]$ for electro-mechanical simulation. The guidelines of the modelling approach used are provided in this section, while details are available in [44].

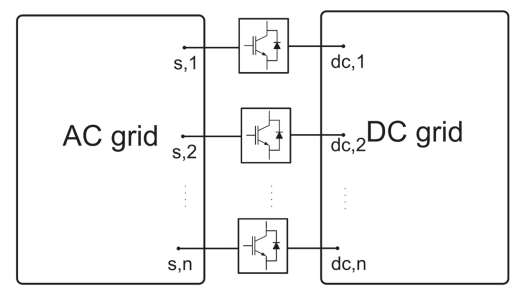

Figure 1. Hybrid voltage source converters (VSC)-based AC/DC system. 


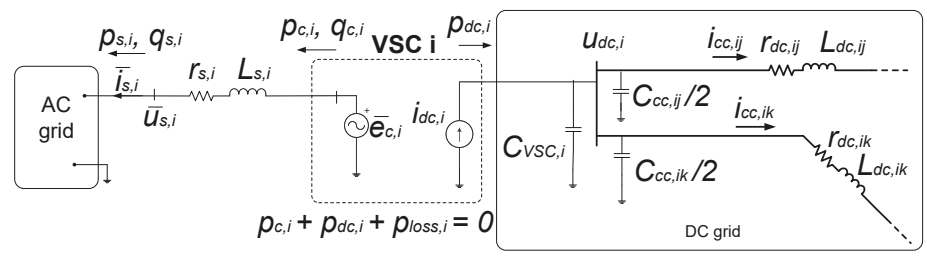

Figure 2. Model of a VSC and the DC grid [42].

\subsection{VSC Stations}

A VSC station is seen, from the AC side, as a voltage source $\left(\bar{e}_{c, i}\right)$ connected through a connection impedance (reactor + transformer: $\bar{z}_{s, i}=r_{s, i}+j x_{s, i}$ ) to the connection point (with voltage $\bar{u}_{s, i}$ ) (Figure 2).

A VSC station is usually controlled with vector control, where mobile $d q$ axes are aligned with the voltage of the connection point: $\bar{u}_{s, i}=u_{s, i}+j 0$. The control system has an inner current loop $\left(i_{s, d, i}\right.$ and $\left.i_{s, q, i}\right)$ and an outer control loop. Since, for transient stability studies, the dynamics of interest (transients spanning 1-20 s) are much slower than the dynamics of the inner controllers of the VSC stations, the closed loop of the inner current loops can be approximated by first-order transfer functions. Every VSC station has two degrees of freedom for the outer loop: (a) the converter can control either the active-power injection into the AC grid $\left(p_{s, i}\right)$ or the DC voltage $\left(u_{d c, i}\right)$ with the $d$-axis current; and (b) the converter can control either the reactive-power injection into the AC grid $\left(q_{s, i}\right)$ or the magnitude of the AC voltage at the connection point $\left(u_{s, i}\right)$ with the $q$-axis current. Operating limits of the converters can be easily implemented in the model [44].

AC and DC sides of a converter station are coupled by the energy conservation principle:

$$
p_{c, i}+p_{l o s s, i}+p_{d c, i}=0
$$

where losses, $p_{\text {loss, } i}$, are best modelled as a quadratic function of the current injection of the VSC, $i_{s, i}(\mathrm{rms})$, as proposed in [45]:

$$
p_{\text {loss }, i}=a_{i}+b_{i} \cdot i_{s, i}+c_{i} \cdot i_{s, i}^{2}
$$

\subsection{Grid}

VSC stations are seen from the DC grid as current injections into the buses: $i_{d c, i}=p_{d c, i} / u_{d c, i}$ (Figure 2). DC lines are represented as lumped $\pi$ models. Every DC branch $i-j$ will have the series resistance and the inductance of the DC line ( $r_{d c, i j}$ and $L_{d c, i j}$, respectively). Every DC bus $i$ will have an equivalent capacitance $\left(C_{d c, i}\right)$, that includes the equivalent capacitance of the DC side of the VSC station $\left(C_{V S C, i}\right)$ and the contribution of the shunt capacitance of the DC lines connected to that bus $\left(C_{c c, i j} / 2\right)$ :

$$
C_{d c, i}=C_{V S C, i}+\sum_{j \neq i} \frac{C_{c c, i j}}{2}
$$

\subsection{Voltage Control in the DC Grid}

Voltage control in the DC grid can be implemented either with a centralised approach (a single DC-slack converter) or with a distributed approach (DC-voltage droop control) [9,10]. In the DC-voltage droop approach, the active-power set point of every VSC station is given by [43]:

$$
p_{s, i}^{r e f}=p_{s, i}^{0}-\frac{1}{k_{d c, i}}\left(u_{d c, i}^{0}-u_{d c, i}\right)
$$




\subsection{Model Implementation}

The dynamic model of a VSC-MTDC system has been implemented in PSS/E [46], following the guidelines of [47-50]. The initial operating point is obtained solving a sequential AC/DC power flow, as proposed in [51]. Details of the PSS/E implementation used for this work and its validation can be found in [44].

\section{Control Strategies}

Figure 3 shows a general diagram for P and Q control in a VSC station. In addition to the constant P set point required by the TSO $\left(p_{s}^{0}\right)$ and the DC-voltage droop, the VSC station has a supplementary P set point $\left(\Delta p_{s}^{r e f}\right)$. Similarly, in addition to the constant Q set point $\left(p_{s}^{0}\right)$, the VSC station has a supplementary $\mathrm{Q}$ set point $\left(\Delta q_{s}^{r e f}\right)$. Supplementary set points for $\mathrm{P}\left(\Delta p_{s}^{r e f}\right)$ and $\mathrm{Q}$ injections $\left(\Delta q_{s}^{r e f}\right)$ are aimed to improve transient stability. Notice that the supplementary controllers could also be implemented with a centralised DC-voltage control in the VSC-MTDC without DC-voltage droop and only one converter looking after the DC voltage. Since voltage control in the HVDC grid is a major concern, any supplementary control strategy for P injections of the VSC stations in VSC-MTDC system must be compatible with the DC-voltage control scheme used.

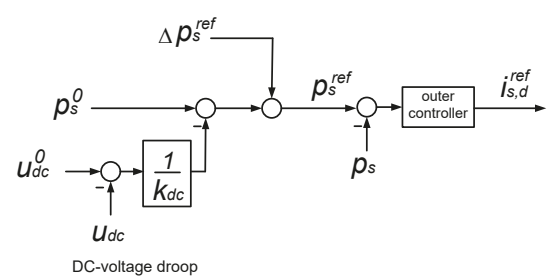

(a)

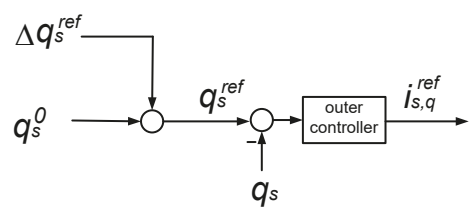

(b)

Figure 3. (a) P control and (b) Q control.

\subsection{Strategy P-WAF}

The block diagram of P control of a VSC station, when using strategy P-WAF, is shown in Figure 4 [38]. A supplement proportional to the frequency error is added to the $\mathrm{P}$ set point. The frequency set point is calculated as the weighted average of the frequencies measured at the AC side of the VSC stations (weighted-averaged frequency, WAF):

$$
\omega^{*}=\bar{\omega}=\sum_{k=1}^{n} \alpha_{k} \omega_{k}, \text { with } \alpha_{k} \in[0,1] \text { and } \sum_{k=1}^{n} \alpha_{k}=1
$$

where $\omega_{k}$ is the frequency measured at the connection point of $V S C_{k}$.

The controller consists of a proportional gain $\left(k_{P}\right)$, a low-pass filter for noise filtering (with time constant $T_{f}$ ), a wash-out filter in order to avoid the actuation of the controller under steady-state frequency deviations (with time constant $\left.T_{W}\right)$ and a saturation parameter $\left(\Delta p_{\max }\right)$. Notice that in Figure 4, the VSC has the DC-voltage droop control $\left(\Delta p_{s}^{r e f, D C}\right)$ implemented together with the supplementary control strategy, but this is not mandatory. 


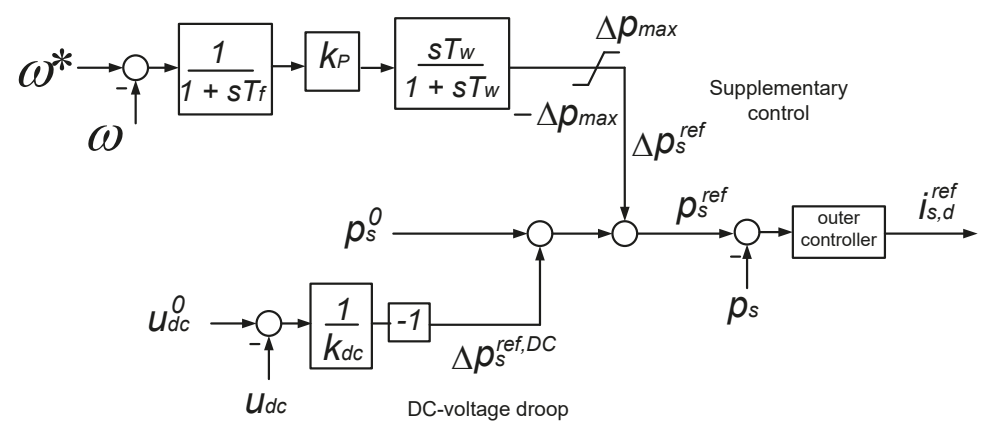

Figure 4. Control for the active-power injection of a VSC.

The performance of this control strategy can be summarised as follows:

- If the frequency at the connection point of a VSC station is above the WAF, the converter will decrease its $\mathrm{P}$ injection into the AC grid, aiming to slow down nearby generators.

- If the frequency at the connection point of a VSC station is below the WAF, the converter will increase its $\mathrm{P}$ injection into the AC grid, aiming to accelerate nearby generators.

- This behaviour should pull together the angles of the generators of the system improving, therefore, transient stability.

The work in [38] proposed the following design of the controller gains $\left(k_{P, k}\right)$ and the weighting factors used to calculate the $\operatorname{WAF}\left(\alpha_{k}\right)$ :

$$
\frac{k_{P, k}}{k_{P, T}}=\alpha_{k}, \text { with } k_{P, T}=\sum_{j=1}^{n} k_{P, j}
$$

This design ensures $\sum_{j=1}^{n} \Delta p_{s, j}^{r e f}=0$ and avoids the interaction of the supplementary controller with the DC-voltage droop control.

\subsection{Strategy $Q-W A F$}

In strategy Q-WAF, a supplement proportional to the frequency error is added to the $\mathrm{Q}$ set point, as shown in Figure 5 [39]. The frequency set point is also calculated as the WAF (5). This controller also consists of a proportional gain $\left(k_{Q}\right)$, a low-pass filter (with time constant $T_{f}$ ), a wash-out filter (with time constant $\left.T_{W}\right)$ and a saturation parameter $\left(\Delta q_{\max }\right)$. Notice that strategy Q-WAF has an additional minus sign (Figure 5).

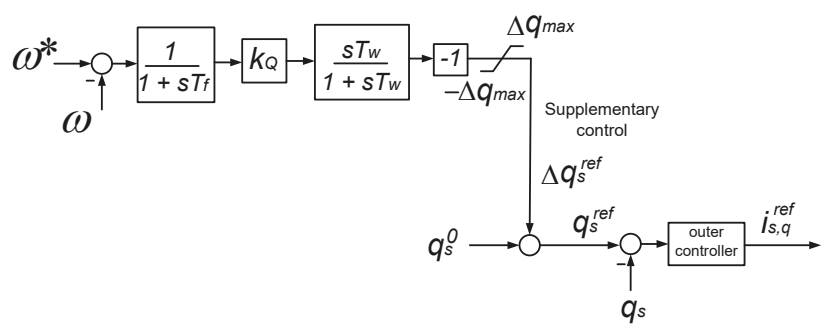

Figure 5. Control for the reactive-power injection of a VSC. 
This control strategy can be summarised as follows:

- If the frequency at the connection point of a VSC station is above the WAF, the converter will increase its $\mathrm{Q}$ injection into the $\mathrm{AC}$ grid, aiming to increase the electromagnetic torque applied to nearby generators and slow them down.

- If the frequency at the connection point of a VSC station is below the WAF, the converter will decrease its $\mathrm{Q}$ injection into the $\mathrm{AC}$ grid, aiming to reduce the electromagnetic torque applied to nearby generators and accelerate them.

- Again, this behaviour should eventually pull together the angles of the generators of the system, improving transient stability.

The following design was used in [39]:

$$
\frac{k_{Q, k}}{k_{Q, T}}=\alpha_{k}, k_{Q, T}=\sum_{j=1}^{n} k_{Q, j}
$$

This ensures $\sum_{j=1}^{n} \Delta q_{s, j}^{r e f}=0$. However, this condition is not mandatory for $\mathrm{Q}$ control.

\subsection{Strategy $P Q-W A F$}

$\mathrm{P}$ and $\mathrm{Q}$ injections of the VSC stations can be modulated simultaneously, according to strategies P-WAF (Figure 4) and Q-WAF (Figure 5), using the weighted-averaged frequency in Equation (5) as the frequency set point. This strategy will be named PQ-WAF in the rest of the paper.

\subsection{Communication Latency}

In strategies P-WAF, Q-WAF and PQ-WAF, every VSC station uses global signals of frequency measurements at the connection point of all the VSC stations of the VSC-MTDC system, in order to calculate the WAF in Equation (5). Hence, communications among the converter stations must be established and the calculation of the WAF will be subject to communication latency. For transient-stability-tailored controllers, fast communication systems are required (faster than $100 \mathrm{~ms}$, in general). The work in [52] proposed a model to represent communication delays in wide-area control system. Total communication delay was divided into two parts: (a) the delay caused by the propagation of the information in the communication system; and (b) the operational delay, that accounts for the time required for the calculations. Total communication delays within the range 50-80 ms were reported in [52], according to phasor measurement unit (PMU) records in the Chinese power system and to real-time simulation experiments.

The impact of the communication latency on the performance of the proposed control strategies is analysed here by introducing a delay in the frequency at the AC bus of VSC station $i$, measured by VSC station $j\left(\omega_{i}^{j}\right)$ :

$$
\omega_{i}^{j}=\omega_{i} e^{-\tau_{i j} s}
$$

where $\tau_{i j}$ accounts for the total communication delay (operational delay + communication delay). Hence, each VSC $j$ will use a frequency set point for P and/or Q modulation ( $\omega_{j}^{*}$ in Figures 4 and 5) using the delayed frequency measurements, according to:

$$
\omega_{j}^{*}=\bar{\omega}^{j}=\sum_{k=1}^{n} \alpha_{k} \omega_{k}^{j}
$$

The implementation of Equation (9) is shown in Figure 6. 
The delay in Equation (8) has been implemented using a second-order Padé's approximation [53]:

$$
e^{-\tau_{i j} s} \approx \frac{1-\frac{\tau_{i j}}{2} s+\frac{\tau_{i j}^{2}}{12} s^{2}}{1+\frac{\tau_{i j}}{2} s+\frac{\tau_{i j}^{2}}{12} s^{2}}
$$

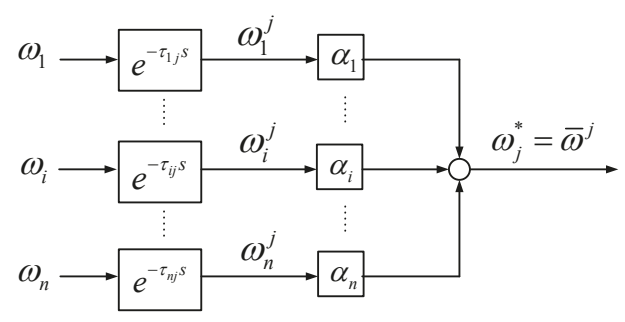

Figure 6. Calculation of the frequency set point of VSC $j$ in the presence of communication latency.

\section{Case Study 1: Kundur's Two-Area Test System with an Embedded VSC-MTDC System}

The Kundur's two-area test system [54] with an embedded 4-terminal VSC-MTDC system was used for simulation (Figure 7). Data are detailed in Appendix A. Converter stations were operated with DC-voltage droop control and reactive-power control. Simulations were carried out in PSS/E software [46], with the VSC-MTDC model presented in [44].

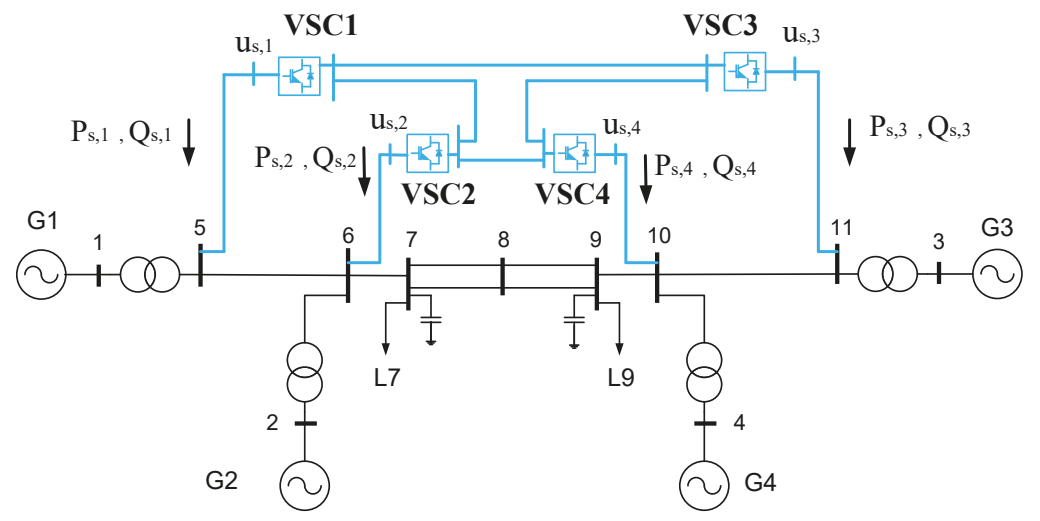

Figure 7. Kundur's 2-area system with an embedded VSC-MTDC.

The initial operating point of the VSC-MTDC system was calculated running an AC/DC power flow, with the following specified variables:

- $\quad$ VSC1: $P_{s, 1}^{0}=-200 \mathrm{MW}$ and $Q_{\mathrm{s} 1}^{0}=0 \mathrm{MVAr}$.

- VSC2: $P_{s, 2}^{\delta 1}=-200 \mathrm{MW}$ and $Q_{s, 2}^{\mathrm{d}}=0 \mathrm{MVAr}$.

- VSC3: $P_{s, 3}^{0}=200 \mathrm{MW}$ and $Q_{s, 3}^{0}=0 \mathrm{MVAr}$.

- VSC4: $u_{d c, 4}^{0}=1$ p.u and $Q_{s, 4}^{0}=0$ MVAr (VSC4 is used as the DC-slack converter for power-flow calculation).

The following cases have been analysed and compared:

- DC0: No supplementary control strategy in the VSC stations.

- $\quad$ Strategy P-WAF (P injections of VSC stations).

- $\quad$ Strategy Q-WAF (Q injections of VSC stations).

- $\quad$ Strategy PQ-WAF (simultaneous modulation of P and Q injections of VSC stations). 


\subsection{Control Strategies}

To start with, the performance of the control strategies was analysed, without communication delays, in order to illustrate the ideally achievable results.

\subsubsection{Fault simulation}

A three-phase-to-ground short circuit at line 7-8 a (close to bus 7) has been simulated. The fault is cleared after $200 \mathrm{~ms}$ by disconnecting the faulted circuit. Figure 8 shows the angle difference between generators 1 and 3. Generators lose synchronism when the VSC stations do not have any supplementary control strategies implemented (DC0), while synchronism is maintained with control strategies P-WAF, Q-WAF and PQ-WAF. Strategies P-WAF and PQ-WAF show better damping of the first swing of the angle difference than strategy Q-WAF.

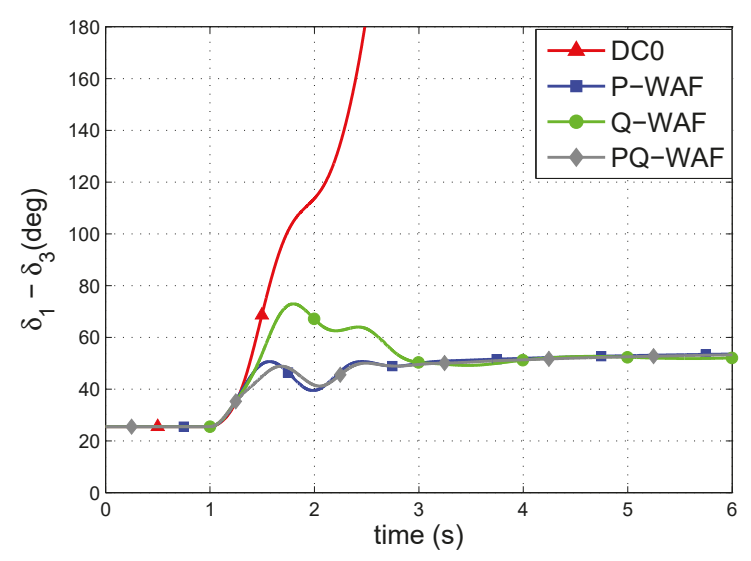

Figure 8. Generator angle difference.

In order to fully understand the effect of the proposed control strategies, the frequencies measured at the VSC stations $\left(\omega_{i}\right)$, the WAF $(\bar{\omega})$ and the frequency deviations with respect to the WAF $\left(\omega_{i}-\bar{\omega}\right)$ are shown in Figure 9 for strategy P-WAF. Strategies Q-WAF and PQ-WAF show a similar pattern. During the short circuit, all synchronous machines of the system accelerate and all frequencies measured at the VSC stations rise. Nevertheless, some frequencies increase more than others. For example, during the fault and immediately after the fault clearance, frequencies measured by VSC1 and VSC2 are above the WAF, while frequencies measured by VSC3 and VSC4 are below the WAF.

Figure 10 shows active- and reactive-power injections of the VSC stations into the AC grid, respectively. Without supplementary control (DC0), P and Q injections remain constant. In strategy P-WAF, P injections are modulated during the transient: immediately after the fault clearance, VSCs 1 and 2 reduce their $P$ injections, since the frequencies measured by those converters are above the WAF. On the contrary, VSCs 3 and 4 increase their P injections, since their frequencies are below the WAF. In strategy Q-WAF, VSCs 1 and 2 increase their Q injections immediately after the fault clearance, while VSCs 3 and 4 reduce their Q injections. In strategy PQ-WAF, both, P and Q injections, are modulated simultaneously and this is why control effort is lower than the one in P-WAF and Q-WAF. By modulating P and Q injections of the VSC stations with strategies P-WAF, Q-WAF and PQ-WAF, the angles of generators are pulled together and transient stability is improved. Finally, Figure 11 shows the $\mathrm{DC}$ voltages of the converter stations, which remain close to 1 p.u. during the simulation. 

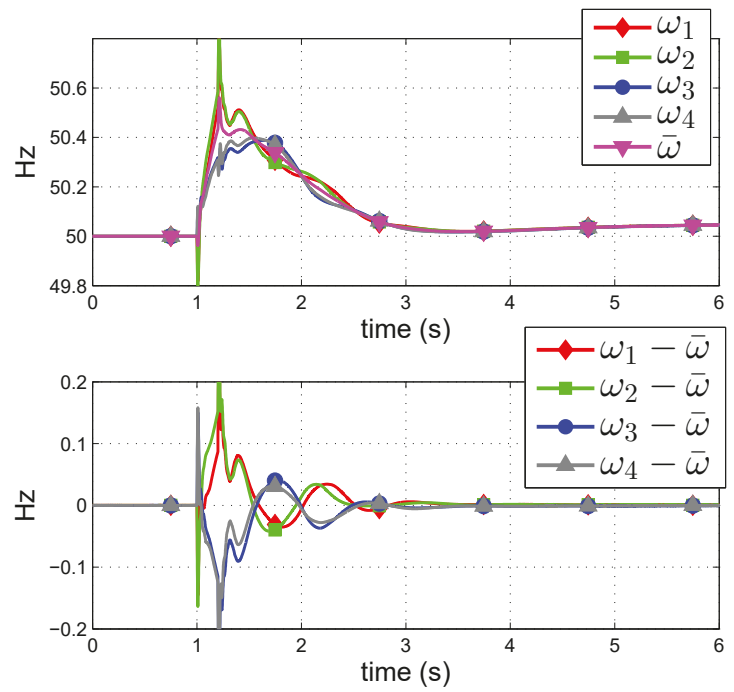

Figure 9. Frequencies measured at the converter stations $\left(\omega_{i}\right)$ and WAF $(\bar{\omega})$ (when using P-WAF).
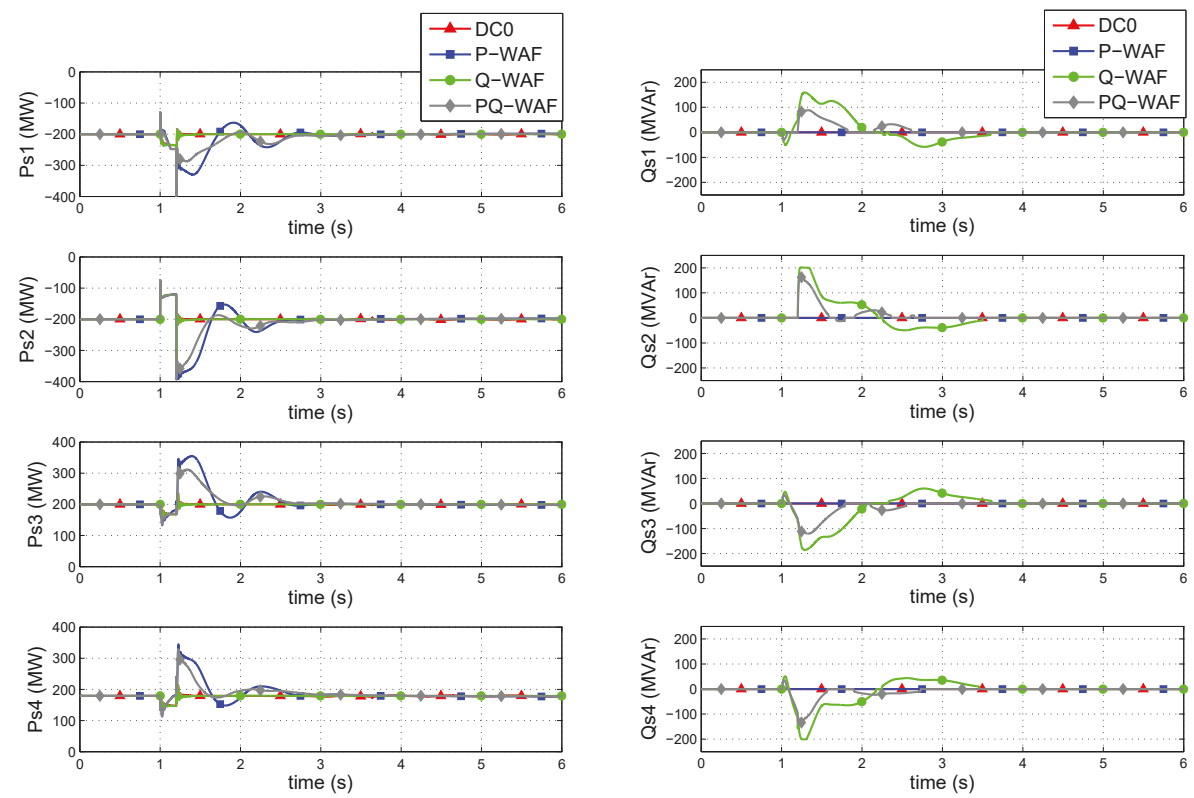

(a)

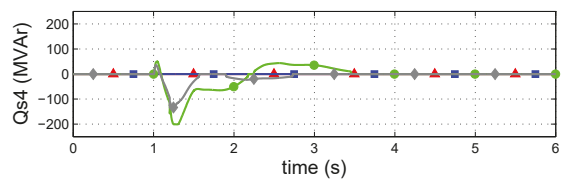

(b)

Figure 10. (a) $\mathrm{P}$ and (b) $\mathrm{Q}$ injections of the converters. 

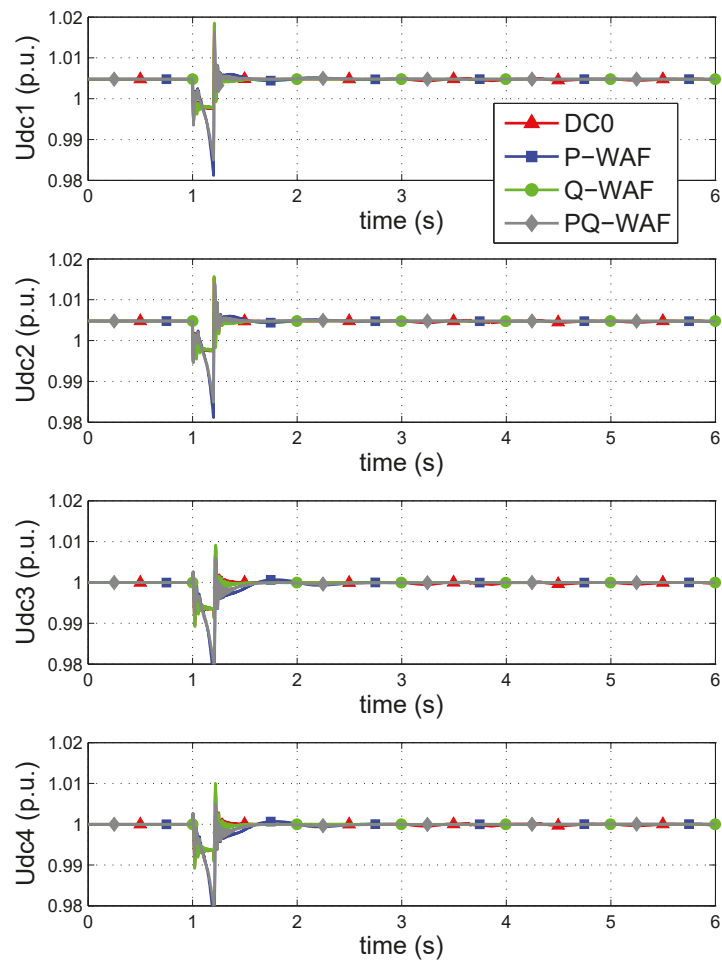

Figure 11. DC voltages.

\subsubsection{Critical Clearing Times}

The critical clearing time (CCT) is defined as the maximum time that a fault can remain before been cleared, without producing loss of synchronism and it is normally used as an indicator of a transient stability margin. The CCTs of the faults described in Table 1 are compared in Table 2, concluding that control strategies P-WAF, Q-WAF and PQ-WAF increase the CCTs significantly, with respect to the base case (DC0).

Table 1. Faults.

\begin{tabular}{lccc}
\hline & Short Circuit at Line $i-j$ & Close to Bus & Clearing \\
\hline Fault I & $7-8$ a & 7 & Disconnection of line 7-8 a \\
Fault II & $5-6$ & 5 & Short circuit cleared (line not disconnected) \\
Fault III & $10-11$ & 10 & Short circuit cleared (line not disconnected) \\
\hline
\end{tabular}

Table 2. Critical clearing times (CCT).

\begin{tabular}{lccc}
\hline CCTs (ms) & Fault I & Fault II & Fault III \\
\hline DC0 & 150 & 178 & 189 \\
P-WAF & 430 & 242 & 479 \\
Q-WAF & 726 & 423 & 339 \\
PQ-WAF & 828 & 369 & 585 \\
\hline
\end{tabular}




\subsection{Impact of Communication Latency}

The effect of latency on the frequencies measured by each VSC station to calculate the WAF in Equation (5) has been investigated. Each converter $i$ will have a delay $\tau_{i i}=0$ (zero delay applied to its own frequency measurement) and $\tau_{i j} \neq 0$ (non-zero delay applied to the frequency measurements of the rest of VSC stations), when calculating the WAF.

\subsubsection{Strategy P-WAF}

The same fault as in Section 4.1.1 was simulated (Fault I of Table 1 cleared after $200 \mathrm{~ms}$ ). Strategy P-WAF was implemented and the frequency signals were used by each converter to calculate the actual WAF communication latency. The following cases will be compared:

- $\quad$ Strategy P-WAF, without communication latency $\left(\tau_{i j}=0 \mathrm{~ms}\right)$.

- $\quad$ Strategy P-WAF, with a communication latency of $50 \mathrm{~ms}\left(\tau_{i i}=0 \mathrm{~ms}\right.$ and $\tau_{i j}=50 \mathrm{~ms}$ if $\left.i \neq j\right)$.

- $\quad$ Strategy P-WAF, with a communication latency of $100 \mathrm{~ms}\left(\tau_{i i}=0 \mathrm{~ms}\right.$ and $\tau_{i j}=100 \mathrm{~ms}$ if $\left.i \neq j\right)$.

First of all, the impact of the communication delay on frequency measurements is illustrated: Figure 12 shows the true frequency at the AC terminal of VSC2 and the frequency of VSC2 measured by VSC1 when calculating the WAF, with a communication delay of $\tau_{12}=100 \mathrm{~ms}$. Clearly, VSC1 sees the frequency of VSC2 delayed.

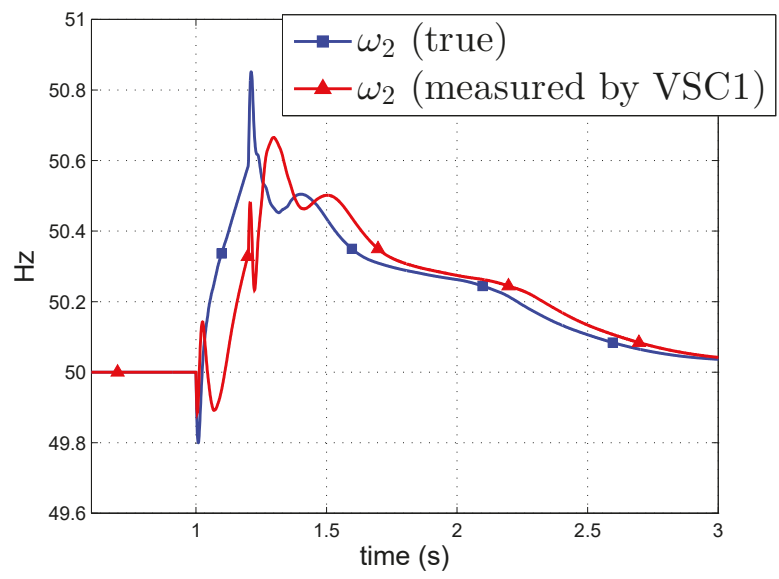

Figure 12. Strategy P-WAF with $\tau_{i j}=100 \mathrm{~ms}$. Frequency of VSC2 measured by VSC1.

Results obtained with strategy P-WAF, with zero delay, $\tau_{i j}=50 \mathrm{~ms}$ and $\tau_{i j}=100 \mathrm{~ms}$ are shown in Figures 13 and 14, respectively. The larger the communication delay is, the larger the generator-angle difference during the first swing is. However, the impact of communication latency on control strategy P-WAF is remarkable small and similar results are obtained in comparison to the case without communication latency. Notice that the time response of the P injections are very similar in the three cases (Figure 14a). This is due to the fact that strategy P-WAF and the DC-voltage droop are implemented together in all converter stations. Communication latency produces $\sum_{j=1}^{n} \Delta p_{j}^{r e f} \neq 0$, provoking DC-voltage fluctuations during the fault and immediately after its clearence (Figure 14b). These DC-voltage fluctuations are compensated with power sharing among all VSC stations thanks to the beneficial effect of the DC-voltage droop control implemented. 


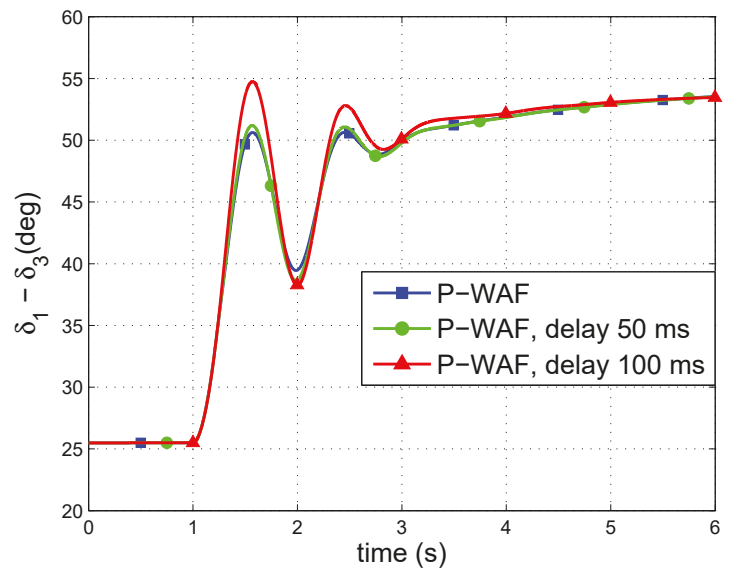

Figure 13. Strategy P-WAF: Impact of communication latency. Generator angle difference.
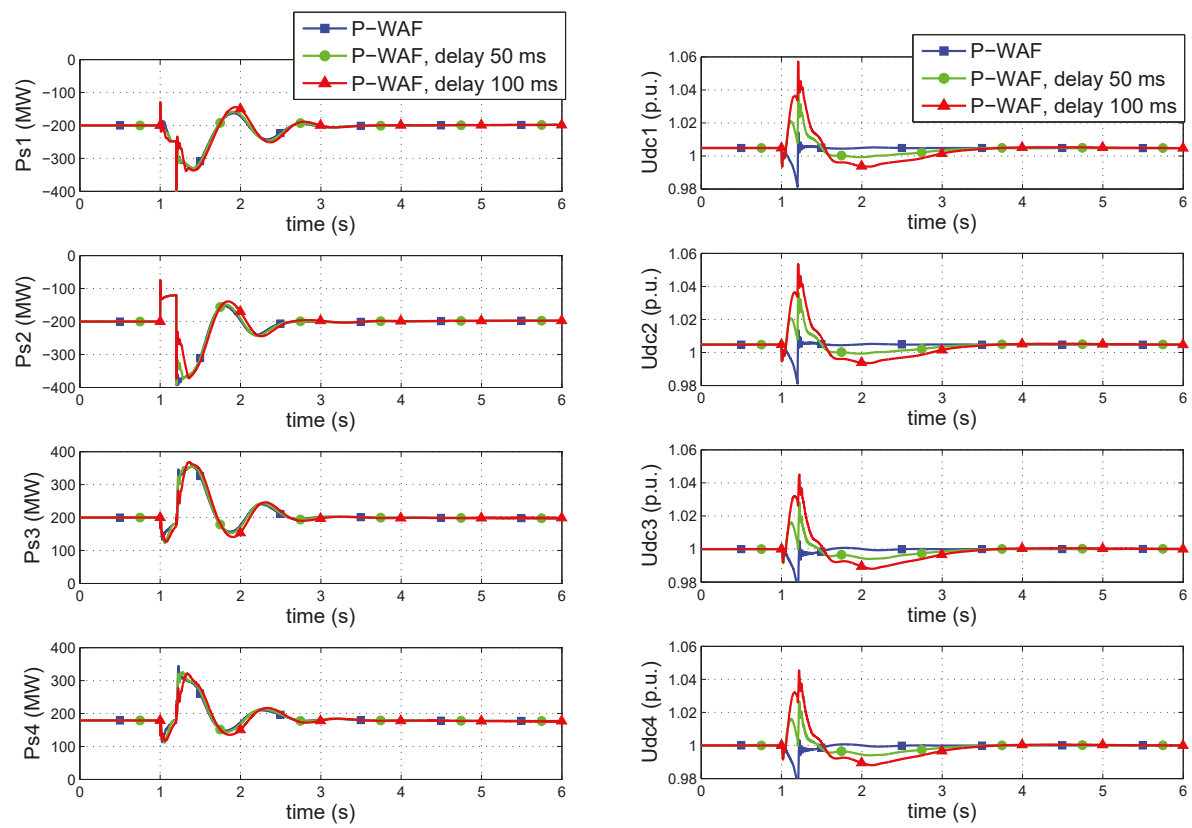

(a)

(b)

Figure 14. (a) P injections of the converters and (b) DC voltages.

\subsubsection{Strategy Q-WAF}

Fault I of Table 1, cleared after $200 \mathrm{~ms}$, was simulated. The following cases are compared:

- $\quad$ Strategy Q-WAF, without communication latency $\left(\tau_{i j}=0 \mathrm{~ms}\right)$.

- Strategy Q-WAF, with a communication latency of $50 \mathrm{~ms}\left(\tau_{i i}=0 \mathrm{~ms}\right.$ and $\tau_{i j}=50 \mathrm{~ms}$ if $i \neq j$ ).

- Strategy Q-WAF, with a communication latency of $100 \mathrm{~ms}\left(\tau_{i i}=0 \mathrm{~ms}\right.$ and $\tau_{i j}=100 \mathrm{~ms}$ if $i \neq j$ ).

Figure 15 shows the generator-angle differences, while Figure 16 shows Q injections of the VSC stations. Q-WAF clearly deteriorates with communication latency. This effect is more noticeable than 
when using strategy P-WAF. However, synchronism is maintained in all three cases. Q modulation with communication latency differs from the one with $\tau_{i j}=0 \mathrm{~ms}$ (Figure 16). Notice that, in the presence of communication latency, Q injections of VSCs 1 and 2 reach their limits (200 MVAr) during the fault and immediately after the fault clearance (Figure 16). The plots of P injections and DC voltages are omitted, since reactive-power control is independent of power sharing and DC voltages of the VSC-MTDC system.

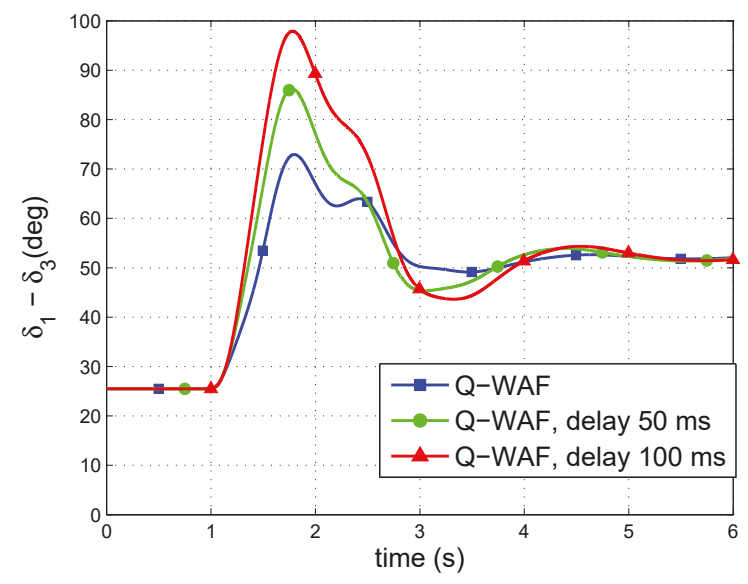

Figure 15. Generator angle difference.

\subsubsection{Strategy PQ-WAF}

The effect of communication latency on strategy PQ-WAF was also analysed. Again, Fault I of Table 1, cleared after $200 \mathrm{~ms}$, was simulated. The following cases are compared:

- $\quad$ Strategy PQ-WAF, without communication latency $\left(\tau_{i j}=0 \mathrm{~ms}\right)$.

- Strategy PQ-WAF, with a communication latency of $50 \mathrm{~ms}\left(\tau_{i i}=0 \mathrm{~ms}\right.$ and $\tau_{i j}=50 \mathrm{~ms}$ if $\left.i \neq j\right)$.

- Strategy PQ-WAF, with a communication latency of $100 \mathrm{~ms}\left(\tau_{i i}=0 \mathrm{~ms}\right.$ and $\tau_{i j}=100 \mathrm{~ms}$ if $\left.i \neq j\right)$.

Figure 17 shows the generator-angle differences. Results deteriorate with communication latency although stability is maintained in all three cases. The rest of the plots are omitted (P injections, $\mathrm{Q}$ injections and DC voltages), since they do not help understanding the system performance. 

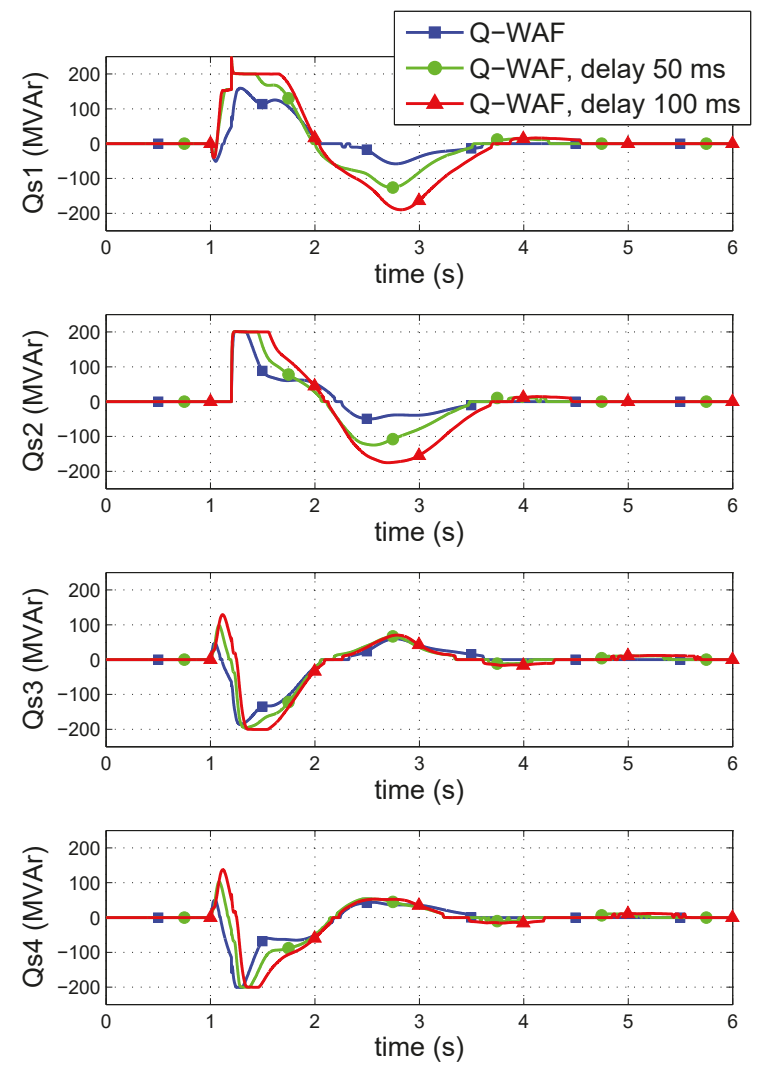

Figure 16. Q injections of the converters.

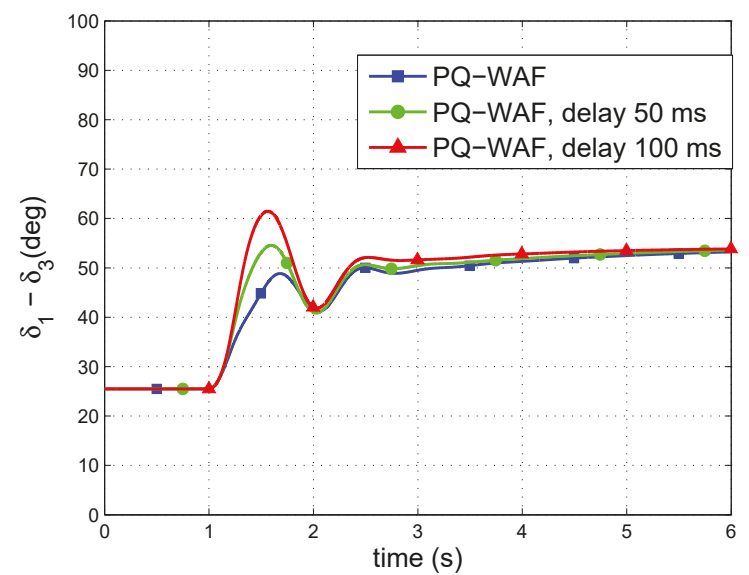

Figure 17. Generator angle difference. 


\subsubsection{Critical Clearing Times}

Table 3 shows the CCTs for the faults of Table 1, obtained with strategies P-WAF, Q-WAF and PQ-WAF, with communication latency of $50 \mathrm{~ms}$ and $100 \mathrm{~ms}$. This case is called Case A, for further comparison with other cases in Section 4.3. The CCTs of all faults decrease as the communication latency increases, for all the control strategies. As already discussed, the impact of communication latency is more noticeable in strategy Q-WAF ( $Q$ injections) than in strategy P-WAF (P injections). The CCTs for all faults, obtained with the three control strategies and with a communication latency of $100 \mathrm{~ms}$, are significantly higher than those obtained in the base case (DC0).

Table 3. Case A. CCT. Effect of communication latency.

\begin{tabular}{lccc}
\hline CCTs (ms) & Fault I & Fault II & Fault III \\
\hline DC0 & 150 & 178 & 189 \\
\hline P-WAF & 430 & 242 & 479 \\
P-WAF, delay 50 ms & 433 & 242 & 443 \\
P-WAF, delay 100 ms & 436 & 243 & 381 \\
\hline Q-WAF & 726 & 423 & 339 \\
Q-WAF, delay 50 ms & 428 & 398 & 295 \\
Q-WAF, delay 100 ms & 273 & 312 & 287 \\
\hline PQ-WAF & 828 & 369 & 585 \\
PQ-WAF, delay 50 ms & 566 & 332 & 534 \\
PQ-WAF, delay 100 ms & 444 & 291 & 471 \\
\hline
\end{tabular}

Finally, Figure 18 shows the CCT for Fault I versus communication-latency delay $\left(\tau_{i j}\right.$ ) (from $0 \mathrm{~ms}$ to $250 \mathrm{~ms}$, using a step of $50 \mathrm{~ms}$ ). The CCT of the base case (DC0) is included in Figure 18 for comparison purposes. An indicator $\eta$ is also plotted in Figure 18, which is defined as the CCT obtained with a certain control strategy divided by the CCT obtained in the base case:

$$
\eta=\frac{C C T(\text { control strategy })}{C C T(D C 0)}
$$

As $\tau_{i j}$ increases, the CCTs obtained with strategies Q-WAF and PQ-WAF decrease faster that the CCT obtained with strategy P-WAF (Figure 18). Notice that, in all three strategies, the CCTs obtained with $\tau_{i j}=250 \mathrm{~ms}$ are greater than the CCT obtained in the base case (DC0). Therefore, strategies P-WAF, Q-WAF and PQ-WAF proved to be robust against communication latency (see the percentage values of $\eta$ in Figure 18).

\subsection{Further Analysis of the Impact of Communication Latency: Equal versus Different Delays in the Communication Channels}

A communication system between the VSC stations can be implemented in several ways. For example, frequency measurements at the AC side of all VSC stations can be collected by a central controller in order to be later distributed so that each converter can calculate the WAF according to Equation (5). Alternatively, each VSC station could be communicated directly with the others. Different communication arrangements will produce different latency patterns. There are two key aspects of communication latency that could affect the performance of the control strategies:

- Total communication delay for frequency measurements at the VSC stations: having a delayed WAF instead of its true value.

- Different communication delays for frequency measurements at the VSC stations: having a perturbed WAF instead of its true value, caused by different values of the communication delays of each frequency measurement. 

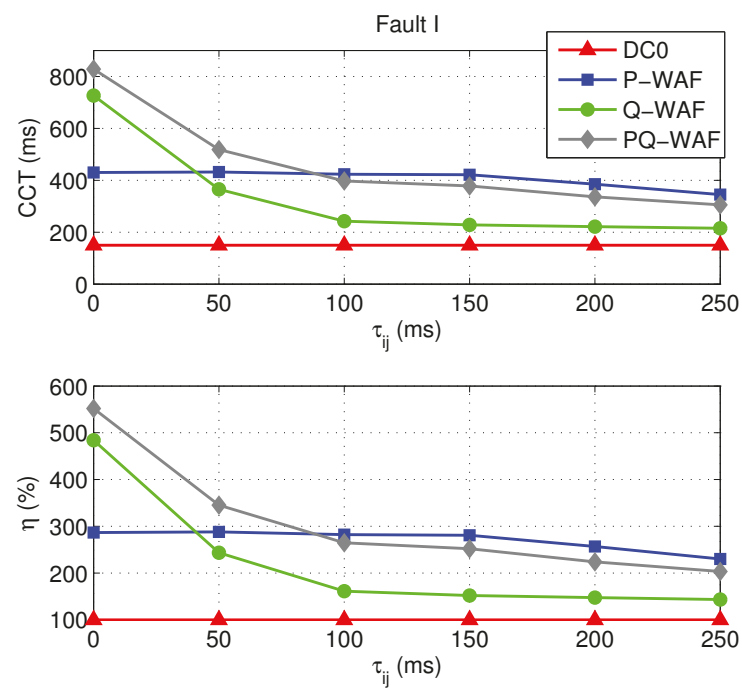

Figure 18. CCTs and $\eta$ versus communication delay.

The robustness of control strategies P-WAF, Q-WAF and PQ-WAF has been analysed in the following three cases:

- Case A: Equal delay for all frequency measurements: $\tau_{i j}=50 \mathrm{~ms}, 100 \mathrm{~ms}$, if $i \neq j$, except for the frequency measured at the VSC station that calculates the WAF, that has zero delay $\left(\tau_{i i}=0 \mathrm{~ms}\right)$ (this is the case analysed in Section 4.2). This case represents a communication system where frequency measurements at the VSC-MTDC systems are collected by a central controller and sent to each VSC station. Each VSC station uses those measurements to calculate the WAF.

- Case B: Equal delay for all frequency measurements: $\tau_{i j}=50 \mathrm{~ms}, 100 \mathrm{~ms}, \forall i, j$. This case represents a communication system where frequency measurements at the VSC-MTDC systems are collected by a central controller and the central controller calculates the WAF, which is send, later, to all VSC stations.

- $\quad$ Case C: Different delays for frequency measurements: $\tau_{i j}, \forall i, j$, is obtained as a random number in the range $[0, \Delta \tau]$, following a uniform distribution $\left(\tau_{i j} \sim U(0, \Delta \tau)\right)$. The values of the delays are maintained constant during the simulation. Two values of $\Delta \tau$ are used: $50 \mathrm{~ms}$ and $100 \mathrm{~ms}$. Samples obtained for $\tau_{i j}$ are given in Table 4 . This case represents a communication system with communication channels between all the VSC stations.

- Case D: Stochastic delays for frequency measurements: At each time step, the delay $\tau_{i j}$, if $i \neq j$, is obtained as a random number following a triangular distribution with mean $\tau_{i j}^{0}$ and upper/lower limits $\tau_{i j}^{0} \pm \Delta \tau_{i j}$. The probability density function of the triangular distribution of $\tau_{i j}$ is shown in Figure 19. Hence, the delay will be within the range:

$$
\tau_{i j}=\tau_{i j}^{0} \pm \Delta \tau_{i j}
$$

As in case A, the frequency measured at the VSC station that calculates the WAF will have a zero delay $\left(\tau_{i i}=0 \mathrm{~ms}\right)$. Two delays will be tested: $\tau_{i j}=50 \pm 10 \mathrm{~ms}$ and $\tau_{i j}=100 \pm 20 \mathrm{~ms}$. Stochastic delays introduce noise, as shown in Figure 20. This case represents a more realistic version of Case A. 
Table 4. Case C. Communication delays used $\left(\tau_{i j}(\mathrm{~ms})\right)$.

\begin{tabular}{lccccc}
\hline$\tau_{i j}(\mathrm{~ms})$ & VSC & $\boldsymbol{\tau}_{\boldsymbol{i 1}}$ & $\boldsymbol{\tau}_{\boldsymbol{i} 2}$ & $\boldsymbol{\tau}_{\boldsymbol{i 3}}$ & $\boldsymbol{\tau}_{\boldsymbol{i 4}}$ \\
\hline$\Delta \tau=50 \mathrm{~ms}$ & VSC1: $\tau_{1 j}$ & 6 & 46 & 32 & 5 \\
& VSC2: $\tau_{2 j}$ & 14 & 27 & 48 & 48 \\
& VSC3: $\tau_{3 j}$ & 8 & 49 & 48 & 24 \\
& VSC4: $\tau_{4 j}$ & 40 & 7 & 21 & 46 \\
\hline$\Delta \tau=100 \mathrm{~ms}$ & VSC1: $\tau_{1 j}$ & 79 & 96 & 66 & 4 \\
& VSC2: $\tau_{2 j}$ & 85 & 93 & 68 & 76 \\
& VSC3: $\tau_{3 j}$ & 74 & 39 & 66 & 17 \\
& VSC4: $\tau_{4 j}$ & 71 & 3 & 28 & 5 \\
\hline
\end{tabular}

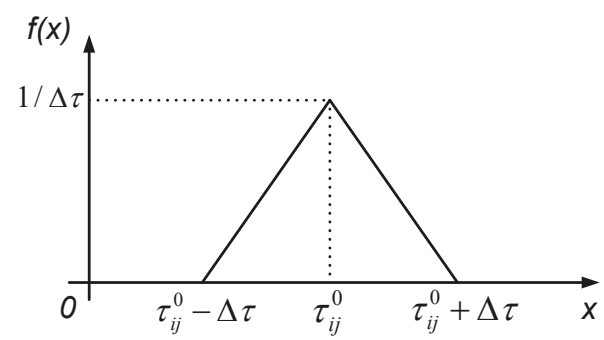

Figure 19. Case D: Communication delays follow a triangular distribution. Probability density function.

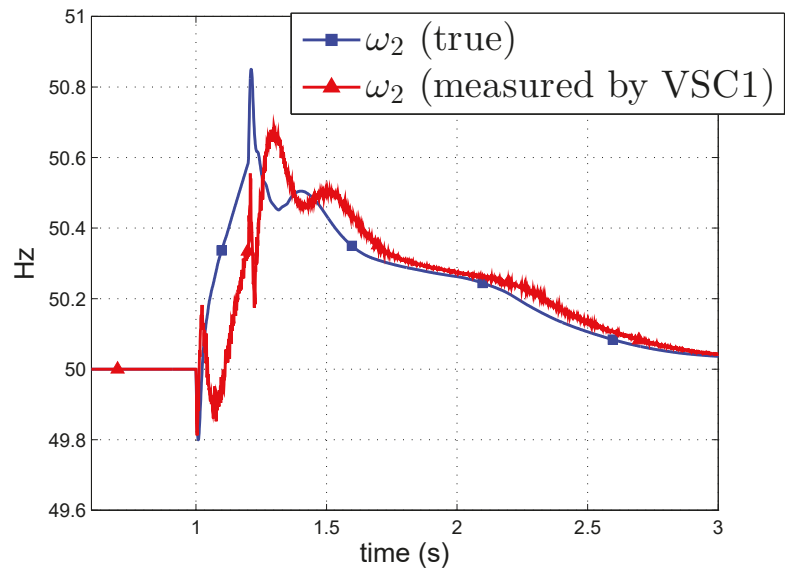

Figure 20. Case D. Strategy P-WAF with $\tau_{i j}=100 \pm 20 \mathrm{~ms}$ (triangular distribution). Frequency of VSC2 measured by VSC1.

CCTs for the faults of Table 1 obtained in cases A, B, C and D are reported in Table 3 of Section 4.2 and Tables 5-7 respectively. In the four cases, CCTs decrease as the communication latency increases and, again, communication latency have a greater impact on strategy Q-WAF than on strategy P-WAF. Nevertheless, even in the presence of communication latency CCTs obtained with the control strategies outperform those obtained in the base case (DC0). Furthermore, no significant differences are observed in cases A (equal delay for all frequency measurements except for the frequency of the VSC station that calculates the WAF, that has $\tau_{i i}=0 \mathrm{~ms}$ ), $\mathrm{B}$ (equal delay for all frequency measurements), C (different delays for frequency measurements) and D (stochastic delays 
for frequency measurements). Moreover, notice that the results of case A (Table 3 of Section 4.2) and case $\mathrm{D}$ (Table 7) are practically the same. This proves that the control strategies are robust against noisy delays and this is due to the low-pass filter used in the control schemes $\left(1 /\left(1+T_{f} s\right)\right.$ in Figures 4 and 5$)$.

Table 5. Case B. CCT.

\begin{tabular}{lccc}
\hline CCTs (ms) & Fault I & Fault II & Fault III \\
\hline DC0 & 150 & 178 & 189 \\
\hline P-WAF & 430 & 242 & 479 \\
P-WAF, delay: $\tau_{i j}=50 \mathrm{~ms} \forall i, j$ & 432 & 242 & 429 \\
P-WAF, delay: $\tau_{i j}=100 \mathrm{~ms} \forall i, j$ & 423 & 242 & 351 \\
\hline Q-WAF & 726 & 423 & 339 \\
Q-WAF, delay: $\tau_{i j}=50 \mathrm{~ms} \forall i, j$ & 365 & 376 & 290 \\
Q-WAF, delay: $\tau_{i j}=100 \mathrm{~ms} \forall i, j$ & 242 & 273 & 277 \\
\hline PQ-WAF & 828 & 369 & 585 \\
PQ-WAF, delay: $\tau_{i j}=50 \mathrm{~ms} \forall i, j$ & 518 & 324 & 519 \\
PQ-WAF, delay: $\tau_{i j}=100 \mathrm{~ms} \forall i, j$ & 397 & 273 & 440 \\
\hline
\end{tabular}

Table 6. Case C. CCT.

\begin{tabular}{lccc}
\hline CCTs (ms) & Fault I & Fault II & Fault III \\
\hline DC0 & 150 & 178 & 189 \\
\hline P-WAF & 430 & 242 & 479 \\
P-WAF, delay: $\tau_{i j} \sim U(0,50 \mathrm{~ms}) \forall i, j$ & 427 & 242 & 459 \\
P-WAF, delay: $\tau_{i j} \sim U(0,100 \mathrm{~ms}) \forall i, j$ & 412 & 242 & 414 \\
\hline Q-WAF & 726 & 423 & 339 \\
Q-WAF, delay: $\tau_{i j} \sim U(0,50 \mathrm{~ms}) \forall i, j$ & 492 & 412 & 295 \\
Q-WAF, delay: $\tau_{i j} \sim U(0,100 \mathrm{~ms}) \forall i, j$ & 421 & 392 & 291 \\
\hline PQ-WAF & 828 & 369 & 585 \\
PQ-WAF, delay: $\tau_{i j} \sim U(0,50 \mathrm{~ms}) \forall i, j$ & 584 & 345 & 542 \\
PQ-WAF, delay: $\tau_{i j} \sim U(0,100 \mathrm{~ms}) \forall i, j$ & 505 & 320 & 511 \\
\hline
\end{tabular}

Table 7. Case D. CCT.

\begin{tabular}{lccc}
\hline CCTs $(\mathbf{m s})$ & Fault I & Fault II & Fault III \\
\hline DC0 & 150 & 178 & 189 \\
\hline P-WAF & 430 & 242 & 479 \\
P-WAF, delay: $\tau_{i j}=50 \pm 10 \mathrm{~ms}$ & 433 & 242 & 443 \\
P-WAF, delay: $\tau_{i j}=100 \pm 20 \mathrm{~ms}$ & 436 & 243 & 382 \\
\hline Q-WAF & 726 & 423 & 339 \\
Q-WAF, delay: $\tau_{i j}=50 \pm 10 \mathrm{~ms}$ & 429 & 400 & 295 \\
Q-WAF, delay: $\tau_{i j}=100 \pm 20 \mathrm{~ms}$ & 275 & 312 & 287 \\
\hline PQ-WAF & 828 & 369 & 585 \\
PQ-WAF, delay: $\tau_{i j}=50 \pm 10 \mathrm{~ms}$ & 566 & 332 & 534 \\
PQ-WAF, delay: $\tau_{i j}=100 \pm 20 \mathrm{~ms}$ & 444 & 291 & 471 \\
\hline
\end{tabular}

4.4. Further Research on the Impact of Communication Latency on Strategy P-WAF with Centralised DC-Voltage Control

So far, strategy P-WAF has been implemented in all VSC stations together with DC-voltage droop control (distributed DC-voltage control). As proved in Section 4.2.1, the presence of the latter 
mitigated the impact of communication latency. This Section investigated the case in which a DC-slack converter controls its DC voltage (centralised DC-voltage control) and all other converters control their P injections according to strategy P-WAF, only (there is not DC-voltage droop control). When modulating P injections in a VSC-MTDC system with centralised DC-voltage control, overloading of the DC-slack converter should be avoided.

Tests reported in this Section have been carried out within the following scenario:

- $\quad$ VSC4 controled its DC voltage to 1 p.u (DC slack).

- VSCs 1, 2 and 3 controled their P injections, using strategy P-WAF. Saturation parameters of the supplementary controller were set to $\Delta p_{i}^{\max }=0.2$ p.u., in order to avoid overloading of the DC slack converter.

- $\quad$ VSC2 was given the role of DC-slack converter, with DC-voltage limits $u_{d c, i}^{\max }=1.1$ p.u. and $u_{d c, i}^{\min }=0.9$ p.u.

- $\quad$ DC-voltage limits of VSCs 1 and 3 were set to $u_{d c, i}^{\max }=1.25$ p.u. and $u_{d c, i}^{\min }=0.7$ p.u., in order to avoid interactions in case that the DC slack is overloaded.

Fault I of Table 1, cleared after $200 \mathrm{~ms}$, was simulated and the following cases were compared:

- $\quad$ Strategy P-WAF (with VSC4 as DC slack), without communication latency $\left(\tau_{i j}=0 \mathrm{~ms}\right)$.

- $\quad$ Strategy P-WAF (with VSC4 as DC slack), with a communication latency of $50 \mathrm{~ms}\left(\tau_{i i}=0 \mathrm{~ms}\right.$ and $\tau_{i j}=50 \mathrm{~ms}$ if $\left.i \neq j\right)$.

- $\quad$ Strategy P-WAF (with VSC4 as DC slack), with a communication latency of $100 \mathrm{~ms}\left(\tau_{i i}=0 \mathrm{~ms}\right.$ and $\tau_{i j}=100 \mathrm{~ms}$ if $i \neq j$ ).

Figure 21 shows the generator-angle difference. Transient stability deteriorates with communication latency and the impact of the communication delay is more noticeable than when using strategy P-WAF together with DC-voltage droop control. Nevertheless, synchronism is maintained in all cases. Figure 22 shows P injections of the VSC stations and DC voltages. VSC stations 1, 2 and 3 modulate their P injections, while VSC4 controls its DC voltage to 1 p.u. Voltages at all DC buses are close to 1 p.u. during the whole simulation.

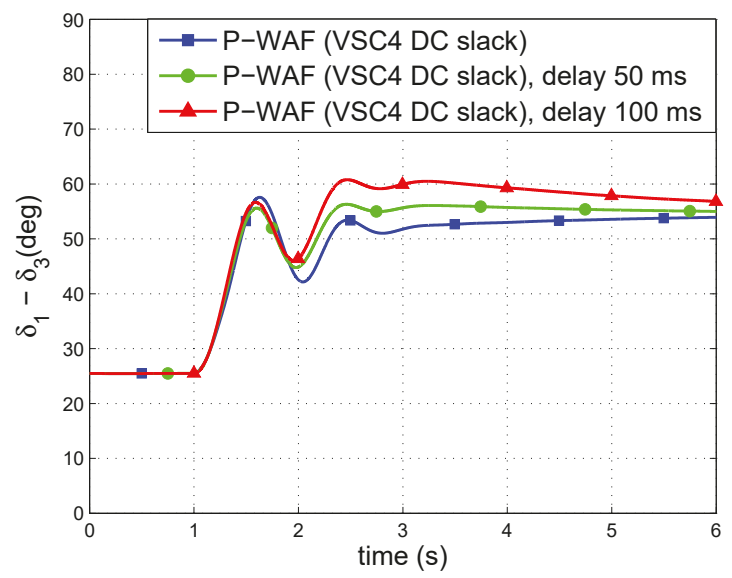

Figure 21. Generator angle difference. 

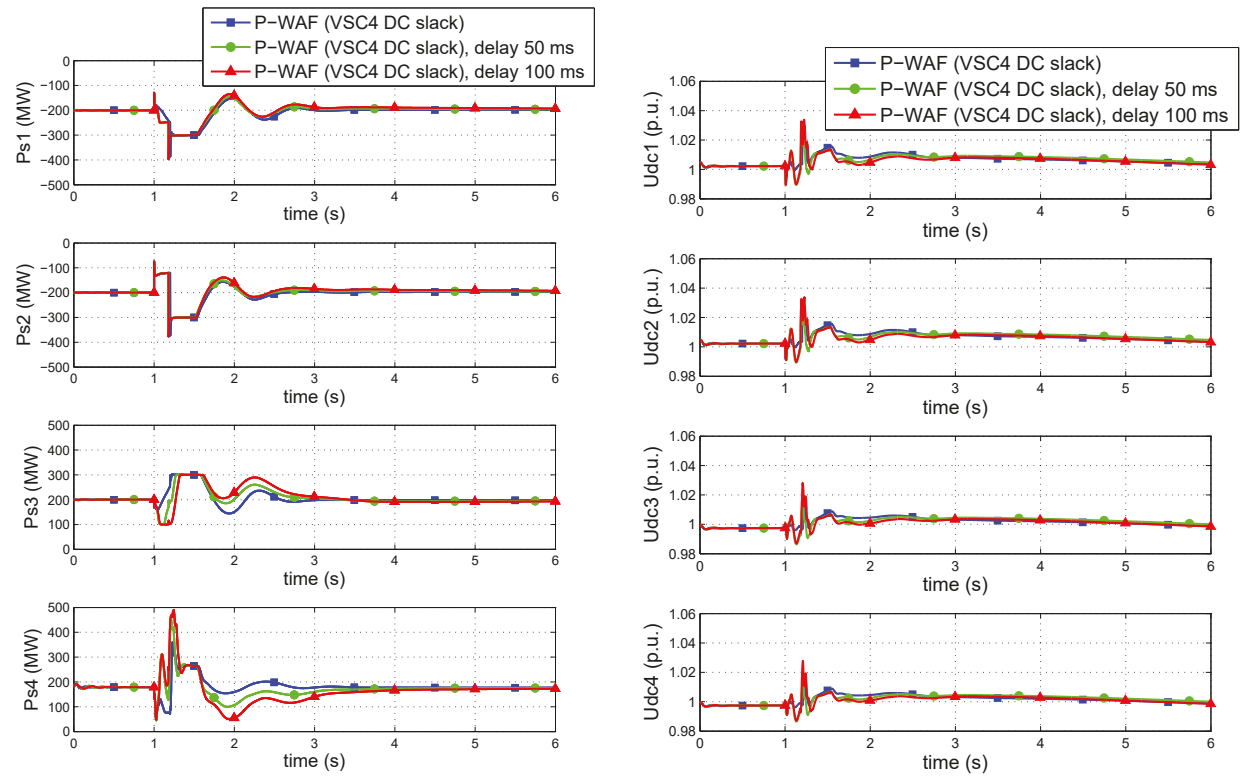

(a)

(b)

Figure 22. (a) P injections of the converters and (b) DC voltages.

The CCTs for the faults of Table 1 are shown in Table 8. As the communication delays increase, the CCTs decrease. Regardless of the communication latency, CCTs are significantly higher than those obtained in the base case (DC0, with VSC4 as DC slack). Finally, Figure 23 shows the CCT and indicator $\eta$ of Fault I as a function of communication latency. The same scale of Figure 18 is used, to facilitate the comparison of the results. The CCT obtained with strategy P-WAF (and DC-voltage droop) is also plotted. In this case, the CCT of Fault I decreases as the communication delay increases, faster than in the case of P-WAF together with the DC-voltage frequency droop. The CCT obatined for $\tau_{i j}=250 \mathrm{~ms}$ is much higher than the one obtained in the base case.

Table 8. CCT. Effect of communication latency on strategy P-WAF when the VSC-MTDC system has a single DC slack.

\begin{tabular}{lccc}
\hline CCTs (ms) & Fault I & Fault II & Fault III \\
\hline DC0 (VSC4: DC slack) & 150 & 200 & 225 \\
\hline P-WAF (VSC4: DC slack) & 408 & 273 & 296 \\
P-WAF (VSC4: DC slack), delay 50 ms & 341 & 260 & 303 \\
P-WAF (VSC4: DC slack), delay 100 ms & 307 & 253 & 301 \\
\hline
\end{tabular}

Results show that strategy P-WAF, when implemented in a VSC-MTDC with centralised DC-voltage control (a single DC slack converter), is robust against communication latency although better results are obtained when implementing strategy P-WAF together with DC-voltage droop control. 

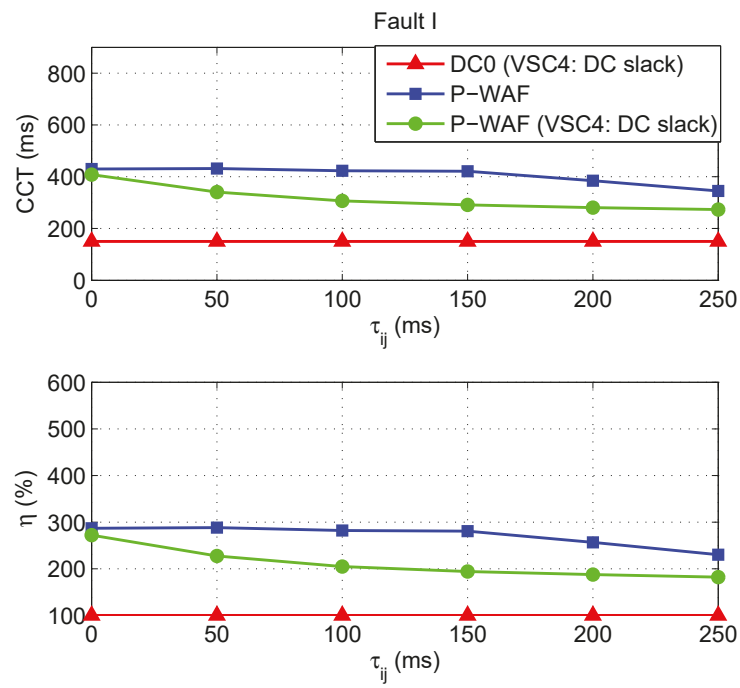

Figure 23. CCTs and $\eta$ versus communication delay.

\section{Case Study 2: Cigré Nordic32A Test System with an Embedded VSC-MTDC System}

The Cigré Nordic32A test system [55] with an embedded 3-terminal VSC-MTDC system was used for simulation (Figure 24). The objective of using this system is to test the control strategy in a larger multi-machine system, in order to test the scalability of the conclusions. Data are detailed in Appendix B. Converter stations were operated with DC-voltage droop control and reactive-power control. Simulations were carried out in PSS/E software [46], with the VSC-MTDC model presented in [44].

The initial operating point of the VSC-MTDC system was calculated running an AC/DC power flow, with the following specified variables:

- $\quad$ VSC1: $P_{s, 1}^{0}=-350 \mathrm{MW}$ and $Q_{s, 1}^{0}=0 \mathrm{MVAr}$.

- VSC2: $P_{s, 2}^{0}=500 \mathrm{MW}$ and $Q_{s, 2}^{0}=150 \mathrm{MVAr}$.

- VSC3: $u_{d c, 3}^{0^{2}}=1$ p.u and $Q_{s, 3}^{0}=100 \mathrm{MVAr}$ (VSC3 is used as the DC-slack converter for power-flow calculation).

The following cases have been analysed and compared:

- DC0: No supplementary control strategy in the VSC stations.

- $\quad$ Strategy P-WAF (P injections of VSC stations).

- Strategy Q-WAF (Q injections of VSC stations).

- $\quad$ Strategy PQ-WAF (simultaneous modulation of P and Q injections of VSC stations).

Since a detailed analysis has been presented in Section 4, this section will focus on the main results, only. The CCTs of the faults described in Table 9 have been calculated. Fault I is the most severe one, since corridor 4031-4041 carries a large amount of power in the operating point considered and both circuits of the corridor are disconnected after the fault clearing. 


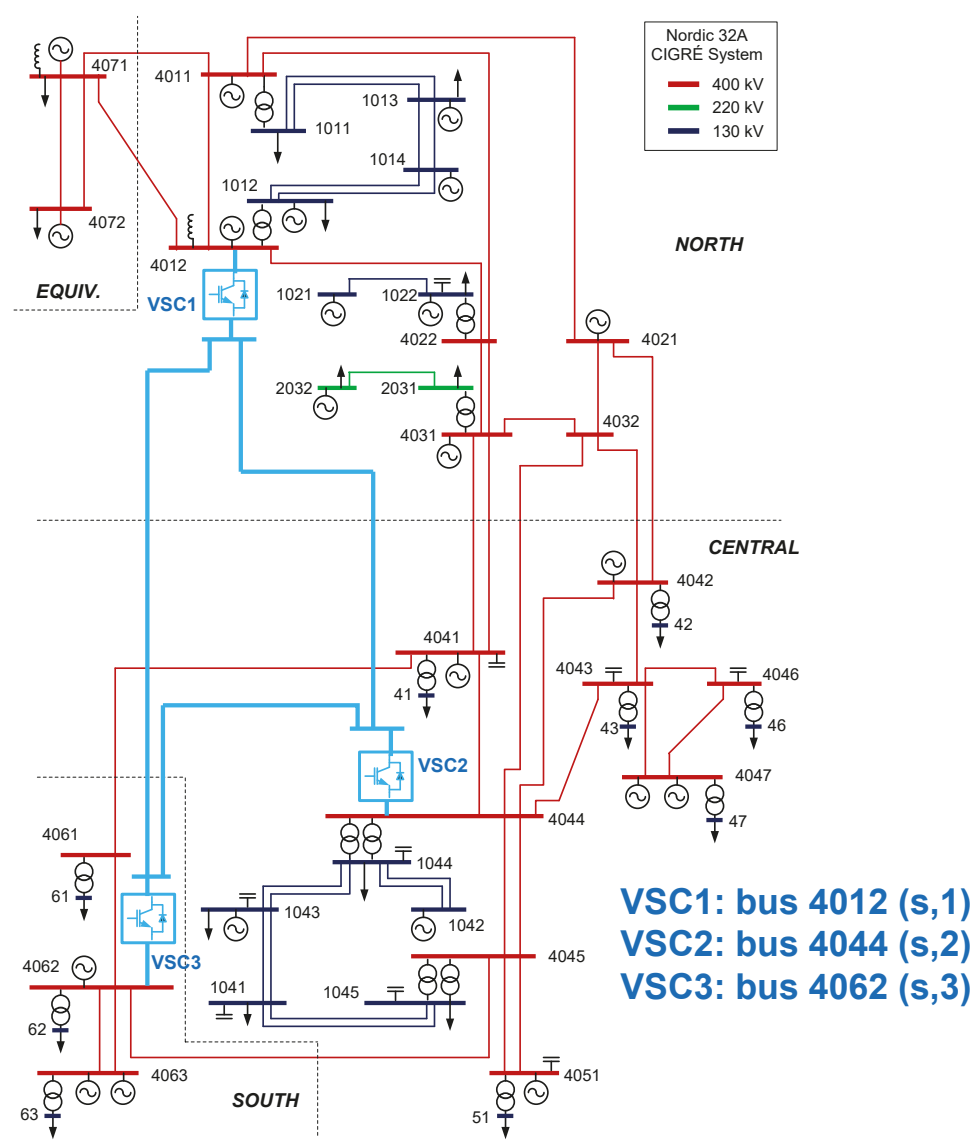

Figure 24. Cigré Nordic 32A system with an embedded VSC-MTDC system.

Table 9. Faults.

\begin{tabular}{lccc}
\hline & Short Circuit at Line $i-j$ & Close to Bus & Clearing \\
\hline Fault I & $4031-4041 \mathrm{a}$ & 4041 & Disconnect 4031-4041 a\&b \\
Fault II & $4012-4022$ & 4012 & Line disconnected \\
Fault III & $4012-4022$ & 4022 & Line disconnected \\
Fault IV & $4032-4044$ & 4044 & Line disconnected \\
Fault V & $4011-4022$ & 4011 & Line disconnected \\
\hline
\end{tabular}

The performance of control strategies P-WAF, Q-WAF and PQ-WAF has been tested in the following three cases:

- $\quad$ Case A: Equal delay for all frequency measurements: $\tau_{i j}=50 \mathrm{~ms}, 100 \mathrm{~ms}$, if $i \neq j$, except for the frequency measured at the VSC station that calculates the WAF, that has zero delay $\left(\tau_{i i}=0 \mathrm{~ms}\right)$.

- $\quad$ Case B: Equal delay for all frequency measurements: $\tau_{i j}=50 \mathrm{~ms}, 100 \mathrm{~ms}, \forall i, j$.

- $\quad$ Case C: Different delays for frequency measurements: $\tau_{i j}, \forall i, j$, is obtained as a random number in the range $[0, \Delta \tau]$, following a uniform distribution $\left(\tau_{i j} \sim U(0, \Delta \tau)\right)$. The values of the delays are maintained constant during the simulation. Two values of $\Delta \tau$ are used: $50 \mathrm{~ms}$ and $100 \mathrm{~ms}$. Samples obtained for $\tau_{i j}$ are provided in Table 10 . 
- $\quad$ Case D: Stochastic delays for frequency measurements: At each time step, the delay $\tau_{i j}$, if $i \neq j$, is obtained as a random number following a triangular distribution with mean $\tau_{i j}^{0}$ and upper/lower limits $\tau_{i j}^{0} \pm \Delta \tau_{i j}$. The probability density function of the triangular distribution of $\tau_{i j}$ is shown in Figure 19. The frequency measured at the VSC station that calculates the WAF will have a zero delay $\left(\tau_{i i}=0 \mathrm{~ms}\right)$. Two delays will be tested: $\tau_{i j}=50 \pm 10 \mathrm{~ms}$ and $\tau_{i j}=100 \pm 20 \mathrm{~ms}$.

Table 10. Case C. Communication delays used $\left(\tau_{i j}(\mathrm{~ms})\right)$.

\begin{tabular}{lcccc}
\hline$\tau_{\boldsymbol{i j}}(\mathrm{ms})$ & VSC & $\boldsymbol{\tau}_{\boldsymbol{i 1}}$ & $\boldsymbol{\tau}_{\boldsymbol{i} \mathbf{2}}$ & $\boldsymbol{\tau}_{\boldsymbol{i 3}}$ \\
\hline \multirow{4}{*}{$\Delta \tau=50 \mathrm{~ms}$} & VSC1: $\tau_{1 j}$ & 2 & 5 & 41 \\
& VSC2: $\tau_{2 j}$ & 35 & 16 & 41 \\
& VSC3: $\tau_{3 j}$ & 2 & 22 & 19 \\
\hline \multirow{4}{*}{$\Delta \tau=100 \mathrm{~ms}$} & VSC1: $\tau_{1 j}$ & 77 & 80 & 19 \\
& VSC2: $\tau_{2 j}$ & 49 & 45 & 65 \\
& VSC3: $\tau_{3 j}$ & 71 & 75 & 28 \\
\hline
\end{tabular}

Tables 11-14 report the CCTs obtained for the faults of Table 9, for cases A-D. Without communication latency, control strategies increase the CCTs significantly. For example, the CCT of Fault I increases from $105 \mathrm{~ms}$ in the base case DC0 to 390, 370 and $404 \mathrm{~ms}$, with control strategies P-WAF, Q-WAF and PQ-WAF, respectively. The three control strategies proved to be robust against communication latency. Results with control strategies P-WAF and PQ-WAF are similar to those obtained without communication latency. As already discussed, communication latency have more impact when modulating reactive-power injections (Q-WAF). For example, with communication delays of $50 \mathrm{~ms}$ and $100 \mathrm{~ms}$ in case A (Table 11), the CCTs of Fault I are $317 \mathrm{~ms}$ and $160 \mathrm{~ms}$, respectively. Those results still improve the base case (CCT of $105 \mathrm{~ms}$ ), but below the improvement without communication latency (CCT of $370 \mathrm{~ms}$ ). The CCTs of cases A-D (Tables 11-14) follow a similar pattern and there are no signicant differences regarding the impact of the different type of delays considered.

Faults III and IV are also interesting to discuss. Fault III is almost unaffected by the control strategies and its CCT cannot be improved. The impact of strategy Q-WAF on Fault IV has a surprising pattern, since its CCT increases as the communication latency increases (when using Q-WAF). This was already observed in [39].

Table 11. Case A. CCT. Effect of communication latency.

\begin{tabular}{lccccc}
\hline CCTs (ms) & Fault I & Fault II & Fault III & Fault IV & Fault V \\
\hline DC0 & 105 & 188 & 237 & 390 & 205 \\
\hline P-WAF & 390 & 224 & 240 & 824 & 235 \\
P-WAF, delay 50 ms & 389 & 225 & 240 & 822 & 235 \\
P-WAF, delay 100 ms & 384 & 225 & 240 & 824 & 236 \\
\hline Q-WAF & 370 & 247 & 253 & 564 & 250 \\
Q-WAF, delay 50 ms & 317 & 236 & 247 & 581 & 240 \\
Q-WAF, delay 100 ms & 160 & 225 & 243 & 603 & 230 \\
\hline PQ-WAF & 404 & 259 & 250 & 854 & 261 \\
PQ-WAF, delay 50 ms & 403 & 252 & 245 & 819 & 254 \\
PQ-WAF, delay 100 ms & 389 & 245 & 242 & 793 & 248 \\
\hline
\end{tabular}


Table 12. Case B. CCT. Effect of communication latency.

\begin{tabular}{lccccc}
\hline CCTs (ms) & Fault I & Fault II & Fault III & Fault IV & Fault V \\
\hline DC0 & 105 & 188 & 237 & 390 & 205 \\
\hline P-WAF & 390 & 224 & 240 & 824 & 235 \\
P-WAF, delay: $\tau_{i j}=50 \mathrm{~ms} \forall i, j$ & 390 & 224 & 240 & 822 & 235 \\
P-WAF, delay: $\tau_{i j}=100 \mathrm{~ms} \forall i, j$ & 390 & 224 & 240 & 825 & 235 \\
\hline Q-WAF & 370 & 247 & 253 & 564 & 250 \\
Q-WAF, delay: $\tau_{i j}=50 \mathrm{~ms} \forall i, j$ & 195 & 233 & 245 & 594 & 237 \\
Q-WAF, delay: $\tau_{i j}=100 \mathrm{~ms} \forall i, j$ & 128 & 220 & 241 & 783 & 226 \\
\hline PQ-WAF & 404 & 259 & 250 & 854 & 261 \\
PQ-WAF, delay: $\tau_{i j}=50 \mathrm{~ms} \forall i, j$ & 408 & 251 & 244 & 802 & 252 \\
PQ-WAF, delay: $\tau_{i j}=100 \mathrm{~ms} \forall i, j$ & 398 & 241 & 242 & 781 & 243 \\
\hline
\end{tabular}

Table 13. Case C. CCT. Effect of communication latency.

\begin{tabular}{lccccc}
\hline CCTs $(\mathrm{ms})$ & Fault I & Fault II & Fault III & Fault IV & Fault V \\
\hline DC0 & 105 & 188 & 237 & 390 & 205 \\
\hline P-WAF & 390 & 224 & 240 & 824 & 235 \\
P-WAF, delay: $\tau_{i j} \sim U(0,50 \mathrm{~ms}) \forall i, j$ & 382 & 224 & 240 & 815 & 235 \\
P-WAF, delay: $\tau_{i j} \sim U(0,100 \mathrm{~ms}) \forall i, j$ & 397 & 224 & 240 & 824 & 235 \\
\hline Q-WAF & 370 & 247 & 253 & 564 & 250 \\
Q-WAF, delay: $\tau_{i j} \sim U(0,50 \mathrm{~ms}) \forall i, j$ & 331 & 240 & 249 & 577 & 244 \\
Q-WAF, delay: $\tau_{i j} \sim U(0,100 \mathrm{~ms}) \forall i, j$ & 174 & 232 & 245 & 603 & 235 \\
\hline PQ-WAF & 404 & 259 & 250 & 854 & 261 \\
PQ-WAF,delay: $\tau_{i j} \sim U(0,50 \mathrm{~ms}) \forall i, j$ & 400 & 256 & 246 & 819 & 258 \\
PQ-WAF, delay: $\tau_{i j} \sim U(0,100 \mathrm{~ms}) \forall i, j$ & 408 & 248 & 243 & 798 & 251 \\
\hline
\end{tabular}

Table 14. Case D. CCT. Effect of communication latency.

\begin{tabular}{lccccc}
\hline CCTs $(\mathrm{ms})$ & Fault I & Fault II & Fault III & Fault IV & Fault V \\
\hline DC0 & 105 & 188 & 237 & 390 & 205 \\
\hline P-WAF & 390 & 224 & 240 & 824 & 235 \\
P-WAF, delay $\tau_{i j}=50 \pm 10 \mathrm{~ms}$ & 390 & 224 & 240 & 823 & 235 \\
P-WAF, delay $\tau_{i j}=100 \pm 20 \mathrm{~ms}$ & 388 & 224 & 240 & 823 & 235 \\
\hline Q-WAF & 370 & 247 & 253 & 564 & 250 \\
Q-WAF, delay $\tau_{i j}=50 \pm 10 \mathrm{~ms}$ & 320 & 235 & 248 & 581 & 240 \\
Q-WAF, delay $\tau_{i j}=100 \pm 20 \mathrm{~ms}$ & 171 & 225 & 243 & 603 & 231 \\
\hline PQ-WAF & 404 & 259 & 250 & 854 & 261 \\
PQ-WAF, delay $\tau_{i j}=50 \pm 10 \mathrm{~ms}$ & 401 & 252 & 245 & 819 & 254 \\
PQ-WAF, delay $\tau_{i j}=100 \pm 20 \mathrm{~ms}$ & 387 & 245 & 242 & 793 & 247 \\
\hline
\end{tabular}

Finally, Figure 25 shows the CCT and $\eta$ of Fault I (the most severe and challenging fault) as a function of communication latency of Case A. Control strategies P-WAF and PQ-WAF present significant improvements, even for large communication delays. In fact, the CCTs obtained are very similar to those obtained without communication delays. The performance of strategy Q-WAF worsens much faster as the value of the communication delay increases. Furthermore, for communication delays of $\tau_{i j}=200 \mathrm{~ms}$ and $\tau_{i j}=250 \mathrm{~ms}$, the performance of strategy Q-WAF is very poor and results are worse than in the base case (a CCT of $0 \mathrm{~ms}$ means that the tripping of lines 4031-4041a\&b produces loss of synchronism, even if there is no solid short circuit). This implies that control strategy Q-WAF requires fast communication systems to be effective (delays should not be greater than $100 \mathrm{~ms}$ ). 

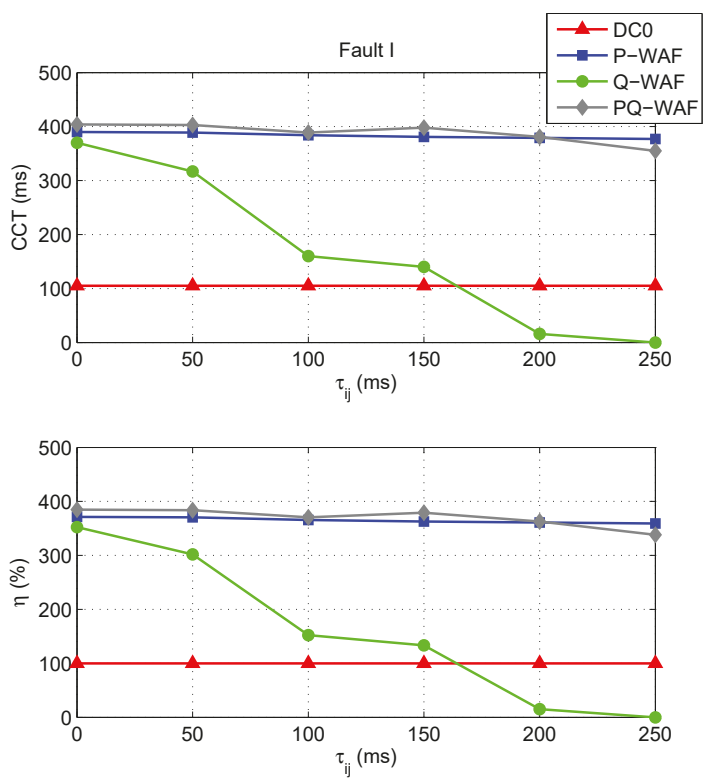

Figure 25. Case A. CCTs and $\eta$ versus communication delay.

\section{Conclusions}

This paper analysed the impact of communication latency on transient-stability-tailored control strategies in VSC-MTDC systems based on the weighted-average frequency (WAF) calculated by the VSC stations. Conclusions can be summarised as follows:

- Strategies P-WAF (modulation of P injections), Q-WAF (modulation of Q injections) and PQ-WAF (simultaneous modulation of P and Q injections), implemented at the VSC stations of MTDC systems, improve transient stability, significantly.

- Strategies P-WAF, Q-WAF and PQ-WAF improve transient stability, significantly, even when subject to communication latency, for realistic values of communication delays.

- Strategy Q-WAF is more sensitive to communication latency than control strategy P-WAF.

- Strategies P-WAF, Q-WAF and PQ-WAF proved to be robust against different types of communication latency (the same communication delay for all frequency measurements and different communication delays for the frequency measurements).

- Strategy P-WAF implemented in a VSC-MTDC system with a single DC-slack converter is more sensitive to communication latency than control strategy P-WAF implemented in a VSC-MTDC system where converters have DC-voltage droop control.

Author Contributions: J.R., A.G.-C., L.R. and L.S. decided to investigate in detail the impact of communication latency on the transient-stability-tailored control strategies in VSC-MTDC systems (main contribution of the paper). J.R. ran the simulations and wrote the first version of the manuscript. J.R., A.G.-C., L.R. and L.S. improved the manuscript and elaborated the conclusions of this study.

Funding: Work supported by the Spanish Government under Project ENE2014-57760-C2-1R of the Spanish RETOS programme and by Madrid Regional Government under PRICAM-CM Project, Ref. S2013/ICE-2933. Work continues supported by PROMINT-CM Ref. S2018/EMT-4366, funded by Madrid Regional Government.

Conflicts of Interest: The authors declare no conflict of interest. 
Appendix A. Data of the Case Study 1: Kundur's Two-Area Test System with an Embedded VSC-MTDC System

Appendix A.1. HVAC Grid

Data of the HVAC system can be found in [54]. In the original test system, the nominal voltage of the transmission system and the nominal frequency were $230 \mathrm{kV}$ and $60 \mathrm{~Hz}$, respectively and those values have been changed to $220 \mathrm{kV}$ and $50 \mathrm{~Hz}$, respectively, in this work.

Synchronous machines are represented with a 6th-order dynamic model, with parameters:

$$
\begin{aligned}
& S_{N}=900 \text { MVA, } H=4.5 \mathrm{~s}(\mathrm{G} 1, \mathrm{G} 2), H=4.175 \mathrm{~s}(\mathrm{G} 3, \mathrm{G} 4), D=0, T_{d 0}^{\prime}=8 \mathrm{~s}, T_{d 0}^{\prime \prime}=0.03 \mathrm{~s}, \\
& T_{q 0}^{\prime}=0.4 \mathrm{~s}, T_{q 0}^{\prime \prime}=0.05 \mathrm{~s}, X_{d}=1.8 \mathrm{p} . \mathrm{u}, X_{q}=1.7 \mathrm{p} . \mathrm{u}, X_{d}^{\prime}=0.3 \mathrm{p} . \mathrm{u}, X_{q}^{\prime}=0.55 \mathrm{p} . \mathrm{u}, \\
& X_{d}^{\prime \prime}=X_{q}^{\prime \prime}=0.25 \text { p.u, } X_{l}=0.2 \text { p.u, } S(1.0)=0.0435 \text { p.u, } S(1.2)=0.2963 \text { p.u. }
\end{aligned}
$$

Generators are equipped with a bus-fed static excitation system, as shown in Figure A1, with parameters:

$$
\begin{aligned}
& T_{R}=0.01 \mathrm{~s}, K_{A}=200 \text { p.u, } K_{C}=0 \text { p.u, } E_{E M A X}=6.4 \text { p.u, } \\
& E_{E M I N}=-6.4 \text { p.u, } E_{F D \max }=6.4 \text { p.u, } E_{F D \min }=-6.4 \text { p.u. }
\end{aligned}
$$

The generators are also equipped with a power system stabiliser (PSS) (STAB1 PSS/E library model [56]), with parameters:

$$
K / T=20 \mathrm{~s}^{-1}, T=10 \mathrm{~s}, T_{1} / T_{3}=2.5, T_{3}=0.02 \mathrm{~s}, T_{2} / T_{4}=0.5555, T_{4}=5.4 \mathrm{~s}, H_{L I M}=0.05 \text { p.u. }
$$

The governor system of the generators use IEEEG1 PSS/E library models [56], with parameters:

$$
\begin{aligned}
& K=20 \text { p.u, } T_{1}=T_{2}=0 \mathrm{~s}, T_{3}=0.3 \mathrm{~s}, U_{0}=1 \text { p.u. } / \mathrm{s}, \quad U_{c}=-1 \text { p.u. } / \mathrm{s}, P_{M A X}=1 \text { p.u, } P_{M I N}=0 \text { p.u, } \\
& T_{4}=0.3 \mathrm{~s}, K_{1}=0.3 \text { p.u, } K_{2}=0 \text { p.u, } T_{5}=7 \mathrm{~s}, K_{3}=0.3 \text { p.u, } K_{4}=0 \text { p.u, } T_{6}=0.6 \mathrm{~s}, \\
& K_{5}=K_{6}=K_{7}=K_{8}=0 \text { p.u, } T_{7}=0 \mathrm{~s} .
\end{aligned}
$$

For time-domain simulation, loads are represented with constant active current and with constant impedance for the reactive-power part.

The following modifications were made in order to consider a critical case for transient stability:

- Inertia constants: $H_{1}=H_{2}=4.5 \mathrm{~s}$ and $H_{3}=H_{4}=4.175 \mathrm{~s}$.

- $\quad$ Loads: $467 \mathrm{MW}$ and $100 \mathrm{MVAr}$ at bus 7 and $2267 \mathrm{MW}$ and 0 MVAr at bus 9.

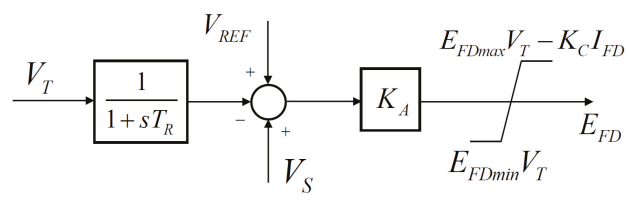

Figure A1. Excitation system. 
Table A1. Converter and HVDC grid parameters.

\begin{tabular}{|c|c|}
\hline $\begin{array}{l}\text { Parameters } \\
\text { VSC's Rating are Base Values for p.u. }\end{array}$ & \\
\hline Rating VSC, DC voltage, AC voltage & $500 \mathrm{MVA}, \pm 320 \mathrm{kV}, 300 \mathrm{kV}$ \\
\hline Configuration & Symmetrical monopole \\
\hline Max. active (reactive) power & $\pm 500 \mathrm{MW}( \pm 200 \mathrm{MVAr})$ \\
\hline Max. current & 1 p.u (d-axis priority) \\
\hline Max. DC voltage & $\pm 10 \%$ \\
\hline Max. modulation index & 1.31 p.u \\
\hline Current-controller time constant $(\tau)$ & $5 \mathrm{~ms}$ \\
\hline $\begin{array}{l}\text { Connection resistance }\left(r_{s}\right) / \text { reactance }\left(x_{s}\right) \\
\text { (reactor }+300 / 220 \mathrm{kV} \text { transformer) }\end{array}$ & 0.02 p.u / 0.20 p.u \\
\hline $\begin{array}{l}\text { P prop./int. control: }\left(K_{d, p 1} / K_{d, i 1}\right) \\
\text { Vdc prop./int. control }\left(K_{d, p 2} / K_{d, i 2}\right)\end{array}$ & $\begin{array}{c}\left.0 / 0 \quad \text { (i.e. } i_{d, i}^{r e f}=p_{s, i}^{r e f} / u_{s, i}\right) \\
4 \text { p.u/0.24 p.u/s }\end{array}$ \\
\hline Q-control prop./int. control: $\left(K_{q, p 1} / K_{q, i 1}\right)$ & $0 / 0 \quad$ (i.e. $\left.i_{q, i}^{r e f}=-q_{s, i}^{r e f} / u_{s, i}\right)$ \\
\hline DC-voltage droop constant $\left(k_{d c, i}\right)$ & 0.1 p.u \\
\hline VSCs' loss coefficients $(a / b)$ in p.u. & $5.25 / 1.65 \times 10^{-3}$ p.u. \\
\hline VSCs' loss coefficients $\left(c_{r e c} / c_{i n v}\right)$ in p.u. & $2.10 / 3.14 \times 10^{-3}$ p.u. \\
\hline DC-bus capacitance $\left(C_{d c, i}\right)$ & $195 \mu \mathrm{F}$ \\
\hline \multirow[t]{3}{*}{ DC-line series parameters $\left(R_{d c, i j} / L_{d c, i j}\right)$} & $0.51 \Omega / 35.03 \mathrm{mH}$ (lines $1-2 \& 3-4)$ \\
\hline & $5.23 \Omega / 357.26 \mathrm{mH}$ (line $1-3)$ \\
\hline & $4.92 \Omega / 336.24 \mathrm{mH}$ (line 2-4) \\
\hline
\end{tabular}

Appendix A.3. Parameters of the Control Strategies

- Strategy P-WAF: Block diagram of Figure 4, with parameters: $k_{P, i}=200$ p.u, $T_{f, i}=0.1 \mathrm{~s}, T_{W, i}=15 \mathrm{~s}, \Delta p_{\max , i}=0.4$ p.u and $\alpha_{k}=1 / 4$. The gains are in nominal p.u. The frequency set point is calculated as Equation (5).

- $\quad$ Strategy Q-WAF: Block diagram of Figure 5, with parameters: $k_{Q, i}=200$ p.u, $T_{f, i}=0.1 \mathrm{~s}$, $T_{W, i}=15 \mathrm{~s}, \Delta q_{\max , i}=0.4$ p.u and $\alpha_{k}=1 / 4$. The gains are in nominal p.u. The frequency set point is calculated as Equation (5).

- $\quad$ Strategy PQ-WAF: Strategies P-WAF and Q-WAF are implemented simultaneously. The same parameters of strategies P-WAF and Q-WAF are used.

\section{Appendix B. Data of the Case Study 2: Cigré Nordic32A Test System with an Embedded VSC-MTDC System}

\section{Appendix B.1. HVAC Grid}

Data of the HVAC system can be found in [55,57]. A comprehensive description of the system, with the analysis of different operating points, can be found in [58]. A heavily loaded operating point is considered in this work, with the modifications of Table A2. Loads are modelled with a constant impedance characteristic for dynamic simulation.

Table A2. Modifications of Nordic32A case.

\begin{tabular}{lccc}
\hline & & Original Value & New Value \\
\hline Loads & Bus 1044 & $800 \mathrm{MW}$ & $1300 \mathrm{MW}$ \\
& Bus 41 & $540 \mathrm{MW}$ & $620 \mathrm{MW}$ \\
& Bus 4071 (equiv.) & $300 \mathrm{MW}$ & $0 \mathrm{MW}$ \\
& Bus 4072 (equiv.) & $2000 \mathrm{MW}$ & $1840 \mathrm{MW}$ \\
& Bus 62 & $300 \mathrm{MW}$ & $200 \mathrm{MW}$ \\
\hline Shunts & Buses 1044 and 4041 & $200 \mathrm{MVAr}$ & $300 \mathrm{MVAr}$ \\
\hline
\end{tabular}


Table A3. Converter and HVDC grid parameters.

\begin{tabular}{|c|c|}
\hline \multicolumn{2}{|l|}{$\begin{array}{l}\text { Parameters } \\
\text { VSC's Rating are Base Values for p.u. }\end{array}$} \\
\hline Rating VSC, DC voltage, AC voltage & $1000 \mathrm{MVA}, \pm 320 \mathrm{kV}, 300 \mathrm{kV}$ \\
\hline Confi & Symmetrical monopole \\
\hline tive (reactive) power & $\pm 1000 \mathrm{MW}( \pm 450 \mathrm{MVAr})$ \\
\hline Max. current & 1 p.u (d-axis priority) \\
\hline ltage & $\pm 10 \%$ \\
\hline n index & 1.31 p.u \\
\hline he constant $(\tau)$ & $5 \mathrm{~ms}$ \\
\hline $\begin{array}{l}\text { Connection resistance }\left(r_{s}\right) / \text { reactance }\left(x_{s}\right) \\
\text { (reactor }+300 / 400 \mathrm{kV} \text { transformer) }\end{array}$ & 0.002 p.u / 0.17 p.u \\
\hline P prop./int. control: $\left(K_{d, p 1} / K_{d, i 1}\right)$ & $0 / 0 \quad$ (i.e., $i_{d, i}^{r e f}=p_{s, i}^{r e f} / u_{s, i}$ ) \\
\hline Vdc prop./int. control $\left(K_{d, p 2} / K_{d, i 2}\right)$ & 2 p.u/0.12 p.u/s \\
\hline Q-control prop./int. control: $\left(K_{q, p 1} / K_{q, i 1}\right)$ & $0 / 0 \quad$ (i.e., $\left.i_{q, i}^{r e f}=-q_{s, i}^{r e f} / u_{s, i}\right)$ \\
\hline DC-voltage droop constant $\left(k_{d c, i}\right)$ & 0.1 p.u \\
\hline VSC $s^{\prime}$ loss coefficients $(a / b)$ in p.u. & $11.033 / 3.464 \times 10^{-3}$ p.u. \\
\hline VSCs' loss coefficients $\left(c_{r e c} / c_{\text {inv }}\right)$ in p.u. & $4.40 / 6.67 \times 10^{-3}$ p.u. \\
\hline DC-bus capacitance $\left(C_{d c, i}\right)$ & $195 \mu \mathrm{F}$ \\
\hline DC-line series parameters $\left(R_{d c, i j} / L_{d c, i j}\right)$ & $2.05 \Omega / 140.10 \mathrm{mH}$ \\
\hline
\end{tabular}

Appendix B.3. Parameters of the Control Strategies

- Strategy P-WAF: Block diagram of Figure 4, with parameters: $k_{P, i}=200$ p.u, $T_{f, i}=0.1 \mathrm{~s}$, $T_{W, i}=15 \mathrm{~s}, \Delta p_{\max , i}=1.0 \mathrm{p} . \mathrm{u}$ and $\alpha_{k}=1 / 3$. The gains are in nominal p.u. The frequency set point is calculated as Equation (5).

- Strategy Q-WAF: Block diagram of Figure 5, with parameters: $k_{Q, i}=200$ p.u, $T_{f, i}=0.1 \mathrm{~s}$, $T_{W, i}=15 \mathrm{~s}, \Delta q_{\max , i}=1.0 \mathrm{p} . \mathrm{u}$ and $\alpha_{k}=1 / 3$. The gains are in nominal p.u. The frequency set point is calculated as Equation (5).

- Strategy PQ-WAF: Strategies P-WAF and Q-WAF are implemented simultaneously. The same parameters of strategies P-WAF and Q-WAF are used.

\section{References}

1. Flourentzou, N.; Agelidis, V.G.; Demetriades, G.D. VSC-Based HVDC Power Transmission Systems: An Overview. IEEE Trans. Power Electron. 2009, 24, 592-602. [CrossRef]

2. Gordon, S. Supergrid to the rescue. Power Eng. 2006, 20, 30-33. [CrossRef]

3. Blau, J. Europe plans a North Sea grid. IEEE Spectr. 2010, 47, 12-13. [CrossRef]

4. Van Hertem, D.; Ghandhari, M. Multi-terminal VSC HVDC for the European supergrid: Obstacles. Renew. Sustain. Energy Rev. 2010, 14, 3156-3163. [CrossRef]

5. Bompard, E.; Fulli, G.; Ardelean, M.; Masera, M. It's a Bird, It's a Plane, It's a... Supergrid. IEEE Power Energy Mag. 2014, 12, 41-50.

6. Lesnicar, A.; Marquardt, R. An Innovative Modular Multilevel Converter Topology Suitable for a Wide Power Range. In Proceedings of the IEEE/PES PowerTech Conference, Bologna, Italy, $23-26$ June 2003; pp. 1-6.

7. Kouro, S.; Malinowski, M.; Gopakumar, K.; Pou, J.; Franquelo, L.G.; Wu, B.; Rodriguez, J.; Pérez, M.A.; Leon, J.I. Recent Advances and Industrial Applications of Multilevel Converters. IEEE Trans. Ind. Electron. 2010, 57, 2553-2580. [CrossRef]

8. Bola, J.; Rivas, R.; Fernández-Alonso, R.; Pérez, G.; Hidalgo, J.; Coronado, L.M.; Longás, C.; Sanz, S.; Lemarchand, G.; Roguin, J.; et al. Operational experience of new Spain-France HVDC interconnection. In Proceedings of the CIGRE Session, Paper B4-117, Paris, France, 21 August 2016, pp. 1-13. 
9. Vrana, T.K.; Beerten, J.; Belmans, R.; Fosso, O.B. A classification of DC node voltage control methods for HVDC grids. Electr. Power Syst. Res. 2013, 103, 137-144. [CrossRef]

10. Bianchi, F.D.; Domínguez-García, J.L.; Gomis-Bellmunt, O. Control of multi-terminal HVDC networks towards wind power integration: A review. Renew. Sustain. Energy Rev. 2016, 55, 1055-1068. [CrossRef]

11. Prieto-Araujo, E.; Bianchi, F.D.; Junyent-Ferré, A.; Gomis-Bellmunt, O. Methodology for Droop Control Dynamic Analysis of Multiterminal VSC-HVDC Grids for Offshore Wind Farms. IEEE Trans. Power Deliv. 2011, 26, 2476-2485. [CrossRef]

12. Egea-Alvarez, A.; Bianchi, F.; Junyent-Ferré, A.; Gross, G.; Gomis-Bellmunt, O. Voltage Control of Multiterminal VSC-HVDC Transmission Systems for Offshore Wind Power Plants: Design and Implementation in a Scaled Platform. IEEE Trans. Ind. Electron. 2013, 60, 2381-2391. [CrossRef]

13. Berggren, B.; Lindén, K.; Majumder, R. DC Grid Control Through the Pilot Voltage Droop Concept-Methodology for Establishing Droop Constants. IEEE Trans. Power Syst. 2014, 30, 2312-2320. [CrossRef]

14. Kirakosyan, A.; El-Saadany, E.F.; El Moursi, M.S.; Acharya, S.; Al Hosani, K. Control Approach for the Multi-Terminal HVDC System for the Accurate Power Sharing. IEEE Trans. Power Syst. 2018, 33, 4323-4334. [CrossRef]

15. Häfner, J.; Jacobson, B. Device and Method to Break the Current of a Power Transmission or Distribution Line and Current Limiting Arrangement. European Patent EP2502248B1, 2009.

16. Davidson, C.C.; Whitehouse, R.S.; Barker, C.D.; Dupraz, J.-P.; Grieshaber, W. A new ultra-fast HVDC Circuit breaker for meshed DC networks. In Proceedings of the 11th IET International Conference on AC and DC Power Transmission, Birmingham, UK, 10-12 February 2015; pp. 1-7.

17. De Kerf, K.; Srivastava, K.; Reza, M.; Bekaert, D.; Cole, S.; Van Hertem, D.; Belmans, R. Wavelet-based protection strategy for DC faults in multi-terminal VSC HVDC systems. IET Gener. Transm. Distrib. 2011, 5, 496-503. [CrossRef]

18. Descloux, J.; Rault, P.; Nguefeu, S.; Curis, J.B.; Guillaud, X.; Colas, P.; Raison, B. HVDC meshed grid: Control and protection of a multi-terminal HVDC system. In Proceedings of the CIGRE Session, Paris, France, 26-31 August 2012; pp. 1-8.

19. Adamczyk, A.; Barker, C.D.; Ha, H. Fault Detection and Branch Identification for HVDC Grids. In Proceedings of the 12th IET International Conference on Developments in Power System Protection (DPSP), Copenhagen, Denmark, 31 March-3 April 2014; pp. 1-6.

20. Leterme, W.; Beerten, J.; Van Hertem, D. Non-unit Protection of HVDC Grids With Inductive DC Cable Termination. IEEE Trans. Power Deliv. 2016, 31, 820-828. [CrossRef]

21. Sneath, J.; Rajapakse, A.D. Fault Detection and Interruption in an Earthed HVDC Grid Using ROCOV and Hybrid DC Breakers. IEEE Trans. Power Deliv. 2016, 31, 973-981. [CrossRef]

22. Torres-Olguin, R.E.; H $\phi$ idalen, H.K. Travelling waves-based fault detection method in multi-terminal HVDC grids connecting offshore wind farms. In Proceedings of the 13th IET International Conference on Developments in Power System Protection (DPSP), Edinburgh, UK, 7-10 March 2016; pp. 1-7.

23. Azad, S.P.; Van Hertem, D. A Fast Local Bus Current-Based Primary Relaying Algorithm for HVDC Grids. IEEE Trans. Power Deliv. 2017, 32, 193-202. [CrossRef]

24. Tzelepis, D.; Dyśko, A.; Fusiek, G.; Nelson, J.; Niewczas, P.; Vozikis, D.; Orr, P.; Gordon, N.; Booth, C. Single-Ended Differential Protection in MTDC Networks using Optical Sensors. IEEE Trans. Power Deliv. 2017, 32, 1605-1615. [CrossRef]

25. Yang, Q.; Le Blond, S.; Aggarwal, R.; Wang, Y.; Li, J. New ANN method for multi-terminal HVDC protection relaying. Electr. Power Syst. Res. 2017, 148, 192-201. [CrossRef]

26. Latorre, H.; Ghandhari, M.; Söder, L. Active and reactive power control of a VSC-HVdc. Electr. Power Syst. Res. 2008, 78, 1756-1763. [CrossRef]

27. Fuchs, A.; Imhof, M.; Demiray, T.; Morari, M. Stabilization of Large Power Systems Using VSC-HVDC and Model Predictive Control. IEEE Trans. Power Deliv. 2014, 29, 480-488. [CrossRef]

28. Sigrist, L.; Echavarren, F.; Rouco, L.; Panciatici, P. A fundamental study on the impact of HVDC lines on transient stability of power systems. In Proceedings of the IEEE/PES PowerTech Conference, Eindhoven, The Netherlands, 29 June-2 July 2015; pp. 1-6. 
29. Martínez Sanz, I.; Chaudhuri, B.; Strbac, G. Coordinated Corrective Control for Transient Stability Enhancement in Future Great Britain Transmission System. In Proceedings of the 19th Power Systems Computation Conference (PSCC), Genoa, Italy, 24-26 June 2016; pp. 1-7.

30. Kundur, P.; Paserba, J.; Ajjarapu, V.; Andersson, G.; Bose, A.; Canizares, C.; Hatziargyriou, N.; Hill, D.; Stankovic, A.; Taylor, C.; et al. Definition and classification of power system stability IEEE/CIGRE joint task force on stability terms and definitions. IEEE Trans. Power Syst. 2004, 19, 1387-1401.

31. Zhou, Y.; Huang, H.; Xu, Z.; Hua, W.; Yang, F.; Liu, S. Wide-area measurement system-based transient excitation boosting control to improve power system transient stability. IET Gener. Transm. Distrib. 2015, 9, 845-854. [CrossRef]

32. Díez-Maroto, L.; Vanfretti, L.; Almas, M.S.; Jónsdóttir, G.M.; Rouco, L. A WACS exploiting generator Excitation Boosters for power system transient stability enhancement. Electr. Power Syst. Res. 2017, 148, 245-253. [CrossRef]

33. Díez-Maroto, L.; Renedo, J.; Rouco, L.; Fernández-Bernal, F. Lyapunov Stability Based Wide Area Control Systems for Excitation Boosters in Synchronous Generators. IEEE Trans. Power Syst. 2019, 34, 194-204. [CrossRef]

34. Machowski, J.; Kacejko, P.; Nogal, L.; Wancerz, M. Power system stability enhancement by WAMS-based supplementary control of multi-terminal HVDC networks. Control. Eng. Pract. 2013, 21, 583-592. [CrossRef]

35. Eriksson, R. Coordinated Control of Multiterminal DC Grid Power Injections for Improved Rotor-Angle Stability Based on Lyapunov Theory. IEEE Trans. Power Deliv. 2014, 29, 1789-1797. [CrossRef]

36. Tang, G.; Xu, Z.; Dong, H.; Xu, Q. Sliding Mode Robust Control Based Active-Power Modulation of Multi-Terminal HVDC Transmissions. IEEE Trans. Power Syst. 2016, 31, 1614-1623. [CrossRef]

37. Fan, X.; Shu, J.; Zhang, B. Coordinated Control of DC Grid and Offshore Wind Farms to Improve Rotor-Angle Stability. IEEE Trans. Power Syst. 2018, 33, 4625-4623. [CrossRef]

38. Renedo, J.; García-Cerrada, A.; Rouco, L. Active Power Control Strategies for Transient Stability Enhancement of AC/DC Grids With VSC-HVDC Multi-Terminal Systems. IEEE Trans. Power Syst. 2016, 31, 4595-4604. [CrossRef]

39. Renedo, J.; García-Cerrada, A.; Rouco, L. Reactive-Power Coordination in VSC-HVDC Multi-Terminal Systems for Transient Stability Improvement. IEEE Trans. Power Syst. 2017, 32, 3758-3767. [CrossRef]

40. Milano, F.; Ortega, A. Frequency divider. IEEE Trans. Power Syst. 2017, 32, 1493-1501.

41. Milano, F. Rotor Speed-Free Estimation of the Frequency of the Center of Inertia. IEEE Trans. Power Syst. 2018, 33, 1153-1155. [CrossRef]

42. Cole, S.; Beerten, J.; Belmans, R. Generalized Dynamic VSC MTDC Model for Power System Stability Studies. IEEE Trans. Power Syst. 2010, 25, 1655-1662. [CrossRef]

43. Beerten, J.; Cole, S.; Belmans, R. Modeling of Multi-Terminal VSC HVDC Systems With Distributed DC Voltage Control. IEEE Trans. Power Syst. 2014, 29, 34-42. [CrossRef]

44. Renedo, J.; García-Cerrada, A.; Rouco, L.; Sigrist, L.; Egido, I.; Sanz Verdugo, S. Development of a PSS/E tool for power-flow calculation and dynamic simulation of VSC-HVDC multi-terminal systems. In Proceedings of the 13th IET International Conference on AC and DC Power Transmission, Manchester, UK, 14-16 February 2017; pp. 1-6.

45. Daelemans, G.; Srivastava, K.; Reza, M.; Cole, S.; Belmans, R. Minimization of steady-state losses in meshed networks using VSC HVDC. In Proceedings of the IEEE/PES General Meeting, Calgary, AB, Canada, 26-30 July 2009; pp. 1-5.

46. Siemens-PTI. PSS/E 33.5 Users Manual; Siemens Power Technologies International: Schenectady, NY, USA, 2013.

47. Chainho, P.J.D. General Modeling of Multi-Terminal VSC-HVDC Systems for Transient Stability Analysis. Master's Thesis, Universidade Técnica de Lisboa, Lisbon, Portugal, 2012.

48. Chainho, P.J.D.; van der Meer, A.A.; Gibescu, M.; Hendriks, R.L.; van der Meijden, M.A.M.M. General Modeling of Multi-Terminal VSC-HVDC Systems for Transient Stability Studies. In Proceedings of the 6th IEEE Young Researchers Symposium in Electrical Power Engineering, Delft, The Netherlands, 16-17 April 2012; pp. 1-6.

49. Ndreko, M. Offshore Wind Power Connected to the Dutch Transmission System by VSC-HVDC Networks: Modeling and Stability Analysis. Master's Thesis, Delft University of Technology, Delft, The Netherlands, 2012. 
50. Liu, S.; Xu, Z.; Hua, W.; Tang, G.; Xue, Y. Electromechanical Transient Modeling of Modular Multilevel Converter Based Multi-Terminal HVDC Systems. IEEE Trans. Power Syst. 2014, 29, 72-83. [CrossRef]

51. Beerten, J.; Cole, S.; Belmans, R. Generalized Steady-State VSC MTDC Model for Sequential AC/DC Power Flow Algorithms. IEEE Trans. Power Syst. 2012, 27, 821-829. [CrossRef]

52. Zhang, F.; Sun, Y.; Cheng, L.; Li, X.; Chow, J.H.; Zhao, W. Measurement and Modeling of Delays in Wide-Area Closed-Loop Control Systems. IEEE Trans. Power Syst. 2015, 30, 2426-2433. [CrossRef]

53. Chompoobutrgool, Y.; Vanfretti, L. Analysis of time delay effects for wide-area damping control design using dominant path signals. In Proceedings of the IEEE/PES General Meeting, National Harbor, MD, USA, 27-31 July 2014; pp. 1-5.

54. Kundur, P. Power System Stability and Control; McGraw-Hill Education: New York, NY, USA, 1994.

55. Stubbe (Convenor), M. Long Term Dynamics Phase II; Technical Report, Cigré Task Force 38.02.08-TB 102; CIGRE: Paris, France, 1995.

56. Siemens-PTI. PSS/E 33.5 Model Library; Siemens Power Technologies International: Schenectady, NY, USA, 2013.

57. Karlsson, B. Comparison of PSSE \& PowerFactory; Degree Project; Uppsala Universitet: Uppsala, Sweden, 2013. Available Online: https://www.diva-portal.org/smash/get/diva2:658793/FULLTEXT01.pdf (accessed on 20 September 2019).

58. Van Cutsem, T.; Papangelis, L. Description, Modeling and Simulation Results of a Test System for Voltage Stability Analysis; Technical Report; Université de Liège: Liège, Belgium, 2014.

(C) 2019 by the authors. Licensee MDPI, Basel, Switzerland. This article is an open access article distributed under the terms and conditions of the Creative Commons Attribution (CC BY) license (http:/ / creativecommons.org/licenses/by/4.0/). 
Article

\title{
A Hybrid DC Circuit Breaker with Fault-Current-Limiting Capability for VSC-HVDC Transmission System
}

\author{
Muhammad Ahmad ${ }^{1,2}$ and Zhixin Wang ${ }^{1,2, *}$ \\ 1 School of Electronics Information and Electrical Engineering, Shanghai Jiao Tong University, \\ Shanghai 200240, China; ahmad1406@sjtu.edu.cn or muhammad.ahmad14@hotmail.com \\ 2 Key Laboratory of Control of Power Transmission and Conversion, Ministry of Education, \\ Shanghai 200240, China \\ * Correspondence: wangzxin@sjtu.edu.cn; Tel.: +86-21-3420-4527
}

Received: 28 April 2019; Accepted: 18 June 2019; Published: 21 June 2019

\begin{abstract}
The direct current circuit breakers are considered a promising option to protect the transmission line against commonly appearing line-to-ground fault. However, the challenges of losses in the nonoperational stage, escalation of response against fault current, and large fault current handling capability remain the debatable issues for direct current circuit breakers. This paper introduces a novel topology of the hybrid circuit breaker with fault-current-limiting characteristics, which contains three branches: the main branch, fault-current-limiting branch, and energy absorption branch. The main branch includes a mechanical switch, breaker impedance, and bidirectional power electronics switches. In the fault-current-limiting branch, a fault-current-limiting circuit is introduced which contains $n$ numbers of bidirectional switches and current-limiting inductors, which are connected in series to make the design modular in nature. During the normal working stage, the current flows through the main branch of the breaker. Once a fault in the system is confirmed, the fault current is transferred to the fault-current-limiting branch. At this stage, the intensity of the fault current is reduced significantly using the fault-current-limiting circuit, and finally, the residual current is shifted to the energy absorption branch. The working principle, design considerations, and parametric analysis concerning the design of hybrid circuit breakers are incorporated in this paper. The performance of the proposed breaker is evaluated using a three-terminal voltage-source converter-based high-voltage direct current transmission network; for this purpose, a PSCAD/EMTDC simulation tool is used. The performance of the proposed breaker is also compared with other topologies. The comparative analysis shows that the proposed breaker is a good alternative considering high fault current interruption requirements, response time against fault current, and power losses.
\end{abstract}

Keywords: breakers; hybrid DC circuit breaker; fault current limiters; non-superconducting fault current limiters; current-limiting inductors; voltage source converter

\section{Introduction}

Due to increased penetration of renewable energy into power grids, the VSC-HVDC transmission projects have gained attention globally because the VSC-HVDC systems allow the independent control of active and reactive power [1-5]. With the passage of time, the rating of VSC-HVDC projects has increased; the details of HVDC projects in [6-8] strengthen this argument. The VSC-HVDC-based transmission shows more vulnerability against frequently appearing L-G faults. The increased ratings of VSC-HVDC networks demand the protection equipment with increased fault current handling capabilities. 
With an increased rating of VSC-HVDC network and vulnerability towards commonly appearing L-G faults, the protection equipment is required to handle large fault current. In this context, the FCLs are generally used and classified into two types: SFCLs and NSFCLs. The studies [9-12] contain some examples under the umbrella of SFCLs; likewise, [13-15] present the examples of NSFCLs. The FCL of both types can limit the fault current to some extent, but the fault current cannot be forced to zero or isolated totally. Therefore, DCCBs are considered a reliable option to isolate the fault current. Generally, DCCBs are divided into three major types: mechanical active and passive resonance circuit breakers, solid-state circuit breakers (SSCB), and hybrid circuit breakers (HCBs) [16]. In 2012, a paradigm shift in the high-voltage DCCBs area was observed with the introduction of HCBs [17,18]. Later on, in 2014, another state-of-the-art HCB was introduced with experimental validation [19]. The [19] highlights the comparative analysis of two important HCBs. Although HCBs possess good features in terms of response time [17-19], they have limitations in handling large fault currents with increased voltage ratings. Therefore, different researchers had used the breakers in a combination of FCLs to ensure the safety, fault isolation capability, and increased fault current handling capacity as well [20,21].

In Reference [22], a compound current limiter and circuit breaker is introduced; likewise in Reference [23], the new topology for HCBs is explained in detail. In Reference [24], the implantation of breakers on a small scale is explained. The new designs of breakers placed between negative and positive terminals of line, and multiterminals are explained in [25-27]. Some miscellaneous protection schemes to protect the line against L-G faults using HCBs and other approaches are elucidated in [28,29]. In addition, some examples of SFCLs with DCCBs are given in [30,31], whereas the comprehensive comparison between NSFCL and SFCL is given in [32].

The recent investigations in $[20,21]$ explain the hybridization of NSFCL and DCCB; these two examples are comprehensively elaborated here, because in the later stages, some results are reproduced for comparative analysis. In Reference [20], three breakers were used; one was called MCB, and the other two were named as BCBs. Apart from breakers, three CLIs were also used. The working principle was explained as follows: during normal operation, the CLIs were connected in parallel and thus the equivalent impedance was reduced. As a result, the on-state loss was reduced too. In case of the fault, the CLIs were used in series and had included heavy impedance during the fault current limitation stage. In this way, the intensity of the fault current was reduced. At the terminal stage, the MOAs used in the MCB and BCBs were used to absorb the residual current. The BCBs had ensured the parallel operation of current-limiting inductors during normal operating condition, and series operation in faulty condition. In Reference [21], a hybrid current-limiting circuit breaker for DC line was proposed which had two major components: energy-dissipating circuit and isolation mechanism. The energy-dissipating circuit (contains) inductance, power electronics-based switches (Thyristors), and energy-dissipating resistor. The working mechanism of the hybrid current-limiting circuit breaker was simple: in case of a fault, the intensity of the fault current was suppressed by employing current-limiting inductance, and then the main circuit was isolated using a mechanical switch. Eventually, the residual current was dissipated by the MOA and resistor.

In this paper, an improved method is developed to limit the quantum of the fault current. Similar tactics as of [20] are chosen to limit the fault current, but with significant modifications, to solve some key issues. In the previous study, to achieve the fault-current-limiting operation, two additional breakers (BCBs) were used to guarantee the series and parallel operation of the CLIs. These additional breakers had significantly increased the cost. Moreover, the CLIs remained in the circuit during normal operating condition, and as a result, the large size of inductors could result in more losses. However, using the proposed FCLC, the CLIs are only used when fault current suppression is required, and this is considered a major advantage. Thus, the use of large CLIs for high fault current handling is possible, and parallel operation of CLIs is alleviated. Since no CLI is used during normal operation, power loss in normal condition due to FCLC is zero. The schematic diagram of the proposed FCLC for DCCB is shown in Figure 1, whereas Figure 2 contains the schematic diagram of the fault current limiter discussed in [20]. In Figure $1, S_{1}, S_{2}, S_{3} \ldots \ldots S_{n}$ represent the bidirectional PE switches and $L_{1}, L_{2}, L_{3}$ 
$\ldots \ldots L_{n}$ represent the CLIs. By employing CLIs, the fault current can be reduced effectively; however, the main branch of the breaker has to tolerate transient overvoltage. To rectify this issue, the concept of parallel arrester is used, and the details are charted in the subsequent part of this study.

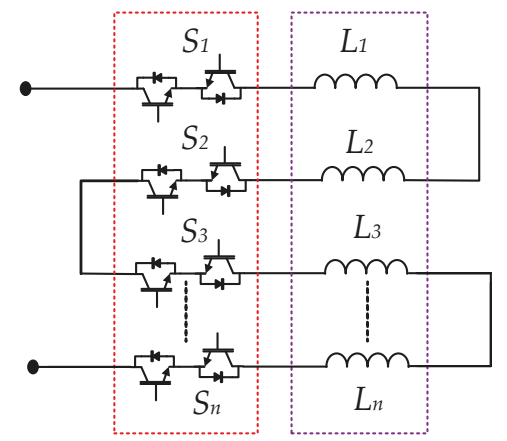

Figure 1. Proposed FCLC for DCCB used in auxiliary branch of breaker.

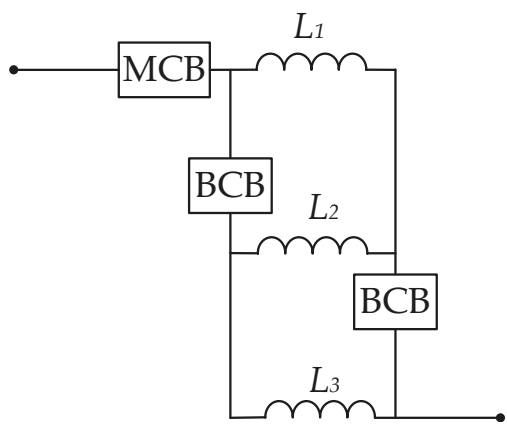

Figure 2. Fault-current-limiting circuit with $\mathrm{MCB}$ and BCB.

The working principle of proposed topology, analysis to determine the size of CLIs, current in different stages, and transient overvoltage analysis are discussed in Section 2 of the paper. In Section 3 , simulation results are presented to verify the theoretical concepts. Section 4 contains the comparative analysis of proposed solutions with other available topologies. Finally, in Section 5, the conclusions of the paper are presented.

\section{Proposed Topology}

\subsection{Working Principle}

The proposed HCB with FCLC contains three branches: the main branch, auxiliary branch, and energy transfer branch, as shown in Figure 3. The main branch constitutes a mechanical switch called UFD, and bidirectional PE switches composed of IGBTs, also known as LCS. The proposed FCLC to limit the fault current is placed in the auxiliary branch. The third branch of the HCB is called the energy absorption branch, which consists of an MOA. In Figure 3, the value of CLR is represented by $L_{b}$, which is called the breaker impedance. Although the design of the FCLC is modular in nature, three CLIs are considered at this stage, namely, $L_{1}, L_{2}$, and $L_{3}$, and three bidirectional PE switches composed of IGBTs are named as $S_{1}, S_{2}$, and $S_{3}$. It must be noted that the CLIs are connected in series, and these are not coupled magnetically. 


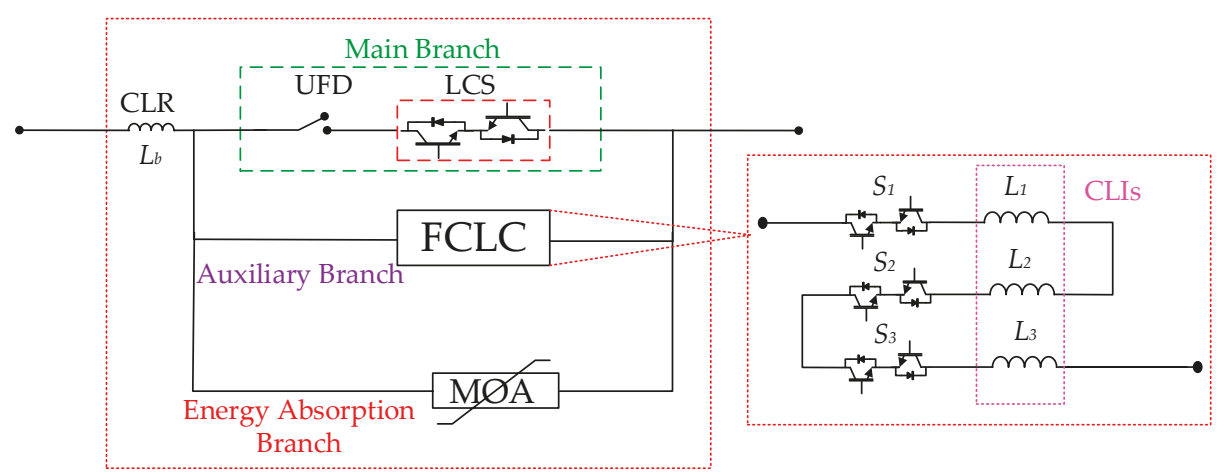

Figure 3. Proposed HCB with FCLC.

In order to understand the working principle of the proposed scheme and its contours, it is divided into four different working periods. The different operating periods with reference of time are shown in Figure 4. During $0 \leq t \leq t_{1}$, normal current flows through the whole system including the main branch of the CB. The path-I indicates the current during this interval (see Figure 5a). Normal current means the rated current of the system, defined according to design considerations. At $t_{1}$, the fault in the system is suspected. After the fault is suspected, it usually takes a few milliseconds to confirm. During this time, the current continues to flow through the main branch of the CB and switches start to open gradually. The direction of current flow during this time remains the same as of $0 \leq t \leq t_{1}$.

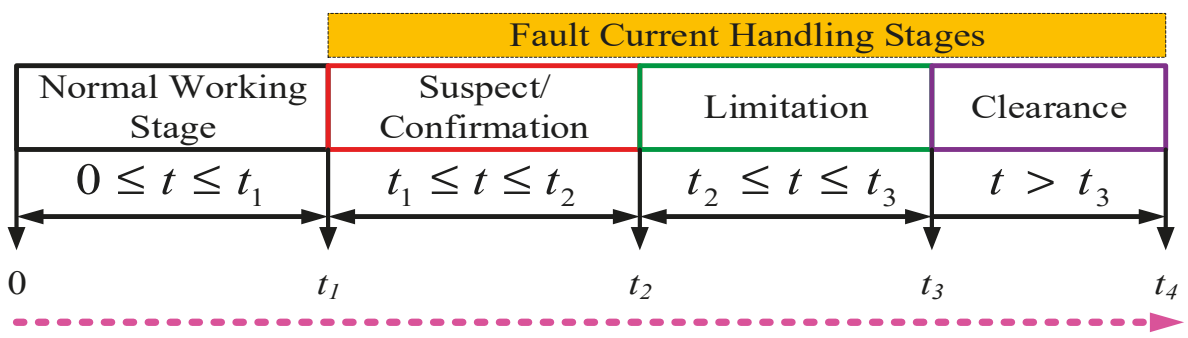

Time Axis

Figure 4. Different operating periods with fault current handling stages.

Once the fault in the system is confirmed at $t_{2}$, the switches associated with the main branch of the CB are opened and the fault current is directed to the FCLC placed in the auxiliary branch of the CB. At this stage, fault current limitation operation is achieved. Figure $5 b$ explains the current flow during $t_{2} \leq t \leq t_{3}$. After $t_{3}$, the switches in the auxiliary branch are opened and the residual fault current is shifted to the MOA. At this stage, the fault current is forced to zero and isolated from the system. The flow of current during this period is elucidated in Figure $5 \mathrm{c}$.

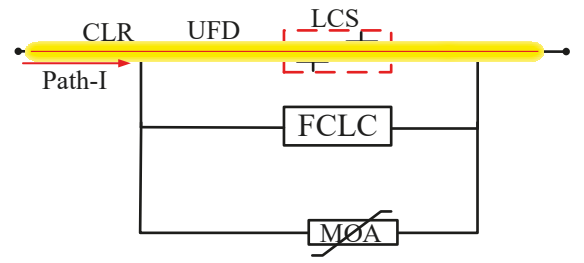

(a)

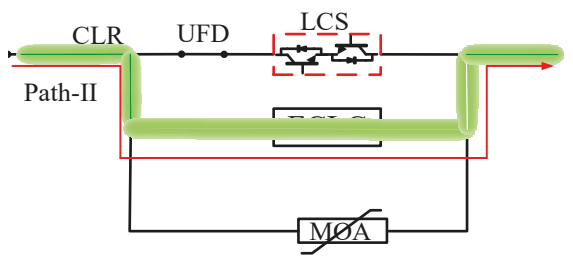

(b)

Figure 5. Cont. 


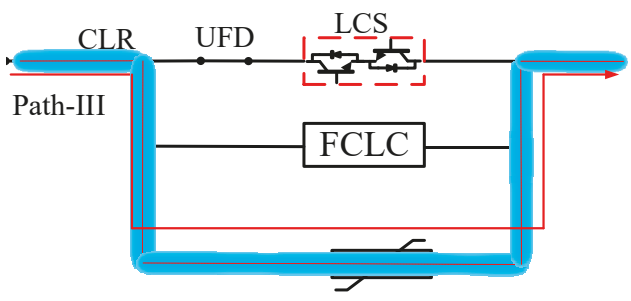

(c)

Figure 5. Flow of current through different branches of breakers during different time intervals: (a) $0 \leq t \leq t_{1}$ and $t_{1} \leq t \leq t_{2} ;$ (b) $t_{2} \leq t \leq t_{3}$; (c) $t>t_{3}$.

\subsection{Determination of Current and Size of Current-Limiting Inductors}

The size of breaker impedance $\left(\mathrm{CLR} / L_{b}\right)$ and current-limiting inductances (CLIs, $L_{1}, L_{2}$, and $L_{3}$ ) depends on design considerations or the desired requirements. The equivalent circuit to estimate the values of current, CLR, and CLIs is divided into two parts: an equivalent circuit of the system before the fault and an equivalent circuit of the system after the fault. The equivalent circuits for the time intervals $0 \leq t \leq t_{1}$ and $t_{1} \leq t \leq t_{2}$ are shown in Figure 6a,b, respectively. The internal resistance of UFD and LCS is minimal, therefore, for simplicity, these are ignored. The second equivalent circuit is drawn for the fault current limitation stage during the time $t_{2} \leq t \leq t_{3}$ and is shown in Figure 6c.

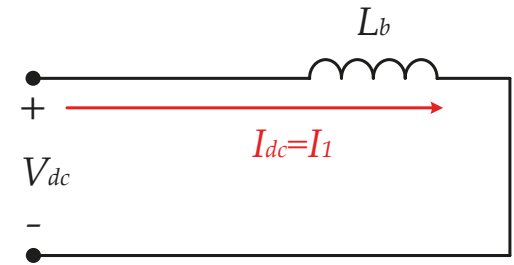

(a)

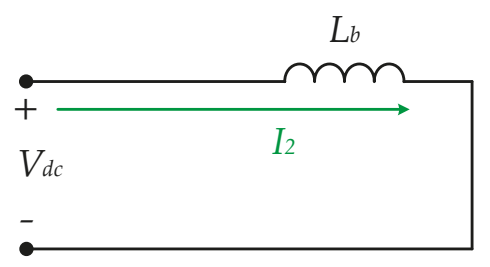

(b)

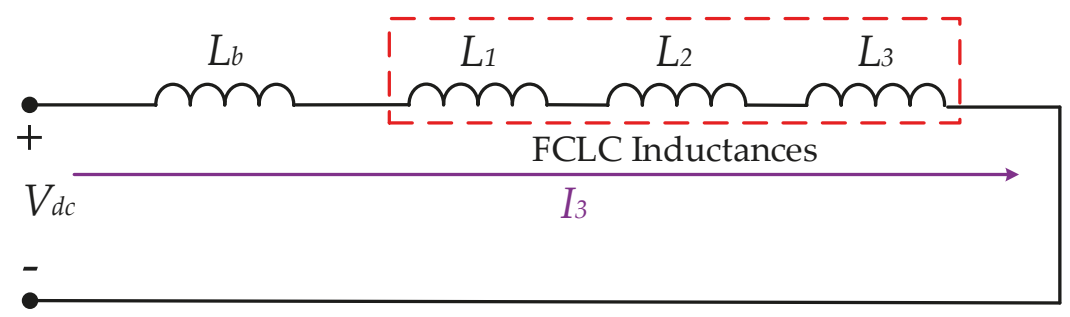

(c)

Figure 6. The simplified equivalent circuits in different working stages: (a) for normal working stage; (b) for fault suspect/confirmation stage; (c) for fault current limitation stage.

During $0 \leq t \leq t_{1}$, the value of the current increases from zero to the rated value. This rated value is considered as the line current which is predefined. The current during this period is defined by Equation (1). In Equation (1), $I_{d c}$ represents the rated value of the line current.

$$
I_{I}=I_{d c}
$$

Once the fault in the system at $t_{2}$ is detected, it takes a few milliseconds to confirm the existence of the fault. During this time, the current continues to flow through the main branch of the CB, and the quantum of the fault current in this interval is calculated using the equivalent circuit in Figure 6b. 
The current during $t_{1} \leq t \leq t_{2}$ is calculated with the application of KVL and Laplace Transformation. The final result is given obtained in the time domain, which is given by Equation (2).

$$
I_{2}=I_{I}+\left(\frac{V_{d c}}{L_{b}}\right) t
$$

In Equation (2), $I_{1}$ is the constant which depends on the initial condition, $V_{d c}$ is the rated line voltage, and $L_{b}$ represents the value of CLR. In Equation (2), the constant $I_{1}$ is accessed by using Equation (1). From Equation (2), an approximate value of $L_{b}$ can be calculated, keeping in view the maximum permissible range of fault current $I_{2}$, which is the peak value of the current the system attains after fault detection. Once the fault is confirmed at $t_{2}$, the FCLC in the auxiliary branch is activated. For this case, the equivalent circuit diagram is shown in Figure 6c. The following constraints are considered for calculating the current during this period:

$$
L_{1}=L_{2}=L_{3}=L
$$

Application of KVL for the circuit in Figure 6c results in the following equation:

$$
V_{d c}=L_{b}\left(\frac{d I_{3}}{d t}\right)+3 L\left(\frac{d I_{3}}{d t}\right)
$$

or

$$
V_{d c}=\frac{d I_{3}}{d t}\left(L_{b}+3 L\right)
$$

Solving Equation (5) to get the current during the time $t_{2} \leq t \leq t_{3}$ :

$$
I_{3}=\frac{I_{2} L_{r}}{L_{b}+3 L}+\frac{V_{d c}}{L_{b}+3 L}(t)
$$

or

$$
I_{3}=\frac{1}{L_{b}+3 L}\left[I_{2} L_{b}+V_{d c}(t)\right]
$$

In Equation (7), the current $I_{2}$ depends on the initial conditions. From Equation (3), it is obvious that $I_{2}$ is the maximum permitted current after fault detection. Since $I_{3}$ represents the amount of suppressed current, Equation (7) is used to estimate the values of inductances $\left(L_{1}=L_{2}=L_{3}=L\right)$ used during the fault current limitation stage. After the time $t_{3}$, the residual current $I_{3}$ is transferred to the energy absorption branch (i.e., MOA) and the fault current at this stage is converged to zero and isolated from the system. The energy absorbed by the MOA at the final stage is calculated using the following mathematical relationship [33]:

$$
E=\int V(t) I(t) d t
$$

In Equation (8), $E$ represents the energy absorbed by the MOA, $V(t)$ represents the voltage across the MOA, and $I(t)$ represents the current through the MOA. The graphical illustration of DC current explaining the behavior of the current in different stages is highlighted in Figure 7. In Figure 7, $t_{f c}$ represents fault clearance time, which is calculated as:

$$
t_{f c}=t_{4}-t_{2}
$$

Based on the above analysis, it can be concluded that the transfer of current from one branch of the breaker to another branch at the switching instants $t_{1}, t_{2}, t_{3}$, and $t_{4}$ depends on two factors: maximum values of the current and time to attain it. In other words, it depends on rate of change of the current. 


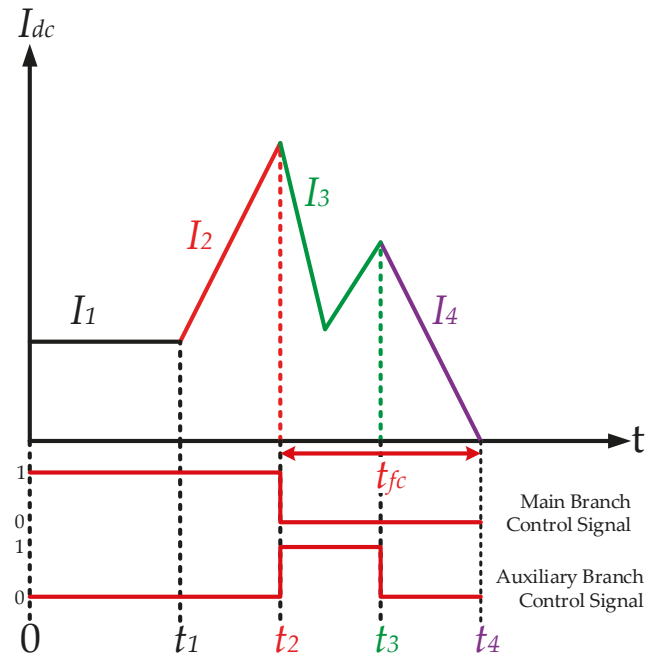

Figure 7. The graphical illustration of estimated DC current with control signals.

\subsection{Transient Overvoltage Analysis}

By application of FCLC in the auxiliary branch of the proposed HCB, the quantum of the fault current can be reduced effectively. However, due to the use of FCLC in the auxiliary branch, the main branch of the breaker has to sustain voltage overshoot for a brief time. To avoid this problem, the protection scheme for the main branch is essential. In this context, several approaches are discussed in the literature. For example, in Reference [34], the concept of parallel MOA was used to guard PE switches against overvoltage; the schematic layout is shown in Figure 8, where $R_{s}$ and $L_{s}$ represent system resistance and inductance, respectively, $L_{p}$ represents stray inductance that exists between IGBT switch and main arrester $\left(\mathrm{MOA}_{\mathrm{m}}\right)$, and $V_{d c}$ represents the terminal DC voltage. The components with dotted lines are used to protect the IGBT switch against overvoltage. A similar approach as discussed in [34] was utilized to protect the switches in the main branch against transient overvoltage; the schematic layout is given in Figure 9.

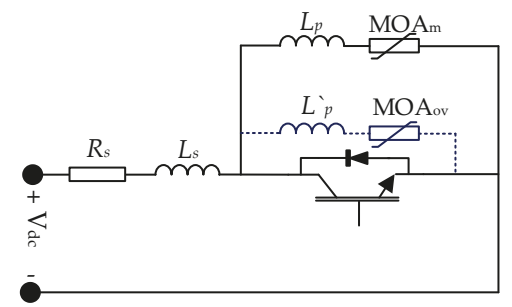

Figure 8. A scheme for protection of PE switches against overvoltage. 


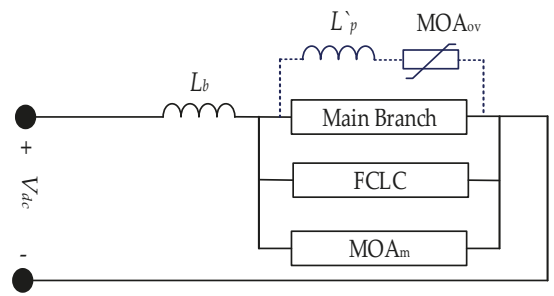

Figure 9. Representing the protection approach for switches in main branch of the HCB with FCLC.

\section{Results and Discussion}

The proposed HCB with FCLC is tested with a three-terminal VSC-HVDC transmission system, using PSCAD/EMTDC simulation tool. The VSC is based on a two-level converter with the standard double-loop control scheme for each terminal. The schematic layout of the system with the placement of HCB is elucidated in Figure 10. The details of parameters for each terminal are given in Table A1 in the Appendix A [21]. The details of parameters used for the proposed HCB with FCLC for preliminary simulation analysis are available in Table A2 in the Appendix A. To test the performance of the proposed HCB with FCLC, the L-G fault on cable 12 is introduced. The proposed breaker to limit and isolate the fault current is commissioned on either side of the transmission line. The overall response DC current with the placement of the proposed breaker is shown in Figure 11. It must be noted that the performance of the proposed HCB is analyzed for $200 \mathrm{kV}$ voltage level. This voltage level is used in various real-world projects; for example, the Zhoushan five-terminal VSC-HVDC project in China is designed for $200 \mathrm{kV}$ voltage level. Thus the simulation results provide a good assessment considering the real-world applications and operating conditions.

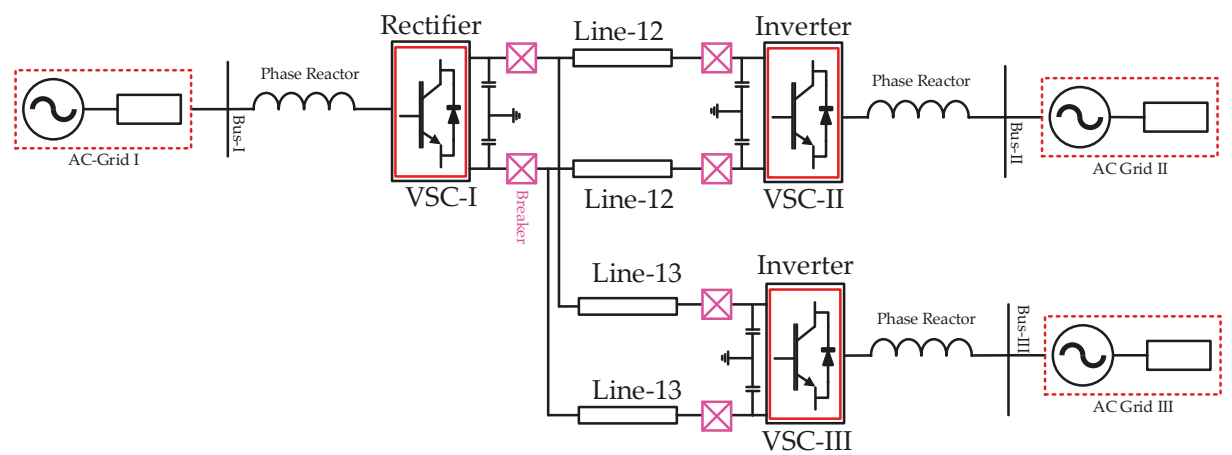

Figure 10. Three-terminal VSC-HVDC system.

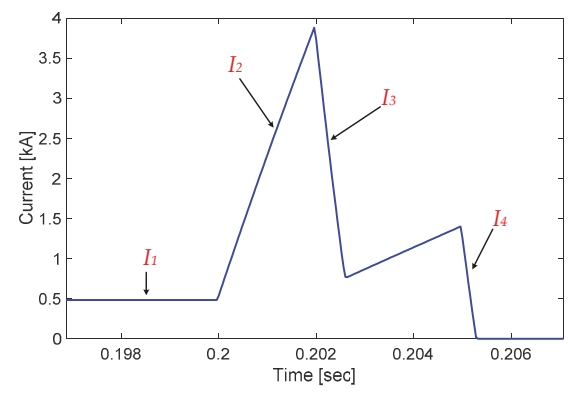

I1 Normal operating region

I2 Fault suspect/conformation Stage

$I_{3} \quad$ Fault current limiting region

I4 Fault current isolation region

Figure 11. Overall response DC current. 
The details of the events for the particular result are as follows. From 0 to $0.2 \mathrm{~s}$, the system is allowed to operate in normal or steady-state condition. During this time, the system carries the rated DC current, which is defined as $0.5 \mathrm{kA}$. At $0.2 \mathrm{~s}$ (say, $t_{1}$ ), the L-G fault is introduced on cable 12 . It can be observed from the result in Figure 11 that the fault current increases with a high rate, and at $0.202 \mathrm{~s}$ $\left(\right.$ say, $\left.t_{2}\right)$, the fault current reaches the level of approximately $4 \mathrm{kA}$. During this interval, the fault current is allowed to flow though the main branch of the breaker.

At $0.202 \mathrm{~s}$, the fault in the system is considered confirmed, and the fault-current-limiting operation begins, by opening the switches in the main branch and closing the switches in the FCLC (in auxiliary branch). The FCLC remains alive for 3 milliseconds and the fault current first drops sharply and then at $0.205 \mathrm{~s}$, it reaches the value of less than $3 \mathrm{kA}$. In this way, by employing the FCLC, the fault current is reduced significantly. After $0.205 \mathrm{~s}$ (say, $t_{3}$ ), the switches in the FCLC are opened and the residual current is shifted to the MOA, and at the instant $t_{4}$, the fault current is fully isolated from the system.

The supplementary results include the current though the main branch, auxiliary branch, and energy absorption branch of the breaker; these results are shown in Figure 12a-c, respectively. These results segregate the response of the DC current during different intervals. For example, in Figure 12a, the current through the LCS is outlined, which shows that from 0 to $0.202 \mathrm{~s}$, the current flows through the main branch, and at $0.202 \mathrm{~s}$, the switches open completely and the current drops to zero. Likewise, from Figure 12b, it can be observed that the FCLC remains inactive until $0.202 \mathrm{~s}$, and after that, the fault-current-limiting operation begins, and due to the three CLIs, the current in this branch is restricted to $1.5 \mathrm{kA}$ (approximately). At $0.205 \mathrm{~s}$, the switches in the FCLC open and the current in the branch is dropped to zero. Right after $0.205 \mathrm{~s}$, the residual current is shifted to the MOA, which is shown in Figure 12c.

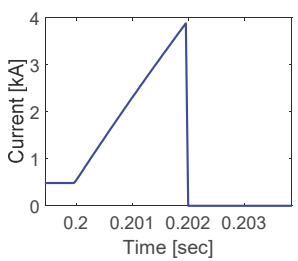

(a)

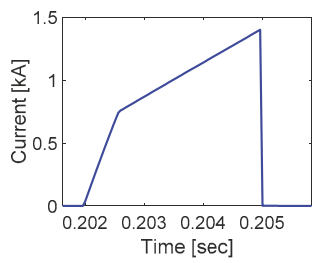

(b)

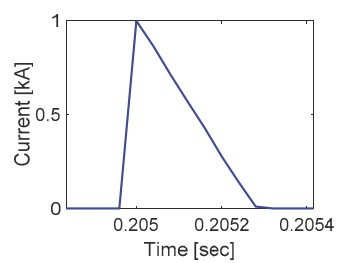

(c)

Figure 12. Current through different branches of breaker: (a) main branch; (b) FCLC (auxiliary branch); (c) $\mathrm{MOA}_{\mathrm{m}}$.

Furthermore, the result in Figure 13a represents the voltage across the circuit breaker. It is important to note that all branches in the circuit breaker are connected in parallel, so the voltage across them is the same. To avoid voltage overshoot across the main branch of the circuit breaker, due to parasitic inductance and CLIs in the auxiliary branch of the breaker, an MOA of larger size $\left(\mathrm{MOA}_{\mathrm{ov}}\right)$ is used with the main branch of the breaker, as discussed in [34]. This MOA shares some part of the energy in the fault current limitation stage and also resists the voltage overshoot across the main branch of the breaker in order to reduce the quantum of the fault current. From Figure 13a, it can be noted that the voltage overshoot is observed twice, first when the fault-current-limiting operation begins at $0.202 \mathrm{~s}$, and secondly at $0.205 \mathrm{~s}$, when the residual current is transferred to the MOA. Figure $13 \mathrm{~b}, \mathrm{c}$ show energy absorbed by overvoltage arrester $\left(\mathrm{MOA}_{\mathrm{ov}}\right)$ and main arrester $\left(\mathrm{MOA}_{\mathrm{m}}\right)$, respectively. 


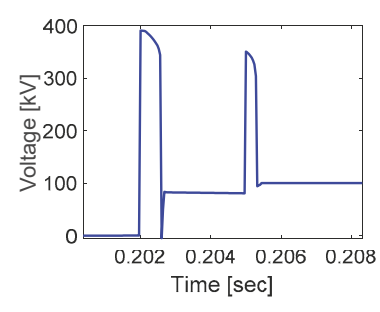

(a)

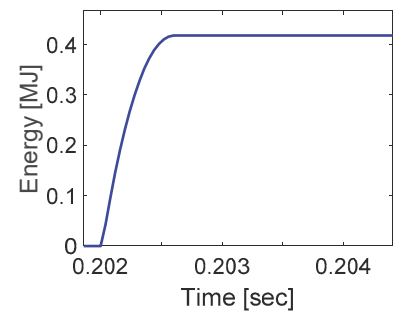

(b)

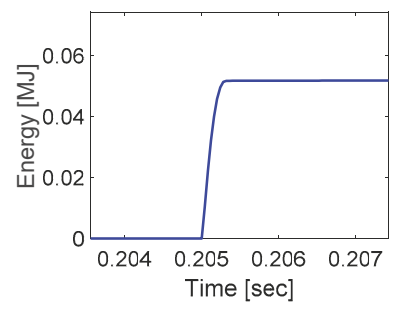

(c)

Figure 13. Miscellaneous results: (a) voltage across breaker; (b) energy absorbed by $\mathrm{MOA}_{\mathrm{ov}}$; (c) energy absorbed by $\mathrm{MOA}_{\mathrm{m}}$.

Moving forward, the impact of varying the values of current-limiting inductances $\left(L_{1}=L_{2}=L_{3}=L\right)$ in the FCLC is also observed, keeping all other parameters unchanged, and Figure 14 shows the overall response of the DC current. It is observed from the results that the larger values of inductances lower the rate of increase of the current and also improve the fault clearance time (i.e., $t_{f c}$ ). In addition, the peak value of the current during the fault current limitation stage reduces with larger L. Figure 15a,b show the corresponding energy absorbed by overvoltage arrester $\left(\mathrm{MOA}_{\mathrm{ov}}\right)$ and main arrester $\left(\mathrm{MOA}_{\mathrm{m}}\right)$, respectively. The quantified data of system response under varying values of $L$ is given in Table 1 .

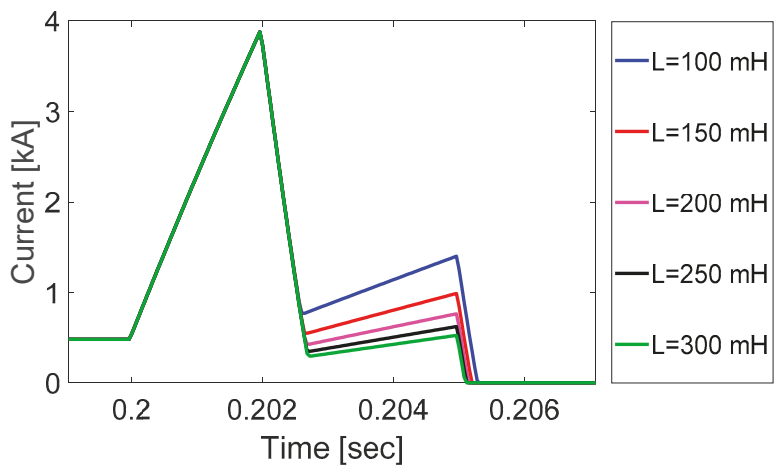

Figure 14. The influene of $L$ on overall DC current.

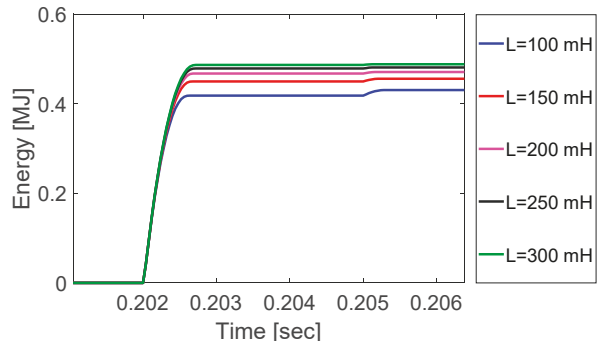

(a)

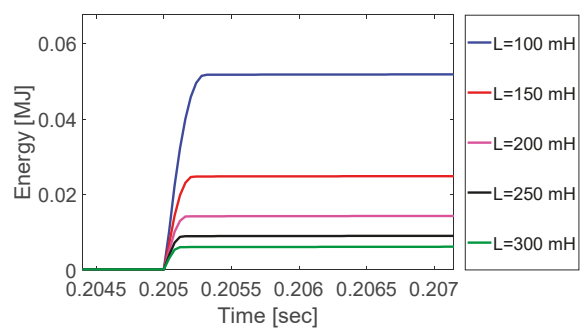

(b)

Figure 15. Energy absorbed by arrester under different values of $L$ : (a) $\mathrm{MOA}_{\mathrm{ov}}$; (b) $\mathrm{MOA}_{\mathrm{m}}$. 
Table 1. Repressing the statistical details of system response under varying values of $L$.

\begin{tabular}{ccccc}
\hline $\begin{array}{c}\text { Size of } \\
\boldsymbol{L}(\mathbf{m H})\end{array}$ & $\begin{array}{c}\text { Fault } \\
\text { Clearance } \\
\text { Time (ms) }\end{array}$ & $\begin{array}{c}\text { Peak Current in Fault } \\
\text { Current Limitation } \\
\text { Stage (kA) }\end{array}$ & $\begin{array}{c}\text { Energy } \\
\text { Absorbed by } \\
\text { MOAov (MJ) }\end{array}$ & $\begin{array}{c}\text { Energy Absorbed } \\
\text { by MOAm (MJ) }\end{array}$ \\
\hline 100 & 3.25 & 1.40 & 0.4306 & 0.052 \\
150 & 3.15 & 1.00 & 0.4558 & 0.024 \\
200 & 3.11 & 0.76 & 0.4705 & 0.014 \\
250 & 3.08 & 0.62 & 0.4810 & 0.009 \\
300 & 3.05 & 0.52 & 0.4881 & 0.006 \\
\hline
\end{tabular}

\section{Comparative Analysis of Proposed Breaker and Other Topologies}

So far, the critical results of the proposed HCB with FCLC under various conditions have been discussed. In this segment of the paper, the performance of the proposed HCB with FCLC is compared with other solutions to evaluate the effectiveness and competitiveness. For this purpose, a three-terminal VSC-HVDC model is used, with the same parameters discussed in Table A1 in the Appendix A. The designs of the proposed FCLC and current-limiting breaker in [20] are modular in nature, therefore the number of CLIs can be changed according to requirements; for compression purpose, one CLR and three CLIs are used. The details of breaker parameters used for compression purpose are the same as in Table A2 in the Appendix A.

The results presented in Figure 16 signify the DC current flowing through the systems for three different cases. The results in Figure 17 show the response of voltage across the breaker, and Figure 18 shows the power absorbed by the main arrester for different solutions. The details of the results discussed in Figure 16 are as follows: at $0.2 \mathrm{~s}$, a fault in the system is introduced, and for 2 milliseconds, the current is allowed to flow through the main branch of breaker discussed in $[18,20]$ and proposed scheme. It is observable that during this time, the rate of increase of the current and maximum value of current for [18] and the proposed scheme is the same. However, in the same interval, the rate of increase of the fault current is less for the solution discussed in [20], and the maximum value of the current is also a bit lower. Because the CLIs are used in parallel even in normal condition, they resist the steep increment in the fault current during fault confirmation stage.

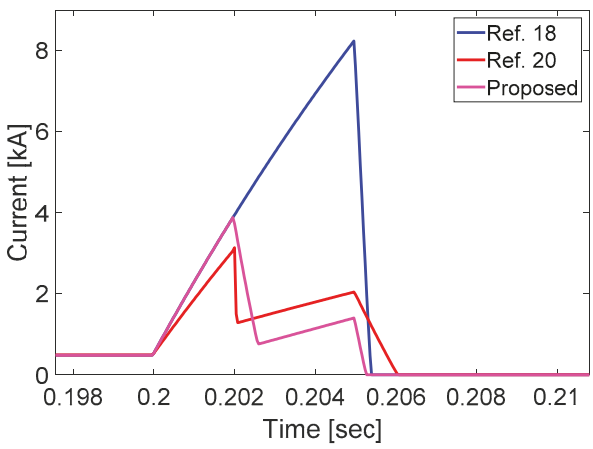

Figure 16. The response of DC current flowing through the system under the influence of different solutions. 


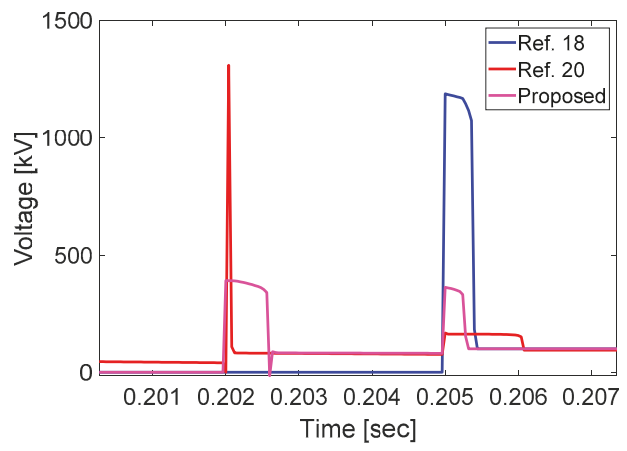

Figure 17. Voltage across the breaker under influence of different solutions.

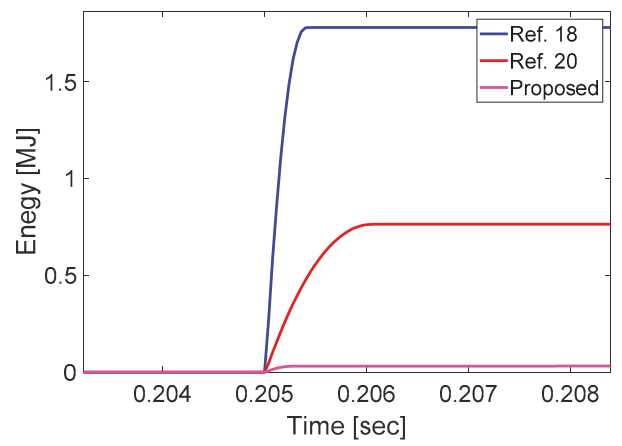

Figure 18. Power absorbed by main MOA under different solutions.

The fault-current-limiting operation is applied for 3 milliseconds. During the fault current limitation stage, the current starts to flow through the auxiliary branch of the breaker in $[18,20]$ and the proposed scheme. Since the design of the breaker in [18] has no capacity to limit the fault current, during this interval, the current continues to increase and reaches the peak value of $8 \mathrm{kA}$ (approximately). For [20], during this time, the intensity of the fault current is first reduced and then increased to the level of $2 \mathrm{kA}$ (approximately). In the proposed scheme, the FCLC is employed in the auxiliary branch, and thus the fault current is first dropped and then increased to $1.4 \mathrm{kA}$ (approximately).

The details of results concerning voltage across the breaker in Figure 17 is as follows. From 0 to $0.2 \mathrm{~s}$, the voltage across the breaker is zero for all cases because during this time, the system is operating in normal condition. At $0.2 \mathrm{~s}$, a fault in the system is introduced for the proposed HCB, and [18] the voltage remains zero until $0.202 \mathrm{~s}$, because for $2 \mathrm{~ms}$ after the introduction of the fault, the current continues to flow through the main branch of the breaker. For Reference [20], the voltage across the breaker is also observed during fault confirmation stage due to the use of parallel CLIs. At $0.202 \mathrm{~s}$, the fault current limitation starts; the transient voltage overshoot is large for Reference [20], however, it can be compensated using capacitors in parallel with BCBs. For the proposed HCB with FCLC, the transient voltage overshoot is controlled using the concept of parallel arresters as mentioned in [34]. The voltage across the breaker discussed in [18] remains zero during the fault-current-limiting stage because no fault-current-limiting component is used. The second voltage overshoot is observed when the current is shifted to the main MOA at the final stage. From Figure 17, it can be observed that during this stage, voltage across the proposed HCB is better than the other two cases. The results in Figure 18 show the power absorbed by the main arrester under different causes, and it is clear that the main arrester in the proposed HCB absorbs the energy less than the others. The performance evaluation charts in Tables 2 and 3 summarize the details of comparative analysis. 
Table 2. Performance evaluation chart for normal and fault suspect/confirmation stage.

\begin{tabular}{cccc}
\hline \multirow{2}{*}{ Schemes } & Current in Normal Working Stage & \multicolumn{2}{c}{ Current in Fault Suspect/Confirmation Stage } \\
\cline { 2 - 4 } & $\boldsymbol{I}_{\boldsymbol{1}}(\mathbf{m a x})[\mathbf{k A}]$ & $\boldsymbol{I}_{\mathbf{2}}(\mathbf{m a x})[\mathbf{k A}]$ & Time to Attain $[\mathrm{ms}]$ \\
\hline$[18]$ & 0.5 & 3.8 & 2 \\
{$[20]$} & 0.5 & 3.2 & 2 \\
Proposed & 0.5 & 3.2 & 2 \\
\hline
\end{tabular}

Table 3. Performance evaluation chart for fault current limitation and clearance stage.

\begin{tabular}{ccccc}
\hline \multirow{2}{*}{ Schemes } & \multicolumn{2}{c}{ Current in Limitation Stage } & \multicolumn{2}{c}{ Clearance Stage } \\
\cline { 2 - 5 } & $\boldsymbol{I}_{\mathbf{3}}(\mathbf{m a x})[\mathbf{k A}]$ & $\begin{array}{c}\text { Time to } \\
\text { Attain [ms] }\end{array}$ & $\begin{array}{c}\text { Energy Absorbed by } \\
\text { MOA [M]] }\end{array}$ & $\begin{array}{c}\text { Clearance Attained } \\
{[\mathbf{m s}]}\end{array}$ \\
\hline$[18]$ & 8.25 & 3 & 1.78 & 3.8 \\
{$[20]$} & 2.04 & 3 & 0.76 & 4.8 \\
Proposed & 1.40 & 3 & 0.05 & 3.8 \\
\hline
\end{tabular}

From the details of the performance evaluation charts in Tables 2 and 3, it is established that the proposed HCB with FCLC can prove to be a good alternative to limit and isolate the fault current in VSC-HVDC transmission systems.

\section{Conclusions}

A novel topology of $\mathrm{HCB}$ is proposed in this paper, with additional characteristics to limit the fault current. The main branch of the breaker is constituted by using UFD and IGBT switches, as used in several other topologies discussed in the literature. In the auxiliary branch, a new circuit named FCLC is introduced. During the fault current suppression stage, the intensity of the fault current is reduced by using FCLC. The reduction in the fault current can cause transient voltage overshoot, which is reduced by using a parallel asserter in the main branch. During fault current limitation, a portion of energy is absorbed by the asserter used for overvoltage protection, thus the requirement for the main asserter is also reduced. The values of CLR and inductances in FCLC can be designed by considering the following aspects: cost, the maximum permissible range of fault current, the required level of fault current suppression, and fault clearance time. A larger size of CLI can reduce the fault current more quickly, but it also causes transient voltage overshoot; consequently, the requirement for protection equipment in the main branch of the breaker also increases, thus a smaller size of CLI is recommended. The simulation results for different case studies and comprehensive comparative analysis indicate that the proposed HCB with FCLC can prove to be a good alternative to limit and isolate the fault current with reasonable efficiency.

Author Contributions: The author M.A. presented the core idea of this paper. Furthermore, he had done the numerical analysis and all simulation-based experiments. W.Z. suggested the pertinent literature for review and supervised the whole process of write-up.

Funding: Authors would like to acknowledge the following agencies for their support: Project Supported by National Key R\&D Program of China (2018YFB0904600); and Special Funding of Technical Standard of Shanghai Science and Technology Commission (18DZ2205700).

Conflicts of Interest: The authors declare no conflict of interest. 


\section{Abbreviations}

$\begin{array}{llll}\text { BCCB } & \text { Branch circuit breaker } & \text { LCC } & \text { Line-commutated converters } \\ \text { CLR } & \text { Current-limiting reactance } & \text { LCS } & \text { Load commutation switch } \\ \text { CLIs } & \text { Current-limiting inductors } & \text { L-G } & \text { Line-to-ground } \\ \text { CB } & \text { Circuit breaker } & \text { MOA } & \text { Metal oxide arrester } \\ \text { DC } & \text { Direct current } & \text { MCB } & \text { Main circuit breaker } \\ \text { DCCB } & \text { Direct current circuit breaker } & \text { ms } & \text { Milliseconds } \\ \text { FCLC } & \text { Fault-current-limiting circuit } & \text { MJ } & \text { Megajoule } \\ \text { FCL } & \text { Fault current limiters } & \text { NSFCLs } & \text { Non-superconducting FCL } \\ \text { HVDC } & \text { High-voltage direct current } & \text { PE } & \text { Power electronics } \\ \text { HVAC } & \text { High-voltage alternating current } & \text { SFCLs } & \text { Superconducting FCL } \\ \text { HCB } & \text { Hybrid circuit breaker } & \text { VSC } & \text { Voltage source converter }\end{array}$

\section{Appendix A}

Table A1. Three-terminal VSC-HVDC parameters.

\begin{tabular}{ccc}
\hline & Parameters & Values \\
\hline \multirow{3}{*}{ DC link parameters } & DC voltage $V_{d n}$ & $\pm 200 \mathrm{kV}$ \\
& DC current $I_{d n}$ & $0.5 \mathrm{kA}$ \\
& DC link capacitor & $300 \mu \mathrm{F}$ \\
\hline \multirow{3}{*}{ Active power } & Terminal-1 $\left(P_{1}\right)$ & $0 \mathrm{MW}$ \\
& Terminal-2 $\left(P_{2}\right)$ & $+200 \mathrm{MW}$ \\
& Terminal-3 $\left(P_{3}\right)$ & $-200 \mathrm{MW}$ \\
\hline \multirow{5}{*}{ DC line parameters } & Length of cable 12 & $200 \mathrm{~km}$ \\
& Length of cable 13 & $100 \mathrm{~km}$ \\
& Resistance per unit length $(R)$ & $0.035 \Omega / \mathrm{kM}$ \\
& Inductance per unit length $(L)$ & $0.156 \mathrm{mH} / \mathrm{kM}$ \\
\hline \multirow{2}{*}{ AC grid } & Grid-1 voltage & $420 \mathrm{kV}$ \\
& Grid-2 voltage & $500 \mathrm{kV}$ \\
& Grid-3 voltage & $420 \mathrm{kV}$ \\
\hline
\end{tabular}

Table A2. Proposed HCB with FCLC parameters.

\begin{tabular}{ccc}
\hline \multicolumn{2}{c}{ Parameters } & Values \\
\hline CLR & $L_{b}$ & $38.4 \mathrm{mH}$ \\
\hline \multirow{3}{*}{ CLIs } & Inductor- $1 L_{1}$ & $100 \mathrm{mH}$ \\
& Inductor- $2 L_{2}$ & $100 \mathrm{mH}$ \\
Parasitic inductance & Inductor-3 $L_{3}$ & $100 \mathrm{mH}$ \\
\hline
\end{tabular}

\section{References}

1. Zappa, W.; Junginger, M.; van den Broek, M. Is a 100\% renewable European power system feasible by 2050 ? Appl. Energy 2019, 233-234, 1027-1050. [CrossRef]

2. The International Renewable Energy Agency (IRENA). Renewable Energy Statistics 2018. Available online: http://www.ren21.net/wp-content/uploads/2018/06/17-8652_GSR2018_FullReport_web_final_.pdf (accessed on 1 March 2019).

3. World Economic Forum (WEF). Three Countries Are Leading the Renewable Energy Revolution. Available online: https://www.weforum.org/agenda/2018/02/countries-behind-global-renewable-energy-growth/ (accessed on 1 March 2019).

4. Renewable Energy Network (REN) for the 21st Century. Renewables 2018 Global Status. Available online: http://www.ren21.net/wp-content/uploads/2018/06/17-8652_GSR2018_FullReport_web_final_.pdf (accessed on 1 March 2019). 
5. Rudervall, R.; Charpentier, J.P.; Sharma, R. High Voltage Direct Current (HVDC) Transmission Systems Technology Review Paper. Presented at the Energy Week 2000, Washington, DC, USA, 7-8 March 2000.

6. Muhammad Rashid. In Power Electronics Hand Book, 4th ed.; BH Publications: Oxford, UK, 2018; pp. 849-851.

7. ABB. High-Voltage Direct Current Transmission Enabling Single EU Energy Market. Available online: http: //www.eem18.eu/gfx/eem-network/userfiles/_public/eem18_lodz_krontiris.pdf (accessed on 1 March 2019).

8. IEEE Transmission and Distribution Committee. HVDC Project Listing. Available online: http://www.ece. uidaho.edu/hvdcfacts/Projects/HVDCProjectsListingDec2006.pdf (accessed on 1 March 2019).

9. Yang, Q.; Le Blond, S.; Liang, F. Design and Application of Superconducting Fault Current Limiter in a Multiterminal HVDC System. IEEE Trans. Appl. Supercond. 2017, 27, 1-5. [CrossRef]

10. Lee, H.Y.; Asif, M.; Park, K.H.; Lee, B.W. Feasible Application Study of Several Types of Superconducting Fault Current Limiters in HVDC Grids. IEEE Trans. Appl. Supercond. 2018, 28, 1-5. [CrossRef]

11. Li, B.; Jing, F.; Li, B.; Chen, X.; Jia, J. Study of the application of active saturated iron-core superconductive fault current limiters in the VSC-HVDC system. IEEE Trans. Appl. Supercond. 2018, 28, 1-6. [CrossRef]

12. Chen, L.; Tang, F.; Ren, L. Comparative study of inductive and resistive SFCL to mitigate the DC fault current in a VSC-HVDC system integrated with wind power farms. In Proceedings of the 2015 IEEE International Conference on Applied Superconductivity and Electromagnetic Devices (ASEMD), Shanghai, China, 20-23 November 2015.

13. Sujuan, X.; Yufeng, Q.; Tianshu, B. Resistive DC fault current limiter. IET J. Eng. 2017, 2017, 1682-1685. [CrossRef]

14. Wang, M.; Leterme, W.; Beerten, J.; van Hertem, D. Using fault current limiting mode of a hybrid DC breaker. IET J. Eng. 2018, 2018, 818-823. [CrossRef]

15. Keshavarzi, D.; Farjah, E.; Ghanbari, T. Hybrid DC Circuit Breaker and Fault Current Limiter with Optional Interruption Capability. IEEE Trans. Power Electron. 2018, 33, 2330-2338. [CrossRef]

16. Franck, C.M. HVDC Circuit Breakers: A Review Identifying Future Research Needs. IEEE Trans. Power Deliv. 2011, 26, 998-1007. [CrossRef]

17. Hassanpoor, A.; Häfner, J.; Jacobson, B. Technical Assessment of Load Commutation Switch in Hybrid HVDC Breaker. IEEE Trans. Power Electron. 2015, 30, 5393-5400. [CrossRef]

18. Callavik, M.; Blomberg, A.; Häfner, J.; Jacobson, B. Break-through!: ABB's hybrid HVDC breaker, an innovation breakthrough enabling reliable HVDC grids. Abb Rev. 2013. Available online: https://www.researchgate.net/publication/297049686_Break-through_ABB \T1\textquoterights_ hybrid_HVDC_breaker_an_innovation_breakthrough_enabling_reliable_HVDC_grids (accessed on 1 March 2019).

19. Nguyen, A.D.; Nguyen, T.T.; Kim, H.M. A comparison of different hybrid direct current circuit breakers for application in HVDC system. Int. J. Control Autom. 2016, 9, 381-394. [CrossRef]

20. Li, S.; Zhang, J.; Xu, J.; Zhao, C. A new topology for current limiting HVDC circuit breaker. Int. J. Electr. Power Energy Syst. 2019, 104, 933-942. [CrossRef]

21. Liu, J.; Tai, N.; Fan, C.; Chen, S. A Hybrid Current-Limiting Circuit for DC Line Fault in Multiterminal VSC-HVDC System. IEEE Trans. Ind. Electron. 2017, 64, 5595-5607. [CrossRef]

22. Heidary, A.; Radmanesh, H.; Bakhshi, A. A Compound Current Limiter and Circuit Breaker. Electronics 2019, 8, 551. [CrossRef]

23. Nguyen, V.-V.; Son, H.-I.; Nguyen, T.-T.; Kim, H.-M.; Kim, C.-K. A Novel Topology of Hybrid HVDC Circuit Breaker for VSC-HVDC Application. Energies 2017, 10, 1675. [CrossRef]

24. Thomas, J.; Geraint, P.C.; Christian, M.F. Small-scale HVDC circuit breaker. IEEE Trans. Compon. Packag. Manuf. Technol. 2017, 7, 1058-1068. [CrossRef]

25. Kontos, E.; Schultz, T.; Mackay, L. Multiline breaker for HVdc applications. IEEE Trans. Power Deliv. 2017, 33, 1469-1478. [CrossRef]

26. Li, C.; Liang, J.; Wang, S. Interlink hybrid DC circuit breaker. IEEE Trans. Ind. Electron. 2018, 65, 8677-8686. [CrossRef]

27. Liu, W.; Liu, F.; Zhuang, Y. A multiport circuit breaker-based multiterminal DC system fault protection. IEEE J. Emerg. Sel. Top. Power Electron. 2018, 7, 118-128. [CrossRef]

28. Nadeem, M.H.; Zheng, X.; Tai, N.; Gul, M. Identification and Isolation of Faults in Multi-terminal High Voltage DC Networks with Hybrid Circuit Breakers. Energies 2018, 11, 1086. [CrossRef] 
29. Cwikowski, O.; Wood, A.; Miller, A. Operating DC Circuit Breakers with MMC. IEEE Trans. Power Deliv. 2018, 33, 260-270. [CrossRef]

30. Xiang, B.; Liu, Z.; Geng, Y.; Yanabu, S. DC Circuit Breaker Using Superconductor for Current Limiting. IEEE Trans. Appl. Supercond. 2015, 25,1-7. [CrossRef]

31. Pei, X.; Cwikowski, O.; Smith, A.C.; Barnes, M. Design and Experimental Tests of a Superconducting Hybrid DC Circuit Breaker. IEEE Trans. Appl. Supercond. 2018, 28, 1-5. [CrossRef]

32. Alam, M.S.; Abido, M.A.Y.; El-Amin, I. Fault Current Limiters in Power Systems: A Comprehensive Review. Energies 2018, 11, 1025. [CrossRef]

33. Filipović-Grčić, B.; Uglešić, I.; Pavic, I. Energy Stress of Surge Arresters Due to Temporary Overvoltages. In Proceedings of the International Conference on Power Systems Transients (IPST), Delft, The Netherlands, 14-17 June 2011.

34. Magnusson, J.; Saers, R.; Liljestrand, L.; Engdahl, G. Separation of the Energy Absorption and Overvoltage Protection in Solid-State Breakers by the Use of Parallel Varistors. IEEE Trans. Power Electron. 2014, 29, 2715-2722. [CrossRef]

(C) 2019 by the authors. Licensee MDPI, Basel, Switzerland. This article is an open access article distributed under the terms and conditions of the Creative Commons Attribution (CC BY) license (http://creativecommons.org/licenses/by/4.0/). 
Article

\title{
Analysis and Mitigation of Subsynchronous Resonance in a Korean Power Network with the First TCSC Installation
}

\author{
Minh-Quan Tran ${ }^{1}$, Minh-Chau Dinh ${ }^{1}$, Seok-Ju Lee ${ }^{1}$, Jea-In Lee ${ }^{1}$, Minwon Park ${ }^{1, *}$, \\ Chur Hee Lee ${ }^{2}$ and JongSu Yoon ${ }^{2}$ \\ 1 Department of Electrical Engineering, Changwon National University, Changwon 51140, Korea \\ 2 Korea Electric Power Research Institute, Seoul 34056, Korea \\ * Correspondence: pakumw1@gmail.com; Tel.: +82-55-213-2866
}

Received: 19 June 2019; Accepted: 22 July 2019; Published: 24 July 2019

\begin{abstract}
This paper presents a detailed analysis results of the effect of a thyristor-controlled series capacitor (TCSC) on subsynchronous resonance (SSR), which was first applied to a Korean power system. First, the TCSC parameters were calculated, the structure of TCSC with synchronous voltage reversal (SVR) controller was presented, and the torsional characteristics of Hanul nuclear power generator rotor were studied to investigate the natural frequency and mode shape. The test signal method was used to determine the electrical damping in the frequency range of SSR operation through an electromagnetic transient analysis program in various system configurations. The SSR phenomenon was analyzed by comparing the electrical and mechanical damping of a conventional fixed series capacitor (FSC), and the case of a TCSC installed, and the effectiveness of the TCSC without any risk of SSR was demonstrated. As a result, when installing FSC, SSR occurred under sensitive operating conditions, but SSR was prevented in the case of TCSC compensation with SVR. The results obtained in this study can be effectively applied to the installation of TCSC in real power systems.
\end{abstract}

Keywords: korean power system; subsynchronous resonance (SSR); synchronous voltage reversal (SVR); thyristor controlled series capacitor (TCSC); test signal method

\section{Introduction}

Nowadays, electric power transmission lines are under the stress of reaching the thermal limit due to the increase of the transmission power. A flexible alternating current transmission system (FACTS) is well known as an effective solution to improve the power transfer capability. One of the FACTS devices, the thyristor controlled series capacitor (TCSC) not only improves power transfer capability but also helps mitigate the subsynchronous resonance (SSR) problem [1]. In 1971, the first SSR accident occurred at the Mohave generator in Arizona, where the generator shaft caused a large vibration and led to shaft fatigue [2]. Since that problem, the mitigation of the SSR effect into power system become an important issue.

A number of studies have been conducted so far on SSR mitigation using TCSC [3-7], the authors in Ref. [8] introduced that TCSC is attractive to SSR mitigation. However, the benefits of TCSC for SSR mitigation depend heavily on TCSC control methods and power system configurations, and may also affect the SSR mitigation characteristics when the grid has significant changes. The influence of control methodology on SSR was also introduced in [9]. The first IEEE benchmark model had three control methods, consisting of constant impedance, constant current and constant power control. This indicates that a TCSC device under constant impedance control can stimulate SSR vibrations. The paper also proposed a solution called synchronous voltage reversal (SVR) control. However, under the SVR control, the TCSC impedance characteristic has a transition frequency band of electrical 
frequency, and it turns into a negative damping band in the mechanical frequency range and poses a risk of the SSR problem [10,11]. In Ref. [12], the authors analyzed the SSR induced by TCSC through a real-time digital simulator (RTDS) in a China power system, and showed that the TCSC system accessed without SSR damping could have the SSR problem. The Korea Electric Power Corporation (KEPCO) plans to install TCSC for the first time in a Korean power system by taking advantage of TCSC $[13,14]$. However, installing TCSC on an actual power system could threaten system stability, including SSR issues. Also, many nuclear and thermal power plants were installed in the Korean grid near the TCSC facility, so detailed analysis of the SSR is needed before installing the TCSC in the actual grid.

In this paper, the SSR behaviors of the real power network with the TCSC compensations were analyzed and compared with a fixed series capacitor (FSC) under various system configurations. As the first step of the study, the configuration of a $345 \mathrm{kV}$ power network with the TCSCs was presented in a PSCAD/EMTDC (power systems computer aided design/electromagnetic transients in DC) simulation model which was simplified based on the power system presented in PSS/E (power system simulator for engineering). All the $345 \mathrm{kV}$ transmission lines were represented by the 'pi' equivalent model. The system with a radial connection as seen from a generator to a compensated line has been identified as the most vulnerable due to the SSR $[15,16]$. The units \#3 and \#4 of the Hanul nuclear power plant were located at the Hanul station, which can be radial with the compensated transmission line. Therefore, the units \#3 and \#4 of Hanul nuclear power plant were selected for this study, they were presented by a detailed generator model while all other generators were represented by a voltage source. A TCSC model with the SVR control method was implemented to vary the TCSC capacitance proportional to the compensated line from $50 \%$ to $70 \%$, which was required by the KEPCO. The modal analysis method was applied to investigate the torsional characteristics of the rotor of the units \#3 and \#4. Mechanical damping constants corresponding to each natural frequency were also calculated. For the SSR study, frequency scanning methods were applied. A comparison of different frequency scanning methods, including the simplified analytical, two-axis analytical, and test signal methods was performed in [2]. In this study, the test signal method was selected, which was implemented in the PSCAD/EMTDC program as a time-domain digital simulation. The PSCAD/EMTDC simulation can build a detailed generator and complex load model for a real power network, which is very important for the accuracy level of results. The test signal method was used to inject a multi-sine signal with various frequencies in a range of the SSR behavior into the generator speed, the response of electrical torque delivered from the generator was recorded, the fast Fourier transform (FFT) analysis was used to calculate the electrical damping corresponding to the subsynchronous frequency of the SSR behavior. Finally, the contingencies under different operational conditions in the $345 \mathrm{kV}$ power network, including normal and sensitive conditions were defined to analyze the SSR behavior. Under severe conditions such as the loss of some transmission lines, it appears almost radial when looking at ShinYoungju-Hanul transmission line from the units \#3 and \#4. These conditions are unlikely to occur; however, they were defined to highlight any potential issues of the SSR in the real power network. The conventional FSC compensation was also implemented equal to the compensation levels of the TCSC to compare the SSR mitigation efficiency. In each simulation case, the responses of electrical damping at each natural oscillation frequency were used to calculate the net damping of mechanical and electrical damping.

As a result, under normal operation, both FSC and TCSC compensation did not pose a risk to SSR. However, in sensitive cases, the electrical damping clearly showed the SSR in the system with the FSC compensation. In the case of the TCSC with the SVR control at the same compensation level, there was no SSR in the power network. These results are necessary for the first TCSC installation in Korean power system. 


\section{Configuration of a $345 \mathrm{kV}$ Transmission System Equipped with TCSCs}

\subsection{Study Model of the $345 \mathrm{kV}$ Transmission System}

The single line diagram of the $345 \mathrm{kV}$ power network with the TCSCs compensation is shown in Figure 1, and the transmission line data are described in Table A1. The power system model provided by KEPCO was simplified and converted from the PSS/E network model to the PSCAD/EMTDC model. The Hanul nuclear power plant and Samcheok coal-fired power plant are important to supply the power for Seoul's load demand [17]. If TCSCs are installed in two $345 \mathrm{kV}$ transmission lines, including ShinJecheon-Donghae and ShinYoungju-Hanul, it is expected that the power flow will increase and the system stability will be improved as well.

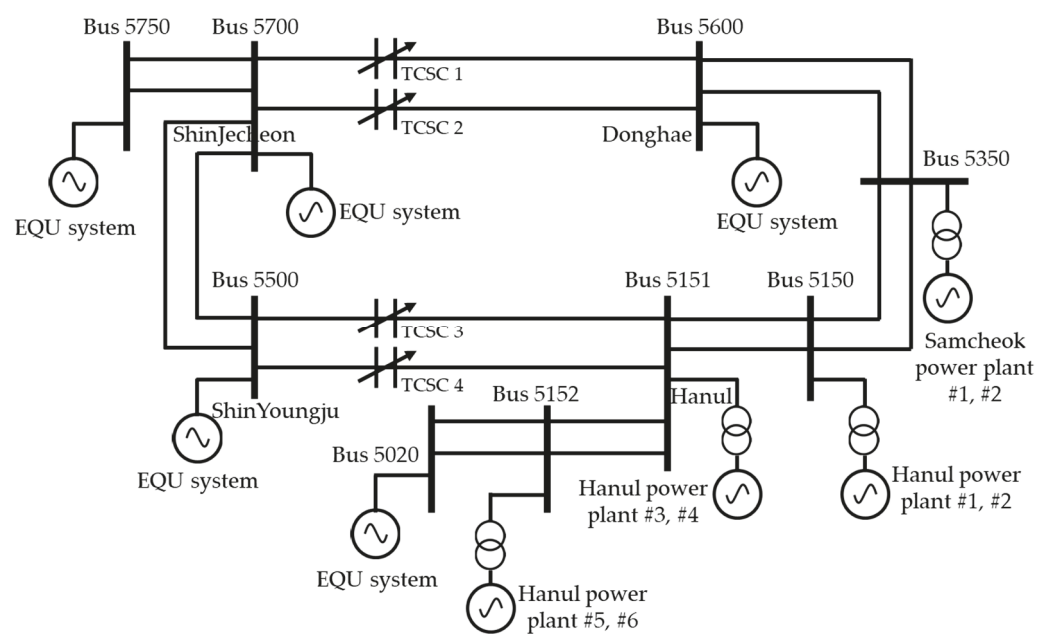

Figure 1. Simplified $345 \mathrm{kV}$ transmission system with thyristor-controlled series capacitors (TCSCs) compensation.

\subsection{Detailed Design of the TCSCS}

The TCSC module has a capacitor bank and a parallel branch, which consists of an inductor connected to back to back thyristors. The TCSC impedance can be changed according to the conduction angle of the thyristors when the two thyristors are triggered. Figure 2 describes the design process of a TCSC.

The design objectives of the TCSCs were determined of 50\% compensation level for normal operation and 70\% compensation level for the first swing operation. The terminologies related to the TCSC design are shown in below equations [18,19]:

$$
\begin{gathered}
k(\%)=\frac{X_{\text {TCSC }}}{X_{\text {Line }}} \times 100 \\
k_{b}=\frac{X_{T C S C}}{X_{C}} \\
\lambda=\sqrt{\frac{X_{C}}{X_{L}}}
\end{gathered}
$$

where $X_{L}$ and $X_{C}$ are the inductor reactance and the capacitor reactance of TCSC. $X_{\text {Line }}$ is the reactance of the compensated transmission line. The compensation level $(k)$ of TCSC was defined in the project objectives. Another parameter related to the design is the boost factor $\left(k_{b}\right)$ that was selected as 1.05 for the two TCSCs, and the resonance factors $(\lambda)$ were selected as 2.6 and 2.68 for ShinYoungju-Hanul and 
ShinJecheon-Donghae, respectively. The results of the TCSCs parameters for two transmission lines can be seen in Table 1.

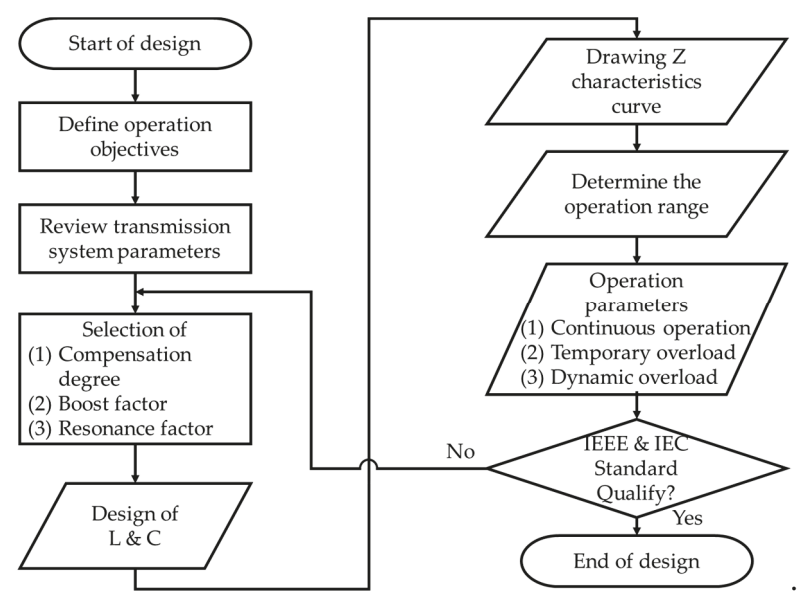

Figure 2. The TCSC design flow chart.

Table 1. The TCSCs parameters for ShinYoungju-Hanul and ShinJecheon-Donghae transmission lines.

\begin{tabular}{ccc}
\hline Items & Shin Youngju-Hanul & ShinJecheon-Donghae \\
\hline Inductor $[\mathrm{mH}]$ & 5.23 & 5.23 \\
Capacitor $[\mu \mathrm{F}]$ & 198.94 & 186.93 \\
\hline
\end{tabular}

As recommended for the SSR mitigation method [20,21], the SVR control method was selected as a controller for the TCSCs in the 345-kV power network. The concept of the SVR control is shown in Figure 3. A phasor measurement was used to measure line current and capacitor voltage. Based on these measurement values, the appearance impedance of the TCSC was calculated at the fundamental frequency. This apparent impedance was then divided to the physical impedance of the series capacitor to get the measured boost level, $k_{\text {bmeas }}$. The boost reference was compared to the measured boost value.

The boost controller uses the PI control, which is based on the error between the reference and measured boost factor for sending angular displacement $\varphi_{C}$ to the SVR trigger pulse generation, and the outputs are the firing time for forward and reverse thyristors. The strategy of the SVR trigger pulse generation block is to control the instant when the capacitor voltage becomes zero. The detailed description of the block is given in the following equations [21]:

$$
\begin{gathered}
u_{C Z}=u_{C M}+X_{0} i_{L M} \lambda \omega_{N}\left(t_{Z}-t_{M}\right) \\
u_{C Z}=X_{0} i_{L M}[\lambda \beta-\tan (\lambda \beta)] \\
t_{F}=t_{Z}-\frac{\beta}{\omega_{N}}
\end{gathered}
$$

where:

$X_{0}=\sqrt{\frac{L}{C}}, \lambda=\frac{X_{0}}{\omega_{N} L}$, and $\omega_{N}=2 \pi f$,

$t_{Z}$ : the desired time when the capacitor voltage becomes zero,

$t_{M}$ : the sampling time when the capacitor voltage $u_{C M}$ and line current $i_{L M}$ are measured,

$t_{F}$ : the thyristor firing time,

$u_{C Z}$ : the capacitor voltage at the desired time $t_{Z}$, 
$u_{C M}$ : the capacitor voltage at the sampling time $t_{M}$,

$i_{L M}$ : the line current at the sampling time $t_{M}$,

$\beta$ : the conduction angle of the thyristor.

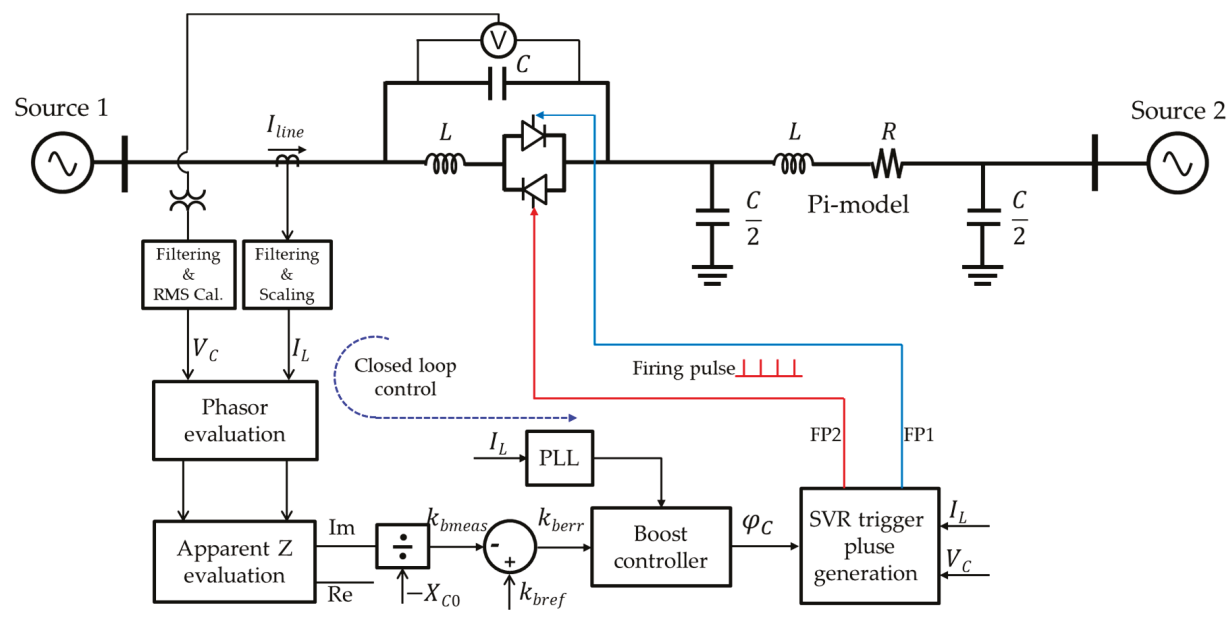

Figure 3. The synchronous voltage reversal (SVR) control strategy.

The SVR control modules were implemented in the PSCAD/EMTDC program by the Fortran codes. The reaction of the SVR control in case of a DC current and a sub-frequency current injected into the line current was shown in Figures 4 and 5. The first case is illustrated in Figure 4, the TCSC operates in a steady state when a DC current is injected into the line current. As shown in the second graph from the top of Figure 4, there is an offset of line current caused by a DC injected current.

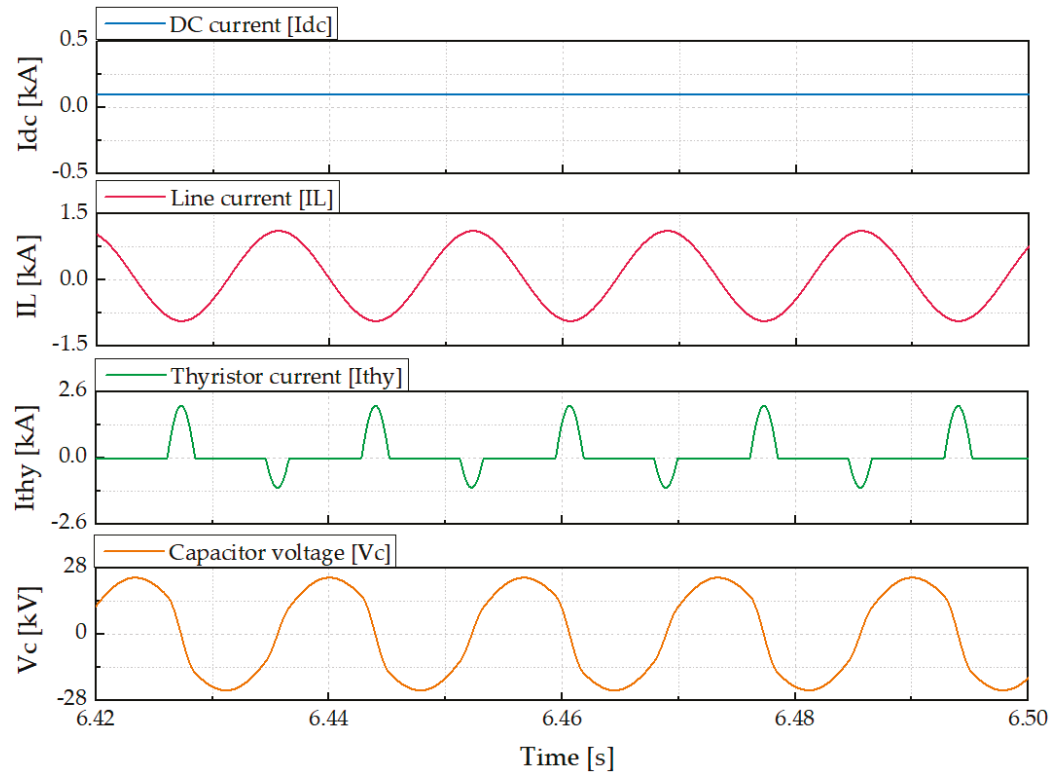

Figure 4. The TCSC-SVR operation with a DC current injection. 

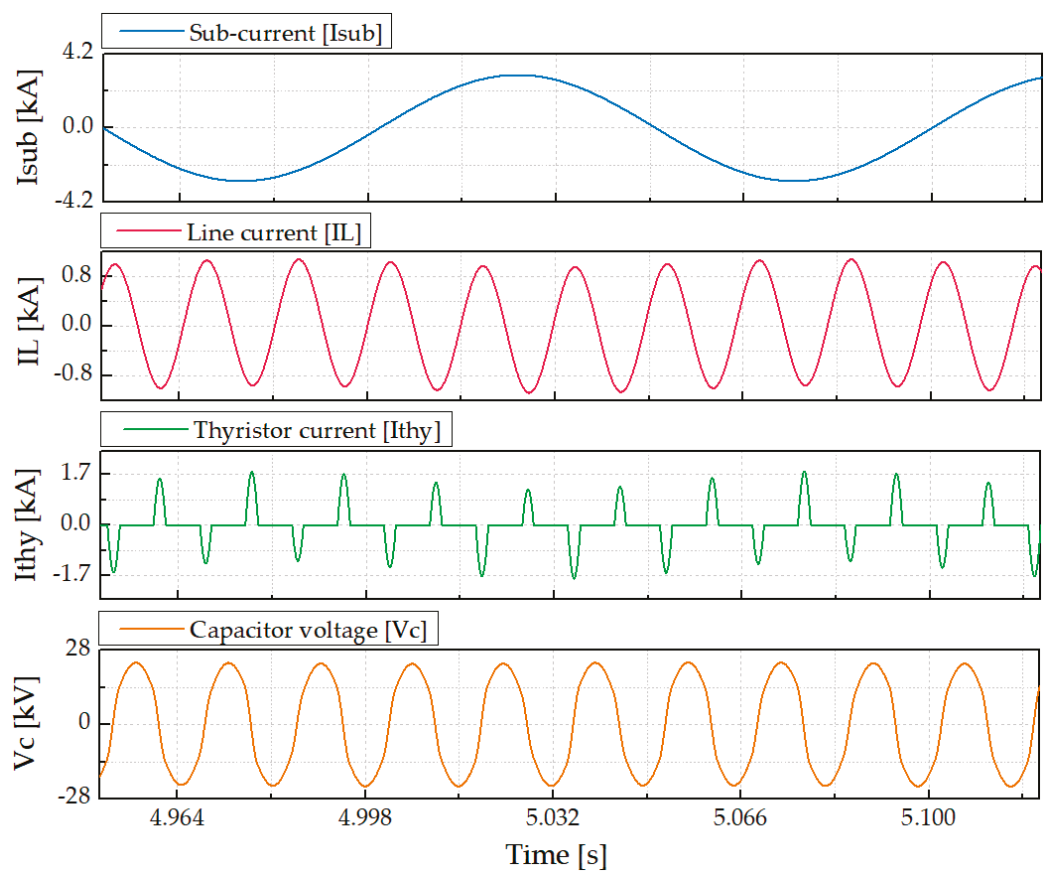

Figure 5. The TCSC-SVR operation with a sub-frequency sine wave current injection.

The SVR operates depending on the set of Equations (4)-(6) for calculating the different firing time for two thyristors which can be seen in the third graph of Figure 4. Thus, the TCSC voltage was kept stable with a DC current added to the line current.

A sine wave with a frequency of $10 \mathrm{~Hz}$ was also injected into the line current, as shown in the upper graph of Figure 5. The second graph from the top shows the total of the line current and the sub-frequency current. The thyristor currents and the TCSC voltage were shown in the third and bottom graph of Figure 5, respectively. The SVR control depends on the values of the line current and capacitor voltage for calculating the next firing time of a thyristor. Therefore, in the third graph of Figure 5, the conduction angles are different for two thyristors. So, there is a similar result in the case of a DC current injected, the TCSC voltage was also kept constant with the disturbance (sub-frequency current) in the system. That means with the SVR control, a disturbance of a DC or a sub-frequency current cannot affect to the TCSC operation, which is the advantage of the SVR controller.

\section{Analysis Method of Subsynchronous Resonance}

\subsection{Torsional Natural Frequency and Mode Shapes Analysis}

The simplified $345 \mathrm{kV}$ transmission system was used to present the Hanul nuclear power plant and the Samcheok coal-fired power plant. It has been mentioned that, when a generator is a radial connection with series compensation such as the FSC and TCSC, the generator is the worst case to the excitation of the SSR at one or more shaft modes. Thus, in this study, the units \#3 and \#4 of the Hanul power plant were considered as detail generator model while the voltage sources represented the other generators. This is a 1219.6 MVA synchronous generator with a rated RMS line to line voltage of $22 \mathrm{kV}$, the generator was presented by a synchronous machine component. It included two damper windings in the $\mathrm{q}$ axis, the multi-mass interface was enabled, and the completed generator input data are presented in Table A2. The multi-mass system shown in Figure 6 configures the shafts of the generator 
units \#3 and \#4 of Hanul nuclear power plant. A multi-masses system including a high-pressure (HP), an intermediate pressure (IP) turbine, two low-pressure (LP-A, LP-B) and generator (GEN) turbines together combined a five-mass spring system with detailed data given in Table 2.

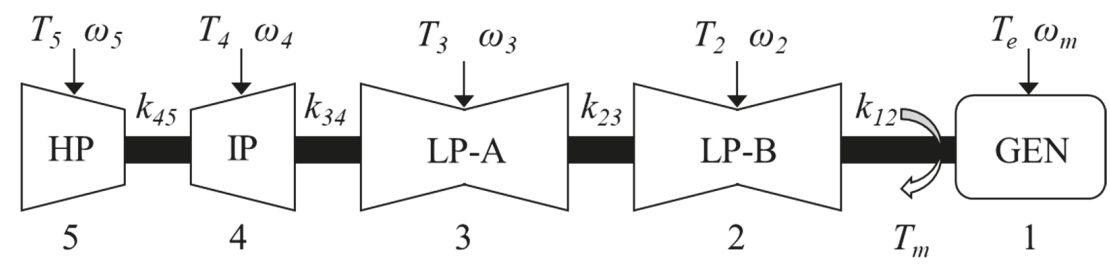

Figure 6. Structure of units \#3 and \#4 multi-mass shaft system model. HP: high-pressure; IP: intermediate pressure; LP-A, LP-B: low-pressure; GEN: generator.

Table 2. The mechanical data of Hanul nuclear generator units \#3 an \#4 for shaft model calculation.

\begin{tabular}{cccc}
\hline Mass & $\begin{array}{c}\text { Inertial } \\
{\left[\mathbf{k g} \cdot \mathbf{m}^{\mathbf{2}}\right]}\end{array}$ & Shaft & $\begin{array}{c}\text { Stiffness } \\
{\left[\mathbf{1 0}^{\mathbf{6}} \mathbf{~} \text {.m/rad }\right]}\end{array}$ \\
\hline 1 & 13,040 & $1-2$ & 218.51 \\
2 & 80,860 & $2-3$ & 356.20 \\
3 & 81,700 & $3-4$ & 638.32 \\
4 & 82,980 & $4-5$ & 447.23 \\
5 & 114,800 & - & - \\
\hline
\end{tabular}

The relationship between the electrical torque and mechanical torque of a synchronous generator can be expressed by the motion equation:

$$
J \frac{d \omega_{m}}{d t}=\sum T=T_{m}-T_{e}
$$

For a detailed study of a multi-mass model of a steam turbine generator, a set of equations of individual masses are illustrated in the following equation [22]:

For generator:

$$
J_{1} \frac{d \omega_{1}}{d t}=-T_{e}+k_{12}\left(\delta_{2}-\delta_{1}\right)-D_{1} \omega_{1}
$$

For LP-B section:

$$
J_{2} \frac{d \omega_{2}}{d t}=T_{2}+k_{23}\left(\delta_{3}-\delta_{2}\right)-k_{12}\left(\delta_{2}-\delta_{1}\right)-D_{2} \omega_{2}
$$

For LP-A section:

$$
J_{3} \frac{d \omega_{3}}{d t}=T_{3}+k_{34}\left(\delta_{4}-\delta_{3}\right)-k_{23}\left(\delta_{3}-\delta_{2}\right)-D_{3} \omega_{3}
$$

For IP section:

$$
J_{4} \frac{d \omega_{4}}{d t}=T_{4}+k_{45}\left(\delta_{5}-\delta_{4}\right)-k_{34}\left(\delta_{4}-\delta_{3}\right)-D_{4} \omega_{4}
$$

For HP section:

$$
J_{5} \frac{d \omega_{5}}{d t}=T_{5}-k_{45}\left(\delta_{5}-\delta_{4}\right)-D_{5} \omega_{5}
$$

where, $J_{i}$ is the moment of inertia, $\omega_{i}$ is the angular velocity, $\delta_{i}$ is the rotor angle, $T_{i}$ is the mechanical torque, and $D_{i}$ is the damping torque coefficient with $i$ from 1 to 5 indicates the individual sections of GEN, LP-B, LP-A, IP, and HP, respectively. $k_{i j}$ is the stiffness between two connected shaft sections. The damping torques between masses are assumed to be negligible in this study. 
An eigenvalue analysis was performed for the generator units \#3 and \#4 based on the shaft system equations given above. The eigenvalues and shaft model parameters such as natural frequency $\left(f_{m}\right)$, modal inertial $\left(H_{m}\right)$, and mechanical damping $\left(D_{m}\right)$ are given in Table 3 , and the rotor natural frequencies with mode shaft of the turbine generator are shown in Figure 7. The relative rotational displacements are shown for one normal operation mode (mode 0 ) and four oscillation modes which are presented with natural frequencies at $8.3 \mathrm{~Hz}, 14.6 \mathrm{~Hz}, 22.2 \mathrm{~Hz}$, and $23.8 \mathrm{~Hz}$, respectively. For the first SSR mode, the mass IP has a strong interaction with the mass LP-A, and the mass LP-B has a strong interaction with the GEN in the second SSR mode. The third SSR mode has three interaction points, and the strongest point lies between the mass LP-B and GEN. Similarly, the fourth SSR mode has four interaction points with the strong interaction between the mass HP and IP.

Table 3. The shaft model parameters of Hanul nuclear generator units \#3, \#4 for the SSR analysis.

\begin{tabular}{ccccc}
\hline Mode & Eigenvalues & $\mathbf{f}_{\mathbf{m}}[\mathrm{Hz}]$ & $\mathbf{H}_{\mathrm{m}}[\mathbf{s}]$ & $\mathbf{D}_{\mathbf{m}}[\mathbf{p} \cdot \mathbf{u}]$ \\
\hline 0 & $-0.0919 \pm \mathrm{j} 5.2 \times 10^{-7}$ & 0 & 5.44 & 1.09 \\
1 & $-0.0412 \pm \mathrm{j} 52.4039$ & 8.3 & 3.93 & 0.79 \\
2 & $-0.0443 \pm \mathrm{j} 92.0062$ & 14.6 & 7.29 & 1.46 \\
3 & $-0.0213 \pm \mathrm{j} 139.596$ & 22.2 & 92.6 & 18.52 \\
4 & $-0.0419 \pm \mathrm{j} 149.387$ & 23.8 & 86.1 & 17.22 \\
\hline
\end{tabular}

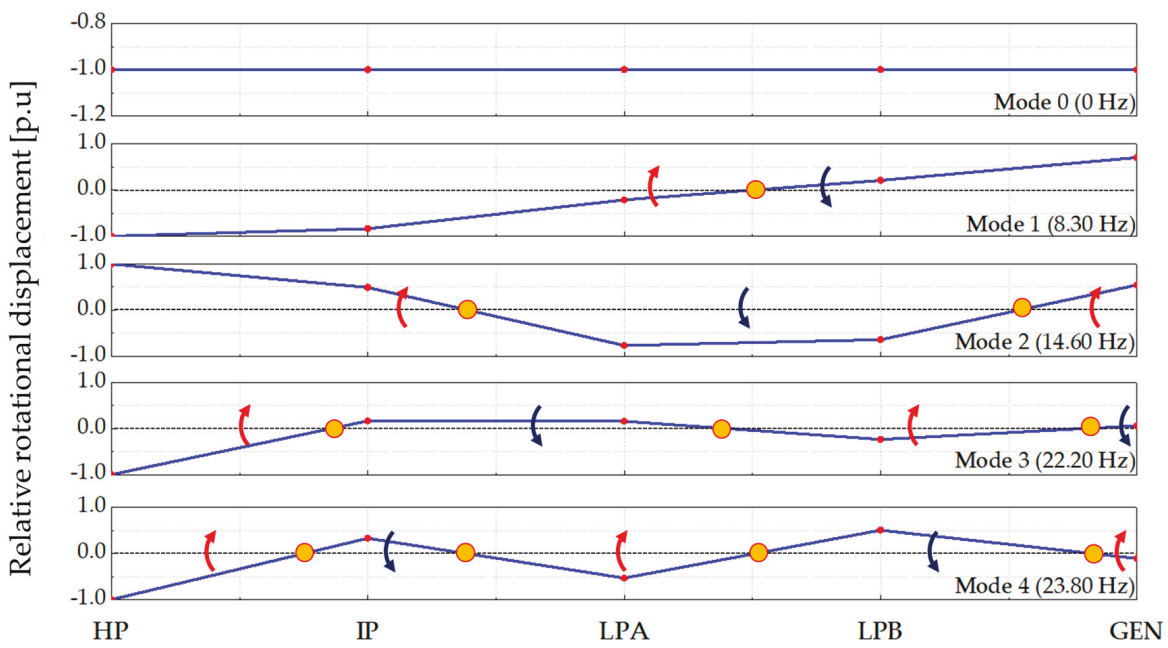

Figure 7. Rotor natural frequencies and mode shapes of the units \#3 and \#4.

\subsection{Frequency Scanning Method for SSR Analysis}

The SSR behavior can occur when the electrical power grid is compensated by a series capacitor. The resonance between electrical synchronous machines shaft and electrical grid can happen at subsynchronous frequencies, which are lower than the fundamental frequency $(60 \mathrm{~Hz}$ for the study power network). Frequency scanning is a method of getting the frequency response of a system. These techniques determine the total impedance of the system viewed from the studying generator as a function of frequency. From that, the scanned impedance and the mechanical parameters of the turbine generator are used for calculating electrical damping of the system [2]. Another type of frequency scanning is the test signal method, which was used in this paper. As it is a method based on time domain simulation, it conforms to the detailed model of a real system application for getting the 
electrical damping of the system. There is no risk of the SSR if the total net damping of the system is positive $[23,24]$, which means that the system satisfies the equation:

$$
D(\omega)=D_{e}(\omega)+D_{m}(\omega)>0
$$

where, $D_{m}(\omega)$ and $D_{e}(\omega)$ are the damping of the mechanical and electrical system, respectively.

The relationship between the mechanical and electrical systems can be described by the closed-loop diagram shown in Figure 8, with $\Delta T_{e}$ is the electrical torque deviation in per unit and $\Delta \omega_{r}$ is generator rotor speed deviation in per unit.

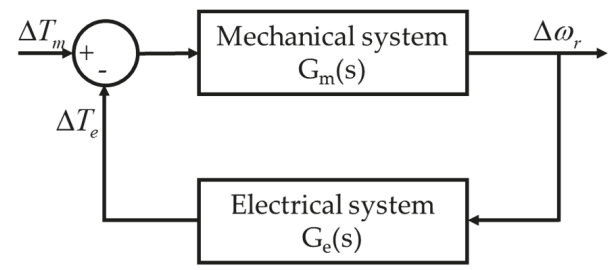

Figure 8. Relationship between the electrical and mechanical system.

The electrical dynamic as a function of frequency can be expressed as the following equation:

$$
G_{e}(j \omega)=D_{e}(\omega)+j K_{e}(\omega)
$$

where, $K_{e}(\omega)$ is the electrical coefficient.

The transfer function between the electrical torque and the generator rotor speed is $G_{e}(s)$. Thus, the damping torque coefficient (electrical damping) is defined as follows:

$$
D_{e}(\omega)=\mathfrak{R}\left[\frac{\Delta T_{e}(j \omega)}{\Delta \omega_{r}(j \omega)}\right]
$$

In this method, a multi-sine signal is injected into the synchronous generator rotor as the speed deviation, and the obtained output is an electrical torque. Thus, the transfer function represents the electrical damping as the function of frequency as given in Equation (15). The injected multi-signals are described as the following Equations (16)-(18):

$$
\begin{gathered}
\Delta \omega_{r}=A_{\omega} \sum_{n=n_{0}}^{N} \sin \left[2 \pi\left(f_{\text {sub_min }}+n f_{\text {sub_gap }}\right) t+\delta_{n}\right] \\
\delta_{n}=-\frac{\left(n-n_{0}\right)\left(n-n_{0}+1\right)}{\left(N-n_{0}+1\right)} \pi \\
N=\frac{f_{\text {sub_max }}-f_{\text {sub_min }}}{f_{\text {sub_gap }}}+1
\end{gathered}
$$

where, the spectrum injected frequencies range $\left[f_{\text {sub_min, }}, f_{\text {sub_max }}\right]$ must cover all the range of subsynchronous frequency from $5 \mathrm{~Hz}$ to $55 \mathrm{~Hz}$, and the $f_{\text {sub_gap }}$ is the increment of each injected frequencies. The amplitude $A_{\omega}$ could be chosen to be very small. With the selected $A_{\omega}$, the Schroeder multi-sine can be applied to choose $\delta_{n}$ as the function of $n$ in (17) for reducing overall amplitude [25].

Figure 9 shows a simple circuit of a synchronous generator connected with a TCSC through the 'pi' model of a transmission line. A multi-sine signal is injected into the speed input of the generator, the measurement as the output of the electrical torque is for carrying out the electrical torque corresponding to the injected signal. This multi-sine signal was implemented in the time-domain simulation in 
PSCAD/EMTDC, which is an interesting tool for frequency screening studies where FACTs devices are located.

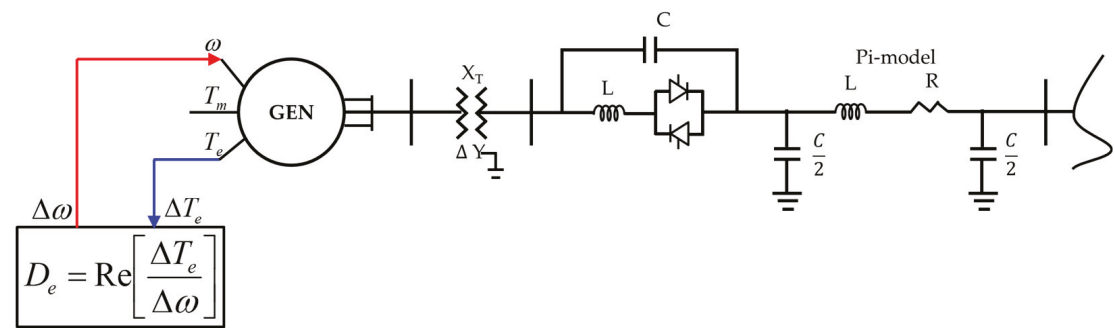

Figure 9. A model for subsynchronous resonance (SSR) analysis using a multi-sine signal injection.

\section{Simulation and the Results}

In this section, we analyzed and described the effects of the series compensation for the SSR behavior in case of using the FSC and TCSC. The FSC compensation was used to confirm the advantages of the TCSC compensation with the SVR control method. As the requirements from KEPCO, the compensation levels are 50\% and 70\% for the normal and dynamic operations, respectively. The signal injection method was used to obtain the electrical damping $D_{e}$, these values are compared to the mechanical damping $D_{m}$ values presented in Table 3. Thus, we can indicate the risks of the SSR in the system as the equation (13).

As discussed in Section 3.1, the selected generators are the Hanul nuclear units \#3 and \#4. The simulation scenarios are shown in Table 4.

Table 4. The simulation scenarios for the subsynchronous resonance analysis.

\begin{tabular}{ccccc}
\hline Simulation Scenarios & \multicolumn{2}{c}{ Bus 5151-Bus 5152 } & \multicolumn{2}{c}{ Bus 5151-Bus 5150 } \\
\hline Cases & Line 1 & Line 2 & Line 1 & Line 2 \\
\hline 1 (normal operation) & Connected & Connected & Connected & Connected \\
2 (disconnected one line) & Connected & Disconnected & Connected & Connected \\
3 (worst case) & Disconnected & Disconnected & Disconnected & Disconnected \\
\hline
\end{tabular}

Each case was studied with no compensation, the FSC compensation, and TCSC compensation, and all results are shown in Figures 10-14. In the figures, the mechanical damping constants of the nuclear generator units \#3 and \#4 with the torsional frequencies of modes 1 and mode 2 are given. The oscillation modes 3 and 4 have large values of the mechanical damping as 18.52 p.u and 17.22 p.u, respectively, so they were neglected in the figures. These values are negative of the mechanical damping in range of $\left[f_{m}-1 \mathrm{~Hz}, f_{m}+1 \mathrm{~Hz}\right]$ with each torsional frequency. The risk of the SSR can be easily seen from the graphs, the SSR occur if any part of the electrical $\left(D_{e}\right)$ line extends below the mechanical $\left(D_{m}\right)$ line.

\subsection{Normal Operation of the $345 \mathrm{kV}$ Power Network}

The simulation results of normal operation for the $345 \mathrm{kV}$ power network are shown in Figure 10a. The figure shows the normal operation of the system in cases of no compensation and compensated by the FSC or TCSC. In that case, the FSC and TCSC were set as 50\% of the compensation level. In Figure 10a, it can be seen that the electrical damping in the study power network with the FSC or TCSC compensations is similar to the no compensation case, and the total of the electrical and mechanical damping are positive for all cases. These results confirmed that in the normal operation condition, the system was stable with TCSC installation. 


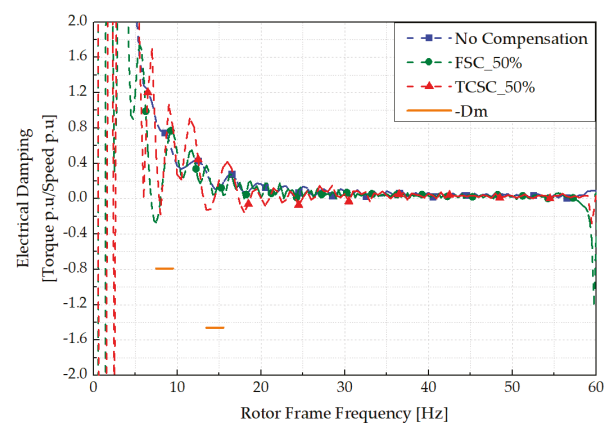

(a)

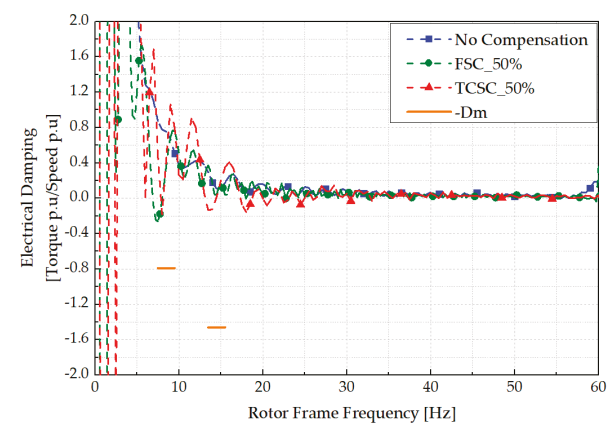

(b)

Figure 10. Comparison of $D_{e}$ for different types of compensation of no compensation, fixed series capacitor (FSC), and TCSC compensation: (a) The compensation of $D_{e}$ for case 1 ; (b) The compensation of $D_{e}$ for case 2 .

\subsection{Sensitive Cases of the $345 \mathrm{kV}$ Power Network}

In this section, two sensitive simulation cases (case 2 and case 3) were performed to quantify the effects of the FSC and TCSC on the SSR behavior. The case 2 disconnected one line between two buses 5151-5152, and the case 3 disconnected all transmission lines between buses 5151-5152 and 5151-5150. The case 3 (worst case) is unlikely to occur, but it was defined to analyze any potential issues. In this case, the system becomes radial as seen from the Hanul nuclear power plant \#3 and \#4 to the compensated transmission line. If the TCSC operation destabilized the torsional mode of the Hanul nuclear power plant, it would be more likely to occur under this worst case.

Figure $10 \mathrm{~b}$ shows the first sensitive case of the $345 \mathrm{kV}$ power network. As a result, one transmission line between two buses 5151-5152 was disconnected but it did not affect the electrical damping. All the results were also similar to the base case in Figure 10a, there was not any risk of the SSR when one line between two buses 5151-5152 was disconnected. There is a different electrical damping characteristic of FSC compensation at $60 \mathrm{~Hz}$ due to a result of the electrical torque increased rapidly in case of disconnecting one transmission line. As compared in Figure 10, the plots of electrical damping in normal operation and the outage of one line nearby the Hanul nuclear power plant are the same with no compensation on the line. That means the series compensation cannot affect the SSR problem in the power network even one-line outage condition.

In the second sensitive simulation case, all transmission lines between buses 5151-5152 and 5151-5150 were disconnected. This is a radial system, as seen from the considered generator to the compensation line. As shown in Figure 11, in case of without any compensation, the electrical damping is positive. But in the case of 50\% FSC compensation level, there is a negative point of the electrical damping at $39 \mathrm{~Hz}$. In this case, the impedance $Z(j \omega)$ of the electrical system is shown in Figure 12. The system reactance is zero at an electrical resonance frequency of $21 \mathrm{~Hz}$, which corresponds to $39 \mathrm{~Hz}$ at the rotor frame frequency.

The red line in the Figure 11 describes the TCSC compensation level of $50 \%$. It can be seen that at $39 \mathrm{~Hz}$, the electrical damping is also around zero which is the same as without compensation, this shows the advantage of the SVR control method. In the frequency range $[5 \mathrm{~Hz}, 20 \mathrm{~Hz}]$ of the TCSC compensation, the electrical damping curve has negative points, but this is also higher than the mechanical damping, that means no risk of the SSR with the TCSC compensation. The simulation results of the system with different FSC compensation levels are shown in Figure 13. When the compensation levels were increased from $50 \%$ to $70 \%$ with the increment of $5 \%$, the electrical damping was deeper more than normal operation at 50\% compensation level. The difference with the FSC compensation, the electrical damping in case of the TCSC compensation, as shown in Figure 14 has not been affected by the compensation 
levels. As the concept of the SVR control, the TCSC appearance impedance changes to the transient zone and become inductive impedance in the range from $40 \mathrm{~Hz}$ to $60 \mathrm{~Hz}$ of electrical frequency. So, it can be seen in Figure 11, the electrical damping was negative from $6 \mathrm{~Hz}$ to $25 \mathrm{~Hz}$ of mechanical frequency, but all of them are higher than mechanical damping curve, i.e., there is no risk of the SSR with the TCSC compensation. Two sensitive simulation results confirmed that the system was stable with TCSC compensation. The detailed data of net damping of all different TCSC compensation levels in different cases were listed in Table 5.

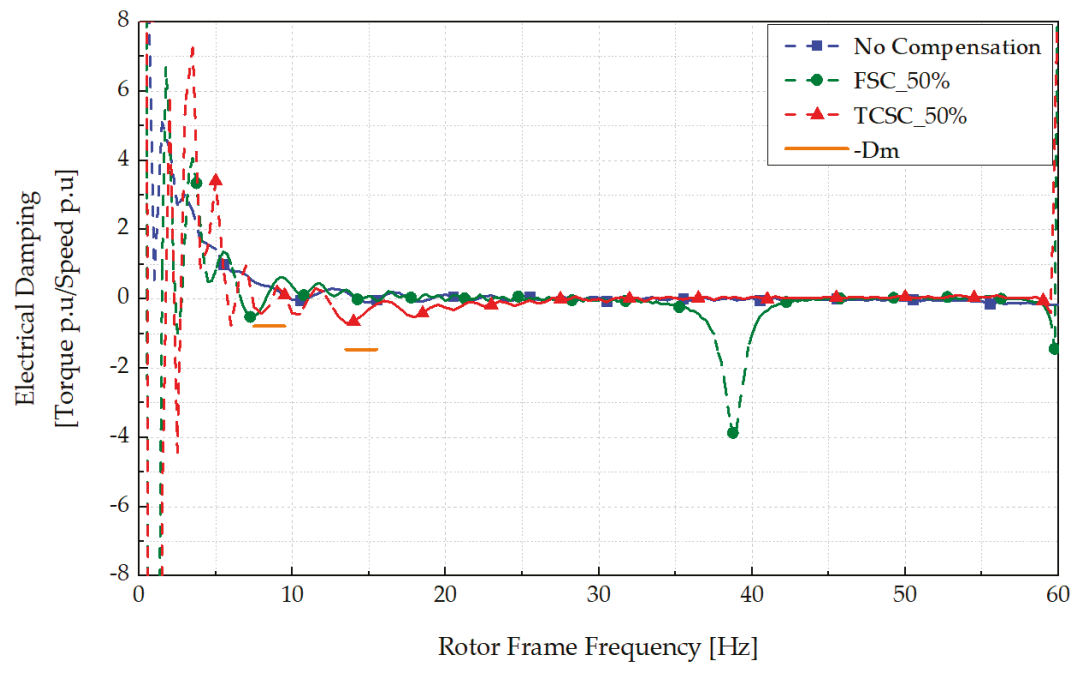

Figure 11. Comparison of $D_{e}$ for a different type of compensations in case 3.

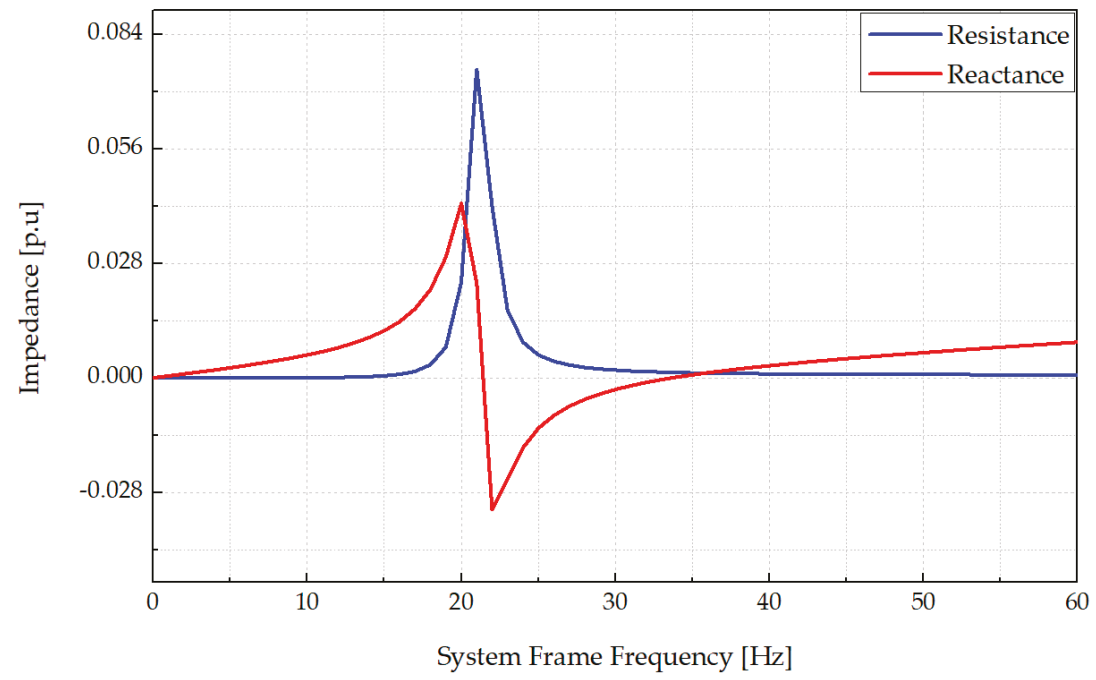

Figure 12. Frequency spectrum of the impedance of network in case of 50\% FSC. 


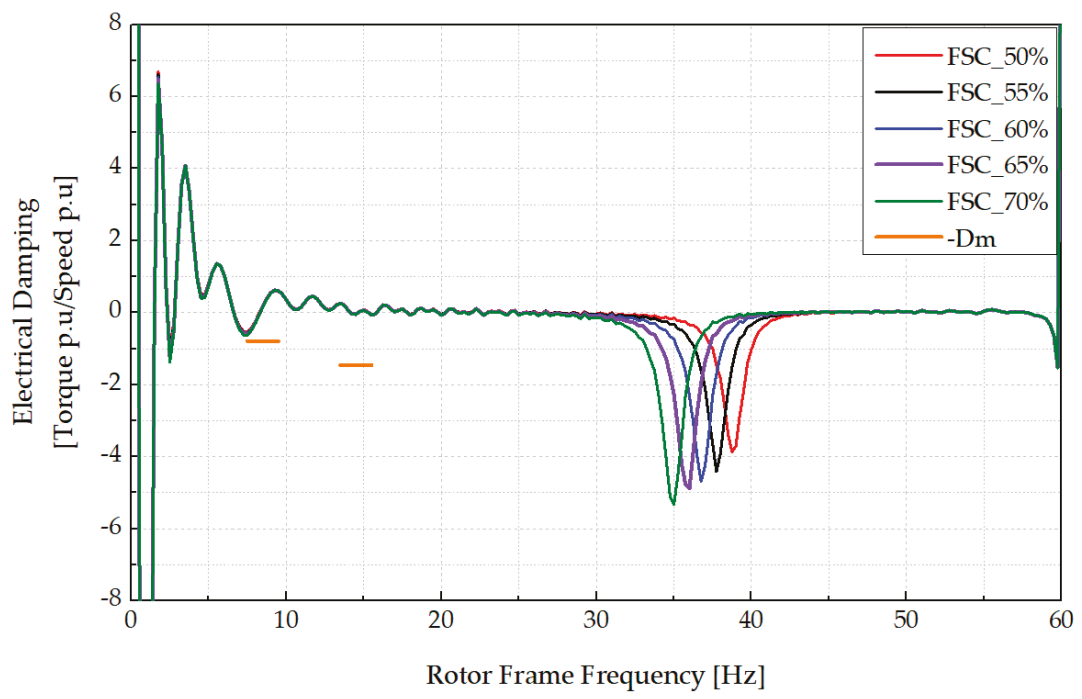

Figure 13. Comparison of $D_{e}$ for different FSC compensation levels in case 3.

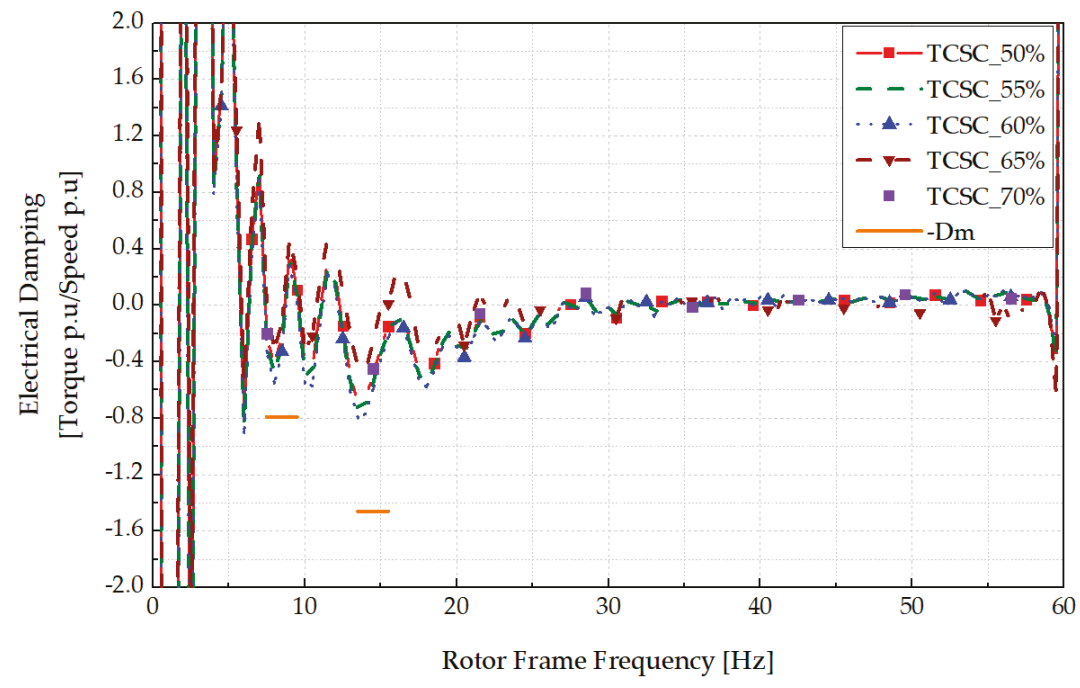

Figure 14. Comparison of $D_{e}$ for different TCSC compensation levels in case 3. 
Table 5. Net damping of different TCSC compensation levels in different cases.

\begin{tabular}{ccccccc}
\hline \multirow{2}{*}{ Case } & Mode & \multicolumn{5}{c}{ Compensation Level [\%] } \\
\cline { 3 - 7 } & & $\mathbf{5 0}$ & $\mathbf{5 5}$ & $\mathbf{6 0}$ & $\mathbf{6 5}$ & $\mathbf{7 0}$ \\
\hline \multirow{2}{*}{1} & 1 & 1.25528 & 1.25798 & 1.25798 & 1.25845 & 1.25769 \\
& 2 & 1.48328 & 1.48675 & 1.48676 & 1.4879 & 1.48668 \\
& 3 & 18.5972 & 18.5934 & 18.59344 & 18.5906 & 18.5919 \\
& 4 & 17.2500 & 17.2525 & 17.25251 & 17.2539 & 17.2531 \\
\hline \multirow{2}{*}{2} & 1 & 1.24981 & 1.2565 & 1.2565 & 1.25405 & 1.25193 \\
& 2 & 1.47807 & 1.48131 & 1.48131 & 1.48016 & 1.47926 \\
& 3 & 18.5909 & 18.5914 & 18.5914 & 18.5914 & 18.5912 \\
& 4 & 17.2448 & 17.2452 & 17.2452 & 17.2455 & 17.2453 \\
\hline \multirow{2}{*}{3} & 1 & 0.57817 & 0.50929 & 0.46084 & 0.67178 & 0.62506 \\
& 2 & 0.96332 & 0.90498 & 0.86561 & 1.19998 & 1.01243 \\
& 3 & 18.4042 & 18.3814 & 18.3674 & 18.4928 & 18.4364 \\
& 4 & 17.1124 & 17.1001 & 17.0797 & 17.2351 & 17.1368 \\
\hline
\end{tabular}

\section{Conclusions}

This study analyzed the SSR problem in the case of installing TCSC in a Korean power system. In order to verify the effect of the TCSC introduced in a $345 \mathrm{kV}$ transmission network for the first time in Korea, the analysis results of the SSR behavior are presented in the case of FSC and TCSC compensations. The detailed design of the TCSC was carried out with the calculated capacitor values of 198.94 $\mu \mathrm{F}$ and $186.93 \mu \mathrm{F}$ for ShinYoungju-Hanul and ShinJecheon-Donghae, respectively. The inductor was chosen to be equal to $5.23 \mathrm{mH}$ for the two transmission lines. We implemented the TCSC with SVR controller and confirmed the performance of the controller by injecting DC and sub frequency current. The Hanul nuclear power plant \#3 and \#4 were selected as target generators. The torsional frequency and mode shaft were also analyzed to show the interaction when the oscillation mode was excited.

Based on the time domain simulation software PSCAD/EMTDC, the test signal injection, one of the frequency scanning methods, has been applied to perform the electrical damping of the system within the sub-frequency range from $5 \mathrm{~Hz}$ to $55 \mathrm{~Hz}$. Simulation of the basic case and two sensitive cases of the power network were performed with different types of compensation and the compensation level from $50 \%$ to $70 \%$. There was no risk of SSR in normal case and the first sensitive operation. However, when the Hanul nuclear power plant was radially connected to the compensated transmission line, an SSR occurred at around $35 \mathrm{~Hz}$ to $39 \mathrm{~Hz}$ of the rotor frame frequency with the FSC compensation. Nonetheless, the TCSC with the SVR control method avoided the risk point. The results obtained in this study can be effectively applied to the TCSC installations in real power networks in the future.

Author Contributions: Conceptualization and investigation M.-Q.T. and M.-C.D.; visualization, S.-J.L.; software, J.-I.L.; writing—original draft preparation and editing, M.-Q.T.; supervision, M.P.; funding acquisition, C.H.L. and J.Y.

Funding: This work was funded by Korea Electric Power Corporation.

Conflicts of Interest: The authors declare no conflict of interest. 


\section{Appendix A}

Table A1. Data of transmission line for the modified Korean power network.

\begin{tabular}{cccccc}
\hline From Bus & To Bus & Length $[\mathbf{k m}]$ & $\mathbf{R}[\mathbf{p . u}]$ & $\mathbf{X}[\mathbf{p . u}]$ & $\mathbf{B}[\mathbf{p . u}]$ \\
\hline 5750 & 5700 & 67.85 & 0.00095 & 0.01728 & 0.42727 \\
5700 & 5600 & 97.50 & 0.00144 & 0.02504 & 0.60843 \\
5700 & 5500 & 76.70 & 0.00113 & 0.01944 & 0.48060 \\
5500 & 5151 & 91.50 & 0.00135 & 0.02348 & 0.57333 \\
5151 & 5150 & 1.16 & 0.00004 & 0.02068 & 0.01701 \\
5150 & 5350 & 18.08 & 0.00027 & 0.01416 & 0.11328 \\
5350 & 5600 & 6.60 & 0.00089 & 0.00079 & 0.37672 \\
\hline
\end{tabular}

Table A1 shows the per unit quantities converted based on the rating of $345 \mathrm{kV}$ and $100 \mathrm{MVA}$.

Table A2. Generator impedance and time constant of Hanul nuclear unit \#3 and \#4.

\begin{tabular}{cccc}
\hline Description & Symbol & Value & Unit \\
\hline Unsaturated d-axis synchronous reactance & $\mathrm{X}_{\mathrm{d}}$ & 1.998 & {$[\mathrm{p} . \mathrm{u}]$} \\
Unsaturated d-axis transient reactance & $\mathrm{X}^{\prime}{ }_{\mathrm{d}}$ & 0.49 & {$[\mathrm{p} \cdot \mathrm{u}]$} \\
Unsaturated d-axis transient time & $\mathrm{T}^{\prime} \mathrm{d}_{0}$ & 9.5 & {$[\mathrm{~s}]$} \\
Unsaturated d-axis sub-transient reactance & $\mathrm{X}^{\prime \prime}{ }_{\mathrm{d}}$ & 0.47 & {$[\mathrm{p} . \mathrm{u}]$} \\
Unsaturated d-axis sub-transient time & $\mathrm{T}^{\prime \prime}{ }_{\mathrm{d} 0}$ & 0.032 & {$[\mathrm{~s}]$} \\
Unsaturated q-axis synchronous reactance & $\mathrm{X}_{\mathrm{q}}$ & 1.61 & {$[\mathrm{p} \cdot \mathrm{u}]$} \\
Unsaturated q-axis transient reactance & $\mathrm{X}^{\prime}{ }_{\mathrm{q}}$ & 0.617 & {$[\mathrm{p} . \mathrm{u}]$} \\
Unsaturated q-axis transient time & $\mathrm{T}^{\prime}{ }_{\mathrm{q} 0}$ & 0.78 & {$[\mathrm{~s}]$} \\
Unsaturated q-axis sub-transient reactance & $\mathrm{X}^{\prime \prime} \mathrm{q}$ & 0.47 & {$[\mathrm{p} \cdot \mathrm{u}]$} \\
Unsaturated q-axis sub-transient time & $\mathrm{T}^{\prime \prime}{ }_{\mathrm{q} 0}$ & 0.047 & {$[\mathrm{~s}]$} \\
\hline
\end{tabular}

\section{References}

1. Joshi, S.R.; Kulkarni, A.M. Analysis of SSR Performance of TCSC Control Schemes Using a Modular High Bandwidth Discrete-Time Dynamic Model. IEEE Trans. Power Syst. 2009, 24, 840-848. [CrossRef]

2. Johansson, N.; Angquist, L.; Nee, H. A Comparison of Different Frequency Scanning Methods for Study of Subsynchronous Resonance. IEEE Trans. Power Syst. 2011, 26, 356-363. [CrossRef]

3. Han, Y.; Shi, W. Frequency response of the thyristor controlled series capacitor. In Proceedings of the International Conference on Power System Technology, Kunming, China, 13-17 October 2002; Volume 1893, pp. 1895-1897.

4. Fan, Z.; Zheng, X. SSR damping study on a generator connected to TCSC. In Proceedings of the IEEE PES Power Systems Conference and Exposition, New York, NY, USA, 10-13 October 2004; Volume 672, pp. 673-678.

5. Mohammadpour, H.A.; Santi, E. Sub-synchronous resonance analysis in DFIG-based wind farms: Mitigation methods-TCSC, GCSC, and DFIG controllers-Part II. In Proceedings of the 2014 IEEE Energy Conversion Congress and Exposition (ECCE), Pittsburgh, PA, USA, 14-18 September 2014; pp. 1550-1557.

6. Kakimoto, N.; Phongphanphanee, A. Calculation of damping torque of power systems compensated with TCSC. Electr. Eng. Japan 2003, 143, 39-49. [CrossRef]

7. Lei, X.; Buchholz, B.; Povh, D. Analysing subsynchronous resonance phenomena in the time- and frequency domain. Eur. Trans. Electr. Power 2007, 10, 203-211. [CrossRef]

8. Baker, D.H.; Boukarim, G.E.; Aquila, R.D.; Piwko, R.J. Subsynchronous resonance studies and mitigation methods for series capacitor applications. In Proceedings of the 2005 IEEE Power Engineering Society Inaugural Conference and Exposition in Africa, Durban, South Africa, 11-15 July 2005; pp. 386-392.

9. Pilotto, L.A.S.; Bianco, A.; Long, W.F.; Edris, A. Impact of TCSC control methodologies on subsynchronous oscillations. IEEE Trans. Power Deliv. 2003, 18, 243-252. [CrossRef]

10. Grunbaum, R.; Halvarsson, P.; Jones, P. Series compensation for increased power transmission capacity. In Proceedings of the 5th IET International Conference on Power Electronics, Machines and Drives, Brighton, UK, 19-21 April 2010; pp. 1-6. 
11. Ängquist, L.; Ingestrom, G.; Jonsson, A.K. Dynamical Performance of TCSC Schemes. CIGRE- 2006 14:302; ABB Power System. Available online: https://ibrary.e.abb.com/public/11125766c267c954c1257d55004d7034/ 14_302e.pdf (accessed on 22 July 2019).

12. Zhang, X.; Song, Y.; Wang, D.; Zheng, Z.; Li, G. Simulation of SSR evoked by TCSC for UHVAC transmission system from Yimin to fengtun on RTDS. In Proceedings of the International Conference on Sustainable Power Generation and Supply (SUPERGEN 2012), Hangzhou, China, 8-9 September 2012; pp. 1-7.

13. Meikandasivam, S.; Nema, R.K.; Jain, S.K. Performance of installed TCSC projects. In Proceedings of the India International Conference on Power Electronics 2010 (IICPE2010), New Delhi, India, 28-30 January 2011; pp. 1-8.

14. Tran, M.Q.; Lee, S.J.; Lee, J.I.; Park, M.; Yu, I.K.; Yoon, J.; Sim, H. Design and performance analysis of a TCSC for real grid application. In Proceedings of the KIEE Annual Conference 2018, Pyeongchang, Korea, 11-13 July 2018; pp. 178-179.

15. Zhu, W.; Spee, R.; Mohler, R.R.; Alexander, G.C.; Mittelstadt, W.A.; Maratukulam, D. An EMTP study of SSR mitigation using the thyristor controlled series capacitor. IEEE Trans. Power Deliv. 1995, 10, 1479-1485. [CrossRef]

16. Liu, Q.; Zhou, C.; Angquist, L.; Rudin, S. Using TCSC scheme for SSR mitigation in a radial transfer corridor. In Proceedings of the 2006 International Conference on Power System Technology, Chongqing, China, 22-26 October 2006; pp. 1-6.

17. KEPCO. Technical Specification for Shin-Youngju and Shin-Jecheon; TCSC Project; KEPCO: Naju-si, Korea, 2017; Available online: http://www.alio.go.kr/informationBidView.do?seq=2335741 (accessed on 23 July 2019).

18. Meikandasivam, S.; Nema, R.K.; Jain, S.K. Selection of TCSC parameters: Capacitor and inductor. In Proceedings of the India International Conference on Power Electronics 2010 (IICPE2010), New Delhi, India, 28-30 January 2011; pp. 1-5.

19. Dinh, M.; Park, S.; Kim, S.; Park, M.; Yu, I. Suggestion of a novel PHILS method for operation analysis of a thyristror controlled series capacitor. In Proceedings of the 2015 IEEE 11th International Conference on Power Electronics and Drive Systems, Sydney, NSW, Australia, 9-12 June 2015; pp. 715-720.

20. Qianjin, L.; Changchun, Z.; Angquist, L.; Rehtanz, C. A novel active damping control of TCSC for SSR suppression in a radial corridor. In Proceedings of the 2008 Third International Conference on Electric Utility Deregulation and Restructuring and Power Technologies, Nanjing, China, 6-9 April 2008; pp. 136-142.

21. Ängquist, L. Synchronous Voltage Reversal Control of Thyristor Controlled Series Capacitor. Ph.D. Thesis, KTH Royal Institute of Technology, Department of Electrical Engineering, Stockholm, Sweden, 2002.

22. Kundur, P. Power System Stability and Control; McGraw-Hill: New York, NY, USA, 1994.

23. Harnefors, L. Proof and Application of the Positive-Net-Damping Stability Criterion. IEEE Trans. Power Syst. 2011, 26, 481-482. [CrossRef]

24. Prabhu, N.; Padiyar, K.R. Investigation of Subsynchronous Resonance With VSC-Based HVDC Transmission Systems. IEEE Trans. Power Deliv. 2009, 24, 433-440. [CrossRef]

25. Das, M.K.; Kulkarni, A.M.; Darji, P.B. Comparison of DQ and Dynamic Phasor based frequency scanning analysis of grid-connected Power Electronic Systems. In Proceedings of the 2016 Power Systems Computation Conference (PSCC), Genoa, Italy, 20-24 June 2016; pp. 1-7.

(C) 2019 by the authors. Licensee MDPI, Basel, Switzerland. This article is an open access article distributed under the terms and conditions of the Creative Commons Attribution (CC BY) license (http://creativecommons.org/licenses/by/4.0/). 


\title{
Reactive Power Compensation and Imbalance Suppression by Star-Connected Buck-Type D-CAP
}

\author{
Xiaosheng Wang ${ }^{1,2}$, Ke Dai ${ }^{2, *}$, Xinwen Chen ${ }^{3}$, Xin Zhang ${ }^{2}$, Qi Wu ${ }^{2}$ and Ziwei Dai ${ }^{4}$ \\ 1 China-EU Institute for Clean and Renewable Energy, Huazhong University of Science and Technology, \\ Wuhan 430074, China; xiaosheng@hust.edu.cn \\ 2 State Key Laboratory of Advanced Electromagnetic Engineering and Technology, School of Electrical and \\ Electronic Engineering, Huazhong University of Science and Technology, Wuhan 430074, China; \\ husterzx@163.com (X.Z.);wuqi_hust@foxmail.com (Q.W.) \\ 3 Wuhan National Laboratory for Optoelectronics, Huazhong Institute of Electro-optics, Wuhan 430223, China; \\ chenxw_hust@sina.cn \\ 4 Department of Electrical, Computer and System Engineering, Rensselaer Polytechnic Institute, \\ Troy, NY 12180, USA; ziweidai@foxmail.com \\ * Correspondence: daike@hust.edu.cn
}

Received: 5 March 2019; Accepted: 16 May 2019; Published: 18 May 2019

\begin{abstract}
Reactive power and negative-sequence current generated by inductive unbalanced load will not only increase line loss, but also cause the malfunction of relay protection devices triggered by a negative-sequence component in the power grid, which threatens the safe operation of the power system, so it is particularly important to compensate reactive power and suppress load imbalance. In this paper, reactive power compensation and imbalance suppression by a three-phase star-connected Buck-type dynamic capacitor (D-CAP) under an inductive unbalanced load are studied. Firstly, the relationship between power factor correction and imbalance suppression in a three-phase three-wire system is discussed, and the principle of D-CAP suppressing load imbalance is analyzed. Next, its compensation ability for negative-sequence currents is determined, which contains theoretical and actual compensation ability. Then an improved control strategy to compensate reactive power and suppress imbalance is proposed. If the load is slightly unbalanced, the D-CAP can completely compensate the reactive power and negative-sequence currents. If the load is heavily unbalanced, the $\mathrm{D}$-CAP can only compensate the positive-sequence reactive power and a part of the negative-sequence currents due to the limit of compensation ability. Finally, a $33 \mathrm{kVar} / 220 \mathrm{~V}$ D-CAP prototype is built and experimental results verify the theoretical analysis and control strategy.
\end{abstract}

Keywords: dynamic capacitor; inductive unbalanced load; reactive power compensation; imbalance suppression; compensation ability

\section{Introduction}

There are a large number of inductive unbalanced loads in three-phase three-wire power systems generating reactive power and negative-sequence current, which not only increase line loss, but also cause malfunctions in overload protection devices triggered by negative-sequence current, thus threatening the safe operation of the power system. It is particularly important to compensate reactive power and negative-sequence current [1,2].

Reactive power compensation is an important means to improve power quality. Shunt power capacitors and shunt reactors have been widely used in power grid [3], but they can only provide constant reactive power. Different from fixed capacitors, static Var compensator (SVC) has advantages of adjustable reactive power and rapid response speed. Elements which may be used to make SVC typically include thyristor-controlled reactor (TCR) and thyristor-switched capacitor (TSC). In [4,5], 
two kinds of reactive power compensation schemes along with harmonic reduction techniques for unbalanced loads are addressed. Although with novel solutions, harmonic problems produced by TCR obtain some improvement, while high energy loss and large volume further limit its development.

Compared with SVC, the static synchronous compensator (STATCOM) has higher compensation accuracy, faster regulation speed, stronger compensation ability, and lower harmonic content based on a fully-controllable power semiconductor device and high switching frequency [6]. Two control strategies for star-connected and delta-connected STATCOMs under an unbalanced load are proposed in $[7,8]$. However, the ability of a STATCOM compensating negative-sequence current is affected by its structure. In [9], the compensation ability of STATCOM with star and delta configurations is indicated and analyzed. The third-harmonic injection method proposed in [10] achieves a significant improvement in STATCOM ability of simultaneous compensation for reactive and negative-sequence current. Considering unbalanced grid voltages, an improved regulation scheme with positive and negative sequence control for modular multilevel converter (MMC) in medium-voltage distribution static synchronous compensator (DSTATCOM) application is proposed in [11].

Although the compensation characteristic of a STATCOM for reactive and negative-sequence currents is good, it is complicated to stabilize and balance DC-link electrolytic capacitors' voltages, which will influence the reliability of STATCOMs [12,13]. Additionally, the high cost of STATCOMs affect their application in low-power applications. Although a matrix converter can be designed as a dynamic compensator without the bulky electrolytic capacitors, large numbers of bi-directional switches have to be used [14,15].

In [16-18], a magnetic energy recovery switch (MERS) is applied in reactive power compensation due to its characteristic equivalent to a variable capacitor. However, it will produce some harmonics because it adopts a phase-shifting control method. Additionally, electrolytic capacitor voltage fluctuation will further increase the harmonic contents of the output current. Similar to MERS, another VAr generator is analyzed in $[19,20]$, which can be equivalent to a variable capacitor with a H-bridge inverter and DC capacitance. The same as with STATCOMs, the voltage fluctuation of the electrolytic capacitor on the DC side will affect their reliability.

Considering a large number of fixed capacitors in a distribution system, it is economical if power electronic technology can be used to reconstruct them to achieve better performance. Compared with the above compensators, the dynamic capacitor (D-CAP) is a simple, reliable, and economical solution without bulky electrolytic capacitors, which is composed of a power capacitor and a thin AC converter (TACC) [21-23]. Furthermore, the TACC could be configured with a simple topology, such as a Buck, Boost, or a Buck-Boost circuit, so the D-CAP has great potential to be used in low-power applications. Extending cells with a series connection, it is also feasible for the D-CAP to be applied in high-voltage applications [24]. Considering harmonic contents in the grid voltage, the output currents of the D-CAP will contain some distortions due to the impacts of self-resonance and on-state voltage drop of the switches. In order to reduce the harmonic content of the output currents, a waveform shaping strategy and a resonance damping method are proposed in $[25,26]$, respectively.

Although reactive power compensation has got some focus for D-CAP, load imbalance suppression has not been discussed. Since the D-CAP is equivalent to a capacitor controlled by the duty ratio, it is meaningful to study how to suppress the load imbalance by capacitors. Reference [27] shows that only adopting capacitors cannot compensate for all unbalanced load, but it does not specify its compensation range. Using a delta-connected D-CAP to compensate the unbalanced load has been studied in the author's previous article [28]. Although the voltage in each phase is the same for a delta-connected D-CAP without the potential deviation at the neutral point, the line voltage of the delta structure is larger than the phase voltage of the star structure. For a star-connected D-CAP, the operating voltage of the switching device is lower than a delta-connected D-CAP, and the number of cascaded units is less, especially in high-voltage applications [24]. Due to the cost advantages, it is also of great significance to study star-connected D-CAPs. In this paper, reactive power compensation and imbalance suppression for a three-phase star-connected Buck-type D-CAP are explored. 
The innovations of this paper can be described as follows: In Section 2, the relationship between power factor correction and load imbalance suppression in three-phase three-wire system is analyzed. In Section 3, the theoretical compensation ability of the D-CAP for negative-sequence current is derived. Considering that the rated voltage of the D-CAP is limited, the actual compensation ability of the D-CAP is also analyzed. In Section 4, an improved control strategy is proposed, which can make the D-CAP compensate negative-sequence current the best. Finally, experimental results verify the correctness of the theoretical analysis and the effectiveness of the control strategy.

\section{Principle of the D-CAP Compensating for Reactive Power and Suppressing the Load Imbalance}

\subsection{Relationship between Power Factor Correction and Imbalance Suppression}

For the system of a three-phase star-connected Buck-type D-CAP and inductive unbalanced load, shown in Figure 1, in order to simplify the analysis, only fundamental components are considered. The load is linear and the three-phase voltages on the grid side $\left[\begin{array}{lll}u_{T a} & u_{T b} & u_{T c}\end{array}\right]$ are balanced and symmetrical, where:

$$
\left\{\begin{array}{l}
u_{T a}=U_{m} \sin (\omega t) \\
u_{T b}=U_{m} \sin \left(\omega t-120^{\circ}\right) \\
u_{T c}=U_{m} \sin \left(\omega t+120^{\circ}\right)
\end{array}\right.
$$

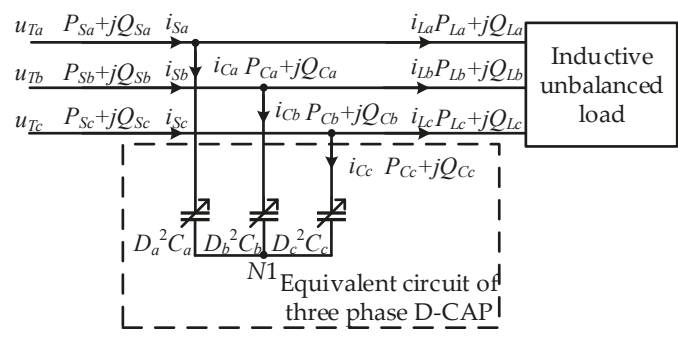

(a)

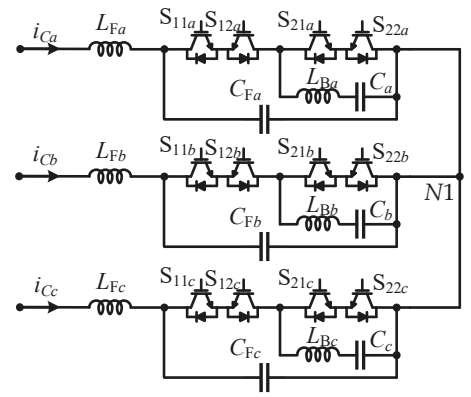

(b)

Figure 1. (a) Three phase star-connected Buck-type D-CAP compensating for inductive unbalanced load; and (b) the structure diagram of the three-phase star-connected Buck-type D-CAP.

As shown in Figure 2, according to the symmetric component method, the three-phase grid side currents $\left[\begin{array}{lll}i_{S a} & i_{S b} & i_{S c}\end{array}\right]$ can be decomposed into positive-sequence components $\left[i_{S a}^{+} i_{S b}^{+} i_{S c}^{+}\right]$and negative-sequence components $\left[i_{S a}^{-} i_{S b}^{-} i_{S c}^{-}\right]$, where:

$$
\left\{\begin{array}{l}
i_{S a}=i_{S a}^{+}+i_{S a}^{-} \\
i_{S a}^{+}=I_{S m}^{+} \sin \left(\omega t-\varphi^{+}\right) \\
i_{S a}^{-}=I_{S m}^{-} \sin \left(\omega t-\varphi^{-}\right)
\end{array}\right.
$$




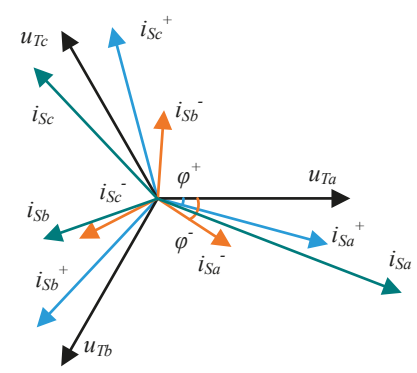

Figure 2. Grid currents phasor decomposition into positive and negative sequence currents.

Reactive power $Q_{S a}$ of phase A can be decomposed into reactive power generated by $i_{S a}^{+}$acting on $u_{T a}$ and reactive power generated by $i_{S a}^{-}$acting on $u_{T a}$. Similarly, $Q_{S b}$ and $Q_{S c}$ can be decomposed in this way. Reactive power at the grid side can be expressed as:

$$
\left\{\begin{array}{l}
Q_{S a}=U_{m}\left(I_{S m}^{+} \sin \varphi^{+}+I_{S m}^{-} \sin \varphi^{-}\right) / 2 \\
Q_{S b}=U_{m}\left[I_{S m}^{+} \sin \varphi^{+}+I_{S m}^{-} \sin \left(120^{\circ}+\varphi^{-}\right)\right] / 2 \\
Q_{S c}=U_{m}\left[I_{S m}^{+} \sin \varphi^{+}-I_{S m}^{-} \sin \left(120^{\circ}-\varphi^{-}\right)\right] / 2
\end{array}\right.
$$

In Equation (3), $\varphi^{+}$is the phase angle of $i_{S a}^{+}$lagging behind $u_{T a}, \varphi^{-}$is the phase angle of $i_{S a}^{-}$lagging behind $u_{T a}$. If power factors of phases $\mathrm{A}, \mathrm{B}$, and $\mathrm{C}$ on the grid side are 1 under the effects of the D-CAP, which means $Q_{S a}=0, Q_{S b}=0, Q_{S c}=0$, then:

$$
\left\{\begin{array}{l}
I_{S m}^{+} \sin \varphi^{+}=0 \\
I_{S m}^{-}=0
\end{array}\right.
$$

Equation (4) shows that both positive-sequence reactive components and negative-sequence components of the three-phase grid side currents are 0 at this time, and only positive-sequence active components are left at the grid side.

Consequently, in three-phase three-wire system with unbalanced load, if three-phase power factors at the grid side are equal to 1 under the effects of the D-CAP, then the D-CAP can compensate the reactive power and suppress load imbalance.

\subsection{Principle of the D-CAP Suppressing the Load Imbalance}

The D-CAP is equivalent to the capacitance of $D_{k}^{2} C_{k}$ under the control of the constant duty ratio [21,22]. Considering that the neutral potential drift of the star-connected D-CAP will bring more complexity and trouble to the analysis, the equivalent capacitance of the D-CAP can be transformed into delta-connected capacitors, shown in Figure 3a, if delta-connected capacitors meet Equation (5):

$$
\left\{\begin{array}{l}
C_{a b}=D_{a}^{2} D_{b}^{2} C_{a} C_{b} /\left(D_{a}^{2} C_{a}+D_{b}^{2} C_{b}+D_{c}^{2} C_{c}\right) \\
C_{b c}=D_{b}^{2} D_{c}^{2} C_{b} C_{c} /\left(D_{a}^{2} C_{a}+D_{b}^{2} C_{b}+D_{c}^{2} C_{c}\right) \\
C_{c a}=D_{c}^{2} D_{a}^{2} C_{c} C_{a} /\left(D_{a}^{2} C_{a}+D_{b}^{2} C_{b}+D_{c}^{2} C_{c}\right)
\end{array}\right.
$$




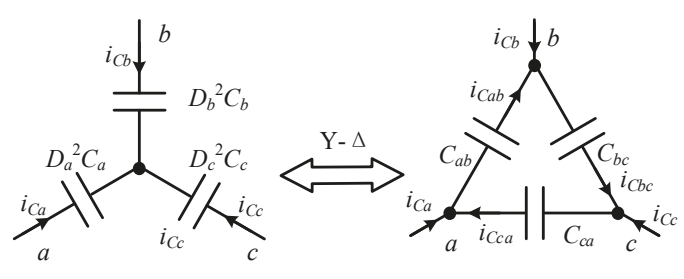

(a)

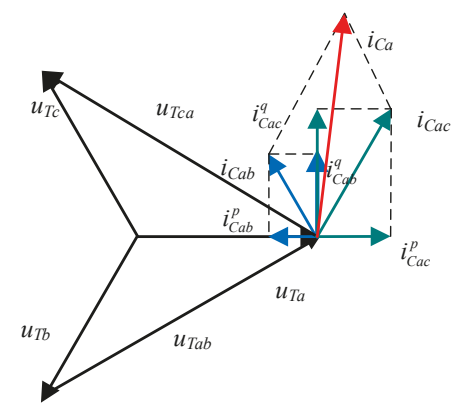

(b)

Figure 3. The principle of the D-CAP suppressing load imbalance: (a) Transformation from the star-connected D-CAP equivalent circuit to delta-connected capacitors; and (b) the phasor decomposition of $i_{C a b}$, and $i_{C a c}$.

Shown in Figure $3 \mathrm{~b}, i_{C a b}$ can be decomposed into active component $i_{C a b}^{p}$ parallel with $u_{T a}$, and reactive component $i_{\mathrm{Cab}}^{q}$, perpendicular to $u_{T a}$. Similarly, $i_{C a c}$ can be decomposed into $i_{C a c}^{p}$ and $i_{C a c}^{q}$. Then the reactive and active components of $i_{\mathrm{Ca}}$ can be expressed with $i_{\mathrm{Cab}}^{q}+i_{\mathrm{Cac}}^{q}$ and $i_{\mathrm{Cab}}^{p}+i_{\mathrm{Cac}}^{p}$. Similarly, $i_{\mathrm{Cb}}$ and $i_{C c}$ also contain active and reactive components. The total active power absorbed by the three-phase D-CAP is 0 , which provides feasibility for the D-CAP to suppress load imbalance by transferring active power and compensating reactive power if the duty ratio can be controlled reasonably.

From Figure 3b, reactive powers absorbed by the D-CAP can be calculated:

$$
\left\{\begin{array}{l}
Q_{C a}=-3 U_{m}^{2} \omega\left(C_{a b}+C_{c a}\right) / 4 \\
Q_{C b}=-3 U_{m}^{2} \omega\left(C_{a b}+C_{b c}\right) / 4 \\
Q_{C c}=-3 U_{m}^{2} \omega\left(C_{c a}+C_{b c}\right) / 4
\end{array}\right.
$$

Supposing $i_{L a}$ can be decomposed into the positive-sequence component $i_{L a}^{+}$and negative-sequence component $i_{L a}^{-}$:

$$
\left\{\begin{array}{l}
i_{L a}=i_{L a}^{+}+i_{L a}^{-} \\
i_{L a}^{+}=I_{L m}^{+} \sin \left(\omega t-\theta^{+}\right) \\
i_{L a}^{-}=I_{L m}^{-} \sin \left(\omega t-\theta^{-}\right)
\end{array}\right.
$$

In Equation (7), $\theta^{+}$is the phase angle of $i_{L a}^{+}$lagging behind $u_{T a}$, and $\theta^{-}$is the phase angle of $i_{L a}^{-}$ lagging behind $u_{T a}$. Three-phase reactive powers at the grid side after the D-CAP put into operation can be deduced:

$$
\left\{\begin{array}{l}
Q_{S a}=Q_{C a}+Q_{L a}=U_{m}\left(I_{L m}^{+} \sin \theta^{+}+I_{L m}^{-} \sin \theta^{-}\right) / 2-3 U_{m}^{2} \omega\left(C_{a b}+C_{c a}\right) / 4 \\
Q_{S b}=Q_{C b}+Q_{L b}=U_{m}\left[I_{L m}^{+} \sin \theta^{+}+I_{L m}^{-} \sin \left(120^{\circ}+\theta^{-}\right)\right] / 2-3 U_{m}^{2} \omega\left(C_{a b}+C_{b c}\right) / 4 \\
Q_{S c}=Q_{C c}+Q_{L c}=U_{m}\left[I_{L m}^{+} \sin \theta^{+}-I_{L m}^{-} \sin \left(120^{\circ}-\theta^{-}\right)\right] / 2-3 U_{m}^{2} \omega\left(C_{c a}+C_{b c}\right) / 4
\end{array}\right.
$$

Assuming $Q_{S a}=0, Q_{S b}=0$ and $Q_{S c}=0$, then:

$$
\left\{\begin{array}{l}
C_{a b}=\left[I_{L m}^{+} \sin \theta^{+}+2 I_{L m}^{-} \sin \left(120^{\circ}-\theta^{-}\right)\right] /\left(3 \omega U_{m}\right) \\
C_{b c}=\left(I_{L m}^{+} \sin \theta^{+}-2 I_{L m}^{-} \sin \theta^{-}\right) /\left(3 \omega U_{m}\right) \\
C_{c a}=\left[I_{L m}^{+} \sin \theta^{+}-2 I_{L m}^{-} \sin \left(120^{\circ}+\theta^{-}\right)\right] /\left(3 \omega U_{m}\right)
\end{array}\right.
$$

If three-phase equivalent capacitances of the D-CAP meet Equation (9), the power factors of the three-phase grid side will be corrected to 1 . According to the relationship between power factor correction and imbalance suppression in Section 2.1, reactive power will be compensated and load imbalance will be suppressed absolutely. 


\section{Compensation Ability of a Star-Connected D-CAP for Negative-Sequence Currents}

\subsection{Theoretical Compensation Ability of a Star-Connected D-CAP}

In Equation (9), we can find $I_{L m}^{+} \sin \theta^{+}$is the positive-sequence reactive component amplitude of the load currents, and $I_{L m}^{-} \sin \theta^{-}, I_{L m}^{-} \sin \left(120^{\circ}+\theta^{-}\right),-I_{L m}^{-} \sin \left(120^{\circ}-\theta^{-}\right)$are the negative-sequence reactive components amplitude of the load currents. For example, under some load conditions, the positive-sequence reactive components' amplitude is smaller than two times of negative-sequence reactive components amplitude. Then the value of $C_{b c}$ is negative according to Equation (9), which is unachievable for the D-CAP. Therefore, the compensation ability of the D-CAP is limited.

Take phase $\mathrm{A}$ as another example shown in Figure 4. Draw vertical line relative to $u_{T a}$ from the end point of $i_{L a}^{+}$and dividing line 1 parallel to $u_{T a}$ at the midpoint of vertical line. The value of $C_{a b}$ is positive if $i_{L a}^{-}$is in the zone 1 which is above dividing line 1. Similarly, the values of $C_{c a}$ and $C_{b c}$ are positive if $i_{L b}^{-}$and $i_{L c}^{-}$are in zone 2 and zone 3 , respectively. Considering that $i_{L a^{\prime}}^{-} i_{L b^{\prime}}^{-}$and $i_{L c}^{-}$are symmetrical, the value of $C_{a b}, C_{b c}$ and $C_{c a}$ are all greater than 0 if and only if $i_{L a^{\prime}}^{-} i_{L b^{\prime}}^{-}$and $i_{L c}^{-}$are all in the $\Delta$ RST.

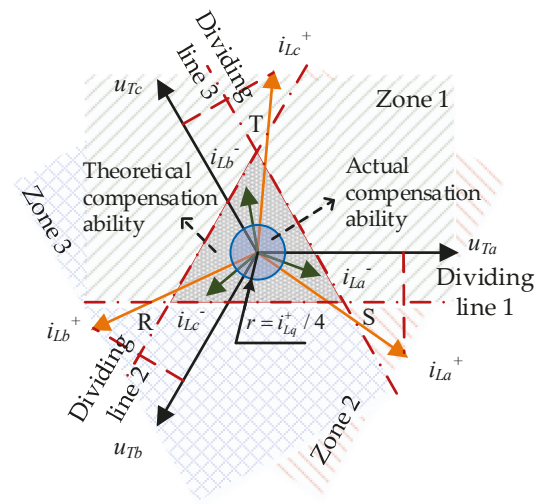

Figure 4. Theoretical and actual compensation ability of the D-CAP for negative-sequence currents.

Consequently, in the three-phase three-wire system, if the negative-sequence components of the load currents are located in the $\triangle \mathrm{RST}$, shown in Figure 4, meaning the value of equivalent capacitances calculated by Equation (9) are positive, the D-CAP can completely compensate the reactive power and suppress the load imbalance. Otherwise, the D-CAP can only compensate the positive-sequence reactive components and a part of the negative-sequence components of the load currents lying in the scope of $\triangle \mathrm{RST}$.

Additionally, the circle with radius $i_{L q}^{+} / 4$ in Figure 4 refers to the actual compensation ability of the D-CAP, which will be illustrated in Section 3.2.

\subsection{Actual Compensation Ability of a Star-Connected D-CAP}

Deviation of potential at the neutral point will occur when the star-connected D-CAP suppresses the load imbalance, which will make one of the voltages between the grid side and the D-CAP neutral point higher. In practice, the rated voltage of each phase D-CAP is generally 1.1-1.3 times higher than the grid voltage in order to maintain a safety margin, so the actual compensation ability of the D-CAP under an unbalanced load will be limited by the rated voltage. 
Shown in Figure 5, the coordinate expressions of three phase grid voltages are:

$$
\left\{\begin{array}{l}
\dot{U}_{T a}=\left(U_{m}, 0\right) \\
\dot{U}_{T b}=\left(-U_{m} / 2,-\sqrt{3} U_{m} / 2\right) \\
\dot{U}_{T c}=\left(-U_{m} / 2, \sqrt{3} U_{m} / 2\right)
\end{array}\right.
$$

In order to compensate reactive power and negative-sequence currents, the coordinate expressions of $\left[i_{C a} i_{C b} i_{C c}\right]$ can be described as:

$$
\left\{\begin{array}{l}
\dot{I}_{C a}=\left(-I_{L m}^{-} \cos \theta^{-}, I_{L m}^{-} \sin \theta^{-}\right)+\left(0, I_{L m}^{+} \sin \theta^{+}\right) \\
\dot{I}_{C b}=\left[-I_{L m}^{-} \cos \left(120^{\circ}-\theta^{-}\right),-I_{L m}^{-} \sin \left(120^{\circ}-\theta^{-}\right)\right]+\left[\sqrt{3}\left(I_{L m}^{+} \sin \theta^{+}\right) / 2,-I_{L m}^{+} \sin \theta^{+} / 2\right] \\
\dot{I}_{C c}=\left[-I_{L m}^{-} \cos \left(120^{\circ}+\theta^{-}\right), I_{L m}^{-} \sin \left(120^{\circ}+\theta^{-}\right)\right]+\left[-\sqrt{3}\left(I_{L m}^{+} \sin \theta^{+}\right) / 2,-I_{L m}^{+} \sin \theta^{+} / 2\right]
\end{array}\right.
$$

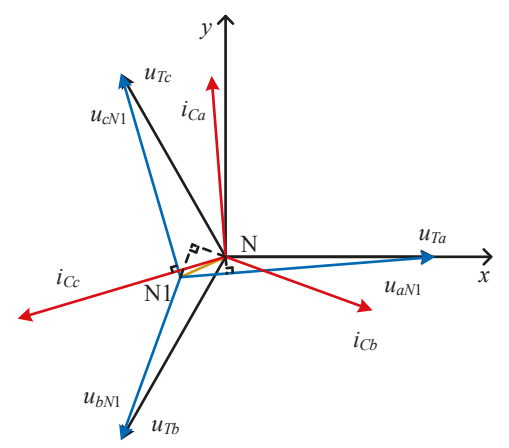

Figure 5. Voltage and current phasor of the star-connected D-CAP with the deviation of the potential at the neutral point for load imbalance suppression.

If the coordinate of the D-CAP neutral point potential is $(x, y)$, then:

$$
\left\{\begin{array}{l}
{\left[\left(U_{m}, 0\right)-(\mathrm{x}, \mathrm{y})\right] \perp \dot{I}_{C a}} \\
{\left[\left(-U_{m} / 2,-\sqrt{3} U_{m} / 2\right)-(\mathrm{x}, \mathrm{y})\right] \perp \dot{I}_{C b}} \\
{\left[\left(-U_{m} / 2, \sqrt{3} U_{m} / 2\right)-(\mathrm{x}, \mathrm{y})\right] \perp \dot{I}_{C c}}
\end{array}\right.
$$

According to the mathematical condition that two phasors are mutually orthogonal, it can be solved:

$$
\left\{\begin{array}{l}
x=U_{m}\left[1-k \sin \theta^{-}-2\left(\sin \theta^{-}\right)^{2}\right] /\left(1-k^{2}\right) \\
y=U_{m} \cos \theta^{-}\left(-2 \sin \theta^{-}+k\right) /\left(1-k^{2}\right) \\
k \triangleq I_{L m}^{+} \sin \theta^{+} / I_{L m}^{-}
\end{array}\right.
$$

Therefore, if the D-CAP can absolutely compensate the reactive power and negative-sequence currents of the load, the neutral point potential of the D-CAP will be affected by the phase angle $\theta^{-}$ and the reactive/imbalance index $k$, where $k$ is the ratio of the positive-sequence reactive components' amplitude $I_{L m}^{+} \sin \theta^{+}$to the negative-sequence components amplitude $I_{L m}^{-}$.

With the coordinate of $u_{T}$ and $N 1$, the amplitudes of $\left[\begin{array}{lll}u_{a N 1} & u_{b N 1} & u_{c N 1}\end{array}\right]$ can be calculated. Here, drift factor $d$ is introduced and defined as $\max \left(u_{a N 1} u_{b N 1} u_{c N 1}\right) / u_{T a}$. Figure 6 presents the relationship between drift factor $d$ and reactive/imbalance index $k, \theta^{-}$. Because the rated voltage of the D-CAP is generally 1.1-1.3 times as high as the grid voltage, the ratio of positive-sequence reactive components amplitude to negative-sequence components amplitude of the D-CAP compensation currents is limited. In Figure $6 \mathrm{~b}$, we can find if reactive/imbalance index $k$ is greater than 4 , the effect of $\theta^{-}$to drift factor $d$ is small. To simplify analysis and make the voltages at both ends of the D-CAP not exceed the rated 
voltage, $\theta^{-}$is assumed to be kept at a value producing the maximal potential deviation at the neutral point. Therefore, for D-CAP currents, the positive-sequence reactive components' amplitude should be greater than four times the negative-sequence components amplitude to ensure the voltages at both ends of the D-CAP do not exceed its rated voltage.

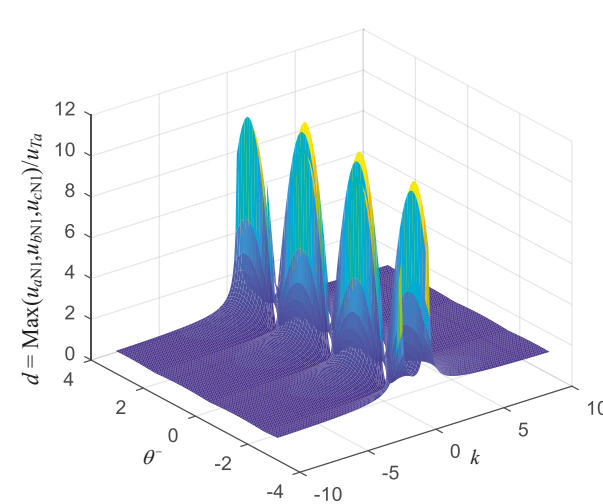

(a)

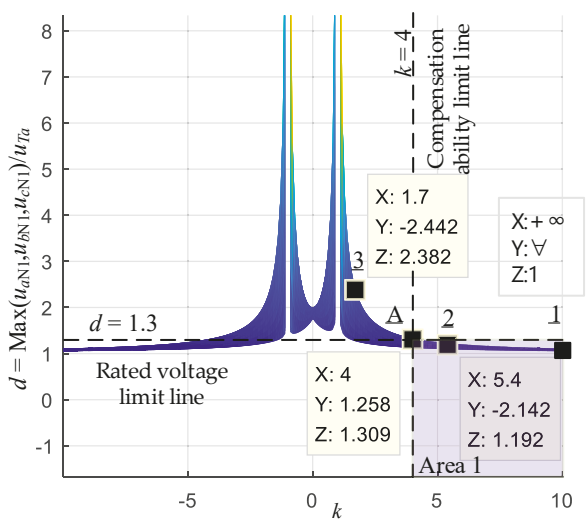

(b)

Figure 6. Relationship between drift factor $d$ and reactive/imbalance index $k, \theta^{-}$: (a) Three-dimensional graphics of $d\left(k, \theta^{-}\right)=\max \left(u_{a N 1} u_{b N 1} u_{c N 1}\right) / u_{T a}$; and (b) projection of the curved surface on the $k-d$ plane.

As shown in Figure $6 \mathrm{~b}$, Point $\underline{\mathrm{A}}$ is the intersection of the rated voltage limit line $(d=1.3)$ and the compensation ability limit line $(k=4)$. Area 1 is below the rated voltage limit line $(d=1.3)$ and on the right of the compensation ability limit line $(k=4)$. Here, area 1 is equivalent to the circle whose radius is $i_{L q}^{+} / 4$ in Figure 4 . If the negative-sequence components of the load currents are in the scope of the circle, that means $\theta^{-}$and the reactive/imbalance index $k$ are in area 1, and D-CAP can compensate the reactive power and suppress the load imbalance without exceeding the rated voltage limit.

\section{Proposed Control Strategy of the D-CAP to Compensate the Reactive Power and Suppress Load Imbalance}

For the three-phase star-connected Buck-type D-CAP, the proposed control strategy to compensate the reactive power and suppress load imbalance is shown in Figure 7.

Firstly, we transform the load currents $\left[i_{L a} i_{L b} i_{L c}\right]$ with Equations (14) and (15), respectively. Then passing through a low-pass filter, the positive-sequence active and reactive components $\left[i_{L d}^{+} i_{L q}^{+}\right]$, and negative-sequence active and reactive components $\left[i_{L d}^{-} i_{L q}^{-}\right]$are obtained:

$$
\begin{aligned}
& \left(\begin{array}{c}
i_{L d}^{+} \\
i_{L q}^{+}
\end{array}\right)=2 / 3\left(\begin{array}{ccc}
\sin \omega t & \sin \left(\omega t-120^{\circ}\right) & \sin \left(\omega t+120^{\circ}\right) \\
\cos \omega t & \cos \left(\omega t-120^{\circ}\right) & \cos \left(\omega t+120^{\circ}\right)
\end{array}\right)\left(\begin{array}{c}
I_{L m}^{+} \sin \left(\omega t-\varphi^{+}\right) \\
I_{L m}^{+} \sin \left(\omega t-\varphi^{+}-120^{\circ}\right) \\
I_{L m}^{+} \sin \left(\omega t-\varphi^{+}+120^{\circ}\right)
\end{array}\right)=\left(\begin{array}{c}
I_{L m}^{+} \cos \varphi^{+} \\
-I_{L m}^{+} \sin \varphi^{+}
\end{array}\right) \\
& \left(\begin{array}{c}
i_{L d}^{-} \\
i_{L q}^{-}
\end{array}\right)=2 / 3\left(\begin{array}{ccc}
-\sin (\omega t) & -\sin \left(\omega t+120^{\circ}\right) & -\sin \left(\omega t-120^{\circ}\right) \\
\cos (\omega t) & \cos \left(\omega t+120^{\circ}\right) & \cos \left(\omega t-120^{\circ}\right)
\end{array}\right)\left(\begin{array}{c}
I_{L m}^{-} \sin \left(\omega t-\varphi^{-}\right) \\
I_{L m}^{-} \sin \left(\omega t-\varphi^{-}+120^{\circ}\right) \\
I_{L m}^{-} \sin \left(\omega t-\varphi^{-}-120^{\circ}\right)
\end{array}\right)=\left(\begin{array}{c}
-I_{L m}^{-} \cos \varphi^{-} \\
-I_{L m}^{-} \sin \varphi^{-}
\end{array}\right)
\end{aligned}
$$


Since the actual compensation ability of the D-CAP for negative-sequence currents is limited by its rated voltage, it is necessary to add an amplitude limit on the negative-sequence currents. The processing method of the negative sequence currents is derived as follows:

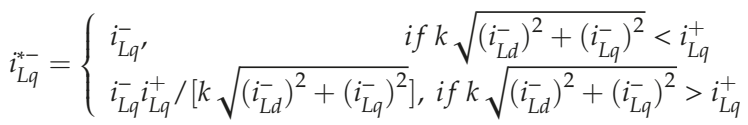

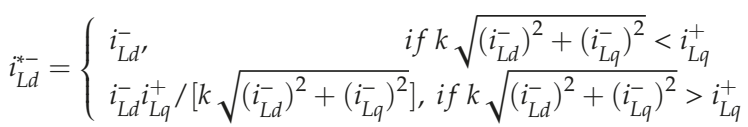

If the D-CAP can compensate the reactive power and negative-sequence currents to the utmost, the amplitudes of $\left[i_{C a} i_{C b} i_{C c}\right]$ are uniquely determined. Command current amplitudes of the D-CAP can be obtained with $i_{L q}^{*+}, i_{L d^{\prime}}^{*-}$ and $i_{L q}^{*-}$ as follows:

$$
\left\{\begin{array}{l}
\left|i_{C a}^{*}\right|=\sqrt{\left(i_{L d}^{*-}\right)^{2}+\left(i_{L q}^{+}+i_{L q}^{*-}\right)^{2}} \\
\left|i_{C b}^{*}\right|=\sqrt{\left(i_{L d}^{*-} / 2-\sqrt{3} i_{L q}^{*-} / 2\right)^{2}+\left(-\sqrt{3} i_{L d}^{*-} / 2-i_{L q}^{*-} / 2+i_{L q}^{+}\right)^{2}} \\
\left|i_{C d}^{*}\right|=\sqrt{\left(i_{L d}^{*-} / 2+\sqrt{3} i_{L q}^{*-} / 2\right)^{2}+\left(\sqrt{3} i_{L d}^{*-} / 2-i_{L q}^{*-} / 2+i_{L q}^{+}\right)^{2}}
\end{array}\right.
$$

We compare the command currents amplitudes calculated by Equation (18) with the actual current amplitudes of $\left[i_{C a} i_{C b} i_{C c}\right.$, which can be extracted and calculated with the RDFT method [29]. Then we regulate the error through a PI controller to control the duty ratio of the D-CAP. Finally, the switches of the Buck-type AC-AC converter are driven through the modulated output signal. By adjusting the duty ratio, the positive-sequence reactive power and negative-sequence currents of the load can be effectively compensated.

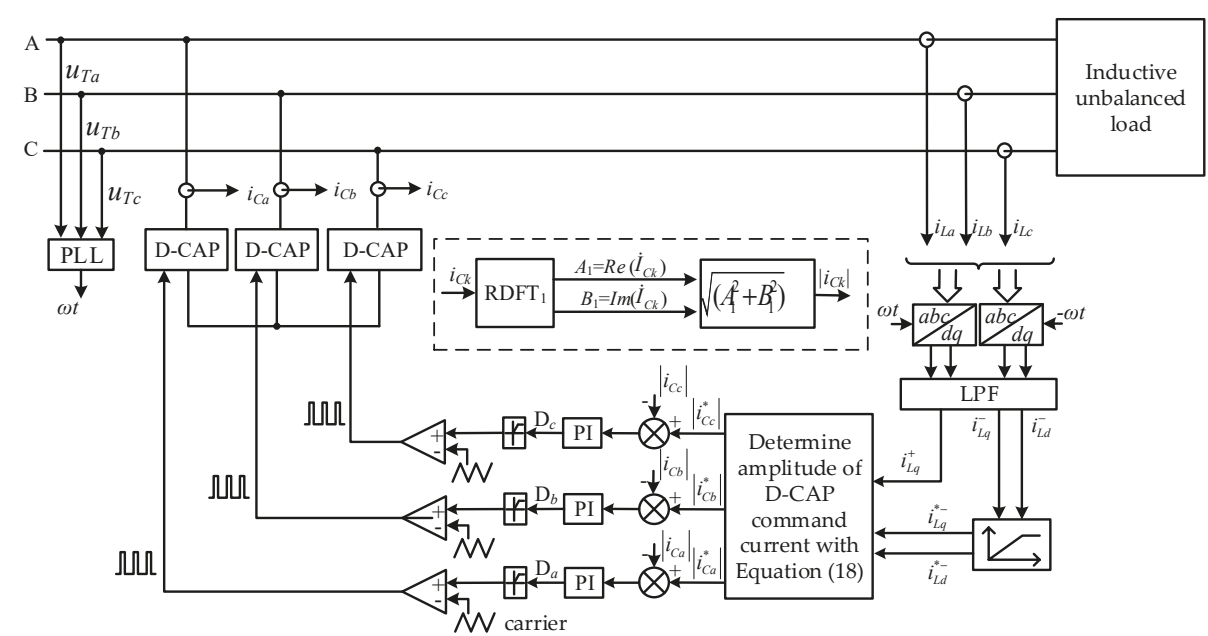

Figure 7. Proposed control strategy of a star-connected D-CAP compensating the reactive power and suppressing the load imbalance.

\section{Experiment Verification}

In order to verify the effectiveness of the control strategy, experimental tests with a $33 \mathrm{kVar} / 220 \mathrm{~V}$ three-phase Buck-type D-CAP are carried out. Figure 1 b shows the system configuration. The D-CAP 
parameters are given in Table 1, which can be determined by the methods in [30]. The experimental prototype is shown in Figure 8. In the front view of Figure 8a, the three-phase main circuits of the prototype are divided into three layers, where the A-phase, B-phase, and C-phase circuits are arranged from the top to the bottom layers, respectively. The A-phase circuit is shown in the top view of Figure 8b.

Table 1. Parameters of the D-CAP.

\begin{tabular}{ccccccc}
\hline $\begin{array}{c}\text { Grid } \\
\text { Voltage } u_{T}\end{array}$ & $\begin{array}{c}\text { Grid } \\
\text { Frequency } f_{\mathrm{T}}\end{array}$ & $\begin{array}{c}\text { Filtering } \\
\text { Inductance } L_{F}\end{array}$ & $\begin{array}{c}\text { Filtering } \\
\text { Capacitor } C_{F}\end{array}$ & $\begin{array}{c}\text { Buffer } \\
\text { Inductance } L_{B}\end{array}$ & $\begin{array}{c}\text { Power } \\
\text { Capacitor } C\end{array}$ & $\begin{array}{c}\text { Switching } \\
\text { Frequency } f_{w}\end{array}$ \\
\hline $220 \mathrm{~V}$ & $50 \mathrm{~Hz}$ & $160 \mu \mathrm{H}$ & $80 \mu \mathrm{F}$ & $180 \mu \mathrm{H}$ & $660 \mu \mathrm{F}$ & $9.6 \mathrm{kHz}$ \\
\hline
\end{tabular}

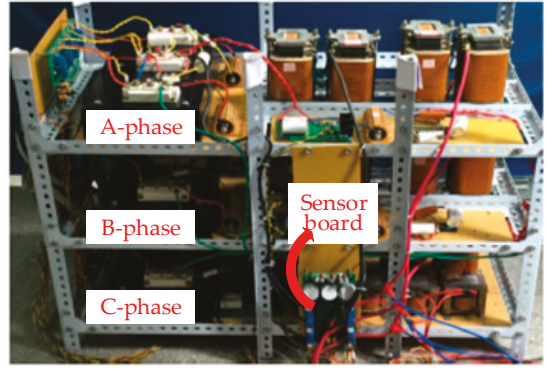

(a)

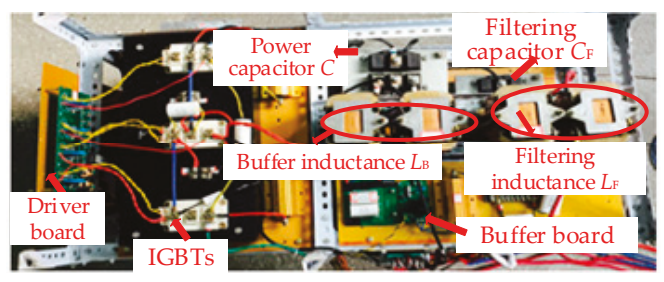

(b)

Figure 8. Three-phase Buck-type D-CAP prototype: (a) front view; and (b) top view.

Experiments are implemented with three different cases in which the load is star-connected with the resistor and inductor in series, as shown as Table 2. Case 1 is implemented under a balanced load, which only needs reactive power compensation. Case 2 is used to verify the feasibility of the D-CAP to compensate the negative-sequence currents, so an unbalanced load is adopted, which corresponds to a reactive/imbalance index $\mathrm{k}>4$. To verify the compensation ability of the D-CAP, Case 3 is operated under a heavily unbalanced load, whose negative-sequence currents are beyond the compensation ability of the D-CAP, which corresponds to a reactive/imbalance index $\mathrm{k}<4$. Only the inductive part of the load is unbalanced in this experiment; it is also effective for the proposed control strategy if the resistive part is unbalanced even if both of the resistive and inductive parts are unbalanced.

Table 2. Parameters of the load.

\begin{tabular}{cccc}
\hline Load Type & $\begin{array}{c}\text { (Case 1) Inductive } \\
\text { Balanced Load }\end{array}$ & $\begin{array}{c}\text { (Case 2) Slightly } \\
\text { Unbalanced Load }\end{array}$ & $\begin{array}{c}\text { (Case 3) Heavily } \\
\text { Unbalanced Load }\end{array}$ \\
\hline Phase A & $6 \Omega / 21.64 \mathrm{mH}$ & $6 \Omega / 21.64 \mathrm{mH}$ & $6 \Omega / 21.64 \mathrm{mH}$ \\
Phase B & $6 \Omega / 21.64 \mathrm{mH}$ & $6 \Omega / 11.64 \mathrm{mH}$ & $6 \Omega$ \\
Phase C & $6 \Omega / 21.64 \mathrm{mH}$ & $6 \Omega / 21.64 \mathrm{mH}$ & $6 \Omega / 21.64 \mathrm{mH}$ \\
\hline
\end{tabular}

\subsection{Case 1: D-CAP for Inductive Balanced Load}

Only reactive power is needed if the load is inductive and balanced. Shown in Figure $9 a, b$, currents at the load side can be considered balanced with values $23.0 \mathrm{~A}, 23.2 \mathrm{~A}$, and $22.3 \mathrm{~A}$, respectively and lag behind grid voltages. Figure $9 \mathrm{c}$ shows the three-phase power factors are $0.74,0.74$, and 0.76 . In this case, the reactive/imbalance index $k$ is toward positive infinity, represented as Point 1 in Figure $6 \mathrm{~b}$. When the $\mathrm{D}-\mathrm{CAP}$ is used to compensate the reactive power with the proposed control strategy, shown in Figure 7, the phase angle of the currents and voltages at the grid side become the same (Figure $9 \mathrm{~d}, \mathrm{e}$ ) and the three-phase power factors are regulated to 1 (Figure 9f). In Figure 9h, the D-CAP currents' lead voltages by $86^{\circ}$, but not $90^{\circ}$, because of active power loss when the D-CAP operates. The three-phase duty 
ratios of the D-CAP are $0.51,0.47$, and 0.47 , respectively. Therefore, the reactive power compensation can be achieved under the effects of the D-CAP if the load is balanced and inductive.

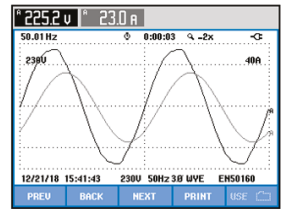

(a)

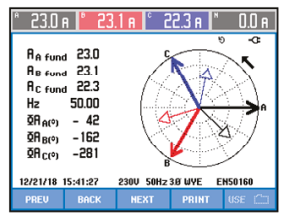

(b)

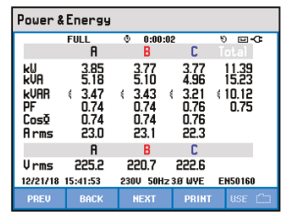

(c)

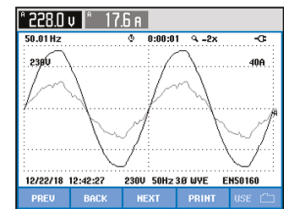

(d)

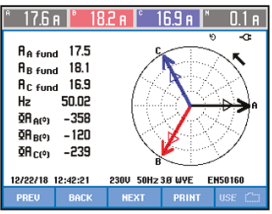

(e)

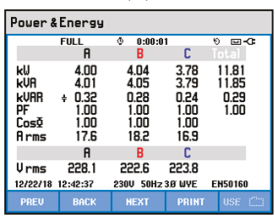

(f)

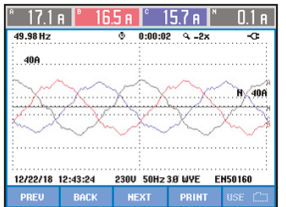

(g)

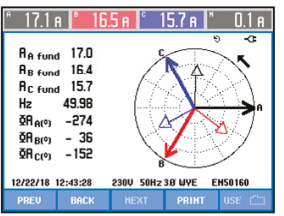

(h)

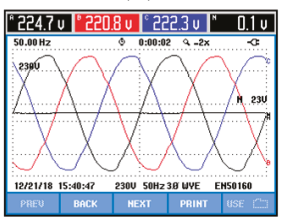

(i)

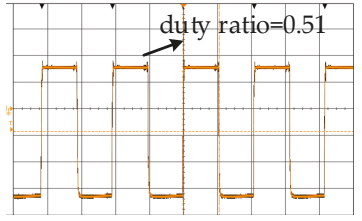

(j)

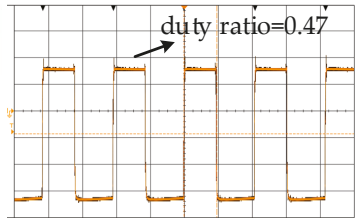

$(\mathbf{k})$

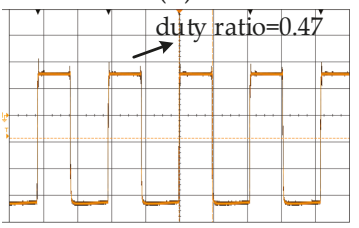

(1)

Figure 9. D-CAP for inductive balanced load: (a) A-phase voltage and current at the load side; (b) voltage and current phasor at the load side; (c) power and energy at the load side; (d) A-phase voltage and current at the grid side after compensation; (e) voltage and current phasor at the grid side after compensation; (f) power and energy at the grid side after compensation; (g) D-CAP currents; (h) voltage and current phasor at the D-CAP side; (i) grid voltages; (j) A-phase duty ratio; (k) B-phase duty ratio; and (1) C-phase duty ratio.

\subsection{Case 2: D-CAP for Slightly Unbalanced Inductive Load}

Comprehensive control of reactive power compensation and imbalance suppression are implemented under a slightly unbalanced load in this case. Calculated by Equation (13), the reactive/imbalance index $k$ is equal to 5.4, which corresponds to Point 2 in Figure $6 \mathrm{~b}$. Shown in Figure 10, currents at the grid side are unbalanced (Figure 10a) and lag behind grid voltages (Figure 10b) when the D-CAP is not put into operation with power factors $0.81,0.85$, and 0.72 , respectively (Figure 10c). Currents at the grid side become balanced (Figure 10d,e) and the three-phase power factors are regulated to 1 (Figure 10f) after the D-CAP is put into operation. The three-phase equivalent capacitances can be regulated properly under different duty ratios, whose values are, respectively, 0.38 , 0.47 , and 0.62 . In the Figure $10 \mathrm{~g}, \mathrm{~h}$, the output currents of the D-CAP are unbalanced due to different equivalent capacitances. Since the negative-sequence components' amplitude is smaller than one quarter of the positive-sequence reactive components' amplitude in this case, which is not constrained by the negative-sequence components' amplitude limit shown in Equations (16) and (17), the greatest voltage at both ends of the three-phase D-CAP is $262.7 \mathrm{~V}$ in Figure 10i. 


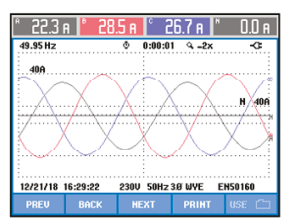

(a)

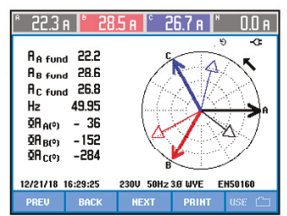

(b)

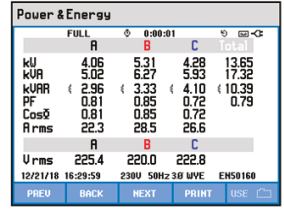

(c)

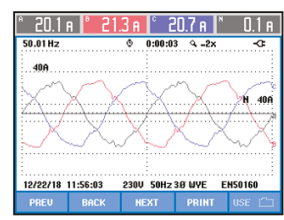

(d)

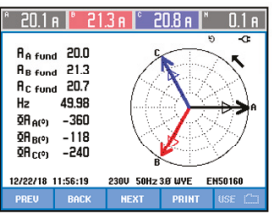

(e)

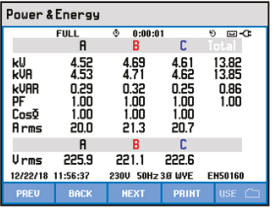

(f)

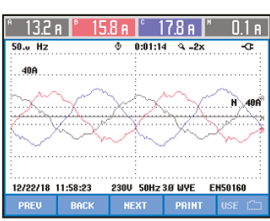

(g)

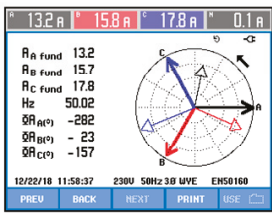

(h)

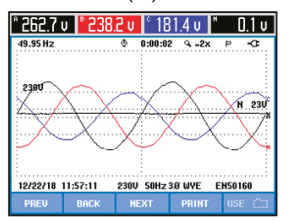

(i)

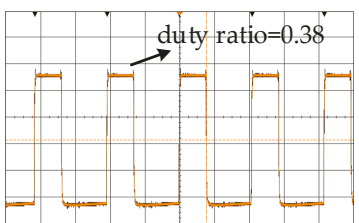

(j)

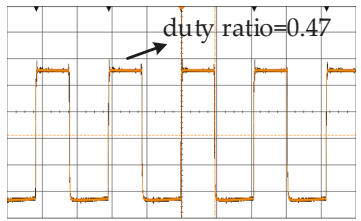

(k)

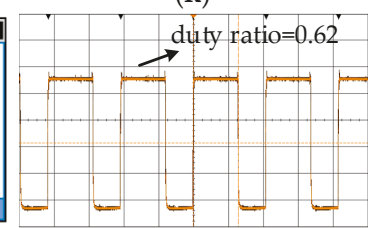

(1)

Figure 10. D-CAP for slightly unbalanced inductive load: (a) currents at the load side; (b) voltage and current phasor at the load side; (c) power and energy at the load side; (d) currents at the grid side after compensation; (e) voltage and current phasor at the grid side after compensation; (f) power and energy at the grid side after compensation; (g) currents at the D-CAP side; (h) voltage and current phasor at the D-CAP side after compensation; (i) voltages $\left[u_{a N 1} u_{b N 1} u_{c N 1}\right.$ ) after compensation; (j) A-phase duty ratio (k) B-phase duty ratio; and (1) C-phase duty ratio.

\subsection{Case 3: D-CAP for Heavily Unbalanced Inductive Load}

This case is implemented under a heavily unbalanced load. Calculated by Equation (13), the reactive/imbalance index $k$ is equal to 1.7, which corresponds to Point $\underline{3}$ in Figure $6 \mathrm{~b}$. Shown in Figure 11, currents at the load side are unbalanced (Figure 11a) and lag behind grid voltages (Figure 11b) with power factors $0.89,0.95$, and 0.76, respectively (Figure 11c). After the D-CAP is put into operation, the positive-sequence reactive power and a part of the negative-sequence currents are compensated. We can find that the amplitude of the three-phase currents at the grid side become more balanced (Figure 11d) and the phase angle difference between grid voltages and currents become smaller (Figure 11e). Power factors are regulated to $0.99,0.99$, and 1, respectively (Figure 11f). In Figure 11i, the greatest voltage at both ends of the three phase D-CAP is $274.8 \mathrm{~V}$, which is constrained in the range of the rated voltage by the negative-sequence components' amplitude limit shown in Equations (16) and (17). Comparing with Case 2, we can find if the ratio of the negative-sequence components' amplitude to the positive-sequence reactive components' amplitude of the load currents is smaller than 0.25, then the D-CAP can compensate its positive-sequence reactive components and negative-sequence components. If not, the D-CAP can only compensate the positive-sequence reactive power and a part of the negative-sequence currents due to the limit of its compensation ability. 


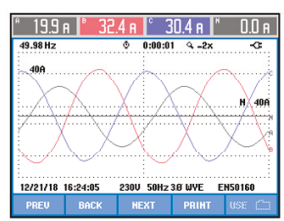

(a)

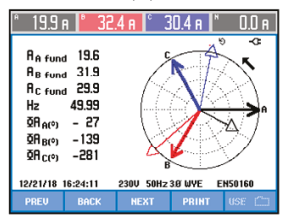

(b)

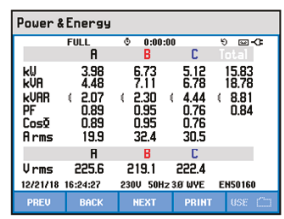

(c)

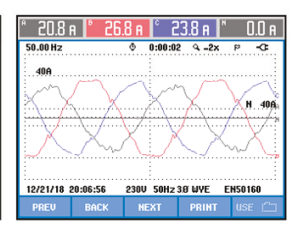

(d)

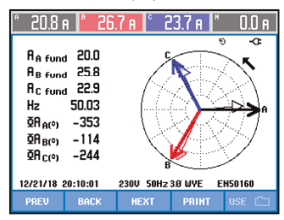

(e)

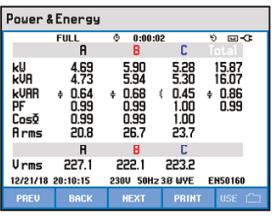

(f)

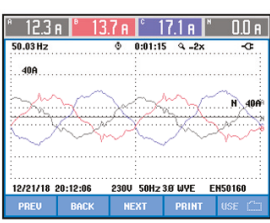

(g)

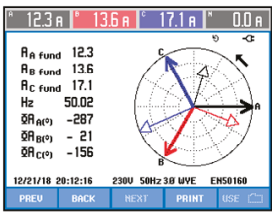

(h)

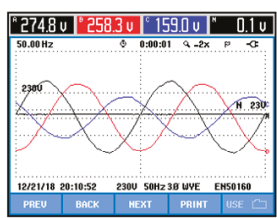

(i)

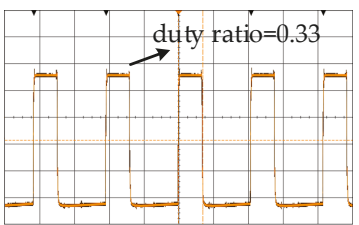

(j)

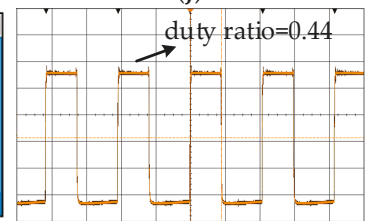

(k)

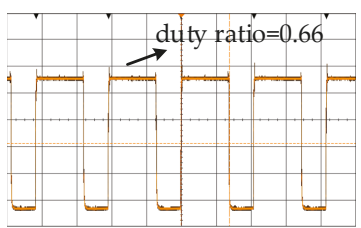

(1)

Figure 11. The D-CAP for heavily unbalanced load: (a) Currents at the load side; (b) voltage and current phasor at the load side; (c) power and energy at the load side; (d) currents at the grid side after compensation; (e) voltage and current phasor at the grid side after compensation; (f) power and energy at the grid side after compensation; (g) currents at the D-CAP side; (h) voltage and current phasor at the D-CAP side after compensation; (i) voltages $\left[u_{a N 1} u_{b N 1} u_{c N 1}\right]$ after compensation; (j) A-phase duty ratio; (k) B-phase duty ratio; and (1) C-phase duty ratio.

\subsection{Summarization and Comparison of Three-Phase Power Factors and the Unbalanced Degree}

A summary of the experimental results of the above three cases are shown in Table 3.

Table 3. Three-phase power factors and the unbalanced degree of grid currents under three types of the load.

\begin{tabular}{|c|c|c|c|}
\hline Load Type & $\begin{array}{c}\text { Inductive Balanced } \\
\text { Load (Case 1) }\end{array}$ & $\begin{array}{l}\text { Slightly Unbalanced } \\
\text { Load (Case 2) }\end{array}$ & $\begin{array}{l}\text { Heavily Unbalanced } \\
\text { Load (Case 3) }\end{array}$ \\
\hline $\begin{array}{l}\text { Phase A power factor at the grid } \\
\text { side before/after compensation }\end{array}$ & $0.74 / 1$ & $0.81 / 1$ & $0.89 / 0.99$ \\
\hline $\begin{array}{l}\text { Phase B power factor at the grid } \\
\text { side before/after compensation }\end{array}$ & $0.74 / 1$ & $0.85 / 1$ & $0.95 / 0.99$ \\
\hline $\begin{array}{l}\text { Phase } C \text { power factor at the grid } \\
\text { side before/after compensation }\end{array}$ & $0.76 / 1$ & $0.72 / 1$ & $0.76 / 1$ \\
\hline $\begin{array}{l}\text { Unbalanced degree of currents } \\
\text { at the grid side before/after } \\
\text { compensation }\end{array}$ & $0.023 / 0.039$ & $0.098 / 0.029$ & $0.279 / 0.126$ \\
\hline
\end{tabular}


In Case 1, it can be found that three-phase power factors are corrected to 1 with the inductive balanced load. The parameters of the load are not exactly the same, so the unbalanced degree of the load current is $2.3 \%$. Additionally, there are some active power loss and sampling errors when the D-CAP operates, so there is still a slight imbalance on the grid currents after compensation. Although the unbalanced degree increases from $2.3 \%$ to $3.9 \%$, we can think the grid currents are balanced and reactive power compensation is achieved under the inductive balanced load. In Case 2, the load is slightly unbalanced with reactive/imbalance index $k=5.4$, the three-phase power factors are corrected from $0.81,0.85$, and 0.72 to 1 , and the unbalanced degree drops from $9.8 \%$ to $2.9 \%$. Reactive power compensation and imbalance suppression are realized. In Case 3 , the load is heavily unbalanced with reactive/imbalance index $k=1.7$, and negative-sequence currents cannot be compensated completely due to the amplitude limit of $i_{L d}^{*-}$ and $i_{L d}^{*-}$. Only positive-sequence reactive components and a part of the negative-sequence components of the load currents are compensated, so the unbalanced degree decreases from $27.9 \%$ to $12.6 \%$, power factors increase from $0.89,0.95$, and 0.76 to $0.99,0.99$, and 1 .

\section{Conclusions}

In this paper, reactive power compensation and imbalance suppression by a $33 \mathrm{kVar} / 220 \mathrm{~V}$ star-connected Buck-type D-CAP in a three-phase three-wire system are studied. An improved control strategy is proposed, which can make full use of the rated voltage margin of the D-CAP to compensate the negative-sequence currents of the load. The following conclusions are obtained through theoretical analysis and experimental verification:

(1) In the three-phase three-wire system, if three-phase power factors at the grid side are equal to 1 under the effects of the D-CAP, then the D-CAP can suppress load imbalance.

(2) If the negative-sequence currents of the load are located in the $\triangle \mathrm{RST}$ shown in Figure 4, the D-CAP can theoretically completely compensate the reactive power and suppress load imbalance. However, the actual compensation ability is limited by its rated voltage.

(3) If the load is inductive balanced, only reactive power compensation is needed. Under the effect of the D-CAP, three-phase power factors can be corrected to 1 .

(4) If the load is slightly unbalanced, whose negative-sequence currents' amplitude is less than $1 / 4$ of the positive-sequence reactive currents' amplitude, the D-CAP can compensate the reactive power and suppress load imbalance.

(5) If the load is heavily unbalanced, whose negative-sequence currents' amplitude is greater than $1 / 4$ of the positive-sequence reactive currents' amplitude, the D-CAP can only compensate the positive-sequence reactive power and a part of the negative-sequence currents due to the rated voltage limit.

Author Contributions: X.W. and K.D. conceived this article and designed the experiments; X.W., X.C., and X.Z. developed control routine and performed the hardware experiment; and all authors wrote the paper.

Funding: This research was funded by National Natural Science Foundation of China [Multimode Resonance Mechanism and Corresponding Multifunction Active Damping Control Technique for Power Electronic Hybrid Systems] grant number [51277086].

Conflicts of Interest: The authors declare no conflict of interest.

\section{References}

1. He, Z.X.; Xu, Q.M.; Luo, A.; Xiao, H.G.; Chen, Y.D.; Jin, G.B.; Ma, F.J. Circulating current derivation and comprehensive compensation of cascaded STATCOM under asymmetrical voltage conditions. IET Gener. Transm. Distrib. 2016, 10, 2924-2932.

2. Tan, K.H.; Lin, F.J.; Chen, J.H. A three-phase four-leg inverter-based active power filter for unbalanced current compensation using a petri probabilistic fuzzy neural network. Energies 2017, 10, 2005. [CrossRef]

3. IEEE. IEEE Guide for Application of Shunt Power Capacitors, IEEE Std. 1036, 2010; IEEE: Piscataway, NJ, USA, 2010. [CrossRef] 
4. Das, S.; Chatterjee, D.; Goswami, S.K. Tuned-TSC based SVC for reactive power compensation and harmonic reduction in unbalanced distribution system. IET Gener. Transm. Distrib. 2018, 12, 571-585. [CrossRef]

5. Chatterjee, D.; Das, S.; Goswami, S. A GSA based modified SVC switching scheme for load balancing and source power factor improvement. IEEE Trans. Power Deliv. 2016, 31, 2072-2082.

6. Xu, C.; Dai, K.; Chen, X.W.; Kang, Y. Voltage droop control at point of common coupling with arm current and capacitor voltage analysis for distribution static synchronous compensator based on modular multilevel converter. IET Power Electron. 2016, 9, 1643-1653. [CrossRef]

7. Song, Q.; Liu, W. Control of a cascade STATCOM with star configuration under unbalanced conditions. IEEE Trans. Power Electron. 2009, 24, 45-58. [CrossRef]

8. Chang, W.N.; Liao, C.H. Design and implementation of a STATCOM based on a multilevel FHB converter with delta-connected configuration for unbalanced load compensation. Energies 2017, 10, 921. [CrossRef]

9. Behrouzian, E.; Bongiorno, M. Investigation of negative-sequence injection capability of cascaded H-bridge converters in star and delta configuration. IEEE Trans. Power Electron. 2016, 32, 1675-1683. [CrossRef]

10. Oghorada, O.J.K.; Zhang, L. Unbalanced and reactive load compensation using MMCC-based SATCOMs with third harmonic injection. IEEE Trans. Ind. Electron. 2019, 66, 2891-2902. [CrossRef]

11. Xu, C.; Dai, K.; Chen, X.W.; Kang, Y. Unbalanced PCC voltage regulation with positive- and negative-sequence compensation tactics for MMC-DSTATCOM. IET Power Electron. 2016, 9, 2846-2858. [CrossRef]

12. She, X.; Huang, A.Q.; Wang, G. 3-D space modulation with voltage balancing capability for a cascaded seven-level converter in a solid-state transformer. IEEE Trans. Power Electron. 2011, 26, 3778-3789. [CrossRef]

13. Zhang, Y.; Adam, G.P.; Lim, T.C. Hybrid multilevel converter: Capacitor voltage balancing limits and its extension. IEEE Trans. Ind. Inform. 2013, 9, 2063-2073. [CrossRef]

14. Wheeler, P.W.; Rodriguez, J.; Clare, J.C. Matrix converters: A technology review. IEEE Trans. Ind. Electron. 2002, 49, 276-288. [CrossRef]

15. Raghuram, M.; Avneet, K.C.; Santosh, K.S. Switched capacitor impedance matrix converter. In Proceedings of the IEEE Energy Conversion Congress and Exposition, Cincinnati, OH, USA, 1-5 October 2001; pp. 1071-1075.

16. Cheng, M.M.; Feng, K.; Isobe, T.; Shimada, R. Characteristics of the magnetic energy recovery switch as a static Var compensator technology. IET Power Electron. 2015, 8, 1329-1338. [CrossRef]

17. Wei, Y.W.; Kang, L.Y.; Huang, Z.Z.; Li, Z.; Cheng, M.M. A magnetic energy recovery switch based terminal voltage regulator for the three-phase self-excited induction generators in renewable energy systems. J. Power Electron. 2015, 15, 1305-1317. [CrossRef]

18. Wei, Y.W.; Fang, B.; Kang, L.Y.; Huang, Z.Z.; Liu, T.G. Parallel-connected magnetic energy recovery switch used as a continuous reactive power controller. J. Power Electron. 2016, 16, 1494-1503. [CrossRef]

19. Chen, R.R.; Liu, Y.T.; Peng, F.Z. A solid state variable capacitor with minimum capacitor. IEEE Trans. Power Electron. 2017, 32, 5035-5044. [CrossRef]

20. Liu, Y.T.; Wang, X.R.; Peng, F.Z. An H-bridge-based single-phase VAr generator with minimum dc capacitance. IEEE J. Emerg. Sel. Top. Power Electron. 2018, 6, 2001-2014. [CrossRef]

21. Prasai, A.; Sastry, J.; Divan, D.M. Dynamic capacitor (D-CAP): An integrated approach to reactive and harmonic compensation. IEEE Trans. Ind. Appl. 2010, 46, 2518-2525. [CrossRef]

22. Prasai, A.; Divan, D.M. Control of dynamic capacitor. IEEE Trans. Ind. Appl. 2011, 47, 161-168. [CrossRef]

23. Liu, Q.; Deng, Y.; He, X. Boost-Type inverter-less shunt active power filter for VAR and harmonic compensation. IET Power Electron. 2013, 6, 535-542. [CrossRef]

24. Dijkhuizen, F.; Gödde, M. Dynamic capacitor for HV applications. In Proceedings of the IEEE Energy Conversion Congress and Exposition, Atlanta, GA, USA, 12-16 September 2010; pp. 1511-1518.

25. Chen, X.; Dai, K.; Xu, C. Reactive power compensation with improvement of current waveform quality for single-phase buck-type dynamic capacitor. In Proceedings of the IEEE Applied Power Electronics Conference and Exposition (APEC), Long Beach, CA, USA, 20-24 March 2016; pp. 1358-1363.

26. Xiong, L.L.; Dai, K.; Chen, X.; Wang, X.S.; Dai, Z.W. Reactive power compensation and resonance damping for three-phase buck-type dynamic capacitor. In Proceedings of the IEEE Applied Power Electronics Conference and Exposition (APEC), San Antonio, TX, USA, 4-8 March 2018; pp. 1473-1478.

27. Pana, A.; Baloi, A.; Molnar-Matei, F. Load balancing by unbalanced capacitive shunt compensation-A numerical approach. In Proceedings of the 14th International Conference on Harmonics and Quality of Power-ICHQP, Bergamo, Italy, 26-29 September 2010; pp. 1-6. 
28. Wang, X.S.; Dai, K.; Chen, X.; Tan, T.; Dai, Z.W. Optimal compensation of delta-connected dynamic capacitor for unbalanced load. In Proceedings of the 2018 IEEE International Power Electronics and Application Conference and Exposition (PEAC), Shenzhen, China, 4-7 November 2018; pp. 1-6.

29. Xu, C.; Dai, K.; Chen, X.W.; Peng, L.; Zhang, Y.X. Parallel resonance detection and selective compensation control for SAPF with square-wave current active injection. IEEE Trans. Ind. Electron. 2017, 64, 8066-8078. [CrossRef]

30. Anish, P. Direct Dynamic Control of Impedance for VAR and Harmonic Compensation. Ph.D. Thesis, Georgia Institute of Technology, Atlanta, Georgia, 2011.

(C) 2019 by the authors. Licensee MDPI, Basel, Switzerland. This article is an open access article distributed under the terms and conditions of the Creative Commons Attribution (CC BY) license (http://creativecommons.org/licenses/by/4.0/). 
Article

\title{
Power Quality Services Provided by Virtually Synchronous FACTS
}

\author{
Andres Tarraso ${ }^{1}$, Ngoc-Bao Lai ${ }^{2}$, Gregory N. Baltas ${ }^{2}$ and Pedro Rodriguez ${ }^{1,2, *}$ \\ 1 Center on Renewable Electrical Energy Systems, Technical University of Catalonia, 08222 Barcelona, Spain \\ 2 LOYOLATECH, Loyola University Andalucia, 41014 Sevilla, Spain \\ * Correspondence: prodriguez@uloyola.es
}

Received: 4 July 2019; Accepted: 26 August 2019; Published: 27 August 2019

\begin{abstract}
The variable and unpredictable behavior of renewable energies impacts the performance of power systems negatively, threatening their stability and hindering their efficient operation. Flexible ac transmission systems (FACTS) devices are able to emulate the connection of parallel and series impedances in the transmission system, which improves the regulation of power systems with a high share of renewables, avoiding congestions, enhancing their response in front of contingencies and, in summary, increasing their utilization and reliability. Proper control of voltage and current under distorted and unbalanced transient grid conditions is one of the most critical issues in the control of FACTS devices to emulate such apparent impedances. This paper describes how the synchronous power controller (SPC) can be used to implement virtually synchronous FACTS. It presents the SPC functionalities, emphasizing in particular the importance of virtual admittance emulation by FACTS devices in order to control transient unbalanced currents during faults and attenuate harmonics. Finally, the results demonstrate the effectiveness of SPC-based FACTS devices in improving power quality of electrical networks. This is a result of their contribution to voltage balancing at point of connection during asymmetrical faults and the improvement of grid voltage quality by controlling harmonics flow.
\end{abstract}

Keywords: FACTS; virtual synchronous machine; synchronous power controller; power quality; harmonics

\section{Introduction}

The continuously increasing penetration of renewable energies (REN), particularly wind and PV generation, is gradually reducing the conventional synchronous generation share from the energy mix. As a result, the overall power system performance degrades, since REN plants do not perform as conventional synchronous generation in terms of regulation and grid support [1]. Hence, the grid codes require modern REN plants to integrate certain grid-interactive functionalities in order to make their response compatible with the natural behavior of the electrical grid in case of grid events [2,3]. In this regard, the power converters used in modern REN plants need additional functionalities, specifically, to provide voltage and frequency support during faults by remaining connected to the grid, known as low-voltage ride-through (LVRT), and to inject instantaneous reactive power. Even so, these functionalities improve the interaction of REN power plants with the electrical grid only at the point of common coupling (PCC). Therefore, other mechanisms are necessary for improving power system performance in the area level. These mechanisms should address issues related to congestion, contingencies, oscillations, inefficiencies and instabilities resulting from the inherent intermittence and lack of inertia of REN power plants. In this regard, flexible ac transmission systems (FACTS) have demonstrated to be an effective approach that enhances controllability and increases utilization of power systems. 


\section{FACTS Based on Virtually Synchronous Power Converters}

The FACTS concept was introduced in the late 1980s [4] and since then the relevant technologies have experienced significant advancements, both in hardware components and control methods. FACTS and High-voltage dc (HVDC) systems possess fundamental differences with respect to their operating principle. However, both are presented together as active solutions based on high-power electronics to enhance regulation and flexibility of transmission systems, and thereby to increase the capacity of power systems [5].

Depending on their configuration and application, different types of FATCS devices are described in the literature [6-8]. In general, they can be classified into two main categories, namely, series-connected and shunt-connected FACTS devices. The series-connected FACTS are installed between two buses of the power system by connecting them in series with a transmission line. Therefore, by regulating the voltage provided through the series-connected FACTS, it is possible to modify the apparent impedance of the power line; in other words, to increase/reduce its capacity and to regulate the power flow in the system. Moreover, proper control of the output voltage from the series-connected FACTS allows the improvement of the systems response against voltage distortions or sudden events, such as grid faults. The thyristor controlled series capacitor (TCSC) [9], the static synchronous series compensator (SSSC) [10], the dynamic voltage restorer (DVR) [11], and the fault current limiter (FCL) [12], among others, can be mentioned as the most popular series-connected FACTS. The shunt-connected FACTS are usually implemented through power converters that are able to control the current injected into a given bus of the system. Through appropriate controllers, the current injected in the grid can be formed by positive- and negative-sequence components at the fundamental frequency as well as harmonic components. This not only makes possible to control the magnitude of the voltage at the bus where the shunt-connected FACTS is connected, but also to compensate for unbalances and distortion. Commonly used shunt-connected FACTS devices are the static synchronous compensator (STATCOM) [13], the static var compensator (SVC) [14], the thyristor controlled reactor (TCR) [15], the thyristor switched capacitor [16], and the shunt active filter (SAF) [17]. The combination of series- and shunt-connected FACTS gives rise to cost-effective devices, which combine features from both FACTS categories. The unified power flow controller (UPFC) [18], the convertible static compensator (CSC) [19] and the unified power quality conditioner (UPQC) [20] are examples of such hybrid FACTS devices.

The majority of existing shunt-connected FACTS devices are based on detecting characteristic parameters of the grid voltage, i.e., amplitude, frequency and phase-angle, and, accordingly, to inject an appropriate current for emulating a given shunt-connected impedance. Series-connected FATCS follow the same rational where the power converter imposes a given voltage in series with the line to emulate a series-connected impedance. Nevertheless, in both cases a synchronization system, such as the well-known phase-locked loop (PLL) [21], is used to detect the grid voltage parameters. However, the conventional PLL does not perform properly under unbalanced and distorted conditions. This necessitates the use of other sophisticated implementations that can accurately detect the grid components even during these demanding operating conditions [22]. Note that the PLL is a non-linear system with a particular dynamic response, which strongly affects the grid-connected power converters response. This is particularly significant during grid faults and transients that can even give rise to hazardous interactions with other controllers in the grid.

For this reason, a new approach to design power converters controllers was proposed around one decade ago. Specifically, this approach demands the equations that define the operation of a synchronous machine to be integrated in the power converter controller [23]. It is worth mentioning that a synchronous machine can synchronize with the electrical grid or even regulate its operation without using a PLL. Recently, the aforementioned approach has materialized in several implementations. For instance, the synchronous power controller (SPC) [24] that has exhibited good performance in both HVDC $[25,26]$ and FACTS systems $[27,28]$ under generic operating conditions.

In this paper, we present the SPC operating principle and set of equations. Special attention is given to the configuration of its virtual output admittance to improve the power quality of the 
electrical grid when it is affected by harmonics and transient balance and unbalanced faults. Finally, we demonstrate the effectiveness of the SPC when used within the power converter controller of a shunt-connected FACTS device through validation by both simulations and experiments.

\section{Synchronous Power Controller}

The SPC has been widely used to enable electronics power converter to behave as a synchronous machine [29-32], being an interesting control solution to implement virtually synchronous FACTS. In contrast to PLL-based conventional control schemes, the SPC relies on a power balancing mechanism to maintain its synchronism with the electrical grid. As illustrated in Figure 1, where a generic dc source has been connected at the power converter dc-bus, the SPC consists of a power controller, a virtual admittance emulator, and a current controller. For the stable operation of the power converter, the parameters of these control blocks should be tuned properly. Due to the fact that these control loops have different bandwidth, they can be separately tuned to meet stability requirements as well as to conform to grid codes. Practically, the current control loop, the virtual admittance loop and the power control loop have very different bandwidth and settling time; therefore, they are decoupled and can be tuned separately.

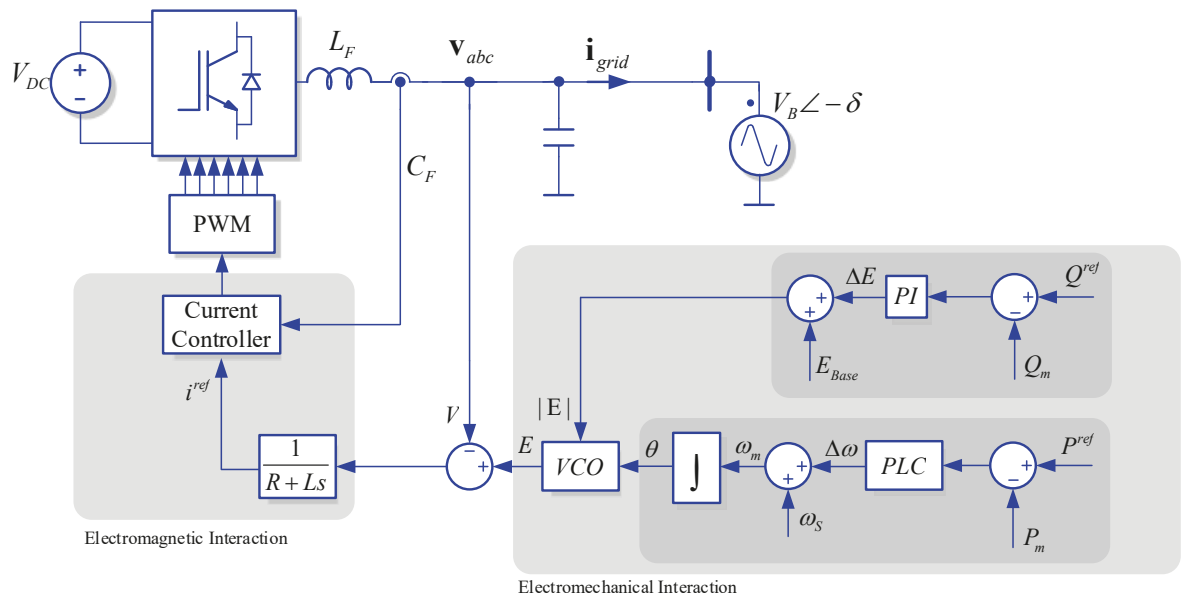

Figure 1. Block diagram of a synchronous power controller (SPC)-based flexible ac transmission systems (FACTS) power converter.

The current controller is the most inner loop of the SPC. The main requirements for this controller are to track the current reference generated by the virtual admittance block and to tolerate the inherently resonant characteristic of the LCL filter. To properly tune the current controller, the LCL filter is modeled on the stationary reference frame as follows:

$$
\left[\begin{array}{c}
\dot{i}_{c}(t) \\
\dot{v}_{f}(t) \\
\dot{i}_{g}(t)
\end{array}\right]=\left[\begin{array}{ccc}
-\frac{R_{c}}{L_{\kappa_{c}}} & -\frac{1}{L_{c}} & 0 \\
\frac{1}{C_{f}}-\frac{R_{c} R_{f}}{L_{c}} & -\frac{R_{f}}{L_{g}+L_{t h}}-\frac{R_{f}}{L_{c}} & R_{f} \frac{R_{g}+R_{t h}}{L_{g}+L_{h t}}-\frac{1}{C_{f}} \\
0 & \frac{1}{L_{g}+L_{t h}} & -\frac{R_{g}+R_{t h}}{L_{g}+L_{t h}}
\end{array}\right]\left[\begin{array}{c}
i_{c}(t) \\
v_{f}(t) \\
i_{g}(t)
\end{array}\right]+\left[\begin{array}{c}
\frac{1}{L_{c}} \\
R_{f} \\
\frac{L_{c}}{0} \\
0
\end{array}\right] v_{c}(t)+\left[\begin{array}{c}
0 \\
\frac{R_{f}}{L_{g}+L_{t h}} \\
-\frac{1}{L_{g}+L_{t h}}
\end{array}\right] v_{t h}(t)
$$

where $i_{c}, v_{f}$ and $i_{g}$ denote converter-side current, capacitor voltage and grid-side current, respectively, $R_{c}, R_{f}$ and $R_{g}$ represent filter resistances, $L_{c}$ and $L_{g}$ represent filter inductances, and $R_{t h}, L_{t h}$ and $v_{t h}$ are 
the grid equivalent parameters which can be calculated from the grid short-circuit ratio (SCR) and the quality factor $(q=X / R)$ ratio as:

$$
R_{t h}=\frac{V^{2}}{S C R \cdot P_{n} \sqrt{1+q^{2}}} \text { and } L_{t h}=\frac{V^{2} q}{S C R \cdot P_{n} \cdot \omega_{g} \sqrt{1+q^{2}}}
$$

The LCL filter model can be concisely expressed as:

$$
\begin{gathered}
\dot{\mathbf{x}}_{l c l c}(t)=\mathbf{A}_{l c l c} \mathbf{x}_{l c l c}(t)+\mathbf{B}_{l c l c} u(t)+\mathbf{G}_{l c l c} w(t) \\
y_{l c l}(t)=\mathbf{C}_{l c l} \mathbf{x}_{l c l c}(t)
\end{gathered}
$$

where $\mathbf{C}_{l c l}=\left[\begin{array}{lll}0 & 0 & 1\end{array}\right]$ is the output matrix.

Taking into account the digital implementation of the current controller, the filter model is discretized as:

$$
\begin{gathered}
\mathbf{x}_{l c l}(k+1)=\mathbf{A}_{l c l} \mathbf{x}_{l c l}(k)+\mathbf{B}_{l c l} u(k)+\mathbf{G}_{l c l} w(k) \\
y_{l c l}(k)=\mathbf{C}_{l c l} \mathbf{x}_{l c l}(k)
\end{gathered}
$$

The delay originated by the digital implementation can also be considered in the controller design by the dummy variable $x_{d}$ as follows:

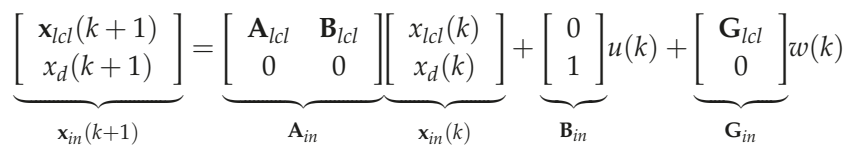

$$
\begin{aligned}
& y_{\text {in }}(k)=\underbrace{\left[\begin{array}{cc}
C_{l c l} & 0
\end{array}\right]}_{C_{\text {in }}} \underbrace{\left[\begin{array}{c}
x_{l c l}(k) \\
x_{d}(k)
\end{array}\right]}_{x_{i n}(k)}
\end{aligned}
$$

To asymptotically track the reference current, the internal model principle is employed to model a proportional resonant $(\mathrm{PR})$ as:

$$
\dot{\mathbf{x}}_{p r c}(t)=\underbrace{\left[\begin{array}{cc}
0 & 1 \\
-\omega_{g}^{2} & 0
\end{array}\right]}_{\mathbf{A}_{p r c}} \mathbf{x}_{p r c}(t)+\underbrace{\left[\begin{array}{l}
1 \\
0
\end{array}\right]}_{\mathbf{B}_{p r c}} e_{i}(t)
$$

where $w_{g}$ denotes fundamental grid frequency, and $e_{i}=i^{*}-i_{g}$ represents tracking error with $i^{*}$ being reference current. The controller model can also be discretized as:

$$
\mathbf{x}_{p r}(k+1)=\mathbf{A}_{p r} \mathbf{x}_{p r}(k)+\mathbf{B}_{p r} e_{i}(k)
$$

The inverter model and the current controller model can be augmented as:

$$
\left[\begin{array}{c}
x_{i n}(k+1) \\
\mathbf{x}_{p r}(k+1)
\end{array}\right]=\left[\begin{array}{cc}
\mathbf{A}_{i n} & 0 \\
-\mathbf{B}_{p r} \mathbf{C} & \mathbf{A}
\end{array}\right]\left[\begin{array}{c}
x_{i n}(k) \\
\mathbf{x}_{p r}(k)
\end{array}\right]+\left[\begin{array}{c}
\mathbf{B}_{i n} \\
0
\end{array}\right] u(k)+\left[\begin{array}{c}
\mathbf{B}_{d} \\
0
\end{array}\right] w(k)+\left[\begin{array}{c}
0 \\
\mathbf{B}_{p r}
\end{array}\right] r(k)
$$

or:

$$
\mathbf{x}(k+1)=\mathbf{A x}(k)+\mathbf{B} u(k)+\mathbf{B}_{d} w(k)+\mathbf{B}_{r} r(k)
$$


Asymptotic tracking of current controller can be achieved by stabilizing the augmented system in (12) using the following feedback controller:

$$
u(k)=\mathbf{K} \mathbf{x}(k)
$$
function:

The feedback controller can be optimally calculated by minimizing the following quadratic cost

$$
J_{\infty}=\sum_{k=0}^{\infty}\left\{\mathbf{x}^{T}(k) \mathbf{Q} \mathbf{x}(k)+u^{T}(k) R u(k)\right\}
$$

where $\mathbf{Q}$ and $R$ are tunable parameters to adjust performance of the current controller. It is worth noting that the choice of $\mathbf{Q}$ and $R$ is based on the relative importance of system states and control signals, which is not always a straightforward process. To simplify the selection of $\mathbf{Q}$ and $R$, one may select $\mathbf{R}$ as an identity matrix i.e., $R=1$ and $\mathbf{Q}$ as $\mathbf{Q}=\rho \mathbf{I}$. Then, $\rho$ can be altered to achieve a desired response. For instance, the higher the value of $\rho$, the faster the transient response and smaller the stability margin.

The virtual impedance shown in Figure 2 is usually chosen according to voltage support requirement by the grid codes. The state space equation for the virtual impedance can be given as:

$$
\ddot{i}_{g}^{*}(t)=-\frac{R_{v}}{L_{v}} i_{g}^{*}(t)+\frac{1}{L_{v}} e(t)-\frac{1}{L_{v}} v_{g}(t)
$$

where $R_{v}$ is the virtual resistance, $L_{v}$ is the virtual inductance, $i_{g}^{*}$ is the reference current for current controller, and $e$ is the reference voltage coming from power control loop.

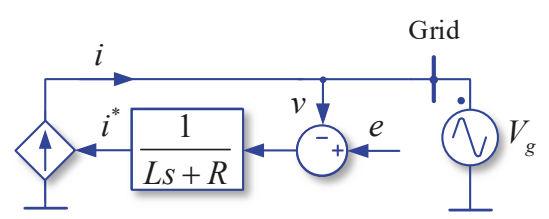

Figure 2. Simplified model of a current-controlled grid-connected power converter with virtual admittance.

The power controllers consisting of an active power and a reactive power controller are the main elements of the SPC scheme. The active power controller is based on the electromechanical swing equation to synchronize the power converter with the electrical grid. The transfer function of swing equation is given by:

$$
\omega_{s p c}=\frac{1}{\omega_{s}(J s+D)}\left(P_{m}-P_{e}\right)+\omega_{s}
$$

where $P_{m}$ and $P_{e}$ are the mechanical and the electrical power, respectively, $\omega_{s p c}$ and $\omega_{s}$ are the SPC and synchronous angular speed, respectively, $J$ is the virtual polar moment of inertia and $D$ is the damping factor.

The reactive power controller is based on a proportional integral (PI) controller defined as follows:

$$
E=\frac{k_{p} s+k_{i}}{s}\left(Q_{m}-Q_{e}\right)+E_{r}
$$

where $E$ is the amplitude reference for the virtual electromotive force (emf) voltage of the virtually synchronous FACTS, $E_{r}$ is a feed-forward reference for such emf voltage and $k_{p}$ and $k_{i}$ are the proportional and the integral gains of the controller. 
To simplify the analysis of the power controller loop, the dynamics of inner control loop are neglected and replaced by static gains. To calculate these gains, the powers exchanged between the SPC-based virtually synchronous FACTS and the electrical grid can be written as:

$$
\begin{aligned}
& P_{e}=\frac{E V}{Z} \cos (\phi-\delta)-\frac{V^{2}}{Z} \cos (\phi) \\
& Q_{e}=\frac{E V}{Z} \sin (\phi-\delta)-\frac{V^{2}}{Z} \sin (\phi)
\end{aligned}
$$

where $Z=\sqrt{R_{v}^{2}+X_{v}^{2}}$ is the magnitude of the virtual impedance, $\phi$ is the phase-angle of such an impedance, $V$ denotes the rms value of the grid line voltage, $E$ the rms value of the virtual emf and $\delta$ is the grid load angle, i.e., the angle between $E$ and $V$ phasors.

The above equations can be rewritten for small-signal analysis as:

$$
\begin{aligned}
& P_{e 0}+\Delta P_{e}=\frac{\left(E_{0}+\Delta E\right) V}{Z}\left(\cos \phi \cos \left(\delta_{0}+\Delta \delta\right)+\sin \phi \sin \left(\delta_{0}+\Delta \delta\right)\right)-\frac{V^{2}}{Z} \cos (\phi) \\
& Q_{e 0}+\Delta Q_{e}=\frac{\left(E_{0}+\Delta E\right) V}{Z}\left(\sin \phi \cos \left(\delta_{0}+\Delta \delta\right)-\cos \phi \sin \left(\delta_{0}+\Delta \delta\right)\right)-\frac{V^{2}}{Z} \sin (\phi)
\end{aligned}
$$

In steady-state, when synchronism takes place, $\delta_{0}=0$, and also $\Delta \delta \approx 0$, then $\cos (\Delta \delta) \approx 1$ and $\sin (\Delta \delta) \approx \Delta \delta$. Therefore:

$$
\begin{gathered}
P_{e 0}+\Delta P_{e}=\frac{E_{0} V \cos (\phi)}{Z}-\frac{V^{2} \cos (\phi)}{Z}+\frac{E_{0} V \sin (\phi)}{Z} \Delta \delta+\frac{V \cos (\phi)}{Z} \Delta E+\frac{V \sin (\phi)}{Z} \Delta E \Delta \delta \\
Q_{e}+\Delta Q_{e}=\frac{E_{0} V \sin (\phi)}{Z}-\frac{V^{2} \sin (\phi)}{Z}-\frac{E_{0} V \cos (\phi)}{Z} \Delta \delta+\frac{V \sin (\phi)}{Z} \Delta E-\frac{V \cos (\phi)}{Z} \Delta E \Delta \delta
\end{gathered}
$$

Omitting the zero- and second-order terms, the small-signal component of the electrical power can be written as:

$$
\begin{gathered}
\Delta P_{e}=\frac{E_{0} V \sin (\phi)}{Z} \Delta \delta+\frac{V \cos (\phi)}{Z} \Delta E \\
\Delta Q_{e}=-\frac{E_{0} V \cos (\phi)}{Z} \Delta \delta+\frac{V \sin (\phi)}{Z} \Delta E
\end{gathered}
$$

From Equations (16), (17), (24) and (25), the state-space representation of the power control loop is given by:

$$
\begin{gathered}
{\left[\begin{array}{c}
\Delta \dot{\omega}_{s p c} \\
\Delta \dot{\delta} \\
\Delta \dot{Q}_{e}
\end{array}\right]=\left[\begin{array}{ccc}
-\frac{D}{J} & \frac{k_{p} k_{p 2} k_{q 1}-k_{p} k_{p 1} k_{q 2}-k_{p 1}}{\left(p_{p} k_{q 2}+1\right) \omega_{g}} & \frac{k_{i} k_{p} k_{p 2} k_{q 2} k_{i} k_{p} k_{q 2}-k_{i}}{\left(k_{p} k_{q 2}+1\right) \omega_{g}} \\
1 & 0 & 0 \\
0 & -\frac{k_{q 1}}{k_{p} k_{q 2}+1} & -\frac{k_{i} k_{q 2}}{k_{p} k_{q 2}+1}
\end{array}\right]\left[\begin{array}{c}
\Delta \omega_{s p c} \\
\Delta \delta \\
\Delta Q_{e}
\end{array}\right]+\left[\begin{array}{cc}
\frac{1}{\omega_{g}} & -\frac{k_{p} k_{p 2}}{\left(k_{p} k_{q 2}+1\right) \omega_{g}} \\
0 & 0 \\
0 & 1-\frac{k_{p} k_{p 2}}{k_{p} k_{q 2}+1}
\end{array}\right]\left[\begin{array}{c}
\Delta P_{m} \\
\Delta Q_{m}
\end{array}\right]} \\
{\left[\begin{array}{c}
\Delta P_{e} \\
\Delta Q_{e}
\end{array}\right]=\left[\begin{array}{ccc}
0 & k_{p 1}-\frac{k_{p} k_{p p} k_{q 1}}{k_{p} k_{2 q}+1} & k_{i}-\frac{k_{i} k_{p} k_{p 2} k_{q 2}}{k_{p} k_{q 2}+1} \\
0 & \frac{k_{q 1}}{k_{p} k_{q 2}+1} & \frac{k_{i} k_{q 2}}{k_{p} k_{q 2}+1}
\end{array}\right]\left[\begin{array}{c}
\Delta \omega_{s p c} \\
\Delta \delta \\
\Delta Q_{e}
\end{array}\right]+\left[\begin{array}{cc}
0 & \frac{k_{p} k_{p 2}}{k_{p} k_{p 2}+1} \\
0 & \frac{k_{p} k_{q 2}}{k_{p} k_{q 2}+1}
\end{array}\right]\left[\begin{array}{c}
\Delta P_{m} \\
\Delta Q_{m}
\end{array}\right]}
\end{gathered}
$$

where $k_{p 1}=\frac{E_{0} V \sin (\phi)}{Z}, k_{p 2}=\frac{V \cos (\phi)}{Z}, k_{q 1}=\frac{E_{0} V \cos (\phi)}{Z}, k_{q 2}=\frac{V \sin (\phi)}{Z}$, and $\delta$ is the grid load angle, as previously defined.

Due to the fact that the three control loops have very different bandwidths, their dynamics are nearly decoupled. Thus, these control loops can be designed separately. The stability of the current control loop can be ensured by choosing a proper value of $\rho$. Since the current control loop is stable, the voltage control loop is also stable, as the virtual admittance is in a form of a low-pass filter. The same analogy is applied to the power control loop. 
Even though the dc-bus voltage level of SPC-based FACTS is naturally regulated thanks to the inherent power balance-based principle of the SPC controller, the dc-bus voltage level might experience dramatic changes due to unexpected events, such as line trips. To prevent the dc-bus voltage of SPC-based FACTS from surpassing safe operational limits, the control loop shown in Figure 3 is added to the SPC schema already shown in Figure 1. This protection loop has two PI controllers devoted to directly change the phase-angle of the virtual emf of the SPC, and thereby its output power, to keep the dc-bus voltage level within given limits. In this way, the protection range for the dc-bus voltage can be adjusted by just setting the $v_{\lim }{ }^{\min }$ and $v_{\lim }{ }^{\max }$ parameters. In addition, a saturation block is added at the output of each PI controller to ensure the protection loop only acts in case the dc-bus voltage level is out of the safe operational range, and to limit the maximum power reference in case of activation. This control loop has a very fast response, since it directly changes the phase-angle of the virtual emf, being its dynamics set by the parameter $k_{\text {phase }}$.

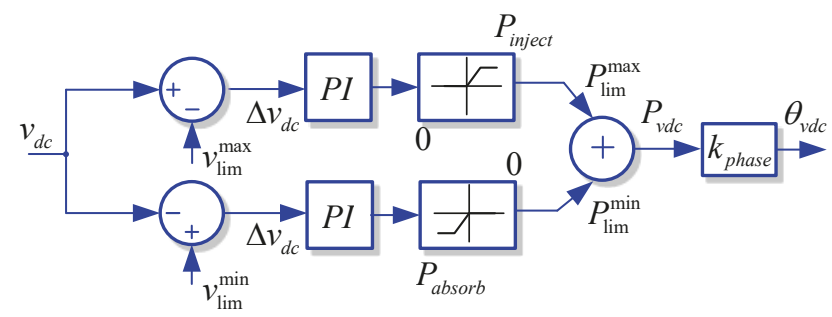

Figure 3. Proportional integral (PI) strategy for dc voltage protection.

\section{Simulation Results}

The setup structure for the simulation results is presented in Figure 4. It is composed by a $100 \mathrm{kVA}$ power converter, a harmonic load and a voltage sag generator. The devices will be connected and disconnected from the PCC during the different simulation tests. In a first simulation case, voltage support results under balanced and unbalanced voltage dips will be presented, where the harmonic load is not connected to the PCC, thus not generating any harmonic disturbances in the grid voltage. In a second simulation case, the voltage sag generator will be disconnected from the system, and the harmonic load will be connected. This load will consume harmonic current which will distort the grid voltage.

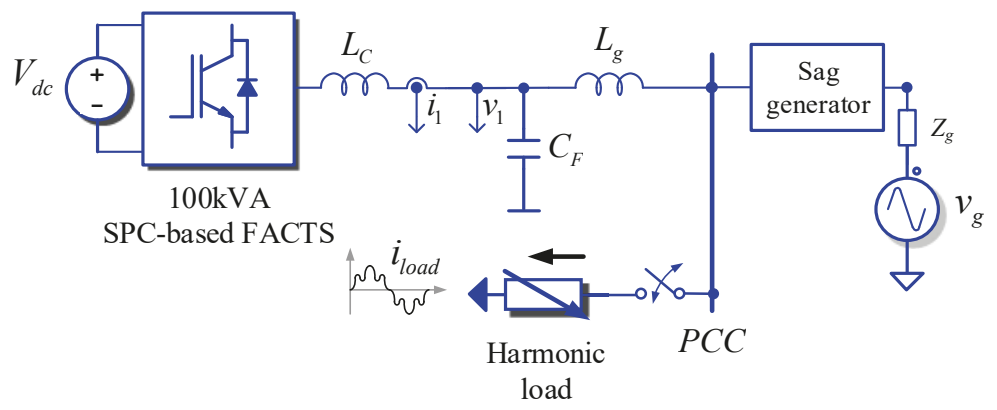

Figure 4. Simulation results setup. PCC: point of common coupling.

The parameters of the $100 \mathrm{kVA}$ power converter and the grid connection are presented in Table 1, which specifies the inductance parameters of the grid and the voltage sag generator. 
Table 1. Of the SPC-based FACTS power converter, the voltage sag generator and the grid.

\begin{tabular}{cc}
\hline \multicolumn{2}{c}{ Inverter Parameters } \\
\hline Total output power & $100 \mathrm{kVA}$ \\
\hline Filter Parameters & \\
Converter Inductor & $777 \mu \mathrm{H}$ \\
Grid Inductor & $294 \mu \mathrm{H}$ \\
Damping resistor & $0.5 \mathrm{ohm}$ \\
Capacitor & $66 \mu \mathrm{F}$ \\
Voltage sag Gen. Inductance & $400 \mu \mathrm{H}$ \\
\hline Grid Parameters \\
Grid Inductor & $400 \mathrm{Uh}$ \\
Grid Resistor & $0.152 \mathrm{ohm}$ \\
\hline
\end{tabular}

In the upcoming subsections, the balanced and unbalanced low voltage ride through (LVRT) simulation results are presented, as well as the harmonic compensation results during harmonic distortions at the grid voltage.

\subsection{Balanced LVRT}

To simulate the performance of an actual voltage sag generator, which is composed by inductors and contactors changing their connection, the voltage sag has two voltage steps during the connection and disconnection of contactors. Figure 5 presents the voltage dip generated at the PCC of the SPC-based FACTS connected to the grid. On the left side, Figure 5a presents the voltage dip at the PCC without the interaction of the SPC-based FACTS. It is possible to see how the voltage drops to zero at the PCC when the SPC-based FACTS does not support the grid voltage. On the right side, Figure 5b presents the voltage dip at the PCC when the SPC-based FACTS interacts with the electrical grid by injecting reactive currents during the voltage disturbance. In this case, once the voltage dip is detected by the control system, the power converter starts injecting reactive currents thanks to the effect of the virtual admittance controller. This allows the power converter to support the grid voltage during voltage sags. The third plot in Figure $5 \mathrm{~b}$ shows the injected current in the synchronous reference frame, evidencing the injection of reactive current $i_{q}$ during the voltage sag. Once the grid fault is released, the power converter stops injecting reactive current to the grid, and returns to the steady state operation set-point.

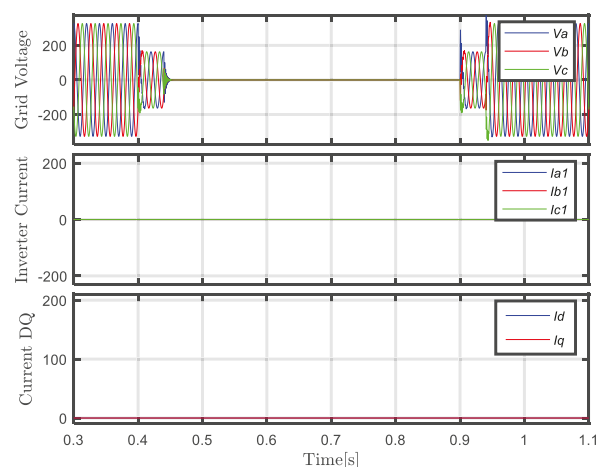

(a)

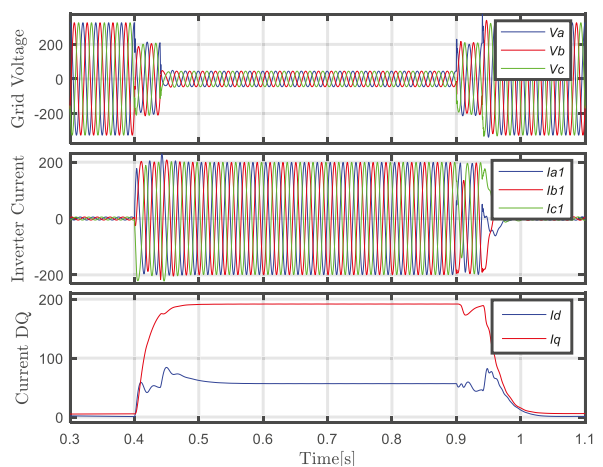

(b)

Figure 5. Balanced low-voltage ride-through (LVRT) test. Voltage sag to $0 \%$ of the voltage (a) LVRT without SPC-based FACTS compensation. (b) LVRT with the compensating current injected by the SPC-based FACTS. 


\subsection{Unbalanced LVRT}

The unbalanced voltage sag is one of the most common voltage disturbances affecting the grid voltage, as it appears when one or two phases of the grid are faulted. This perturbation generates negative-sequence voltages along the grid, which can be observed as unbalanced voltages at the PCC. Figure 6 presents an unbalanced voltage dip at the PCC. On the left, Figure 6 a presents the PCC voltage when the SPC-based FACTS does not provide any support to the grid voltage. In this case, the negative-sequence component of the gird voltage reached $70 \mathrm{~V}$. Figure $6 \mathrm{~b}$ displays the PCC voltage when the SPC-based FACTS supports the grid voltage in front of unbalances. In this case, the SPC-based FACTS injects negative-sequence currents to keep the grid voltage balanced. Comparing Figure 6a and Figure $6 \mathrm{~b}$, it is possible to appreciate that there is a significant reduction of the negative-sequence component of the grid voltage, which is reflected in reducing the imbalance degree among phases at the PCC.

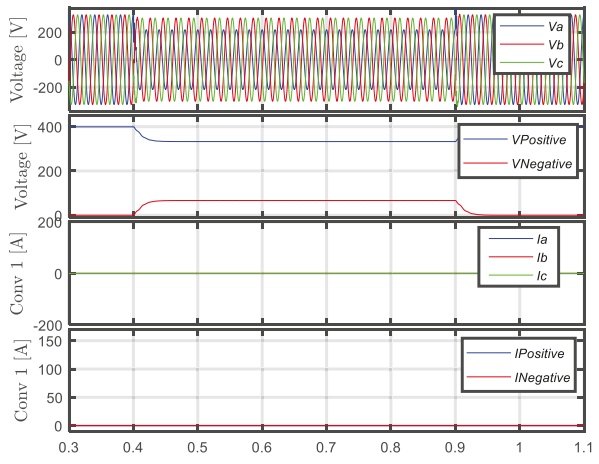

(a)

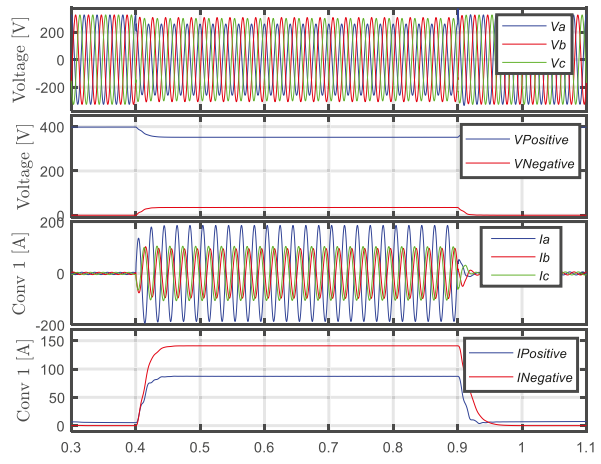

(b)

Figure 6. Unbalanced LVRT test. (a) LVRT without SPC-based FACTS. (b) LVRT with the compensating current injected by the SPC-based FACTS.

\subsection{Harmonic Compensation}

Harmonics can be generated by a large amount of systems, commonly the ones using power converters to process power. Systems such as diode rectifiers, charging systems or even computers produce harmonics that flow through the grid and distort the grid voltage. In addition to hazardous grid resonances, such distorted voltages can damage to the equipment connected to the grid. By enabling several parallel virtual admittances in a SPC-based FACTS, it is possible to control harmonics flow and to minimize their impact on the grid. Figure 7 presents the PCC voltage resulting from the connection of a harmonic load to the grid, and the effect of the SPC-based FACTS in conditioning such a voltage. Figure 7a displays the PCC voltage waveform resulted from the connection of a harmonic load. The amplitude for the 5th and the 7th voltage harmonic arises to $14 \mathrm{~V}$ and $16 \mathrm{~V}$, respectively. Once the harmonic admittances of the SPC-based FACTS are enabled, the power converter starts injecting compensating currents. Figure $7 \mathrm{~b}$, shows the compensating currents injected by the SPC-based FACTS and how they dramatically reduce the grid voltage distortion. A comparison between Figure 7a and Figure $7 \mathrm{~b}$ shows the significant reduction of 5 th and 7 th harmonic components of the grid voltage.

The simulation results shown in this section have demonstrated how SPC-based FACTS can improve the power quality of the electrical grid in front of voltage transients and distortions. In the following section, some experimental results are presented to validate such simulation results. In this manner, the same tests shown in simulation are now conducted in the lab by using real equipment. 

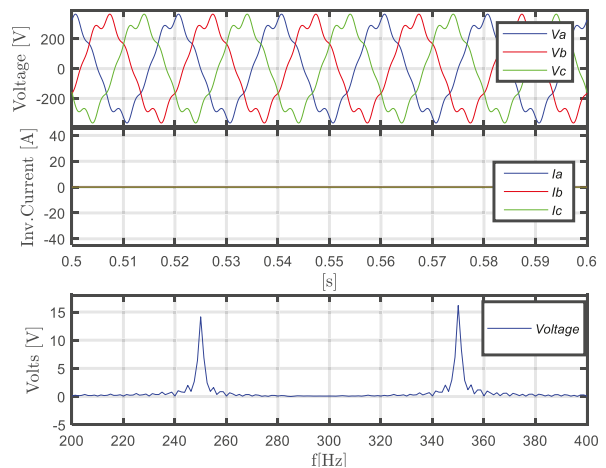

(a)

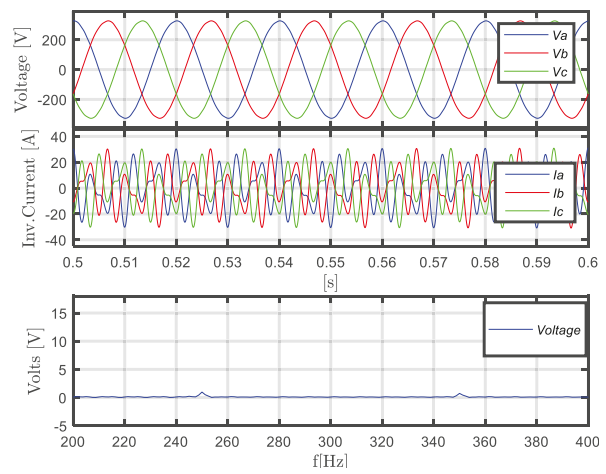

(b)

Figure 7. Harmonic control simulation result. (a) Harmonic load without SPC-based FACTS compensation. (b) Harmonic load with SPC-based FACTS injecting harmonic current to the PCC.

\section{Experimental Results}

The experimental setup used for obtaining experimental results consists of two $100 \mathrm{kVA}$ power converters connected to the PCC, a dc-voltage generator, a voltage sag generator and a harmonic load to absorb harmonic currents from the grid, as shown in Figure 8.
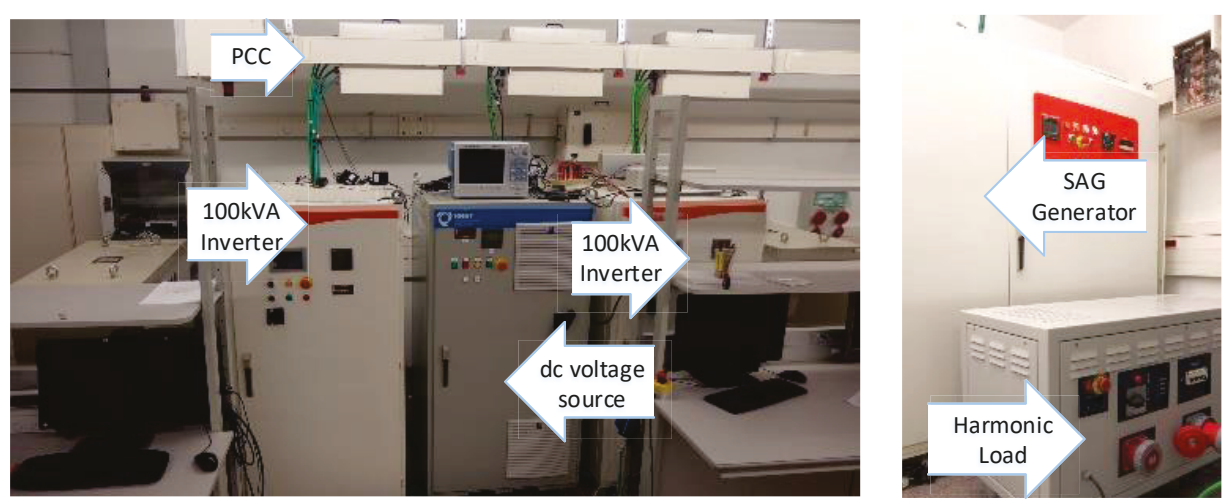

Figure 8. Experimental setup.

By following the sequence as in simulations, the first test to be conducted will deal with the grid support provided by the SPC-based FACTS when a balanced voltage sags happens in the grid, i.e., when the three phases of the grid are affected equally by the voltage sag. In a second test, the response of the SPC-based FACTS in front of unbalanced voltage sags will be shown. After that, the impact of the SPC-based FACTS when conditioning a distorted grid voltage due to harmonic currents will be evaluated experimentally. These test will show how the SPC-based FACTS perfectly withstand voltage transients and distortions, inject reactive currents and harmonics to improve the quality of the voltage waveform.

\subsection{Balance LVRT}

In this experiment, voltage sags are generated through a voltage sag generator, which consists of several inductances and tap switches to generate different voltage levels at the PCC. In the case of a 
balanced voltage sag, the three phases decease the voltage amplitude to a certain value during the sag time. In this experiment, the SPC-based FACTS will inject reactive current to restore the voltage level at the PCC. Figure 9 presents the scheme of the experimental setup used for this experiment.

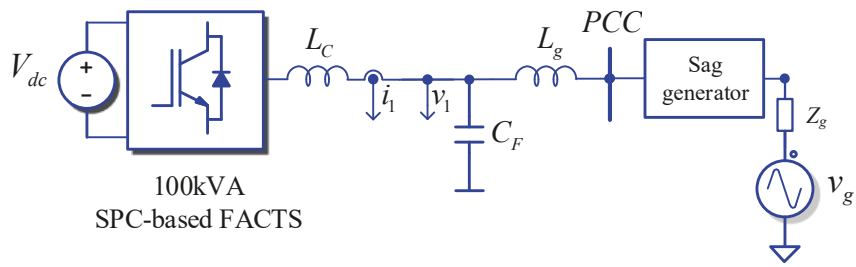

Figure 9. Scheme of the SPC-based FACTS connected to the grid for the balance LVRT test.

As shown in simulations, the SPC-based FACTS presents an inherit capability to inject reactive current in the electrical grid during voltage sags thanks to the effect of the virtual admittance. Once the virtual admittance controller detects a significant difference between the measured gird voltage, $v_{1}(t)$, and the virtual emf, $e(t)$, it generates an instantaneous reference current to counteract such a difference by injecting reactive current into the electrical grid. Figure 10a shows the beginning of the voltage sag. During this transient, the SPC-based FACTS detects the grid voltage reduction at the PCC and start increasing the reactive current injected into the grid. Later, once the voltage sag is released, the SPC-based FACTS stops providing reactive current and returns to its regular state. Figure 10b presents the end of the voltage sag, when the SPC-based FACTS returns to steady-state operation set-point.

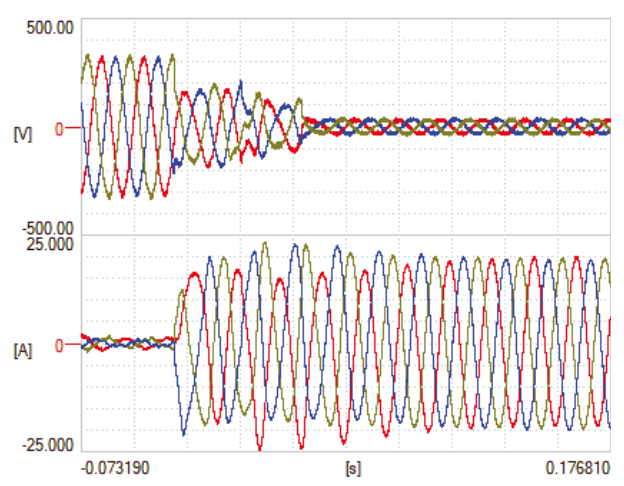

(a)

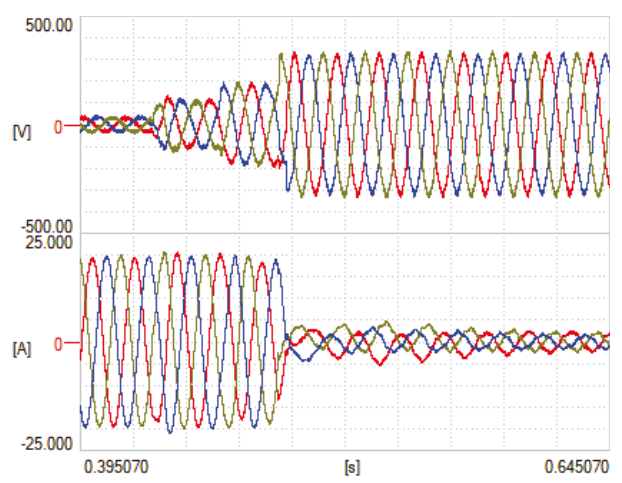

(b)

Figure 10. Response of the SPC-based FACTS to a balanced sag. Voltage sag to $0 \%$ (a) Beginning of the voltage sag. (b) End of the voltage sag.

Analyzed the system on the synchronous reference frame, it can be appreciated how the SPC-based FACTS inject reactive current $i_{q}$ during the grid fault to contribute to restore the voltage at the PCC. In Figure 11, the $d q$ current components $i_{d q}$ are plotted. It can be appreciated in this figure how the current $i_{q}$ is triggered at $t=2.18 \mathrm{~s}$, when the voltage sag is detected by the SPC-based FACTS controller. The system remains injecting reactive current to the grid until the voltage sag is cleared at $t=2.7 \mathrm{~s}$. Once the voltage dip is cleared, the current $i_{q}$ goes to zero. 


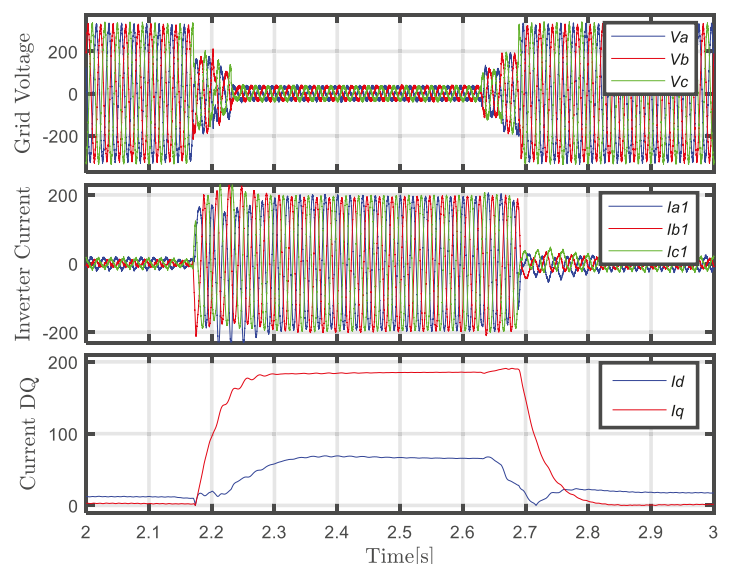

Figure 11. SPC-based FACTS dq currents during a balanced LVRT test.

\subsection{Unbalanced LVRT}

Single-phase and phase-to-phase faults generate unbalanced voltages, which gives rise to negative-sequences components in the grid voltage, which affects negatively to all the connected elements. The control algorithm of the SPC-based FACTS is able to detect the negative-sequence component of the grid voltage and provides a negative-sequence reference current aimed to restore the unbalanced grid voltage. This response in front of unbalanced voltage sags due to the action of the virtual admittance controller, which, after calculating the negative-sequence component of the grid voltage, sets such a voltage component as an input for a virtual admittance block, which generates a negative-sequence reference current addressed to reduce the negative-sequence component of the gird voltage at the PCC. Figure 12 shows the scheme of the setup used for conducting the unbalanced LVRT test. In this case, two SPC-based FACTS are connected to the PCC, which will experience the unbalanced voltage sag created through the sag generator. During the fault, the SPC-based FACTS will inject reactive currents to contribute to balance the grid voltage. Additionally, both SPC-based FACTS will share the amount of negative sequence current injected into the grid as a function of the parameters set for the virtual admittance in each SPC-based FACTS.

100kVA

SPC-based FACTS

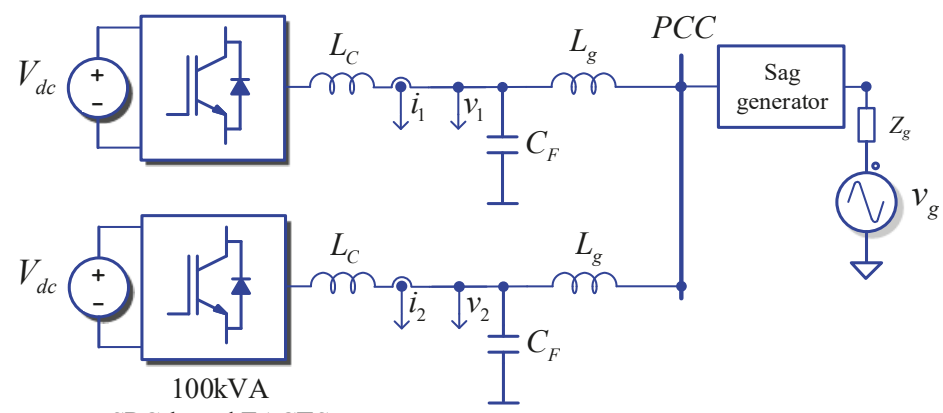

SPC-based FACTS

Figure 12. Electrical schematic for two SPC-based FACTS affected by an unbalanced voltage sag.

In this experiment, a voltage sag generator is used to generate the unbalanced grid voltage. In a first test, the SPC-based FACTS does not inject any reactive current into the grid when the unbalanced 
sag happens. Plots for this test are shown in Figure 13a, where unbalanced voltages can be seen at the PCC when the SPC-based FACTS do not provide any support. In Figure 13b, the two SPC-based FACTS are enabled to provide support to the electrical grid. In this test, once the sag is detected by the virtual admittance controller, the SPC-based FACTS starts injecting negative-sequence current into the grid in order contribute to balance the grid voltage at the PCC.

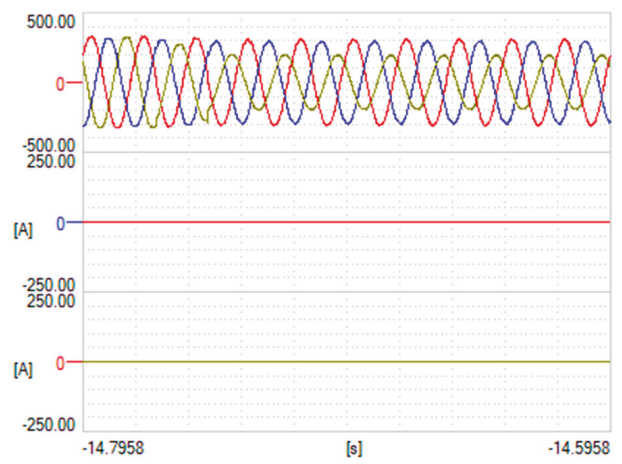

(a)

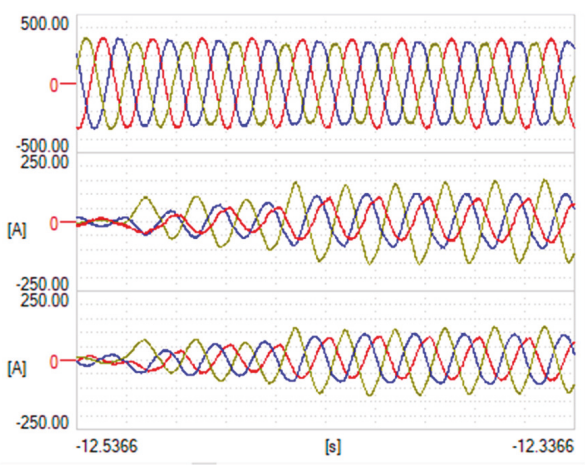

(b)

Figure 13. Response of the SPC-based FACTS to an unbalanced sag. (a) Unbalanced voltage sag without SPC-based FACTS (b) Two SPC-based FACTS inject reactive current to balance the gird voltage at the PCC.

The positive- and negative-sequence components of the voltage and current resulting from this experiment can be analyzed to assess the support provided to the electrical grid by the SPC-based FACTS. Figure 14a presents the voltage sag components when no reactive current is injected by the SPC-based FACTS. In this case, the positive-sequence component of the grid voltage decreases to $81 \%$ of its rated value, whereas the amplitude for the negative-sequence component grows until $20 \%$ of the rated grid voltage. As shown Figure 14b, once the SPC-based FACTS controllers are enabled to compensate unbalanced grid voltages, the positive-sequence component of the grid voltage at the PCC during the unbalanced sag decreases to the $92 \%$ of its rated value, while the negative-sequence component of the unbalanced voltage at the PCC just increases to the $5 \%$ of the rated grid voltage. Those effects can be seen in the difference between the sinusoidal waveforms from Figure 14. In this experiment, both SPC-based FACTS inject the same amount of reactive current since both of them set the same values for the virtual impedance used for processing the negative-sequence component of the PCC voltage.

\subsection{Harmonic Compensation}

The SPC-based FACTS can integrate multiple virtual admittances, each of them tuned to a given frequency, which can generate compensating currents addressed to the minimize distortion of the grid voltage at the PCC. To do that, the frequency components of the grid voltage should be measured, e.g., using band-pass filters tuned to the frequencies of interest, and provided as inputs to corresponding harmonic admittances in order to generate the compensating harmonic currents to be injected into the grid.

In this experiment, a non-linear load connected to the PCC, which will generate some harmonic components at the PCC voltage. The admittance controller of the SPC-based FACTS is enabled to detect such a voltage distortion at the PCC, and to inject compensating currents to attenuate the distortion of the grid voltage at the PCC. Figure 15 presents the setup used in this experiment, where a harmonic load is connected to the PCC in parallel to the SPC-based FATCS. Additionally, a $400 \mu \mathrm{H}$ line inductance has been added to increase distortion at the PCC voltage. 


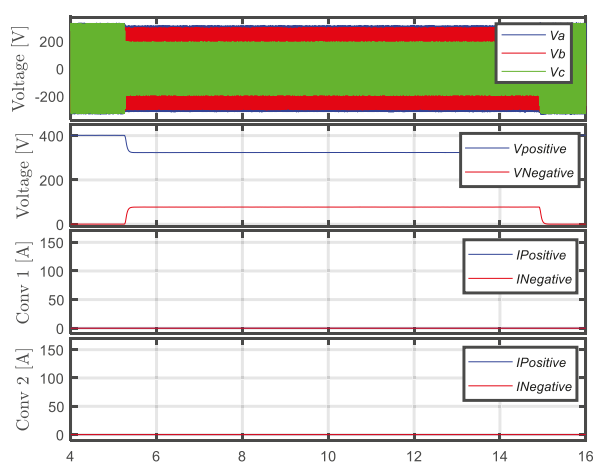

(a)

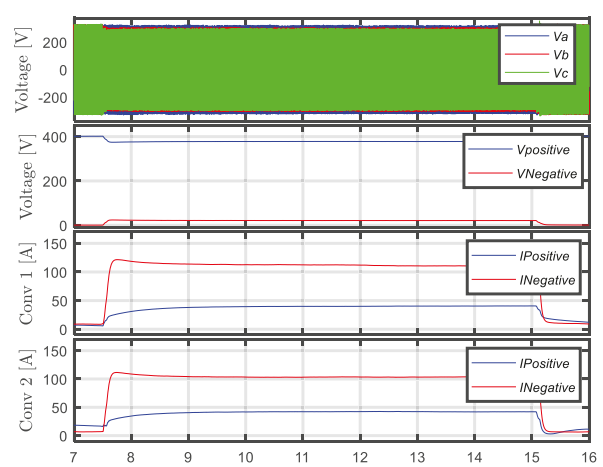

(b)

Figure 14. Response of the SPC-based FACTS to an unbalanced voltage sag. (a) Positive- and negative-sequence components of the PCC voltage and current when the SPC-based FACTS is disabled. (b) Positive- and negative-sequence components of the PCC voltage and current when the SPC-based FACTS is enabled.

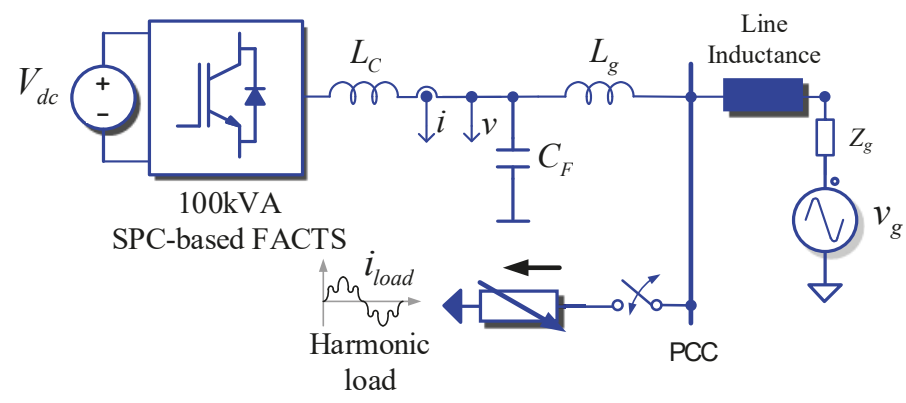

Figure 15. Electrical schematic for harmonic compensation control test.

In this experiment, a non-linear load is connected, giving rise to a notable amount of 5th and 7th harmonic in the current absorbed form the electrical grid. The SPC-based FACTS is able to detect the harmonic components at the PCC voltage, e.g., using multiple band-pass filters, and to inject proper currents reduce the voltage distortion at the PCC. Figure 16, from top to bottom, shows the grid voltage at the PCC, the current injected by the SPC-based FATCS and the current absorbed by the non-linear load. As appreciated in this figure, the current injected by the SPC-based FACTS compensates the one demanded by the load and the quality of the voltage at the PCC is improved. This is evidenced when the SPC-based FACTS is disabled at $t=-0.73 \mathrm{~s}$. From that time on, the harmonic load currents flow through the line impedance, instead through the SPC-based FACTS, which notably increases the grid voltage distortion.

A more detailed analysis of the grid voltage, paying special attention to the 5th and 7th harmonic components, allows assessing the effectiveness of the SPC-based FACTS in improving power quality. Figure 17a,b show the PCC voltage spectrum in case the SPC-based is disabled and enabled, respectively. As Figure 17a shows, when the harmonics control of the SPC-based FACTS is disabled, the grid voltage at the PCC presents remarkable levels for the 5th and 7th harmonic components, namely, $12 \mathrm{~V}$ and $7 \mathrm{~V}$, respectively. However, once the harmonics compensation function is enabled in the SPC-based FATCS, the quality of the PCC voltage improves significantly. In such a case, Figure $17 \mathrm{~b}$ shows how 
the amplitude levels for the 5th and 7th harmonic components has been reduced to $6 \mathrm{~V}$ and $2.5 \mathrm{~V}$, respectively, which can be also appreciated on the sinusoidal waveform shape.

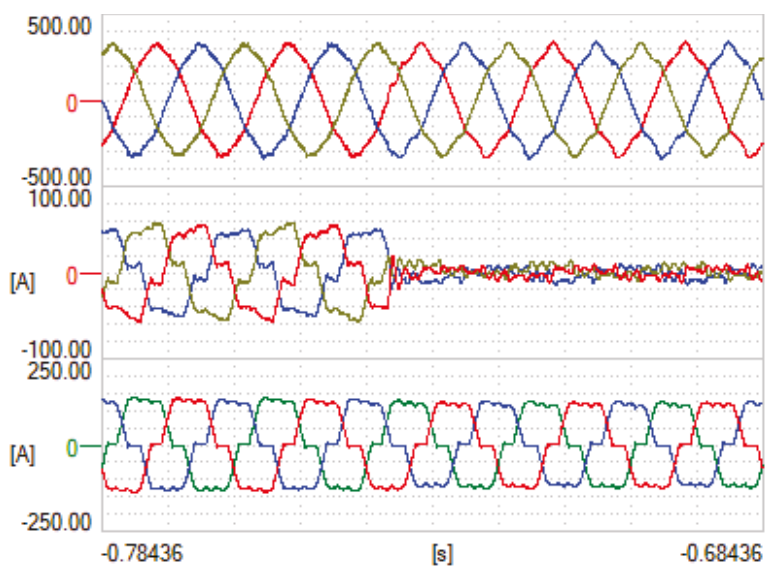

Figure 16. Grid voltage distortion reduction by the SPC-based FATCS.
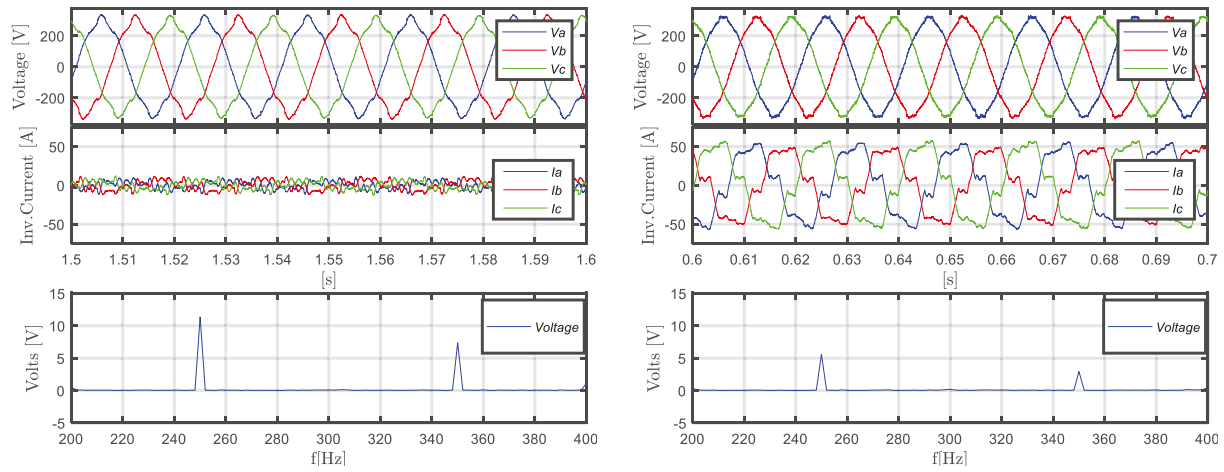

(a)

(b)

Figure 17. Effect of the SPC-based FACTS in grid voltage reduction (a) Harmonics compensation disabled. (b) Harmonics compensation enabled.

\section{Conclusions}

This paper has presented the application of the synchronous power controller (SPC) to FACTS with the aim of improving power quality in electrical grids. This paper has conducted an overview on FACTS devices and has highlighted that the virtual synchronous power has gained notable popularity among engineers and researchers in the last years to interface power converters to ac synchronous electrical grid. The control scheme and the main equations governing the SPC, which are essential to implement simulation models and analyses, have been presented in the paper. Based on such models, the paper has presented some simulations results addressed to evaluate the performance of a SPC-based FACTS when improving power quality in the electrical grid. In such an evaluation, the positive impact of the SPC-based FACTS to improve the grid voltage quality during balanced and unbalanced voltage sags, as well as in case of current harmonics flowing along the grid, has been illustrated by representative simulations. Moreover, such simulation results have been validated through experiments in the lab, obtaining satisfactory results. As a conclusion, this paper has presented 
the SPC formulation and has evidenced the interest of the SPC-based FACTS for improving power quality in electrical grids.

\section{Patents}

The Synchronous Power Controller technology is protected by the following patents:

- WO 2012/117131 A1. "Synchronous controller for a generating system based on static power converters", Priority date: 18/02/2011 Licensed by: Abengoa Solar NT, S.A.

- WO 2012/117132 A1 "Controller of the electro-mechanical characteristic of a static power converter", Priority date: 18/02/2011 Licensed by: Abengoa Solar NT, S.A.

- WO 2012/117133 A1 "Virtual admittance controller for a static power converter", Priority date: 18/02/2011 Licensed by: Abengoa Solar NT, S.A.

Author Contributions: G.N.B. conducted an overview of FACTS systems. N.-B.L. developed the SPC's formulation and simulation models. A.T. conducted simulations and lab experiments. P.R. provided conceptual and technical support as the inventor of the SPC. All the co-authors contributed to writing and reviewing the paper. Conceptualization, P.R., A.T. and N.-B.L.; methodology, A.T. and N.-B.L.; software, N.-B.L. and G.N.B.; validation, A.T. and P.R.; formal analysis, A.T. and N.-B.L.; investigation, N.-B.L. and P.R.; resources, A.T.; data curation, G.N.B.; writing-original draft preparation, A.T. and N.-B.L.; writing-review and editing, G.N.B. and P.R.; visualization, G.N.B.; supervision, P.R.; project administration, P.R.; funding acquisition, P.R.

Funding: This work was supported by the European Commission under the project FLEXITRANSTORE H2020-LCE-2016-2017-SGS-774407 and by the Spanish Ministry of Science Innovation and Universities under project SMARTNODES ENE2017-88889-C2-1-R. Any opinions, findings and conclusions or recommendations written in this work are those of the authors and do not necessarily reflect those of the host institutions and funders.

Conflicts of Interest: The authors declare no conflict of interest.

\section{References}

1. Machowski, J.; Bialek, J.; Bumby, J. Power System Dynamics: Stability and Control, 2nd ed.; Wiley: Hoboken, NJ, USA, October 2008.

2. Morjaria, M.; Anichkov, D.; Chadliev, V.; Soni, S. A Grid-Friendly Plant: The Role of Utility-Scale Photovoltaic Plants in Grid Stability and Reliability. IEEE Power Energy Mag. 2014, 12, 87-95. [CrossRef]

3. Bae, Y.; Vu, T.; Kim, R. Implemental Control Strategy for Grid Stabilization of Grid-Connected PV System Based on German Grid Code in Symmetrical Low-to-Medium Voltage Network. IEEE Trans. Energy Convers. 2013, 28, 619-631. [CrossRef]

4. Hingorani, N.G. High Power Electronics and flexible AC Transmission System. IEEE Power Eng. Rev. 1988, 8, 3-4. [CrossRef]

5. Van Wyk, J.D.; Lee, F.C. On a Future for Power Electronics. IEEE Trans. Emerg. Sel. Top. Power Electron. 2013, 1, 59-72. [CrossRef]

6. Edris, A.A. Proposed terms and definitions for flexible AC transmission system (FACTS). IEEE Trans. Power Deliv. 1997, 12, 1848-1853.

7. Gandoman, F.; Ahmadi, A.; Sharaf, A.; Siano, P.; Pou, J.; Hredzak, B.; Agelidis, V. Review of FACTS technologies and applications for power quality in smart grids with renewable energy systems. Renew. Sustain. Energy Rev. 2018, 82, 502-514. [CrossRef]

8. Padiyar, K.R.; Kulkarni, A.M. Modeling and Analysis of FACTS and HVDC Controllers. Dynamics and Control of Electric Transmission and Microgrids; Wiley-IEEE Press: Hoboken, NJ, USA, 2019; pp. 145-194.

9. Bruno, S.; de Carne, G.; la Scala, M. Transmission Grid Control Through TCSC Dynamic Series Compensation. IEEE Trans. Power Syst. 2016, 31, 3202-3211. [CrossRef]

10. Farahani, M. Damping of subsynchronous oscillations in power system using static synchronous series compensator. IET Gener. Transm. Distrib. 2012, 6, 539-544. [CrossRef]

11. Jiang, F.; Tu, C.; Guo, Q.; Shuai, Z.; He, X.; He, J. Dual-Functional Dynamic Voltage Restorer to Limit Fault Current. IEEE Trans. Ind. Electron. 2019, 66, 5300-5309. [CrossRef]

12. Kim, H.; Yu, S.-D.; Kim, H.; Kim, W.-S.; Yang, S.-G.; Lee, J.-Y. Demonstration of a Superconducting Fault Current Limiter in a Real Grid. IEEE Trans. Appl. Supercond. 2013, 23, 5603604. 
13. Singh, B.; Saha, R.; Chandra, A.; Al-Haddad, K. Static synchronous compensators (STATCOM): A review. IET Power Electron. 2009, 2, 297-324. [CrossRef]

14. Teleke, S.; Abdulahovic, T.; Thiringer, T.; Svensson, J. Dynamic Performance Comparison of Synchronous Condenser and SVC. IEEE Trans. Power Deliv. 2018, 23, 1606-1612. [CrossRef]

15. Rahmani, S.; Hamadi, A.; Al-Haddad, K.; Dessaint, L.A. A Combination of Shunt Hybrid Power Filter and Thyristor-Controlled Reactor for Power Quality. IEEE Trans. Ind. Electron. 2014, 61, 2152-2164. [CrossRef]

16. Ghosh, S.; Ali, M.H. Power quality enhancement by coordinated operation of thyristor switched capacitor and optimal reclosing of circuit breakers. IET Gener. Transm. Distrib. 2015, 9, 1301-1307. [CrossRef]

17. Akagi, H.; Watanabe, E.H.; Aredes, M. Shunt Active Filters. Instantaneous Power Theory and Applications to Power Conditioning; John Wiley \& Sons: Hoboken, NJ, USA, 2017.

18. Gyugyi, L.; Schauder, C.D.; Williams, S.L.; Rietman, T.R.; Torgerson, D.R.; Edris, A. The unified power flow controller: A new approach to power transmission control. IEEE Trans. Power Deliv. 1995, 10, 1085-1097. [CrossRef]

19. Arabi, S.; Hamadanizadeh, H.; Fardanesh, B.B. Convertible static compensator performance studies on the NY state transmission system. IEEE Trans. Power Syst. 2002, 17, 701-706. [CrossRef]

20. Fujita, H.; Akagi, H. The unified power quality conditioner: the integration of series- and shunt-active filters. IEEE Trans. Power Electron. 1998, 13, 315-322. [CrossRef]

21. Hsieh, G.-C.; Hung, J.C. Phase-locked loop techniques. A survey. IEEE Trans. Ind. Electron. 1996, 43, $609-615$. [CrossRef]

22. Rodriguez, P.; Pou, J.; Bergas, J.; Candela, J.I.; Burgos, R.P.; Boroyevich, D. Decoupled Double Synchronous Reference Frame PLL for Power Converters Control. IEEE Trans. Power Electron. 2007, 22, 584-592. [CrossRef]

23. Beck, H.; Hesse, R. Virtual synchronous machine. In Proceedings of the 2007 th International Conference on Electrical Power Quality and Utilisation, Barcelona, Spain, 9-11 October 2007; pp. 1-6.

24. Rodriguez, P.; Candela, I.; Luna, A. Control of PV generation systems using the synchronous power controller. In Proceedings of the 2013 IEEE Energy Conversion Congress and Exposition, Denver, CO, USA, 15-19 September 2013; pp. 993-998.

25. Zhang, W.; Rouzbehi, K.; Luna, A.; Gharehpetian, G.B.; Rodriguez, P. Multi-terminal HVDC grids with inertia mimicry capability. IET Renew. Power Gener. 2016, 7, 752-760. [CrossRef]

26. Rakhshani, E.; Remon, D.; Cantarellas, A.M.; Garcia, J.M.; Rodriguez, P. Virtual Synchronous Power Strategy for Multiple HVDC Interconnections of Multi-Area AGC Power Systems. IEEE Trans. Power Syst. 2017, 32, 1665-1677. [CrossRef]

27. Li, C.; Burgos, R.; Cvetkovic, I.; Boroyevich, D.; Mili, L.; Rodriguez, P. Evaluation and control design of virtual-synchronous-machine-based STATCOM for grids with high penetration of renewable energy. In Proceedings of the 2014 IEEE Energy Conversion Congress and Exposition (ECCE), Pittsburgh, PA, USA, 14-18 September 2014; pp. 5652-5658.

28. Khoshooei, A.; Moghani, J.S.; Candela, I.; Rodriguez, P. Control of D-STATCOM During Unbalanced Grid Faults Based on DC Voltage Oscillations and Peak Current Limitations. IEEE Trans. Ind. Appl. 2018, 54, 1680-1690. [CrossRef]

29. Rodriguez, P.; Candela, J.I.; Rocabert, J.; Teodorescu, R. Synchronous Power Controller for a Generating System Based on Static Power Converters. U.S. Patent 9,166,508, 20 October 2015.

30. Tarrasó, A.; Candela, J.I.; Rocabert, J.; Rodriguez, P. Grid voltage harmonic damping method for SPC based power converters with multiple virtual admittance control. In Proceedings of the 2017 IEEE Energy Conversion Congress and Exposition (ECCE), Cincinnati, OH, USA, 1-5 October 2017.

31. Remon, D.; Cantarellas, A.M.; Mauricio, J.M.; Rodriguez, P. Power system stability analysis under increasing penetration of photovoltaic power plants with synchronous power controllers. IET Renew. Power Gener. 2017, 11, 733-741. [CrossRef]

32. Zhang, W.; Cantarellas, A.M.; Rocabert, J.; Luna, A.; Rodriguez, P. Synchronous power controller with flexible droop characteristics for renewable power generation systems. IEEE Trans. Sustain. Energy 2016, 7, 1572-1582. [CrossRef]

(C) 2019 by the authors. Licensee MDPI, Basel, Switzerland. This article is an open access article distributed under the terms and conditions of the Creative Commons Attribution (CC BY) license (http://creativecommons.org/licenses/by/4.0/). 

Article

\title{
Modeling and Control of a Novel Hybrid Power Quality Compensation System for 25-kV Electrified Railway
}

\author{
Minwu Chen ${ }^{1,2}$, Yinyu Chen ${ }^{1,2, *}$ and Mingchi Wei ${ }^{1,2}$ \\ 1 National Rail Transportation Electrification and Automation Engineering Technology Research Center, \\ Chengdu 611756, China \\ 2 School of Electrical Engineering, Southwest Jiaotong University, Chengdu 611756, China \\ * Correspondence: yinyuchen@my.swjtu.edu.cn
}

Received: 25 July 2019; Accepted: 26 August 2019; Published: 27 August 2019

\begin{abstract}
The severe power quality problems aroused by the single-phase 25-kV traction power supply system (TPSS), especially for the voltage unbalance (VU) and high-frequency harmonic resonance, have attracted increasing attention nowadays. In this paper, a novel hybrid power quality compensation system, including a power flow controller (PFC) and thyristor-controlled $L$ and C-type filter (TCL-CTF), is proposed. The PFC can be used for VU compensation, and the TCL-CTF can be designed to filter out harmonics as well as compensate reactive power. Furthermore, an optimized compensation strategy is proposed, and the power quality of the TPSS can meet the requirements of the technology standard. Compared with the conventional scheme, the compensation capacity of the PFC can be reduced by $12 \%$, as well as the cost. Finally, the effectiveness of the proposed system is verified by the simulation and experimental results.
\end{abstract}

Keywords: power quality; hybrid power quality compensation system; the thyristor-controlled $L$ and C-type filter (TCL-CTF)

\section{Introduction}

The Chinese government is rapidly constructing massive electrical railways to promote economic prosperity [1,2], which are mainly represented by their high speed and heavy load. According to the government's report [3], the railway mileage will exceed 150,000 km, including 30,000 km high-speed railway, and the proportion of electrified railway will rise to $70 \%$ by 2020 . As a result, the serious power quality problem aroused by the single-phase $25-\mathrm{kV}$ traction power supply system (TPSS) has drawn increasing attention $[4,5]$, especially for the voltage unbalance (VU) and the high-order harmonic problem in the weak power grid.

FACTS technology has increasingly drawn wide attention regarding the power quality of the government [6,7]. The power flow controller (PFC) scheme has been adopted to the TPSS [8], for example, by way of the railway static power conditioner (RPC) and co-phase TPSS. Mochinaga proposed the RPC [9]; different control strategies and structures have also been proposed [10-12]. On the other hand, Li proposed the co-phase TPSS configuration [13], which was applied to engineering in 2011 [14]; various other structures have also been proposed [15-17]. Compared with the co-phase TPSS, the apparent drawback of RPC is that it cannot eliminate the neutral zones. The super slope region—such as the length of the slope-has risen to $70 \mathrm{~km}$ in the Sichuan-Tibet railway, which will cause serious speed losses for electric multiple units (EMUs) and energy loss for the TPSS. Thus, the co-phase TPSS is a trend for the next-generation TPSS. However, the high-order harmonic resonance problem and the investment cost of high voltage and kVA power electronic devices are still obstructing its application in the TPSS. 
The alternating current/direct current/alternating current (AC/DC/AC) traction converters are widely adopted to CRHs series of EMUs, and the $\mathrm{HX}_{\mathrm{D}}$ series of AC electric locomotives benefit from their excellent control performance and high power factor (PF). Nevertheless, a series of harmonic resonance accidents have been aroused by the high-frequency harmonic in recent years, which interferes with the safety and efficient operation of the TPSS $[18,19]$. Note that the PFC used in the TPSS possesses poor performance on compensating harmonic [20]. The passive power filter (PPF) and active power compensation device are frequently used for solving this problem. Nevertheless, the PPF is more available in terms of the cost and reliability. In this regard, the $C$-type filter has drawn attention to the railway field in recent years, as it not only filters out the particular high-order harmonic region, but also compensates for the reactive power to improve system performance [21]. Unfortunately, the over-compensation caused by the fixed Var capacity of C-type filters leads to the PF deterioration; it is unaccepted that the railway operator will pay a high fine to the power grid. Hence, how to greatly offset harmonic as well as PF is the main challenge. Fortunately, the power semiconductor switches, such as the thyristor, metal-oxide-semiconductor field-effect transistor (MOSFET), and insulated gate bipolar transistor (IGBT), have been adopted to control the inductance to achieve the reactive power compensation since the 1960s; most of the time, the thyristor will be involved when handling high voltage and simple AC circuit [22]. Thus, a thyristor-controlled LC-coupling (TCLC) structure has been introduced to govern the distortion and PF of the three-phase load in the power grid [23]. Furthermore, the different structure has been proposed, which combines the TCLCs in series/parallel with the active power filters (APFs), such as the TCLC + APF in [24], and the static var compensator (SVC)/APF in [25]. In other words, a novel hybrid compensation structure combined with the PPF and TCL can be designed to handle the above problem in railways. However, the relevant research in the railway field still lacks study.

Alternatively, the PFC of the TPSS is initially designed to compensate for VU and PF problems. However, due to the fluctuation of the traction load, the instant power demand has attached to 50 MVA, whereas the normal power demand has arrived 20 MVA; the PFC cannot provide a satisfactory compensation performance if the actual demand exceeds the designed capacity. Moreover, the cost also should be considered; the cost of a PFC is about $\$ 60 / \mathrm{kVA}$ according to the cost study in [24]. Therefore, a high-efficiency PFC is required to design the hybrid compensation system. On the one hand, the different multilevel constructs of PFC have been presented in recent years, which can reduce the switching frequency, power loss, and harmonic distortion [17,26]. In [17], a cascaded H-bridge multilevel construct is used for the PFC device. In [27], a novel PFC with a modular multilevel converter (MMC) construct has been adopted to the railway. On the other hand, an optimized compensation technique compensating for the power quality of load to satisfy the national standard is introduced to reduce the rating kVA. In [16], a hybrid compensation is proposed to reduce the capacity of PFC in the TPSS. Furthermore, a clear relationship between the power quality standard and the reference current is established in [17]. However, the capacity of a PFC is associated with not only the reactive power compensation, but also the active power balance. Therefore, a feasible method is using the PPF + TCL to compensate for reactive power, as they cost just 1/12th of the PFC, using PFC to compensate for the VU. Simultaneously, the control strategy of PFC should be redesigned to fit this hybrid power quality compensation system.

The rest of this paper is structured as follows: Section 2 introduces the circuit configuration of the proposed system. Furthermore, the power flow is analyzed in Section 3. In Section 4, the control strategy is proposed. The parameters of the TCL-CTF are designed in Section 5. The effectiveness is testified by simulation and experiment in Section 6. Finally, the conclusions are reached in Section 7.

\section{Circuit Configuration of the Proposed Hybrid Compensation System}

Figure 1 shows the circuit configuration of the novel hybrid power quality compensation system for the TPSS. The proposed system consists of a TCL-CTF part, a traction transformer (TT) part, and a PFC part. The TCL-CTF part is composed of a thyristor-controlled reactor with an $L_{1}$ and C-type 
filter (CTF). The CTF is constituted by a capacitor $C_{1}$, an auxiliary capacitor $C_{2}$, a damping resistor R, and an inductor $L_{2}$. The TCL and capacitor $C_{1}$ are responsible for supporting the fundamental reactive power to improve PF, which are controlled by triggering the firing angles $\alpha$ of the thyristor $T_{1}$ and $T_{2}$. The CTF is designed to filter high-order harmonics. The TT is a balance transformer in which the negative-sequence current (NSC) is eliminated if the power of two ports is equal, which comprise a single-phase transformer (SPT) and a Y/D transformer. The PFC part consists of a DC-link capacitor $C_{d c}$ and two voltage source converters. It is employed to transfer the partial active power and selectively compensate for VU.

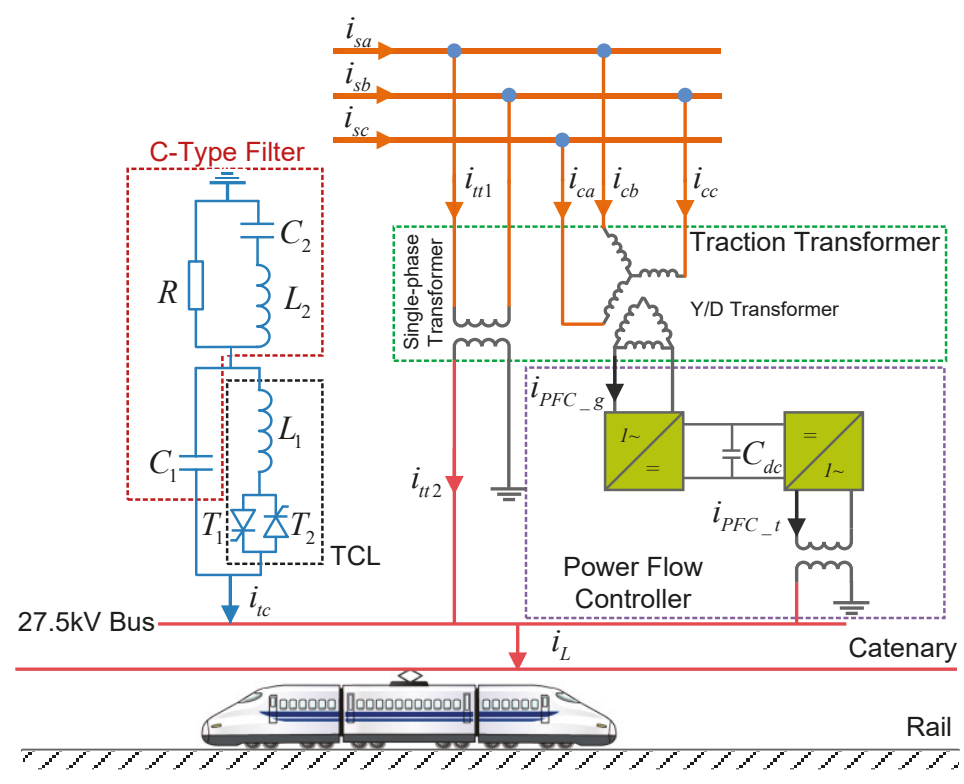

Figure 1. Circuit configuration of the hybrid power quality compensation system.

In Figure $1, i_{s x}$, and $i_{c x}$ are the source currents and the compensating currents where the $x$ stands for phases $a, b$, and $c$ in the following analysis. $i_{t t 1}$ and $i_{t t 2}$ are the primary and secondary side currents of the single-phase transformer, respectively. $i_{g}$ and $i_{t}$ are the grid and traction-side port currents of the PFC, respectively. $i_{t c}$ is the current of the TCL-CTF part.

\section{Power Analysis of the Proposed Hybrid Compensation System}

According to the research $[28,29]$, there is some coupling power between the different components, not just the positive-sequence or negative-sequence power. Thus, the excited power calculation approach of load, based on the sequence component or vector method, could become invalid under the non-sinusoidal and asymmetrical conditions. To cope with this problem, the IEEE Standards Association (IEEE-SA) released IEEE Std. 1459 in 2010, which introduced the 'effective' value of voltage, current, and apparent power. Furthermore, the total effective apparent load power $\left(S_{L}\right)$ can be defined as:

$$
\begin{aligned}
S_{L}^{2} & =S_{L 1}^{2}+S_{L h}^{2} \\
& =\left(S_{L 1}^{+}\right)^{2}+\left(S_{L u 1}\right)^{2}+\left(S_{L h}\right)^{2}
\end{aligned}
$$

where $S_{L 1}$ and $S_{L h}$ are the fundamental and harmonic-component of the load apparent power, respectively. $S_{L 1}^{+}$and $S_{L u 1}$ are fundamental positive-sequence and unbalanced component of the load apparent power, respectively. 
Moreover, the fundamental positive-sequence component of the load apparent power $\left(S_{L 1}^{+}\right)$can be divided into two terms: active power and reactive power.

$$
\left(S_{L 1}^{+}\right)^{2}=\left(P_{L 1}^{+}\right)^{2}+\left(Q_{L 1}^{+}\right)^{2}
$$

where $P_{L 1}^{+}$and $Q_{L 1}^{+}$are the load active power and load reactive power, respectively.

On the basis of Figure 1, the fundamental load active power $\left(P_{L 1}^{+}\right)$comes from the single-phase transformer (SPT) and PFC branches.

$$
\left(P_{L 1}^{+}\right)^{2}=\left(P_{S P T}^{+}\right)^{2}+\left(P_{P F C}^{+}\right)^{2}
$$

where $P_{S P T}^{+}$and $P_{P F C}^{+}$are the active power through the SPT and PFC branches, respectively.

The fundamental load reactive power $\left(Q_{L 1}^{+}\right)$is mainly supported by the TCL-CTF branch, and the rest is provided by the SPT and PFC branches. The $Q_{L 1}^{+}$can be fully or partly compensated via the TCL-CTF.

$$
\left(Q_{L 1}^{+}\right)^{2}=\left(Q_{S P T}^{+}\right)^{2}+\left(Q_{P F C}^{+}\right)^{2}+\left(K_{Q} \cdot Q_{T C L-C T F}^{+}\right)^{2}
$$

where $Q_{S P T}^{+}, Q_{P F C^{\prime}}^{+}$and $Q_{T C L-C T F}^{+}$are the active power through the SPT, PFC, and TCL-CTF branches, respectively. $K_{Q}$ is a compensation coefficient, depending on the reference PF.

The fundamental load unbalanced component of the apparent power $\left(S_{L u 1}\right)$ can be divided into the SPT and PFC branches.

$$
\left(S_{L u 1}\right)^{2}=\left(S_{L u 1 \_S P T}\right)^{2}+\left(k_{U} \cdot S_{L u 1 \_P F C}\right)^{2}
$$

where $Q_{S P T}^{+}, Q_{P F C}^{+}$, and $Q_{T C L-C T F}^{+}$are the active power through the SPT, PFC, and TCL-CTF branches, respectively. $K_{U}$ is a compensation coefficient, depending on the reference voltage unbalance factor (VUF).

In addition, the fundamental system unbalanced component of the apparent power $\left(S_{S u 1}\right)$ that discharge into the power grid can be less than or equal to $S_{L u 1}$ with the different compensation targets. After being compensated by PFC, the VU problem could be thoroughly eliminated if $S_{L u 1 \_S P T}=K_{U} \cdot S_{L u 1 \_P F C}$; otherwise, the VU can be selectively compensated based on the national power quality standard.

$$
\left(S_{S u 1}\right)^{2} \leq\left(S_{L u 1 \_S P T}\right)^{2}-\left(k_{U} \cdot S_{L u 1 \_P F C}\right)^{2}
$$

\section{Control Strategy of the Proposed Hybrid Compensation System}

The proposed hybrid compensation system consists of a TCL-CTF part, a traction transformer (TT) part, and a PFC part. The TCL-CTF part is controlled to offset high-order harmonic $\left(S_{L h}\right)$ and selectively compensate the load reactive power $\left(Q_{L 1}^{+}\right)$to improve the PF. The PFC part is used for transferring the partial active power and selectively compensating for the $\mathrm{VU}\left(S_{L u 1}\right)$. In the following, the control strategy will be discussed.

\subsection{PFC Part Control}

At present, the instantaneous power theory is widely adopted to detect the reactive, negative-sequence, and harmonic currents to provide an accurate reference for the power quality conditioner. Therefore, the positive and negative sequence components for each branch should be obtained before calculating the reference current, which can utilize the notch filter as [30]:

$$
\begin{aligned}
& {\left[y_{z x}^{+}\right]_{x=a, b, c}=M_{2} \cdot\left[y_{z x}\right]_{x=a, b, c}-M_{1} \cdot\left[S_{\pi / 4} y_{z x}\right]_{x=a, b, c}} \\
& {\left[y_{z x}^{-}\right]_{x=a, b, c}=M_{2} \cdot\left[y_{z x}\right]_{x=a, b, c}+M_{1} \cdot\left[S_{\pi / 4} y_{z x}\right]_{x=a, b, c}}
\end{aligned}
$$


where $S_{\pi / 4}$ stands for a $\pi / 4$ phase-shift operator in the time domain, $x$ stands for phases $a, b$, and $c, y$ stands for current $i$ or voltage $u$ in the following analysis, $z$ stands for the SPT part, PFC part, and so on. $M_{1}$ and $M_{2}$ are $3 \times 3$ matrices given by:

$$
\begin{aligned}
& M_{1}=\frac{1}{2 \sqrt{3}}\left[\begin{array}{ccc}
0 & 1 & -1 \\
-1 & 0 & 1 \\
1 & -1 & 0
\end{array}\right] \\
& M_{2}=\frac{1}{3}\left[\begin{array}{ccc}
1 & -0.5 & -0.5 \\
-0.5 & 1 & -0.5 \\
-0.5 & -0.5 & 1
\end{array}\right]
\end{aligned}
$$

Then, the positive-sequence and negative-sequence component in the $\alpha-\beta$ frame are transformed from the $a-b-c$ frame, which can be expressed as:

$$
\begin{aligned}
& {\left[\begin{array}{l}
y_{z \alpha}^{+}(t) \\
y_{z \beta}^{+}(t)
\end{array}\right]=\left[\begin{array}{ccc}
1 & -\frac{1}{2} & -\frac{1}{2} \\
0 & \frac{\sqrt{3}}{2} & -\frac{\sqrt{3}}{2}
\end{array}\right]\left[\begin{array}{l}
y_{z a}^{+} \\
y_{z b}^{+} \\
y_{z c}^{+}
\end{array}\right]} \\
& {\left[\begin{array}{l}
y_{z \alpha}^{-}(t) \\
y_{z \beta}^{-}(t)
\end{array}\right]=\left[\begin{array}{ccc}
1 & -\frac{1}{2} & -\frac{1}{2} \\
0 & \frac{\sqrt{3}}{2} & -\frac{\sqrt{3}}{2}
\end{array}\right]\left[\begin{array}{l}
y_{z a}^{-} \\
y_{z b}^{-} \\
y_{z c}^{-}
\end{array}\right]}
\end{aligned}
$$

Furthermore, based on the instantaneous power theory, the positive and negative-sequence components of instantaneous power can be obtained by Equations (13) and (14):

$$
\begin{aligned}
& {\left[\begin{array}{c}
p_{z}^{+} \\
q_{z}^{+}
\end{array}\right]=\left[\begin{array}{cc}
u_{z \alpha}^{+} & u_{z \beta}^{+} \\
-u_{z \beta}^{+} & u_{z \alpha}^{+}
\end{array}\right] \cdot\left[\begin{array}{c}
i_{z \alpha}^{+} \\
i_{z \beta}^{+}
\end{array}\right]} \\
& {\left[\begin{array}{c}
p_{z}^{-} \\
q_{z}^{-}
\end{array}\right]=\left[\begin{array}{cc}
u_{z \beta}^{+} & u_{z \alpha}^{+} \\
-u_{z \alpha}^{+} & u_{z \beta}^{+}
\end{array}\right] \cdot\left[\begin{array}{c}
i_{z \alpha}^{-} \\
i_{z \beta}^{-}
\end{array}\right]}
\end{aligned}
$$

where $p_{z}^{+}$and $q_{z}^{+}$are positive-sequence components of the active and reactive instantaneous power, respectively. $p_{z}^{-}$and $q_{z}^{-}$are negative-sequence components of the active and reactive instantaneous power, respectively.

Under the non-sinusoidal and asymmetrical conditions, it should be noticed that the negative-sequence component of the instantaneous power calculated from Equations (13) and (14) includes two parts: DC composition and AC composition. To raise compensation performance, a low-pass filter (LPF) is added to obtain the DC component, due to AC composition including an almost harmonic element. Further, the unbalanced power $\left(\bar{p}_{P F C}^{-}\right.$and $\left.\bar{q}_{P F C}^{-}\right)$is partly compensated by a compensation coefficient $K_{U}$.

$$
\begin{gathered}
{\left[\begin{array}{c}
i_{\alpha_{-} P F C}^{+} \\
i_{\beta_{-} P F C}^{+}
\end{array}\right]=\frac{1}{\left(u_{\alpha_{-} P F C}^{+}\right)^{2}+\left(u_{\beta_{-} P F C}^{+}\right)^{2}}\left[\begin{array}{ll}
u_{\alpha_{-} P F C}^{+} & -u_{\beta_{-} P F C}^{+} \\
u_{\beta_{-} P F C}^{+} & u_{\alpha_{-} P F C}^{+}
\end{array}\right]\left[\begin{array}{c}
\bar{p}_{P F C}^{+} \\
\bar{q}_{P F C}^{+}
\end{array}\right]} \\
{\left[\begin{array}{c}
i_{\alpha_{-} P F C}^{-} \\
i_{\beta_{-} P F C}^{+}
\end{array}\right]=\frac{1}{\left(u_{\alpha_{-} P F C}^{+}\right)^{2}+\left(u_{\beta_{-} P F C}^{+}\right)^{2}}\left[\begin{array}{ll}
u_{\beta_{-} P F C}^{+} & -u_{\alpha_{-} P F C}^{+} \\
u_{\alpha_{-} P F C}^{+} & u_{\beta_{-} P F C}^{+}
\end{array}\right]\left[\begin{array}{l}
k_{U} \cdot \bar{p}_{P F C}^{-} \\
k_{U} \cdot \bar{q}_{P F C}^{-}
\end{array}\right]}
\end{gathered}
$$


The final reference currents of the grid side for PFC in a $p-q$ frame are transformed from the $\alpha-\beta$ frame:

$$
\left[\begin{array}{l}
i_{p_{-} g}^{*} \\
i_{q_{-} g}^{*}
\end{array}\right]=\left[\begin{array}{cl}
\sin \omega t & -\cos \omega t \\
-\cos \omega t & \sin \omega t
\end{array}\right] \cdot\left[\begin{array}{c}
i_{\alpha_{\_} P F C}^{+}+i_{\alpha_{\alpha} P F C}^{-} \\
i_{\beta_{-} P F C}^{+}+i_{\beta_{-} P F C}^{-}
\end{array}\right]
$$

where $\omega$ is a rated angular frequency of the power grid, which can be calculated from the PLL.

On the other hand, the operating characteristics of PFC can use the power balance principle to express as:

$$
\begin{aligned}
& u_{T} i_{p_{-} t t 2}+u_{g} i_{p_{-} g}=u_{T} i_{p_{-} L} \\
& u_{T} i_{q_{-} t 2}+u_{g} i_{q_{-} g}=u_{T} i_{q_{-} L}
\end{aligned}
$$

The reference currents of the traction side for PFC in a $p-q$ frame can be expressed as:

$$
\left[\begin{array}{c}
i_{p_{-} t}^{*} \\
i_{q_{-} t}^{*}
\end{array}\right]=N_{1} \cdot\left(\left[\begin{array}{c}
i_{p_{-} L} \\
i_{q_{-} L}
\end{array}\right]-\left[\begin{array}{c}
i_{p_{-} t t 2} \\
i_{q_{-} t}
\end{array}\right]\right)
$$

where $i_{p_{-} L}$ and $i_{q_{-} L}$ are the load active and reactive current, respectively, which can be expressed as:

$$
i_{p_{-} L}=i_{L} \cos \varphi_{L}, i_{q_{-} L}=i_{L} \sin \varphi_{L},
$$

where $\varphi_{L}$ is the power factor angle of the traction load.

The compensation current of PFC tracks with its reference value $i_{p_{-} g^{\prime}}^{*} i_{q_{-} g^{\prime}}^{*}$ and $i_{p_{-} t^{*}}^{*}$, while $i_{q_{-} t}^{*}$ is calculated by above proposed method.

Furthermore, the capacity of PFC is calculated in the following equation based on [16,17]:

$$
S_{P F C}=S_{P F C_{-} g}+S_{P F C_{-} t}=U_{P F C_{-} g} I_{P F C_{-} g}+U_{P F C_{-} t} I_{P F C_{-} t}
$$

\subsection{TCL-CTF Part Control}

The TCL achieves the dynamic adjustment of the inductive reactive power through changing the current's amplitude, which is controlled by the firing delay angle of the thyristor. Afterward, it is combined with the fixed capacitive reactive power to compensate for the given PF. The equivalent fundamental impedance of the TCL and the capacitor $C_{1}$ can be expressed as:

$$
X_{T C L-C T F}(\alpha)=-\frac{X_{T C L}(\alpha) \cdot X_{C_{1}}}{X_{T C L}(\alpha)-X_{C_{1}}}
$$

where $X_{T C L}(\alpha)$ is the equivalent fundamental impendence of the TCL, which can be expressed as:

$$
X_{T C L}(\alpha)=\frac{\pi}{2 \pi-2 \alpha+\sin 2 \alpha} \cdot X_{L_{1}}
$$

where $\alpha$ is a firing angle of thyristor.

The compensating reactive power $Q_{T C L-C T F}^{+}$is associated with the equivalent fundamental impendence of the TCL-CTF, which can be expressed as shown in Equation (23):

$$
Q_{T C L \_C T F}^{+}=\frac{U_{L}^{2}}{X_{T C L-C T F}(\alpha)}
$$

In other words, the $Q_{T C L-C T F}^{+}$is coupled with the capacitor $C_{1}$, reactor $L_{1}$, and firing angle $\alpha$. Thus, the relationships among these paraments are shown in Figure 2. 

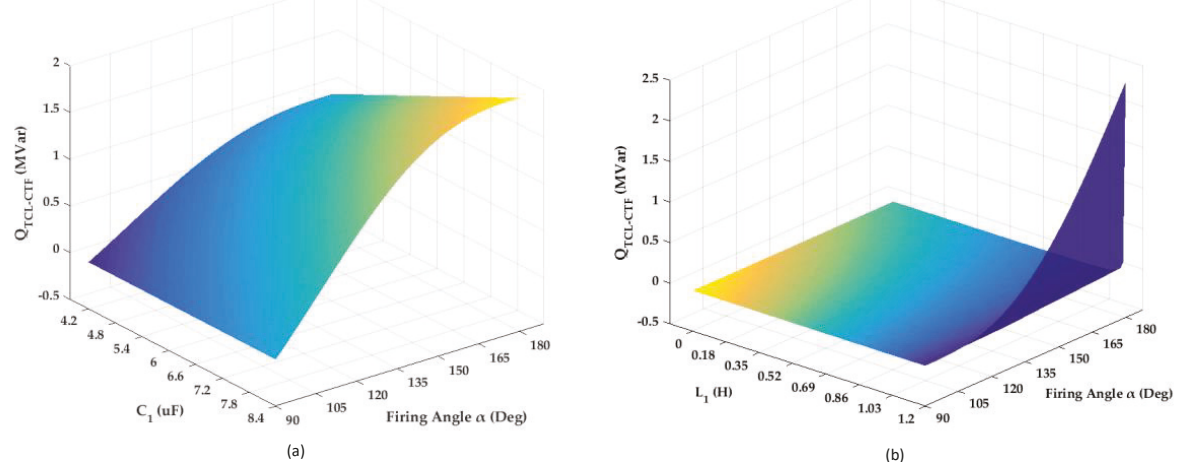

(b)

Figure 2. Relationship between the $Q_{T C L}^{+} C T F^{\prime}, C_{1}, L_{1}$, and $\alpha$. In (a), the varying between the $C_{1}$ and $\alpha$, $L_{1}$ is fixed; in (b), the varying between the $L_{1}, \alpha$, and $C_{1}$ is fixed.

As can be observed in Figure 2a, the firing angle $\alpha$ increases from $90^{\circ}$ to $180^{\circ}$, and the reactive power increases from 0 to $2 \mathrm{MVar}$ with the $C_{1}=8.4 \mu \mathrm{F}$, which means that the compensating inductive reactive power is decreasing and controlled by the thyristor. Similarly, the reactive power is totally offset when $L_{1}=1.2 \mathrm{H}, \alpha=90^{\circ}$; then, the compensating capacitive reactive power increases when the firing angle $\alpha$ changes from $90^{\circ}$ to $180^{\circ}$ in Figure $2 \mathrm{~b}$.

To control the TCL, the equivalent fundamental susceptance of the TCL can be expressed as:

$$
B_{T C L}(\alpha)=\frac{1}{X_{L_{1}}} \cdot\left(2-\frac{2 \alpha}{\pi}+\sin 2 \alpha\right)=\frac{1}{X_{L_{1}}} \cdot \frac{\delta-\sin \delta}{\pi}
$$

where $\delta$ is a conduction angle, $\delta=2(\pi-\alpha)$.

However, the relationship between the $B_{T C L}(\alpha), \delta$ and $\alpha$ is nonlinear, which means that it should add a linearization between the input and output of trigger pulse. In this paper, a look-up table (LUT) is adopted to address this obstruct [24].

\subsection{Compensation Parameters Calculation between $K_{U}$ and $K_{Q}$}

\subsubsection{Compensation Coefficient of $\mathrm{VU} K_{U}$}

Associating with Equations (5) and (6), the compensation coefficient of $\mathrm{VU}\left(K_{U}\right)$ can be expressed as:

$$
K_{U}=\frac{S_{L u 1}-S_{S u 1}^{*}}{S_{L u 1 \_P F C}}
$$

where $S_{L u 1}$ and $S_{L u 1 \_P F C}$ can be obtained as:

$$
S_{L_{L 1 \_} P F C}=\sqrt{\left(\bar{p}_{P F C}^{-}\right)^{2}+\left(\bar{q}_{P F C}^{-}\right)^{2}}, S_{L u 1}=\sqrt{\left(\bar{p}_{L}^{-}\right)^{2}+\left(\bar{q}_{L}^{-}\right)^{2}}
$$

Simultaneously, the reference fundamental unbalanced component of the system apparent power $\left(S_{S u 1}^{*}\right)$ can be represented by a function containing VUF.

$$
\begin{aligned}
S_{S u 1}^{*} & =u_{s}^{+} i_{s}^{-}+u_{s}^{-} i_{s}^{+}+u_{s}^{-} i_{s}^{-} \\
& =S_{S 1}^{+}(\mathrm{CUF}+\mathrm{VUF})+S_{S 1}^{-} \\
& =S_{S 1}^{+} \cdot\left[\frac{Z_{T P S S}^{+}}{Z_{T P S S}}\left(\mathrm{VUF}+\mathrm{VUF}^{2}\right)+\mathrm{VUF}\right]
\end{aligned}
$$


where $S_{S 1}^{+}$is the fundamental positive-sequence component of the system apparent power, while $Z_{T P S S}^{+}$ and $Z_{T P S S}^{-}$are the positive and negative sequence impedance of the TPSS.

The VUF values are dependent on the compensating target, which is restricted by the national power quality standard. The comparison of VU limits between the various countries is shown in Table 1.

Table 1. The comparison of voltage unbalance (VU) limits between the various countries.

\begin{tabular}{ccccc}
\hline & EN 50160 & $\begin{array}{c}\text { EDF Emeraude } \\
\text { Contract A.2 }\end{array}$ & Grid Code & $\begin{array}{c}\text { GB/T } \\
\mathbf{1 5 5 4 3 - 2 0 0 8}\end{array}$ \\
\hline Country/Organizations & EU & France & Britain & China \\
\hline $\begin{array}{c}\text { VU limit in low-voltage, } \\
\text { medium-voltage power system }\end{array}$ & $2 \%$ & $2 \%$ & $2 \%(<150 \mathrm{kV})$ & $2 \%$ \\
\hline $\begin{array}{c}\text { VU limit in high-voltage, } \\
\text { extra-high-voltage power system }\end{array}$ & $/$ & $2 \%$ & $1.5 \%$ & $2 \%$ \\
\hline
\end{tabular}

\subsubsection{Compensation Coefficient of PF $K_{Q}$}

According to the compensation target, the compensation coefficient of $\mathrm{PF}\left(K_{Q}\right)$ can be expressed as:

$$
K_{Q}=\frac{S_{L}^{+} \sin \left(\cos ^{-1} P F^{*}\right)}{Q_{L}^{+}}
$$

where, $P F^{*}$ is an expected power factor after compensating.

Furthermore, the equivalent fundamental susceptance of the TCL can be obtained as:

$$
B_{T C L}(\alpha)=\frac{Q_{L_{1}}^{*}}{U_{L}^{2}}=\frac{K_{Q} Q_{L}^{+}-Q_{C_{1}}}{U_{L}^{2}}
$$

\subsection{Control Block of the Proposed System}

Figure 3 shows the overall control block with the proposed optimized compensation control approach. The control block includes two parts, which are the PFC controller and TCL-CTF controller. The compensation currents of the grid side for the PFC follow their reference currents, which controlled by $K_{U}$ to achieve the $\mathrm{VU}$ compensation target. Note that the $K_{U}$ is a dynastic variable that depends on the traction load power and system condition reflected by the impedance variation. Similarly, the trigger signals of the TCL can be generated based on its equivalent fundamental susceptance, which associates with the capacitive reactive power depending on the traction net voltage, traction load power, and PF compensation target. 


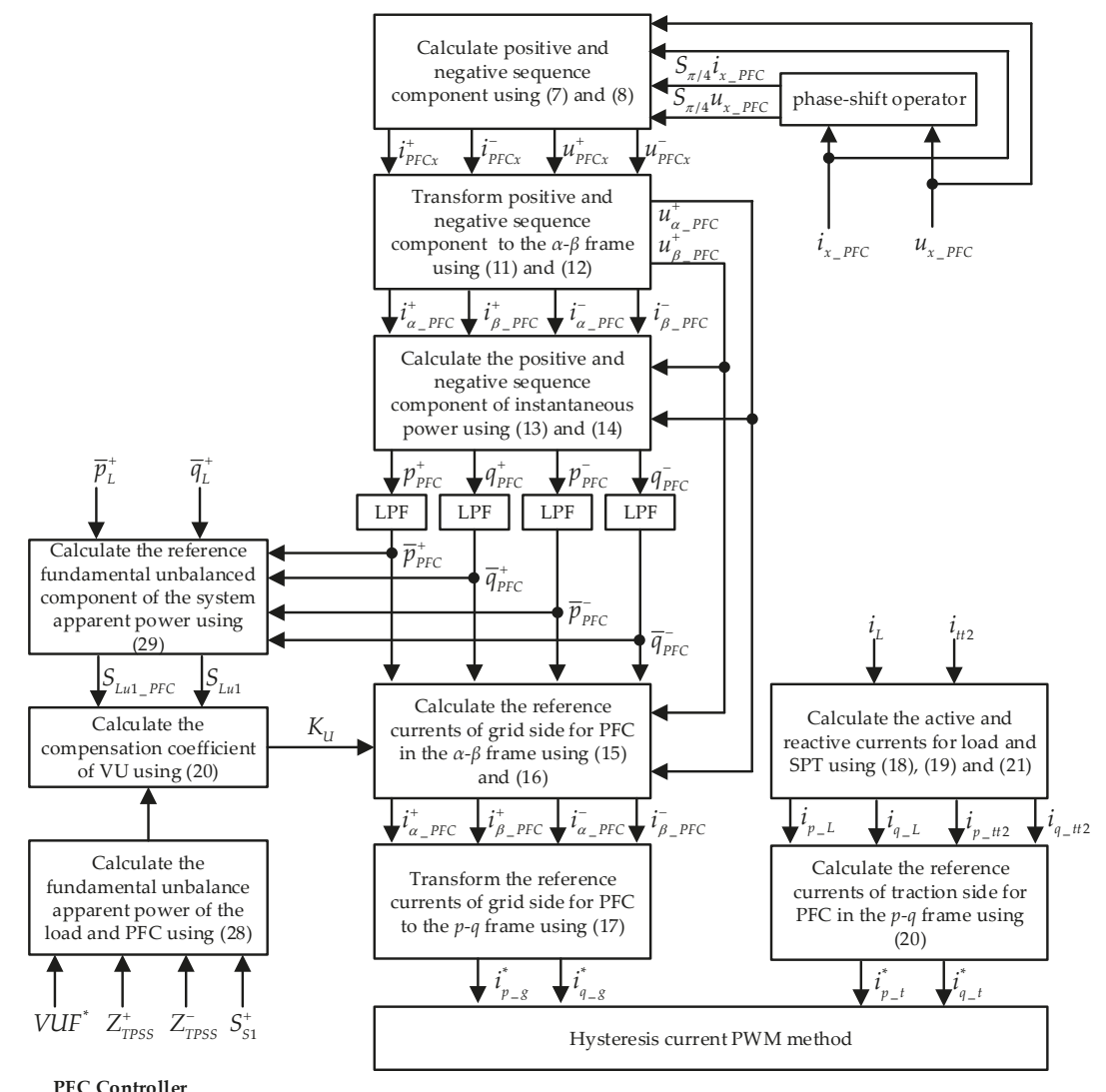

TCL-CTF Controller

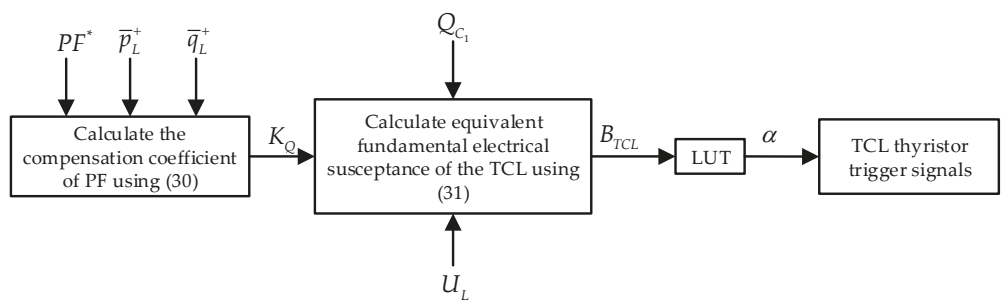

Figure 3. Control block of the optimized compensation strategy.

\section{Designing Parameters of the TCL-CTF}

\subsection{Resonance Damping Analysis}

To research the characteristics of the proposed TCL-CTF, the equivalent impedance of the CTF is given as a function of the angular frequency and the parameters as follows:

$$
\begin{aligned}
Z_{T C L-C T F}(\omega) & =-j X_{C_{1}}(\omega) / / j X_{L_{1}}(\omega)+R / /\left[j X_{L_{2}}(\omega)-j X_{C 2}(\omega)\right] \\
& =\frac{\frac{1}{j \omega C_{1}} \cdot j \omega L_{1}}{\frac{1}{j \omega C_{1}}+j \omega L_{1}}+\frac{\left(j \omega L_{2}+\frac{1}{j \omega C_{2}}\right) \cdot R}{R+j \omega L_{2}+\frac{1}{j \omega C_{2}}}=\frac{j \omega L_{1}}{1-\omega^{2} L_{1} C_{1}}+\frac{R\left(1-\omega^{2} L_{2} C_{2}\right)}{1-\omega^{2} L_{2} C_{2}+j \omega R C_{2}}
\end{aligned}
$$


Figure 4 shows the impedance-frequency response of the TCL-CTF between the various parameters changing. In Figure $4 \mathrm{a}$, when $Q_{L 1}^{+}$varies from 1 Mvar to 3 MVar, the resonance point increase from $36 \mathrm{~Hz}$ to $63 \mathrm{~Hz}$. Note that the resonance point at the fundamental frequency if $Q_{L 1}^{+}=Q_{C 1}^{+}$, which means that it is so dangerous that it should be avoided. However, the impedance characteristics of CTF maintain a stable status, the TCL-CTF obtains a minimum impedance when the frequency at the designated turning point $h_{t}$ is $1000 \mathrm{~Hz}$, and the impedance is close to 1 when the frequency is close to infinite. It is well known that the impedance-frequency characteristic of CTF is between the single-tuned filter and high-pass filter. In Figure $4 \mathrm{~b}$, when increasing the value of $R$, the minimum impedance is decreasing, and the character is more similar to that of a single-tuned filter, and vice versa. In Figure 4c, the turning point moves to a low-frequency area while increasing the value of $Q_{C 1}^{+}$.

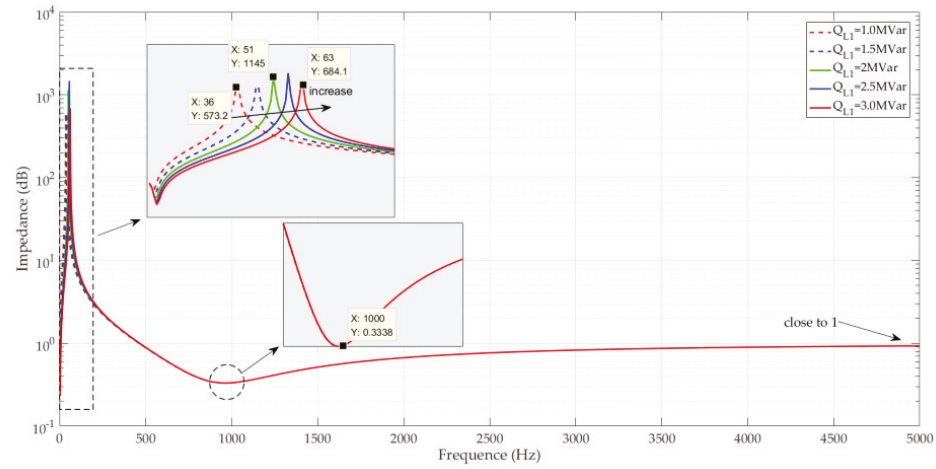

(a)

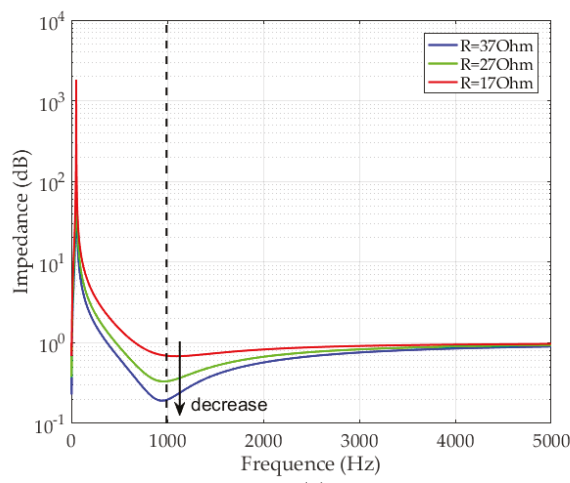

(b)

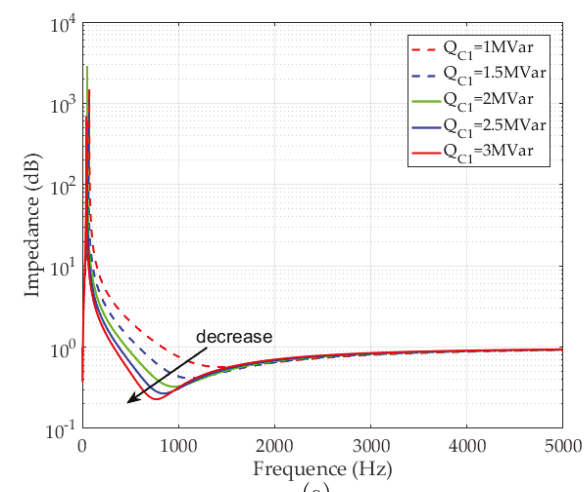

(c)

Figure 4. Resonance Damping Analysis. (a) Impedance-frequency response determined by different $L_{1}$; (b) Impedance-frequency response determined by different R; (c) Impedance-frequency response determined by different $C_{1}$.

Based on the above discussion, the parameters of the TCL-CTF can be divided into two independent parts: the TCL part and the CTF part. Meanwhile, the impedance of $L_{1}$ should be less than $C_{1}$ to avoid the parallel resonance at the fundamental frequency.

Furthermore, the impedance model has been constructed as shown in Figure 5. It includes three parts: system equivalent impedance, TCL-CTF impedance, and traction network impedance using the $\pi$ equivalent model. The traction load is a harmonic source, and the point of evaluation (POE) 1 and POE2 are set to assess the performance of the TCL-CTF. 


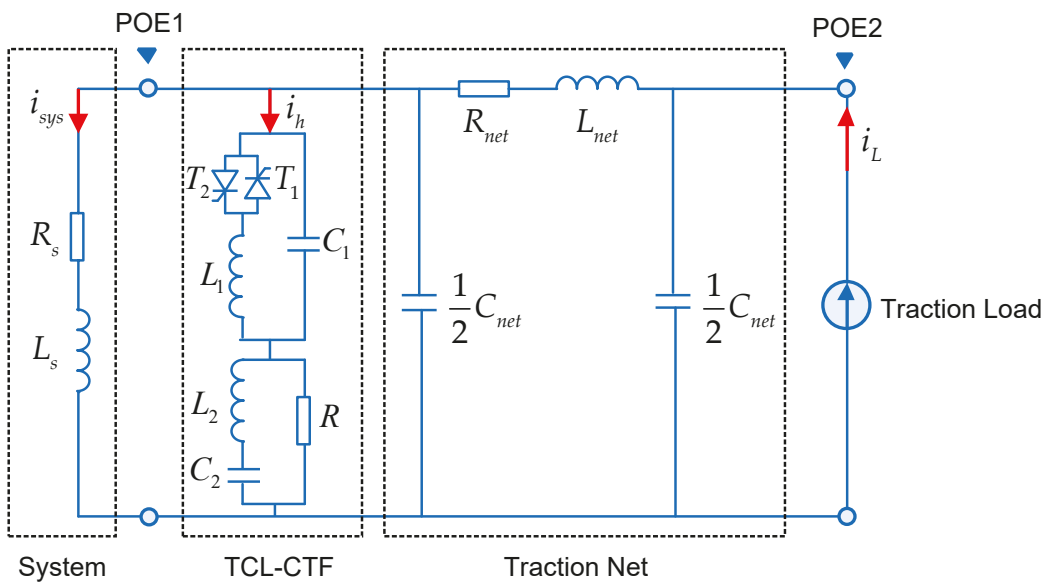

Figure 5. Impedance model of the system, thyristor-controlled $L$ and C-type filter (TCL-CTF), and traction net.

The impedance equation at the POE2 can be expressed as:

$$
\begin{aligned}
Z_{\text {eq }}(\omega) & =Z_{\text {net }}(\omega)+\left[Z_{s}(\omega) / / Z_{T C L-C T F}(\omega)\right] \\
& =Z_{\text {net }}(\omega)+\frac{Z_{s}(\omega) \cdot Z_{\text {TCL-CTF }}(\omega)}{Z_{s}(\omega)+Z_{\text {TCL-CTF }}(\omega)}
\end{aligned}
$$

where, $Z_{s}(\omega)=R_{s}+j \omega L_{s}, Z_{\text {net }}(\omega)=R_{\text {net }}+j X_{\text {net }}$, and the $Z_{\text {net }}(\omega)$ can be simplified from the $\pi$ equivalent model.

\subsection{Designing Parameters of CTF}

The capacitor $C_{1}$ is designed to compensate the reactive power at the fundamental frequency as well as improve the PF. Therefore, the value of $Q_{\mathrm{C} 1}^{+}$is determined by the expected PF and actual PF, which can be expressed as:

$$
Q_{C_{1}}^{+}=P_{L 1}^{+}\left[\sqrt{\left(\frac{1}{\cos \varphi_{L}}\right)^{2}-1}-\sqrt{\left(\frac{1}{\cos \varphi^{*}}\right)^{2}-1}\right]
$$

On the other hand, the function of improving PF can be seen as a particular solution for adjusting the voltage of the system. Thus, the ability of compensating voltage can be expressed as:

$$
\Delta U_{L}=1-\frac{Q_{c}^{+}}{S_{s c}}
$$

Furthermore, the value of $C_{1}$ can be calculated by Equation (35):

$$
C_{1}=\frac{Q_{C_{1}}^{+}}{\omega_{1} U_{L}^{2}}
$$

After selecting a turning point $\left(h_{t}\right)$, the value of $C_{2}$ is restricted by $h_{t}$ and $C_{1}$.

$$
\left(h_{t}^{2}-1\right) C_{1}>C_{2} \geq\left(\frac{h_{t}^{2}-1}{h_{t}^{2}}\right) C_{1}
$$


Moreover, the value of $C_{2}$ is limited by a relationship $\omega_{1} L_{2}=1 /\left(\omega_{1} C_{2}\right)$, which is why the $C_{2}$ is not used for compensating reactive power, but rather is used for reducing the fundamental loss of $R$.

$$
L_{2}=\frac{1}{\omega_{1}^{2} C_{2}}
$$

Finally, the filter reactance $R$ can be obtained as shown in Equation (38). Note that the R should equal zero when the frequency is at $h_{t}$.

$$
R=\frac{1}{\omega_{1} h_{t} \sqrt{\left(h_{t}^{2}-1\right) C_{1} C_{2}-C_{2}^{2}}}
$$

\section{Simulation and Experimental Validation}

\subsection{Field Testing and Designing Parameter of TCL-CTF}

As an illustration, a field testing of a typical railway has been implemented in China, in which the sampling frequency of power-quality monitor is $10 \mathrm{KHz}$, and the testing cycle is $24 \mathrm{~h}$. The main circuit of the traction substation (TSS) and the monitoring points are shown in Figure 6a, the CT1 to CT4 are the high-voltage current transformers of the single-phase traction side, which was utilized for accurately measuring the currents for different feeding sections; PT1 and PT2 are the voltage transformers of the single-phase traction side, which are used for accurately measuring the busbar voltage; the CT5 and PT3 are the current and voltage transformer for the three-phase power grid side, respectively. The monitoring points are installed on these transformers' low-voltage side. The equipment's connection and layout are shown in Figure 6b. Take CT1 and PT1 as examples; the voltage can be measured by using the probe to connect the voltage port, and the current can be detected by warping the Rogowski coils around the current wire. The current sensor uses a Fluke i5s current clamp and Rogowski coils. The rated parameters of the current sensor and current transformer are shown in Table 2. The power quality monitor satisfies the requirements of IEC61000-4-5 and IEC 61000-4-7, which can be used for measuring the harmonic. Alternatively, the various algorithms are presented to improve the accuracy of harmonic detection, such as the adaptive Kaiser self-convolution window in [31], which is an adaptive variational mode decomposition in [32].

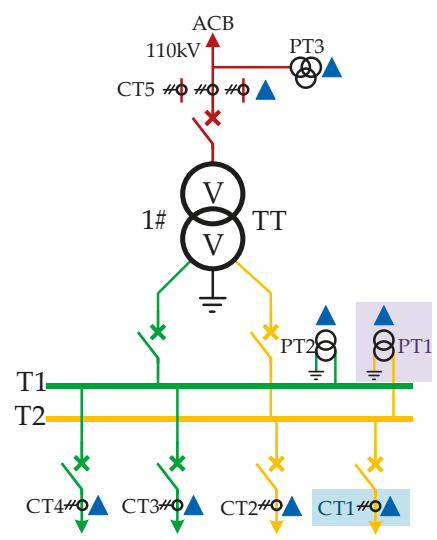

(a)

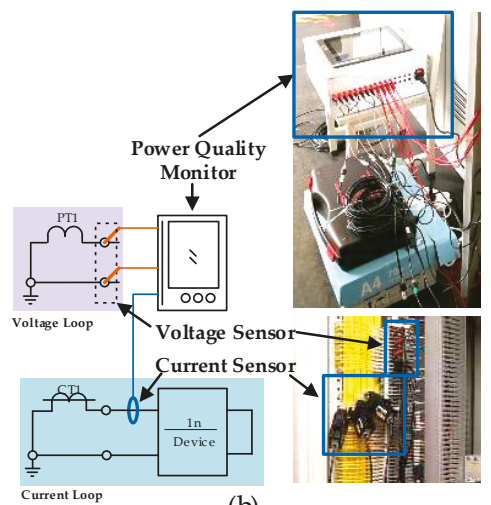

(b)

Figure 6. Power quality test in a traction substation (TSS). (a) Main circuit of TSS and monitoring points ( $\Delta$ is the monitoring point); (b) Equipment's connection and layout in the field. 
Table 2. The key parameters of the current sensor and current transformer.

\begin{tabular}{cccccc}
\hline & Parameters & Values & Parameters & Values \\
\hline $\begin{array}{c}\text { Current } \\
\text { Transformer }\end{array}$ & Rated current of primary side (A) & 1500 & Current & Nominal current range (A) & $5 \mathrm{~A}$ \\
& Rated current of second side (A) & 5 & Basic Accuracy & $1 \%$ \\
& & & Sensor & Useable frequency (Hz) & $40 \sim 5 \mathrm{~K}$ \\
\hline
\end{tabular}

An integral load current process is shown in Figure 7a. Since the train is an impact load, the load current of the feeding section could rapidly increase from 0 to $2500 \mathrm{~A}$ in a short time when multiple trains accelerated simultaneously. Moreover, the $95 \%$ probability value of the load current is $972 \mathrm{~A}$, although the $50 \%$ probability value of the load current is $223 \mathrm{~A}$. In Figure $7 \mathrm{~b}$, the voltage of the feeding section is associated with the current process; the $25.44 \mathrm{kV}$ and $27.93 \mathrm{kV}$ are the lowest and highest voltage during a day, respectively, which means that the voltage fluctuation has arrived at $2.49 \mathrm{kV}$ due to the intense load change. Furthermore, the $50 \%$ probability value of voltage and the $95 \%$ probability value of voltage are $27.5 \mathrm{kV}$ and $27.7 \mathrm{kV}$, respectively. In Figure $7 \mathrm{c}$, the load current is mainly distributed in [392 A 416.5 A], [220 A 245 A], and [784 A 808.5 A] based on the mathematical statistics. In Figure 7d, the voltage of the feeding section is stale in [27.75 27.78] most of the time, which benefits from the strong ability of the power supply. As shown in Figure 8, the instantaneous PF can reach 1 when the trains are running on the railway line, but the avenge PF of the feeding section is equal to 0.86 for the whole day.

On the other hand, the fundamental current variation and harmonic ratio of current (HRI) variation are shown in Figure 9a,b, respectively. When a train is running on the railway line, it not only emits the low-frequency harmonics, such as the third, fifth, and seventh harmonics, but also issues the high-frequency harmonics, especially for 25th, 35th, and 40th harmonics. In recent years, the threat that the high-frequency harmonic variation problem poses to the security of trains has drawn wide attention $[18,19]$; it is an important influencing factor on traction network resonance. According to the field testing result and published academic research studies [18], the 20th harmonic is an appropriate turning point $\left(h_{t}\right)$ of the TCL-CTF.

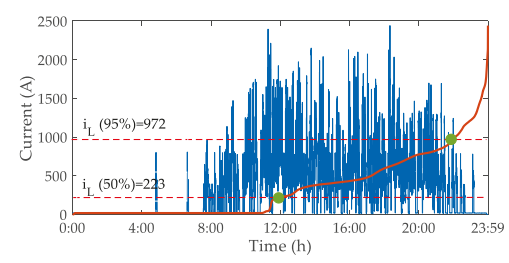

(a)

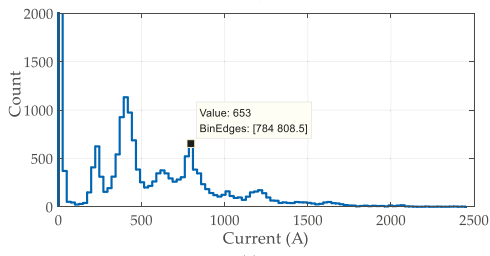

(c)

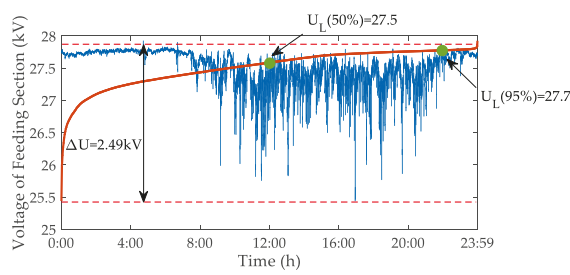

(b)

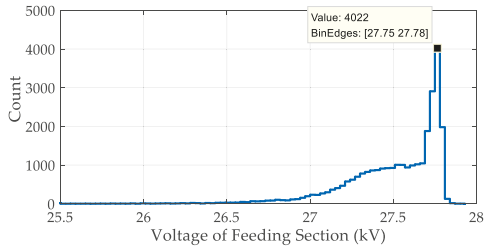

(d)

Figure 7. The measurements and statistical results of the $\alpha$ feeding section. (a) The current variation during a day; (b) the voltage variation during a day; (c) the histogram of current in (a); (d) the histogram of voltage in (b). 


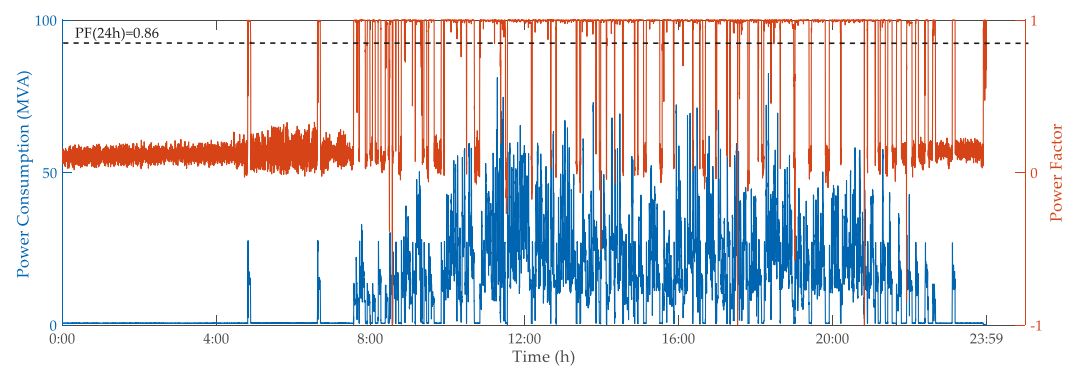

Figure 8. Power factor (PF) distribution and power consumption of the $\alpha$ feeding section.

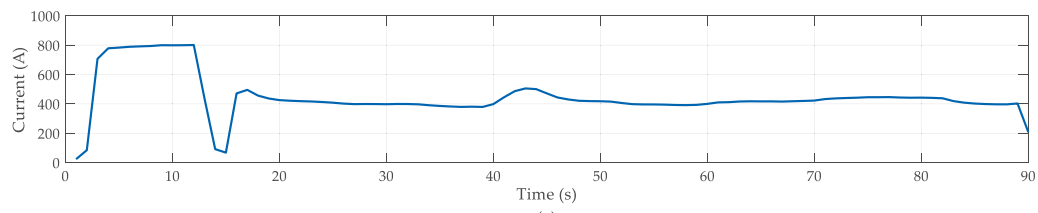

(a)

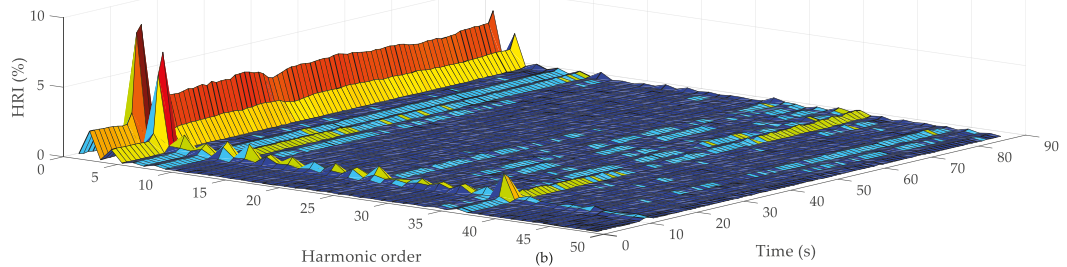

Figure 9. Harmonic ratio of current (HRI) variation. (a) Current process of traction load; (b) HRI process of traction load between the second and 50th harmonic order.

Based on Section 5.2 and field testing results, the key parameters of the TCL-CTF are shown in Table 3. Moreover, the positive sequence of active power $P_{L}^{+}$is calculated by the $95 \%$ probability value of load current and the $95 \%$ probability value of voltage $U_{L}$.

Table 3. The key parameters of the TCL-CTF.

\begin{tabular}{cccc}
\hline Input Parameters & Values & Output Parameters & Values \\
\hline $\cos \varphi_{L}^{*}$ & 0.90 & $C_{1}(\mu \mathrm{F})$ & 10 \\
$\cos \varphi_{L}$ & 0.86 & $L_{1}(\mathrm{H})$ & 1.2 \\
$P_{L}^{+}(\mathrm{MW})$ & 22 & $C_{2}(\mathrm{mF})$ & 3.5 \\
$U_{L}(\mathrm{kV})$ & 27.7 & $L_{2}(\mathrm{mH})$ & 2.9 \\
$Q_{C_{1}}^{+}(\mathrm{MVar})$ & 2.45 & $R(\Omega)$ & 27.12 \\
$h_{t}$ & 20 & & \\
\hline
\end{tabular}

It should be emphasized that the impact of the impedance frequency of the TPSS should also be considered; an ideal TCL-CTF can not only filter the high-order harmonic, but also move the resonance points of the TPSS to a specific region, which can reduce the probability of resonance. Therefore, based on the field parameters, the simulation model including the TSS and traction net is established by MATLAB/SIMULINK, and then the frequency-scanning module is used to obtain the impedance-frequency response of the TPSS; the impedance-frequency response seen from the train side is shown in Figure 10. 

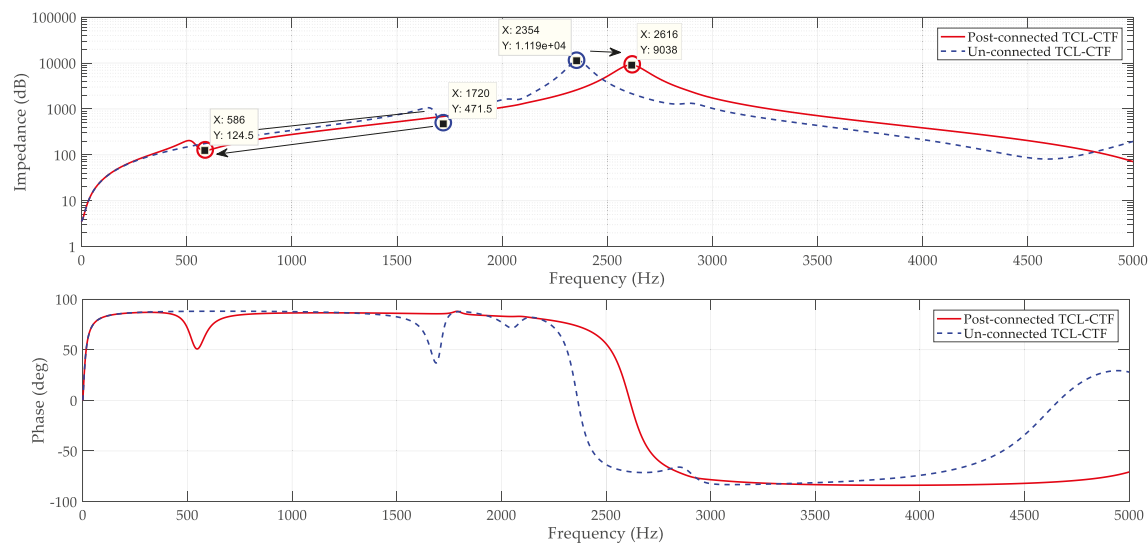

Figure 10. Bode diagram of the traction power supply system (TPSS) with the TCL-CTF.

As shown in Figure 10, before the TCL-CTF connects to the TPSS, the resonance points are $1720 \mathrm{~Hz}$ (34th) and $2354 \mathrm{~Hz}$ (47th); after it connected, one point moves to a low-frequency area (586 Hz, 11th), while the other point moves to the high-frequency area $(2616 \mathrm{~Hz}, 52 \mathrm{th})$. However, the value of the capacitor will decrease as time goes by, the resonance points will also move to the high-frequency area. For example, the resonance points at the 11th can transfer to the 12th or 13th, which possess poor harmonic content relative to another harmonic region, as shown in Figure 9b. Consequently, the TCL-CTF is completely designed via the theoretical calculation; then, it still needs to test its filtering performance by simulation and experiment.

\subsection{Vaildation of Filtering Performance}

\subsubsection{Simulation Results}

To simulate the filtering characteristic of the TCL-CTF, a simulation model of the TPSS is established with MATLAB/SIMULINK, as shown in Figure 11. The simulation model assumes the system parameters $S_{S C}=2000 \mathrm{MVA}, \mathrm{X} / \mathrm{R}=7$; the basic parameters of traction net and TT come from the field TSS in Section 6.1; the typical harmonic current model of the train comes from the field testing result.

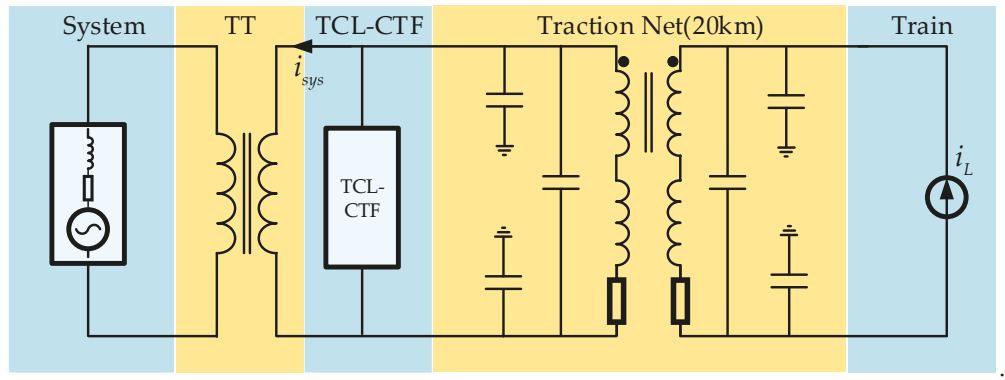

Figure 11. Diagram of filtering characteristic simulation.

In Figure 12, the equal amplitude's currents with the different harmonic order $i_{L}$ are injected to the model respectively, the currents flowing into power system $i_{\text {sys }}$ are measured at the same time. On the one hand, when the ninth and 11th harmonic currents are injected, the $i_{s y s}$ is larger than $i_{L}$ for 
each frequency, which means that the resonance point of the TPSS is correctly portrayed. On the other hand, it can be seen that the amplitude of $i_{s y s}$ is less than $i_{L}$ when the currents of frequency arrived at the 17th, 19th, 23rd and 37th harmonic currents. Furthermore, the amplitude of $i_{s y s}$ is smaller with the harmonic order increasing. Thus, it can be concluded that the filtering characteristic of the TCL-CTF meets the design requirements, which can filter out the high-frequency harmonic current.
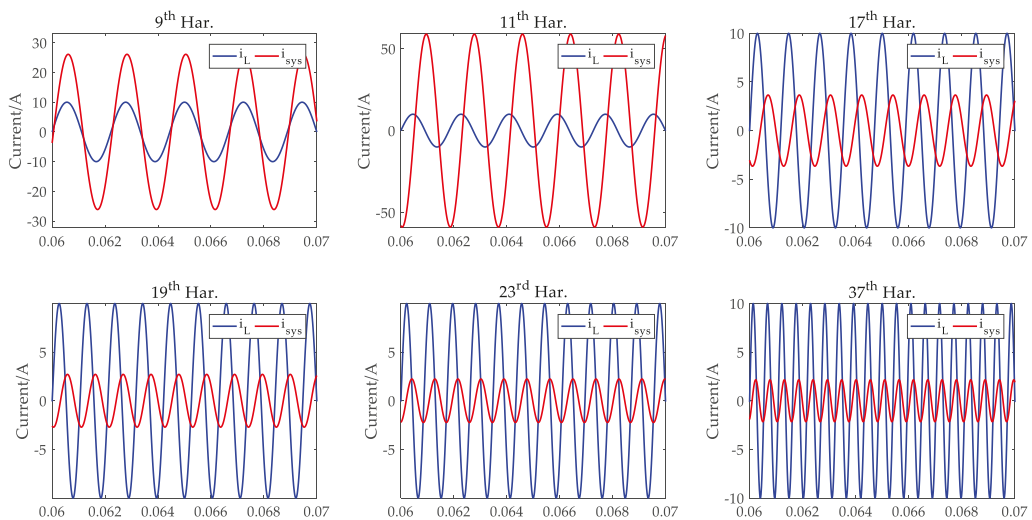

Figure 12. Simulation result of filtering characteristic for the TCL-CTF.

In Figure 13, the real harmonic currents are injected into the model. It can be seen that the high-frequency harmonic components can be effectively diminished by the TCL-CTF. Thus, the designed parameter of the TCL-CTF can effectively filter out the high-frequency harmonics. On the other hand, compared with bode diagram of the TPSS with the TCL-CTF in Figure 10, the resonance point at $586 \mathrm{~Hz}$ is accurately portrayed, which verifies that Equation (33) can be used to study the impedance-frequency response.

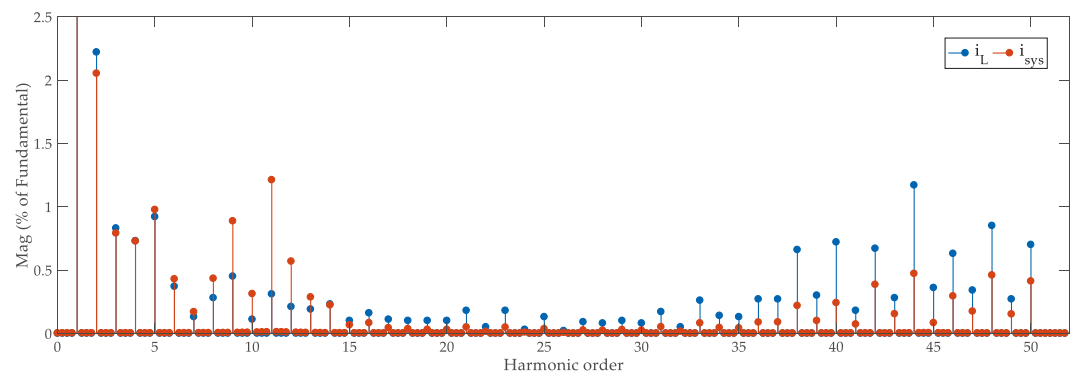

Figure 13. Waveforms and fast Fourier transform (FFT) spectrum of $i_{L}$ and $i_{\text {sys }}$.

\subsubsection{Experimental Results}

To test the actual filtering characteristic of the TCL-CTF, an experimental prototype of the TCL-CTF is constructed in the laboratory, as shown in Figure 14. Constrained by the voltage level and actual condition, it is difficult to establish a high-voltage system, TT, and actual traction net in the laboratory. Thus, a passive RL series component can be adopted to portray the impedance-frequency response of these components, and the equivalent impedance can be obtained by scanning the simulation model via using the frequency-scanning module in MATLAB/SIMULINK. The relative values are shown in Table 4. Finally, a passive simplified equivalent circuit is built, as shown in Figure 5. The traction 
load can be simplified as a harmonic current source. The waveforms are acquired by a DSO-7014A scope recorder.

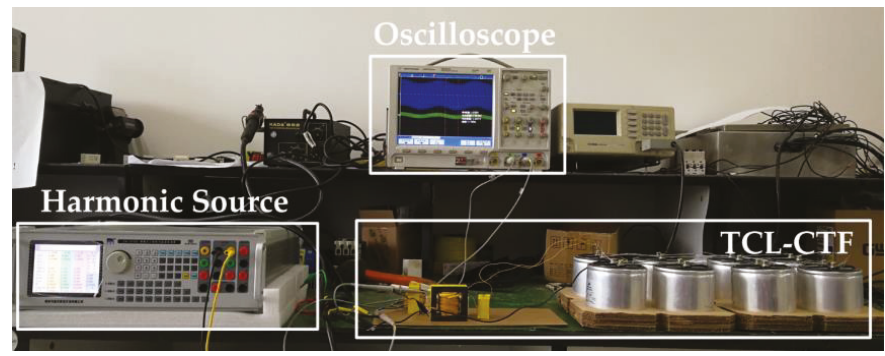

Figure 14. Experimental system of the TCL-CTF.

Table 4. The impedance parameter of an equivalent system and simplified traction network.

\begin{tabular}{cc}
\hline Parameters & Values \\
\hline$R_{S}$ & $0.122 \Omega$ \\
$L_{S}$ & $6.27 \mathrm{mH}$ \\
$R_{\text {net }}$ & $3.5 \Omega$ \\
$L_{\text {net }}$ & $39.01 \mathrm{mH}$ \\
\hline
\end{tabular}

Figure 15 shows the experimental results of harmonic voltage at the POE1 and POE2, with ninth and 11th harmonics. In Figure 15, the system resonance point around $586 \mathrm{~Hz}$ has been verified. The system causes a severe oscillation, causing the scope recorder to not correctly identify the frequency when injecting an 11th harmonic current at POE2. Furthermore, the experimental platform can be used to demonstrate the effectiveness of the TCL-CTF.
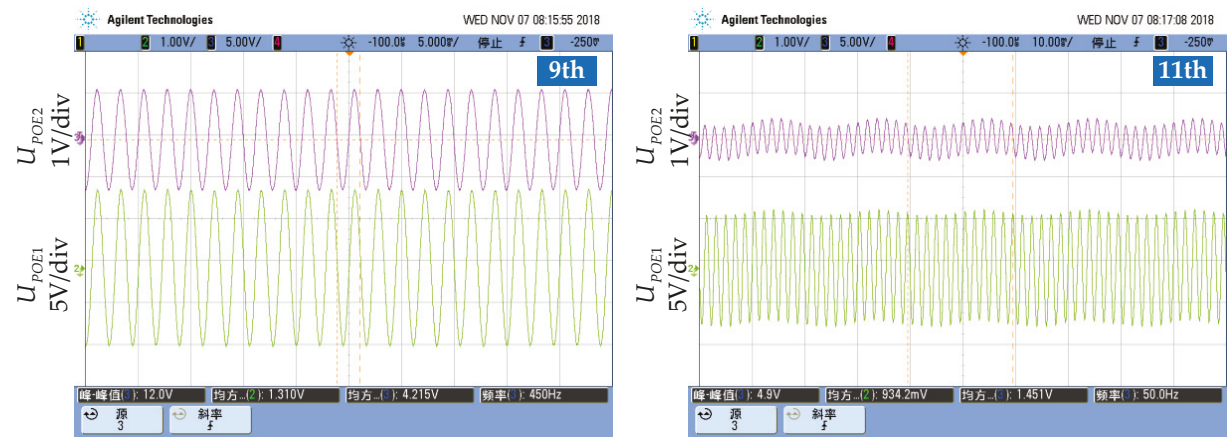

Figure 15. Experimental results of harmonic voltage at the point of evaluation 1 (POE1) and POE2 (9th, 11th harmonic).

Figure 16 shows the experimental results of harmonic voltage at the POE1 and POE2, with the 17th, 19th, 23th, and 37th harmonics. In Figure 16, the harmonic voltage of POE1 is less than $100 \mathrm{mV}$ when the harmonic voltage of POE2 is approximately equal to $2 \mathrm{~V}$, which means that the harmonic current can be effectively filtered out after 19th harmonic. Thus, it can be concluded that the proposed TCL-CTF structure is available to impair the influence of high-frequency harmonics on the TPSS. 

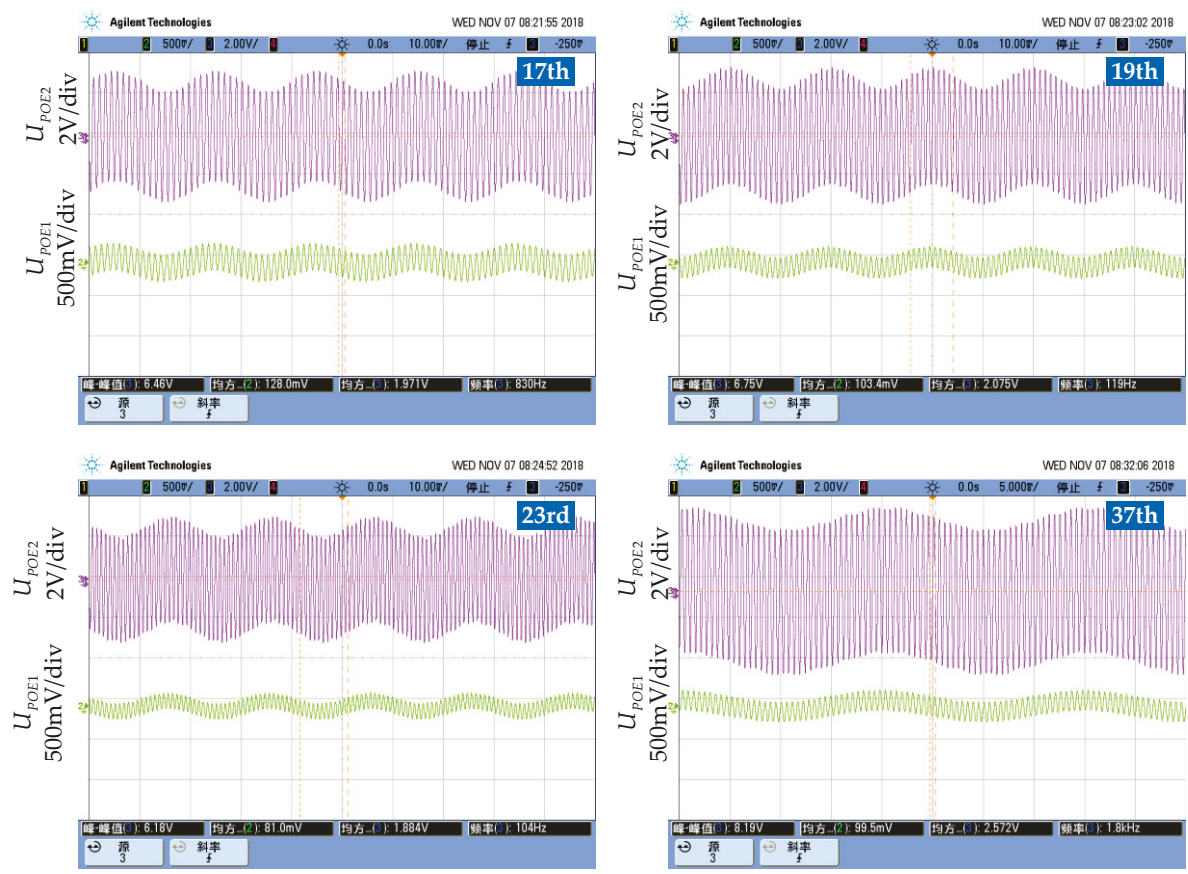

Figure 16. Experimental results of harmonic voltage at the POE1 and POE2 (17th, 19th, 23rd, and 37th harmonic).

\subsection{Vaildation of Compensation Performance}

To testify the compensation performance of the hybrid power quality compensation system, a simulation model is established with MATLAB/SIMULINK, as shown in Figure 17. In the simulation model, a cascaded H-bridge multilevel construct is adopted to the PFC; the related parameters are shown in Table 5. Moreover, the constant power source is used for simulating the trains.

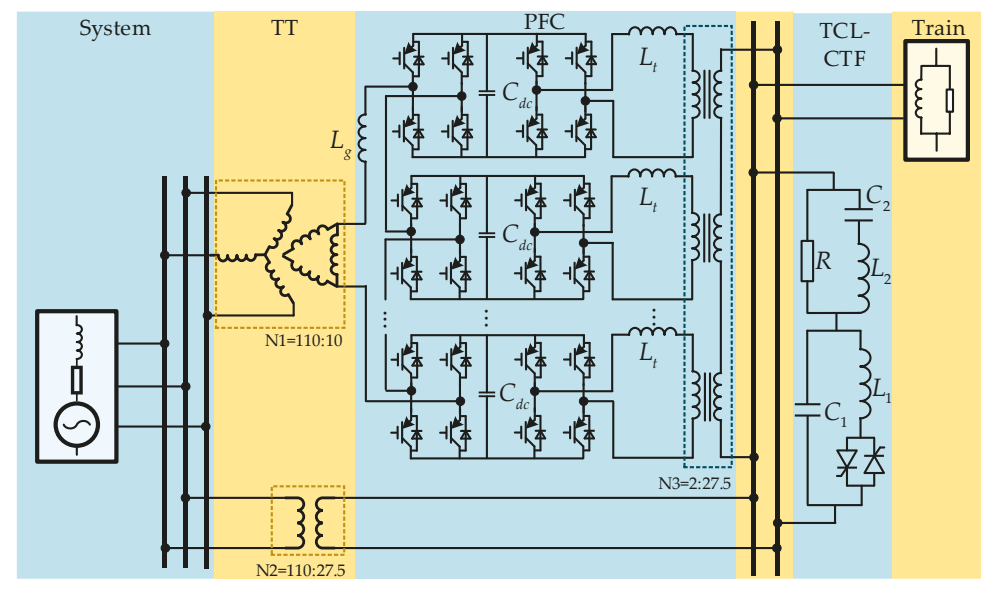

Figure 17. Diagram of compensation controlling simulation. 
Table 5. The parameters of the power flow controller (PFC).

\begin{tabular}{cc}
\hline Parameters & Values \\
\hline$L_{g}$ & $20 \mathrm{mH}$ \\
$C_{d c}$ & $4000 \mu \mathrm{F}$ \\
$U_{d c}$ & $3 \mathrm{kV}$ \\
$L_{t}$ & $3 \mathrm{mH}$ \\
Number of H-bridges & 5 \\
\hline
\end{tabular}

Figure 18 shows the simulation results of unbalanced compensation performance. When VU compensation is disabled, the $S_{S p}$ is approximately equal to the $S_{S u 1}$, and the VUF of the system arrives at $2.8 \%$. After the VU compensation is enabled at $1 \mathrm{~s}$, the $S_{S u 1}$ is apparently decreased to $20 \mathrm{MVA}$, and the VUF of the system is controlled to the VU compensation target $2 \%$. On the other hand, the compensation performance can be still stably maintained, even though the traction load fluctuates from 30 MVA to 40 MVA at $1.5 \mathrm{~s}$. Thus, the proposed control strategy for VU compensation is available, even when the load changes rapidly.
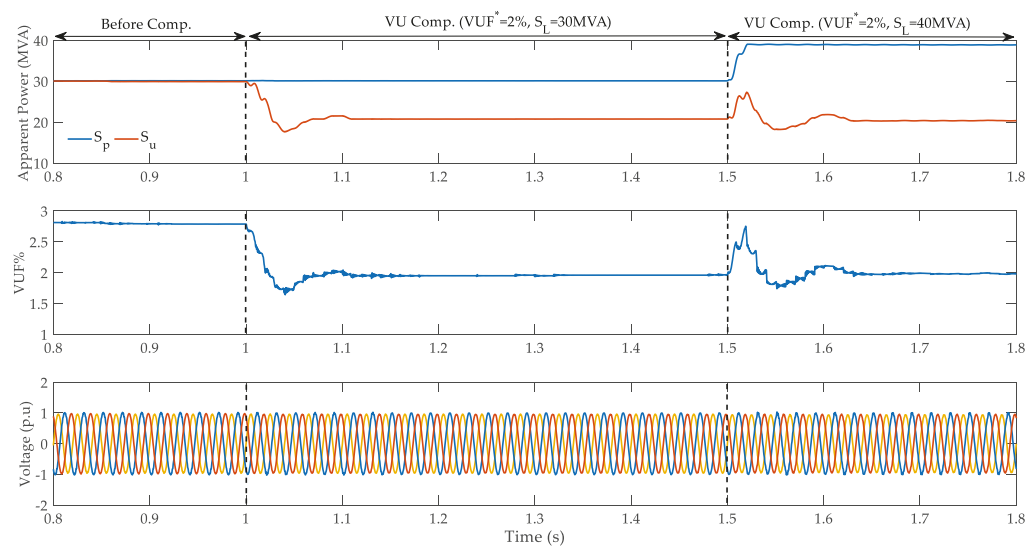

Figure 18. Simulation results of unbalanced compensation performance.

Figure 19 shows the simulation results of the PFC working process with unbalanced compensation. It can be seen that the negative sequence current aroused by traction load is almost injected to the system via the SPT branch when the VU compensation is disabled. After the VU compensation is enabled, the negative sequence current flowing through the SPT branch dramatically decreases with the increase of the PFC branch current, which means that the PFC block is working for VU compensation. Simultaneously, the instantaneous current can respond to the reference current change timely between the grid side and traction side of the PFC.

With regard to reducing the kVA rating of the converter, we compare the strategy proposed in this paper and [17]. The calculation results are shown in Table 6, which are based on Equation (22). After adopting the PFC to transfer the partial active power and optimize and compensate for the VU, $12 \%$ of the capacity of PFC can be released, to 29.84 MVA. Furthermore, the proposed control strategy and scheme can save $\$ 261,000$, at least according to the cost investigate result. 

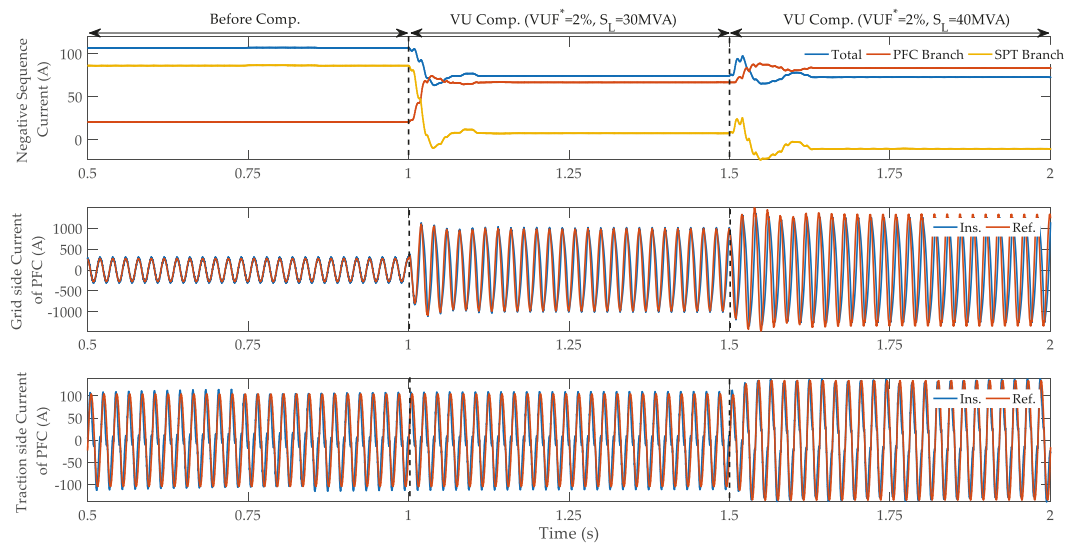

Figure 19. Simulation results of the power flow controller (PFC) working process with unbalanced compensation.

Table 6. Comparisons between improved strategy and strategy proposed in [17].

\begin{tabular}{cccccccc}
\hline Strategy & $S_{L}$ (MVA) & VUF* $\left.^{*} \%\right)$ & $u_{P F C_{-} g^{\prime}} u_{P F C_{-} t}(\mathbf{k V})$ & $i_{P F C_{-} g}(\mathrm{~A})$ & $i_{P F C_{-} t}(\mathrm{~A})$ & $S_{P F C}$ (MVA) & $\Delta S_{P F C}$ (p.u.) \\
\hline Case in [17] & 30 & 2 & 27.5 & 1054 & 179 & 33.91 & 1 \\
Case in this paper & 30 & 2 & 27.5 & 981 & 104 & 29.84 & 0.88 \\
\hline
\end{tabular}

Figure 20 shows the simulation results of reactive power compensation by using the TCL-CTF; the TCL-CTF can compensate for the reactive power of the traction load to $10 \mathrm{MVar}$ via the original $15 \mathrm{MVar}$, and the PF has been increased to 0.9 from the original 0.8 , even when the load changes rapidly. Thus, the proposed control strategy of the TCL-CTF can effectively compensate for the PF.
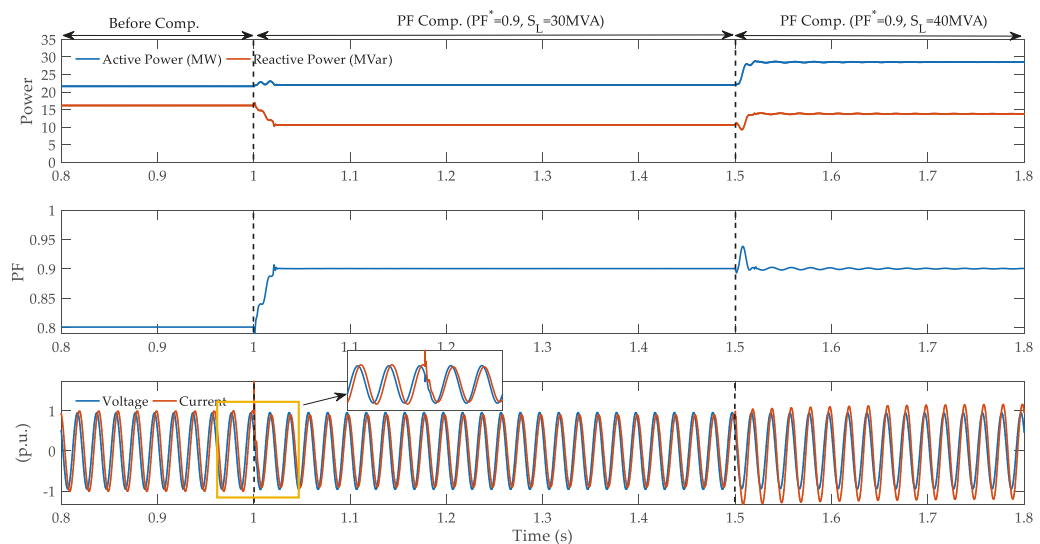

Figure 20. Simulation results of reactive power compensation by using the TCL-CTF.

\section{Conclusions}

In this paper, a novel hybrid power quality compensation system was proposed to compensate for the VU, reactive power, and filter out the high-frequency harmonics. Furthermore, an optimized compensation strategy was presented to offset the power quality of the TPSS, which meets the requirement of the technology standard. Moreover, the resonance damping and design method of 
the TCL-CTF were analyzed and discussed. Finally, the effectiveness of the proposed configuration and control approach was demonstrated by the simulation and experiment. Due to adopting the novel hybrid power quality compensation system, the PFC capacity can be apparently reduced by $12 \%$ compared with the conventional scheme.

Author Contributions: M.C. and Y.C. proposed the idea, developed the model, performed the simulation works, and wrote the paper. M.W. was in charge of the simulation and experimental works.

Acknowledgments: This work was supported by the Open Project Foundation of National Rail Transportation Electrification and Automation Engineering Technology Research Center (Grant No. NEEC-2018-A03), National Natural Science Foundation of China (Grant No. 51877182) and the Science and Technology Projects of Sichuan Province (Grant No. 2018FZ0107).

Conflicts of Interest: The authors declare no conflict of interest.

$\begin{array}{ll}\text { Abbreviations } \\ \text { AC } & \text { Alternating current } \\ \text { APF } & \text { Active power filter } \\ \text { DC } & \text { Direct current } \\ \text { EMU } & \text { Electric multiple unit } \\ \text { IGBT } & \text { Insulated gate bipolar transistor } \\ \text { LUT } & \text { Look-up table } \\ \text { MMC } & \text { Modular multilevel converter } \\ \text { MOSFET } & \text { Metal-oxide-semiconductor field-effect transistor } \\ \text { NSC } & \text { Negative-sequence current } \\ \text { PF } & \text { Power factor } \\ \text { PFC } & \text { Power flow converter } \\ \text { POE } & \text { Point of evaluation } \\ \text { PPF } & \text { Passive power filter } \\ \text { RPC } & \text { Railway static power conditioner } \\ \text { SPT } & \text { Single-phase transformer } \\ \text { SVC } & \text { Static var compensator } \\ \text { TCLC } & \text { Thyristor-controlled LC-coupling } \\ \text { TCL-CTF } & \text { Thyristor-controlled } L \text { and C-type filter } \\ \text { TPSS } & \text { Traction power supply system } \\ \text { TT } & \text { Traction transformer } \\ \text { VU } & \text { Voltage unbalance } \\ \text { VUF } & \text { Voltage unbalance factor } \\ & \end{array}$

\section{References}

1. Chen, Z.; Haynes, K.E. Impact of high-speed rail on regional economic disparity in China. J. Trans. Geog. 2017, 65, 80-91. [CrossRef]

2. Diao, M. Does growth follow the rail? The potential impact of high-speed rail on the economic geography of China. Trans. Res. Part A Policy Pract. 2018, 113, 279-290. [CrossRef]

3. Development Plan of Modern Integrated Transport System in the 13th Five-Year Plan. Available online: http://www.ndrc.gov.cn/gzdt/201703/t20170302_840225 (accessed on 3 February 2017).

4. Gazafrudi, S.M.M.; Langerudy, A.T.; Fuchs, E.F.; Al-Haddad, K. Power Quality Issues in Railway Electrification: A Comprehensive Perspective. IEEE Trans. Ind. Electron. 2015, 62, 3081-3090. [CrossRef]

5. Chen, Y.; Chen, M.; Tian, Z.; Liu, L.; Hillmansen, S. VU limit pre-assessment for high-speed railway considering a grid connection scheme. IET Gener. Transm. Distrib. 2019, 13, 1121-1131. [CrossRef]

6. Kotsampopoulos, P.; Georgilakis, P.; Lagos, D.T.; Kleftakis, V.; Hatziargyriou, N. FACTS Providing Grid Services: Applications and Testing. Energies 2019, 12, 2554. [CrossRef]

7. Gandoman, F.H.; Ahmadi, A.; Sharaf, A.M.; Siano, P.; Pou, J.; Hredzak, B.; Agelidis, V.G. Review of FACTS technologies and applications for power quality in smart grids with renewable energy systems. Renew. Sustain. Energy Rev. 2018, 82, 502-514. [CrossRef] 
8. Serrano-Jiménez, D.; Abrahamsson, L.; Castaño-Solís, S.; Sanz-Feito, J. Electrical railway power supply systems: Current situation and future trends. Int. J. Electr Power Energy Syst. 2017, 92, 181-192. [CrossRef]

9. Morimoto, H.; Ando, M.; Mochinaga, Y.; Kato, T.; Yoshizawa, J.; Gomi, T.; Oozeki, S. Development of railway static power conditioner used at substation for Shinkansen. In Proceedings of the Power Conversion Conference, Osaka, Japan, 2-5 April 2002; pp. 1108-1111.

10. Roudsari, M.H.; Jalilian, A.; Jamali, S. Flexible Fractional Compensating Mode for Railway Static Power Conditioner in a $v / v$ Traction Power Supply System. IEEE Trans. Ind. Electron. 2018, 65, 7963-7974. [CrossRef]

11. Cui, G.; Luo, L.; Li, Y.; Liang, C.; Hu, S.; Xie, B.; Wang, T. YN/VD connected balance transformer-based hybrid power quality compensator for harmonic suppression and reactive power compensation of electrical railway power systems. Int. J. Electr. Power Energy Syst. 2019, 113, 481-491. [CrossRef]

12. Zhang, Z.; Xie, B.; Hu, S.; Li, Y.; Luo, L.; Rehtanz, C.; Krause, O. Reactive Power Compensation and Negative-Sequence Current Suppression System for Electrical Railways with YNvd-Connected Balance Transformer-Part I: Theoretical Analysis. IEEE Trans. Power Electron. 2018, 33, 272-282. [CrossRef]

13. Li, Q. New Generation Traction Power Supply System and its Key Technologies for Electrified Railways. J. Mod. Transp. 2015, 23,1-11. [CrossRef]

14. Shu, Z.; Xie, S.; Lu, K.; Zhao, Y.; Nan, X.; Qiu, D.; Zhou, F.; Gao, S.; Li, Q. Digital Detection, Control, and Distribution System for Co-Phase Traction Power Supply Application. IEEE Trans. Ind. Electron. 2013, 60, 1831-1839. [CrossRef]

15. He, X.; Ren, H.; Lin, J.; Han, P.; Wang, Y.; Peng, X.; Shu, Z. Power Flow Analysis of the Advanced Co-Phase Traction Power Supply System. Energies 2019, 12, 754. [CrossRef]

16. Dai, N.Y.; Lao, K.; Lam, C. Hybrid Railway Power Conditioner with Partial Compensation for Converter Rating Reduction. IEEE Trans. Ind. Appl. 2015, 51, 4130-4138. [CrossRef]

17. Chen, M.; Li, Q.; Roberts, C.; Hillmansen, S.; Tricoli, P.; Zhao, N.; Krastev, I. Modelling and performance analysis of advanced combined co-phase traction power supply system in electrified railway. IET Gener. Transm. Distrib. 2016, 10, 906-916. [CrossRef]

18. Chen, M.; Roberts, C.; Weston, P.; Hillmansen, S.; Zhao, N.; Han, X. Harmonic modelling and prediction of high-speed electric train based on non-parametric confidence interval estimation method. Int. J. Electr. Power Energy Syst. 2017, 87, 176-186. [CrossRef]

19. Zhang, R.; Lin, F.; Yang, Z.; Cao, H.; Liu, Y. A harmonic resonance suppression strategy for a high-speed railway traction power supply system with a SHE-PWM four-quadrant converter based on active-set secondary optimization. Energies 2017, 10, 1567. [CrossRef]

20. Kalair, A.; Abas, N.; Kalair, A.R.; Saleem, Z.; Khan, N. Review of harmonic analysis, modeling and mitigation techniques. Renew. Sustain. Energy Rev. 2017, 78, 1152-1187. [CrossRef]

21. Lamlom, A.; Ibrahim, A.; Balci, M.E.; Karadeniz, A.; Aleem, S.H.A. Optimal design and analysis of anti-resonance C-type high-pass filters. In Proceedings of the 2017 IEEE International Conference on Environment and Electrical Engineering and 2017 IEEE Industrial and Commercial Power Systems Europe (EEEIC/I\&CPS Europe), Milan, Italy, 6-9 June 2017; pp. 1-6.

22. Iwamuro, N.; Laska, T. IGBT History, State-of-the-Art, and Future Prospects. IEEE Trans. Electron. Devices 2017, 64, 741-752. [CrossRef]

23. Wang, L.; Lam, C.; Wong, M. Design of a Thyristor Controlled LC Compensator for Dynamic Reactive Power Compensation in Smart Grid. IEEE Trans. Smart Grid 2017, 8, 409-417. [CrossRef]

24. Wang, L.; Lam, C.; Wong, M. Selective Compensation of Distortion, Unbalanced and Reactive Power of a Thyristor-Controlled LC -Coupling Hybrid Active Power Filter (TCLC-HAPF). IEEE Trans. Power Electron. 2017, 32, 9065-9077. [CrossRef]

25. Wang, L.; Lam, C.; Wong, M. Hybrid Structure of Static Var Compensator and Hybrid Active Power Filter (SVC//HAPF) for Medium-Voltage Heavy Loads Compensation. IEEE Trans. Ind. Electron. 2018, 65, 4432-4442. [CrossRef]

26. Leon, J.; Vazquez, S.; Franquelo, L. Multilevel Converters: Control and Modulation Techniques for Their Operation and Industrial Applications. Proc. IEEE 2017, 105, 2066-2081. [CrossRef]

27. Chen, M.; Liu, R.; Xie, S.; Zhang, X.; Zhou, Y. Modeling and Simulation of Novel Railway Power Supply System Based on Power Conversion Technology. In Proceedings of the 2018 International Power Electronics Conference (IPEC-Niigata 2018-ECCE Asia), Niigata, Japan, 20-24 May 2018; pp. 2547-2551. 
28. Kukačka, L.; Kraus, J.; Kolář, M.; Dupuis, P.; Zissis, G. Review of AC power theories under stationary and non-stationary, clean and distorted conditions. IET Gener. Transm. Distrib. 2016, 10, 221-231. [CrossRef]

29. Emanuel, E.A. Summary of IEEE standard 1459: Definitions for the measurement of electric power quantities under sinusoidal, nonsinusoidal, balanced, or unbalanced conditions. IEEE Trans. Ind. Appl. 2004, 40, 869-876. [CrossRef]

30. Yazdani, D.; Mojiri, M.; Bakhshai, A.; JoÓs, G. A Fast and Accurate Synchronization Technique for Extraction of Symmetrical Components. IEEE Trans. Power Electron. 2009, 24, 674-684. [CrossRef]

31. Yao, W.; Teng, Z.; Tang, Q.; Gao, Y. Measurement of power system harmonic based on adaptive Kaiser self-convolution window. IET Gener. Transm. Distrib. 2016, 10, 390-398. [CrossRef]

32. Cai, G.; Wang, L.; Yang, D.; Sun, Z.; Wang, B. Harmonic detection for power grids using adaptive variational mode decomposition. Energies 2019, 12, 232. [CrossRef]

(C) 2019 by the authors. Licensee MDPI, Basel, Switzerland. This article is an open access article distributed under the terms and conditions of the Creative Commons Attribution (CC BY) license (http://creativecommons.org/licenses/by/4.0/). 

MDPI

St. Alban-Anlage 66

4052 Basel

Switzerland

Tel. +41616837734

Fax +41 613028918

www.mdpi.com

Energies Editorial Office

E-mail: energies@mdpi.com www.mdpi.com/journal/energies

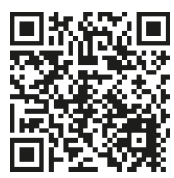



MDPI

St. Alban-Anlage 66

4052 Basel

Switzerland

Tel: +41 616837734

Fax: +41 613028918 